UNIVERSIDADE DE SÃO PAULO

INSTITUTO DE ASTRONOMIA, GEOFÍSICA E CIÊNCIAS ATMOSFÉRICAS DEPARTAMENTO DE GEOFÍSICA

GELVAM ANDRÉ HARTMANN

\title{
ARQUEOMAGNETISMO NO BRASIL: VARIAÇÕES DA INTENSIDADE DO CAMPO MAGNÉTICO TERRESTRE NOS ÚLTIMOS CINCO SÉCULOS
}

SÃO PAULO 

GELVAM ANDRÉ HARTMANN

\section{ARQUEOMAGNETISMO NO BRASIL: VARIAÇÕES DA INTENSIDADE DO CAMPO MAGNÉTICO TERRESTRE NOS ÚLTIMOS CINCO SÉCULOS}

Tese apresentada ao Instituto de Astronomia, Geofísica

e Ciências Atmosféricas da Universidade de São Paulo como requisito parcial à obtenção do título de Doutor em Ciências.

Área de Concentração: Geofísica

Orientador:

Prof. Dr. RICARDO IVAN FERREIRA DA TRINDADE

SÃO PAULO 



\section{Agradecimentos}

Gostaria de expressar os meus sinceros agradecimentos a todas as pessoas e instituições que de uma maneira ou de outra contribuíram para a execução desta tese.

Em primeiro lugar, agradeço especialmente ao meu orientador Prof. Dr. Ricardo Ivan Ferreira da Trindade pela orientação recebida durante esses cinco anos de doutoramento. Este trabalho é fruto dos ensinamentos e das excelentes discussões das quais tive o privilégio de me beneficiar. Agradeço pela confiança depositada em mim na condução deste fantástico assunto de pesquisa, pelo incentivo constante no caminho da Ciência e, principalmente, pela sua generosidade e amizade. Muito obrigado!

Aos pesquisadores Dr. Yves Gallet e Dra. Agnès Genevey por minha formação em Arqueomagnetismo, pela orientação cuidadosa, o grande suporte na condução do trabalho de laboratório e pelo agradável convívio durante os quatorze meses de estágio no Institut de Physique du Globe de Paris (IPGP). Aos pesquisadores Maxime Le Goff, Dr. Bernard Henry e Dr. Jean-Claude Tanguy agradeço pelas discussões, pela hospitalidade e pelo excelente ambiente de trabalho que me foi proporcionado no Laboratório de Paleomagnetismo de St. Maur-des-Fossés (IPGP).

Os primeiros trabalhos de Arqueomagnetismo da tese foram efetuados em colaboração com os pesqusiadores Avto Goguichaichvili e Juan Morales, do grupo de Paleomagnetismo da Universidade Autónoma de México, aos quais agradeço encarecidamente.

À Profa. Dra. Marisa Afonso, ao Prof. Dr. Carlos Etchevarne e à Profa. Dra. Rosana Najjar que colaboraram de forma irrestrita com esta pesquisa. A eles se deve a excelente coleção de material arqueológico com a qual trabalhamos. Agradeço também pela disponibilidade e pelo apoio no andamento do trabalho. Os resultados obtidos nesta tese só foram alcançados com a colaboração de vários arqueólogos, curadores, historiadores e arquitetos, a quem agradeço imensamente. Uma lista não exaustiva de colaboradores inclui: Carlos Costa, Fabiana Comerlato, Luydy Fernandes, Alvandyr Bezerra e Carlos Caroso (MAE/UFBA); Cláudio Souza e Silva, Catarina Menezes, Luiz Pacheco, Samuel Gordenstein, Alexandre, Paula Paoli (Projeto Monumenta de Salvador); Reuben Costa (Museu Náutico, Farol da Barra, Salvador); Daniel Rangel (Solar do Unhão, Salvador); Francisco Portugal (MAS/UFBA); Neuvânia Ghetti, Jackeline Macedo, Ana Sampaio e Regiane Gambim (Assessoria de Arqueologia do IPHAN/RJ); Profa. Dra. Margarida Andreatta, Anicleide Zequini, Janete Gutierre (amostragem na FLONA/Ipanema); Guilherme Michelin e José Candeias (Fazenda Lageado, UNESP); Paulo Zanettini e Camila Moraes (Zanettini Arqueologia). 
Aos professores do Departamento de Geofísica do IAG/USP, pelo apoio e pelas importantes contribuições à minha formação acadêmica. Agradeço em especial ao Prof. Dr. Igor Pacca pelo constante incentivo no desenvolvimento da pesquisa e pela gentileza em ler a tese em uma versão preliminar. Suas sugestões e críticas foram fundamentais para melhorar o texto final. Agradeço também ao Prof. Dr. Manoel D'Agrella pelo acompanhamento do doutorado através dos relatórios do Departamento de Geofísica, com sugestões e críticas sempre construtivas.

Agradeço a todos os funcionários do IAG/USP, em especial à Teca, Virgínia, Rosemary, Marcel, Carolina; aos técnicos, Daniele, Airton, Giovani, Maísa e Roberto; ao pessoal da mecânica, Iran Godoi, José Silva e José Fialho, pela colaboração e agradável convívio.

Agradeço nominalmente a todas as instituições que contribuíram para esse trabalho de tese. Contribuíram com apoio logístico e autorizações para as campanhas de amostragem nos diferentes sítios arqueológicos: o Instituto do Patrimônio Histórico e Artístico Nacional (IPHAN), o Museu de Arqueologia e Etnologia da Universidade de São Paulo (MAE/USP), o Museu de Arqueologia e Etnologia da Universidade Federal da Bahia (MAE/UFBA), a Floresta Nacional Ipanema (FLONA/Ipanema), a Fazenda Lageado da Universidade Estadual Júlio de Mesquita Filho (UNESP). Contribuíram com suporte logístico, de laboratório e admnistrativo: o Institut de Physique du Globe (IPGP) e o Instituto de Astronomia, Geofísica e Ciências Atmosféricas da Universidade de São Paulo (IAG/USP). Contribuíram com suporte financeiro: a Fundação de Amparo à Pesquisa do Estado de São Paulo (FAPESP, processo 2005/57782-4), a Coordenação de Aperfeiçoamento de Pessoal de Nível Superior (CAPES, processo 3971/08-2) e o Conselho Nacional de Desenvolvimento Científico e Tecnológico (CNPq).

Aos amigos e colegas do IAG: Elder (Japonês), Everton (Gaúcho), Jairo (Bisonho), Grasiane (Miss), Edgard (Alice), Ivan (Zeca Pagodinho), Daniele (Loca), Franklin, Everton (Baiano), Sérgio (Bob), Danilo, Alanna, Eduardo, Victor, Liliane, Manuelle, Marcus, Nilton, Oleg (Russo), Breno, Andrea, Érika, Vinicius e Cassiano (Pira), pelas discussões, pelo apoio, pela excelente convivência e, principalmente, pela amizade!

Agradeço à minha família pelo apoio incondicional em todos os momentos bons $\mathrm{e}$ difíceis desta caminhada. Em especial, aos meus queridos pais pela paciência e carinho que tiveram comigo durante todo esse tempo.

Agradeço especialmente à minha querida Alê, pelo amor, carinho, compreensão e dedicação ao longo de todo o doutoramento. 


\section{Resumo}

HARTMANN, G. A. Arqueomagnetismo no Brasil: variações da intensidade do campo magnético terrestre nos últimos cinco séculos. 2010. 244pp. Tese (Doutorado) - Instituto de Astronomia, Geofísica e Ciências Atmosféricas, Universidade de São Paulo, São Paulo, 2010.

O campo magnético da Terra varia em diferentes escalas de tempo, de milissegundos a bilhões de anos. Os dados de observatórios magnéticos e satélites obtidos nos últimos 150 anos indicam que o momento do dipolo magnético terrestre está diminuindo continuamente. Essa queda está associada à presença de fontes não-dipolares do campo em uma extensa região que abrange todo o Atlântico Sul e uma porção da América do Sul, sendo que no Brasil a contribuição dessas fontes varia fortemente com a latitude. Em escala de tempo arqueomagnética $\left(\sim 10^{3}-10^{4}\right.$ anos) a evolução do campo magnético terrestre não é tão bem estabelecida, principalmente em função da escassez de dados no hemisfério Sul, que contribui com apenas 5\% dos dados de intensidade obtidos para os últimos 4.000 anos. A América do Sul, com alguns poucos resultados no Peru, Equador e Bolívia, pode ser considerada a terra incógnita da arqueointensidade. Nesta tese são apresentados os primeiros resultados arqueomagnéticos para o território brasileiro. Foram escolhidas duas regiões de estudo, o Nordeste e o Sudeste do Brasil, situadas em diferentes faixas de latitude de modo a investigar diferentes contribuições de componentes não-dipolares do campo. No Nordeste, as amostras foram coletadas na cidade de Salvador (BA), a primeira capital do Brasil, fundada em 1549 AD. Na região Sudeste a amostragem foi efetuada nas cidades de Anchieta (ES), Rio de Janeiro (RJ), Niterói (RJ), Iperó (SP), Piracicaba (SP) e Botucatu (SP). Nas duas regiões, a paleointensidade do campo magnético terrestre foi obtida em materiais construtivos (tijolos e alguns fragmentos de telhas) datados entre 1550 AD e 1920 AD. As idades desses materiais foram estabelecidas com base em estudos arqueológicos e registros históricos das construções, fornecendo incertezas inferiores a 30 anos para a grande maioria das amostras. As paleointensidades foram estimadas utilizando-se dois métodos: (a) duplo aquecimento com medidas em temperatura ambiente, pelo protocolo de Thellier modificado por Coe; (b) duplo aquecimento com medidas contínuas em alta temperatura, pelo protocolo Triaxe. Após as medidas e correções magnéticas, todas as amostras foram analisadas com base em rigorosos critérios de seleção, que resultaram em 23 novas determinações de intensidade de alta qualidade (correspondendo a um total de 584 espécimes analisados, com uma taxa de sucesso de 57\%). A partir desses resultados foram traçadas duas curvas de variação da intensidade do campo magnético para cada uma das regiões estudadas, abrangendo os últimos 500 anos. Essas curvas revelam uma oscilação do momento de dipolo nos últimos cinco séculos, que não foi prevista nos modelos de campo disponíveis atualmente, trazendo implicações importantes no entendimento da evolução dos campos dipolar e não-dipolar nessa escala de tempo. As variações rápidas descritas nessas curvas permitem aplicar o arqueomagnetismo como ferramenta de datação arqueológica, como exemplificado pela datação de uma casa do Pelourinho em Salvador.

Palavras chave: arqueomagnetismo, variação secular geomagnética, campo não-dipolar, paleointensidade, datação arqueomagnética. 



\begin{abstract}
HARTMANN, G. A. Archeomagnetism in Brazil: Intensity variations of the Earth's magnetic field for the past five centuries. 2010. 244pp. Thesis (Doctorate) - Instituto de Astronomia, Geofísica e Ciências Atmosféricas, Universidade de São Paulo, São Paulo, 2010.

The Earth's magnetic field varies in different timescales, from milliseconds to billions of years. Magnetic data from observatories and satellites indicate that the dipole moment has continuously been decreasing for the past 150 years. This decay is associated to the presence of non-dipole sources covering a wide region that encompasses the South Atlantic and part of South America; in Brazil, the contribution of the non-dipole fields varies strongly with latitude. In the archeomagnetic timescale $\left(\sim 10^{3}-10^{4}\right.$ years), the evolution of the Earth's magnetic field is not well established, mainly due to the scarcity of data from southern hemisphere, which contributes with only $5 \%$ of the intensity data for the past 4,000 years. South America is the terra incognita of archeointensity, counting only a handful of results from Peru, Ecuador and Bolivia. This thesis presents the first archeomagnetic results from Brazil. In order to investigate different contributions of non-dipolar sources, we concentrated our sampling in two regions located in different latitudes - the Northeast and Southeast regions of Brazil. In the Northeast region, all samples were collected in the city of Salvador (BA), the first Brazilian capital settled in 1549 AD. In the Southeast region, sampling was conducted in the cities of Anchieta (ES), Rio de Janeiro (RJ), Niterói (RJ), Iperó (SP), Piracicaba (SP) and Botucatu (SP). All paleointensity data was obtained from architectural fragments (bricks and some tiles) dated between $1550 \mathrm{AD}$ and $1920 \mathrm{AD}$. The age of bricks and tiles was established on the basis of archeological studies and the historical record of the buildings, providing age uncertainties of less than 30 years for most of the samples. Paleointensity estimates were obtained by two methods: (a) double-heating with measurements in room temperature, using the modified version of the Thellier protocol; (b) double-heating with measurements in high temperatures, using the Triaxe protocol. After measurements and magnetic corrections, all samples were screened using strict selection criteria resulting in 23 high-quality new site-mean intensity values (from 584 analyzed specimens, with a success rate of $57 \%$ ). These results were integrated into two curves of geomagnetic intensity variation for each studied region over the past five centuries. These curves reveal an oscillating dipole moment for the past five centuries, a behavior not predicted in currently available geomagnetic field models, thus providing key information on the dipole and non-dipole field evolutions in this timescale. The rapid intensity changes described in these curves permit the application of archeointensity techniques as an archeological dating tool, as exemplified by the dating of a house from the Pelourinho area, in Salvador city.
\end{abstract}

Keywords: archeomagnetism, geomagnetic secular variation, non-dipole field, paleointensity, archeomagnetic dating. 


\section{Sumário}

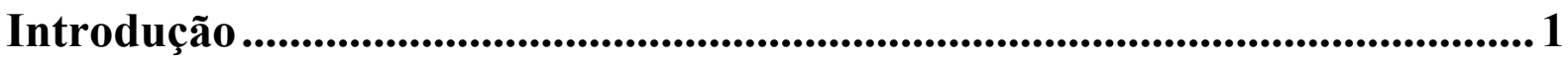

Capítulo 1 .............................................................................................................

1.1 Origem do campo magnético da Terra ....................................................................... 3

1.1.1 Representação do CMT por harmônicos esféricos.................................................. 4

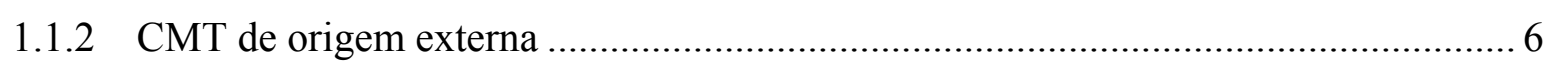

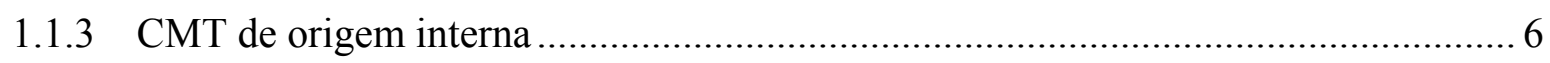

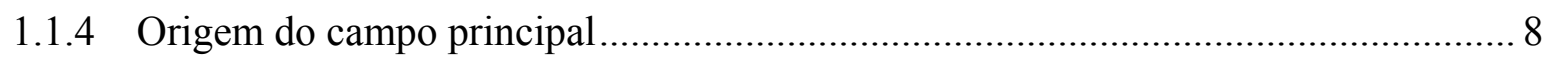

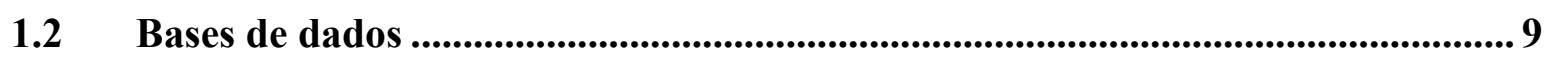

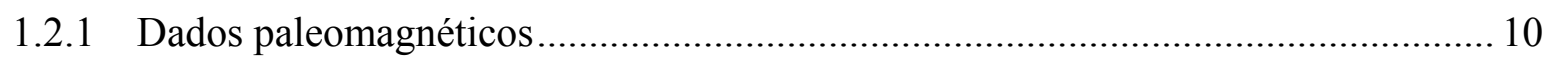

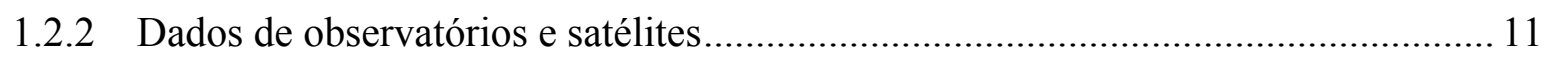

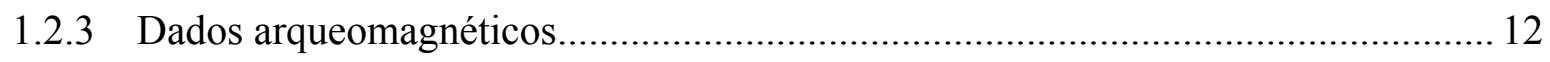

1.3 Modelos de campo para os últimos milênios......................................................... 14

1.4 Variação do CMT para os últimos milênios ...................................................... 18

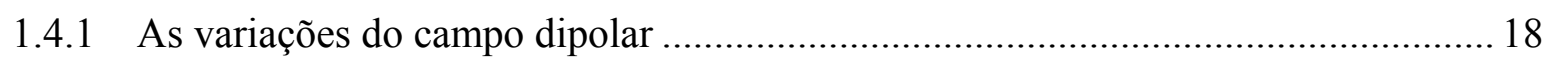

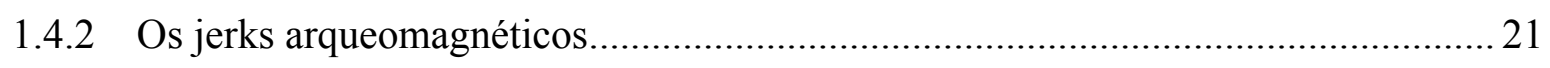

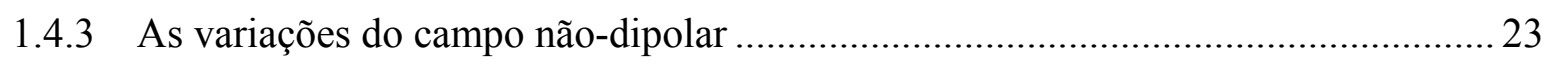

Capítulo 2 ................................................................................................................ 29

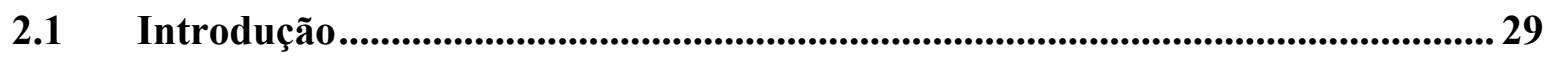

2.2 Coleção Nordeste ............................................................................................... 31

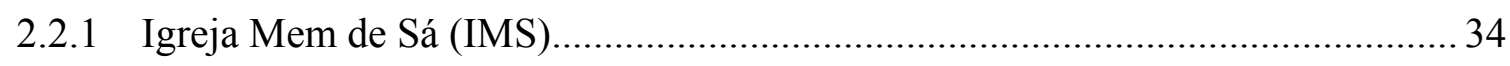

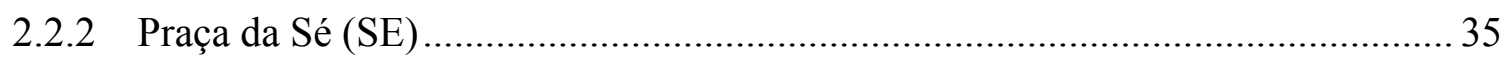

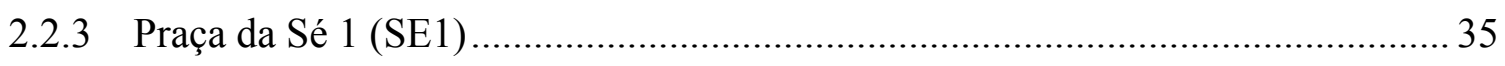

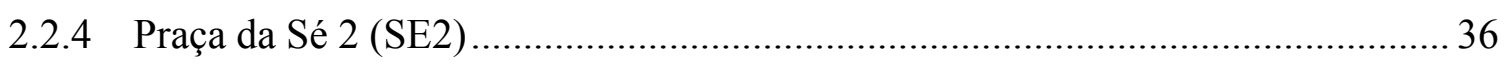

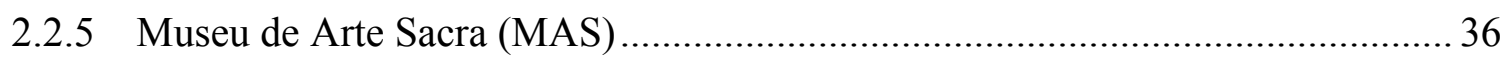

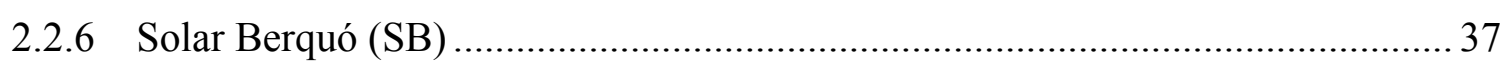

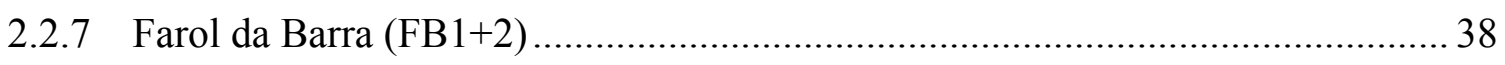

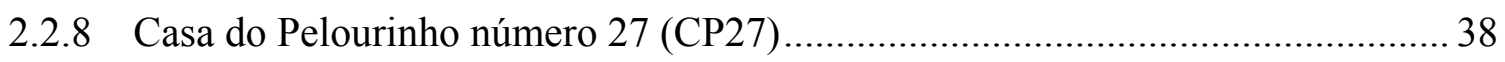

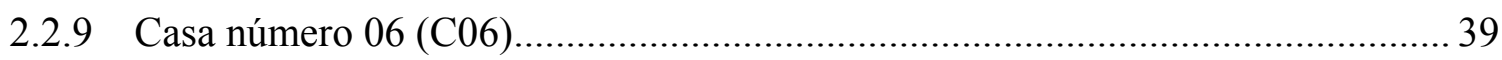




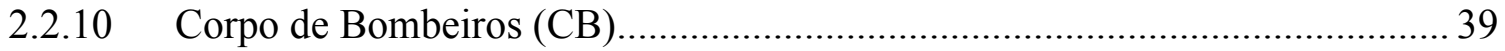

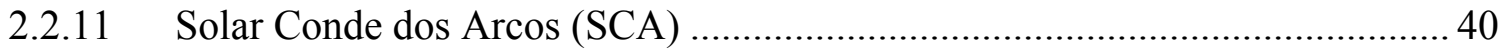

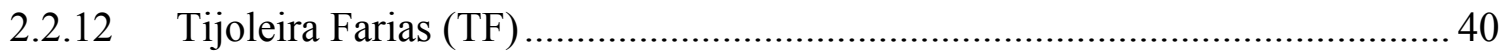

2.2.13 Museu de Arqueologia e Etnologia da Universidade Federal da Bahia (MAE4) 40

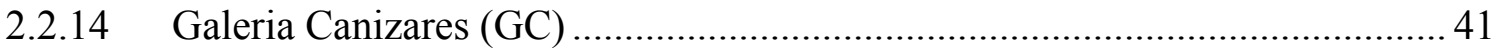

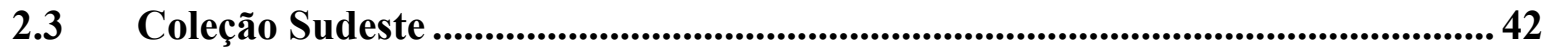

2.3.1 Igreja de Nossa Senhora Assunção (INSA) .......................................................... 45

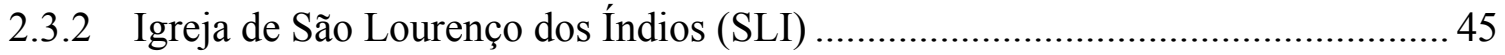

2.3.3 Igreja da Venerável Ordem Terceira de São Francisco da Penitência (OTP) ...... 46

2.3.4 Igreja de Nossa Senhora da Saúde (INS) .......................................................... 47

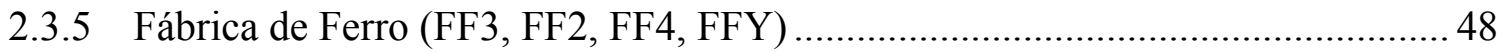

2.3.6 Museu Prudentes de Moraes (MPM1+2) ............................................................ 50

2.3.7 Fazenda Lageado 1, 3, 4 e 5 (FL1+3+4+5, FL2) ............................................ 51

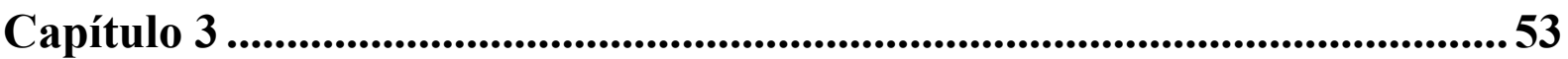

3.1 Magnetização termoremanente..........................................................................53

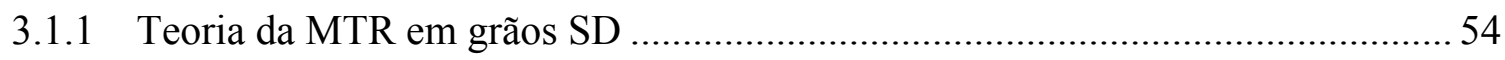

3.1.2 Leis da magnetização termoremanente parcial ................................................ 57

3.2 Determinação de paleointensidade absoluta por duplo aquecimento ............... 58

3.3 Métodos de paleointensidade com medidas em temperatura ambiente............59

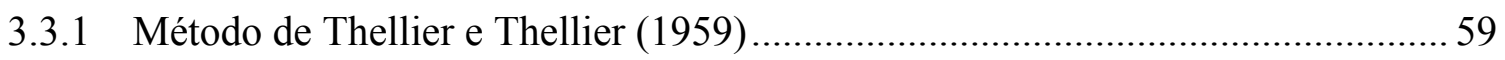

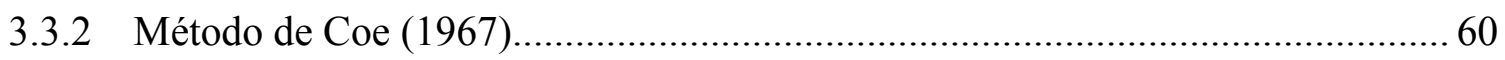

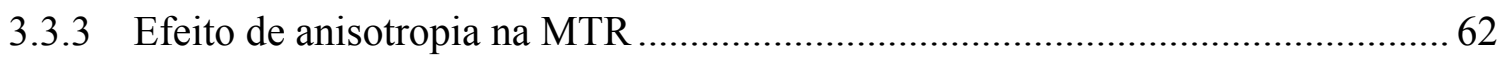

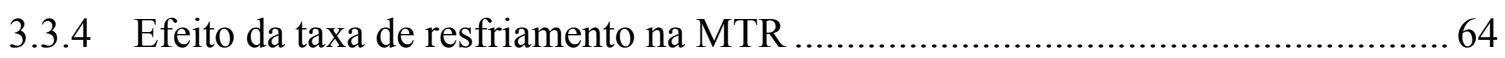

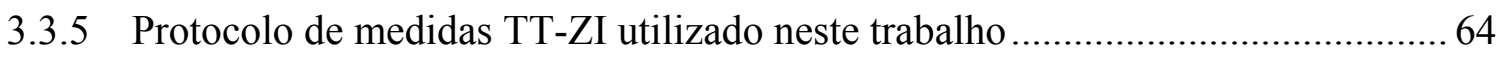

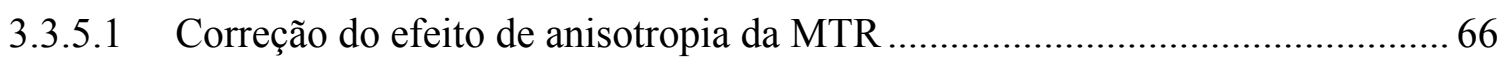

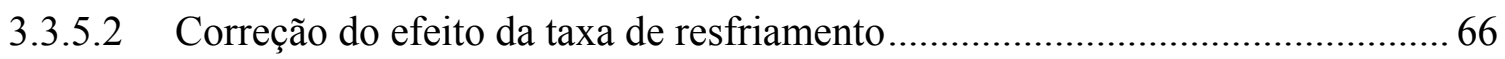

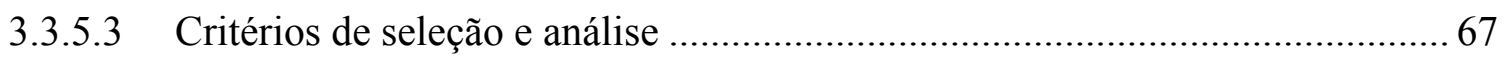

3.4 Método de paleointensidade com medidas em alta temperatura........................69

3.4.1 Medidas da magnetização termoremante em altas temperaturas ......................... 69

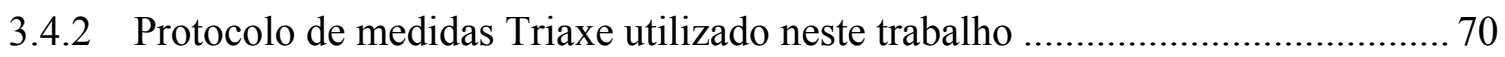

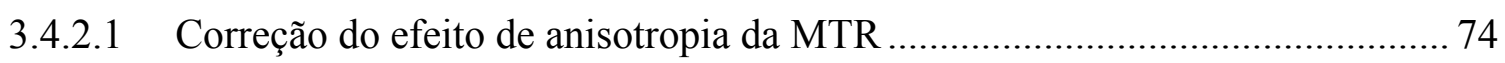

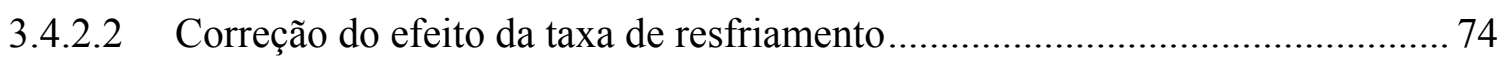

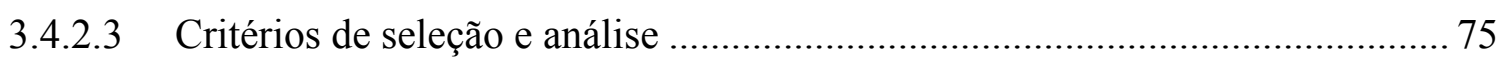

3.5 Estudos de Mineralogia magnética ...................................................................... 76 


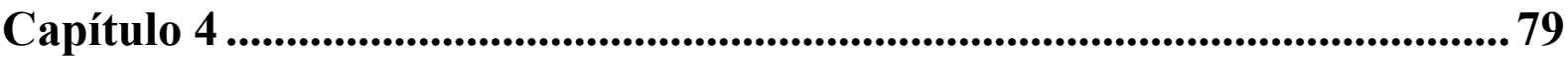

4.1 Resultados da coleção Nordeste ....................................................................... 79

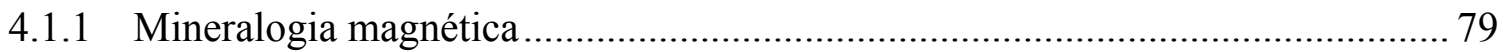

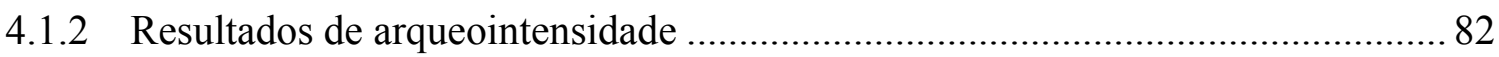

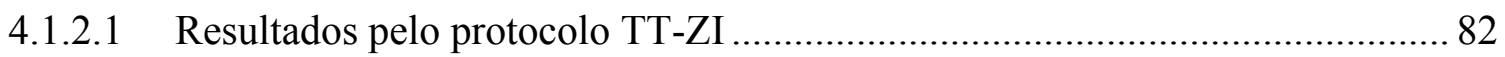

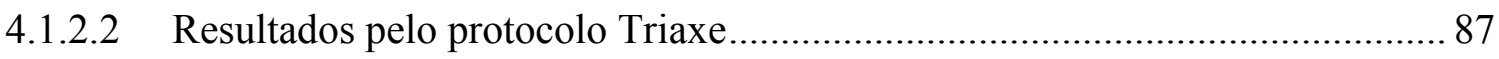

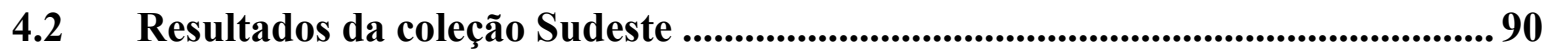

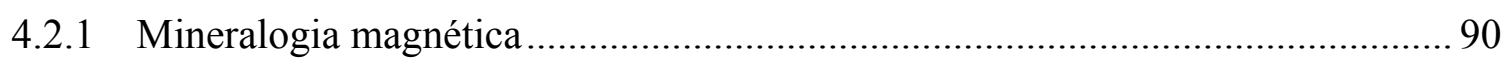

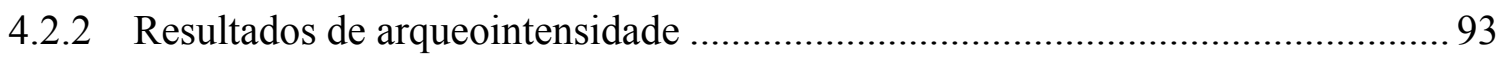

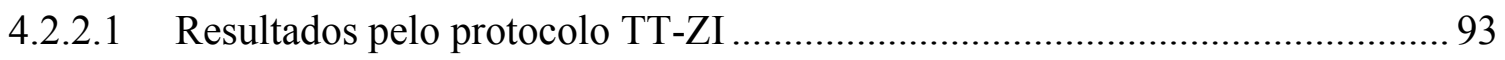

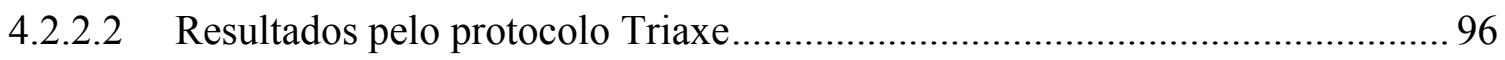

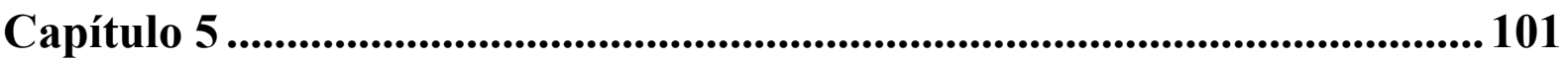

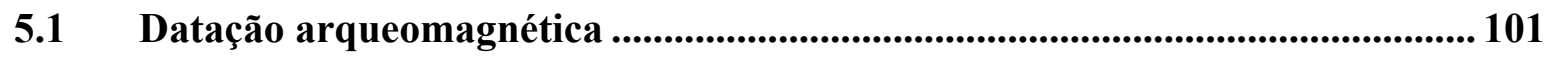

5.2 Um exemplo de datação arqueomagnética............................................................. 104

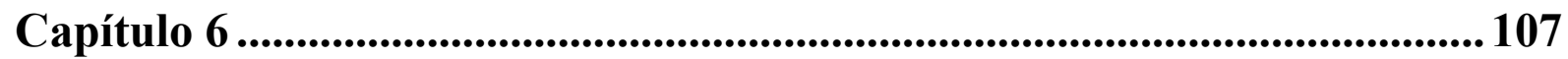

6.1 Variação da intensidade do CMT para os últimos 500 anos ............................ 107

6.1.1 Curva de referência para a região Nordeste do Brasil............................................. 107

6.1.2 Curva de referência para a região Sudeste do Brasil............................................. 109

6.1.3 Implicações na evolução do CMT em escala de centenas de anos ........................ 111

6.2 Considerações finais e perspectivas ................................................................ 113

Referências ............................................................................................................. 115

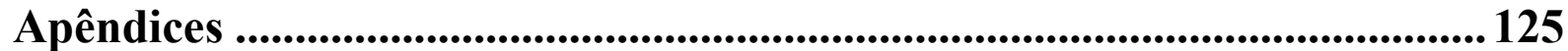

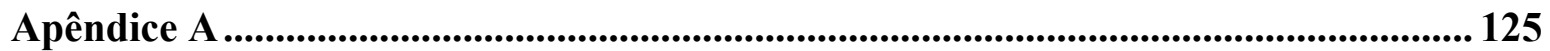

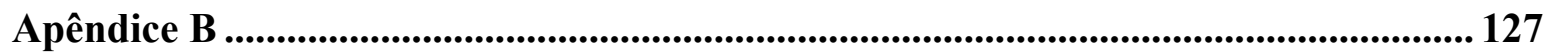

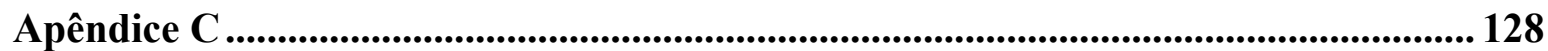

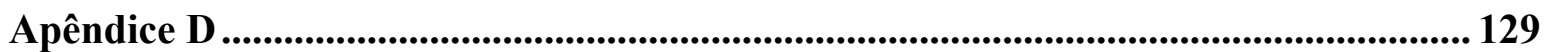




\section{Introdução}

O campo magnético terrestre varia em diferentes escalas de tempo. Variações na orientação do campo foram notadas pelos chineses ainda no século VIII. Curiosamente, na Europa o primeiro a notar essas variações foi um homônimo, G. Hartmann, ao medir a declinação em Roma no ano de 1510 AD (Chapman e Bartels, 1940). Desde então, uma grande quantidade de registros do campo foi coletada nos oceanos durante as grandes navegações, em observatórios geomagnéticos distribuídos em todos os continentes e, mais recentemente, por meio de satélites. Os períodos anteriores às grandes navegações são investigados apenas de forma indireta, pelo estudo do magnetismo fóssil em materiais geológicos e arqueológicos. Esses dados revelam que nos últimos milênios o campo magnético terrestre é dominantemente dipolar e que nos últimos séculos o momento de dipolo está diminuindo continuamente (e.g. Bloxham et al., 1989; Hulot et al., 2010). Essa queda no momento de dipolo está associada à presença de uma feição não-dipolar de grande escala situada no hemisfério Sul, a Anomalia Magnética do Atlântico Sul (SAMA, em inglês) (Olson e Amit, 2006). No mesmo período o hemisfério Norte apresenta uma contribuição aproximadamente constante para o momento de dipolo. O contraste na contribuição de cada hemisfério para o momento de dipolo revela a necessidade de obtenção de dados em ambos os hemisférios para estudar a evolução da intensidade do campo durante os últimos séculos e milênios. Apesar dos esforços recentes na obtenção de dados paleomagnéticos, arqueomagnéticos e geomagnéticos, nota-se ainda uma forte heterogeneidade na distribuição espacial e temporal dos registros disponíveis. A deficiência de dados de arqueointensidade é marcante para a porção Sul do globo, cujos dados representam menos de $5 \%$ da base de dados mundial (Genevey et al., 2008). Desses, quase todos os dados provêm do Peru, Bolívia e Equador. O Brasil, sem dados disponíveis quando do início desse trabalho, era a terra incógnita da arqueointensidade.

O campo magnético sobre o Brasil apresenta um comportamento singular, devido à presença da SAMA. Essa anomalia recobre boa parte do Sudeste brasileiro e é responsável pelo caráter fortemente não-dipolar do campo magnético nessa região. As regiões Norte e Nordeste sofrem menor influência por estarem mais distantes do centro da SAMA. Portanto, a evolução do campo e a influência da SAMA podem ser estudadas a partir da comparação de dados arqueomagnéticos provenientes das regiões Nordeste e Sudeste. Com esse propósito 
foram escolhidos como alvos de estudo algumas das primeiras cidades brasileiras. Na região Nordeste foi escolhida a cidade de Salvador (BA), primeira capital do Brasil. Na região Sudeste foram escolhidas as cidades de Anchieta (ES), Rio de Janeiro (RJ), Niterói (RJ), Iperó (SP), Piracicaba (SP) e Botucatu (SP). Nesses locais foi coletado material construtivo histórico (tijolos e algumas telhas) com idade entre 1550 AD e 1920 AD. Somente construções com idades bem estabelecidas através de estudos arqueológicos e/ou registros históricos foram amostradas, resultando em incertezas na determinação das idades sempre inferiores a 30 anos. Os resultados de arqueointensidade obtidos neste trabalho permitiram traçar duas curvas de variação do campo magnético para os últimos cinco séculos nas duas regiões do país, com implicações importantes na compreensão do campo magnético terrestre nessa escala de tempo. Além disso, as rápidas variações da intensidade observadas para a região Nordeste permitiram a aplicação do método na datação de materiais arqueológicos, demonstrada na determinação da idade de uma casa do centro histórico de Salvador.

A tese está estruturada em 6 Capítulos. O Capítulo 1 trata das diferentes bases de dados, dos métodos para descrever o campo magnético terrestre e de sua evolução nos últimos milênios. O Capítulo 2 apresenta o contexto arqueológico e histórico de todos os sítios analisados. O Capítulo 3 apresenta aspectos teóricos da paleointensidade, os métodos utilizados no presente trabalho e uma aplicação em cerâmicas portuguesas coletadas em escavações efetuadas no centro histórico de Salvador. O Capítulo 4 mostra os resultados obtidos nas regiões Nordeste e Sudeste. Ele faz referência a dois artigos elaborados durante o doutoramento. As potencialidades do uso do arqueomagnetismo como ferramenta de datação são discutidas no Capítulo 5. Por fim, o Capítulo 6 traz uma discussão sobre a evolução do campo magnético terrestre com base no novo acervo de dados apresentados na tese e as perspectivas para a continuação das pesquisas em arqueomagnetismo no Brasil. A tese contém quatro artigos e um capítulo de livro, publicados ou submetidos durante o período do doutoramento. Dois desses trabalhos, escritos em português, foram incorporados diretamente no corpo da tese. São eles: um artigo que trata da metodologia de datação arqueomagnética, publicado na Revista do Museu de Arqueologia e Etnologia, e um dos capítulos do livro Projeto Monumenta de Salvador, que apresenta um exemplo de datação arqueomagnética em uma das casas do Pelourinho. Outros três artigos, publicados ou submetidos aos periódicos Earth, Planets and Space, Earth and Planetary Science Letters e Journal of Geophysical Research, são apresentados nos Apêndices A, B e C, respectivamente, uma vez que o regimento da Universidade de São Paulo impede a incorporação de textos em língua estrangeira no corpo da tese. 


\section{Capítulo 1}

\section{O campo magnético da Terra para os últimos milênios}

O campo magnético da Terra (CMT) varia em diferentes escalas de tempo e espaço. Estas variações são fonte de informação sobre os processos que geram o campo magnético no núcleo externo da Terra através do geodínamo. As variações de direção e intensidade em escalas de tempo da ordem de anos até poucos milhares de anos, conhecidas como variações secular e arqueomagnética, fornecem também importantes informações sobre o campo nãodipolar produzido pelo núcleo externo. Neste capítulo serão apresentadas as variações do campo geomagnético a partir das bases de dados históricos e arqueomagnéticos e dos modelos de campo disponíveis para os últimos milênios.

\subsection{Origem do campo magnético da Terra}

A idéia de que a Terra apresentava magnetismo surgiu aproximadamente em 250 AC com os chineses através de observações de uma agulha imantada utilizada para orientação, a bússola. Muito tempo depois, William Gilbert no famoso "De Magnete" de 1600, identificou e atribuiu ao campo magnético uma origem interna, no centro da Terra. Na primeira metade do século XVII, René Descartes desenvolveu a idéia de que o campo magnético poderia ser representado por "linhas de campo" que entravam no pólo Norte e saíam no pólo Sul, de maneira que formavam uma espécie de "circuito fechado de linhas de campo". Em 1839, Carl Friederich Gauss melhorou as técnicas de observação direta do campo (com as primeiras medidas de intensidade total) e introduziu o método moderno de análise por harmônicos esféricos do campo geomagnético. Através deste tipo de análise é possível distinguir três campos magnéticos de origem diferente, os campos interno, externo e crustal (e.g. Merrill et al., 1998). 


\subsubsection{Representação do CMT por harmônicos esféricos}

O CMT é um vetor e a sua representação se dá através do módulo, direção e sentido. Por determinação da International Association of Geomagnetism and Aeronomy (IAGA), deve-se usar o vetor B para representar o campo geomagnético. A análise por harmônicos esféricos desenvolvida por Gauss em 1839 é descrita por duas das equações de Maxwell:

$$
\begin{array}{ll}
\nabla \times \mathbf{B}=\mu_{0}\left(\mathbf{J}+\frac{\partial \mathbf{D}}{\partial t}\right) & \text { (Lei de Ampère) } \\
\nabla \cdot \mathbf{B}=0 & \text { (Lei de Gauss para o campo magnético) }
\end{array}
$$

onde $\mu_{0}$ é a permeabilidade magnética no vácuo, $\mathbf{J}$ é a densidade de corrente elétrica e $\partial \mathbf{D} / \partial t$ é a corrente de deslocamento. Se forem desprezadas as correntes entre a superfície da Terra e a ionosfera e as variações do campo externo, $\nabla \times \mathbf{B}=0$ e o campo deriva de um potencial escalar, de maneira que B pode ser representado como o gradiente de um potencial escalar $V$ :

$\mathbf{B}=-\nabla V$

Pela equação (1.2) o divergente de B é nulo e $V$ satisfaz a equação de Laplace:

$\nabla^{2} V=0$

As representações de B satisfazem as equações (1.3) e (1.4) de modo que $V$ pode ser escrito como uma série, em função dos harmônicos esféricos. Assim, em termos de coordenadas esféricas a equação (1.4) pode ser escrita da seguinte forma:

$$
\frac{\partial}{\partial r}\left(r^{2} \frac{\partial V}{\partial r}\right)+\frac{1}{\sin \theta} \frac{\partial}{\partial \theta}\left(\sin \theta \frac{\partial V}{\partial \theta}\right)+\frac{1}{\sin ^{2} \theta} \frac{\partial^{2} V}{\partial \phi^{2}}=0
$$

onde $\theta$ é a colatitude, $\phi$ é a longitude e $r$ é a distância do centro da Terra até um determinado ponto P, conforme indica a Figura 1.1. A solução da equação (1.5) pode ser encontrada em detalhe em Chapman e Bartels (1940) e Langel (1987). Essa equação permite descrever o potencial geomagnético ( $V$ ) sob a forma de uma soma de funções, dependentes das coordenadas:

$$
\begin{aligned}
& V=V_{\mathrm{int}}+V_{\text {ext }} \\
& =a \sum_{n=1}^{N_{\mathrm{int}}} \sum_{m=0}^{n}\left(g_{n}^{m} \cos m \phi+h_{n}^{m} \sin m \phi\right) \cdot\left(\frac{a}{r}\right)^{n+1} P_{n}^{m}(\cos \theta) \\
& +a \sum_{n=1}^{N_{\text {ext }}} \sum_{m=0}^{n}\left(c_{n}^{m} \cos m \phi+s_{n}^{m} \sin m \phi\right) \cdot\left(\frac{a}{r}\right)^{n} P_{n}^{m}(\cos \theta)
\end{aligned}
$$

onde $a=6371.2 \mathrm{~km}$ é o raio da Terra, $P_{n}^{m}(\cos \theta)$ são os polinômios associados de Legendre normalizados por Schmidt, $N_{\text {int }}$ representa o grau e a ordem $\left(g_{n}^{m}\right.$ e $\left.h_{n}^{m}\right)$ máximos devido ao 
potencial interno $\left(V_{\text {int }}\right), N_{\text {ext }}$ representa o grau e a ordem $\left(c_{n}^{m}\right.$ e $\left.s_{n}^{m}\right)$ máximos devido ao potencial externo $\left(V_{e x t}\right)$. O multiplicador $a$ é adicionado na solução para que os coeficientes tenham a mesma dimensão de B. O potencial $V$ evidentemente não é diretamente observável, mas as componentes do campo medidas na superfície da Terra $(r=a)$ são observáveis.

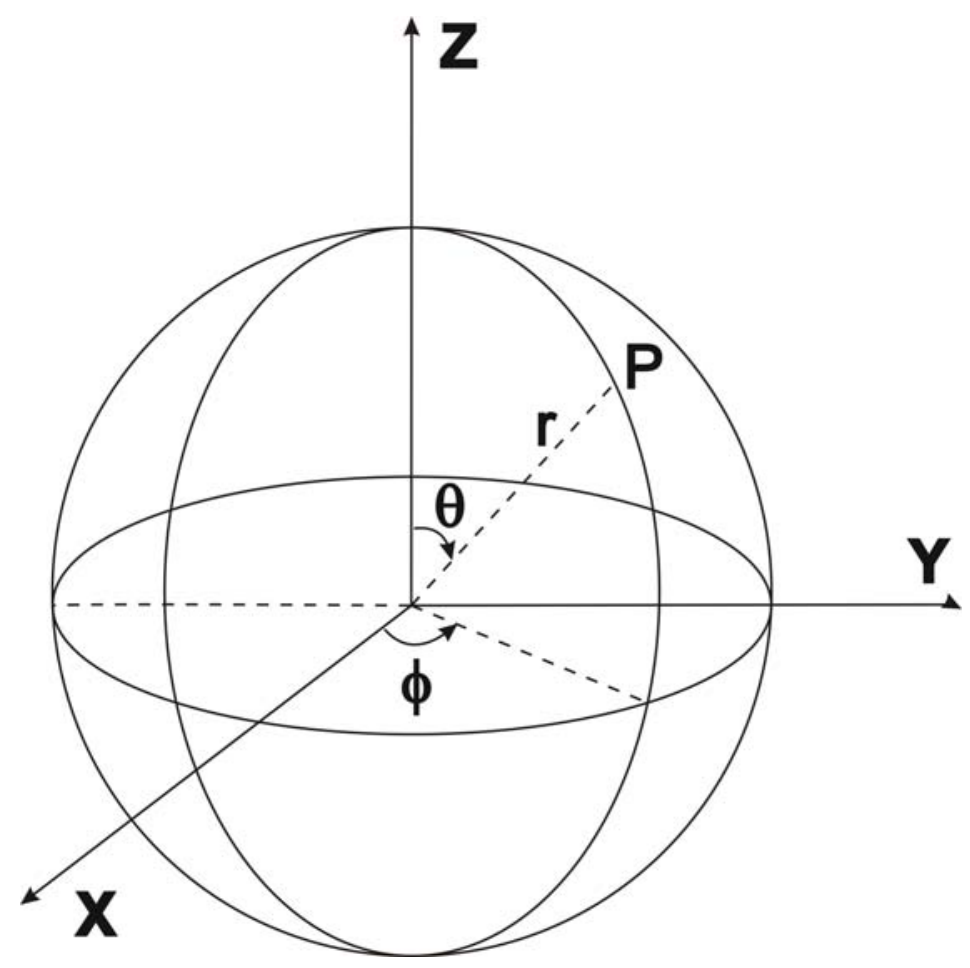

Figura 1.1: Representação das coordenadas esféricas no referencial terrestre.

As componentes do campo podem ser definidas a partir da equação (1.5) da seguinte forma:

Norte:

$$
X=-B_{\theta}=\frac{1}{r} \frac{\partial V}{\partial \theta}
$$

Leste: $\quad Y=B_{\phi}=\frac{1}{r(\sin \theta)} \frac{\partial V}{\partial \phi}$

Vertical: $\quad Z=-B_{r}=\frac{\partial V}{\partial r}$

Horizontal: $\quad H=\left(X^{2}+Y^{2}\right)^{1 / 2}$

Campo total: $\quad F=\left(X^{2}+Y^{2}+Z^{2}\right)^{1 / 2}$

Inclinação: $\quad I=\arctan \left(\frac{Z}{H}\right) \quad-\frac{\pi}{2} \leq I \leq \frac{\pi}{2}$

Declinação: $\quad D=\arctan \left(\frac{Y}{X}\right) \quad-\pi \leq D \leq \pi$ 
onde $\left(B_{r}, B_{\theta}, B_{\phi}\right)$ são as componentes de $\mathbf{B}$ em coordenadas polares esféricas.

A solução matemática do potencial geomagnético indica que o campo apresenta uma soma de fontes individuais. Os termos da solução radial do tipo $(a / r)^{n+1}$ correspondem às fontes de origem interna do campo, pois $a>r$. Os termos da solução radial $(a / r)^{n}$ correspondem à fontes de origem externa do campo, pois $a<r$.

Os coeficientes $g_{n}^{m}, h_{n}^{m}, c_{n}^{m}, s_{n}^{m}$ são chamados de coeficientes de Gauss e sua unidade fundamental nos modelos de campo é o nanoTesla (nT). Os coeficientes de Gauss são calculados a partir de medidas diretas do CMT realizadas pelos observatórios magnéticos e satélites ou por medidas indiretas feitas em materiais arqueológicos e geológicos. Para este cálculo são utilizados métodos de inversão que fornecem o conjunto de coeficientes que melhor representa as medidas no globo (e.g. Langel, 1987). Cada conjunto de coeficientes corresponde a um modelo de campo geomagnético.

\subsubsection{CMT de origem externa}

Os coeficientes que representam o CMT de origem externa $\left(c_{n}^{m}, s_{n}^{m}\right)$ contribuem com menos de $1 \%$ para o campo total observado em superfície. Em geral, a atividade solar é responsável pelas variações geomagnéticas de origem externa, que podem responder por algumas poucas dezenas de nT em dias de baixa atividade solar, mas podem representar até $1 \%$ do campo total em dias de tempestades magnéticas. Estas variações ocorrem porque o fluxo de partículas ionizadas vindas do Sol (bem como o fluxo cósmico) interage com o CMT de origem interna gerando correntes elétricas em altitudes acima de $100 \mathrm{~km}$, dentro da ionosfera e em parte da magnetosfera (e.g. Chapman e Bartels, 1940). O período das variações do CMT de origem externa varia de milissegundos até dias. Variações mais longas, da ordem de 11 a 22 anos, são também reguladas pela atividade solar de longo período (e.g. Merrill et al., 1998).

\subsubsection{CMT de origem interna}

O CMT de origem interna responde por grande parte da soma dos campos na equação (1.6). A partir da análise dos coeficientes $\left(g_{n}^{m}, h_{n}^{m}\right)$ é possível distinguir duas fontes de origem interna. A primeira delas é chamada de campo principal, que é gerado através das 
correntes elétricas que circulam no núcleo externo da Terra. A segunda corresponde ao campo crustal, cujas fontes são os materiais magnetizados presentes na crosta terrestre.

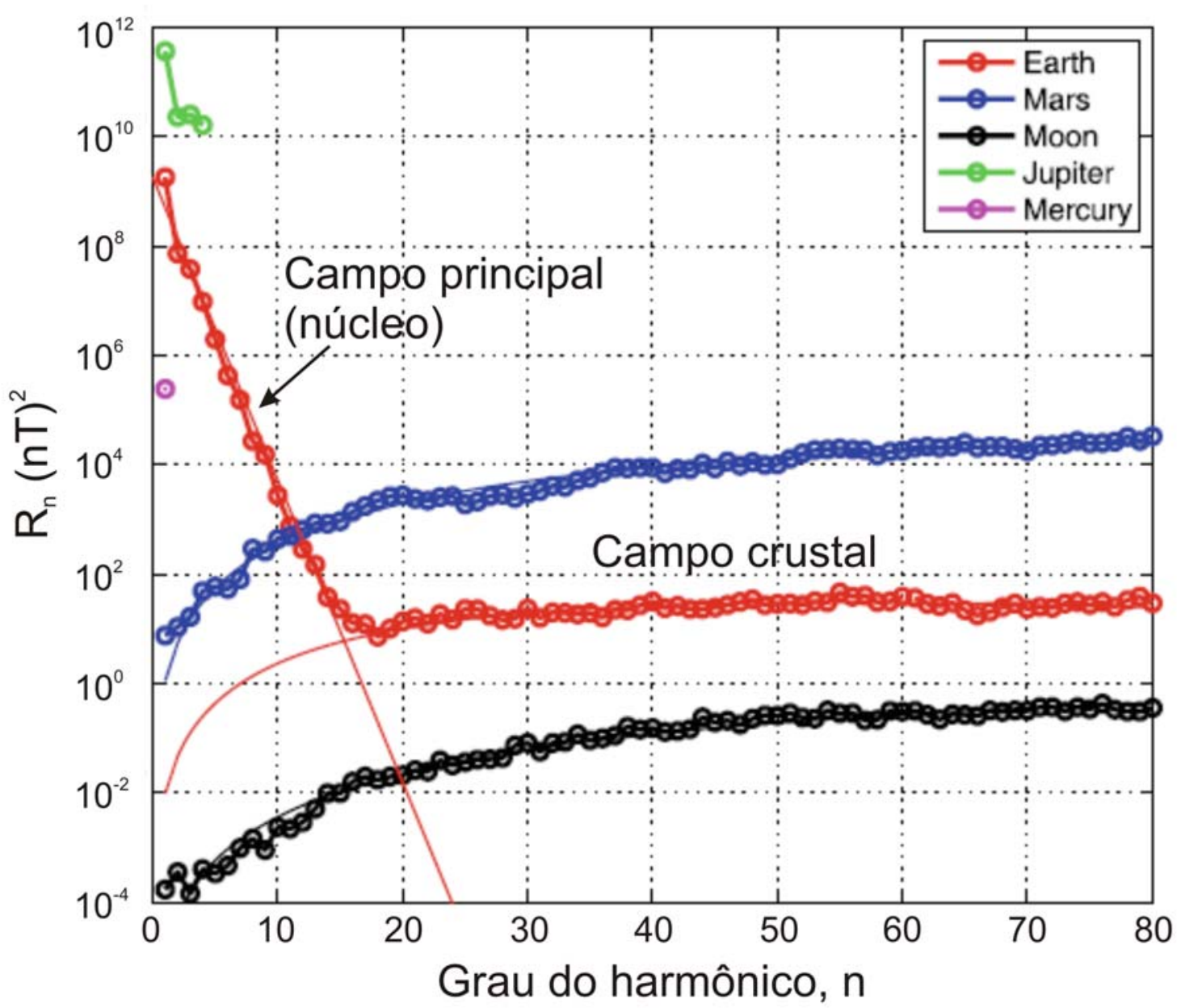

Figura 1.2: Espectro de energia dos coeficientes de Gauss em função do grau dos harmônicos. A curva em vermelho representa a Terra, em azul Marte, em preto a Lua, em verde Júpiter e o ponto em lilás Mercúrio. Note que a diferença de potência dos coeficientes distingue muito bem a contribuição das duas fontes do campo de origem interna. Pode-se observar também que Marte e a Lua têm apenas a contribuição do campo crustal. Figura modificada de Hulot et al. (2010).

A teoria do potencial não fornece uma maneira formal de distinguir entre esses dois campos. Entretanto, pode-se utilizar para essa análise o espectro de energia $\left(R_{n}\right)$ do campo de origem interna, que é chamado de espectro de Lowes-Mauersberger. Esse espectro mostra a contribuição dos diferentes graus $n$ dos harmônicos esféricos para o campo médio em superfície com relação a um raio de referência (Lowes, 1974). Os resultados sugerem claramente uma queda nos valores de $R_{n}$ até o grau $n=13$. Essa é, portanto, uma feição de grande escala e dominada pelo campo gerado no núcleo. A partir do grau $n=14$ o espectro é invariável, o que indica que estes termos representam o campo crustal (Figura 1.2). Esta 
separação natural do campo interno, em componentes de alta energia $(n<13)$ produzidas pelo núcleo, e componentes de baixa energia $(n>13)$ produzidas pela crosta, é uma característica fundamental para a modelagem do campo (e.g. Langel, 1987). Isto implica em que somente as componentes de alta energia do campo interno podem ser associadas com o campo gerado no núcleo. Portanto, somente essas componentes podem ser extrapoladas até a interface manto-núcleo utilizando o potencial $V_{\text {int }}$ da equação (1.6).

Pelo espectro é possível observar que o harmônico de grau 1 domina amplamente a energia do campo principal. Expandindo-se a equação (1.6) para os 3 primeiros coeficientes, que representam o grau e a ordem 1, tem-se:

$V=g_{1}^{0}\left(\frac{a^{3}}{r^{2}}\right)(2 \cos \theta)+g_{1}^{1}\left(\frac{a^{3}}{r^{2}}\right)(2 \sqrt{2} \sin \theta \cos \phi)+h_{1}^{1}\left(\frac{a^{3}}{r^{2}}\right)(2 \sqrt{2} \sin \theta \cos \phi)$

O primeiro termo da equação corresponde ao dipolo geocêntrico axial centrado, ou seja, situado no centro da Terra e orientado na direção do eixo de rotação do planeta. Os outros dois termos representam os potenciais de dois dipolos centrados, porém perpendiculares entre si e orientados no plano equatorial. O coeficiente $g_{1}^{0}$ indica a contribuição do dipolo axial centrado, e os coeficientes $g_{1}^{1}$ e $h_{1}^{1}$ indicam as respectivas contribuições dos dipolos centrados equatoriais. Os três termos $g_{1}^{0}, g_{1}^{1}$ e $h_{1}^{1}$ descrevem o campo dipolar do CMT enquanto que os termos de grau e ordem superior da equação (1.6) $(2 \leq n \leq 13,2 \leq m \leq 13)$ representam o campo não-dipolar. Por exemplo, os termos de grau e ordem $2(n=m=2)$ na expansão do potencial magnético correspondem aos quadrupolos magnéticos, os termos de grau e ordem $(n=m=3)$ correspondem aos octupolos magnéticos, e assim por diante.

\subsubsection{Origem do campo principal}

Atualmente, estima-se que o núcleo da Terra é constituído basicamente de ferro e níquel e de $10 \%$ a $20 \%$ de elementos leves (como enxofre ou oxigênio). As evidências sismológicas indicam também que ele é subdividido em um núcleo interno sólido e um núcleo externo líquido (e.g. Merrill et al., 1998). O núcleo interno tem aproximadamente $1200 \mathrm{~km} \mathrm{de}$ diâmetro, enquanto que o núcleo externo que o envolve tem seu limite com o manto terrestre a uma profundidade de $\sim 2900 \mathrm{~km}$ em relação à superfície.

O modelo mais aceito, que descreve os movimentos do fluido condutor no núcleo externo considera como uma das fontes de energia o calor latente de solidificação na cristalização contínua do ferro na interface entre os núcleos interno e externo. Os gradientes 
térmicos devidos às diferenças de temperatura entre as duas interfaces produzem uma convecção térmica. Outra parte da energia advém da diferenciação química entre os elementos mais leves e mais pesados no processo de cristalização do núcleo interno, gerando os movimentos de convecção composicional (e.g. Merrill et al., 1998).

O modelo de geodínamo mais simples é aquele proposto por Larmor em 1919 e formalizado por Bullard (1955), que associa as equações mecânicas e as equações eletromagnéticas (magnetohidrodinâmica) permitindo compreender as variações espaciais e temporais do CMT observado em superfície. Há duas formas de estudar a geração do CMT no núcleo externo. A primeira delas, mais usual, é através de modelos matemáticos produzidos a partir da solução numérica das equações da magnetohidrodinâmica, que são em seguida comparadas às observações geomagnéticas feitas em superfície (e.g. Glatzmaier e Roberts, 1995a; 1995b; Kageyama et al., 1995; Kuang e Bloxham, 1997; Roberts e Glatzmaier, 2000). Duas abordagens são utilizadas para resolver essas equações: (a) os modelos de dínamo cinemático, onde se considera que o fluxo magnético é nulo de maneira a se obter a velocidade do fluido magnético no núcleo externo; (b) os modelos de dínamo hidrodinâmico, aqueles obtidos pela solução simultânea das equações mecânicas e eletromagnéticas. A segunda forma de estudar a geração do CMT é através de modelos experimentais de dínamos de laboratório (e.g. Busse, 2000; Tilgner, 2000; Gailitis et al., 2002; Nataf, 2003). A maioria dos dínamos experimentais utiliza uma esfera, que rotaciona em torno de um eixo e que contém em seu interior um metal líquido que se movimenta devido à rotação e à convecção produzida no interior da esfera. A limitação desses experimentos é que cada um dos movimentos só pode ser considerado separadamente, de maneira que a cada experimento só é possível estudar um fenômeno particular do CMT. Assim, para se ter um esboço completo do geodínamo é necessário realizar vários experimentos independentes. A representatividade dos resultados obtidos, tanto pelos modelos matemáticos, quanto pelos modelos experimentais, ainda é debatida. Isto porque características fundamentais do campo, como a predominância do campo dipolar e o porquê das reversões do CMT, permanecem em aberto (e.g. Jones, 2007).

\subsection{Bases de dados}

A análise por harmônicos esféricos do CMT permite separar os diferentes períodos de variação em três intervalos. As variações na escala temporal de alguns anos até $5 \times 10^{2}$ anos 
são conhecidas como 'variações do campo no período histórico', variações da ordem de 1,7 $\times 10^{3}$ a $10^{4}$ anos são conhecidas como 'variações arqueomagnéticas' e variações da ordem de $7,8 \times 10^{5}$ a $5 \times 10^{6}$ anos são conhecidas como 'variações paleomagnéticas' (Carlut et al, 1999). Modelos de campo histórico e arqueomagnético são baseados no vetor completo, ou seja, na direção e na intensidade do campo, enquanto que os modelos do campo paleomagnético (milhões de anos) são baseados somente em dados direcionais, porque dados de paleointensidade são muito escassos.

\subsubsection{Dados paleomagnéticos}

Para longos períodos de tempo, os dados de direção e intensidade do campo provêm essencialmente de observações indiretas feitas em rochas vulcânicas e sedimentos. O intervalo de tempo dos últimos 5 milhões de anos é particularmente interessante para modelagem do CMT porque apresenta algumas vantagens em relação a dados paleomagnéticos para períodos mais antigos: (a) este intervalo de tempo é o que têm o maior número de dados disponíveis, (b) os efeitos devido ao movimento das placas tectônicas podem ser facilmente estimados e corrigidos nas análises paleomagnéticas, (c) a alteração magnética em rochas bastante recentes é potencialmente menor do que em rochas mais antigas (e.g. Lawrence et al., 2006). As rochas vulcânicas e os sedimentos apresentam diferenças com respeito aos processos de registro do campo magnético. As rochas vulcânicas podem registrar a direção e a intensidade do campo a partir de uma magnetização termoremanente que é adquirida após o resfriamento da rocha em um intervalo de tempo relativamente curto para o tempo geológico. O problema, neste caso, reside na estimativa acurada da idade da rocha e na duração entre sucessivos derrames vulcânicos, que podem ocorrer em diferentes intervalos de tempo. Os sedimentos podem registrar a direção e a intensidade do campo a partir de uma magnetização remanente deposicional. Neste caso, o registro depende fortemente da taxa de sedimentação e do controle de idade. Em alguns casos o registro magnético de um único espécime pode representar um campo médio da ordem de centenas de anos até dezenas de milhares de anos (e.g. Carlut e Courtillot, 1998). A diferença de registro do campo nesses dois tipos de material implica que a base de dados para os últimos 5 Ma seja composta na sua maior parte por dados de direção (declinação e inclinação) obtidos em rochas vulcânicas. Dados de paleointensidade absoluta obtidos em rochas vulcânicas são muito escassos por causa dos problemas de alteração magnética que ocorrem durante os experimentos em laboratório. A base de dados paleomagnéticos para os últimos 5 Ma foi recentemente compilada por Johnson et al. (2008). 
Nesta compilação, os dados estão espacialmente distribuídos em diferentes locais entre $78^{\circ} \mathrm{S}$ e $53^{\circ} \mathrm{N}$ (em latitude) e mais concentrados ao longo das Américas (em longitude). A distribuição temporal dos dados mostra que $67 \%$ deles concentram-se no chron de Brunhes $(0-0,78 \mathrm{Ma})$ e $26 \%$ entre os chrons de Brunhes e de Matuyama (0,78-2,58 Ma).

\subsubsection{Dados de observatórios e satélites}

O campo geomagnético atual pode ser estudado a partir de medidas diretas de direção (declinação e inclinação) e intensidade total feitas pelos observatórios magnéticos e pelos satélites. As primeiras medidas de satélites iniciaram na década de $70 \mathrm{com}$ a missão POGO, que operou entre 1965 e 1971 e efetuou apenas a medida do campo escalar (intensidade total). Nas missões seguintes iniciaram-se as medidas do vetor completo. Elas compreendem as missões Magsat (1979-1980), Oersted (1999), CHAMP (2000), SAC-C (2000-2004) e, por fim, a missão da ESA Swarm Sattelite Constellation, que entrará em operação em 2011 (e.g. Friis-Christensen et al., 2006). Os dados geomagnéticos obtidos por satélites apresentam uma excelente cobertura espacial e também asseguram que o campo em diferentes regiões da Terra seja medido pelo mesmo instrumento. A desvantagem das medidas feitas pelos satélites é que elas contém implicitamente uma incerteza associada ao posicionamento do satélite (que se move a uma velocidade de $\sim 8 \mathrm{~km} / \mathrm{s}$ ), além dos problemas associados às variações temporais do campo geomagnético externo. A altitude da órbita dos satélites varia entre $300 \mathrm{~km}$ e $850 \mathrm{~km}$ em relação à superfície da Terra e a precisão das medidas fica entre 0,5 nT e 2 nT (e.g. Olsen et al., 2006).

Antes do advento dos satélites, todas as medidas do campo eram realizadas somente pelos observatórios na superfície da Terra. As primeiras medidas do CMT começaram a ser feitas em meados do século XVI, com dados de declinação e inclinação medidos pelos observatórios de Londres (Malin e Bullard, 1981), Paris (Alexandrescu et al., 1996), Roma (Cafarella et al., 1992) e Edimburgo (Barraclough, 1995). Estes mesmos observatórios iniciaram as medidas de intensidade total somente por volta de 1840 AD. Atualmente, cerca de 150 observatórios magnéticos estão distribuídos pelo globo e aqueles que atendem a rígidos critérios de controle das medidas, disponibilizando-as em tempo real, fazem parte do consórcio internacional de observatórios INTERMAGNET. Por permanecerem fixos, os observatórios apresentam a vantagem de poderem registrar as variações contínuas do CMT e servirem de referência para as medidas feitas pelos satélites. A desvantagem reside no fato da cobertura espacial ser desigual ao longo da superfície da Terra, com forte concentração de 
observatórios na Europa e na América do Norte, e escassez de observatórios no hemisfério Sul e nos oceanos. O avanço tecnológico dos sensores magnéticos permite atualmente uma precisão de medida entre $\pm 1 \mathrm{nT}$ e $\pm 5 \mathrm{nT}$, que varia em função do equipamento e da resolução temporal adotada pelo observatório.

\subsubsection{Dados arqueomagnéticos}

Os dados arqueomagnéticos provém de medidas diretas e indiretas do CMT. As medidas diretas advêm dos dados direcionais de declinação e inclinação obtidos pelos navegadores durante o período das grandes navegações, compreendido entre os séculos XVI e XIX (e.g. Bloxham et al., 1989; Jonkers et al., 2003). A compilação feita por Jonkers et al. (2003), que é a mais utilizada para fins de modelagem, compreende um extenso banco de dados com 151.560 dados de declinação, 19.525 dados de inclinação e 16.219 dados de intensidade. Os dados de declinação dominam amplamente a distribuição temporal dos dados ao longo desses quatro séculos. Os dados de inclinação começaram a ser feitos no final do século XVI. Porém, esses dados são muito mais escassos em comparação com os dados de declinação. Os primeiros dados de intensidade são aqueles obtidos por Gauss em 1832. Temporalmente, a maior parte das medidas concentra-se entre os séculos XVIII (85.070 dados) e XIX (78.162 dados), sendo que apenas 13.673 dados foram coletados no século XVII. Espacialmente, os dados estão dominantemente concentrados nos Oceanos Atlântico e Índico, com muito menos dados nas regiões polares e no Oceano Pacífico. Jackson et al. (2000) desenvolveram uma técnica para estimar os erros das medidas, levando em conta a influência de anomalias crustais e as incertezas de posicionamento. Os resultados mostraram que o erro de medida devido a essas fontes foi de $0,5^{\circ} \mathrm{em}$ média para os dados de declinação.

O CMT para intervalos de tempo da ordem de séculos a milênios pode ser estudado pelas medidas indiretas de direção (declinação e inclinação) e intensidade, a partir da análise da magnetização remanente registrada em materiais arqueológicos e geológicos. Os materiais arqueológicos utilizados para determinação da intensidade do CMT incluem principalmente cerâmicas, telhas e tijolos. Os dados direcionais são obtidos em fornos, solo queimado e pinturas rupestres. Os materiais geológicos mais utilizados para estudos desse tipo são as rochas vulcânicas de erupções históricas e os sedimentos recentes. Apesar dos registros arqueológicos e geológicos apresentarem um limite de até 50.000 anos (compilação GEOMAGIA, feita por Korhonen et al., 2008), grande parte deles apresenta datações acuradas somente em materiais com idades de até 10.000 anos (e.g. Korte et al., 2005; 
Genevey et al., 2008; Korhonen et al., 2008; Donadini et al., 2009). Neste aspecto, os estudos em materiais arqueológicos apresentam melhores condições para datação e determinação dos elementos geomagnéticos do que aqueles efetuados em materiais geológicos. A análise de dados arqueomagnéticos dos últimos 10.000 anos revela que a maior parte concentra-se no hemisfério Norte (principalmente na Europa) e nos últimos 4.000 anos. Para este intervalo de tempo, a compilação mais recente inclui 2877 dados de declinação, 4304 dados de inclinação e 3001 dados de intensidade (Figura 1.3; Donadini et al., 2009). A distribuição espacial desses dados mostra que o hemisfério Sul contribui com menos de 3\% dos dados arqueomagnéticos (direção e intensidade) da base de dados mundial. No caso dos dados de intensidade, o hemisfério Sul contribui com aproximadamente 5\% dos dados globais, sendo que desse conjunto $\sim 3,7 \%$ foram obtidos em materiais arqueológicos do Peru, Equador e Bolívia datados entre 2000 AC e 1800 AD (Genevey et al., 2008; Donadini et al., 2009). Além da escassez de dados no hemisfério Sul, a qualidade dos dados obtidos é motivo de debate (e.g. Genevey et al., 2008; Donadini et al., 2009). Alguns desses dados foram obtidos há mais de duas décadas e não obedecem aos critérios mínimos de qualidade utilizados atualmente. Por exemplo, na maioria dos dados de intensidade não foram efetuados testes de estabilidade térmica durante as medidas nem correções magnéticas de anisotropia e taxa de resfriamento. Outro fator que interfere na qualidade dos dados arqueomagnéticos é a datação. Boa parte das amostras foi datada por métodos radiométricos, que apresentam incertezas de idades superiores àquelas determinadas por critérios arqueológicos e/ou históricos (e.g. Genevey et al., 2008; Genevey et al., 2009).

A escala de tempo arqueomagnética permite definir a periodicidade do momento de dipolo axial, o principal termo de representação do CMT. Contudo, o forte desequilíbrio em quantidade e qualidade dos dados direcionais e de intensidade é um fator limitante ao desenvolvimento dos modelos que traçam a evolução do campo. Portanto, dados nessas escalas de tempo e em regiões ainda pouco estudadas são essenciais para a compreensão de aspectos fundamentais do geodínamo. É a partir desses dados que diferentes fenômenos de origem interna do CMT podem ser estudados, tais como: a deriva para Oeste, as variações do campo não-dipolar e o comportamento do CMT durante uma reversão. 

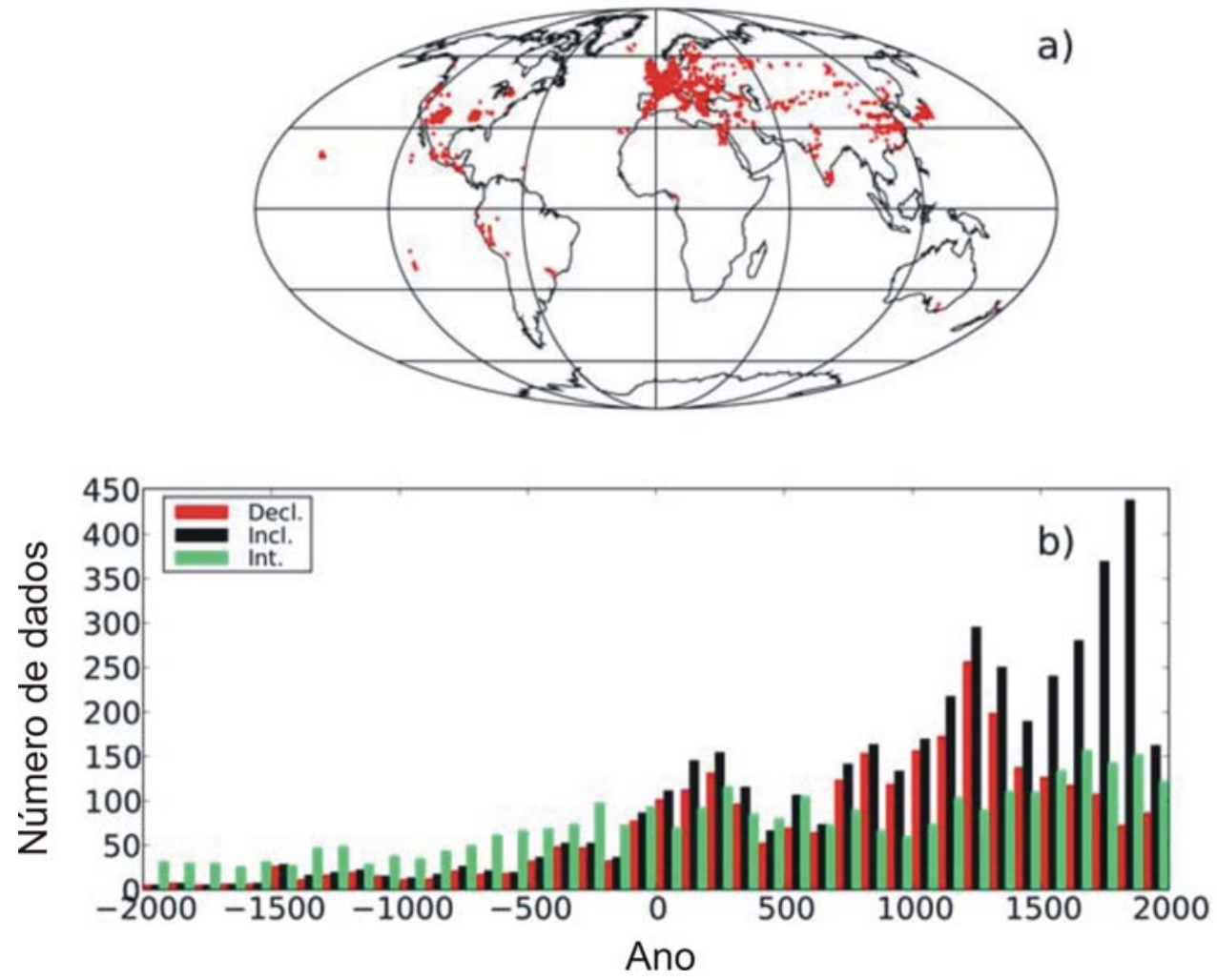

Figura 1.3: Distribuição dos dados arqueomagnéticos para os últimos 4000 anos. Em (a), a distribuição geográfica dos dados no globo; em (b), a distribuição temporal das declinações (vermelho), inclinações (preto) e intensidade total. Os dados estão agrupados em intervalos de 100 anos. Os anos em negativo indicam anos AC (Antes de Cristo) e os anos positivos indicam anos AD (Ano do Senhor). Figura modificada de Donadini et al. (2009).

\subsection{Modelos de campo para os últimos milênios}

Como visto acima, os modelos por harmônicos esféricos são desenvolvidos pela inversão de dados de direção e intensidade do CMT. Para o período de 1900 em diante, a IAGA tem se encarregado de desenvolver o International Geomagnetic Reference Field (IGRF), que é elaborado a cada cinco anos a partir dos dados de observatórios e satélites. O IGRF é considerado um modelo de alta resolução. Para o intervalo entre 1900 e 1995 os coeficientes de Gauss dos modelos são truncados até grau e ordem $n=m=10$, enquanto os modelos de 2000 em diante são truncados até grau e ordem $n=m=13$ com erro de $0,1 \mathrm{nT}$. O IGRF é mundialmente utilizado para fins de pesquisa, navegação e prospecção mineral (e.g. Maus et al., 2005a). Há também outros modelos de alta resolução, tais como: o World Magnetic Model - WMM (desenvolvido pelo British Geological Survey e pelo US Geological Survey), o Comprehensive Model - CM4 (Sabaka et al., 2004), o POtsdam Magnetic Model of 
the Earth - POMME (Maus et al., 2005b) e o CHAMP, Ørsted and SAC-C Model - CHAOS (Olsen et al., 2006).

Para períodos anteriores a 1900 AD, os modelos se baseiam em medidas diretas e também indiretas. Um dos primeiros modelos para os últimos 400 anos foi desenvolvido por Barraclough (1974), que utilizou exclusivamente os dados de navegadores. Esse modelo incorpora apenas dados direcionais e tem baixa resolução, com truncamento em $n=m=4$. Nos modelos mais recentes foram utilizadas técnicas de inversão mais avançadas e contaram com um acervo de dados direcionais muito mais amplo, resultado da compilação dos registros de diversas campanhas marítimas efetuadas nos séculos XVI a XIX, além de dados mais recentes de observatórios e satélites (Bloxham e Gubbins, 1985; Bloxham e Jackson, 1989; Bloxham et al., 1989; Bloxham e Jackson, 1992; Jackson et al., 2000). Entre estes, o modelo mais utilizado atualmente para estudos da variação secular do CMT é o gufm1 desenvolvido por Jackson et al. (2000). O gufm1 é um modelo de alta resolução espacial truncado até $n=m=14$, que descreve o CMT com resolução temporal de um ano para o período compreendido entre 1590 AD e 1990 AD. Tendo em vista a ausência de dados de intensidade para períodos anteriores a $1840 \mathrm{AD}$, Jackson et al. (2000) foram obrigados a definir de forma arbitrária a evolução do $g_{1}^{0}$ entre 1590 AD e 1840 AD. Para tal, os autores utilizaram o mesmo ajuste de Barraclough (1974), onde o $g_{1}^{0}$ varia de forma constante de $-15 \mathrm{nT} / \mathrm{ano}$. No entanto, esse ajuste parece ser inadequado quando o comparamos com o conjunto de dados arqueomagnéticos atualmente disponível (e.g. Gubbins et al., 2006; Finlay, 2008; Genevey et al., 2009). Mais recentemente, Gubbins et al. (2006) e Finlay (2008) utilizaram a mesma geometria de campo do modelo gufm1, porém, incorporaram dados de intensidade total obtidos em materiais arqueológicos para o período de 1590 AD a 1850 AD. Gubbins et al. (2006) determinaram uma variação de $2.28 \pm 2.72 \mathrm{nT} /$ ano para o $g_{1}^{0}$. Por outro lado, Finlay (2008) argumenta que as eventuais variações do $g_{1}^{0}$ neste intervalo de tempo estão compreendidas nos erros de ajuste e prefere propor um comportamento constante para o $g_{1}^{0}$ no mesmo período. A Figura 1.4 mostra a evolução do $g_{1}^{0}$ nos diferentes modelos do CMT discutidos anteriormente. 


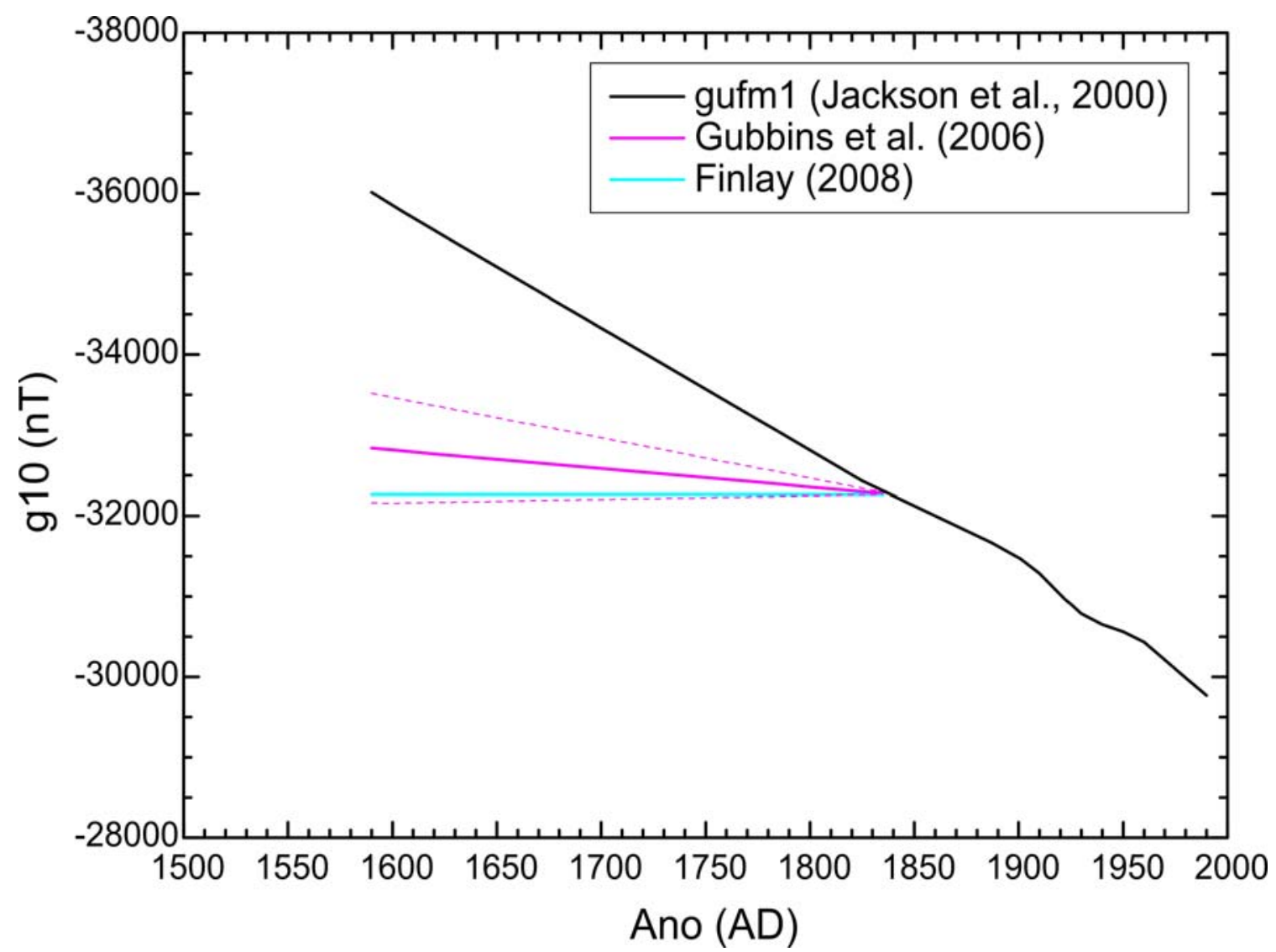

Figura 1.4: Variação do $g_{1}^{0}$ determinado pelos modelos para o intervalo de tempo histórico. A curva em preto representa o modelo gufm1 (Jackson et al., 2000), a curva em rosa representa o modelo de Gubbins et al. (2006) (as curvas em tracejado rosa representam os limites superior e inferior desse modelo), e a curva em azul representa o modelo de Finlay (2008).

Outros modelos com menor resolução temporal e espacial foram desenvolvidos a partir de dados obtidos em materiais arqueológicos e geológicos (Constable et al., 2000; Korte e Constable, 2003; Korte e Constable, 2005a; Korte et al., 2009). Os modelos do tipo Continuous Archeomagnetic and Lake Sediment Geomagnetic Model (CALSxK) foram construídos para dois intervalos distintos de tempo: os modelos de 3.000 anos (modelos $3 \mathrm{~K}$ ) e os modelos de 7.000 anos (modelos 7K). Para os últimos 7.000 anos, o modelo CALS7K.2 (Korte e Constable, 2005a) foi desenvolvido com dados arqueomagnéticos e dados de sedimentos de lagos, ambas as bases apresentando dados direcionais e de intensidade (Korte et al., 2005). Apesar desse modelo descrever o CMT continuamente para os últimos 7.000 anos, os coeficientes de Gauss são bastante "suavizados" no tempo. Isso ocorre porque o modelo incorpora dados de fontes bastante distintas, como é o caso de dados de intensidade em materiais arqueológicos e os dados direcionais em sedimentos de lagos. Além disso, os registros arqueomagnéticos mostram que nesse modelo o $g_{1}^{0}$ não está bem ajustado para os últimos 500 anos (e.g. Genevey et al., 2009). Os modelos para os últimos 3.000 anos (1000 
AC a 1950 AD), CALS3K.1 (Constable et al., 2000) e CALS3K.2 (Korte e Constable, 2003) foram construídos com dados arqueomagnéticos (direção e intensidade), dados de derrames basálticos, sedimentos de lagos, além de incorporar medidas diretas dos observatórios magnéticos. O truncamento em ambos foi de grau e ordem 10 para os coeficientes de Gauss. A diferença entre os modelos construídos em 2000 (CALS3K.1) e 2003 (CALS3K.2) é o aumento do número de dados utilizados. Mais recentemente, Korte et al. (2009) construíram cinco modelos distintos para os últimos 3000 anos, utilizando diferentes bases de dados compilados por Korte et al. (2005), Korhonen et al. (2008), Genevey et al. (2008) e Donadini et al. (2009). A Figura 1.3 mostra a distribuição dos dados arqueomagnéticos utilizados na construção destes modelos. É importante notar que o período de 3.000 anos foi escolhido, pois apresenta a maior concentração de dados de direção e intensidade. O primeiro e o segundo modelo (ARCH3K.1 e ARCH3K_cst.1, respectivamente) foram construídos com base apenas nos dados arqueomagnéticos, sendo que o ARCH3K.1 incorpora todos os dados arqueomagnéticos existentes para os últimos 3.000 anos, enquanto que o ARCH3K_cst.1 incorpora somente os dados arqueomagnéticos que atendem aos critérios de seleção de dados (estimativas de erros) determinados por Donadini et al. (2009). Como o hemisfério Norte contribui com a grande maioria dos dados, estes modelos descrevem melhor a evolução do CMT naquele setor do planeta, o que limita a utilização deste modelo para estudos globais (Korte et al., 2009). O terceiro modelo é baseado somente nos dados de sedimentos de lagos (SED3K.1). Este critério foi escolhido porque a aquisição da magnetização em sedimentos é bastante distinta daquela de materiais arqueológicos (Donadini et al., 2009), conseqüentemente, o modelo também é distinto dos modelos baseados em dados arqueomagnéticos. Conforme Korte et al. (2009), o SED3K.1 é significativamente diferente dos dois primeiros modelos devido à baixa qualidade dos dados de sedimentos. Os dois últimos modelos (CALS3K.3 e CALS3K_cst.1) foram desenvolvidos a partir da combinação dos dados arqueomagnéticos e sedimentares. O modelo CALS3K.3 incorpora as duas bases de dados, enquanto que o CALS3K_cst.1 incorpora somente os dados que atendem aos critérios de seleção estabelecidos por Donadini et al. (2009). Segundo Korte et al. (2009), a comparação entre os modelos ARCH3K.1, ARCH3K_cst.1, CALS3K.3 e CALS3K_cst.1 mostra que alguns deles descrevem bem a evolução do campo no hemisfério Norte (ARCH3K.1, ARCH3K_cst.1 e CALS3K_cst.1), enquanto que o CALS3K.3 seria o mais adequado para os estudos globais do campo.

Em resumo, com base nos diferentes modelos de campo disponíveis para os períodos histórico e pré-histórico, observa-se que vários fatores contribuem para a sua resolução 
temporal e espacial. Os principais fatores que limitam o desenvolvimento de modelos de campo são as acurácias das medidas de campo e as idades dos materiais arqueológicos e geológicos estudados, a distribuição espacial dos dados e a resolução temporal das medidas (e.g. Hulot et al., 2010). A discrepância na distribuição dos dados para os períodos histórico e pré-histórico e a escassez de dados no hemisfério Sul impedem atualmente uma melhor solução para o $g_{1}^{0}$.

\subsection{Variação do CMT para os últimos milênios}

\subsubsection{As variações do campo dipolar}

Em escalas de tempo de alguns milênios umas das principais características do CMT que podem ser observadas são as variações do campo dipolar. Uma aproximação normalmente utilizada para estudar o campo dipolar refere-se ao momento de dipolo, que pode ser estimado pelo cálculo dos momentos de dipolo virtual axial (VADM) ou dos momentos de dipolo virtual (VDM). O momento de dipolo ( $p$ ) é determinado a partir de um dado de intensidade total $B$ :

$$
p=\frac{4 \pi a^{3}}{\mu_{0}} \cdot \frac{B}{\sqrt{1+3 \cos ^{2} \theta}}
$$

Se a inclinação $(I)$ for conhecida para a posição onde foi determinada a intensidade, a colatitude magnética $\left(\theta_{m}\right)$ pode ser determinada pela relação trigonométrica:

$$
\tan I=2 \cot \theta_{m}
$$

nesse caso $\theta_{m}$ pode ser usado na equação (1.15) e o $p$ determinado corresponde a um VDM, que é o momento magnético de um dipolo, que pode ser um dipolo inclinado. Caso o valor da inclinação $(I)$ seja desconhecido utiliza-se diretamente a colatitude geográfica do local de amostragem $\theta$ e o $p$ representa um VADM.

Utilizando as últimas compilações de dados arqueomagnéticos feitas por Valet et al. (2008), Genevey et al. (2008), Donadini et al. (2009) e os modelos de campo de Korte e Constable (2005b) e Korte et al. (2009), pode-se avaliar a evolução do CMT para os últimos 3 milênios. A Figura 1.5a mostra as variações do momento de dipolo para os últimos 3.000 anos com base nesses modelos. Todos os resultados obtidos mostraram que o momento de dipolo apresentou uma tendência de valores mais elevados para períodos anteriores ao século XV. O 
momento de dipolo obtido pelos modelos e pelas compilações oscilou de $\sim 11,6 \times 10^{22} \mathrm{Am}^{2} \mathrm{em}$ $400 \mathrm{AC}$ até os valores atuais em torno de $7,8 \times 10^{22} \mathrm{Am}^{2}$. Pode-se observar também a ocorrência de alguns 'picos' de intensidade a 900 AC, 400 AC, 400 AD e 1100 AD (Genevey et al., 2008). Entretanto, esses picos não são reproduzidos em todas as compilações. Os modelos de campo CALS3K.3 e ARCH3K.1 são parecidos dentro das incertezas, enquanto que o modelo CALS7K.2 apresenta valores inferiores aos outros modelos e aos momentos de dipolo determinados pelas compilações. As incertezas das compilações são condizentes com os valores previstos pelo modelo ARCH3K.1, exceto para o intervalo de 300 AD a 1200 AD. A diferença entre os modelos CALS7K.2 e CALS3K.3 pode ser devida, em parte, à suavização dos dados de sedimentos. Entretanto, Korte e Constable (2005b) indicam que diferentes tendências de variação de intensidade em diferentes locais do globo podem afetar as tendências nas médias dos VADM/VDM. Além disso, componentes não-dipolares podem persistir por alguns séculos. A fim de tentar minimizar este efeito, Genevey et al. (2008) calcularam médias de VADM/VDM para oito regiões diferentes do globo em intervalos temporais de 200 anos. Em seguida, determinaram médias "globais" dos VADM/VDM onde cada região teve o mesmo peso estatístico no cálculo da média global. No entanto, o problema da má distribuição de dados é evidente, pois apenas um setor do hemisfério Sul contribuiu para o cálculo global dos VADM/VDM. Na compilação de Valet et al. (2008) também foram calculadas médias regionais dos VADM/VDM. Cada média foi calculada em intervalos de 25 anos e integrados em médias globais de 100 anos. Em seguida os dados foram ajustados por um polinômio de grau 3, sugerindo que toda a variação do CMT seria descrita por um dipolo simples na escala dos últimos 2.000 anos. A diferença entre as compilações de Valet et al. (2008) e Genevey et al. (2008) é que a última utiliza uma quantidade maior de dados e faz uma revisão detalhada da qualidade dos dados de paleointensidade da base mundial.

Outra aproximação utilizada para estudar o campo dipolar refere-se à determinação da posição do dipolo. O pólo geomagnético virtual (VGP) é descrito pelas posições em latitude $\left(\lambda_{p}\right)$ e longitude $\left(\phi_{p}\right)$ a partir das medidas de declinação $(D)$ e inclinação $(I)$ em um determinado sítio com posições de latitude $\lambda_{s}$ e longitude $\phi_{s}$, tal que:

$\sin \lambda_{p}=\sin \lambda_{s} \cos \theta+\cos \lambda_{s} \sin \theta \cos D$

sendo $\cot \theta=\tan I / 2$. O valor de $\phi_{p}$ é dado por:

$\phi_{p}=\phi_{s}+\beta \quad$ se $\cos \theta \geq \sin \lambda_{s} \sin \lambda_{p}$ 
ou então é dado por:

$\phi_{p}=\phi_{s}+180-\beta \quad$ se $\cos \theta<\sin \lambda_{s} \sin \lambda_{p}$

onde $\beta=\sin \theta \sin D / \cos \lambda_{p}$.

Em ambos os casos, a declinação e a inclinação são devidas exclusivamente a um dipolo inclinado e novamente as contribuições não-dipolares não são consideradas.

a)

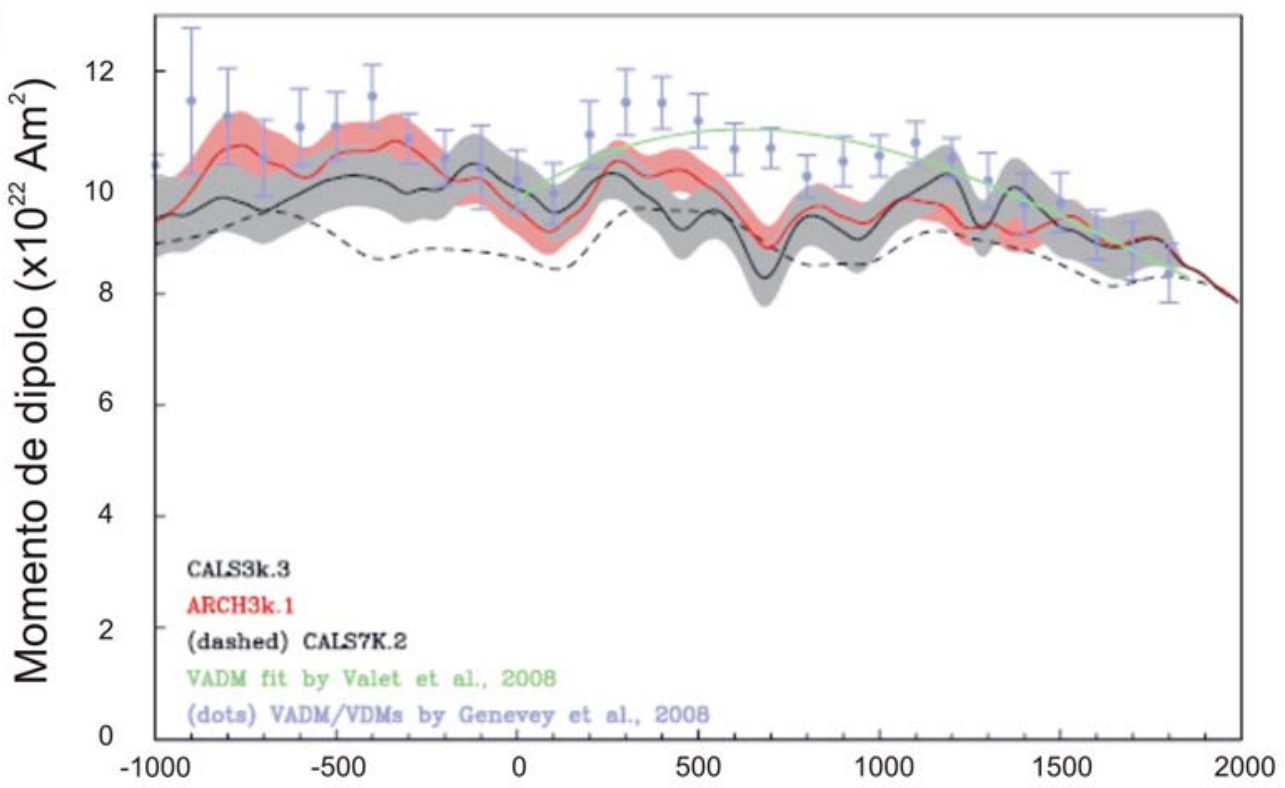

b)

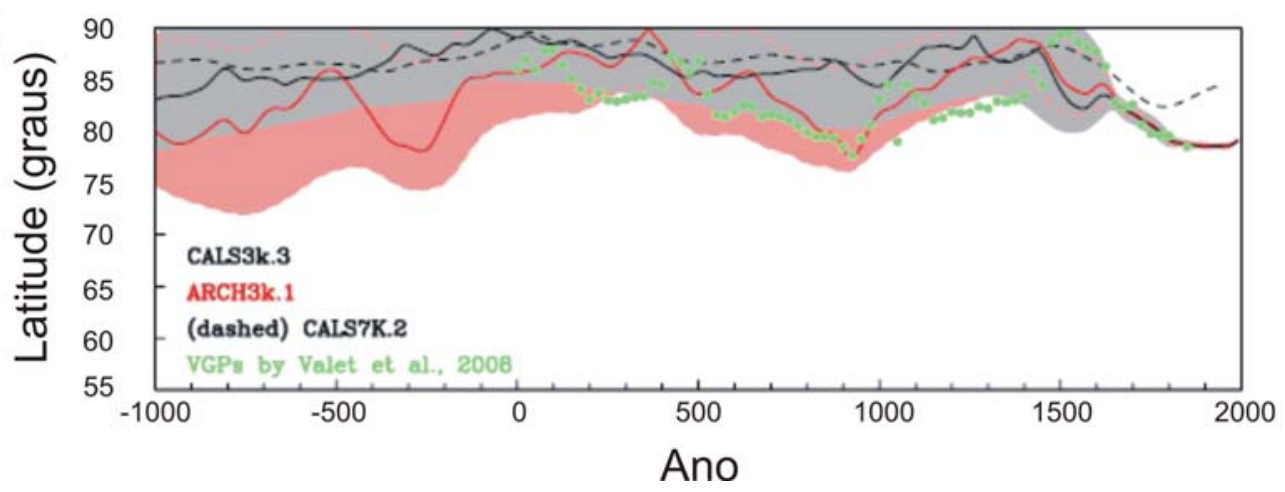

Figura 1.5: Em (a), o momento de dipolo e em (b) a latitude do eixo do dipolo (dipolo inclinado) a partir de diferentes compilações e modelos. A linha em preto representa o modelo CALS3K.3, a linha tracejada em preto o CALS7K.2, a linha em vermelho o modelo ARCH3K.1 e, as áreas em cinza claro e vermelho claro representam as incertezas dos modelos CALS3K.3 e ARCH3K.1, respectivamente. A linha e os pontos em verde representam o ajuste do dipolo inclinado para a compilação de dados de Valet et al. (2008). Os pontos em azul representam as médias temporais dos VADM/VDM determinados por Genevey et al. (2008). Os anos em negativo indicam anos AC (Antes de Cristo) e os anos positivos indicam anos AD (Ano do Senhor). Figura modificada de Donadini et al. (2010).

Assim como no caso dos dados de intensidade, a maior parte dos dados arqueomagnéticos direcionais provêm do hemisfério Norte (e.g. Merril et al., 1998). Vários trabalhos têm descrito as variações direcionais do dipolo através da posição dos VGPs para os 
últimos milênios (e.g. Barbetti, 1977; Kovacheva e Veljovich, 1977; Kovacheva, 1980; Ohno e Hamano, 1992; Ohno e Hamano, 1993; Daly e Le Goff, 1996). De modo geral, todos estes trabalhos mostram que o dipolo oscila dentro de um "círculo polar" a $85^{\circ}$ de latitude Norte. Contudo, algumas migrações polares foram observadas tanto nas compilações de dados arqueomagnéticos para os últimos 2.000 anos (Daly e Le Goff, 1996), quanto nas compilações de dados sedimentares para os últimos 10.000 anos (Ohno e Hamano, 1992). A Figura 1.5b mostra a variação da latitude dos VGPs a partir das compilações e dos modelos de campo mais recentes. Os modelos CALS7K.2 e CALS3K.3 também variam dentro de um círculo a $85^{\circ}$ de latitude Norte e apresentam as mesmas incertezas, exceto para o intervalo histórico dos últimos 500 anos, quando o modelo CALS3K.3 incorpora a geometria do modelo gufm1 (Jackson et al., 2000). As diferenças entres os modelos que incorporam dados sedimentares (CALS7K.2 e CALS3K.3), o modelo ARCH3K.1 e a compilação de Valet et al. (2008), podem ser explicadas pela utilização de diferentes bases de dados. A compilação de Valet et al. (2008) ajusta o dipolo inclinado para os dados arqueomagnéticos da Europa, mas não ajusta para outras regiões, como Austrália, o Pacífico e o Sudeste da Ásia. O modelo ARCH3K.1 ajusta um pouco melhor os dados para o dipolo inclinado no hemisfério Sul, embora uma comparação com os dados sedimentares da Argentina revele que o modelo não ajusta adequadamente os dados (Donadini et al., 2010).

\subsubsection{Os jerks arqueomagnéticos}

Além das variações do dipolo, outra feição interessante revelada pelos dados arqueomagnéticos é a evidência de variações bruscas da direção e intensidade do campo, chamadas de "jerks arqueomagnéticos" ou "impulsos de variação secular em escalas de tempo arqueológicas" (Gallet et al., 2003). Nesse trabalho, os autores encontraram mudanças abruptas de direção e intensidade do CMT nos dados arqueomagnéticos para a Eurásia em $\sim 800 \mathrm{AC}, \sim 200 \mathrm{AD}, \sim 800 \mathrm{AD}$ e $\sim 1400$ AD (Figura 1.6). Outros trabalhos também determinaram variações bruscas de direção e intensidade do CMT em sedimentos de lagos da Suécia (Snowball e Sandgren, 2004), Canadá (Barletta et al., 2008) e somente na direção em materiais arqueológicos de diversos fornos estudados na Coréia do Sul (Yu et al., 2010). Para explicar essas feições, Gallet et al. (2009) sugeriram que os jerks arqueomagnéticos são gerados por variações na posição de um de dipolo excêntrico do geodínamo. No entanto, essa proposta foi efetuada utilizando o modelo CALS7K.2 (Korte e Constable, 2005a), que apresenta grandes problemas de ajuste dos coeficientes de baixo e alto grau no período mais 
recente. Além disso, as variações descritas no modelo não explicam os dados obtidos recentemente no hemisfério Sul do planeta.

a)

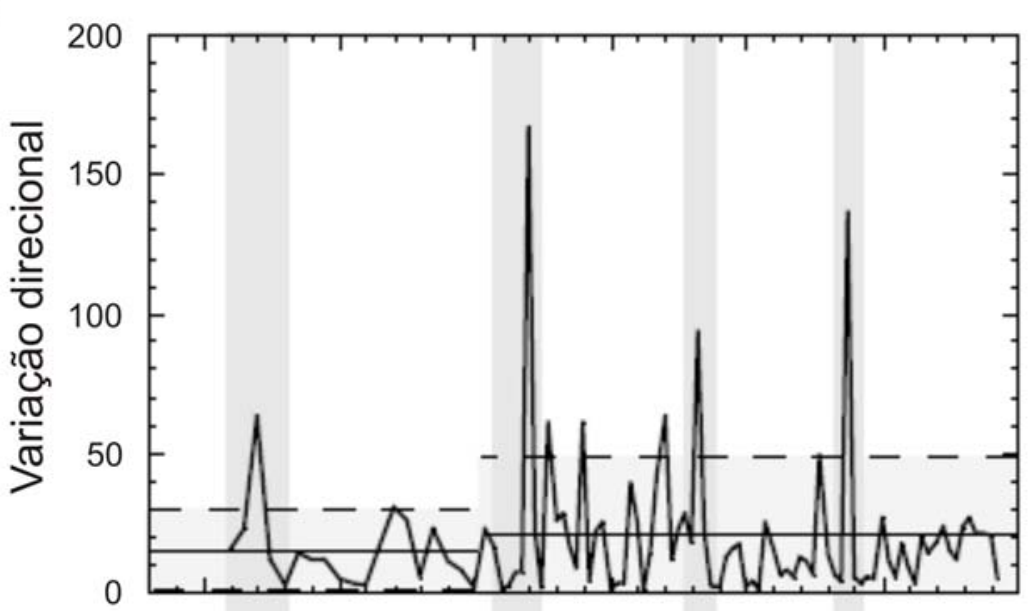

b)

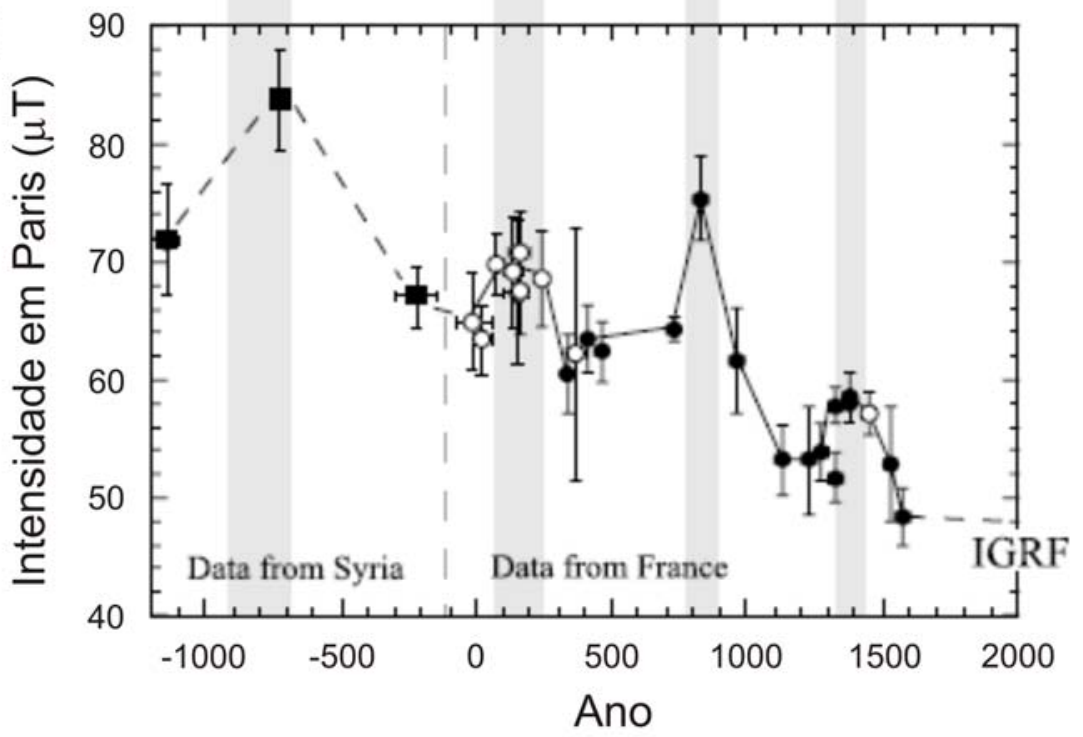

Figura 1.6: Em (a), variação da curva dos dados direcionais suavizados. As médias e variâncias dos dados da curva são dadas separadamente entre $1000 \mathrm{AC}$ e $0 \mathrm{AD}$ e entre $0 \mathrm{AD}$ e $2000 \mathrm{AD}$, pois têm diferentes resoluções. $\mathrm{O}$ pico na parte mais antiga e os três picos do intervalo mais recente coincidem com as mudanças direcionais bruscas e com os picos de intensidade em (b), como indicado através das bandas em cinza. Em (b), variação da curva de intensidade para a Europa e Oriente Médio nos últimos 3.000 anos. Os anos em negativo indicam anos $\mathrm{AC}$ (Antes de Cristo) e os anos positivos indicam anos AD (Ano do Senhor). Figura modificada de Gallet et al. (2003)

A completa caracterização dos jerks arqueomagnéticos demanda o aprimoramento da curva de variação do CMT na Eurásia, mas ainda mais importante é a necessidade de obtenção de novas curvas arqueomagnéticas em outros setores do globo, principalmente no hemisfério Sul. Na verdade, ainda não se pode afirmar se as mudanças abruptas em escala milenar são devidas exclusivamente ao comportamento dipolar do campo, ou se elas refletem 
a "passagem" de uma feição não-dipolar do campo, como aquela que ocorreu no hemisfério Sul nos últimos 500 anos em função do deslocamento do mínimo de campo total da África até o Brasil (Hartmann e Pacca, 2009). Os jerks arqueomagnéticos seriam, nesse caso, o reflexo de feições do campo não-dipolar persistentes em intervalos de tempo mais longos que o tempo histórico (ver também Constable et al., 2000).

\subsubsection{As variações do campo não-dipolar}

As variações do CMT para os últimos 500 anos são conhecidas como variações do período histórico (Carlut et al., 1999). Para esse intervalo de tempo, as variações podem ser analisadas através do momento de dipolo geomagnético $(m)$ e do deslocamento da posição do pólo geomagnético. Pode-se utilizar os coeficientes de grau e ordem $n=m=1$ em uma expressão semelhante à equação (1.15) para determinar $m$ :

$$
m=\frac{4 \pi a^{3}}{\mu_{0}} \sqrt{\left(g_{1}^{0}\right)^{2}+\left(g_{1}^{1}\right)^{2}+\left(h_{1}^{1}\right)^{2}}
$$

O pólo geomagnético Sul é o ponto onde a direção do momento de dipolo encontra a superfície da Terra e o pólo geomagnético Norte (NGP) é o seu antípoda. A colatitude geocêntrica e a longitude Leste do NGP são dadas, respectivamente, por:

$$
\begin{aligned}
& \theta_{N}=\cos ^{-1}\left(-\frac{g_{1}^{0}}{g}\right) \\
& \phi_{N}=\tan ^{-1}\left(\frac{h_{1}^{1}}{g_{1}^{1}}\right)
\end{aligned}
$$

onde $g=\sqrt{\left(g_{1}^{0}\right)^{2}+\left(g_{1}^{1}\right)^{2}+\left(h_{1}^{1}\right)^{2}}$. Note que os pólos definidos dessa maneira são distintos dos pólos magnéticos. A diferença é devido ao fato que os pólos magnéticos são afetados tanto pela parte dipolar quanto pela parte não-dipolar do campo.

Utilizando os coeficientes $\left(g_{1}^{0}, g_{1}^{1}, h_{1}^{1}\right)$ dos modelos do IGRF e gufml na equação (1.20) pode-se ter uma estimativa da variação do momento de dipolo desde 1840 AD. Durante o período entre $1840 \mathrm{AD}$ e $2005 \mathrm{AD}$, a diminuição do momento de dipolo foi de $0,73 \times 10^{22} \mathrm{Am}^{2}$, o que corresponde a um decréscimo da ordem de 5,4\% por século (Figura 1.7). Como muitos autores têm notado, se o atual decréscimo continuar na mesma taxa linear, o momento de dipolo deverá ser reduzido a zero dentro de aproximadamente 2.000 anos (e.g. Fraser-Smith, 1987; Merrill et al., 1998; Olson, 2002). No entanto, dados arqueomagnéticos indicam que as variações do momento de dipolo oscilam entre máximos e mínimos, sem 
apresentar ciclicidade clara (e.g. Constable e Korte, 2006). Os modelos do IGRF e o modelo gufm1 podem ser utilizados para determinar a posição do momento de dipolo para todo o período histórico a partir das equações (1.21) e (1.22). A Figura 1.8 mostra a variação de latitude e longitude do NGP. Entre 1590 AD e 1810 AD, a variação em latitude (distanciamento do pólo Norte geográfico) foi de $4,5^{\circ}$ para $11,5^{\circ}$, numa taxa média de 0,03\% ano. Neste mesmo intervalo de tempo a longitude (deriva para Oeste) variou em $36^{\circ}$, com uma taxa média de -0,16\%ano. De 1810 AD a 1960 AD, a posição Norte-Sul praticamente não variou, enquanto a deriva para Oeste foi de $8^{\circ}$, com uma taxa de $-0,05^{\circ} /$ ano. A partir de 1960 AD, o NGP voltou a ter um deslocamento para o Norte de aproximadamente $1^{\mathrm{o}}\left(0,02^{\mathrm{o}} / \mathrm{ano}\right)$ e a deriva para Oeste permaneceu constante em $-0,05^{\circ} / \mathrm{ano}$. A deriva para Oeste do NGP é bem marcada na Figura 1.8 e pode ser utilizada como evidência para a rotação diferencial do núcleo externo com relação ao manto e à crosta (e.g. Bullard et al., 1950).

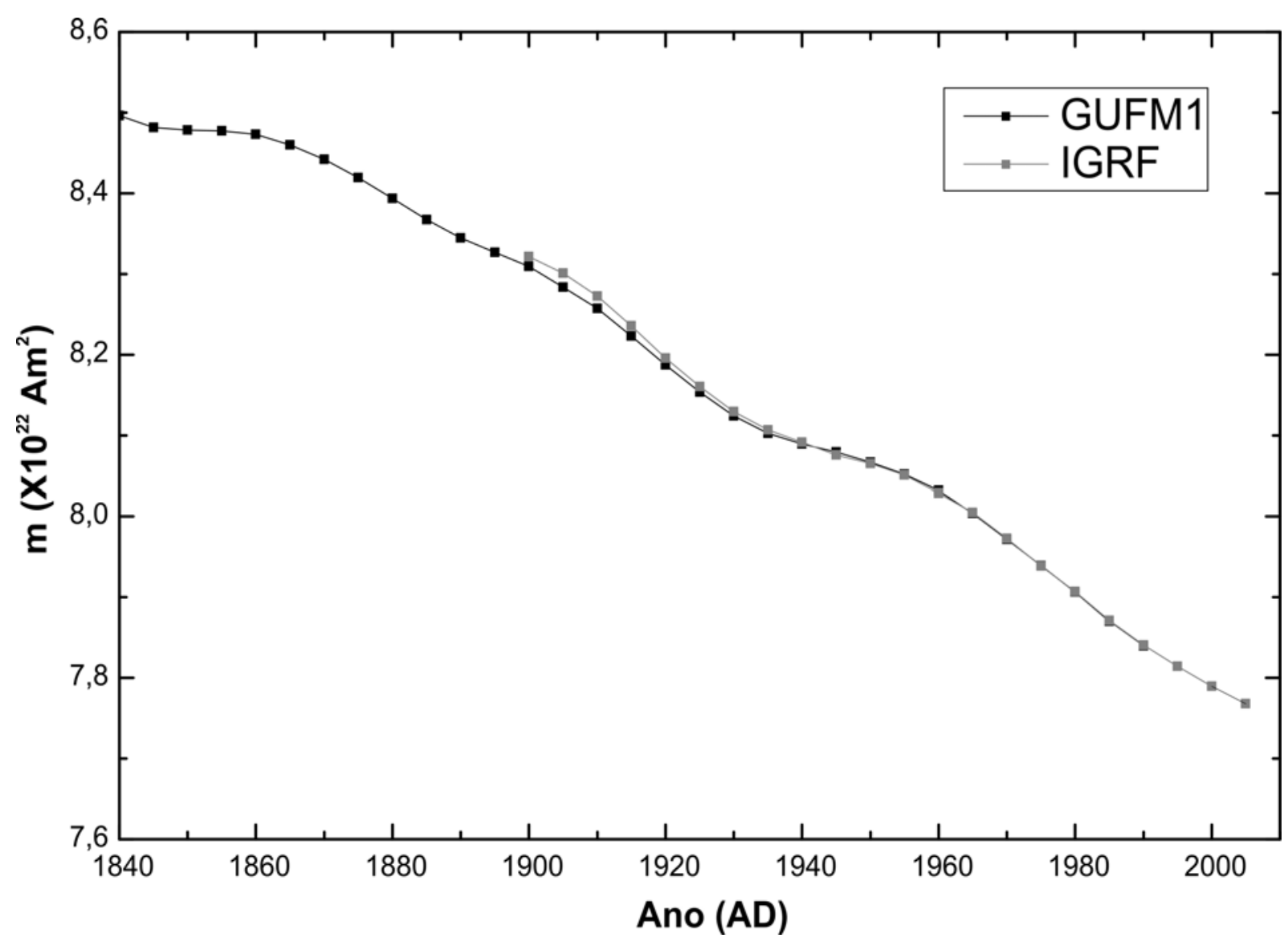

Figura 1.7: Variação do momento de dipolo geomagnético para o período histórico obtido pelos modelos GUFM1 e IGRF. 


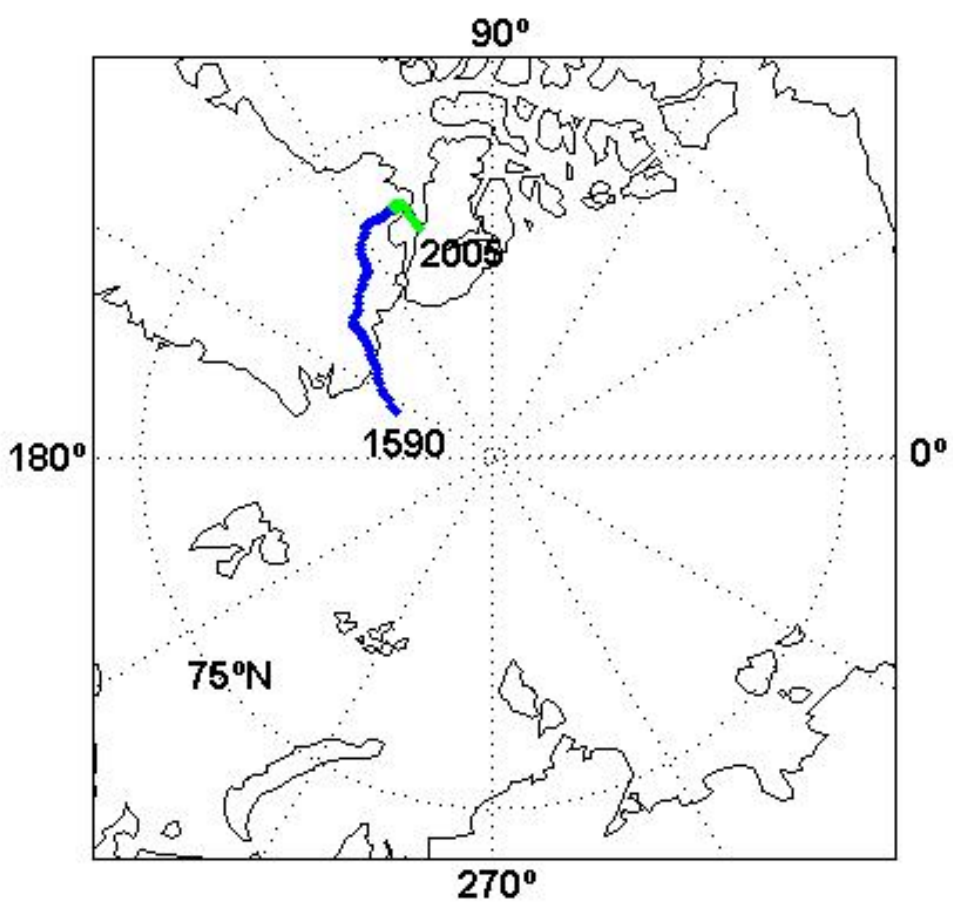

Figura 1.8: Posição do NGP utilizando os modelos GUFM1 (círculos em azul) e IGRF (círculos em verde); projeção estereográfica.

Embora as variações do campo dipolar pareçam significativas, as grandes variações na direção e intensidade do CMT durante os últimos 500 anos estão associadas dominantemente à parte não-dipolar do campo. Isto pode ser visualizado através do movimento para Oeste de vários focos isopóricos (máximos ou mínimos) para cartas isomagnéticas de diferentes épocas (Figura 1.9). As análises destes dados indicam que a deriva para Oeste do campo não-dipolar é primariamente confinada à região do Atlântico Sul. O campo não-dipolar é muito menos significativo em outras partes do globo. Uma das feições mais importantes do campo magnético não-dipolar para a escala de tempo histórico é a Anomalia Magnética do Atlântico Sul (SAMA). A análise de modelos do campo para o período de 1590-2005 AD indica que esta anomalia é uma feição persistente do CMT para os últimos 5 séculos e pode estar relacionada a efeitos de instabilidade na interface mantonúcleo, que são as principais fontes geradoras do campo não-dipolar. No caso da SAMA, nota-se que fontes de quadrupolo são persistentes no tempo e podem estar diretamente ligadas à origem da anomalia (Hartmann e Pacca, 2009). O campo não-dipolar aumentou com o tempo e como a SAMA é uma anomalia de baixa intensidade total, pode-se considerar as quatro partes do campo (total, não-dipolar, quadrupolar e octupolar) separadamente, de modo a fornecer informações importantes sobre o comportamento do campo. 
a) 1590

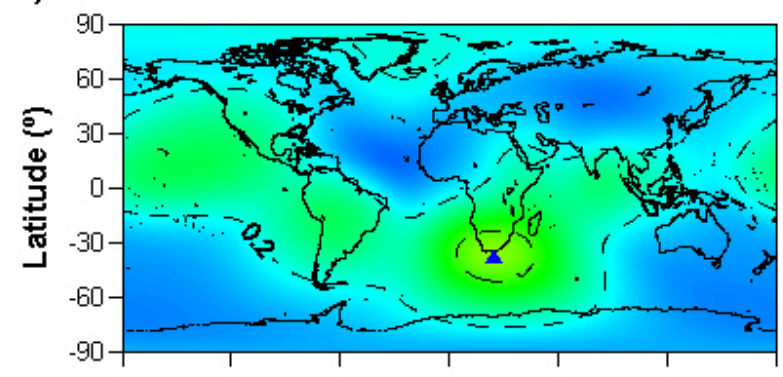

c) 1790

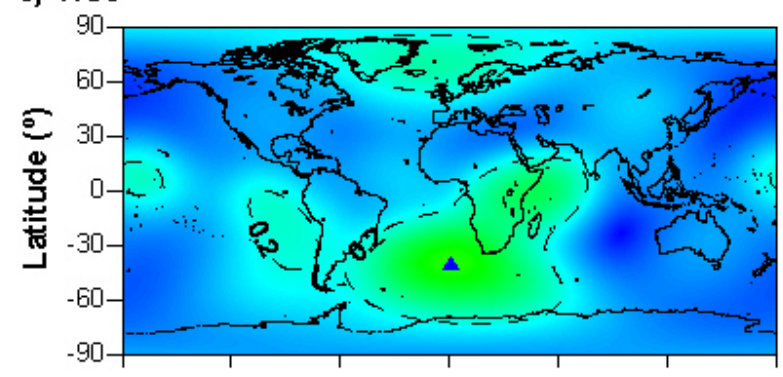

e) 1950

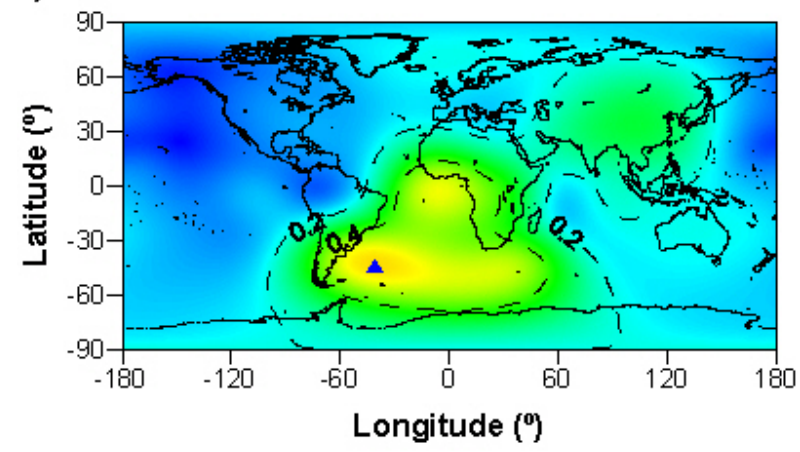

b) 1690

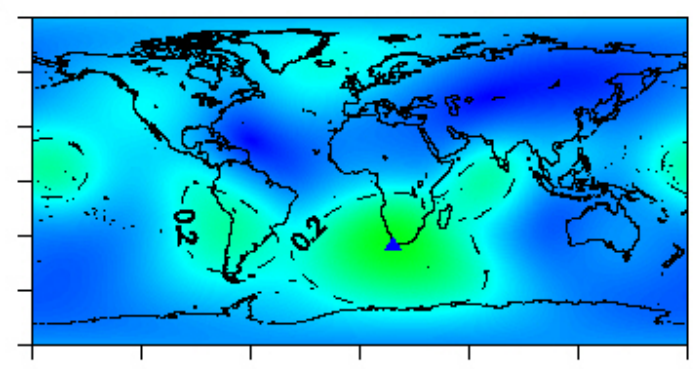

d) 1890

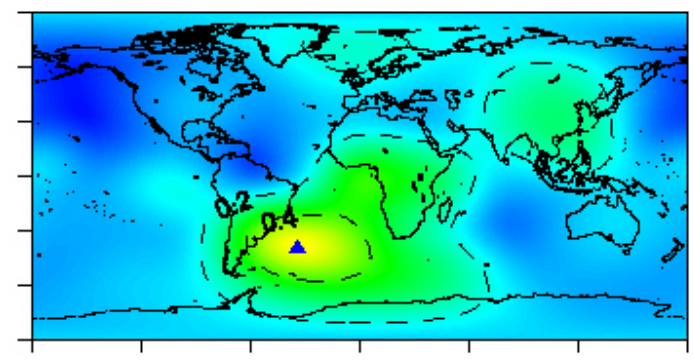

f) 2005

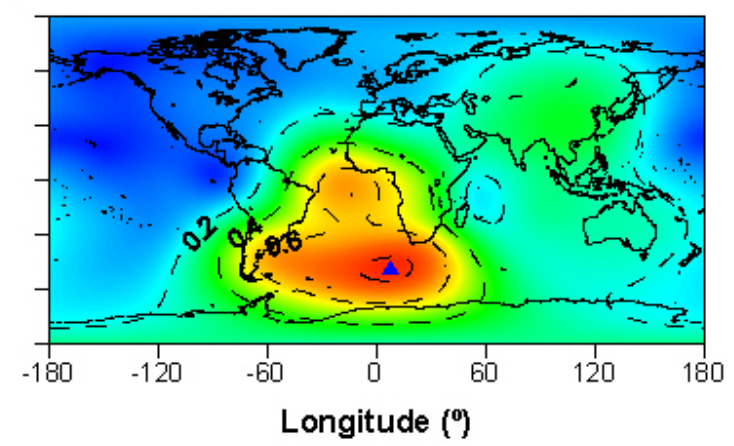

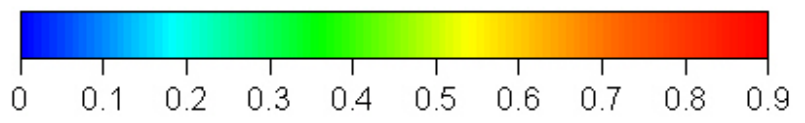

Figura 1.9: Razão do campo não-dipolar pelo total, utilizando os modelos gufm1 e IGRF. O triângulo denota o centro dos pontos de máxima razão. Modificado de Hartmann e Pacca (2009).

A Figura 1.10a mostra um quadro comparativo entre a razão da soma dos coeficientes (não-dipolares/total - NPT, quadrupolar/total - QPT e octupolar/total - OPT) e os valores de máximos dessas razões no globo. Estes máximos correspondem a anomalias que se encontram exclusivamente no Atlântico Sul. Atualmente, a contribuição não-dipolar para essas anomalias é de aproximadamente $17 \%$ do campo total. Para o século passado, a parte não-dipolar aumentou cerca de 5\%, enquanto a parte dipolar diminuiu cerca de $5 \%$. A partir de $\sim 1750 \mathrm{AD}$, as fontes de campo não-dipolar, quadrupolar e octupolar apresentam um aumento bastante significativo. Atualmente, o máximo não-dipolar alcança $85 \%$ do campo total e os máximos quadrupolares e octupolares $48 \%$ e $40 \%$, respectivamente. 

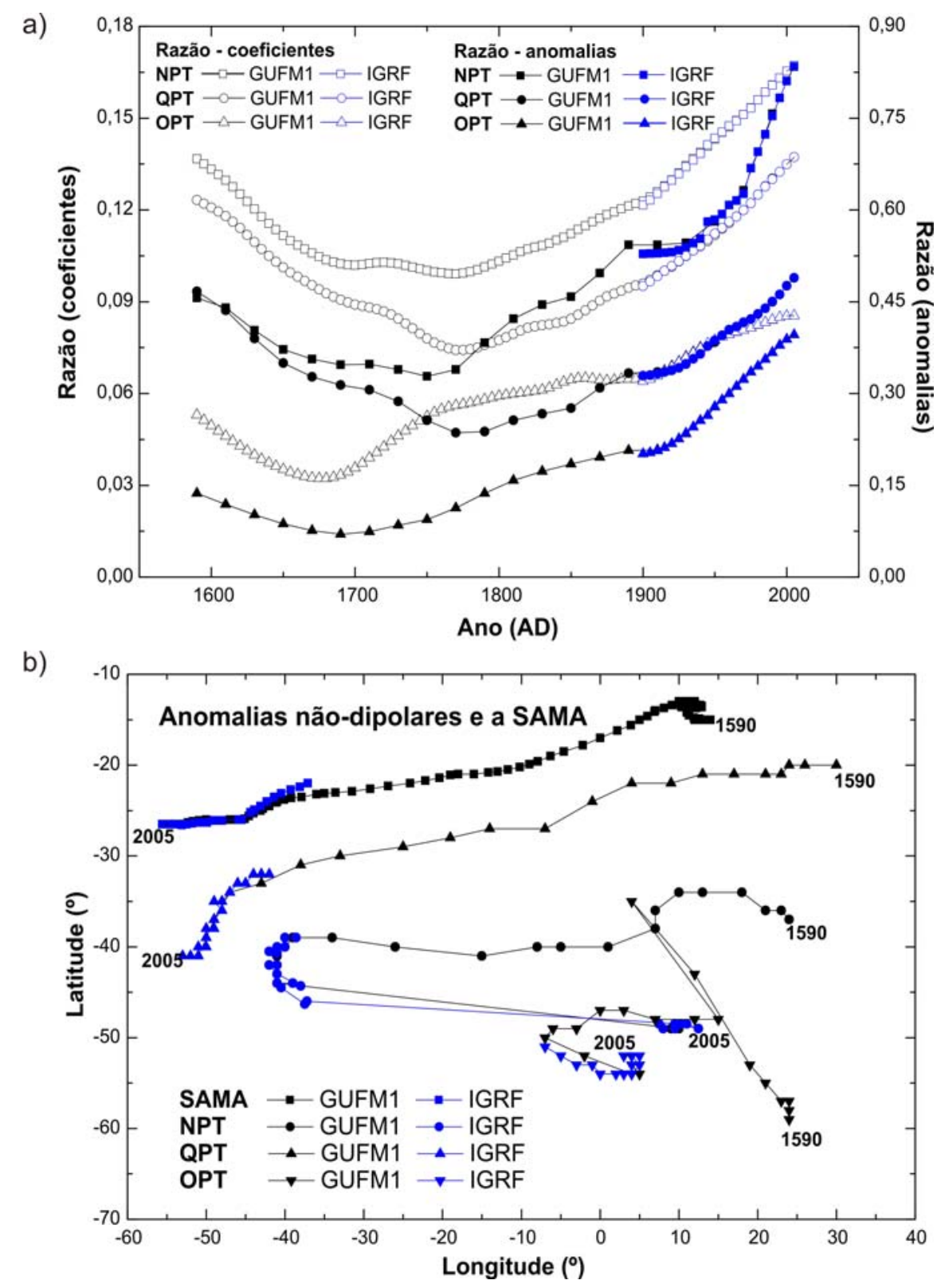

Figura 1.10: (a) Razão entre os coeficientes não-dipolares e total e os máximos não-dipolares para o globo. (b) Deriva dos máximos de anomalias não-dipolares comparadas com a deriva da SAMA. Note a alta correlação de deriva do máximo quadrupolar com a SAMA. Modificado de Hartmann e Pacca (2009).

A Figura 1.10b mostra a deriva dos máximos comparados com a deriva da SAMA. Os máximos NPT e OPT apresentam derivas bastante distintas quando comparadas com as derivas do máximo QPT e da SAMA. Isto ocorre porque as fontes não-dipolar e octupolar não obedecem a uma deriva para Oeste cíclica. Yukutake $(1967,1993)$ distinguem dois tipos de anomalias do campo não-dipolar: aquelas que apresentam deriva para Oeste ou Leste e as anomalias estacionárias. Estas anomalias, de certa forma são "aleatórias" no espaço e, portanto, difíceis de determinar suas derivas (como pode ser observado nos mapas da Figura 
1.9). No entanto, é interessante observar a alta correlação da deriva do máximo QPT com a deriva da SAMA, o que indica a predominância do campo quadrupolar para esta anomalia.

O CMT apresenta fortes variações no território brasileiro, tanto em intensidade quanto em direção. Uma parte dessas variações pode ser creditada à influência da SAMA. A SAMA varia com a localização geográfica, tanto na velocidade de sua deriva para Oeste, como no deslocamento para o Sul (Hartmann e Pacca, 2009), sendo esse comportamento creditado à presença mais importante de fontes não-dipolares nas regiões Sul e Sudeste. Essas fontes são bem menos importantes em regiões localizadas em baixas latitudes, como é o caso das regiões Norte, Nordeste e parte do Centro-Oeste. Os modelos históricos sugerem que a SAMA pode ser uma feição de longa duração que tem afetado o campo magnético sobre o território brasileiro pelo menos nos últimos 500 anos. No entanto, os modelos históricos na região da SAMA são baseados exclusivamente em dados direcionais obtidos pelos navegadores. Faltam informações de detalhe nessa escala de tempo na área de abrangência da SAMA, principalmente de paleointensidades. Uma forma de resolver estas incertezas é com a aquisição de dados de intensidade em setores distantes em torno de $10^{\circ}$ a $20^{\circ}$ em latitude, como as regiões Nordeste e Sudeste do Brasil, permitindo assim traçar de forma mais adequada a evolução temporal do CMT em escalas de tempo de séculos a milênios. 


\section{Capítulo 2}

\section{Contexto arqueológico e amostragem}

Neste capítulo será apresentado o contexto arqueológico das amostras obtidas nas regiões Nordeste e Sudeste do Brasil, incluindo: aspectos gerais da evolução da ocupação nas regiões amostradas, as idades dos locais de amostragem e os métodos de datação empregados, bem como o tipo de material coletado. Todos os 25 sítios analisados foram amostrados em construções erguidas durante o período histórico, abrangendo os últimos 500 anos. As idades foram determinadas utilizando o contexto arqueológico e, principalmente, documentos históricos que fazem referência a cada um dos sítios amostrados. Foram amostrados apenas materiais construtivos, que compreendem diversos fragmentos de tijolos e alguns fragmentos de telhas.

\subsection{Introdução}

A história do Brasil colonial pode ser divida em três períodos distintos: (a) o primeiro, vai da chegada de Cabral à instalação do governo geral em 1549, com a fundação da Cidade de Salvador; (b) o segundo, vai da instalação do governo até as últimas décadas do século XVIII; (c) o terceiro, vai dessa época até à Independência, em 1822 (e.g. Fausto, 2008). Após o primeiro período colonial, o povoamento do Brasil foi caracterizado pela fixação de portugueses com a implantação de vilas, que posteriormente viriam a se tornar cidades. A Figura 2.1 mostra algumas das vilas mais antigas do Brasil, sendo que a maioria delas foi fundada durante o segundo período colonial.

A ocupação do território brasileiro ocorreu do litoral para o interior do país, seguindo os ciclos econômicos que se sucederam durante os períodos colonial e pós-colonial (e.g. Ross, 2005; Fausto, 2008). Inicialmente, a colonização baseou-se na exploração da madeira (no caso o pau-brasil), seguida da cana-de-açúcar que garantiu aos portugueses a ocupação definitiva do litoral. Em meados do século XVI, o açúcar tinha grande valor de mercado, sendo a cultura dominante no litoral. Durante esse período, a Igreja teve um papel fundamental na ocupação 
territorial e na catequização indígena. Os padres jesuítas, através da Companhia de Jesus, foram os principais responsáveis pelo desenvolvimento das capitanias da Bahia, de Porto Seguro, de Pernambuco e de São Vicente, e sua principal função era a criação de vilas com construção de igrejas, casas e colégios. A partir dessas ocupações surgiram várias cidades históricas que levam, inclusive, o nome de alguns religiosos, como é o caso de Anchieta, no Estado do Espírito Santo (Najjar, 1999). No começo do século XVII, Portugal começa a enfrentar dificuldades políticas e econômicas para a exportação do açúcar, o que estimulou a conquista do interior do país em busca de novas riquezas. Já na segunda metade do século XVII, iniciaram-se as expedições armadas (bandeiras) em busca de riquezas minerais. Essas bandeiras saíam do litoral em direção ao interior, principalmente da Capitania de São Vicente em direção a Minas Gerais, onde surgiram os chamados "arraiais" que posteriormente se tornariam cidades, como por exemplo, Ouro Preto (Fausto, 2008). A economia colonial se desenvolveu não somente com a descoberta de riquezas minerais no interior do país, mas também com outros tipos de atividade econômica, como o cultivo de fumo na Bahia, o cultivo de algodão no Maranhão e no Pará e a pecuária, que também avançou do litoral para o interior. Em meados do século XVIII, a siderurgia surge como uma importante alternativa econômica para a região Sudeste do Brasil, a partir da instalação da Real Fábrica de Ferro em Araçoiaba da Serra, Estado de São Paulo (Salazar, 1998).

No começo do século XIX, as crises políticas na Europa fizeram com que a Corte portuguesa se transferisse de Portugal para o Brasil. A presença de Dom João VI no Brasil estimulou o desenvolvimento urbano em várias cidades, principalmente o Rio de Janeiro, local onde a Realeza se instalou (Ross, 2005). Contudo, a queda dos preços dos produtos agrícolas brasileiros para exportação e a crise política e econômica em Portugal após o fim da ocupação francesa, culminaram com o retorno da família Real para Portugal em 1821. Em 1822, o Brasil declara a Independência de Portugal, dando fím ao período colonial.

A consolidação do Estado brasileiro se dá em meados de 1840, no segundo reinado. A estabilidade política e econômica do império coincide com a expansão da cultura do café no Rio de Janeiro e em São Paulo. Muitas fazendas de café do interior desses Estados surgiram nessa época, como a Fazenda Lageado, em Botucatu, no Estado de São Paulo (Michellin e Argollo-Ferrão, 2008). O fim do império em 1889 marcou uma era de transição no Brasil, com o fim da escravidão e uma forte imigração européia. O país deixou de ser essencialmente rural e passou por um processo de aceleramento da urbanização. O final do século XIX e início do século XX marcam a consolidação política e econômica da República sob o domínio do café, que transformou São Paulo e o Rio de Janeiro em grandes metrópoles. Todos esses 
elementos históricos auxiliaram no delineamento dos alvos de amostragem nas regiões Nordeste e Sudeste do Brasil.

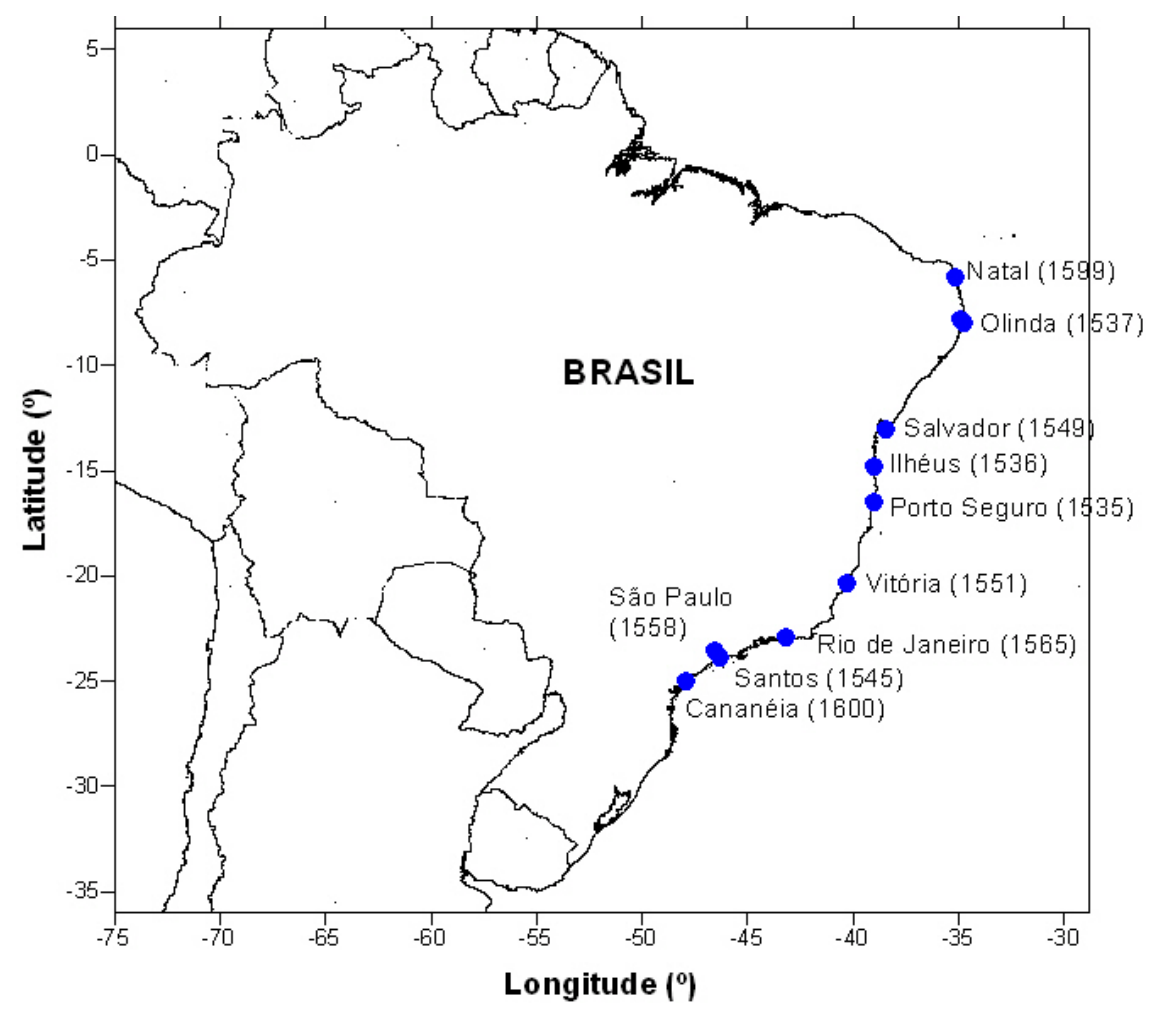

Figura 2.1: Este mapa mostra algumas das cidades mais antigas do Brasil. O ano de fundação está entre parênteses. Note que essas cidades se encontram no litoral, sendo que a ocupação ocorre do litoral para o interior do país. Figura modificada de Fausto (2008).

\subsection{Coleção Nordeste}

A coleção Nordeste consiste de 14 grupos de tijolos, amostrados em Salvador $\left(13^{\circ} \mathrm{S}\right.$, $38,5^{\circ} \mathrm{W}$ ), Estado da Bahia (Figura 2.2a e Tabela 2.1). Desses sítios foram coletados 104 fragmentos, variando de 4 a 19 fragmentos por sítio. Salvador foi emancipada em 1549 e foi a primeira capital do Brasil. Durante os séculos XVI e XVII, Salvador era um importante centro de comércio nas Américas porque devido à posição geográfica estratégica era um dos pontos de parada no caminho marítimo entre Europa, África, Índia e China. Nesse período, a cidade cresceu aceleradamente com a construção de vários prédios públicos, religiosos e privados. Esse fato tem duas implicações importantes. Primeiro, que a produção de tijolos foi bastante significativa, de modo a contemplar todas as construções do período e resultando em vasto material para as análises. Segundo, porque isto implica que a utilização dos tijolos nas construções foi imediata. Portanto, a idade dos prédios pode ser vista como uma boa 
aproximação da idade dos tijolos. Os fragmentos de tijolos foram amostrados principalmente no Centro Histórico de Salvador, mais conhecido como Pelourinho, mas também foram investigadas construções de outros locais de Salvador. A descrição sucinta de todas as construções amostradas é apresentada mais adiante e sumarizada na Tabela 2.1.
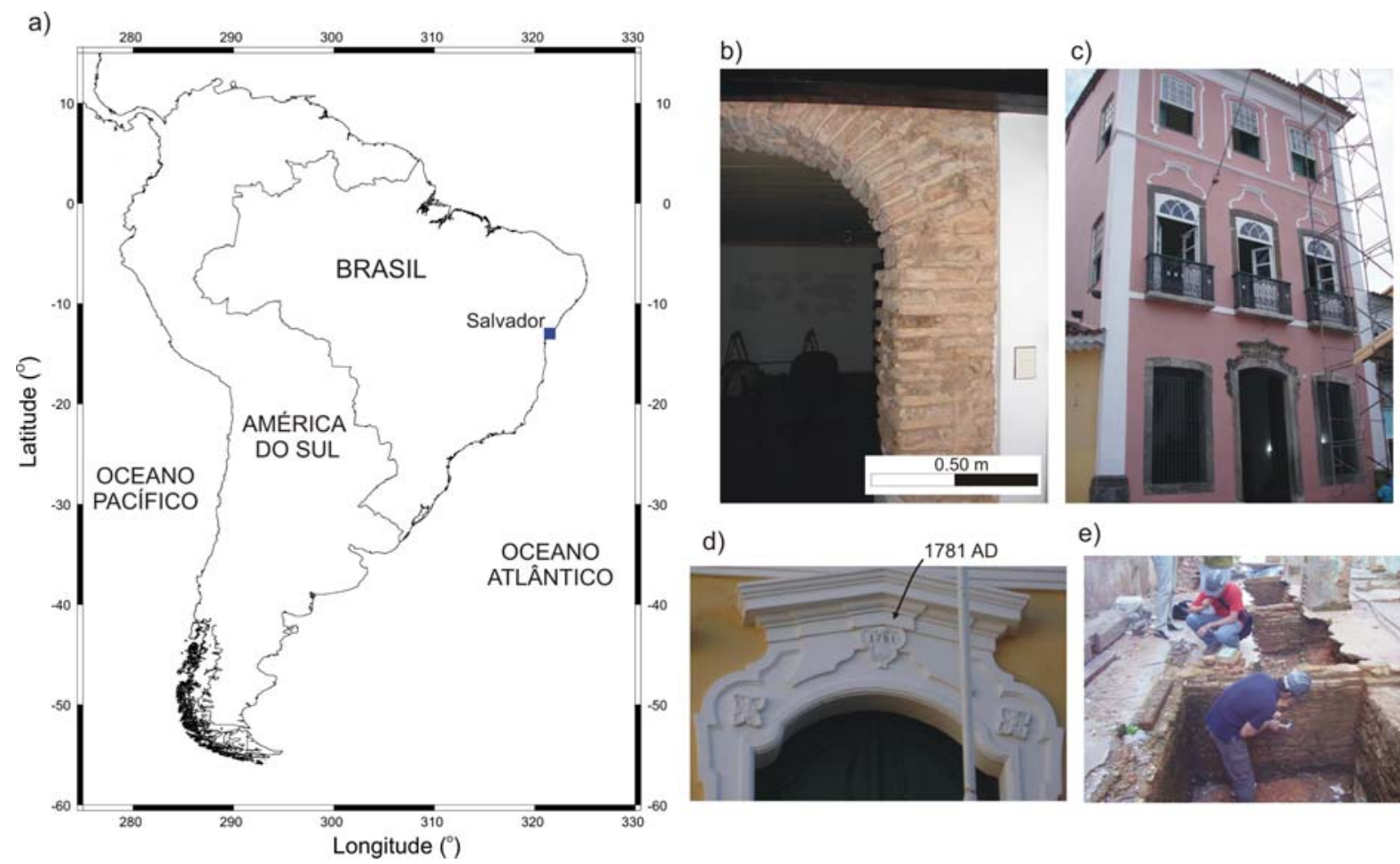

e)

Figura 2.2: Em (a), mapa de localização de Salvador. Em (b) e (c), a casa Número 06: os arcos feitos de tijolos amostrados no porão da casa (b) e a fachada da casa (c). Em (d), a fachada do Solar do Conde dos Arcos, onde o ano de construção (1781) está inscrito. Em (e), um exemplo da amostragem conduzida na base da Casa do Pelourinho de número 27 (CP27).

Nessa coleção de amostras foram consideradas apenas construções bem datadas e historicamente documentadas. A datação foi basicamente assegurada por informações históricas das construções. Essas informações incluem relatórios e registros que foram usados no Inventário de Proteção do Acervo Cultural da Bahia (Bahia, 1997). Esses arquivos permitem refinar as estimativas de idades, em alguns casos chegando a incertezas inferiores a 3 anos. Deve-se ressaltar que em todos os casos as idades foram estabelecidas com incertezas inferiores a 50 anos (Tabela 2.1). Por exemplo, os tijolos que foram amostrados nas fundações da Casa Número 06 (C06), também conhecida como "Centro Automobilístico da Bahia", apresentam arquivos históricos que datam a casa em 1705 \pm 5 AD (Figura 2.2b e Figura 2.2c). Os tijolos do "Solar do Conde dos Arcos" (sítio SCA), a casa do primeiro prefeito de Salvador, são datados por documentos históricos que registram o início de sua construção. 
Como se não bastassem os registros impressos, o ano da construção da casa está inscrito na sua fachada (Figura 2.2d).

Informações adicionais de idades são fornecidas pelos vínculos arqueológicos, que incluem: estilo arquitetônico das construções, estratigrafia das escavações arqueológicas, evolução tipológica dos tijolos, desde aqueles feitos manualmente pelos Jesuítas no século XVI até aqueles feitos com o uso de prensas do século XIX (Costa, 2005a). Esta tipologia foi particularmente útil para detectar e evitar setores com reconstruções mais recentes. Além disso, a amostragem foi realizada sempre que possível nas fundações das construções para assegurar que os tijolos selecionados estão realmente associados com a fase inicial de construção, excluindo qualquer restauro posterior (Costa, 2005a).

Tabela 2.1: Sítios arqueológicos da região Nordeste do Brasil. Todos os sítios foram amostrados na Cidade de Salvador $\left(13^{\circ} \mathrm{S}, 38,5^{\circ} \mathrm{W}\right)$, Estado da Bahia.

\begin{tabular}{|c|c|c|c|c|}
\hline \multirow{2}{*}{ Sítio } & \multirow{2}{*}{ Descrição do sítio } & \multicolumn{2}{|c|}{\begin{tabular}{|c|} 
Método de \\
datação
\end{tabular}} & \multirow{2}{*}{$\begin{array}{l}\text { Intervalo } \\
\text { de idade } \\
\text { (AD) }\end{array}$} \\
\hline & & Hist. & Arq. & \\
\hline $\begin{array}{l}\text { Igreja Mem de Sá } \\
\text { (IMS) }\end{array}$ & $\begin{array}{l}\text { A Igreja Mem de Sá foi construída pelos Jesuítas no final do século } \\
\text { XVI e recebeu o nome do Governador do Estado da Bahia, que } \\
\text { financiou sua construção. }\end{array}$ & $\mathrm{X}$ & $\mathrm{X}$ & $1561-1591$ \\
\hline Praça da Sé (SE) & $\begin{array}{l}\text { A Igreja da Sé foi a principal construção religiosa feita pelos } \\
\text { Jesuítas na Cidade de Salvador durante o século XVII. O sítio SE } \\
\text { corresponde a primeira fase de sua construção. }\end{array}$ & $\mathrm{X}$ & $\mathrm{X}$ & $1590-1620$ \\
\hline $\begin{array}{l}\text { Praça da Sé } 1 \\
(\mathrm{SE} 1)\end{array}$ & $\begin{array}{l}\text { O sítio SE1 corresponde à segunda fase de construção da Igreja da } \\
\text { Sé. }\end{array}$ & $\mathrm{X}$ & $\mathrm{X}$ & $1600-1650$ \\
\hline $\begin{array}{l}\text { Praça da Sé } 2 \\
\text { (SE2) }\end{array}$ & $\begin{array}{l}\text { O sítio SE2 corresponde à terceira fase de construção da Igreja da } \\
\text { Sé. }\end{array}$ & $\mathrm{X}$ & $X$ & $1650-1700$ \\
\hline $\begin{array}{l}\text { Museu de Arte } \\
\text { Sacra (MAS) }\end{array}$ & $\begin{array}{l}\text { O sítio MAS corresponde ao atual Museu de Arte Sacra da Bahia, } \\
\text { que foi inicialmente construído no final do século XVII (como } \\
\text { indicado nos registros históricos) para servir ao Convento de Santa } \\
\text { Teresa de Ávila. }\end{array}$ & $\mathrm{X}$ & & $1666-1686$ \\
\hline $\begin{array}{l}\text { Solar Berquó } \\
\text { (SB) }\end{array}$ & $\begin{array}{l}\text { O Solar Berquó tem estilo arquitetônico característico da segunda } \\
\text { metade do século XVII. Documentos históricos atestam o curto } \\
\text { período de sua construção. }\end{array}$ & $\mathrm{X}$ & & $1691-1693$ \\
\hline $\begin{array}{l}\text { Farol da Barra } 1 \\
+2(\mathrm{FB} 1+2)\end{array}$ & $\begin{array}{l}\text { O Farol da Barra foi originalmente concebido como um forte } \\
\text { construído para defender a Cidade de Salvador. Posteriormente, } \\
\text { serviu de farol para guiar os navegadores que cruzavam a Baía de } \\
\text { Todos os Santos. Os números } 1 \text { e } 2 \text { referem às duas amostragens } \\
\text { efetuadas no local, datadas da fase inicial de construção do forte. }\end{array}$ & $\mathrm{X}$ & & $1696-1702$ \\
\hline $\begin{array}{l}\text { Casa do } \\
\text { Pelourinho } 27 \\
(\mathrm{CP} 27)\end{array}$ & $\begin{array}{l}\text { O sítio CP27 corresponde a uma casa localizada no Pelourinho, } \\
\text { Centro Histórico de Salvador. Esta casa está em uma área de } \\
\text { ocupação estimada historicamente e arquitetonicamente entre o } \\
\text { começo do século XVII e a metade do século XVIII. Os resultados } \\
\text { de paleointensidade foram utilizados para datar esta casa (ver } \\
\text { Capítulo 5) }\end{array}$ & $\mathrm{X}$ & $X$ & $1675-1725$ \\
\hline $\begin{array}{l}\text { Casa Número } 6 \\
(\mathrm{C} 06)\end{array}$ & $\begin{array}{l}\text { O sítio C06 corresponde à casa onde ficava o "Centro } \\
\text { Automobilístico da Bahia". Informações históricas e arquitetônicas } \\
\text { permitem definir precisamente a idade de sua construção no começo } \\
\text { do século XVIII. }\end{array}$ & $\mathrm{X}$ & & $1700-1710$ \\
\hline
\end{tabular}




\begin{tabular}{|c|c|c|c|c|}
\hline \multirow{2}{*}{ Sítio } & \multirow{2}{*}{ Descrição do sítio } & \multicolumn{2}{|c|}{\begin{tabular}{|c|} 
Método de \\
datação
\end{tabular}} & \multirow{2}{*}{$\begin{array}{l}\text { Intervalo } \\
\text { de idade } \\
\text { (AD) }\end{array}$} \\
\hline & & Hist. & Arq. & \\
\hline $\begin{array}{l}\text { Corpo de } \\
\text { Bombeiros (CB) }\end{array}$ & $\begin{array}{l}\text { O sítio CB corresponde à antiga Capela de Nossa Senhora de } \\
\text { Guadalupe, cuja construção durou } 10 \text { anos conforme indicado nos } \\
\text { documentos históricos. }\end{array}$ & $\mathrm{X}$ & $\mathrm{X}$ & $1767-1777$ \\
\hline $\begin{array}{l}\text { Solar Conde dos } \\
\text { Arcos (SCA) }\end{array}$ & $\begin{array}{l}\text { O sítio SCA foi a residência do primeiro prefeito de Salvador, o } \\
\text { Conde dos Arcos, e foi construída no final do século XVIII. A } \\
\text { precisão da datação é assegurada pela inscrição na fachada da casa e } \\
\text { por documentos históricos. Essa construção atualmente está sob a } \\
\text { custódia do Colégio } 2 \text { de Julho. }\end{array}$ & $\mathrm{X}$ & & $1780-1781$ \\
\hline $\begin{array}{l}\text { Tijoleira Farias } \\
\text { (TF) }\end{array}$ & $\begin{array}{l}\text { A datação precisa desta construção é assegurada pelo ano de } \\
\text { fabricação estampado nos tijolos. }\end{array}$ & $X$ & & 1887 \\
\hline $\begin{array}{l}\text { Museu de } \\
\text { Arqueologia e } \\
\text { Etnologia } 4 \\
\text { (MAE4) }\end{array}$ & $\begin{array}{l}\text { Esta construção é parte do Museu de Arqueologia e Etnologia da } \\
\text { Universidade Federal da Bahia. Os tijolos correspondem à fase final } \\
\text { da construção. }\end{array}$ & $\mathrm{X}$ & $X$ & 1896-1906 \\
\hline $\begin{array}{l}\text { Galeria Canizares } \\
(\mathrm{GC})\end{array}$ & $\begin{array}{l}\text { O sítio GC foi amostrado em uma casa localizada na região de } \\
\text { Salvador próximo ao Pelourinho, que se desenvolveu no começo do } \\
\text { século XX. Informações históricas e arquitetônicas asseguram a } \\
\text { datação desta casa, onde atualmente funciona uma galeria de artes. }\end{array}$ & $\mathrm{X}$ & $X$ & $1900-1920$ \\
\hline
\end{tabular}

Na coluna "Sítio" está indicado o nome e a sigla dos sítios estudados. Na coluna "Descrição dos sítios", uma curta descrição de cada sítio analisado fornece os elementos que guiaram as amostragens. Na coluna "Método de datação" estão indicados os métodos usados para determinar as idades ("Hist.", a partir de informações históricas e "Arq.", a partir de informações arqueológicas). Por fim, na coluna "Intervalo de idade" é indicado as estimativas de idade de cada sítio baseadas nas informações históricas e/ou arqueológicas.

Foram amostrados entre 4 e 19 fragmentos por construção (sítio arqueológico). Para os sítios FB1+2 e MAE4, os tijolos foram amostrados com a ajuda de uma perfuratriz para amostragem de cilindros de 2,2 cm de diâmetro. Para os outros sítios, os fragmentos foram amostrados diretamente dos tijolos com ajuda de martelo e cinzel (Figura 2.2e).

\subsubsection{Igreja Mem de Sá (IMS)}

A igreja de Mem de Sá constitui um dos mais antigos prédios do Colégio dos Jesuítas, estando relacionada à parte do complexo construída entre os anos de 1561 e 1591, ou seja, da segunda metade do século XVI (Costa, 2005b). Recebe este nome justamente porque foi erigida a partir de dotações concedidas pelo Governador Geral Mem de Sá, durante sua gestão em Salvador. Este edifício foi demolido no último quartel do século XVII, quando foi edificada a nova Igreja do Colégio, a atual Catedral Basílica de Salvador, que substituiu as antigas instalações inacianas. No seu espaço foi construído o Pátio dos Estudos Gerais, com áreas destinadas a salas de aula e um espaço destinado a jardim ou pomar. As fundações da Igreja Mem de Sá foram identificadas e mapeadas durante as escavações arqueológicas realizadas pela equipe do Museu de Arqueologia e Etnologia da Universidade Federal da 
Bahia (MAE/UFBA), ocorridas entre 1999 e 2002. Amostragem realizada: tijolos da base da Igreja.

\subsubsection{Praça da Sé (SE)}

O material arqueológico obtido nesse sítio foi coletado durante as escavações realizadas nas ruínas da antiga Igreja da Sé de Salvador, demolida em 1933. O setor da Praça da Sé, exterior à antiga igreja, fica próxima à falésia que separa a Cidade Alta da Cidade Baixa. O local escavado apresenta um bolsão de fragmentos de material cerâmico (objetos para preparação e serviço de alimentos). Sua tipologia (decoração, forma e composição) permite associá-los a um período correspondente ao final de século XVI e início do século XVII, entre 1590-1620. Os formatos típicos da faiança malagueira, por exemplo, são bastante característicos e permitem situar temporalmente com segurança o conjunto de amostras coletados para este trabalho (Costa, 2005b). Portanto, o mesmo intervalo de idades pode ser atribuído aos tijolos com base nessas informações arqueológicas, mas também pelas informações históricas desta igreja, muito importante em Salvador durante todo o período colonial (Bahia, 1997). Amostragem realizada: tijolos coletados durante as escavações realizadas na base da Igreja.

\subsubsection{Praça da Sé 1 (SE1)}

Refere-se a um conjunto de tijolos coloniais coletados nas escavações arqueológicas da área correspondente a uma das sacristias da antiga Igreja da Sé de Salvador. Pela situação deposicional, tipologia dos fragmentos e traços mineralógicos dos objetos, conhece-se o contexto primário de um dos momentos de re-estruturação da Igreja da Sé. Tendo em vista a comparação com outros contextos identificados nessa edificação, há uma forte possibilidade de corresponderem a materiais da primeira metade do XVII (1600-1650) (Costa, 2005b). Fontes documentais indicam também este intervalo para construção desta parte da igreja (Bahia, 1997). Amostragem realizada: tijolos coletados durante as escavações realizadas na base da sacristia da Igreja. 


\subsubsection{Praça da Sé 2 (SE2)}

Corresponde a um conjunto de tijolos derivados de demolições e coletados no interior da caixa de escadas da torre do relógio da antiga Igreja da Sé. Este conjunto apresenta boa coesão relacionada a estratigrafia, tipologia e traços mineralógicos, de maneira a não deixar dúvidas que se referem a um momento deposicional muito específico do sítio. Documentos históricos relatam que as torres da Igreja da Sé começaram a ser construídas somente a partir de 1672. A demolição dessas torres, em decorrência de problemas estruturais da igreja, só ocorreu no final do século XVII. Portanto, esses materiais correspondem provavelmente à segunda metade do século XVII, 1650-1700 (Costa, 2005b). Além disso, fontes documentais e iconográficas indicam este mesmo intervalo de idades para esta fase de reconstrução da antiga Igreja da Sé de Salvador. Amostragem realizada: tijolos coletados nas escadas da antiga torre do relógio da Igreja da Sé.

\subsubsection{Museu de Arte Sacra (MAS)}

O MAS encontra-se instalado no antigo Convento de Santa Teresa de Ávila. A construção do convento iniciou-se em 1666, pelo Frei José do Espírito Santo, com recursos de particulares e do poder público. No local havia uma igrejinha dedicada a Santa Teresa de Ávila. Em 1668 foi expedida a licença para a sua construção, embora os documentos da época revelem que esta já estava bem adiantada. Por fim, em 14 de outubro 1686, acontece a inauguração do convento. Assim, a construção do MAS (ou antigo Convento Santa Teresa de Ávila) pode ser enquadrada entre 1666-1686. O convento apresenta elevado valor monumental como exemplar da arquitetura jesuítica, tendo sido desenvolvido em torno de um claustro quadrado. A igreja foi precedida de uma galilé (galeria situada na extensão do pórtico de uma igreja) com coro superposto e possui nave em forma de cruz latina. $\mathrm{O}$ altar-mor primitivo se perdeu e o atual, de prata, é proveniente da antiga Igreja da Sé. O afresco da capela, situada entre a igreja e o claustro, é considerado o mais antigo do Brasil. Há azulejos de meados do século XVII na sacristia e nas escadas. Atualmente, o MAS apresenta a maior coleção de arte sacra do Brasil (Bahia, 1997). A Figura 2.3a mostra uma parte interna do Museu, onde pode-se observar tijolos originais utilizados na construção do Convento. Amostragem realizada: tijolos da base do convento. 
a)

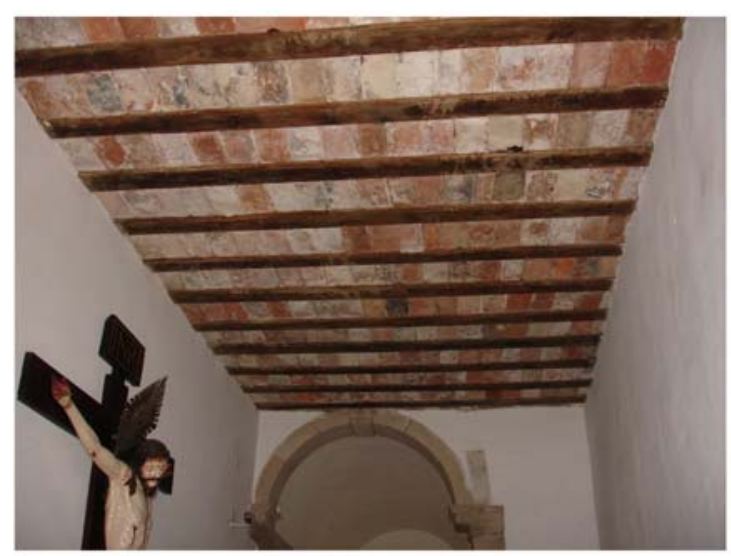

c)

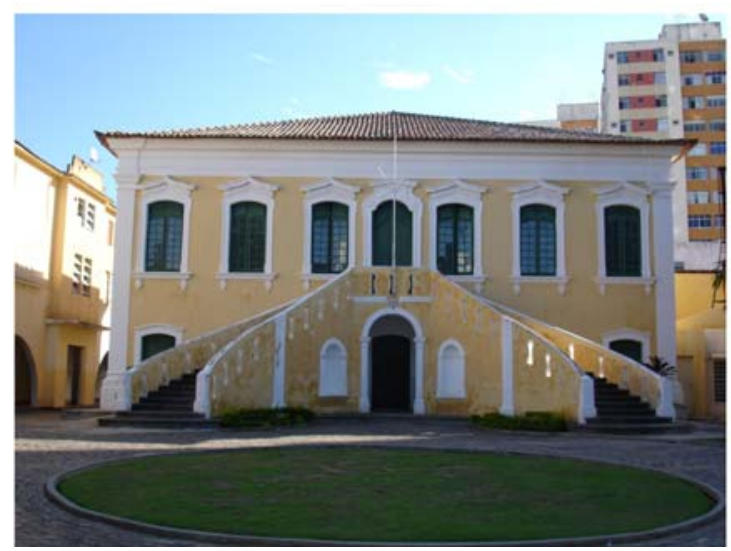

b)

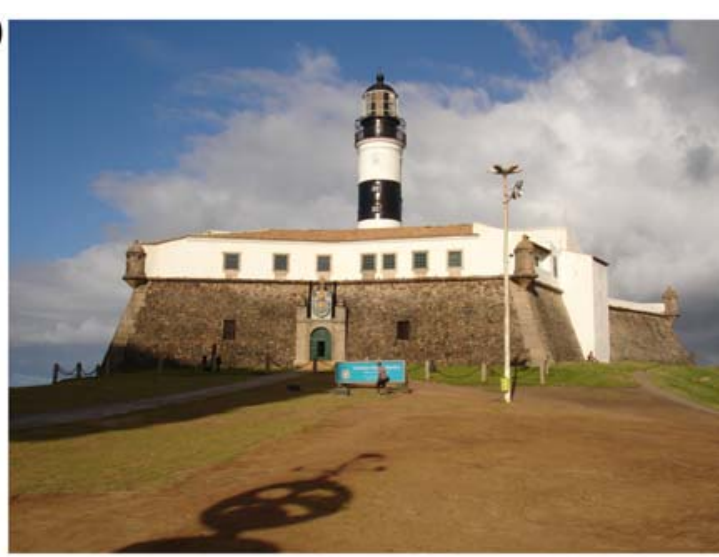

d)

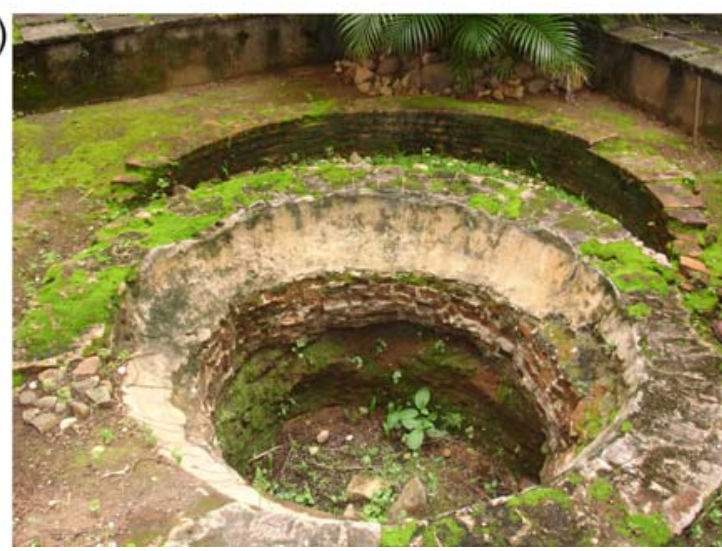

Figura 2.3: A foto (a) mostra o teto com tijolos originais de construção do Museu de Arte Sacra (MAS). A foto (b) mostra a parte externa do Farol da Barra $(\mathrm{FB} 1+2)$, no formato original de um hexágono. A foto (c) mostra a fachada principal do Solar do Conde dos Arcos (SCA), com arquitetura típica do final do século XVIII e início do século XIX. A foto (d) mostra a cisterna interna e externa do MAE4, onde a cisterna interna corresponde a modificação mais recente do início do século XX.

\subsubsection{Solar Berquó (SB)}

Segundo registros históricos essa casa foi construída em 1691. Essa compreende também a data gravada acima da portada. Já em 1693, segundo escritura de 28/X, José Alves Lima (proprietário do solar) contraiu empréstimo de 1000 cruzados na Santa Casa de Misericórdia para melhorias no entorno da casa. Portanto, o intervalo cronológico de 16911693 define o período mínimo e máximo para a construção da casa. Essa antiga residência tem notável mérito arquitetônico, se destacando na região onde se encontra, uma vez que representa um dos mais expressivos exemplares de casa nobre no final do século XVII. A construção é robusta e severa, possuindo, além do subsolo, dois pavimentos sobre a rua. A casa apresenta uma planta quase quadrada, em torno de um pequeno pátio interno, em uma configuração típica das residências mais abastadas da época. O pavimento nobre, ainda hoje usado como residência, possui balcões sobre a rua, tetos agamelados e peças de mobiliário e louça antiga, que dão uma idéia da suntuosidade da casa no passado (Bahia, 1997). Existem 
azulejos do século XVII no corredor situado no topo da escada, do tipo tapete, e um silhar (pedra lavrada em quadrado, própria para revestimento de paredes) com florão central do tipo camélia, limitado por barras de dois azulejos em um dos salões do pavimento nobre. Atualmente, a casa é a sede da $7^{\text {a }}$ Superintendência Regional do IPHAN (Instituto do Patrimônio Histórico e Artístico Nacional). Amostragem realizada: tijolos do subsolo da casa, cujas paredes são de alvenaria mista (tijolos e pedras).

\subsubsection{Farol da Barra (FB1+2)}

Neste edifício, hoje conhecido como Farol da Barra, funcionou o antigo Forte Santo Antônio da Barra. Entre 1583 e 1587, Dom Manuel Telles Barreto construiu a primeira fortificação no local. De 1591 a 1602, o prédio foi reformado por Dom Francisco de Souza que o teria reconstruído em pedra e cal com forma octogonal. Em 1624, ele resistiu, mas não pode impedir o desembarque holandês no atual Porto da Barra, o que motivaria mais tarde a construção de outros fortes como Santa Maria e São Diogo. Em 1656, ele sofreu grandes obras dirigidas por um arquiteto francês que o transformou em um forte hexagonal, medindo 10 metros cada lado (Figura 2.3b). Entre 1696 e 1702, o Governador Dom João de Lancastro o reconstrói em sua forma atual. Nessa época, foi também erguida em seu terrapleno uma torre quadrada para servir de farol. Um relato de 1752 revela que o prédio começava a arruinar-se, embora conservasse ainda o farol de base quadrada e a ponte levadiça. Entre 1756 e 1801 foi eliminada a ponte levadiça e criada uma cozinha externa situada à direita da entrada, que foi demolida mais tarde. Por fim, entre 1836 e 1839 foi construído o farol atual de base circular (Bahia, 1997). Pelo contexto histórico e arquitetônico, o intervalo cronológico da amostragem realizada na abóbada da capela do Forte permite situar as amostras entre 1696-1702. Amostragem realizada: tijolos de duas paredes do teto da abóbada da capela do Forte. Esta parte da construção data do período de 1696-1702.

\subsubsection{Casa do Pelourinho número 27 (CP27)}

A Casa do Pelourinho localizada na Rua Monte Alverne número 27 foi uma das casas do Centro Histórico de Salvador estudadas pela Assessoria de Arqueologia da $7^{\text {a }}$ Superintendência Regional do IPHAN (Instituto do Patrimônio Histórico e Artístico Nacional) durante a execução do Projeto Monumenta em Salvador. O Projeto Monumenta de Salvador (Bahia) consiste no trabalho de resgate arqueológico e reconstrução das casas, 
edifícios e igrejas do centro histórico da primeira capital do Brasil. O IPHAN executa o Projeto Monumenta em diversas cidades históricas do Brasil, sendo o núcleo de Salvador o maior deles. As coletas de material arqueológico (tijolos, telhas, cerâmicas) foram feitas em diversas construções do centro histórico, entre elas a CP27. Esta casa está localizada em uma área de ocupação estimada historicamente e arquitetonicamente entre o começo do século XVII e a metade do século XVIII. A idade desta casa foi inferida através da determinação dos valores de arqueointensidade obtidos em diversos tijolos coletados em uma fundação. Os valores apontam para um intervalo de construção entre 1675 e 1725. Amostragem realizada: tijolos da base da casa coletados durante a campanha de amostragem em 2008 (Figura 2.2e).

\subsubsection{Casa número 06 (C06)}

Essa casa também é conhecida como Centro Automobilístico da Bahia. A casa de 3 andares apresenta um estilo arquitetônico que é típico do século XVIII, ainda que tenha sofrido alterações com o passar dos anos. Documentos relatam que essa casa foi construída no começo do século XVIII, muito provavelmente até 1710. Pareceres arquitetônicos atestam elementos típicos para este período de construção, como saguão, escadas, arcos, azulejos e as bacias rasgadas das janelas do $1^{\mathrm{o}}$ pavimento. Assim, levando-se em conta as fontes documentais, bem como os pareceres arquitetônicos, pode-se atribuir um intervalo de 17001710 como período de construção desta casa (Bahia, 1997). Amostragem realizada: tijolos dos arcos do térreo da casa (Figura 2.2b e Figura 2.2c).

\subsubsection{Corpo de Bombeiros (CB)}

$\mathrm{O}$ sítio $\mathrm{CB}$ corresponde à antiga Capela de Nossa Senhora de Guadalupe, cuja construção durou 10 anos, entre 1767 e 1777, conforme indicado nos documentos históricos. Atualmente, as bases dessa capela estão encobertas pelo piso do estacionamento do Corpo de Bombeiros. A intervenção feita em 2008 pela Equipe de Arqueologia do Projeto Monumenta permitiu a identificação das bases da capela e o seu mapeamento. Amostragem realizada: tijolos da base da capela coletados durante as escavações. 


\subsubsection{Solar Conde dos Arcos (SCA)}

Este Solar também é conhecido como Casa do Conde dos Arcos. Atualmente está ali instalado o Colégio 2 de Julho. O edifício é de notável mérito arquitetônico, desenvolvido em dois pavimentos. A planta da casa, como a maioria das residências da época, é quase quadrada. As estruturas arquitetônicas dessa casa são típicas de casas do final do século XVIII e início do século XIX, como a escadaria externa de ligação entre o pavimento nobre e o jardim (Figura 2.3c). Este solar inicia na Bahia a transição entre o sobrado urbano tradicional e o novo padrão de casa térrea, ligeiramente elevada, integrada ao jardim. A data de $\mathbf{1 7 8 1}$ na portada do solar indica o ano de sua construção (Bahia, 1997). Amostragem realizada: tijolos de uma das paredes do andar térreo da casa.

\subsubsection{Tijoleira Farias (TF)}

Os tijolos foram encontrados em escavações realizadas no Pelourinho. Neles estava inscrito o nome da olaria (Tijoleira Farias) bem como o ano de fabricação dos tijolos, que é de 1887. Amostragem realizada: tijolos coletados durante as escavações da Equipe de Arqueologia do Projeto Monumenta no Pelourinho.

\subsubsection{Museu de Arqueologia e Etnologia da Universidade Federal da Bahia} (MAE4)

O espaço físico onde hoje se encontra o Museu de Arqueologia e Etnologia da Universidade Federal da Bahia (MAE/UFBA) é parte de um amplo conjunto de edifícios, correspondente ao prédio de Estudos Superiores e à Residência dos padres do antigo Colégio dos Jesuítas. A construção desse complexo de edifícios ocorreu em vários momentos do século XVI, ocupando um importante setor da Cidade de Salvador, fato que demonstra a marcante presença da ordem jesuítica durante o período colonial. Após a expulsão dos jesuítas, em 1760, o edifício dos Estudos Gerais foi demolido e o prédio da Residência e de preparação dos padres foi utilizado como hospital militar. Nele, em 1808, foi instalada a primeira Escola de Cirurgia, fundada por Dom João VI, pouco depois da sua chegada ao Brasil. No final do século XIX, esse mesmo conjunto arquitetônico foi, em grande parte, demolido e em alguns setores foram alterados para edificar um novo prédio destinado aos estudos de Medicina. Um incêndio, ocorrido em 1905, resultou em uma reestruturação para abrigar, outra vez, a Faculdade de Medicina (Costa, 2005b). Como resultado dessas 
sucessivas intervenções, somente uma parte do plano inferior do conjunto escapou das alterações estruturais e é exatamente esse o espaço ocupado atualmente pelo MAE/UFBA.

Uma intervenção arqueológica, realizada em 2006 no pátio interno do MAE/UFBA, revelou a existência de dois grandes anéis de tijolos sobrepostos correspondentes às beiradas de duas cisternas (Figura 2.3d). A forma circular mais antiga foi construída com materiais semelhantes aos utilizados na construção do prédio do século XVI e é, portanto, considerada do mesmo período. A essa estrutura foi sobreposta uma fina cisterna, talvez com fins decorativos, entre o final do século XIX e o início do século XX, época da edificação da Faculdade de Medicina. Prova disso são os materiais utilizados que se assemelham àqueles das intervenções construtivas feitas nesses dois últimos momentos. Outro forte elemento indicador da segunda cisterna é a situação central que tem a fonte em relação ao pequeno pátio interior do prédio, pertencente ao período mais recente do prédio. Ou seja, a parte superior e mais superficial do círculo deve corresponder ao período compreendido entre 1896, quando se constrói o edifício da Faculdade de Medicina, e o ano de 1906, quando foi reconstruída a parte incendiada (1896-1906) (Bahia, 1997; Costa, 2005b). Amostragem realizada: cilindros de tijolos da cisterna interna, mais recente, do MAE (MAE4). Note-se que os tijolos da cisterna interna são bastante diferentes dos tijolos da cisterna externa, mais antiga (Figura 2.3d).

\subsubsection{Galeria Canizares (GC)}

A casa onde atualmente funciona a Galeria Canizares, espaço de exposição da vizinha Escola de Belas Artes da Universidade Federal da Bahia (EBA/UFBA), situa-se em uma zona da Cidade de Salvador que foi urbanizada entre fins do século XIX e início do século XX. Os dois edifícios contíguos que compõem essa unidade universitária correspondem, justamente, a esse período e são exemplos de moradias elegantes de famílias abastadas da Cidade de Salvador que começaram a ocupar os bairros de Vitória, Graça e Canela, com mansões rodeadas de jardins e quintais. Os registros históricos e a tipologia arquitetônica da Galeria Canizares, com traços de influência do estilo Art Nouveau, indicam que ela foi construída no período entre 1900 e 1920, momento em que estavam em voga na cidade os princípios decorativos desse estilo (Bahia, 1997). Amostragem realizada: tijolos da base do casarão. 


\subsection{Coleção Sudeste}

A coleção Sudeste consiste de 11 grupos de tijolos e, em menor proporção, telhas, compreendendo entre 6 e 31 fragmentos por sítio. Estes sítios estão localizados em 6 cidades dos Estados de São Paulo, Rio de Janeiro e Espírito Santo, dentro de uma faixa de apenas 2,5 de latitude e 7,8 $8^{\circ}$ longitude (Figura 2.4a e Tabela 2.2). Os sítios são datados entre o fim do século XVI e o começo do século XX, correspondendo aos períodos colonial e pós-colonial no Brasil. Devido ao rápido desenvolvimento das cidades, a produção de materiais de construção (como tijolos, telhas, etc) era toda local e praticamente todos estes materiais eram utilizados logo após serem produzidos (e.g. Costa, 2005a).

a)

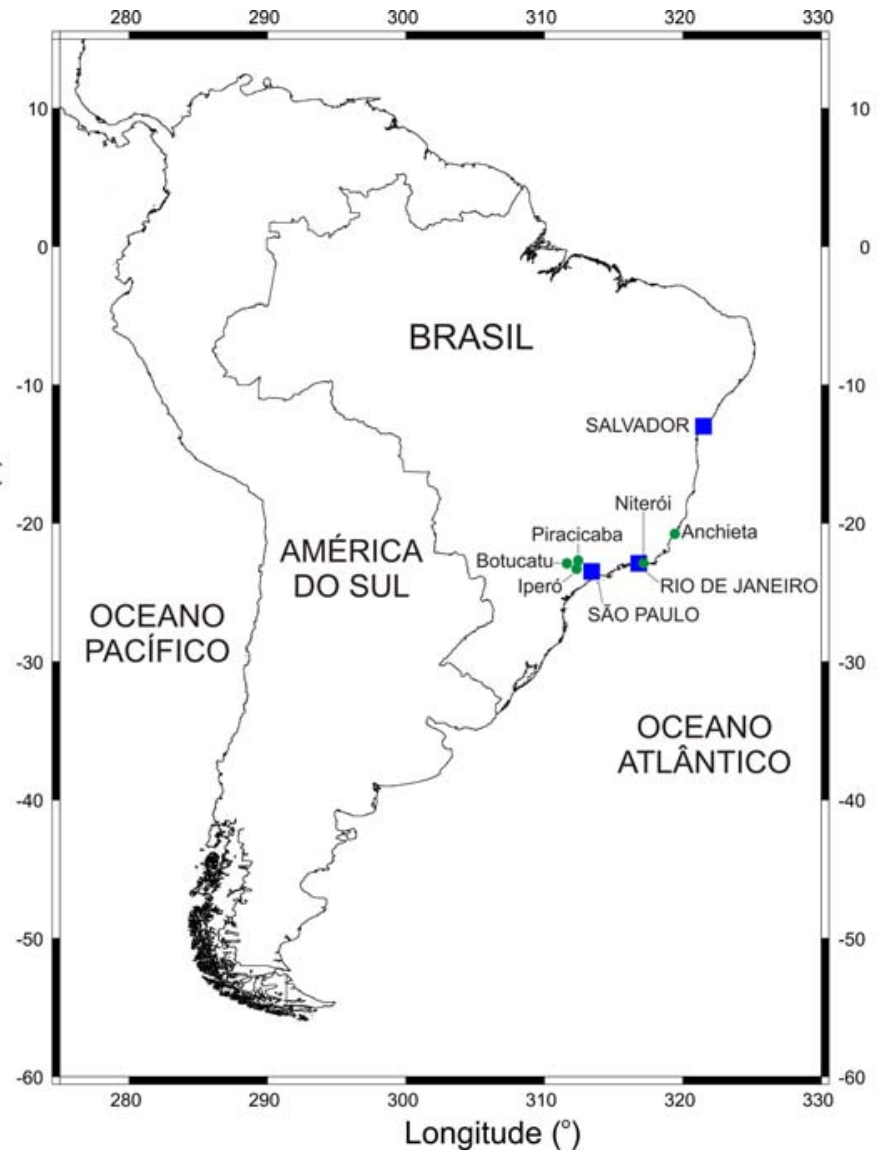

b)

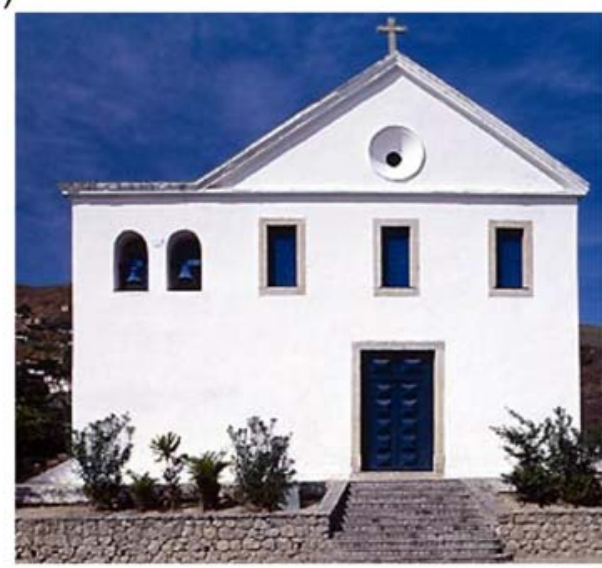

c)

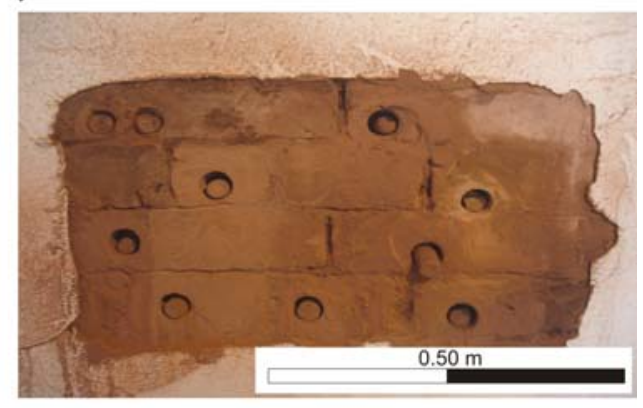

Figura 2.4: Em (a), mapa de localização das cidades onde os sítios foram amostrados. Em (b), a fachada da Igreja de São Lourenço dos Índios (SLI). Em (c), amostragem de cilindros nos tijolos da casa sede da Fazenda Lageado $(\mathrm{FL} 1+3+4+5)$.

A amostragem foi conduzida em construções bem documentadas e datadas dos últimos 500 anos na região Sudeste do Brasil (Tabela 2.2). Em todos os sítios, as idades foram determinadas por documentos históricos. Em muitos casos, as incertezas nas idades são estimadas em menos de 10 anos. Por exemplo, a Igreja de São Lourenço dos Índios, localizada na Cidade de Niterói, Estado do Rio de Janeiro, foi erguida entre 1623 e 1633 de 
acordo com os registros históricos que datam a sua construção. Esta igreja é um exemplo da arquitetura de igrejas jesuíticas do período colonial (Figura 2.4b). Os sítios FF2, FF4 e FFY foram amostrados na primeira fábrica de ferro do Brasil (Real Fábrica de Ferro Ipanema), cujas idades são determinadas pelos arquivos históricos da Fábrica que operou de 1811 a 1895 por ordem de Dom João VI em Carta Régia, assinada em 4 de dezembro de 1810 (e.g. Salazar, 1998). Outro exemplo de determinação de idades com base em registros históricos é a antiga residência do primeiro presidente da República do Brasil, Prudente de Moraes (sítio MPM1+2), situada na Cidade de Piracicaba, Estado de São Paulo, cujo ano de construção de 1870 é muito bem determinado pelos arquivos históricos.

O contexto arqueológico foi também utilizado para aprimorar a determinação da idade de três igrejas: Igreja de Nossa Senhora da Assunção (Cidade de Anchieta, Estado do Espírito Santo), Igreja da Venerável Ordem Terceira de São Francisco da Penitência e a Igreja de Nossa Senhora da Saúde (ambas situadas na Cidade do Rio de Janeiro, Estado do Rio de Janeiro). Os estilos arquitetônicos destas igrejas são bastante semelhantes ao estilo da Igreja de São Lourenço dos Índios (Figura 2.4b), que serviu de referência para a amostragem das outras igrejas pelas equipes de Arqueologia do IPHAN (Najjar, 1999; 2000a; 2000b; 2000c; 2004; Plens et al., 2000; Pereira, 2004). A estratigrafia das escavações antes das restaurações das igrejas e a tipologia dos fragmentos ajudaram a identificar e distinguir os fragmentos mais jovens daqueles mais antigos, utilizados no presente trabalho (Najjar, 2004). Por fim, a amostragem foi realizada nas fundações das construções, assegurando que os fragmentos selecionados correspondem à fase inicial de construção dos edifícios.

Tabela 2.2: Sítios arqueológicos da região Sudeste do Brasil.

\begin{tabular}{|c|c|c|c|c|}
\hline \multirow[t]{2}{*}{ Sítio } & \multirow[t]{2}{*}{ Descrição do sítio } & \multicolumn{2}{|c|}{$\begin{array}{c}\text { Método de } \\
\text { datação }\end{array}$} & \multirow{2}{*}{$\begin{array}{c}\text { Intervalo } \\
\text { de idade } \\
\text { (AD) }\end{array}$} \\
\hline & & Hist. & Arq. & \\
\hline $\begin{array}{l}\text { Igreja de Nossa Senhora da } \\
\text { Assunção (INSA) } \\
\text { Cidade: Anchieta } \\
\left(20,8^{\circ} \mathrm{S}, 40,6^{\circ} \mathrm{W}\right)\end{array}$ & $\begin{array}{l}\text { A Igreja de Nossa Senhora da Assunção foi construída } \\
\text { pelos Jesuítas no final do século XVI. É importante } \\
\text { mencionar que o padre Jesuíta José de Anchieta foi o } \\
\text { principal responsável pela construção e a data de } \\
\text { inauguração ocorreu logo após a morte do padre. Este } \\
\text { é o único sítio estudado localizado no Estado do } \\
\text { Espírito Santo. }\end{array}$ & $X$ & $\mathrm{X}$ & $1584-1598$ \\
\hline $\begin{array}{l}\text { Igreja de São Lourenço dos } \\
\text { Índios (SLI) } \\
\text { Cidade: Niterói } \\
\left(22,9^{\circ} \mathrm{S}, 43,1^{\circ} \mathrm{W}\right)\end{array}$ & $\begin{array}{l}\text { A Igreja de São Lourenço dos Índios foi também } \\
\text { construída pelos Jesuítas na primeira metade do } \\
\text { século XVII. O estilo arquitetônico é característico de } \\
\text { igrejas jesuíticas deste período. Isso inclui a nave da } \\
\text { igreja, um altar, um presbitério, duas sacristias e um } \\
\text { campanário. }\end{array}$ & $X$ & $X$ & $1623-1633$ \\
\hline
\end{tabular}




\begin{tabular}{|c|c|c|c|c|}
\hline \multirow[t]{2}{*}{ Sítio } & \multirow[t]{2}{*}{ Descrição do sítio } & \multicolumn{2}{|c|}{$\begin{array}{c}\text { Método de } \\
\text { datação }\end{array}$} & \multirow{2}{*}{$\begin{array}{l}\text { Intervalo } \\
\text { de idade } \\
\text { (AD) }\end{array}$} \\
\hline & & Hist. & Arq. & \\
\hline $\begin{array}{l}\text { Igreja da Venerável Ordem } \\
\text { Terceira de São Francisco } \\
\text { da Penitência (OTP) } \\
\text { Cidade: Rio de Janeiro } \\
\left(22,9^{\circ} \mathrm{S}, 43,2^{\circ} \mathrm{W}\right) \\
\end{array}$ & $\begin{array}{l}\text { A Igreja da Venerável Ordem Terceira de São } \\
\text { Francisco da Penitência foi construída pela “Ordem } \\
\text { Terceira da Penitência" na segunda metade do século } \\
\text { XVII. Esta foi uma das mais importantes igrejas } \\
\text { construídas no Rio de Janeiro. }\end{array}$ & $X$ & $X$ & $1622-1654$ \\
\hline $\begin{array}{l}\text { Igreja de Nossa Senhora da } \\
\text { Saúde (INS) } \\
\text { Cidade: Rio de Janeiro } \\
\left(22,9^{\circ} \mathrm{S}, 43,2^{\circ} \mathrm{W}\right)\end{array}$ & $\begin{array}{l}\text { A Igreja de Nossa Senhora da Saúde foi construída na } \\
\text { antiga fazenda de Manuel da Costa Negreiros na } \\
\text { metade do século XVIII. Atualmente, nesta fazenda } \\
\text { fica o bairro Morro da Saúde. Neste período, era } \\
\text { muito comum construir igrejas em propriedades } \\
\text { particulares. }\end{array}$ & $X$ & $\mathrm{X}$ & $1742-1750$ \\
\hline $\begin{array}{l}\text { Real Fábrica de Ferro } \\
\text { Ipanema } 3 \text { (FF3) } \\
\text { Cidade: Iperó } \\
\left(23,3^{\circ} \mathrm{S}, 47,7^{\circ} \mathrm{W}\right)\end{array}$ & $\begin{array}{l}\text { A Fazenda Ipanema tem várias construções que foram } \\
\text { feitas durante o período de extração e produção de } \\
\text { ferro entre o final do século XVI e começo do século } \\
\text { XIX. Esta amostragem corresponde a tijolos retirados } \\
\text { de um forno utilizado para fundir o ferro. As idades } \\
\text { deste forno correspondem à construção e utilização } \\
\text { final. }\end{array}$ & $X$ & & $1790-1800$ \\
\hline $\begin{array}{l}\text { Real Fábrica de Ferro } \\
\text { Ipanema } 2 \text { (FF2) } \\
\text { Cidade: Iperó } \\
\left(23,3^{\circ} \mathrm{S}, 47,7^{\circ} \mathrm{W}\right)\end{array}$ & $\begin{array}{l}\text { Esta parte da Fazenda Ipanema foi construída após a } \\
\text { publicação da Carta Régia do Rei Dom João VI em } \\
\text { 1810. A Real Fábrica de Ferro Ipanema funcionou } \\
\text { entre } 1811 \text { e } 1895 \text { para produção de ferro. Esta } \\
\text { amostragem corresponde a tijolos de um forno } \\
\text { utilizado para fundir o ferro. O intervalo de idade } \\
\text { deste forno corresponde à construção e utilização } \\
\text { final. }\end{array}$ & $X$ & & $1815-1819$ \\
\hline $\begin{array}{l}\text { Museu Prudente de Moraes } \\
1 \text { e } 2 \text { (MPM1+2) } \\
\text { Cidade: Piracicaba } \\
\left(22,7^{\circ} \mathrm{S}, 47,6^{\circ} \mathrm{W}\right)\end{array}$ & $\begin{array}{l}\text { Este Museu serviu de residência para o primeiro } \\
\text { Presidente da República do Brasil, Prudente de } \\
\text { Moraes. Esta casa, em estilo arquitetônico imperial, } \\
\text { foi construída em } 1870 \text { e serviu para várias reuniões } \\
\text { políticas durante o período da Proclamação da } \\
\text { República. }\end{array}$ & $\mathrm{X}$ & & 1870 \\
\hline $\begin{array}{l}\text { Real Fábrica de Ferro } \\
\text { Ipanema } 4 \text { (FF4) } \\
\text { Cidade: Iperó } \\
\left(23,3^{\circ} \mathrm{S}, 47,7^{\circ} \mathrm{W}\right)\end{array}$ & $\begin{array}{l}\text { O sítio FF4 foi amostrado em um dos fornos } \\
\text { utilizados para produção de ferro na Fazenda } \\
\text { Ipanema. Este forno foi construído para produzir } 7 \\
\text { toneladas de ferro por dia. }\end{array}$ & $\mathrm{X}$ & & $1888-1895$ \\
\hline $\begin{array}{l}\text { Real Fábrica de Ferro } \\
\text { Ipanema Y (FFY) } \\
\text { Cidade: Iperó } \\
\left(23,3^{\circ} \mathrm{S}, 47,7^{\circ} \mathrm{W}\right)\end{array}$ & $\begin{array}{l}\text { O sítio FFY também foi amostrado em um dos fornos } \\
\text { utilizados para produção de ferro na Fazenda } \\
\text { Ipanema. }\end{array}$ & $\mathrm{X}$ & & $1888-1895$ \\
\hline $\begin{array}{l}\text { Fazenda Lageado } 1,3,4 \text { e } 5 \\
\text { (FL1+3+4+5) } \\
\text { Cidade: Botucatu } \\
\left(22,9^{\circ} \mathrm{S}, 48,4^{\circ} \mathrm{W}\right)\end{array}$ & $\begin{array}{l}\text { A Fazenda Lageado foi uma importante fazenda } \\
\text { produtora e exportadora de café. Atualmente, a } \\
\text { fazenda sedia o Museu do Café da Universidade } \\
\text { Estadual Júlio de Mesquita Filho. A amostragem } \\
\text { correspondeu a tijolos da casa sede da fazenda. }\end{array}$ & $\mathrm{X}$ & & $1895-1901$ \\
\hline $\begin{array}{l}\text { Fazenda Lageado } 2 \text { (FL2) } \\
\text { Cidade: Botucatu } \\
\left(22,9^{\circ} \mathrm{S}, 48,4^{\circ} \mathrm{W}\right)\end{array}$ & $\begin{array}{l}\text { Esta amostragem da Fazenda Lageado corresponde a } \\
\text { tijolos do terreiro de café. O intervalo de idade é } \\
\text { assegurado pela documentação histórica da própria } \\
\text { fazenda. }\end{array}$ & $\mathrm{X}$ & & $1908-1910$ \\
\hline
\end{tabular}

Na coluna "Sítio" está indicado o nome, a sigla e a localização dos sítios estudados. Na coluna "Descrição dos sítios", uma curta descrição de cada sítio analisado fornece os elementos que guiaram as amostragens. Na coluna "Método de datação" estão indicados os métodos usados para determinar as idades ("Hist.", a partir de informações históricas e "Arq.", a partir de informações arqueológicas). Por fim, na coluna "Intervalo de idade" é indicado as estimativas de idade de cada sítio baseadas nas informações históricas e/ou arqueológicas. 
Para a maioria dos sítios amostrados, os fragmentos foram coletados diretamente das paredes utilizando martelo e cinzel. Para os sítios MPM1+2 e FL1+3+4+5 os tijolos foram amostrados utilizando uma perfuratriz portátil para amostragem de cilindros com 2,2 $\mathrm{cm}$ de diâmetro (Figura 2.4c).

\subsubsection{Igreja de Nossa Senhora Assunção (INSA)}

A Igreja Nossa Senhora da Assunção é um importante exemplar do barroco jesuítico do século XVI, estando localizada na Cidade de Anchieta, Estado do Espírito Santo. Em geral, os assentamentos jesuíticos não se iniciavam pela construção de uma igreja propriamente dita. Ao fundarem uma vila, os jesuítas inicialmente erguiam uma construção única para múltiplos usos, incluindo a celebração de cultos, catequese, residência dos padres e índios convertidos, além de servir de espaço para sepultamentos. Depois de estabelecidos e já com certo contingente de indígenas catequizados e europeus colonizadores, é que se iniciava a construção da igreja propriamente dita (Najjar, 1999). A fundação da Aldeia de Nossa Senhora da Assunção seguiu este padrão. Ela foi fundada em fins do século XVI pelo Padre José de Anchieta, jesuíta português de grande importância para a colonização do litoral brasileiro. Registros históricos indicam que a vila foi fundada no ano de 1584. Não existe informação quanto ao início da construção da Igreja, mas sabe-se que seu término só deve ter ocorrido por volta de 1597, ano da morte do Padre José de Anchieta. Isso porque o padre Anchieta não foi sepultado na Igreja que ajudou a construir, indicando que esta devia estar inacabada (Najjar, 1999). Durante um trabalho de restauração da Igreja, executado entre 1997 e 2000, foram feitas pesquisas arqueológicas e arquitetônicas no pátio interno, nas alas da residência, na capela mor, na nave, na calçada fronteiriça à Igreja e em parte da sacristia, além de terem sido conduzidas prospecções de algumas paredes. Foram constatados dois limites distintos do conjunto arquitetônico: um menor e mais antigo, outro maior e mais recente. Amostragem realizada: os fragmentos amostrados são tijolos extraídos do pátio interno da Igreja, o que corresponde à primeira fase de construção da mesma. A idade para esses fragmentos pode ser atribuída entre 1584-1597.

\subsubsection{Igreja de São Lourenço dos Índios (SLI)}

A Igreja de São Lourenço dos Índios também é uma igreja jesuítica, neste caso construída na Cidade de Niterói, Estado do Rio de Janeiro. O assentamento de São Lourenço 
dos Índios é um dos primeiros da Ordem dos Jesuítas no Brasil e seguiu o mesmo modelo adotado em Anchieta. A Igreja de São Lourenço dos Índios teve três momentos construtivos bastante distintos. No primeiro, a Igreja foi construída em 1568 em taipa e apresentava uma arquitetura bastante modesta, com apenas uma grande janela acima da porta. No segundo momento, por volta 1622, a capela de taipa foi substituída por uma capela de pedra e cal, técnica construtiva muito comum para esse tipo de edificação naquela época. Sua arquitetura é simples, com uma única nave, presbitério, duas sacristias dispostas lateralmente e um altar. No terceiro momento, a Igreja manteve a mesma arquitetura da segunda fase, porém, foi acrescida uma sineira, cujas paredes têm dois pequenos arcos que suportam dois sinos e que também permitiram a construção de uma escada para dar acesso ao coro (Najjar, 2000b). Trabalhos arqueológicos foram realizados em 2000 com o objetivo de resgatar informações sobre os religiosos e as populações que ali viviam. As escavações arqueológicas foram feitas em várias partes do terreno e da Igreja antes do processo de restauração da mesma. Durante as escavações foi coletada uma grande quantidade e variedade de materiais, como cerâmica, louça, vidro, metais e ossos (humanos e de animais). Foram também identificados vestígios diretamente relacionados à edificação, como telhas, reboco, tijolos e lajotas de piso. Estes materiais apresentam características típicas do final do século XVI, o que reforça o fato de que a substituição da Igreja de taipa por uma de pedra e cal tenha mesmo ocorrido por volta 1622, como sugerem estudos em documentos históricos da época (Najjar, 2000b). Através da arquitetura da Igreja foi possível indicar um intervalo para construção da mesma, que neste caso foi de aproximadamente 10 anos. Durante os trabalhos de escavação foram coletados materiais construtivos, como tijolos, lajotas do piso, telhas e reboco. A coleta de tijolos e telhas foi concentrada basicamente na nave principal e na sacristia, que foram construídas no segundo momento de edificação da Igreja, ou seja, entre 1622-1632. Amostragem realizada: tijolos da nave principal e da sacristia. Estas duas partes da Igreja foram construídas no segundo momento, entre 1622-1632. É importante salientar que a tipologia e as dimensões de todos os tijolos amostrados são idênticas.

\subsubsection{Igreja da Venerável Ordem Terceira de São Francisco da Penitência (OTP)}

A Ordem Terceira de São Francisco da Penitência foi fundada em 1619 e passou a funcionar primeiramente na Capela da Nossa Senhora da Conceição, na Cidade do Rio de Janeiro. Os irmãos terceiros deram início à construção da Igreja em 17 de setembro de $\mathbf{1 6 2 2}$, 
em terreno contíguo ao primeiro convento franciscano do Rio de Janeiro, o Convento de Santo Antônio (Coaracy, 1988). A construção foi concluída em 1653 quando a Ordem Terceira adquiriu um terreno lateral anexo ao Convento. Neste local a Ordem construiu sua Capela dos Exercícios, que foi finalizada em 1773. A partir desse núcleo, várias alterações na Igreja e novas construções foram se interpondo. Atualmente, esse complexo religioso junto com o Convento de Santo Antônio, compõe um dos conjuntos arquitetônicos mais significativos do centro da Cidade do Rio de Janeiro (Najjar, 2000c). As pesquisas arqueológicas na Igreja da Venerável Ordem Terceira foram realizadas entre fevereiro de 1999 e abril de 2000. Os levantamentos históricos e arqueológicos constataram que as obras de ampliação da Igreja foram definidas ao longo dos séculos, com a configuração atual do complexo arquitetônico sendo definida somente em 1850, com a finalização do cemitério e da “Casa do Administrador" (Plens et al., 2000). A amostragem de tijolos foi feita na parte da Igreja construída entre 1622-1653. Amostragem realizada: tijolos de partes da Igreja construídas entre 1622-1653. É importante salientar que a tipologia e as dimensões são idênticas em todos os tijolos amostrados.

\subsubsection{Igreja de Nossa Senhora da Saúde (INS)}

A Igreja de Nossa Senhora da Saúde foi edificada na chácara de Manuel da Costa Negreiros entre os anos de 1742 e 1750, no morro da Saúde, Cidade do Rio de Janeiro (Pereira, 2004). Nesta época era muito comum a construção de igrejas em chácaras. Essas edificações substituíam os pequenos oratórios presentes no interior das casas. A Igreja Nossa Senhora da Saúde foi construída numa área afastada do núcleo urbano e que apresentava pouca ocupação nos séculos XVI e XVII, sendo que esta área foi sendo progressivamente ocupada a partir do século XVIII e com maior impulso no século XIX. A área só recebeu o nome de Saúde a partir da construção da Igreja. Até então era conhecida como Valongo (Pereira, 2004). A arquitetura da Igreja de Nossa Senhora da Saúde apresenta características barrocas, com fachada de superfície plana e rigidez formal, mas com elementos decorativos internos de estilo rococó, que é típico de meados do século XVIII (Alvim, 1996). As amostras coletadas na Igreja de Nossa Senhora da Saúde são fragmentos de tijolos e telhas coletados durante os trabalhos de escavação realizados em 2004 pela equipe de Arqueologia da $6^{\text {a }}$ Superintendência Regional do IPHAN. Os tijolos foram amostrados da base da Igreja e a idade atribuída ao material é aquela do período de construção da mesma (1742-1750). As telhas, por sua vez, são o tipo de material mais trocado em construções visto que se quebram 
com mais freqüência. No entanto, a amostragem das telhas analisadas neste trabalho foi feita em uma parede que foi decapada, evidenciando a linha do telhado acima dos arcos, correspondente à linha do telhado original. Isto ficou detalhado pelos estudos arqueológicos e arquitetônicos efetuados por Najjar (2004). A Figura 2.5a mostra uma foto de uma parede decapada da sacristia da igreja, revelando a linha do telhado original onde foi feita a amostragem. Além disso, os levantamentos históricos e arquitetônicos indicam que as alterações ocorreram em épocas bem conhecidas e bastante distintas do período de construção da Igreja. A primeira reforma relatada historicamente foi realizada entre 1904 e 1905, sendo que outras sucederam nos anos de 1962-1969, 1976-1979 e em 1986. O material referente a essas reformas foi evitado durante as análises. Amostragem realizada: fragmentos de tijolos e telhas das paredes da sacristia. Esta parte da Igreja (assim como a própria Igreja) foi construída entre 1742 e 1750. É importante salientar que a tipologia e as dimensões são idênticas em todos os tijolos amostrados, sendo que o mesmo vale para os fragmentos de telhas.

\subsubsection{Fábrica de Ferro (FF3, FF2, FF4, FFY)}

A Real Fábrica de Ferro está localizada dentro da Fazenda Ipanema, atualmente Floresta Nacional de Ipanema (FLONA), no Município de Iperó, Estado de São Paulo. A FLONA de Ipanema é gerenciada pelo Instituto Nacional dos Recursos Naturais Renováveis (IBAMA). A Fazenda Ipanema tem vários edifícios que foram construídos para o desenvolvimento da produção de ferro durante o período colonial. A história de produção de ferro na Fazenda Ipanema tem dois períodos bastante distintos. O primeiro período de produção se iniciou no final do século XVI e terminou no final do século XVIII. Afonso Sardinha foi quem primeiro começou a produzir ferro em 1589 no morro de Araçoiaba, que fica dentro da área da Fazenda Ipanema e a efetiva produção de ferro na região durou até aproximadamente 1765 (e.g. Salazar, 1998; Zequini, 2006; 2007). O segundo grande momento de produção surge com a implantação da Real Fábrica de Ferro, através da promulgação da Carta Régia de 4 de dezembro de 1810, que ocorreu após a vinda da Família Real para o Brasil em 1808. A Real Fábrica de Ferro tinha por objetivo a produção de ferro e armas e seu funcionamento durou entre 1811 e 1895 (e.g. Salazar, 1998). As amostragens foram conduzidas em duas construções que marcam períodos distintos do desenvolvimento da Fazenda Ipanema. Uma das coletas foi feita na construção mais antiga da Fazenda, que é um pouco anterior as instalações da Real Fábrica de Ferro. A outra foi feita nos altos fornos 
geminados, que foram construídos para produção de ferro em larga escala entre 1815 e 1819 . Os levantamentos históricos indicam que os tijolos usados nas construções foram produzidos na própria Fazenda.

O sítio FF3 corresponde à parte mais antiga do complexo de edificações da Fazenda Ipanema (FF3) onde se produziu ferro entre 1790 e 1800. Os levantamentos arqueológicos indicam que esta foi a primeira construção feita no local, anteriormente ao funcionamento da Real Fábrica de Ferro. A edificação corresponde a um antigo forno que foi utilizado para produção de ferro por um intervalo de tempo bastante curto (1790-1800), do qual atualmente restam apenas ruínas (Figura 2.5b). Pode-se notar na mesma Figura 2.5b que as estruturas posteriores se sobrepõem às estruturas mais antigas, o que corrobora a posição estratigráfica atribuída a essa estrutura. Amostragem realizada: fragmentos de tijolos da base do forno. Este forno foi utilizado para produção de ferro em um intervalo de tempo bastante curto (1790-1800). É importante salientar que toda a produção de tijolos era local.

O sítio FF2 corresponde aos altos fornos geminados construídos para produção de ferro entre 1815 e 1819, após a chegada de Friederich Wilherm Varnhagen, o Visconde de Porto Seguro, o primeiro diretor da Real Fábrica de Ferro. Muitos documentos históricos, incluindo cartas e registros de negócios, atestam as idades atribuídas para esses fornos (Salazar, 1998). A amostragem de tijolos dos fornos foi feita nas partes externas dos mesmos, buscando-se amostrar tijolos que não sofreram a influência das altas temperaturas internas durante a fundição do minério de ferro. A Figura 2.5c mostra os altos fornos de Varnhagen que ainda se encontram em bom estado de conservação. Amostragem realizada: fragmentos de tijolos da base externa dos altos fornos geminados. Estes fornos foram construídos para produção de ferro entre 1815-1819. É importante salientar que toda a produção de tijolos ocorria na própria Fazenda Ipanema.

O sítio FF4 refere-se a um dos fornos mais recentes, utilizado para produção de ferro na Fazenda Ipanema. Este alto forno foi construído para produzir 7 toneladas de ferro por dia. Porém, ele data do período em que a Fazenda Ipanema estava começando o seu declínio. Ele foi construído em 1888 e a Fazenda Ipanema deixou de produzir ferro completamente em 1895. Amostragem realizada: fragmentos de tijolos da base externa do alto forno. Estes fornos foram construídos para produção de ferro entre 1888-1895. É importante salientar que toda a produção de tijolos ocorria na própria Fazenda Ipanema.

O sítio FFY tem contexto arqueológico semelhante ao sítio FF4, pois trata-se de um forno com as mesmas características e que foi construído no mesmo período, ou seja, 18881895. Amostragem realizada: fragmentos de tijolos da base externa do alto forno. Estes 
fornos foram construídos para produção de ferro entre 1888-1895. É importante salientar que toda a produção de tijolos ocorria na própria Fazenda Ipanema.

a)

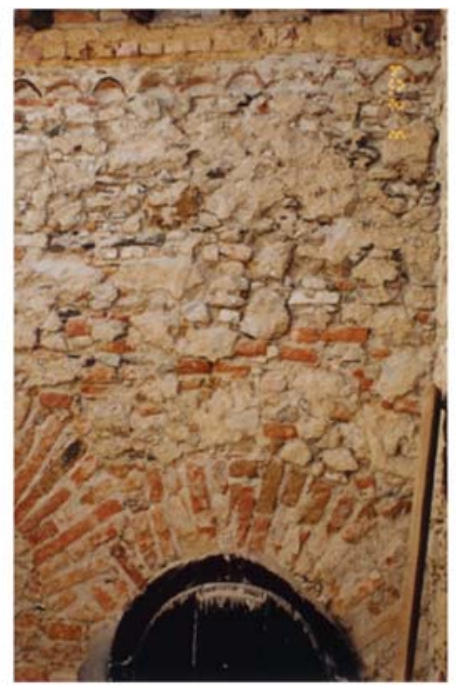

c)

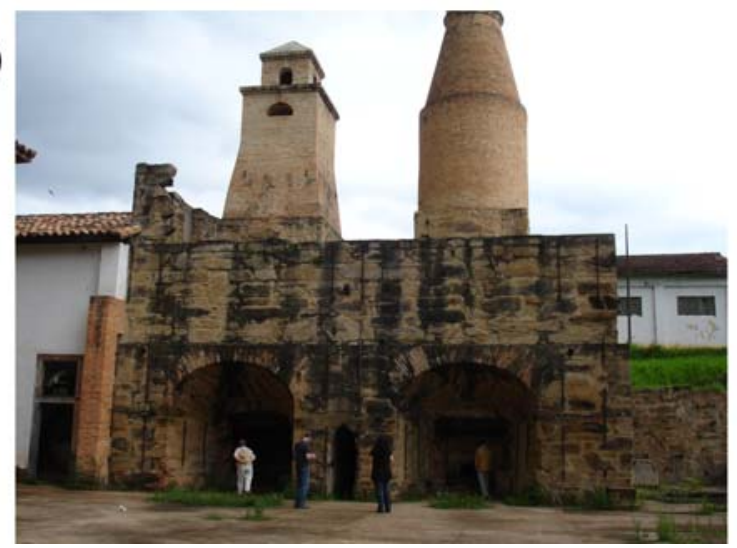

b)

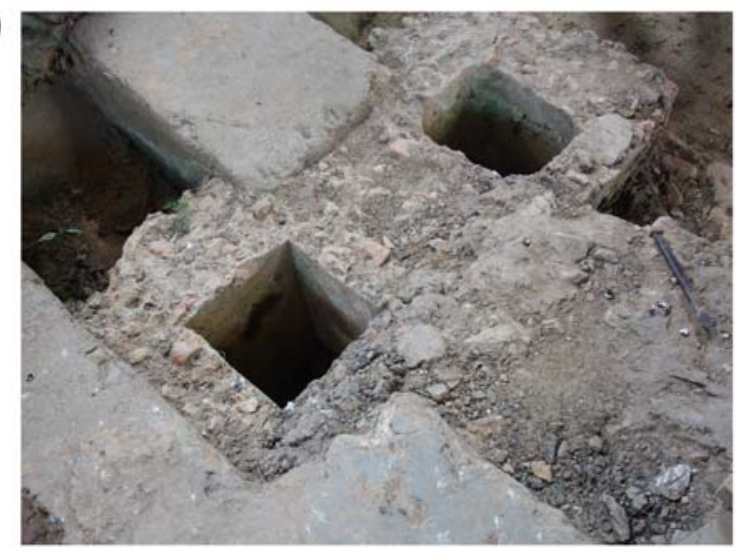

d)

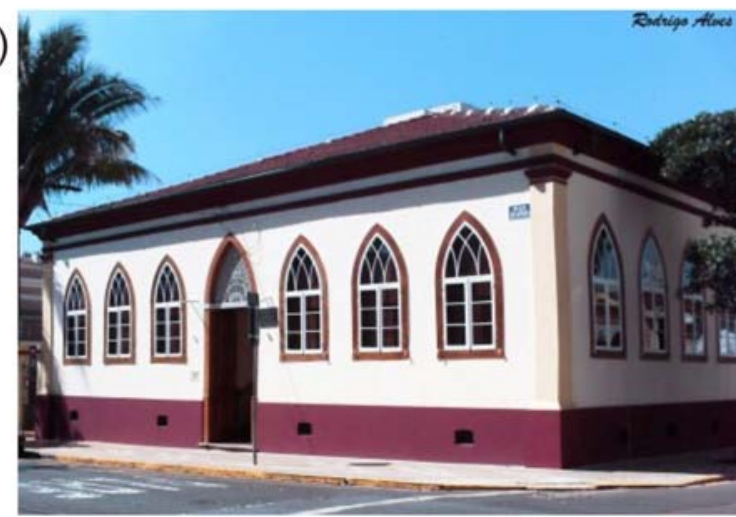

Figura 2.5: A foto (a) mostra a estrutura dos arcos da sacristia da Igreja de Nossa Senhora da Saúde (INS), evidenciando a linha do telhado original acima dos arcos. A foto (b) mostra partes do que restou do forno que foi construído para produção de ferro em 1790-1800, pouco antes da construção da Real Fábrica de Ferro de Ipanema (FF3). A foto (c) mostra os fornos geminados de Varnhagen construídos entre 1815 e 1819 para produção de ferro na Real Fábrica de Ferro de Ipanema (FF2). A foto (d) mostra a fachada do Museu Prudente de Moraes (MPM1+2) após a restauração realizada entre 2008 e 2009.

\subsubsection{Museu Prudentes de Moraes (MPM1+2)}

O Museu Histórico e Pedagógico Prudente de Moraes está localizado na Cidade de Piracicaba, Estado de São Paulo. A antiga casa de estilo arquitetônico imperial serviu de residência para o terceiro presidente da República Federativa do Brasil, Prudente José de Moraes Barros. A casa, construída em 1870, foi local de muitos encontros políticos durante o período de Proclamação da República. A antiga residência foi transformada em Museu em 1957 e passou por uma restauração física completa entre 2008 e 2009, sendo que neste 
intervalo foram feitas as amostragens de tijolos da casa. Basicamente, a reforma englobou a troca de sustentação do telhado, o madeiramento que estava infestado por cupins, pintura e adequação das instalações para visitação. Neste caso, não ocorreram mudanças na estrutura de alvenaria, mesmo porque os levantamentos estruturais e arquitetônicos mostraram que não houve alterações durante a história da casa. A amostragem foi feita na base da casa, retirandose fragmentos de tijolos das colunas de sustentação. Este tipo de amostragem foi possível devido aos trabalhos de reforma que estavam sendo executados. Pode-se atribuir aos fragmentos de tijolos amostrados a idade de construção da casa, que ocorreu no ano de 1870, conforme consta nos registros históricos do município de Piracicaba e também do próprio Museu. A Figura 2.5d mostra uma foto do Museu Prudente de Moraes após a restauração. Amostragem realizada: tijolos das colunas da base da casa. A amostragem foi feita com o auxílio de um martelo e cinzel durante os trabalhos de restauração do Museu. A numeração utilizada na sigla (MPM1+2) refere-se a diferentes paredes da base da casa, construída em 1870.

\subsubsection{Fazenda Lageado 1, 3, 4 e 5 (FL1+3+4+5, FL2)}

A Fazenda Lageado está localizada no Campus Universitário da Universidade Estadual Paulista "Júlio de Mesquita Filho" (UNESP), no município de Botucatu, Estado de São Paulo. Os históricos mostram três períodos distintos de uso da Fazenda (Michelin e Argollo-Ferrão, 2008). O primeiro deles refere-se ao período de uso particular para produção e exportação de café. A Fazenda foi comprada em 1881 e até 1934 a produção de café era bastante intensa. O segundo período de uso da Fazenda foi entre 1934 e 1972, quando ocorre a construção de grandes edificações para desenvolvimento e análise de grãos. Nesse período a Fazenda Lageado passou a ser de uso Federal, sendo utilizada como "Estação Experimental". No terceiro período que é de 1972 em diante, a Fazenda passou a ser de domínio do Estado de São Paulo com a implantação do Campus Universitário da UNESP. As campanhas de amostragem na Fazenda Lageado foram feitas visando coletar fragmentos de tijolos do primeiro período de uso da Fazenda. Neste caso, foram amostrados tijolos das paredes da casa da sede da Fazenda (ou casa grande) e do terreiro de café, que correspondem a dois intervalos distintos de edificação da Fazenda.

O sítio $\mathbf{F L 1 + 3 + 4 + 5}$ corresponde à casa da sede, construída no período de edificação das principais construções da Fazenda Lageado, entre 1895 e 1900. Atualmente, na antiga casa da sede funciona o Museu do Café da Fazenda Lageado. Os registros históricos e os 
estudos arquitetônicos não indicam modificações de construção ao longo do tempo. De qualquer forma, para evitar problemas em função de modificações mais recentes, a amostragem foi conduzida nas paredes do porão da casa, o que corresponde ao intervalo inicial de desenvolvimento da Fazenda. A coleta de material para as análises foi feita com a extração de cilindros com $2.2 \mathrm{~cm}$ de diâmetro e comprimento variável, usando para isso uma perfuratriz portátil movida a gasolina. Amostragem realizada: tijolos do porão da casa. A amostragem foi feita com o auxílio de uma perfuratriz portátil movida a gasolina. A numeração utilizada na sigla $(\mathrm{FL} 1+3+4+5)$ refere-se a diferentes paredes do porão da casa, cujo período de construção situa-se entre 1895-1900.

O sítio FL2 foi amostrado no terreiro de café, construído entre 1908 e 1910 para uso na secagem de café (Michelin e Argollo-Ferrão, 2008). O piso do terreiro é constituído de tijolos de coloração vermelha, menos espessos que os tijolos utilizados nas paredes das construções mais antigas da Fazenda, o que reforça o intervalo de idades atribuído pelos registros históricos e arquitetônicos. Amostragem realizada: fragmentos de tijolos do terreiro de café. A amostragem foi feita com o auxílio de martelo e cinzel. O período correspondente à construção do terreiro é de 1908-1910. 


\section{Capítulo 3}

\section{Paleointensidade absoluta: fundamentos teóricos e métodos}

A paleointensidade absoluta pode ser determinada em materiais geológicos e arqueológicos que foram aquecidos a altas temperaturas durante sua formação e/ou produção. Isso porque a magnetização termoremanente adquirida pelo material apresenta uma relação linear com o campo magnético ambiente, que neste caso é o campo magnético da Terra. A paleointensidade é determinada através de técnicas experimentais que tentam reproduzir em laboratório o processo natural de aquisição da magnetização. Neste capítulo serão apresentados os aspectos teóricos que regem a aquisição da intensidade do campo magnético em materiais geológicos e arqueológicos, bem como os métodos e protocolos utilizados nos procedimentos experimentais.

\subsection{Magnetização termoremanente}

A teoria que explica o processo de aquisição da Magnetização Termoremanente (MTR) em rochas e materiais arqueológicos foi estabelecida por Néel $(1949,1955)$ para o caso de grãos ferrimagnéticos idênticos, sem interação, com estrutura do tipo monodomínio (grãos SD), cujos estados de energia podem variar entre paralelo ou antiparalelo em relação a um campo magnético fraco $\mathbf{H}_{\mathbf{0}}$. A teoria da MTR em grãos SD, embora bastante simples, consegue explicar muito bem as propriedades experimentais das magnetizações termoremanentes parciais (pMTR) descritas anteriormente por Thellier (1938) e que servem de base para a definição dos protocolos de medidas da paleointensidade pelos métodos de duplo aquecimento (Thellier e Thellier, 1959). Algumas revisões atualizadas sobre o modelo teórico da MTR e sobre os métodos de paleointensidade podem ser encontradas em Dunlop e Özdemir (1997) e Tauxe (2010). 


\subsubsection{Teoria da MTR em grãos SD}

Quando minerais ferrimagnéticos são resfriados a partir de uma temperatura superior à temperatura de Curie $\left(T_{C}\right)$ na presença de um campo magnético $\mathbf{H}_{\mathbf{0}}$, eles adquirem uma MTR na direção de $\mathbf{H}_{\mathbf{0}}$, com intensidade proporcional a $\mathbf{H}_{\mathbf{0}}$. A MTR é considerada a Magnetização Remanente Natural (MRN) primária de rochas ígneas e de materiais arqueológicos que foram submetidos a aquecimento durante a fabricação ou uso. Esta magnetização apresenta uma característica importante, essencial para o paleomagnetismo, que é a forte estabilidade da MTR para longos períodos de tempo. Essa alta estabilidade se deve ao fato de que a MTR é adquirida de forma permanente após o resfriamento até a temperatura ambiente, onde a barreira de energia térmica e as coercividades do material magnético são muito altas (e.g. Dunlop e Özdemir, 1997).

Considere um conjunto de grãos SD esféricos com campo interno uniforme e campo desmagnetizante isotrópico, cujas mudanças de orientação dos momentos com relação a um campo $\mathbf{H}_{\mathbf{0}}$ são coerentes entre si. Esse conjunto de grãos pode ser considerado como equivalente a um único grão com anisotropia uniaxial e alinhado com o campo $\mathbf{H}_{\mathbf{0}}$. Nesse caso, a anisotropia magnetocristalina pode ser desprezada, pois a barreira de energia correspondente é menor do que aquela representada pela anisotropia de forma. Portanto, haveria somente dois estados de equilíbrio magnético possíveis para a magnetização do grão: um estado de baixa energia, no sentido de $\mathbf{H}_{\mathbf{0}}$, e um estado de alta energia, oposto a $\mathbf{H}_{\mathbf{0}}$. Os estados de alta energia $\left(E_{1}\right)$ e de baixa energia $\left(E_{2}\right)$ são expressos, respectivamente, por:

$$
\begin{aligned}
& E_{1}=+\mu_{0} V \mathbf{M}_{\mathbf{S}} \cdot \mathbf{H}_{\mathbf{0}} \\
& E_{2}=-\mu_{0} V \mathbf{M}_{\mathbf{s}} \cdot \mathbf{H}_{\mathbf{0}}
\end{aligned}
$$

onde $\mu_{0}$ é a permeabilidade magnética $\left(\mu_{0}=4 \pi \times 10^{-7} \mathrm{H} / \mathrm{m}\right), V$ é o volume do grão e $\mathbf{M}_{\mathbf{S}}$ é a magnetização de saturação. Usando a estatística de Boltzmann para $N$ grãos idênticos, $o$ número de grãos nos dois estados de energia $\left(N_{1}\right.$ e $\left.N_{2}\right)$ será:

$$
\begin{aligned}
& N_{1}=\frac{N e^{-\left(\mu_{0} V \mathbf{M}_{\mathrm{s}} \cdot \mathbf{H}_{0}\right) / k T}}{e^{+\left(\mu_{0} V \mathbf{M}_{\mathrm{S}} \cdot \mathbf{H}_{0}\right) / k T}+e^{-\left(\mu_{0} V \mathbf{M}_{\mathrm{S}} \cdot \mathbf{H}_{0}\right) / k T}} \\
& N_{2}=\frac{N e^{+\left(\mu_{0} V \mathbf{M}_{\mathbf{s}} \cdot \mathbf{H}_{0}\right) / k T}}{e^{+\left(\mu_{0} V \mathbf{M}_{\mathbf{S}} \cdot \mathbf{H}_{0}\right) / k T}+e^{-\left(\mu_{0} V \mathbf{M}_{\mathrm{s}} \cdot \mathbf{H}_{0}\right) / k T}}
\end{aligned}
$$

onde $k$ é a constante de Boltzmann e $T$ é a temperatura (em Kelvin). O denominador nas equações (3.3) e (3.4) refere-se à função de partição de Boltzmann. A magnetização $(M)$ do 
conjunto de grãos é determinada resolvendo as equações (3.3) e (3.4) para os estados de energia 1 e 2 :

$$
\mathbf{M}=N_{1} V \mathbf{M}_{\mathbf{s}}-N_{2} V \mathbf{M}_{\mathbf{s}}=N V \mathbf{M}_{\mathbf{s}} \tanh \left(\frac{\mu_{0} V \mathbf{M}_{\mathbf{S}} \cdot \mathbf{H}_{\mathbf{0}}}{k T}\right)
$$

Se considerarmos que as excitações térmicas apresentam uma distribuição estatística suficientemente grande, a magnetização global do conjunto de grãos não muda abruptamente, mas relaxa gradualmente enquanto os grãos revertem aleatoriamente até uma magnetização de equilíbrio ( $\mathbf{M}_{\mathrm{eq}}$ ). Para um número ( $\left.N\right)$ de grãos estatisticamente elevado, as equações (3.3) e (3.4) podem ser solucionadas, fornecendo a magnetização de equilíbrio do conjunto de grãos:

$$
\mathbf{M}_{\mathrm{eq}}=\mathbf{M}_{\mathrm{s}} \tanh \left(\frac{\mu_{0} V \mathbf{M}_{\mathbf{s}} \cdot \mathbf{H}_{\mathbf{0}}}{k T}\right)
$$

A teoria de Néel (1955) explica a estabilidade da MTR em longos períodos de tempo. Em qualquer instante $t, N_{1}$ grãos estão no estado 1 e $N-N_{1}$ grãos estão no estado 2. Para que ocorra uma rotação do estado 2 para o estado 1 , o momento magnético do grão $\left(V \mathbf{M}_{\mathrm{s}}\right)$ deve receber energia térmica em quantidade igual ou superior à barreira de energia $E_{\max }-E_{2}$. As rotações do estado 1 para o estado 2 requerem uma energia pelo menos igual a $E_{\max }-E_{1}$. Se $\mathbf{H}_{\mathbf{0}}>0$, o estado 1 fica energicamente favorecido, de maneira que as transições do estado 2 para o estado 1 requerem menos energia do que as transições no sentido inverso. Como $d N / d t$ é proporcional à diferença dos estados de energia, tem-se que:

$$
\begin{aligned}
& d N_{1}=\frac{1}{2 \tau}\left(N_{2}-N_{1}\right) \\
& d N_{2}=\frac{1}{2 \tau}\left(N_{1}-N_{2}\right)
\end{aligned}
$$

onde $2 \tau$ são os tempos de relaxação. Subtraindo a equação (3.8) da equação (3.7) e integrando na equação (3.5), obtém-se:

$$
\mathbf{M}(t)=\mathbf{M}_{0} e^{-t / \tau}+\mathbf{M}_{\text {eq }}\left(1-e^{-t / \tau}\right)
$$

sendo $\mathbf{M}_{0}$ a magnetização em $t=0$ e $\mathbf{M}_{\text {eq }}$ a magnetização de equilíbrio em $t \rightarrow \infty$. O tempo de relaxação $\tau$ obedece a seguinte relação:

$$
\frac{1}{\tau}=\frac{1}{\tau_{12}}+\frac{1}{\tau_{21}}
$$

Os tempos $\tau_{12}$ e $\tau_{21}$ variam com a temperatura $T$, com o campo $\mathbf{H}_{\mathbf{0}}$, com o volume do grão $V$ e com a coercividade do grão $\mathbf{H}_{\mathbf{K}}$. Considerando o tempo de reorganização atômica dos grãos 
( $\tau_{0} \approx 10^{-9} \mathrm{~s}$, que é o período entre os impulsos térmicos) o tempo de relaxação na presença de um campo $\mathbf{H}_{\mathbf{0}}$ é dado por:

$$
\frac{1}{\tau}=\frac{1}{\tau_{0}} \exp \left[-\frac{\mu_{0} V \mathbf{M}_{\mathbf{S}} \cdot \mathbf{H}_{\mathbf{K}}}{2 k T} \cdot\left(1-\frac{\mathbf{H}_{\mathbf{0}}}{\mathbf{H}_{\mathbf{K}}}\right)^{2}\right]
$$

Se $\mathbf{H}_{\mathbf{0}}=0$ as barreiras de energia serão equivalentes, resultando em:

$$
\frac{1}{\tau}=\frac{2}{\tau_{0}} \exp \left(-\frac{\mu_{0} V \mathbf{M}_{\mathbf{S}} \cdot \mathbf{H}_{\mathbf{K}}}{2 k T}\right)
$$

Note que $\tau$ muda exponencialmente com $T$, com $V$ e com $\mathbf{H}_{\mathbf{K}}$. Para temperaturas acima da temperatura de bloqueio $\left(T_{B}\right), \tau<<t$ e a magnetização total relaxa instantaneamente até $\mathbf{M}_{\text {eq }}$. Em temperaturas abaixo de $T_{B}$ a magnetização permanece estável por longos períodos de tempo. Substituindo $\tau=t$ na equação (3.11) obtém-se uma expressão para $T_{B}$ :

$$
\frac{T_{B}}{\beta^{2} T_{B}}=\left(\frac{\mu_{0} V \mathbf{M}_{\mathbf{s} \mathbf{0}} \cdot \mathbf{H}_{\mathbf{K} \mathbf{0}}}{2 k \ln \left(t / \tau_{0}\right)}\right) \cdot\left[1-\frac{\mathbf{H}_{\mathbf{0}}}{\mathbf{H}_{\mathbf{K} \mathbf{0}} \beta\left(T_{B}\right)}\right]^{2}
$$

Do mesmo modo, a equação (3.6) pode ser reescrita da seguinte forma:

$$
\mathbf{M}_{\mathbf{T R}}(T)=\mathbf{M}_{\mathbf{R S}}(T) \tanh \left(\frac{\mu_{0} V \mathbf{M}_{\mathbf{S B}} \cdot \mathbf{H}_{\mathbf{0}}}{k T_{B}}\right)
$$

onde $\mathbf{M}_{\mathbf{T R}}$ denota a intensidade de magnetização termoremanente, $\mathbf{M}_{\mathbf{R S}}$ é a magnetização remanente de saturação e $\mathbf{M}_{\mathbf{S B}}$ é a magnetização de saturação em $T_{B} ; \beta(T) \equiv M_{S}(T) / M_{S 0}$. As equações (3.6), (3.9) e (3.11) formam a base da teoria de Néel (1949, 1955). De acordo com (3.6), a MTR em um campo fraco (como o campo da Terra de até $100 \mu \mathrm{T}$ ) deverá ser proporcional a $\mathbf{H}_{\mathbf{0}}$ porque $\tanh (\alpha) \approx \alpha$ para valores pequenos de $\alpha$. A equação (3.9) mostra próximo de $T_{C}$, onde a energia magnética é baixa, a magnetização de equilíbrio é atingida quase instantaneamente (superparamagnetismo). Por outro lado, em temperatura ambiente, onde a energia magnética é alta, a magnetização de equilíbrio é alcançada lentamente, de forma que em condições geológicas esse tempo pode ser da ordem de $1 \mathrm{Ga}\left(10^{9}\right.$ anos). Finalmente, de acordo com a equação (3.11), se $\mathbf{H}_{\mathbf{0}}<<\mathbf{H}_{\mathbf{K}}$ as temperaturas de bloqueio e desbloqueio são equivalentes. Assim, a MTR só pode ser desmagnetizada por reaquecimento a uma temperatura igual ou superior à temperatura de bloqueio original. 


\subsubsection{Leis da magnetização termoremanente parcial}

Uma rocha ou artefato arqueológico contém diferentes conjuntos de grãos magnéticos, com uma ampla variedade de tamanhos e formas, podendo ser descritos como uma distribuição do tipo $f\left(V, H_{K 0}\right)$, onde $H_{K 0}=H_{K}\left(T_{0}\right)$. Como $T_{B}$ e $\mathbf{H}_{\mathbf{C}}$ (força coerciva) dependem de $V$ e $H_{K}$, a MTR total de um determinado material representa uma série de MTRs parciais (pMTR, em notação vetorial $\mathbf{M}_{\mathbf{p T R}}$ ), cada uma delas portada por conjuntos de grãos com valores semelhantes de $\left(V, H_{K 0}\right)$. Experimentalmente, se uma rocha ou artefato arqueológico é resfriado de $T_{C}$ até $T_{1}$ em campo nulo e de $T_{1}$ até $T_{2}$ em um campo fraco $\mathbf{H}_{0}$, somente os conjuntos de grãos SD com $T_{2} \leq T_{B} \leq T_{1}$ irão adquirir uma MTR. A magnetização remanente dessa fração de temperatura de bloqueio é uma $\mathbf{M}_{\mathbf{p T R}}\left(T_{1}, T_{2}, \mathbf{H}_{0}\right)$. Thellier (1938) demonstrou que as pMTRs obedecem três leis experimentais, as quais posteriormente foram explicadas pela teoria de Néel (1955):

1. Lei da reciprocidade: uma $\mathbf{M}_{\mathbf{p T R}}\left(T_{1}, T_{2}, \mathbf{H}_{0}\right)$, adquirida entre $T_{1}$ e $T_{2}$ pode ser desmagnetizada somente quando aquecida em campo nulo no mesmo intervalo de temperaturas $\left(T_{1}, T_{2}\right)$. Isto é, as temperaturas de bloqueio e desbloqueio $\left(T_{B}\right.$ e $\left.T_{U B}\right)$ são idênticas. Isso resulta do fato que $T_{B}$ e $T_{U B}$ são independentes de $\mathbf{H}_{0}$ (mas essa propriedade só é válida para campos fracos, como o campo da Terra).

2. Lei da independência: uma $\mathbf{M}_{\mathrm{pTR}}\left(T_{1}, T_{2}, \mathbf{H}_{0}\right)$ é independente, em direção e intensidade, de qualquer outra pMTR produzida em um intervalo de temperatura diferente de $\left(T_{1}, T_{2}\right)$, pois os grãos que portam as duas pMTRs representam diferentes partes do espectro de temperaturas de bloqueio.

3. Lei da aditividade: as pMTRs produzidas pelo mesmo $\mathbf{H}_{0}$ têm intensidades que são aditivas,

$\mathbf{M}_{\mathbf{p T R}}\left(T_{C}, T_{1}, \mathbf{H}_{0}\right)+\mathbf{M}_{\mathbf{p T R}}\left(T_{1}, T_{2}, \mathbf{H}_{0}\right)+\ldots+\mathbf{M}_{\mathbf{p T R}}\left(T_{n}, T_{0}, \mathbf{H}_{0}\right)=\mathbf{M}_{\mathbf{T R}}\left(T_{C}, T_{0}, \mathbf{H}_{0}\right)$

uma vez que o espectro de $T_{B}$ pode ser decomposto em diferentes frações de grãos, cada uma associada com uma pMTR independente.

As leis das pMTRs propostas por Thellier (1938) são válidas para grãos SD sem interação. Para grãos com estrutura multidomínio (MD) estas três leis não são válidas (Dunlop e Özdemir, 1997). A lei da reciprocidade para grãos MD falha porque o espectro de $T_{U B}$ nesses grãos abrangem um amplo intervalo de temperaturas que vai desde a $T_{B}$ até 
temperaturas próximas a $T_{C}$ (Dunlop e Özdemir, 2001). A lei da independência não é obedecida por dois motivos: (a) como as $T_{B}$ e $T_{U B}$ não são idênticas, as pMTRs adquiridas por grãos MD devem se sobrepor para um determinado espectro de temperaturas, (b) diferentes pMTRs são produzidas por diferentes paredes de domínio dentro de um mesmo grão MD (isso não ocorre com grãos SD porque as pMTRs são produzidas por diferentes grãos). Por fim, a lei da aditividade para grãos MD somente é obedecida considerando uma média de diferentes pMTRs, uma vez que as várias pMTRs não são independentes umas das outras (Dunlop e Xu, 1994).

\subsection{Determinação de paleointensidade absoluta por duplo aquecimento}

Existem diversos métodos para determinação de paleointensidade em rochas e materiais arqueológicos que portem uma MTR. Neste trabalho serão abordados apenas os métodos do tipo Thellier e Thellier (1959) e as determinações por duplo aquecimento com medidas em altas temperaturas.

O método original para medidas de paleointensidade absoluta foi desenvolvido por Thellier e Thellier (1959). A intensidade da $\operatorname{MTR}\left(\mathbf{M}_{\mathbf{T R}}\right)$, adquirida por uma rocha ou artefato arqueológico durante o resfriamento é proporcional à intensidade do campo indutor antigo $\left(\mathbf{H}_{\mathrm{A}}\right)$, desde que este seja suficientemente baixo (campos $\left.\leq 100 \mu \mathrm{T}\right)$. Logo,

$$
\mathbf{M}_{\mathbf{T R}}=C_{1} \mathbf{H}_{\mathbf{A}}
$$

onde $C_{1}$ é uma constante de proporcionalidade que depende das propriedades magnéticas da amostra. Assim, determinando-se a constante $C_{1}$, pode-se deduzir a intensidade do campo magnético da Terra à época do resfriamento a partir da intensidade da magnetização remanente natural da amostra. Para determinar o valor de $C_{1}$, pode-se obter uma magnetização termoremanente em laboratório $\left(\mathbf{M}_{\mathbf{L}}\right)$, produzida por um campo de laboratório conhecido $\left(\mathbf{H}_{\mathbf{L}}\right)$, tal que:

$$
\mathbf{M}_{\mathbf{L}}=C_{2} \mathbf{H}_{\mathbf{L}}
$$

Se as propriedades da amostra não foram alteradas desde a sua formação, então $C_{1}=C_{2}$, e pode-se determinar $\mathbf{H}_{\mathbf{A}}$ da seguinte forma:

$$
\mathbf{H}_{\mathrm{A}}=\mathbf{H}_{\mathrm{L}} \frac{\mathbf{M}_{\mathrm{TR}}}{\mathbf{M}_{\mathrm{L}}}
$$


Como a magnetização remanente total corresponde à soma de diversas pMTRs, aquecimentos parciais podem fornecer várias estimativas independentes de $\mathbf{H}_{\mathbf{A}}$ ao longo de todo o espectro de temperaturas de bloqueio da amostra. Valores espúrios de $\mathbf{H}_{\mathbf{A}}$ para altas e baixas temperaturas, causados por alterações químicas ou por eventos de remagnetização que afetaram a amostra são facilmente reconhecidos e rejeitados. Para detecção destes problemas são utilizados testes experimentais incorporados aos experimentos de duplo aquecimento. As alterações termoquímicas são monitorados pelas checagens das pMTRs (os conhecidos "pTRMs checks"), que correspondem à repetição de passos de aquecimento na presença de $\mathbf{H}_{\mathbf{L}}$ para verificar se a capacidade de aquisição da remanência foi alterada (Coe, 1967). Já a influência de grãos MD é detectada pelos "pTRMs tail checks", que correspondem a passos de aquecimento em campo nulo. Esta checagem verifica a lei da reciprocidade e indica se uma pMTR adquirida por grãos MD é completamente removida pelo aquecimento em campo nulo para o mesmo intervalo de temperatura (Riisager e Riisager, 2001).

\subsection{Métodos de paleointensidade com medidas em temperatura ambiente}

\subsubsection{Método de Thellier e Thellier (1959)}

Há várias formas possíveis de substituir progressivamente a magnetização termoremanente original por uma magnetização de laboratório. No método original de Thellier e Thellier (1959), inicialmente mede-se a MRN, que é a $\mathbf{M}_{\mathbf{T R}}\left(T_{0}\right)$. Em seguida, a amostra é aquecida a uma temperatura $\left(T_{1}\right)$ e resfriada no campo de laboratório $\left(\mathbf{H}_{\mathbf{L}}\right)$. A medida da remanência combinada (que é a MRN somada à nova pMTR de laboratório, $\left.\mathbf{M}_{\mathbf{p L}}\left(T_{1}\right)\right)$ é:

$\mathbf{M}_{1}\left(T_{1}\right)=\mathbf{M}_{\mathbf{T R}}\left(T_{1}\right)+\mathbf{M}_{\mathbf{p L}}\left(T_{1}\right)$

$\mathrm{Na}$ seqüência a amostra é aquecida uma segunda vez e resfriada em um campo $-\mathbf{H}_{L}$. A segunda remanência medida será:

$\mathbf{M}_{2}\left(T_{1}\right)=\mathbf{M}_{\mathbf{T R}}\left(T_{1}\right)-\mathbf{M}_{\mathbf{p L}}\left(T_{1}\right)$

A subtração vetorial simples de $\mathbf{M}_{2}\left(T_{1}\right)$ por $\mathbf{M}_{1}\left(T_{1}\right)$ permite a determinação da MRN restante em $T_{1}$ e a pMTR adquirida. A Figura 3.1 é um esquema que mostra as frações de aquisição da paleointensidade pelo método Thellier-Thellier original. 
O método Thellier e Thellier (1959) não requer um ambiente de campo nulo. $\mathrm{Na}$ prática, os resfriamentos de $T_{i}$ ocorrem num mesmo campo $\mathbf{H}_{\mathbf{L}}$, mas a amostra é rotacionada $180^{\circ}$ entre os aquecimentos. Um importante requerimento na versão Thellier-Thellier original é que a temperatura $T_{i}$ seja precisamente repetida no segundo par dos ciclos de aquecimentoresfriamento.
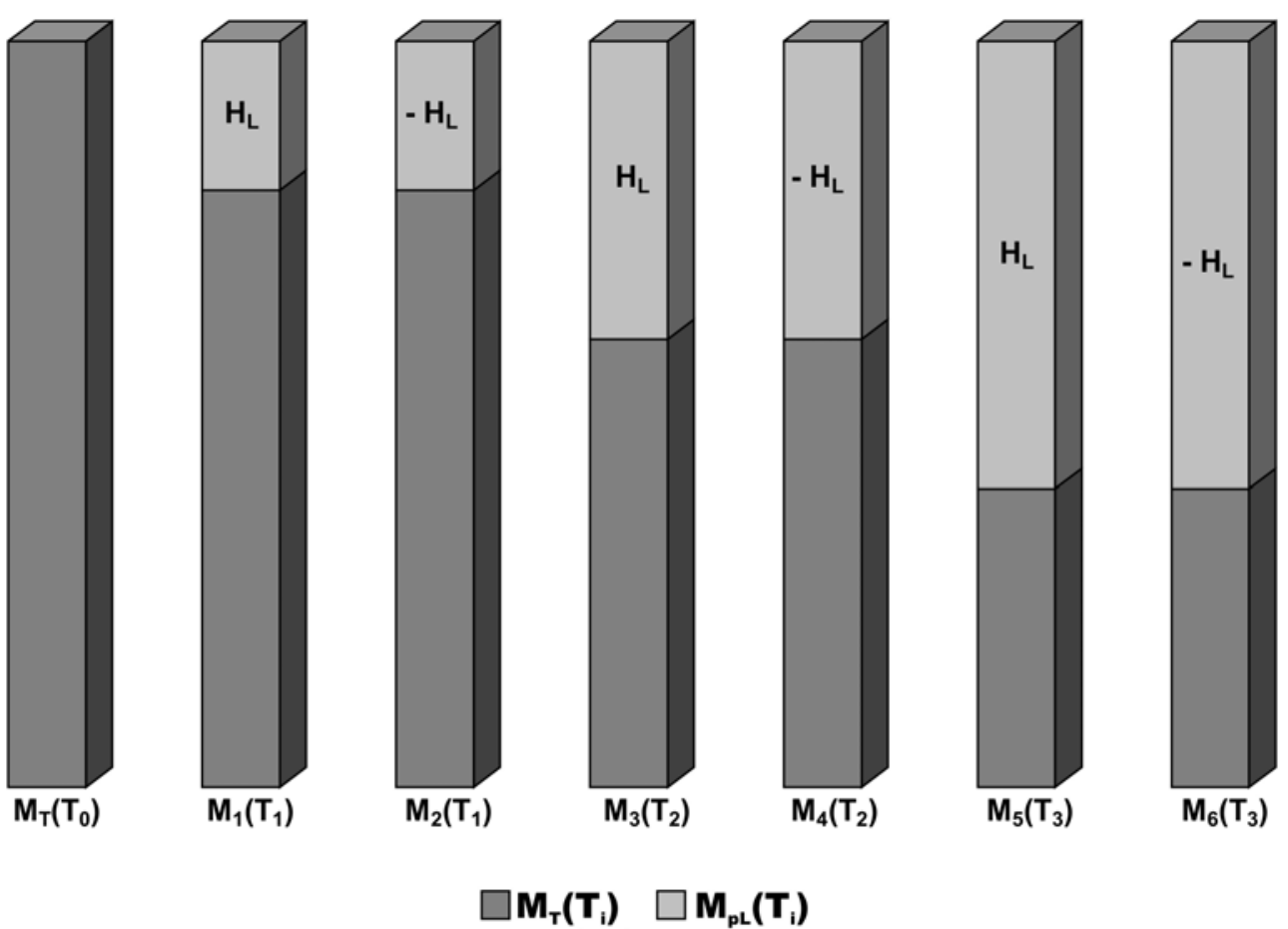

Figura 3.1: Método Thellier-Thellier original. $\mathbf{M}_{\mathbf{T}}\left(T_{0}\right)$ é a MRN original do espécime. Essa magnetização é gradativamente substituída por uma magnetização de laboratório paralela, $\mathbf{M}_{i}\left(T_{i}\right)$, ao campo $\mathbf{H}_{\mathbf{L}}$, e antiparalela, $\mathbf{M}_{i+1}\left(T_{i}\right)$, ao campo $\mathbf{H}_{\mathbf{L}}$.

Atualmente, salas e fornos blindados são amplamente disponíveis e muitos laboratórios realizam experimentos Thellier-Thellier modificados, onde um dos passos de aquecimento-resfriamento ocorre em campo nulo e o outro em $\mathbf{H}_{\mathbf{L}}$ (Coe, 1967; Aitken et al., 1988).

\subsubsection{Método de Coe (1967)}

Na versão de Coe (1967) do método Thellier-Thellier (TT), a amostra é duplamente aquecida a uma temperatura $T_{1}$ e resfriada a $T_{0}$, primeiro em campo nulo, depois num campo 
conhecido $\mathbf{H}_{\mathbf{L}}$. Este método também é chamado de TT-ZI (ZI de Zero-field, In-field, ou campo nulo, campo aplicado). Inicialmente, mede-se a magnetização inicial, $\mathbf{M}_{\mathbf{T R}}\left(T_{0}\right)$. Em seguida, mede-se a $\mathbf{M}_{\mathbf{p T R}}\left(T_{1}\right)$ obtida pelo aquecimento-resfriamento em campo nulo; depois mede-se a $\mathbf{M}_{\mathbf{p L}}\left(T_{1}\right)$ obtida pelo primeiro passo de aquecimento-resfriamento em campo de laboratório. O valor da magnetização original compreendida entre $T_{0}$ e $T_{1}$ é dado pela subtração vetorial entre $\mathbf{M}_{\mathbf{T R}}\left(T_{0}\right)$ e $\mathbf{M}_{\mathbf{p T R}}\left(T_{1}\right)$. Os aquecimentos duplos são repetidos em passos $\left(T_{i}, T_{0}\right)$ sucessivamente, para temperaturas cada vez mais altas.
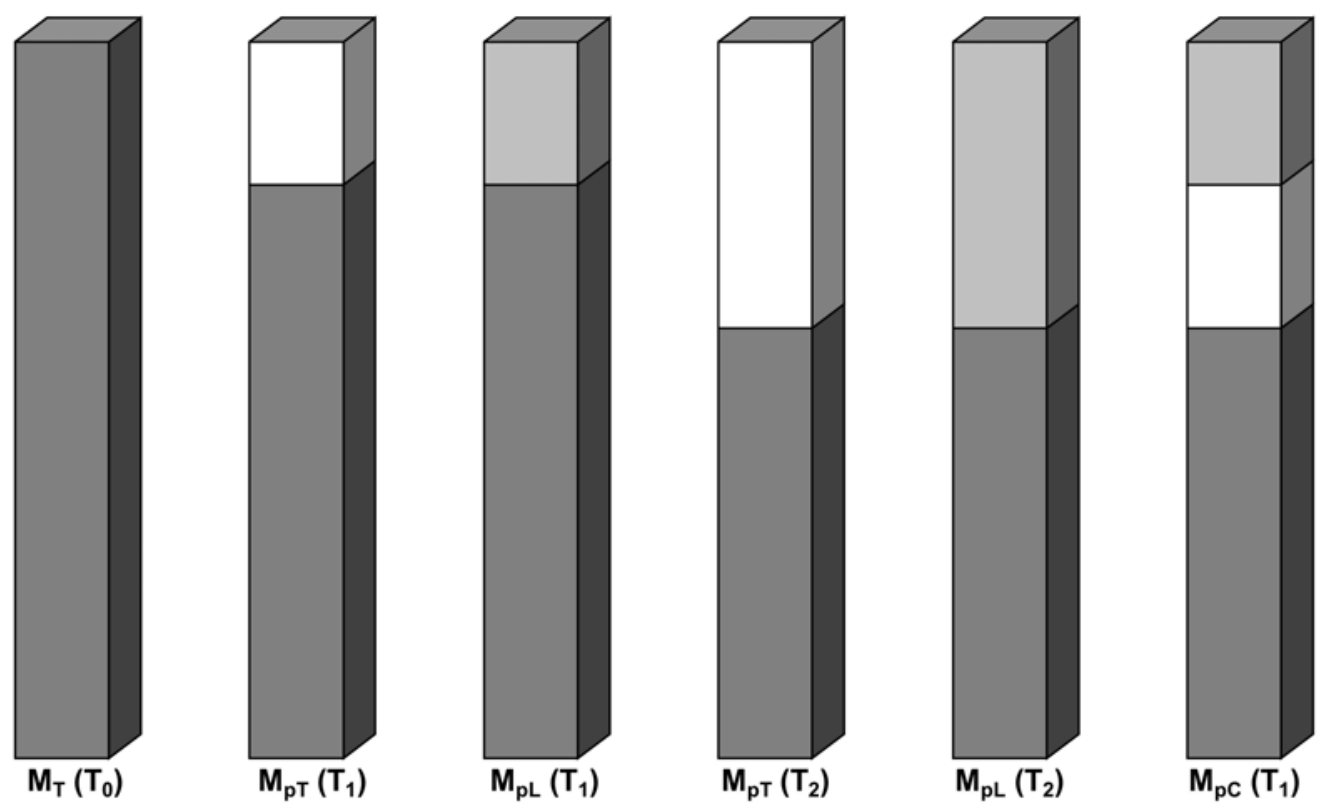

\section{$\square \mathbf{M}_{\mathbf{T}}\left(\mathbf{T}_{\mathbf{i}}\right) \quad \square \mathbf{Z}_{\mathbf{T}}\left(\mathbf{T}_{\mathbf{i}}\right) \quad \square \mathbf{I}_{\mathbf{T}}\left(\mathbf{T}_{\mathbf{i}}\right)$}

Figura 3.2: Método Coe (1967). $\mathbf{M}_{\mathbf{T}}\left(T_{0}\right)$ é a MRN original do espécime. A aquisição de $\mathbf{M}_{\mathbf{p T}}\left(T_{i}\right)$ em campo nulo $Z\left(T_{i}\right)$ e $\mathbf{M}_{\mathbf{p L}}\left(T_{i}\right)$ com campo aplicado $I\left(T_{i}\right)$; além do pTRM check $\mathbf{M}_{\mathbf{p C}}\left(T_{i}\right)$.

Coe (1967) incluiu os pTRM checks ( $\mathbf{M}_{\mathbf{p C}}$ ) com o objetivo de determinar possíveis alterações de mineralogia magnética durante os procedimentos experimentais. Em geral, os $\mathbf{M}_{\mathrm{pC}}$ são feitos a cada dois passos de aquecimento-resfriamento, conforme mostra a Figura 3.2. Os pTRM tail checks ( $\mathbf{M}_{\mathbf{p T C}}$ ) foram incluídos posteriormente neste método como um terceiro passo de aquecimento-resfriamento em campo nulo para uma determinada temperatura $T_{i}$ por Riisager e Riisager (2001). 
Os resultados são apresentados na forma de gráficos da $M R N$ restante após os passos de aquecimento-resfriamento versus a MTR adquirida, conhecidos como diagrama de Arai (Nagata et al., 1963; ver exemplos no Capítulo 4, Figuras 4.5 e 4.15). Idealmente, o gráfico é linear e o coeficiente de inclinação da reta fornece a relação $-\mathbf{H}_{\mathbf{A}} / \mathbf{H}_{\mathbf{L}}$. A técnica utilizada para determinação da inclinação é o ajuste por mínimos quadrados (York, 1966; 1967). A não-linearidade nos diagramas de Arai é indicativa de um comportamento não-ideal do registro de paleointensidade, advinda de problemas de alteração mineralógica ou pela presença de grãos magnéticos com estrutura MD. Além dos problemas de alteração magnética e do efeito de grãos MD, dois outros efeitos são importantes na aquisição da MTR e devem ser considerados durante as medidas. O primeiro deles está relacionado à anisotropia magnética do material e o segundo é devido à taxa de resfriamento.

\subsubsection{Efeito de anisotropia na MTR}

O registro de paleointensidade pode ser afetado pela anisotropia magnética dos materiais. O efeito de anisotropia de termoremanência magnética (ATR) é notado quando existe uma diferença angular entre o campo de laboratório $\mathbf{H}_{\mathbf{L}}$ e o campo antigo $\mathbf{H}_{\mathrm{A}}$. $\mathrm{O}$ efeito da anisotropia na MTR pode ser corrigido de duas formas. Uma delas consiste em produzir a $\mathbf{M}_{\mathbf{L}}$ o mais próximo possível da direção da $\mathbf{M}_{\mathrm{TR}}$ original (em um ângulo máximo de $10^{\circ}$ ), evitando assim a necessidade de quantificar e corrigir os dados de magnetização pela ATR (e.g. Rogers et al., 1979; Aitken et al., 1981). Nesse caso, deve-se utilizar equipamentos que permitam realizar isso de forma precisa, como por exemplo, o magnetômetro Triaxe desenvolvido por Le Goff e Gallet (2004). Na segunda forma, mais usual, a ATR é estimada através de medidas de pMTR adquiridas em diferentes direções, possibilitando a determinação do tensor de ATR. Um fator de ATR é então calculado e usado para corrigir o valor de intensidade (e.g. Veitch et al., 1984).

Considere o vetor magnetização termoremanente $\left(\mathbf{M}_{\mathbf{i}}, i=1,2,3\right)$ induzido por um vetor de campo $\left(\mathbf{H}_{\mathbf{i}}, i=1,2,3\right)$, de maneira que os dois estão relacionados pelo tensor de susceptibilidade de remanência $K_{i j}$. Como a relação linear entre dois vetores fornece um tensor de segunda ordem, a equação pode ser escrita da seguinte forma:

$$
\mathbf{M}_{\mathrm{TR}}=K_{i j} \mathbf{H}_{\mathbf{i}}
$$

ou em forma matricial: 
$\left[\begin{array}{l}M_{x} \\ M_{y} \\ M_{z}\end{array}\right]=\left[\begin{array}{lll}K_{x x} & K_{x y} & K_{x z} \\ K_{y x} & K_{y y} & K_{y z} \\ K_{z x} & K_{z y} & K_{z z}\end{array}\right] \cdot\left[\begin{array}{l}H_{x} \\ H_{y} \\ H_{z}\end{array}\right]$

onde $M_{x}, M_{y}$ e $M_{z}$ são as componentes de $\mathbf{M}_{\mathbf{T R}}$ nas direções $X, Y$ e $Z ; H_{x}, H_{y}$ e $H_{z}$ são as componentes de $\mathbf{H}_{\mathbf{i}}$ nas direções $X, Y$ e $Z ; K_{i j}=K_{j i}$ (para $i \neq j$ ). Em um esquema de medidas de 6 posições, a magnetização termoremanente induzida em cada posição fornece um termo diagonal e dois termos simétricos do tensor de ATR $\left(K_{1, j}, K_{2, j}, K_{3, j}, j=1,2,3\right)$. Subseqüentemente, os termos $K_{i, j}(i \neq j)$ são substituídos pelos termos $\left(K_{i j}+K_{j i}\right) / 2$ e os autovalores e os tensores da anisotropia da MTR são calculados.

Uma vez determinado o tensor de anisotropia é possível derivar um fator de correção para a paleointensidade $\left(f\right.$ ). Conhecendo-se a direção da $\mathbf{M}_{\mathbf{T R}}$ original, pode-se determinar a direção do campo antigo $\mathbf{H}_{\mathbf{A}}$ através da seguinte relação:

$\mathbf{h}_{\mathbf{A}}=\frac{K^{-1} \mathbf{M}_{\mathbf{T R}}}{\left|K^{-1} \mathbf{M}_{\mathrm{TR}}\right|}$

onde $\mathbf{h}_{\mathbf{A}}$ é o vetor unitário na direção de $\mathbf{H}_{\mathbf{A}}$ e $K^{-1}$ é o tensor inverso de anisotropia. $\mathrm{O}$ fator $f$ será a razão entre a $\mathbf{M}_{\mathbf{T R}}$ adquirida paralelo à direção do campo de laboratório $\left(\mathbf{H}_{\mathbf{L}}\right)$ e a $\mathbf{M}_{\mathbf{T R}}$ adquirida paralelo à direção de $\mathbf{h}_{\mathbf{A}}$ :

$f=\frac{\left|K \mathbf{h}_{\mathbf{L}}\right|}{\left|K \mathbf{h}_{\mathbf{A}}\right|}$

onde $\mathbf{h}_{\mathbf{L}}$ é o vetor unitário na direção de $\mathbf{H}_{\mathbf{L}}$.

A partir das direções do tensor de anisotropia da MTR é possível estimar outros parâmetros de anisotropia (e.g. Tarling e Hrouda, 1993). Os eixos de susceptibilidade máximo $\left(K_{1}\right)$, intermediário $\left(K_{2}\right)$ e mínimo $\left(K_{3}\right)$, com respeito às coordenadas da amostra, podem ser utilizados para definição dos seguintes parâmetros: (a) lineação $\left(L=K_{1} / K_{2}\right)$, foliação ( $\left.F=K_{2} / K_{3}\right)$ e o grau de anisotropia $\left(P=K_{1} / K_{3}\right)$. Sendo que este último é particularmente importante nos estudos de paleointensidade em artefatos arqueológicos (e.g. Kovacheva et al., 2009; Hartmann et al., 2010a). 


\subsubsection{Efeito da taxa de resfriamento na MTR}

A dependência da intensidade da MTR com a taxa de resfriamento é prevista pela teoria de Néel (1955). Este efeito, que consiste em um aumento progressivo da MTR com o aumento do tempo de resfriamento foi descrito teoricamente e experimentalmente por Dodson e McClelland-Brown (1980), Halgedahl et al. (1980) e Fox e Aitken (1980).

Assumindo-se que a aquisição da MTR se dá pelo resfriamento de um conjunto de grãos SD sem interação em uma estreita faixa de temperatura, pode-se dizer que em $T_{B} \mathrm{O}$ tempo de resfriamento $\Theta$ pode ser determinado por (Dodson e McClelland-Brown, 1980):

$\frac{\varepsilon\left(T_{B}\right)}{k T}=\ln (1.78 C \Theta)$

onde $\varepsilon$ é a energia de ativação térmica ( $\operatorname{com} \tau_{0} \approx 10^{-9} \mathrm{~s}$ ) e $C$ é uma constante de freqüência $\left(\sim 10^{10} \mathrm{~Hz}\right)$ prevista na teoria de Néel (1949). Como $\varepsilon$ varia com a temperatura, a constante de resfriamento pode ser dada por:

$$
\frac{1}{\Theta}=\left(\frac{1}{k T_{B}}\right)\left(\frac{d \varepsilon}{d T}-\frac{\varepsilon}{T_{B}}\right) \frac{d T}{d t}
$$

Assim, quanto mais lenta for a taxa de resfriamento (menores valores de $\Theta$ ), maior será o tempo que os grãos terão para continuar mudando a magnetização de equilíbrio, de maneira que a intensidade da MTR tende a aumentar com a diminuição lenta da temperatura (Dodson e McClelland-Brown, 1980). Resultados indicam ainda que em rochas com resfriamento lento $\left(\sim 3^{\circ} \mathrm{C} / \mathrm{Ma}\right)$ a intensidade da $\operatorname{MTR}\left(\mathbf{M}_{\mathbf{T R}}\right)$ pode ser até $50 \%$ maior do que aquela adquirida em laboratório $\left(\mathbf{M}_{\mathbf{L}}\right)$ levando, portanto, a estimativas equivocadas de paleointensidade (Halgedahl et al., 1980). Essas estimativas são confirmadas experimentalmente por Fox e Aitken (1980), que obtiveram estimativas de paleointensidades em materiais arqueológicos modificadas pelo efeito da taxa de resfriamento em até $10 \%$ a $20 \%$ do valor real.

\subsubsection{Protocolo de medidas TT-ZI utilizado neste trabalho}

Nas duas coleções de amostras (Nordeste e Sudeste), foram efetuadas determinações de paleointensidade pelo método Thellier e Thellier (1959) modificado por Coe (1967). Para cada fragmento arqueológico foram preparados 3 espécimes de $\sim 1 \mathrm{~cm}^{3}$, sendo dois para as medidas de paleointensidade e um para os experimentos da taxa de resfriamento. Os aquecimentos tiveram duração de 30 minutos e foram efetuados em um forno especialmente 
desenvolvido para as determinações de arqueointensidade no Institut de Physique du Globe de Paris. A posição dos espécimes no forno foi sempre a mesma, de modo a garantir a reprodutibilidade das etapas de aquecimento. Para os passos na presença de campo $\mathbf{H}_{\mathbf{L}}$, foi escolhido um campo de laboratório de $35 \mu \mathrm{T}$, aplicado paralelo ao eixo $X$ do espécime durante o ciclo de aquecimento-resfriamento. Em duas etapas de aquecimento-resfriamento $\left(350{ }^{\circ} \mathrm{C}\right.$ e $\left.500^{\circ} \mathrm{C}\right)$ foram efetuadas aquisições de magnetização termoremanente ao longo de 6 posições com o objetivo de determinar o tensor de ATR. As medidas de magnetização foram feitas em um magnetômetro horizontal SQUID (Superconducting Quantum Interference Device, 2G Enterprises) instalado em uma sala magneticamente blindada. Foram feitos 20 passos de duplo aquecimento entre $100{ }^{\circ} \mathrm{C}$ e $600{ }^{\circ} \mathrm{C}$, conforme mostra a Tabela 3.1. As checagens da MTR foram feitas a cada 2 passos de temperatura a fim de monitorar a alteração magnética dos espécimes. As checagens da presença de grãos MD (pTRM tail checks) foram feitas em 6 passos de temperatura (Tabela 3.1). O monitoramento da massa nos espécimes foi feito durante todo o procedimento experimental a fim de avaliar e corrigir os resultados de magnetização em espécimes que apresentaram perda significativa de massa (Schnepp, 2003).

Tabela 3.1: Z refere-se a passos em campo nulo, I passos em campo aplicado, C são as checagens de alteração, D checagens de presença de grãos multidomínio, e os números nos dois passos de anisotropia (P e A) indicam as posições das amostras durante o aquecimento $(1:-X ; 2: Y ; 3:-Y ; 4: Z ; 5:-Z)$.

\begin{tabular}{|c|c|}
\hline Temperatura & Passo \\
\hline $20^{\circ} \mathrm{C}$ & MRN \\
\hline $100^{\circ} \mathrm{C}$ & ZI \\
\hline $150^{\circ} \mathrm{C}$ & ZI \\
\hline $175^{\circ} \mathrm{C}$ & ZI \\
\hline $200^{\circ} \mathrm{C}$ & ZCID \\
\hline $225^{\circ} \mathrm{C}$ & ZI \\
\hline $250{ }^{\circ} \mathrm{C}$ & $\mathrm{ZCI}$ \\
\hline $275^{\circ} \mathrm{C}$ & ZI \\
\hline $300^{\circ} \mathrm{C}$ & ZCID \\
\hline $325^{\circ} \mathrm{C}$ & ZI \\
\hline $350{ }^{\circ} \mathrm{C}$ & ZCID \\
\hline $350^{\circ} \mathrm{C}$ & $\mathrm{P} 1, \mathrm{P} 2, \mathrm{P} 3, \mathrm{P} 4, \mathrm{P} 5$ \\
\hline $375^{\circ} \mathrm{C}$ & ZI \\
\hline $400{ }^{\circ} \mathrm{C}$ & ZCID \\
\hline $425^{\circ} \mathrm{C}$ & ZI \\
\hline $450^{\circ} \mathrm{C}$ & ZCI \\
\hline $475^{\circ} \mathrm{C}$ & ZI \\
\hline $500{ }^{\circ} \mathrm{C}$ & ZCID \\
\hline $500^{\circ} \mathrm{C}$ & $\mathrm{A} 1, \mathrm{~A} 2, \mathrm{~A} 3, \mathrm{~A} 4, \mathrm{~A} 5$ \\
\hline $525^{\circ} \mathrm{C}$ & ZI \\
\hline $550^{\circ} \mathrm{C}$ & ZCI \\
\hline $575^{\circ} \mathrm{C}$ & ZI \\
\hline $600^{\circ} \mathrm{C}$ & ZCID \\
\hline
\end{tabular}




\subsubsection{Correção do efeito de anisotropia da MTR}

A anisotropia da MTR resulta dominantemente do alinhamento preferencial dos grãos magnéticos na rocha ou no artefato arqueológico (Jackson, 1991). Em geral, a correção para anisotropia da MTR é realizada após a remoção de pelo menos $50 \%$ da MRN. O protocolo adotado aqui utiliza dois diferentes passos de temperatura $\left(T_{1}=350^{\circ} \mathrm{C}\right.$ e $T_{2}=500^{\circ} \mathrm{C}$ ) porque os espécimes não desmagnetizam de maneira uniforme. Conforme descrito na Seção 3.3.3, o tensor de ATR é determinado através da aquisição de 6 pMTRs com o campo aplicado em diferentes posições dos espécimes: $X,-X, Y,-Y, Z$ e $-Z$. Após cada medida são determinados um termo diagonal e dois termos simétricos do tensor $\left(K_{1, j}, K_{2, j}, K_{3, j}, j=1,2,3\right)$. Subseqüentemente, os termos $K_{i, j}(i \neq j)$ são substituídos pelos termos $\left(K_{i j}+K_{j i}\right) / 2$ e os tensores de ATR são calculados.

Como a anisotropia é medida em duas temperaturas distintas, dois fatores de correção $\left(f_{1}\right.$ e $\left.f_{2}\right)$ são calculados. Para amostras que não apresentam alteração durante as medidas de paleointensidade, utiliza-se a média dos fatores $f_{1}$ e $f_{2}$ para corrigir o valor de intensidade. Caso a amostra apresente um percentual de desmagnetização da MRN pequeno (inferior a 40\%) na temperatura $T_{1}$, a correção deve ser feita utilizando somente o fator de correção de alta temperatura $f_{2}$. Nesse caso, deve-se verificar também que a amostra não apresenta alteração magnetomineralógica a $500{ }^{\circ} \mathrm{C}$. Caso a amostra apresente um percentual de desmagnetização significativo (superior a 40\%) em $T_{1}$ e mostre alteração magnetomineralógica entre $T_{1}$ e $T_{2}$, utiliza-se o fator de correção de baixa temperatura $f_{1}$.

O grau de anisotropia $(P)$ foi calculado para cada espécime com o objetivo de identificar aqueles mais anisotrópicos. Em arqueointensidade, os limites de $P$ para seleção dos espécimes que são submetidos à correção de anisotropia são definidos de maneira arbitrária e não existe ainda um critério padrão para seleção das amostras. No entanto, muitos trabalhos têm efetuado as correções de anisotropia para amostras arqueológicas que apresentam um grau de anisotropia entre $15 \%$ e 20\% (e.g. Genevey e Gallet, 2002; Gómez-Paccard et al., 2006; Hartmann et al., 2010a).

\subsubsection{Correção do efeito da taxa de resfriamento}

Este efeito foi avaliado em cada fragmento estudado através de experimentos em um espécime adicional, especialmente preparado para essas medidas. O procedimento implica em 
sucessivas aquisições de MTR realizadas da seguinte maneira: (a) um ciclo de aquecimentoresfriamento rápido, $\mathbf{M}_{\mathbf{p T R} 1}\left(T_{i}\right)$, nesse caso equivalente ao ciclo de 30 minutos utilizado nos experimentos TT-ZI; (b) em seguida, um ciclo com taxa de resfriamento lenta, $\mathbf{M}_{\mathbf{p T R S}}\left(T_{i}\right)$; por fim, (c) um novo passo de aquecimento-resfriamento rápido, $\mathbf{M}_{\mathbf{p T R 2}}\left(T_{i}\right)$. Calcula-se então um fator de alteração $\left(F_{A}\right)$, que indica o grau de alteração magnética antes e após o resfriamento em taxa lenta da seguinte forma:

$$
F_{A}=\frac{\left|\mathbf{M}_{\mathbf{p T R 2}}\left(T_{i}\right)\right|-\left|\mathbf{M}_{\mathbf{p T R} 1}\left(T_{i}\right)\right|}{\left|\mathbf{M}_{\mathbf{p T R 2}}\left(T_{i}\right)\right|}
$$

Quando o fator de alteração magnética durante o procedimento é inferior a 5\%, determina-se um fator de correção $\left(F_{C}\right)$ da taxa de resfriamento a partir de:

$$
F_{C}=\frac{\left|\mathbf{M}_{\mathbf{p T R S}}\left(T_{i}\right)\right|-\left|\mathbf{M}_{\mathbf{p T R} 1}\left(T_{i}\right)\right|}{\left|\mathbf{M}_{\mathbf{p T R S}}\left(T_{i}\right)\right|}
$$

Note que a temperatura na qual os experimentos são efetuados deve incluir pelo menos $50 \%$ da MTR original.

Para corrigir os dados de intensidade pelo efeito da taxa de resfriamento é importante reproduzir corretamente a taxa de resfriamento lenta da queima original. Para isso, os experimentos foram conduzidos utilizando 3 taxas de resfriamento distintas para a $\mathbf{M}_{\mathbf{p T R S}}\left(T_{i}\right)$, de maneira que o procedimento acima foi repetido 3 vezes. As três taxas correspondem aos tempos de resfriamento de $5 \mathrm{~h}, 10 \mathrm{~h}$ e $25 \mathrm{~h}$, de $450{ }^{\circ} \mathrm{C}$ até a temperatura ambiente. Estas três taxas foram escolhidas com o objetivo de reproduzir as condições originais de queima dos materiais arqueológicos. Elas estão relacionadas com o tamanho dos fornos onde estes materiais foram queimados, dos menores para os maiores, respectivamente. Evidências arqueológicas sugerem que a taxa de resfriamento de $25 \mathrm{~h}$ é aquela que mais se aproxima da queima original (Costa, 2005a). Portanto, essa taxa de resfriamento foi escolhida para corrigir os valores de intensidade. Todavia, as outras duas taxas de resfriamento lentas fornecem indicações das incertezas na determinação de intensidade caso a taxa de resfriamento seja significativamente diferente daquela escolhida.

\subsubsection{Critérios de seleção e análise}

A interpretação dos dados obtidos pelos experimentos TT-ZI foi efetuada para cada espécime usando a "MRN removida" versus a "MTR adquirida" nos diagramas de Arai 
(Nagata et al., 1963). Um valor de intensidade foi calculado a partir do ajuste de mínimos quadrados dos segmentos lineares (Coe et al., 1978). Os critérios de seleção utilizados são aqueles definidos por Genevey e Gallet (2002), Genevey et al. (2009) e Hartmann et al. (2010a) e estão sintetizados na Tabela 3.2.

Tabela 3.2: critérios de seleção aplicados para determinação dos resultados de arqueointensidade obtidos pelo protocolo TT-ZI.

\begin{tabular}{|c|c|}
\hline \multicolumn{2}{|r|}{ Critérios de seleção } \\
\hline $\begin{array}{l}\text { 1. Diagramas de } \\
\text { desmagnetização ortogonais }\end{array}$ & $\begin{array}{l}\text { a) Foi utilizada apenas a componente de magnetização } \\
\text { primária isolada completamente e que apresentou um } \\
\text { limite de } 5^{\circ} \text { para o máximo desvio angular (MAD). }\end{array}$ \\
\hline 2. Diagramas de Arai & $\begin{array}{l}\text { a) Segmento linear no mesmo intervalo de temperatura } \\
\text { definido no diagrama ortogonal. } \\
\text { b) Mínimo de } 5 \text { passos de temperatura utilizados para } \\
\text { cálculo do ajuste da curva. } \\
\text { c) Para estes } 5 \text { passos de temperatura deve ser } \\
\text { considerado um mínimo de } 40 \% \text { da MRN total } \\
\text { envolvida no cálculo da intensidade. } \\
\text { d) Estabilidade magnética durante os experimentos de } \\
\text { paleointensidade: } \\
\text { - um limite de } 5 \% \text { foi adotado para a diferença entre a } \\
\text { pMTR e a checagem da pMTR normalizada pelos } \\
\text { dados do comprimento da hipotenusa MRN/pMTR ou } \\
\text { pela MTR total. } \\
\text { um limite de } 10 \% \text { foi adotado para o erro cumulativo } \\
\text { das checagens de pMTRs como definido por Leonhardt } \\
\text { et al. (2003). } \\
\text { - um limite de } 5 \% \text { foi aplicado para as checagens dos } \\
\text { pTRM-tail checks. }\end{array}$ \\
\hline $\begin{array}{l}\text { 3. Experimentos da taxa de } \\
\text { resfriamento }\end{array}$ & $\begin{array}{l}\text { a) Um limite de } 5 \% \text { foi aplicado para a alteração } \\
\text { magnética durante o procedimento de medidas da taxa } \\
\text { de resfriamento, caso contrário o fragmento foi } \\
\text { rejeitado. }\end{array}$ \\
\hline $\begin{array}{l}\text { 4. Coerência entre } \\
\text { determinações de intensidade } \\
\text { em nível de fragmento }\end{array}$ & $\begin{array}{l}\text { a) Um valor médio de intensidade foi calculado utilizando } \\
\text { pelo menos } 2 \text { ou mais espécimes. } \\
\text { b) Um desvio padrão máximo de } 5 \% \text { foi aplicado em } \\
\text { nível de fragmento. }\end{array}$ \\
\hline $\begin{array}{l}\text { 5. Coerência da intensidade } \\
\text { obtida em nível de sítio }\end{array}$ & $\begin{array}{l}\text { a) Um valor médio de intensidade foi calculado em nível } \\
\text { de sítio utilizando no mínimo } 3 \text { valores independentes } \\
\text { de intensidade (isto é, } 3 \text { fragmentos). } \\
\text { b) Um desvio padrão de } 10 \% \text { foi fixado em nível de sítio. }\end{array}$ \\
\hline
\end{tabular}




\subsection{Método de paleointensidade com medidas em alta temperatura}

\subsubsection{Medidas da magnetização termoremante em altas temperaturas}

O método da paleointensidade com medidas de magnetização em altas temperaturas consiste na comparação da MRN removida durante a desmagnetização térmica com a MTR produzida pelo campo de laboratório $\left(\mathbf{H}_{\mathbf{L}}\right)$. A determinação da paleointensidade em altas temperaturas pode ser feita de duas formas: (a) através de um único passo de aquecimentoresfriamento ou (b) através de dois ou mais ciclos de aquecimento-resfriamento da amostra.

$\mathrm{O}$ método de paleointensidade com medidas contínuas da magnetização em altas temperaturas utilizando somente um ciclo de aquecimento-resfriamento foi primeiramente desenvolvido por Wilson $(1961,1962)$, sendo recentemente testado por Dunlop (2008) e Muxworthy (2010). A grande vantagem deste método refere-se ao tempo de obtenção de um valor de paleointensidade, que é muito mais rápido que os métodos de duplo aquecimento. Por outro lado, a utilização de um único passo de aquecimento-resfriamento implica na impossibilidade de se efetuar correções de anisotropia e taxa de resfriamento na amostra. Estas duas correções são muito importantes e devem ser consideradas, principalmente em amostras arqueológicas (Le Goff e Gallet, 2004).

O método utilizando dois ou mais ciclos de duplo aquecimento foi primeiramente desenvolvido por Burakov e Nachasova (1978), com posteriores modificações por Walton (1984), Boyd (1986), Tanaka et al. (1995) e, mais recentemente, por Le Goff e Gallet (2004). Na versão original do método são definidas duas temperaturas nas quais são feitos os ciclos de aquecimento-resfriamento $\left(T_{1}\right.$ e $\left.T_{2}\right)$. A seqüência de medidas inicia com o aquecimento de um determinado espécime da temperatura ambiente $T_{0}$ até uma temperatura de base $T_{1}$; em geral, nessa temperatura a magnetização viscosa já deve ter sido eliminada. Mede-se então a magnetização até $T_{1}$ (fornecendo um conjunto de medidas contínuo, indicado aqui por $\mathbf{M}_{1}$ ). Em seguida, o espécime é aquecido até $T_{2}$ e a magnetização é registrada continuamente durante o aquecimento (conjunto de medidas $\mathbf{M}_{2}$ ). Na seqüência, o espécime é resfriado até $T_{1}$ em campo nulo para a obtenção do conjunto de medidas $\mathbf{M}_{\mathbf{3}}$. Em $T_{1}$, um campo $\mathbf{H}_{\mathbf{L}}$ é aplicado e mantido enquanto o espécime é aquecido até $T_{2}$ e novamente resfriado até $T_{1}$, fornecendo assim um conjunto de valores de MTR de laboratório $\mathbf{M}_{\mathbf{L}}$. Por fim, uma seqüência de aquecimento até $T_{2}$ e de resfriamento até $T_{1}$ é aplicada ao espécime fornecendo uma curva de magnetização $\mathbf{M}_{4}$. 
Este procedimento leva em conta os grãos com $T_{B}$ entre $T_{1}$ e $T_{2}$. A MRN medida entre estas duas temperaturas corresponde à diferença entre $\mathbf{M}_{1}$ e $\mathbf{M}_{3}$, enquanto a diferença entre $\mathbf{M}_{4}$ e $\mathbf{M}_{3}$ fornece a MTR de laboratório. A razão entre estas curvas, combinada com o campo $\mathbf{H}_{\mathbf{L}}$ conhecido fornece uma estimativa da intensidade do campo antigo $\mathbf{H}_{\mathbf{A}}$ :

$$
\mathbf{H}_{\mathbf{A}}=\mathbf{H}_{\mathbf{L}} \frac{\mathbf{M}_{\mathbf{1}}(T)-\mathbf{M}_{\mathbf{3}}(T)}{\mathbf{M}_{\mathbf{4}}(T)-\mathbf{M}_{\mathbf{3}}(T)}
$$

Para determinar a magnetização dos grãos com $T_{B}$ entre $T_{2}$ e $T_{3}$ o ciclo de medidas deve ser repetido e a temperatura de base passa a ser $T_{2}$. Como a medida de $\mathbf{M}_{2}$ é equivalente a $\mathbf{M}_{1}$ neste segundo ciclo de aquecimento-resfriamento, a medida inicial da magnetização pode ser omitida. Estes ciclos são repetidos diversas vezes até a $T_{C}$ do espécime, fornecendo $n$ valores independentes de intensidade.

Avanços recentes na instrumentação para medidas de magnetização em altas temperaturas vêm sendo feitos (e.g. Le Goff e Gallet, 2004; Dunlop, 2008; Muxworthy, 2010) e têm permitido que aquisições de paleointensidade de alta qualidade sejam obtidas com esse método. Abaixo segue a descrição do protocolo de medidas do tipo Triaxe (Le Goff e Gallet, 2004), que foi utilizado para obtenção dos dados de intensidade das coleções Nordeste e Sudeste.

\subsubsection{Protocolo de medidas Triaxe utilizado neste trabalho}

O protocolo de medidas Triaxe é uma versão do método Thellier e Thellier (1959) com as modificações propostas por Coe (1967) para altas temperaturas. O método é similar àquele descrito por Boyd (1986) e Tanaka et al. (1995). A determinação da paleointensidade ocorre na forma usual, com duplo aquecimento, sendo um para determinação da MRN original e outro para aquisição da MTR de laboratório. Para este tipo de medida, a equipe de Arqueomagnetismo do Institut de Physique du Globe de Paris desenvolveu o magnetômetro Triaxe, que realiza automaticamente a correção de anisotropia caso seja necessário (Le Goff e Gallet, 2004).

A Figura 3.3 mostra o magnetômetro Triaxe de forma esquemática. O equipamento contém três pares de bobinas ortogonais utilizadas para medidas da magnetização da amostra, que vibra horizontalmente, três pares de bobinas de Helmholtz ortogonais (para indução de campo) e um pequeno forno. As dimensões e distâncias entre as bobinas foram desenhadas 
em função do volume da amostra - cilindros de $1 \mathrm{~cm}$ de altura por $1 \mathrm{~cm}$ de diâmetro $(\sim 0,75$ $\mathrm{cm}^{3}$ de volume). A freqüência de vibração $(11,18 \mathrm{~Hz})$ associada às dimensões dos conjuntos de bobinas determinam a sensibilidade do equipamento, que é de $10^{-8} \mathrm{Am}^{2}$ (ou $\sim 10^{-2} \mathrm{~A} / \mathrm{m}$ ). No centro do magnetômetro há um pequeno forno acoplado a um sistema de refrigeração a água. O forno aquece a amostra enquanto o magnetômetro realiza as medidas de magnetização continuamente. A freqüência produzida pelo forno para temperaturas de até 650 ${ }^{\circ} \mathrm{C}$ é da ordem de 2,5 kHz numa resistência coaxial, o que evita interferências nas medidas devido a ruídos indesejáveis. O magnetômetro e o forno estão centrados em outros três pares de bobinas de Helmholtz coaxiais que podem gerar campos de até $200 \mu \mathrm{T}$ nas direções $X, Y$ e $Z$. Todo este conjunto (magnetômetro, bobinas de indução e forno) está encapsulado em um conjunto de três blindagens cilíndricas de $\mu$-metal. Completam o sistema um porta-amostras feito de alumina e que contém um termopar para controle da temperatura da amostra e um motor de passo, utilizado para vibração horizontal da amostra (Figura 3.3).

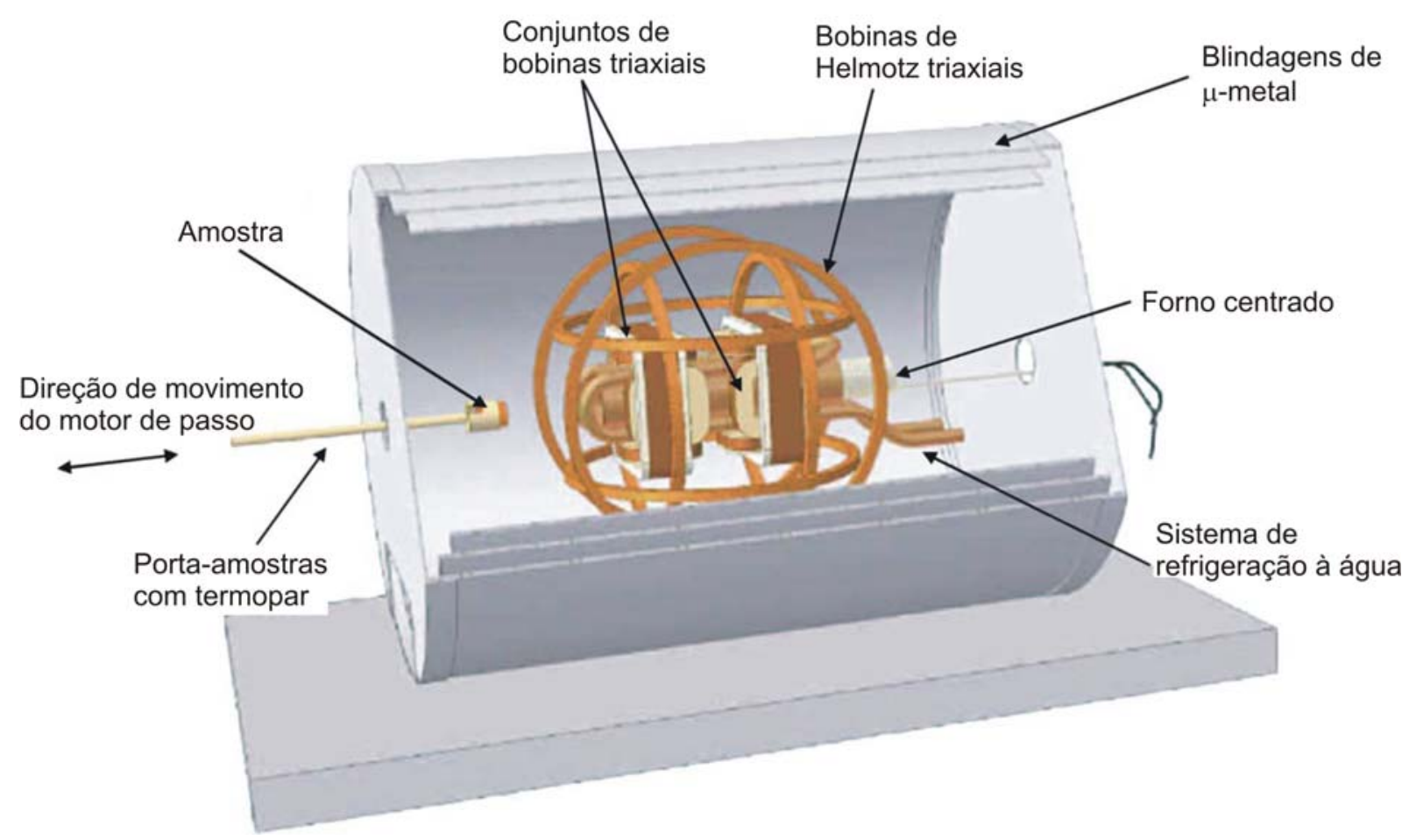

Figura 3.3: Figura esquemática do magnetômetro Triaxe, que inclui um pequeno forno centrado e um sistema de refrigeração à água que fica dentro de três conjuntos de bobinas ortogonais. Todo o conjunto fica encapsulado em três bobinas de Helmotz e em três camadas de blindagem de $\mu$-metal. O magnetômetro permite a medida da magnetização em altas temperaturas para um espécime cilíndrico de $0.75 \mathrm{~cm}^{3}$. Figura modificada de Le Goff e Gallet (2004).

A determinação da intensidade magnética utilizando o sistema Triaxe se dá por meio de medidas de 5 curvas distintas de magnetização: 
Curva 1: inicialmente define-se um intervalo de temperaturas $\left(T_{1}\right.$ e $\left.T_{2}\right)$ para o qual a primeira curva de magnetização $\mathbf{M}_{1}$ será adquirida. $T_{1}$ é a temperatura de aquisição inicial da magnetização e $T_{2}$ representa a temperatura final. A amostra começa a ser aquecida em campo nulo até $T_{1}$. A partir de $T_{1}$ a amostra continua a ser desmagnetizada até $T_{2}$, com uma taxa de aquecimento pré-definida pelo usuário. Esta taxa é escolhida em função do tipo de material que está sendo medido. Por exemplo, para amostras de cerâmica esta taxa é de 30 ${ }^{\circ} \mathrm{C} / \min$. A curva $\mathbf{M}_{1}$ mostra a variação da $\mathrm{MRN}$ com a temperatura; neste passo a direção é monitorada continuamente. Caso a amostra apresente variação direcional importante, ela já pode ser rejeitada neste passo e o processo de medida é finalizado.

Curva 2: em seguida a amostra é resfriada até $T_{1}$ em campo nulo, fornecendo a curva $\mathbf{M}_{2}$.

Curva 3: a amostra é novamente aquecida em campo nulo até $T_{2}$, fornecendo a curva $\mathbf{M}_{3}$. A curva $\mathbf{M}_{3}$ mostra a fração da MRN com $T_{B}$ acima de $T_{2}$. Se esta curva apresentar um percentual de MRN não desmagnetizada significativo, é necessário determinar um novo intervalo entre $T_{1}$ e $T_{2}$. Neste caso, será necessário medir um novo espécime do mesmo fragmento.

Curva 4: em $T_{2}$, um campo de laboratório $\mathbf{H}_{\mathbf{L}}$ escolhido pelo usuário é aplicado à amostra $\mathrm{e}$ inicia-se o resfriamento até $T_{1}$. O tempo em que a amostra permanece com campo aplicado em $T_{2}$ é de 2 minutos, sendo em seguida resfriada até $T_{1}$ em $\mathbf{H}_{\mathbf{L}}$, fornecendo a curva $\mathbf{M}_{4}$.

Curva 5: a amostra é novamente aquecida de $T_{1}$ a $T_{2}$ em campo nulo, fornecendo a curva $\mathbf{M}_{5}$. A curva $\mathbf{M}_{5}$ representa a MTR de laboratório.

Por fim, a amostra é resfriada de $T_{2}$ a $T_{0}$ em campo nulo, finalizando o procedimento de aquisição de paleointensidade.

Segundo Le Goff e Gallet (2004) o campo antigo $\mathbf{H}_{\mathbf{A}}$ pode ser calculado a partir das curvas $\mathbf{M}_{1}, \mathbf{M}_{3}$ e $\mathbf{M}_{5}$ de duas maneiras distintas. A primeira consiste em determinar as frações da MRN $\left(\Delta 1\left(T_{i}\right)\right)$ e da MTR de laboratório $\left(\Delta 5\left(T_{i}\right)\right)$ entre $T_{i}$ e $T_{2}$. A temperatura de desbloqueio dos grãos deve estar contemplada neste intervalo de $T_{i}$ e $T_{2}$. A determinação é feita da seguinte maneira:

$$
\begin{aligned}
& \Delta 1\left(T_{i}\right)=\mathbf{M}_{1}\left(T_{i}\right)-\mathbf{M}_{3}\left(T_{i}\right) \\
& \Delta 5\left(T_{i}\right)=\mathbf{M}_{5}\left(T_{i}\right)-\mathbf{M}_{3}\left(T_{i}\right)
\end{aligned}
$$


onde $\mathbf{M}_{1}\left(T_{i}\right), \mathbf{M}_{3}\left(T_{i}\right)$ e $\mathbf{M}_{5}\left(T_{i}\right)$ correspondem à magnetização medida nas curvas $\mathbf{M}_{1}, \mathbf{M}_{3}$ e $\mathbf{M}_{5}$, respectivamente. O campo antigo é determinado como no método Thellier e Thellier (1959), da seguinte forma:

$$
\mathbf{R}\left(T_{i}\right)=\mathbf{H}_{\mathbf{L}} \cdot \frac{\Delta 1\left(T_{i}\right)}{\Delta 5\left(T_{i}\right)}
$$

É interessante observar, neste caso, que em função da grande quantidade de dados obtidos pelas medidas contínuas do Triaxe um valor de intensidade pode ser determinado para cada passo de temperatura, diferente do que ocorre no método Thellier e Thellier (1959) onde há necessidade de pelo menos 5 pontos para determinar um valor de intensidade.

A segunda forma de determinar o campo antigo é estimar as frações da MRN e da MTR de laboratório entre $T_{1}$ e $T_{i}$. Para isto, podem-se utilizar duas aproximações. A primeira considera o comportamento da curva $\mathbf{M}_{3}$ no intervalo de $T_{1}$ e $T_{i}$ :

$$
\begin{aligned}
& \Delta \mathbf{l}^{\prime}\left(T_{i}\right)=\mathbf{M}_{\mathbf{1}}\left(T_{1}\right)-\left(\frac{\mathbf{M}_{\mathbf{3}}\left(T_{1}\right)}{\mathbf{M}_{\mathbf{3}}\left(T_{i}\right)} \cdot \mathbf{M}_{\mathbf{1}}\left(T_{i}\right)\right) \\
& \Delta 5^{\prime}\left(T_{i}\right)=\mathbf{M}_{\mathbf{5}}\left(T_{1}\right)-\left(\frac{\mathbf{M}_{\mathbf{3}}\left(T_{1}\right)}{\mathbf{M}_{\mathbf{3}}\left(T_{i}\right)} \cdot \mathbf{M}_{\mathbf{5}}\left(T_{i}\right)\right)
\end{aligned}
$$

A segunda aproximação leva em conta que se a fração acima de $T_{2}$ é pequena, pode-se simplesmente desprezar a variação da magnetização espontânea da curva $\mathbf{M}_{3}$. Assim:

$$
\begin{aligned}
& \Delta \mathbf{l}^{\prime}\left(T_{i}\right)=\left(\mathbf{M}_{1}\left(T_{1}\right)-\mathbf{M}_{\mathbf{1}}\left(T_{i}\right)\right)-\left(\mathbf{M}_{\mathbf{3}}\left(T_{1}\right)-\mathbf{M}_{\mathbf{3}}\left(T_{i}\right)\right) \\
& \Delta 5^{\prime}\left(T_{i}\right)=\left(\mathbf{M}_{\mathbf{5}}\left(T_{1}\right)-\mathbf{M}_{\mathbf{5}}\left(T_{i}\right)\right)-\left(\mathbf{M}_{\mathbf{3}}\left(T_{1}\right)-\mathbf{M}_{\mathbf{3}}\left(T_{i}\right)\right)
\end{aligned}
$$

Nas duas aproximações, o campo antigo pode ser determinado por:

$$
\mathbf{R}^{\prime}\left(T_{i}\right)=\mathbf{H}_{\mathbf{L}} \cdot \frac{\Delta 1^{\prime}\left(T_{i}\right)}{\Delta 5^{\prime}\left(T_{i}\right)}
$$

Os experimentos realizados por Le Goff e Gallet (2004) indicam que o cálculo de $\mathbf{R}^{\prime}\left(T_{i}\right)$ pelas duas aproximações é idêntico. As diferenças são desprezíveis quando $\mathbf{M}_{\mathbf{3}}\left(T_{i}\right)$ é linear. Desta forma, adotam-se aqui as aproximações das equações (3.35) e (3.36) para o cálculo do campo antigo. Nas determinações de $\mathbf{R}\left(T_{i}\right)$ e $\mathbf{R}^{\prime}\left(T_{i}\right)$ as medidas das curvas $\mathbf{M}_{1}$, $\mathbf{M}_{3}$ e $\mathbf{M}_{5}$ são interpoladas para as mesmas temperaturas $T_{i}$. Um intervalo de $5{ }^{\circ} \mathrm{C}$ é usado para a interpolação, pois corresponde ao intervalo mais próximo daquele utilizado nas medidas. Os diagramas de comparação das curvas de intensidade levam em conta as duas formas de determinação de $\mathbf{H}_{\mathbf{A}}, \mathbf{R}\left(T_{i}\right)$ e $\mathbf{R}^{\prime}\left(T_{i}\right)$. No entanto, a intensidade utilizada para as 
médias é aquela obtida a partir de $\mathbf{R}^{\prime}\left(T_{i}\right)$, pois esta apresenta menor desvio padrão do que $\mathbf{R}\left(T_{i}\right)$ em altas temperaturas. Os experimentos indicam que esta diferença ocorre porque as curvas $\mathbf{M}_{1}, \mathbf{M}_{3}$ e $\mathbf{M}_{5}$ podem apresentar pequenas variações em alta temperatura durante $\mathbf{o}$ processo de medida.

A análise de um dado de intensidade obtido no Triaxe apresenta desvio padrão da média superior ao valor de corte aplicado às determinações pelo método Thellier-Thellier. Isto pode ser justificado pelo fato de que o número de pontos utilizados no ajuste é muito maior do que o número de pontos mínimo (5) usados no ajuste dos dados no método clássico TT-ZI.

Por fim, é importante mencionar que a presença de grãos MD (se houver) não afeta as determinações de intensidade pelo protocolo Triaxe porque a MRN e a MTR são medidas em condições semelhantes de alta temperatura e, portanto, muito próximas das $T_{B}$ dos portadores magnéticos.

\subsubsection{Correção do efeito de anisotropia da MTR}

Diferentemente da correção de ATR realizada no protocolo TT-ZI, no Triaxe o campo de laboratório é aplicado paralelo à MRN. A direção da MTR de laboratório é adquirida em um intervalo de temperatura pequeno (em torno de $1 / 10$ do intervalo $T_{1}-T_{2}$ ) e é comparada com a direção da MRN para que possa ser ajustada. Caso a diferença entre a direção da MRN e a direção da MTR de laboratório seja menor que $4^{\circ}$ (equivalente ao fator de anisotropia $K=1.5$ ), o Triaxe realiza o procedimento normal de medida para a curva $\mathbf{M}_{4}$. Uma diferença de orientação de $4^{\circ}$ entre a MRN e a MTR de laboratório implica em um erro de estimativa de paleointensidade inferior a $1 \%$ (Le Goff e Gallet, 2004). No entanto, se a diferença direcional for superior a $4^{\circ}$, a amostra é reaquecida até $T_{2}$ e a direção de $\mathbf{H}_{\mathbf{L}}$ é reajustada de forma que a MTR obtida se aproxime da direção da MRN. Em $T_{2}$, com a direção da MTR recalculada, a amostra é novamente resfriada até $T_{1}$ (ciclo da curva $\mathbf{M}_{4}$ ). Todo este procedimento é feito automaticamente pelo Triaxe.

\subsubsection{Correção do efeito da taxa de resfriamento}

A correção da taxa de resfriamento foi experimentalmente testada com o Triaxe. Le Goff e Gallet (2004) realizaram os testes em uma amostra com intensidade magnética 
conhecida $(50 \mu \mathrm{T})$, que foi aquecida até $500{ }^{\circ} \mathrm{C}$ e resfriada com campo aplicado durante $16 \mathrm{~h}$ (tempo equivalente ao resfriamento de manufatura de uma peça cerâmica ou tijolo, por exemplo). As taxas de resfriamento utilizadas durante o resfriamento da curva $\mathbf{M}_{4}$ foram de $25^{\circ} \mathrm{C} /$ min (rápida), $6{ }^{\circ} \mathrm{C} / \min$ (moderada) e $2{ }^{\circ} \mathrm{C} / \min$ (lenta). Estimativas de $\mathbf{H}_{\mathbf{A}}$ foram efetuadas para as três taxas usando as curvas $\mathbf{R}\left(T_{i}\right)$ e $\mathbf{R}^{\prime}\left(T_{i}\right)$. As determinações de intensidade para as três taxas utilizando $\mathbf{R}\left(T_{i}\right)$ indicaram que quanto mais rápido é o resfriamento, maior a intensidade estimada. Além disso, as 3 curvas apresentam uma tendência de aumento de intensidades para altas temperaturas. Este problema poderia ser solucionado utilizando-se uma taxa de resfriamento elevada em todas as medidas no Triaxe. No entanto, o tempo de medida seria inadequado para os experimentos de paleointensidade. Uma forma de contornar este efeito é considerar as frações de magnetização com $T_{U B}$ entre $T_{1}$ e $T_{i}$. Neste caso, a estimativa da intensidade que melhor se aproxima do valor esperado é aquela que utiliza a curva $\mathbf{R}^{\prime}\left(T_{i}\right)$ (Le Goff e Gallet, 2004). Um bônus ainda não explicado de forma satisfatória, é que as curvas $\mathbf{R}^{\prime}\left(T_{i}\right)$ parecem ser independentes da taxa de resfriamento utilizada. Assim, a taxa de $25{ }^{\circ} \mathrm{C} /$ min pode ser utilizada para artefatos arqueológicos, fornecendo uma estimativa de intensidade em menos de 2,5 horas para cada espécime.

\subsubsection{Critérios de seleção e análise}

A paleointensidade foi determinada em nível de espécime utilizando a média dos valores de $\mathbf{R}^{\prime}\left(T_{i}\right)$ calculados entre $T_{1}$ e $T_{2}$. Quando uma componente de magnetização secundária é observada em temperaturas acima de $T_{1}$, a média é então recalculada dentro do intervalo correspondente da magnetização primária. Os critérios de análise e seleção são semelhantes àqueles definidos por Genevey et al. (2009) e Hartmann et al. (2010a) e estão apresentados na Tabela 3.3.

Tabela 3.3: critérios de seleção aplicados para determinação dos resultados de arqueointensidade obtidos pelo protocolo Triaxe.

\section{Critérios de seleção}

1. Diagramas de desmagnetização ortogonais

2. Diagramas de intensidade a) Foi utilizada apenas a componente de magnetização primária isolada completamente e que apresentou um limite de $5^{\circ}$ para o MAD.

a) Os valores de $\mathbf{R}^{\prime}\left(T_{i}\right)$ devem ser constantes de $T_{1}$ a $T_{2}$. 


\section{Critérios de seleção}

b) Para o cálculo da intensidade, um mínimo de $50 \%$ da MRN total deve ser usado para o cálculo dos valores de $\mathbf{R}^{\prime}\left(T_{i}\right)$.

c) $\mathrm{O}$ desvio do segmento linear calculado entre $\mathbf{R}^{\prime}\left(T_{1}\right)$ e $\mathbf{R}^{\prime}\left(T_{2}\right)$ deve ser inferior a $10 \%$, com o desvio sendo definido por $\mathbf{R}^{\prime}\left(T_{2}\right)-\mathbf{R}^{\prime}\left(T_{1}\right) / \overline{\mathbf{R}^{\prime}\left(T_{i}\right)}$, onde $\overline{\mathbf{R}^{\prime}\left(T_{i}\right)}$ é a média de $\mathbf{R}^{\prime}\left(T_{i}\right)$.

3. Coerência entre determinações de intensidade em nível de fragmento

4. Coerência da intensidade obtida em nível de sítio a) Um valor médio de intensidade foi calculado utilizando pelo menos 2 ou mais espécimes.

b) Um desvio padrão máximo de $5 \%$ foi aplicado em nível de fragmento.

a) Um valor médio de intensidade foi calculado em nível de sítio utilizando no mínimo 3 valores independentes de intensidade (isto é, 3 fragmentos).

b) Um desvio padrão de $10 \%$ foi fixado em nível de sítio.

\subsection{Estudos de Mineralogia magnética}

Todos os fragmentos das duas coleções (Nordeste e Sudeste) foram submetidos a medidas de mineralogia magnética com o objetivo de: (a) verificar a estabilidade térmica durante ciclos de aquecimento-resfriamento e (b) determinar os portadores magnéticos das amostras. Os testes de mineralogia magnética, que podem ser divididos em testes de campos baixos e campos altos, foram feitos antes das medidas de paleointensidade e serviram como critérios para seleção das amostras.

Para determinação da estabilidade térmica foram obtidas curvas de susceptibilidade magnética em baixos campos variando em função da temperatura. Amostras de pó de cada um dos fragmentos estudados (algumas miligramas) foram aquecidas até $550{ }^{\circ} \mathrm{C}$ e resfriadas até a temperatura ambiente utilizando um susceptômetro Kappabridge KLY4-CS3 (Agico LTD). Esta temperatura foi escolhida porque em geral representa a temperatura máxima alcançada por um espécime durante os experimentos de paleointensidade. Este foi um dos principais testes para seleção de amostras. Somente curvas reversíveis e que apresentassem pouca (até $10 \%$ ) ou nenhuma alteração magnetomineralógica durante os ciclos de aquecimentoresfriamento foram utilizadas para os experimentos de paleointensidade. Em algumas amostras das duas coleções, as curvas foram feitas até temperaturas de $700{ }^{\circ} \mathrm{C}$ para determinação dos portadores magnéticos. 
Para obtenção dos portadores e determinação dos estados de domínios magnéticos foram feitas as seguintes aquisições em campos altos:

a. Curvas de aquisição da magnetização remanente isotérmica (MRI): estas aquisições foram feitas com o objetivo de determinar o campo de saturação dos portadores magnéticos. Minerais de baixas coercividades (magnetita e titanomagnetitas, por exemplo) saturam em campos de até $150 \mathrm{mT}$. Por outro lado, se a curva para uma determinada amostra não satura isto indica a presença de minerais de alta coercividade, como as titanohematitas e hematita. Amostras sólidas (entre $1 \mathrm{~g}$ e $2 \mathrm{~g}$ ) foram medidas para campos de até 1 Tesla no magnetômetro de amostra vibrante para campos altos do Institut de Physique du Globe de Paris.

b. Curvas de histerese: os ciclos foram feitos após as medidas de MRI com o objetivo de determinar os portadores e a estrutura de domínio magnético. Foram excluídas dos experimentos de paleointensidade as amostras cujas razões entre a magnetização remanente de saturação e a magnetização de saturação $\left(M_{R S} / M_{S}\right)$ e a força coerciva de remanência e a força coerciva $\left(H_{C R} / H_{C}\right)$ indicassem tamanhos de grão MD no diagrama de Day (Day et al., 1977). Neste procedimento foram utilizadas as mesmas amostras das aquisições de MRI e foi utilizado o mesmo equipamento em campos de até 1 Tesla.

c. Curvas de aquisição da MRI triaxial (Lowrie, 1990): este teste foi feito com o objetivo de separar os diferentes portadores magnéticos presentes nas amostras através das diferentes $T_{B}$. O teste consistiu em aplicar três campos magnéticos mutuamente ortogonais: $0,2 \mathrm{~T}$ na direção $X, 0,4 \mathrm{~T}$ na direção $Y$ e 1,2 T na direção $Z$. Em seguida foi feita a desmagnetização térmica em diferentes passos de temperatura entre $T_{0}$ e $700{ }^{\circ} \mathrm{C}$. Para cada um dos três campos foram determinadas uma ou mais fases magnéticas, dependendo das coercividades e das diferentes $T_{B}$ de cada fase. Esta aquisição foi feita em 40 amostras cúbicas (1 cm de lado) préselecionadas da coleção Nordeste. As medidas foram efetuadas utilizando um indutômetro (para indução dos campos nos espécimes), um forno paleomagnético e um magnetômetro horizontal SQUID (Superconducting Quantum Interference Device, 2G Enterprises).

Todos estes testes serviram para selecionar as amostras mais adequadas para os experimentos de paleointensidade, visto que diferentes variáveis como estabilidade térmica, estados de domínio e portadores magnéticos podem influenciar estes experimentos. 
Os primeiros resultados obtidos neste trabalho de tese tiveram por finalidade implantar a metodologia de duplo aquecimento com medidas em temperatura ambiente no Laboratório de Paleomagnetismo do IAG-USP. Este trabalho foi desenvolvido em cerâmicas portuguesas encontradas nas escavações do centro histórico de Salvador, Bahia, e contou com a parceria do grupo de Arqueologia da Universidade Federal da Bahia e do grupo de Paleomagnetismo da Universidad Autónoma de México. Os resultados correspondem aos primeiros dados de arqueointensidade de Portugal, e originaram um artigo intitulado "First archeointensity results from Portuguese potteries (1550-1750 AD)", por G. A. Hartmann, R. I. F. Trindade, A. Goguitchaitchvili, C. Etchevarne, J. Morales e M. C. Afonso, publicado na revista Earth, Planets and Space. A cópia do artigo encontra-se no Apêndice A desta tese. 


\section{Capítulo 4}

\section{Resultados de arqueointensidade e mineralogia magnética}

Neste capítulo serão apresentados os resultados obtidos nas coleções de materiais arqueológicos das regiões Nordeste e Sudeste do Brasil. As medidas de paleointensidade foram feitas utilizando os métodos de duplo aquecimento com medidas em temperatura ambiente e em altas temperaturas. Esses resultados representam o conjunto de dados de dois artigos, que se encontram nos Apêndices B e C. O primeiro artigo, publicado na revista Earth and Planetary Science Letters, refere-se à coleção Nordeste. O segundo artigo, que será submetido para a revista Journal of Geophysical Research, apresenta os resultados obtidos para a coleção Sudeste e faz uma análise global da variação do campo magnético no Brasil nos últimos cinco séculos. Cada seção traz inicialmente uma descrição dos portadores magnéticos de cada coleção e depois os dados de intensidade para as duas regiões do Brasil.

\subsection{Resultados da coleção Nordeste}

\subsubsection{Mineralogia magnética}

Todas as amostras da coleção Nordeste (104 fragmentos) foram submetidas a experimentos de magnetismo de rocha a fim de caracterizar os portadores magnéticos e testar a estabilidade durante o tratamento térmico. Todos os procedimentos de aquisição de curvas de histerese, curvas de aquisição da MRI, curvas de aquisição da MRI triaxial e curvas de susceptibilidade magnética em função da temperatura, estão descritos em detalhe no Capítulo 3.

As medidas em altos campos (curvas de histerese, curvas de aquisição da MRI e da MRI triaxial) revelam um comportamento magnético bastante semelhante para todos os fragmentos. A grande maioria dos fragmentos tem uma magnetização dominada por minerais de baixa coercividade com temperaturas de desbloqueio abaixo de $580{ }^{\circ} \mathrm{C}$, provavelmente associada à presença de magnetita ou titanomagnetita com diferentes concentrações de titânio. 
A presença de uma pequena fração de minerais de alta coercividade é evidenciada pela não saturação das curvas de MRI a 1,2 T (Figura 4.1a) e pelas curvas de histerese no formato de cintura de vespa (wasp-waisted) (Figura 4.1b). Essa fração de alta coercividade é representada em grande parte por hematita ou titanohematita, como sugerem os resultados da desmagnetização térmica da MRI triaxial (Figura 4.1c). A proporção de minerais de alta coercividade varia entre as amostras (Figura 4.1d), com algumas curvas de histerese apresentando formato de cintura de vespa bastante pronunciado (Figura 4.1e). É importante ressaltar que a fração de alta coercividade não está associada à hematita pura e pode exibir um amplo espectro de temperaturas de desbloqueio, com valores entre $200{ }^{\circ} \mathrm{C}$ a $400{ }^{\circ} \mathrm{C}$. Esta observação sugere que diferentes fases magnéticas contribuem para a magnetização total. A presença de uma fase de hematita com baixas temperaturas de desbloqueio $\left(<500{ }^{\circ} \mathrm{C}\right) \mathrm{em}$ materiais arqueológicos já foi proposta em alguns trabalhos (e.g. Chauvin et al., 2000; Genevey e Gallet, 2002; McIntosh et al., 2007). Em particular, minerais de alta coercividade com temperaturas de desbloqueio em torno de $200{ }^{\circ} \mathrm{C}$ (Figura 4.1f) já foram reportados por McIntosh et al. (2007), que sugeriram tratar-se de uma hematita não-estequiométrica.
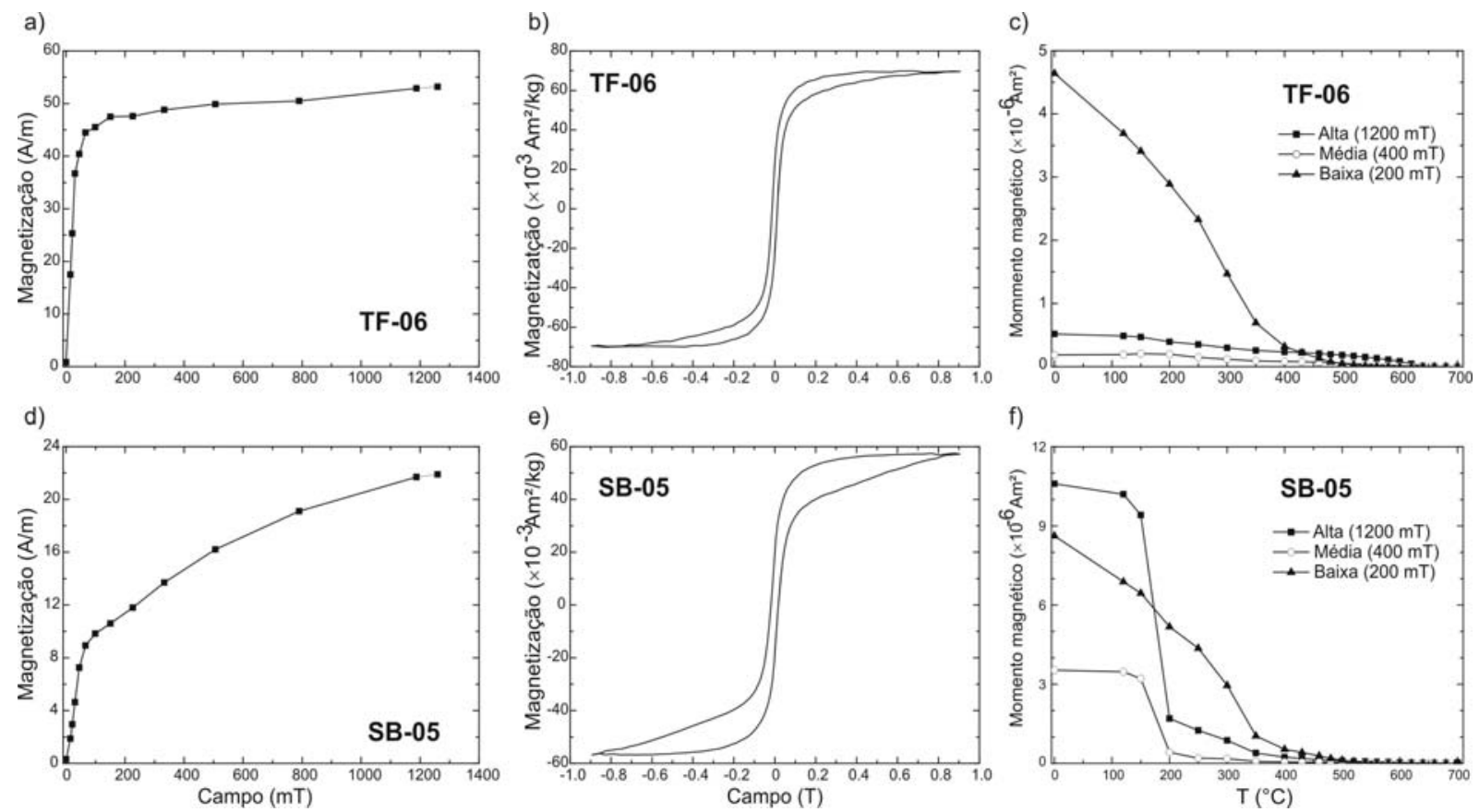

Figura 4.1: Exemplos típicos dos experimentos de magnetismo de rochas realizados nas amostras da coleção Nordeste. Curvas de aquisição da MRI (a, d), curvas de histerese (b, e) e curvas de desmagnetização térmica da MRI triaxial (c, f). 
As curvas de susceptibilidade magnética variando em função da temperatura foram efetuadas para temperaturas de até $\sim 550{ }^{\circ} \mathrm{C}$. A reversibilidade dos ciclos foi utilizada para testar a estabilidade térmica da mineralogia magnética durante o aquecimento. Somente as amostras que apresentaram ciclos reversíveis foram utilizadas nos experimentos de paleointensidade (94 fragmentos). Exemplos de curvas termomagnéticas obtidos em 6 amostras selecionadas são mostrados na Figura 4.2. É importante observar que estas curvas confirmam a estabilidade térmica de todos os portadores magnéticos, inclusive dos minerais de alta coercividade e baixa temperatura de desbloqueio. Alguns exemplos de curvas termomagnéticas de amostras que foram rejeitadas são mostrados na Figura 4.3.
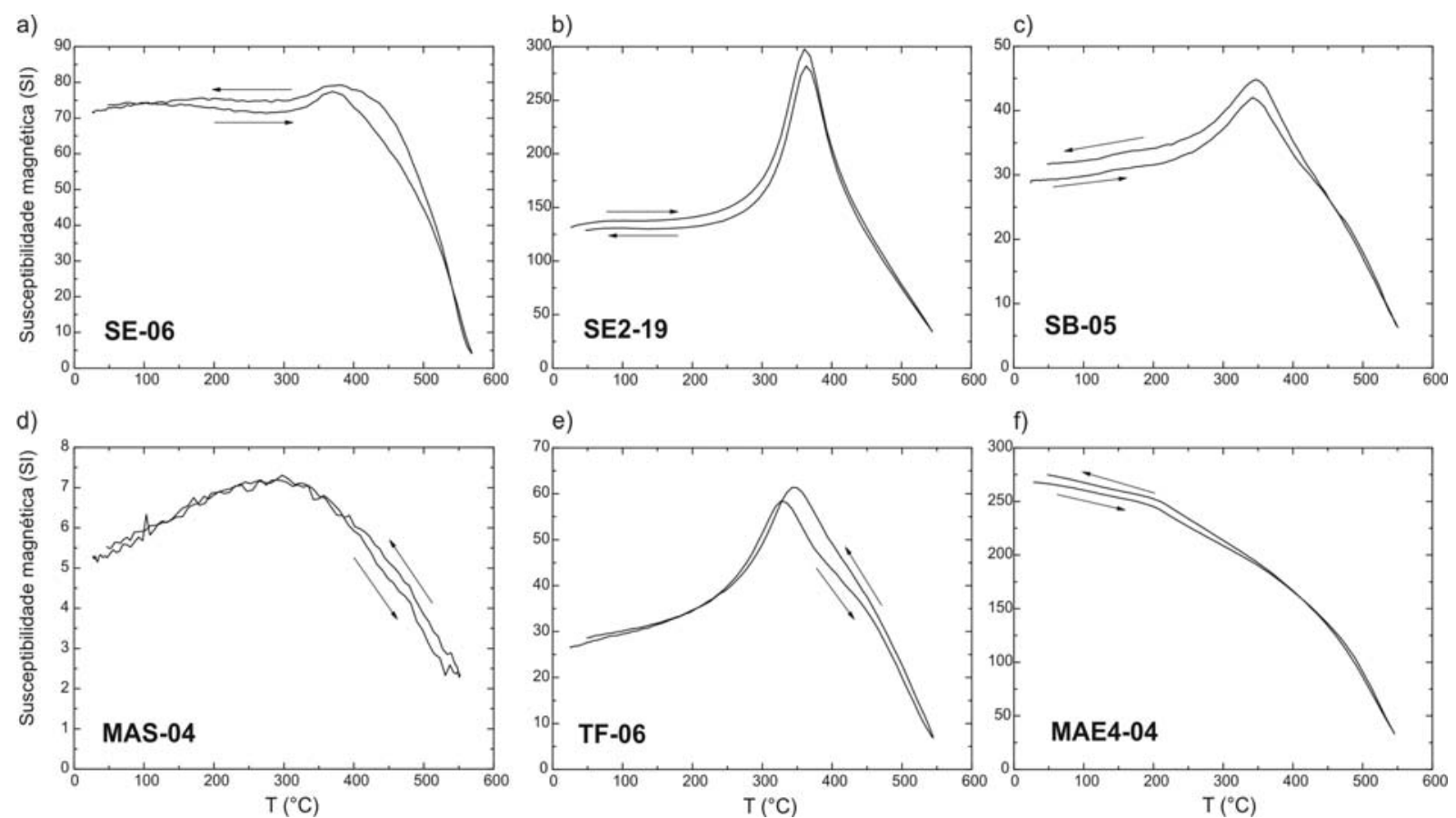

Figura 4.2: Exemplos de curvas de susceptibilidade magnética medidas durante ciclos de aquecimentoresfriamento até $550^{\circ} \mathrm{C}$. A susceptibilidade é adimensional.
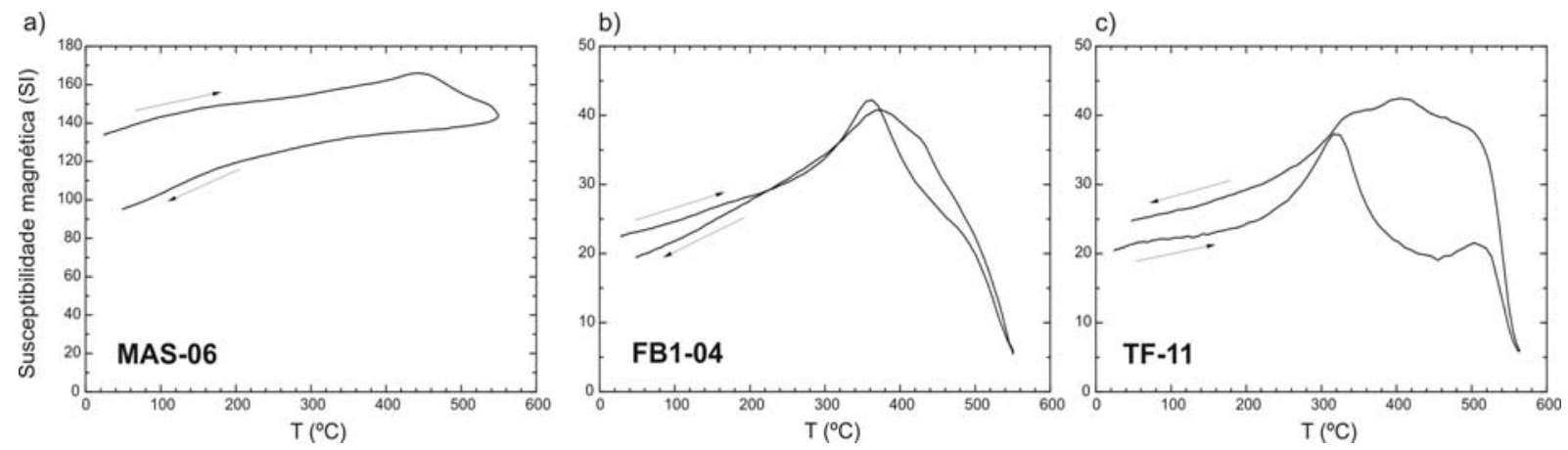

Figura 4.3: Exemplos de curvas de susceptibilidade magnética medidas em ciclos de aquecimento-resfriamento até $550{ }^{\circ} \mathrm{C}$, indicando amostras inadequadas para os experimentos de paleointensidade. A susceptibilidade é adimensional. 


\subsubsection{Resultados de arqueointensidade}

As medidas foram feitas em 94 fragmentos dos 14 sítios que compõe a coleção Nordeste, totalizando 295 espécimes medidos através dos protocolos TT-ZI e/ou Triaxe. Considerando os critérios de análise e seleção apresentados no Capítulo 3, um total de 57 fragmentos (183 espécimes) foi utilizado para o cálculo dos valores médios de intensidade, o que equivale a uma taxa de sucesso de $62 \%$. Todos os resultados em nível de sítio são apresentados na Tabela 4.1 .

\subsubsection{Resultados pelo protocolo TT-ZI}

O protocolo TT-ZI foi aplicado em 50 fragmentos (100 espécimes) de 9 sítios, entre os 14 que compõem a coleção Nordeste. Foram analisados de 2 a 7 fragmentos por sítio. Considerando o critério de seleção apresentado no Capítulo 3, 28 fragmentos (56 espécimes) foram utilizados para os cálculos das médias, sendo que os outros fragmentos foram descartados principalmente em função de alteração magnética detectada nos respectivos espécimes durante os experimentos de arqueointensidade ou na determinação da taxa de resfriamento. Estes resultados correspondem a uma taxa de sucesso de 56\% (ver Tabela A1 do Apêndice D). Nenhum espécime foi rejeitado devido à presença de grãos multidomínio (os pTRM-tail checks foram inferiores a 5\%). Além disso, nenhum fragmento foi rejeitado devido a diferenças maiores que 5\% entre valores de intensidade. Para a maioria dos espécimes, as variações de massa medidas durante os experimentos TT-ZI foram bastante moderadas, com perdas de massa inferiores a $5 \%$ para $90 \%$ da coleção. Alguns espécimes mais friáveis tiveram perda de massa importante, alcançando 11\%. Cada espécime teve a MRN e a MTR corrigidas pela perda de massa, conforme proposto por Schnepp (2003). O valor de intensidade foi deduzido a partir de um ajuste linear nos diagramas de Arai.

A Figura 4.4 mostra três exemplos de fragmentos que foram rejeitados. O espécime SE1-121-01 foi rejeitado devido a rápida queda da $M R N$, nos dois primeiros passos de aquecimento (Figura 4.4a). O espécime C06-05-01 foi rejeitado em função de alteração magnetomineralógica durante o procedimento demonstrado pela falha dos pTRMs checks e pelo comportamento côncavo do diagrama de Arai (Figura 4.4c). O espécime SCA-03-02, embora tenha $p T R M s$ checks positivos, ele não apresenta percentual de MRN suficiente para a determinação da intensidade, pois o percentual da MRN deve ser superior a 40\%, conforme os critérios estabelecidos no Capítulo 3 (Figura 4.4e). 


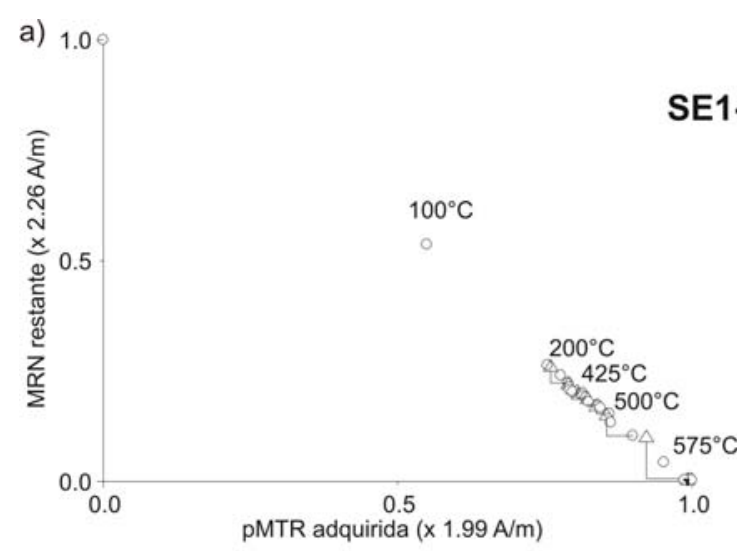

b)

\section{SE1-121-01}

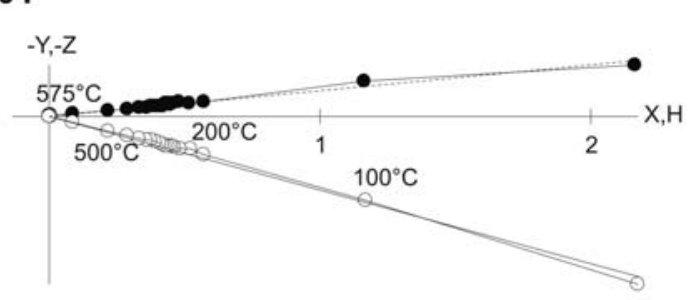

c) $1.0100^{\circ} \mathrm{C} 275^{\circ} \mathrm{C}$

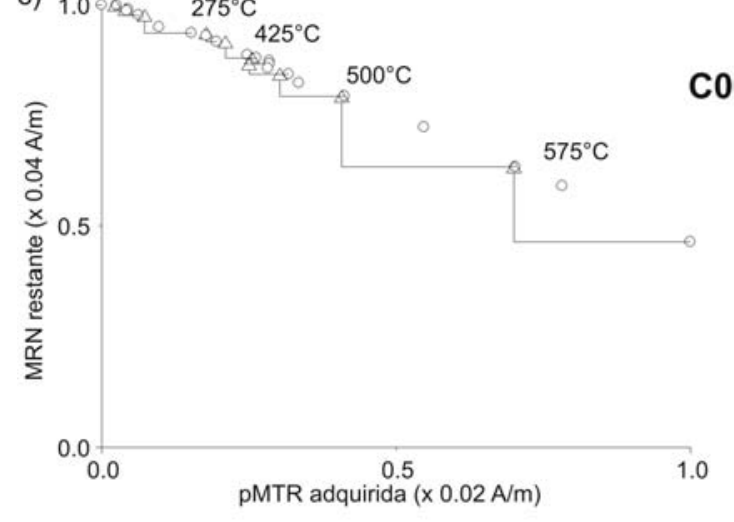

d)

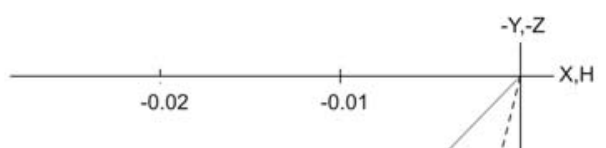

C06-05-01

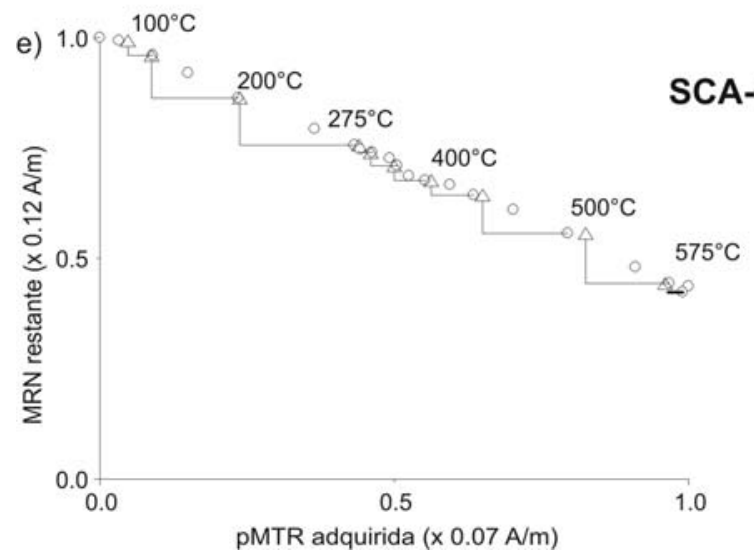

f)

CA-03-02

Figura 4.4: Experimentos de paleointensidade utilizando o protocolo TT-ZI. Exemplos de espécimes rejeitados nas análises de paleointensidade devido a problemas nos diagramas de Arai (a, c, e) e os respectivos digramas ortogonais (b, d, f, h). Nos diagramas de Arai, os círculos representam a MRN restante versus a MTR adquirida e os triângulos mostram os PTRM's checks realizados a cada 2 passos de temperatura. Nos diagramas ortogonais, os símbolos cheios indicam o vetor magnetização projetado no plano horizontal e os símbolos vazados indicam o vetor projetado no plano vertical (sistema de coordenadas do espécime).

A Figura 4.5 mostra quatro exemplos de diagramas de Arai e de projeção ortogonal para espécimes que atenderam aos critérios de análise e seleção. As projeções ortogonais mostram que em todos os fragmentos analisados a componente primária da magnetização é isolada entre $150{ }^{\circ} \mathrm{C}$ e $600{ }^{\circ} \mathrm{C}$ (Figura $4.5 \mathrm{~b}, \mathrm{~d}, \mathrm{f}, \mathrm{h}$ ). A fração da magnetização com temperaturas $<150{ }^{\circ} \mathrm{C}$ corresponde à magnetização viscosa e não foi utilizada na definição da direção da magnetização. 


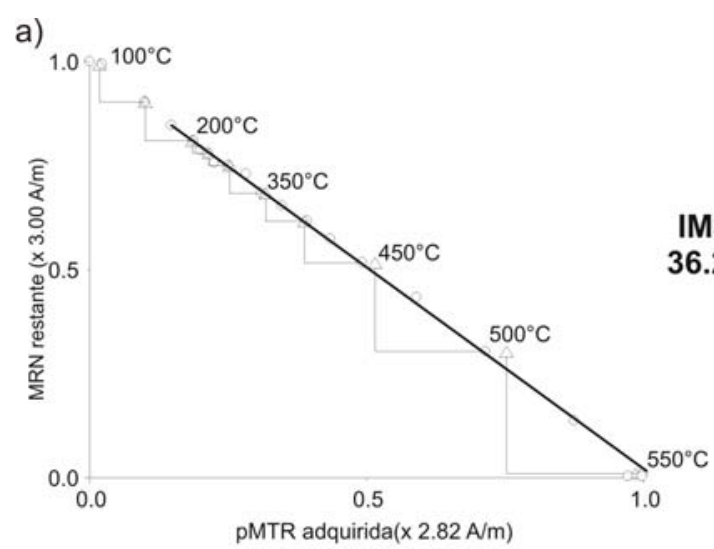

c)
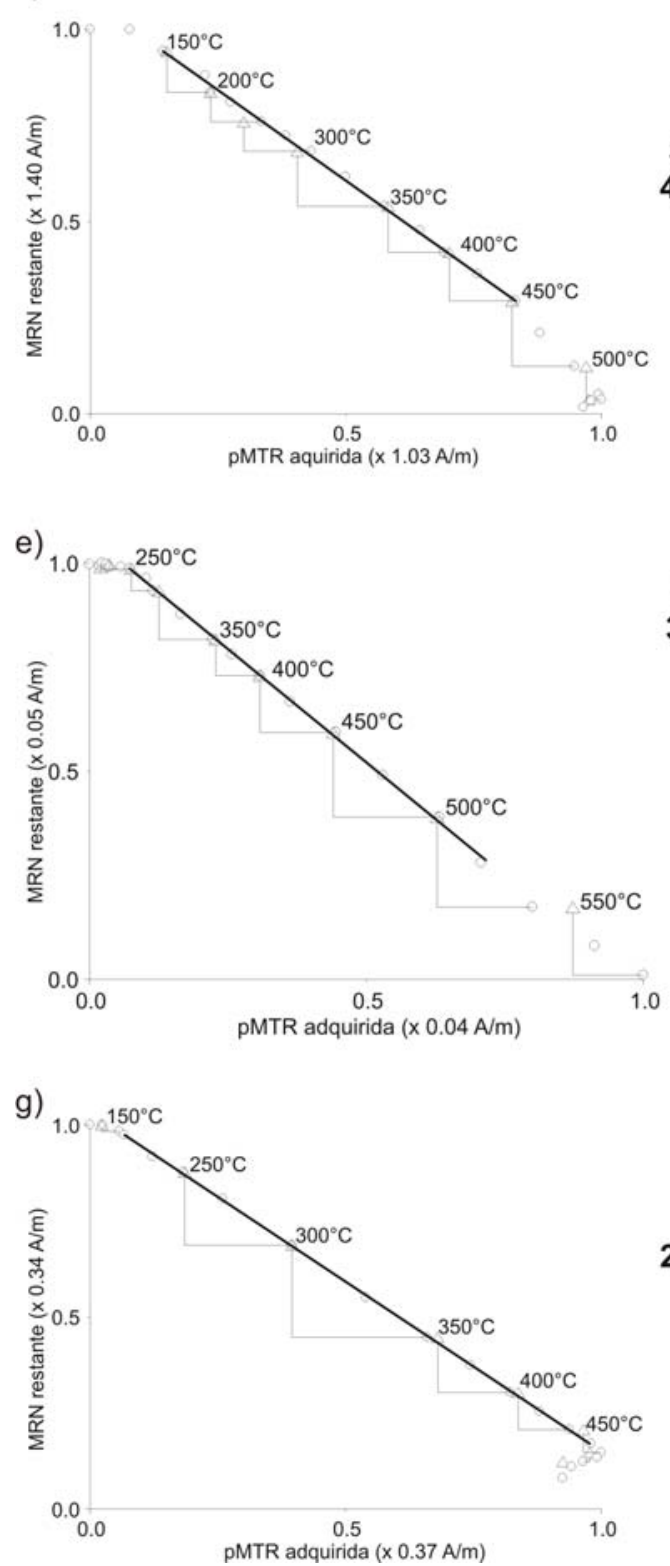

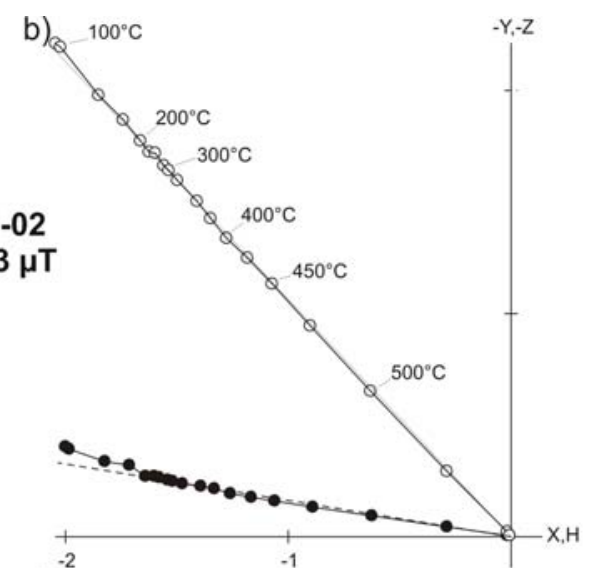

d)

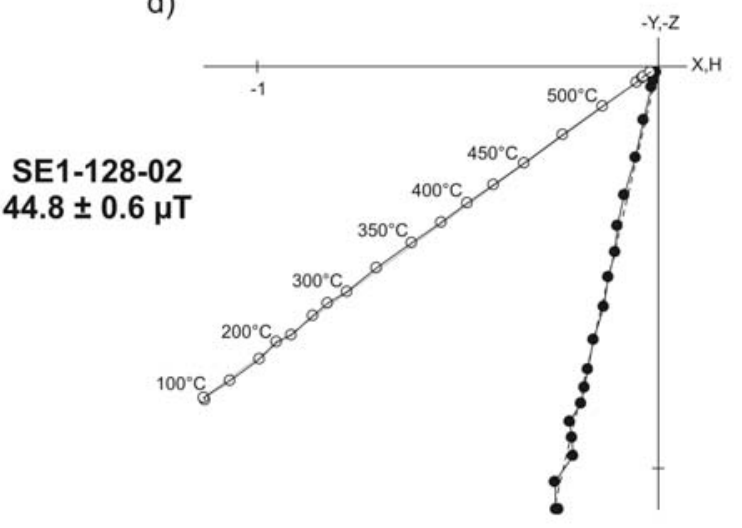

f)

$39.9 \pm 0.5 \mu \mathrm{T}$

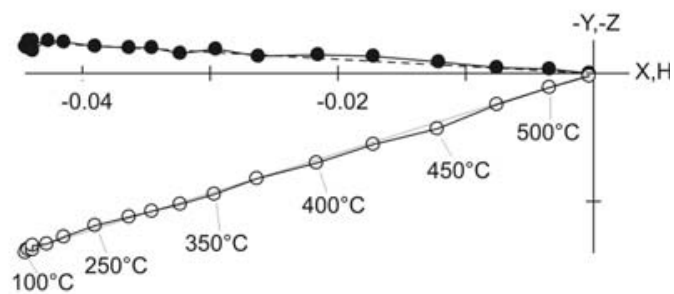

h)

TF-04-02

$28.6 \pm 0.1 \mu \mathrm{T}$

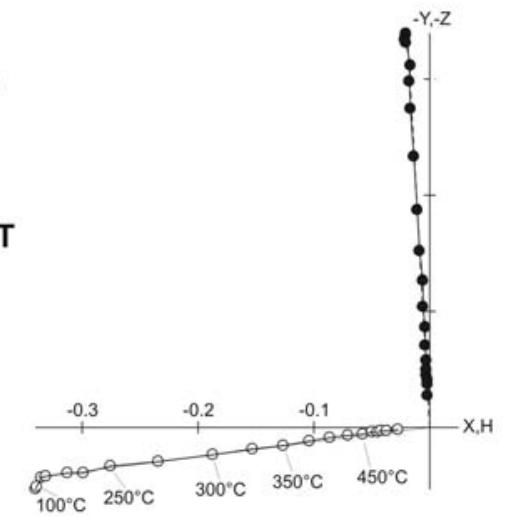

Figura 4.5: Determinações de intensidade pelo protocolo TT-ZI. Exemplos de diagramas de Arai (a, c, e, g) e os respectivos digramas ortogonais $(b, d, f, h)$. Nos diagramas de Arai, os círculos representam a MRN restante versus a MTR adquirida e os triângulos mostram os pTRM's checks realizados a cada 2 passos de temperatura. Os valores de intensidade foram calculados a partir do ajuste linear dos pontos dos diagramas de Arai. Nos diagramas ortogonais, os símbolos cheios indicam o vetor magnetização projetado no plano horizontal e os símbolos vazados indicam o vetor projetado no plano vertical (sistema de coordenadas do espécime). 
Nos diagramas de Arai, as intensidades foram calculadas no intervalo de temperatura mais estreito possível a fim de levar em conta somente os passos de temperatura em que nenhuma alteração magnética foi detectada (Figura 4.5c, e, g). Quando a alteração magnética ocorreu abaixo dos $500{ }^{\circ} \mathrm{C}$ (Figura $4.5 \mathrm{c}, \mathrm{g}$ ), o valor de intensidade determinado foi corrigido pelo fator de correção de anisotropia obtido em $350{ }^{\circ} \mathrm{C}$ (fator $f_{1}$ ). Nesses casos, que correspondem a menos de 50\% dos espécimes, foi assegurado que a porcentagem de desmagnetização em $350{ }^{\circ} \mathrm{C}$ era superior a $40 \%$, de modo a permitir uma determinação confiável do tensor de anisotropia. Quando esta porcentagem foi inferior a $40 \%$ e nenhuma alteração magnética foi observada até $500{ }^{\circ} \mathrm{C}$, o fator $f_{2}$ foi utilizado para a correção da anisotropia (Figura 4.5a, e). Somente em um fragmento o fator de anisotropia foi calculado a partir da média entre $f_{1}$ e $f_{2}$.
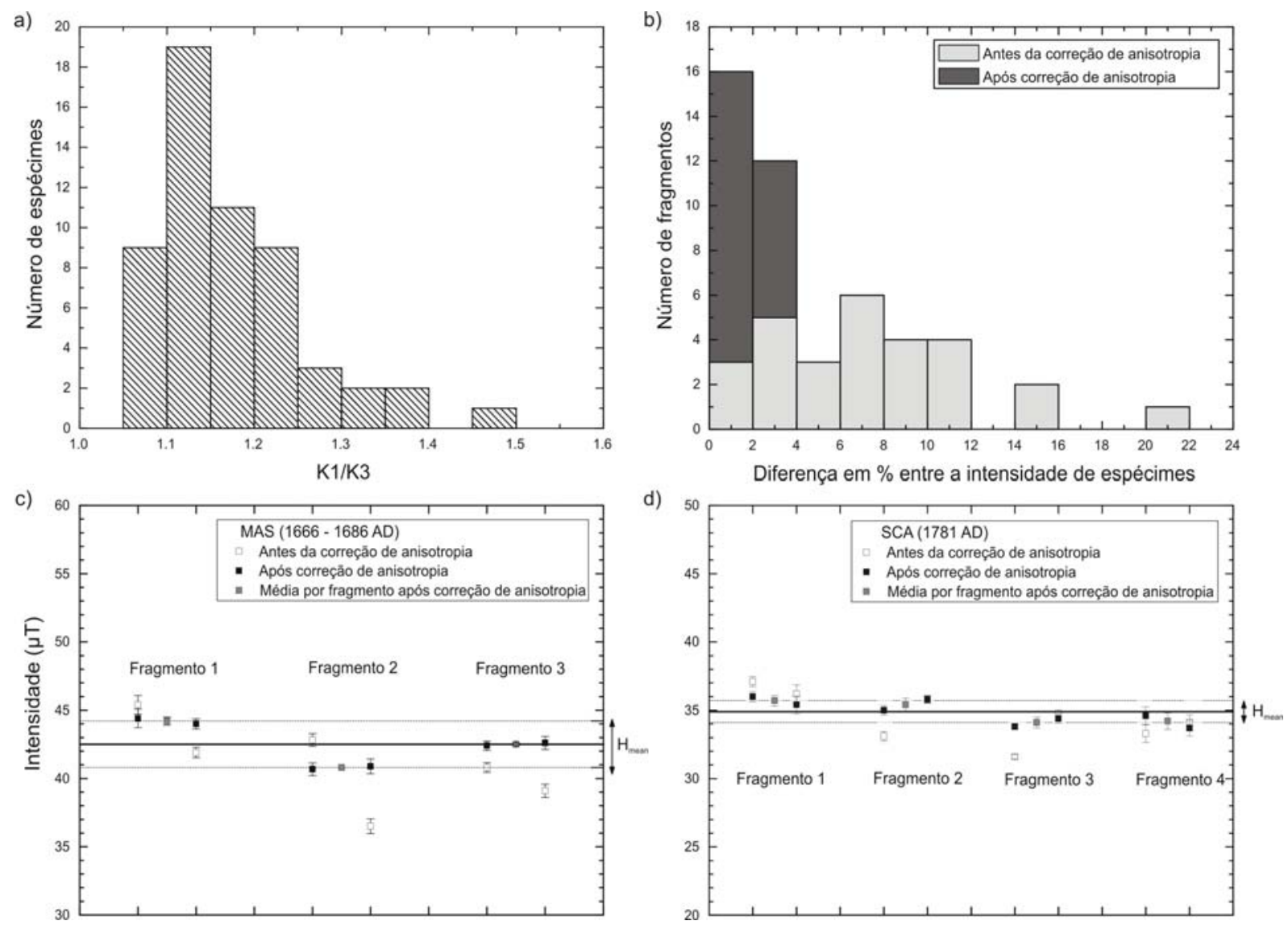

Figura 4.6: Correção do efeito de anisotropia da MTR. Em (a) é mostrado o diagrama com o grau de anisotropia obtido para todos os espécimes utilizados no cálculo das médias. Em (b) é mostrado o diagrama das diferenças entre espécimes do mesmo fragmento antes (cinza claro) e depois (cinza escuro) da correção para o efeito de anisotropia. Em (c) e (d) são ilustrados os valores de intensidade obtidos em cada espécime antes (quadrados vazados) e depois (quadrados cheios) da correção de anisotropia para os sítios MAS e SCA. São mostradas também as médias de intensidade em nível de fragmento após a correção de anisotropia (quadrados em cinza). Em ambos os sítios, a intensidade média calculada após a correção de anisotropia da MTR é mostrada com uma linha em preto e as linhas tracejadas mostram os respectivos desvios padrão. 
A distribuição do grau de anisotropia da MTR $\left(K_{1} / K_{3}\right)$ para os espécimes analisados revela que a maioria deles $(70 \%)$ apresenta uma anisotropia relativamente baixa, com $K_{1} / K_{3}$ entre 1,05 e 1,2, enquanto que $\sim 30 \%$ dos tijolos analisados são mais anisotrópicos com $K_{1} / K_{3}$ variando entre 1,2 e 1,45 (Figura 4.6a). Kovacheva et al. (2009) obtiveram uma distribuição do grau de anisotropia similar para uma grande coleção de tijolos e telhas amostrados na França e na Bulgária. A Figura 4.6b mostra um histograma das diferenças percentuais entre os dois valores de intensidade obtidos em nível de espécime para um mesmo fragmento antes e depois da correção de anisotropia. Estes resultados mostram claramente uma menor dispersão entre os valores de intensidade no mesmo fragmento após a correção de anisotropia, ressaltando a importância deste tipo de correção para as estimativas de intensidade. Esta constatação é ilustrada nas Figura 4.6c e 4.6d para os fragmentos dos sítios MAS e SCA.

a)

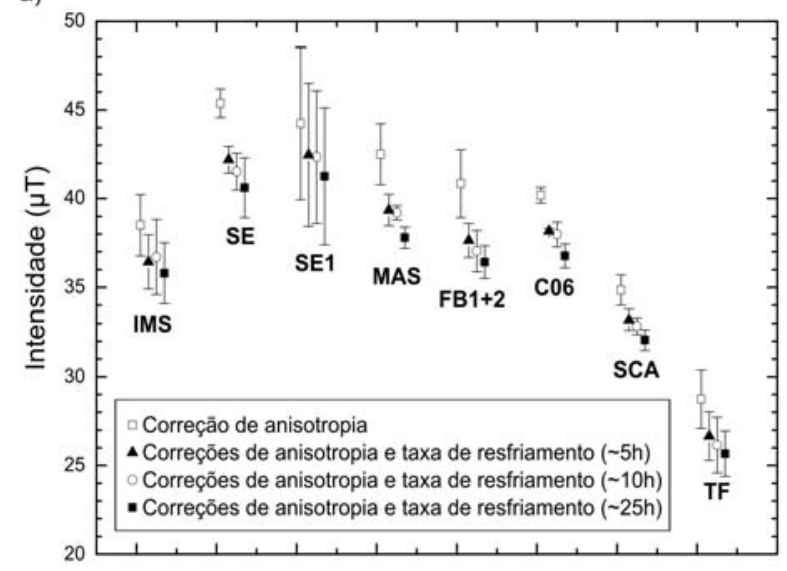

b)

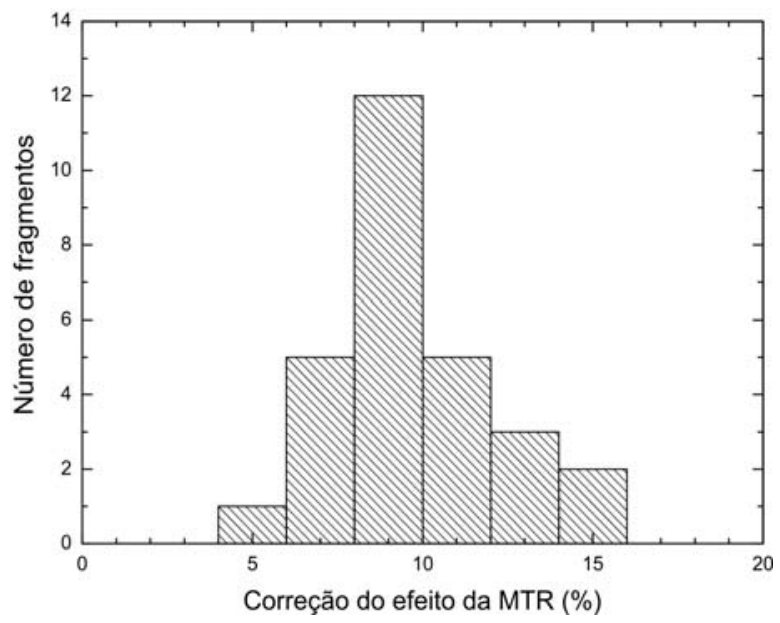

Figura 4.7: Correção do efeito da taxa de resfriamento na MTR. A figura (a) mostra uma comparação entre médias de intensidade calculadas antes (quadrados vazados) e depois da correção da taxa de resfriamento para as três taxas lentas de $\sim 5 \mathrm{~h}$ (triângulos cheios), $\sim 10 \mathrm{~h}$ (círculos vazados) e $\sim 25 \mathrm{~h}$ (quadrados cheios), obtidas entre a temperatura de $450{ }^{\circ} \mathrm{C}$ e a temperatura ambiente. Note que as intensidades médias foram calculadas quando pelo menos 2 fragmentos por sítio foram analisados e que a perda de massa foi desprezível para todos os espécimes. A figura (b) mostra o histograma da correção da MTR considerando o tempo de resfriamento lento de $\sim 25 \mathrm{~h}$.

O efeito da taxa de resfriamento na aquisição da MTR foi investigado para o protocolo TT-ZI utilizando três taxas de resfriamento distintas de $5 \mathrm{~h}, 10 \mathrm{~h}$ e $25 \mathrm{~h}$ a partir da temperatura de $450{ }^{\circ} \mathrm{C}$ até a temperatura ambiente. Os resultados indicam que quanto maior a taxa de resfriamento, maior o valor de intensidade estimado. Este fato é ilustrado na Figura 4.7a onde os valores médios de intensidade obtidos em nível de sítio antes da correção da taxa de resfriamento são sempre inferiores àqueles corrigidos. Além disso, quanto mais lenta for a taxa de resfriamento maior será a correção para este efeito. Os dados mostram também que o efeito da taxa de resfriamento pode ser importante se os tijolos foram resfriados mais 
rapidamente, como é o caso do sítio SE, que apresenta uma variação média de 7\% para a taxa de resfriamento de $5 \mathrm{~h}$. Nesta coleção de fragmentos foi escolhida uma taxa de resfriamento de $25 \mathrm{~h}$, que parece reproduzir de maneira mais próxima as condições originais de queima dos tijolos relatadas nos trabalhos arqueológicos (Costa, 2005a). Esta escolha resulta em um decréscimo dos dados de intensidade em nível de fragmento de $4 \%$ a $14 \%$, com uma média de 9\% (Figura 4.7b). Um ponto importante a ser considerado é que mesmo se a taxa de resfriamento escolhida for mais lenta, o erro na determinação da intensidade não será muito importante, conforme sugerem a proximidade dos pontos que correspondem às médias de intensidade corrigidas para $5 \mathrm{~h}, 10 \mathrm{~h}$ e $25 \mathrm{~h}$ na Figura $4.7 \mathrm{a}$.

\subsubsection{Resultados pelo protocolo Triaxe}

O protocolo Triaxe foi aplicado em 60 fragmentos (195 espécimes) de 13 sítios, dos 14 estudados para a coleção Nordeste. Para cada sítio (grupo de fragmentos), foram feitas medidas de magnetização em vários espécimes de cada fragmento, totalizando de 1 a 7 fragmentos por sítio. Todos os valores de intensidade que atenderam os critérios de análise e seleção (conforme mostrados no Capítulo 3) são apresentados na Tabela A2 do Apêndice D, totalizando 44 fragmentos (127 espécimes). A taxa de sucesso destas determinações é de 65\%, bastante semelhante às de Genevey et al. (2008) e Genevey et al. (2009). As rejeições em nível de espécime foram devidas principalmente a alteração magnética durante os experimentos ou a ajustes com erro superior a $10 \%$ nas curvas de $R^{\prime}\left(T_{i}\right)$, conforme mostrados nos quatro exemplos na Figura 4.8. Note que para os sítios FB1+2, C06 e TF, somente dois fragmentos por sítio apresentaram reprodutibilidade, provavelmente porque esses sítios apresentaram baixa magnetização, próxima à sensibilidade do magnetômetro Triaxe.

A Figura 4.9 mostra quatro exemplos de determinações de intensidade obtidos para quatro sítios diferentes que atendem os critérios de seleção definidos no Capítulo 3. Nos diagramas, cada curva representa a $R^{\prime}\left(T_{i}\right)$ obtida para um determinado espécime, sendo vários espécimes por fragmento. Estes digramas mostram também a boa consistência dos dados obtidos tanto em nível de fragmento quanto em nível de sítio.

A magnetização fraca foi o principal fator que limitou as medidas de magnetização no Triaxe. Esta é a razão pela qual muitos fragmentos foram estudados somente pelo protocolo TT-ZI. Os sítios SB, CP27, CB, MAE4 e GC, que apresentaram forte magnetização, foram estudados somente pelo protocolo Triaxe. A comparação entre os 
protocolos TT-ZI e Triaxe foi possível em 15 fragmentos dos sítios IMS, SE, SE1, MAS, C06 e TF. Para quase todos os fragmentos, a consistência entre os resultados TT-ZI após a correção da taxa de resfriamento de $25 \mathrm{~h}$ e os resultados do Triaxe ficou em $\pm 5 \%$, exceto para três fragmentos que apresentaram resultados de intensidade nos dois métodos com diferenças em torno de $\pm 9 \%$. A Figura 4.10 mostra a comparação em nível de sítio entre os valores médios de intensidade obtidos pelos dois métodos, considerando todos os 15 fragmentos. Os desvios são sistemáticos entre os dois conjuntos de dados antes da correção do efeito da taxa de resfriamento (quadrados vazados na Figura 4.10). Após a correção da taxa de resfriamento no protocolo TT-ZI os valores de intensidade são similares àqueles do Triaxe em $\pm 5 \%$ (quadrados cheios na Figura 4.10). Esses resultados sugerem que as medidas feitas no Triaxe não são afetadas de forma significativa pelo efeito da taxa de resfriamento, conforme mostrado anteriormente por Gallet e Le Goff (2006), Gallet et al. (2006) e Genevey et al. (2009).
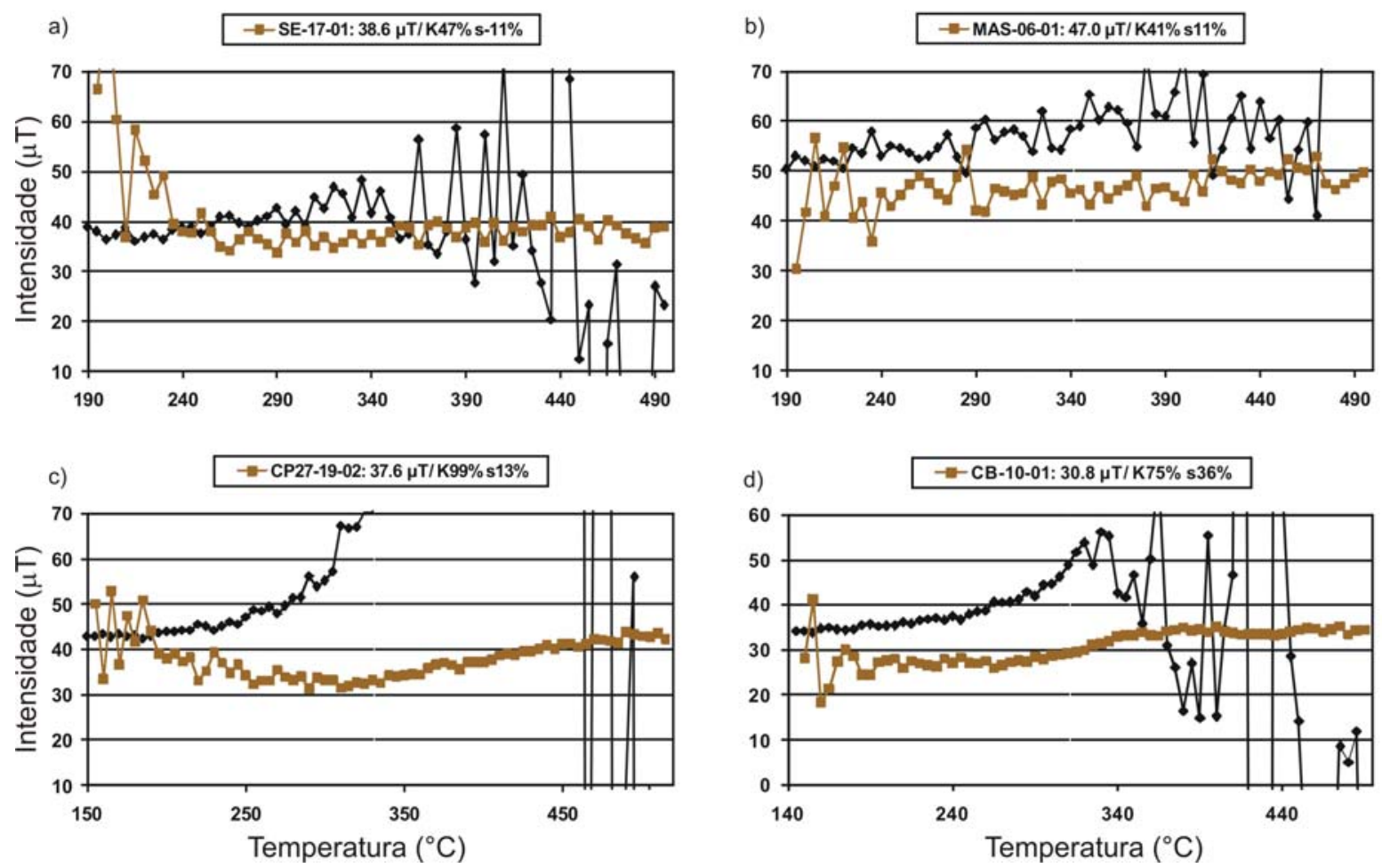

Figura 4.8: Exemplos de espécimes rejeitados pelo protocolo Triaxe. Cada curva representa os valores de $R^{\prime}(T i)$ obtidos a partir de um determinado espécime. Note que as curvas são significativamente dispersas em baixas temperaturas porque a fração da magnetização considerada em $R$ '(Ti) é pequena. Note que estes espécimes foram descartados porque os resultados violaram um ou mais critérios de seleção. 

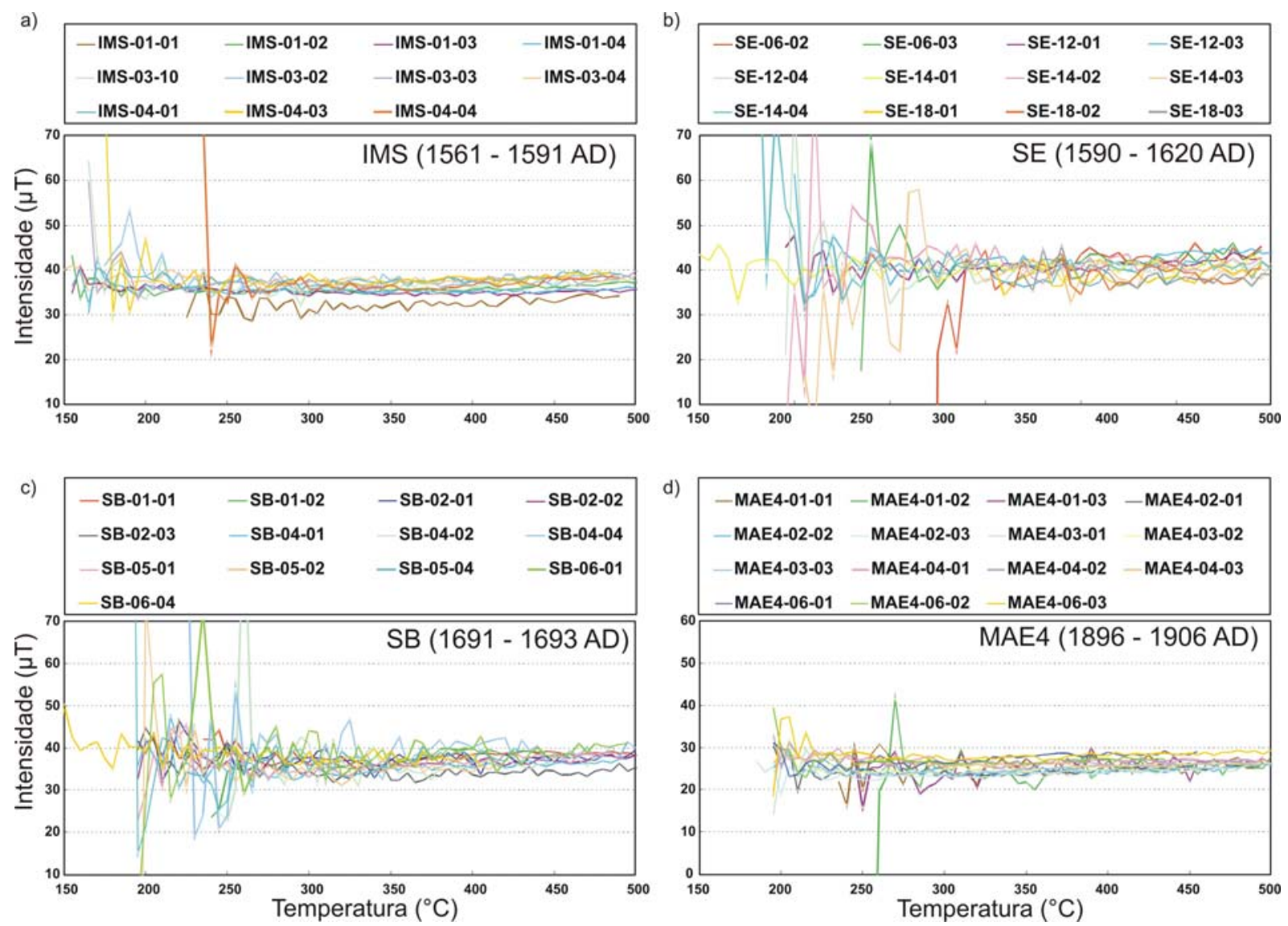

Figura 4.9: Exemplos de intensidade obtidos pelo protocolo Triaxe. Cada curva representa os valores de $R^{\prime}(T i)$ obtidos a partir de um determinado espécime. Note que as curvas são significativamente dispersas em baixas temperaturas porque a fração da magnetização considerada em $R^{\prime}(T i)$ é pequena. Entretanto, este ruído não contribui para o cálculo médio de $R^{\prime}(T i)$ no intervalo de temperatura entre $T_{1}$ e $T_{2}$. A boa consistência dos resultados de intensidade obtidos em cada sítio arqueomagnético é constatada visualmente nos diagramas.

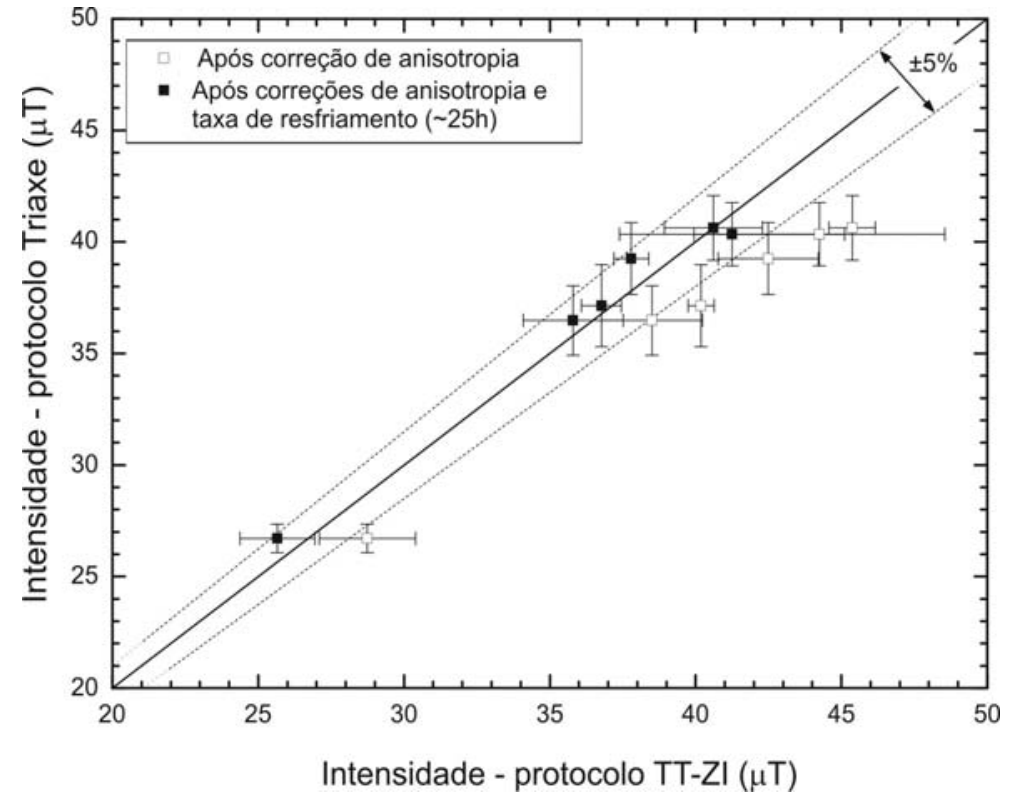

Figura 4.10: Comparação entre os valores médios em nível de sítio para os protocolos TT-ZI e Triaxe. As médias foram calculadas utilizando no mínimo dois fragmentos analisados com sucesso em cada protocolo. Para o protocolo TT-ZI, os valores médios foram calculados antes (quadrados vazados) e depois (quadrados cheios) da correção da taxa de resfriamento. As linhas tracejadas limitam a área de consistência de $\pm 5 \%$. 
Tabela 4.1: Resultados de arqueointensidade obtidos dos fragmentos de tijolos amostrados em construções históricas da cidade de Salvador $\left(13^{\circ} \mathrm{S}, 38.5^{\circ} \mathrm{W}\right)$, região Nordeste do Brasil.

\begin{tabular}{|c|c|c|c|c|c|}
\hline Sítio & Idade (AD) & Métodos & N Frag. & n Esp. & $\underset{(\mu T)}{\mathbf{F m} \pm \sigma \mathbf{F}}$ \\
\hline Igreja Mem de Sá (IMS) & 1561-1591 & TT-ZI e Triaxe & $3 / 4$ & $17 / 20$ & $36.2 \pm 1.6$ \\
\hline Praça da Sé (SE) & $1590-1620$ & TT-ZI e Triaxe & $4 / 6$ & $16 / 23$ & $40.4 \pm 1.2$ \\
\hline Praça da Sé 1 (SE1) & $1600-1650$ & TT-ZI e Triaxe & $4 / 6$ & $15 / 25$ & $41.4 \pm 3.2$ \\
\hline Praça da Sé 2 (SE2) & $1650-1700$ & TT-ZI e Triaxe & $3 / 5$ & $10 / 21$ & $37.9 \pm 0.7$ \\
\hline Museu de Arte Sacra (MAS) & $1666-1686$ & TT-ZI e Triaxe & $4 / 6$ & $12 / 25$ & $38.3 \pm 0.6$ \\
\hline Solar Berquó (SB) & $1691-1693$ & Triaxe & $5 / 5$ & $13 / 17$ & $37.2 \pm 1.1$ \\
\hline Farol da Barra $1+2(\mathrm{FB} 1+2)$ & 1696-1702 & TT-ZI e Triaxe & $4 / 7$ & $11 / 18$ & $36.5 \pm 0.9$ \\
\hline Casa do Pelourinho 27 (CP27) & $1675-1725$ & Triaxe & $5 / 7$ & $14 / 21$ & $35.8 \pm 2.1$ \\
\hline Casa Número 6 (C06) & $1700-1710$ & TT-ZI e Triaxe & $3 / 6$ & $9 / 18$ & $36.7 \pm 1.1$ \\
\hline Corpo de Bombeiros (CB) & $1767-1777$ & Triaxe & $3 / 6$ & $9 / 29$ & $32.7 \pm 2.0$ \\
\hline Solar Conde dos Arcos (SCA) & $1780-1781$ & TT-ZI & $4 / 7$ & $8 / 14$ & $32.1 \pm 0.6$ \\
\hline Tijoleira Farias (TF) & 1887 & TT-ZI e Triaxe & $5 / 7$ & $14 / 21$ & $25.8 \pm 1.6$ \\
\hline Museu de Arqueologia e Etnologia 4 (MAE4) & 1896-1906 & Triaxe & $5 / 6$ & $15 / 18$ & $25.7 \pm 1.3$ \\
\hline Galeria Canizares (GC) & $1900-1920$ & Triaxe & $5 / 6$ & $20 / 25$ & $25.0 \pm 0.5$ \\
\hline
\end{tabular}

Na coluna "Sítio" está indicado o nome do sítio e a respectiva sigla. Na coluna "Idade" está indicado o intervalo de idade atribuído para cada sítio. A coluna "Métodos" indica os métodos de paleointensidade utilizado em cada sítio. A coluna "N Frag." indica o número de fragmentos utilizados no cálculo das médias de intensidade e o número de fragmentos estudado. A coluna "n Esp." indica o número de espécimes utilizados no cálculo das médias de intensidade e o número total de espécimes estudados. A coluna "Fm $\pm \sigma F(\mu T)$ " é a média calculada em nível de sítio e o respectivo desvio padrão em $\mu \mathrm{T}$.

\subsection{Resultados da coleção Sudeste}

\subsubsection{Mineralogia magnética}

A mineralogia magnética foi investigada em todas as amostras da coleção Sudeste, compreendendo um total de 136 fragmentos. Foram feitas curvas de susceptibilidade magnética variando em função da temperatura, ciclos de histerese e curvas de aquisição da MRI para determinar os portadores da magnetização e testar a estabilidade térmica durante o aquecimento. 
Os ciclos de histerese e as curvas de aquisição da MRI apresentaram dois comportamentos. Cerca de $40 \%$ dos fragmentos apresentaram curvas de histerese com cintura fina (Figura 4.11a) e curvas de aquisição da MRI (Figura 4.11d) que saturam em campos entre $0,1 \mathrm{~T}$ e $0,3 \mathrm{~T}$. Este comportamento indica que a magnetização é portada exclusivamente por minerais de baixa coercividade magnética, provavelmente magnetita ou titanomagnetita com estrutura de domínio do tipo pseudo-monodomínio. Para cerca de $60 \%$ das amostras desta coleção, os ciclos de histerese são do tipo cintura de vespa e as aquisições de MRI não saturam em 1 T. Este comportamento revela a presença de uma mistura de fases magnéticas com baixa e alta coercividade em proporções variáveis, incluindo fragmentos com baixa quantidade de fração mais coerciva (Figura 4.11 b e Figura 4.11d) e fragmentos em que essa fração é dominante (Figura 4.11c e Figura 4.11f). Os diagramas de projeção ortogonal indicam que as fases de alta coercividade têm temperaturas de desbloqueio abaixo de $580{ }^{\circ} \mathrm{C}$. As fases de alta coercividade têm comportamento semelhante àquelas encontradas na coleção Nordeste e são interpretadas de forma preliminar como uma fase de hematita nãoestequiométrica (Hartmann et al., 2010b).

a)

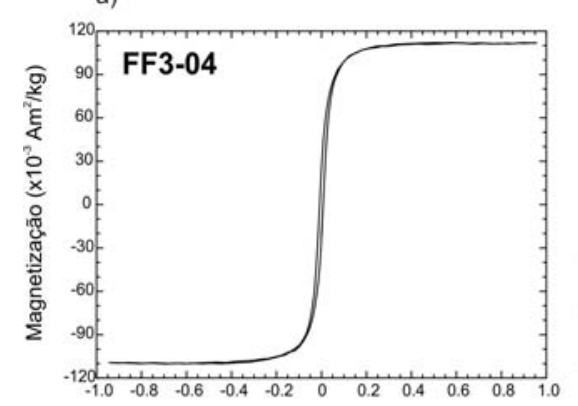

d)

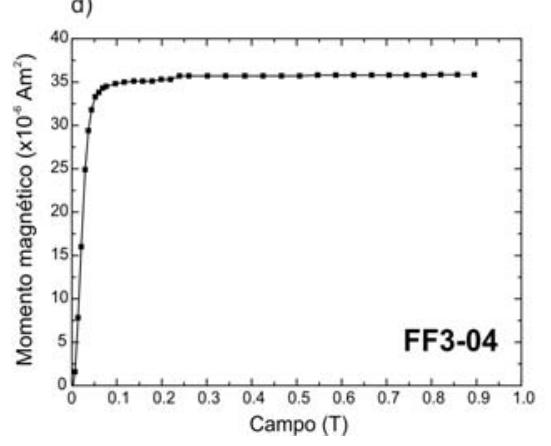

b)

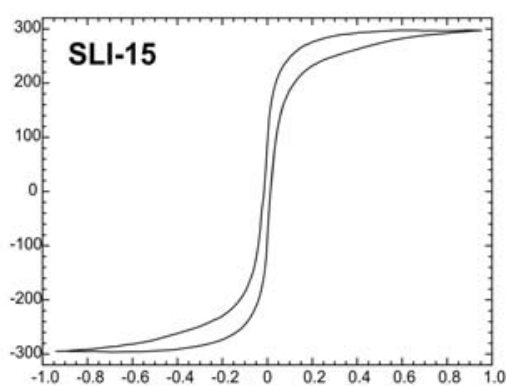

e)

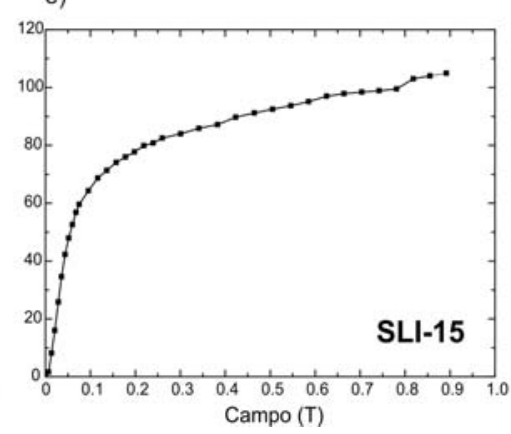

c)

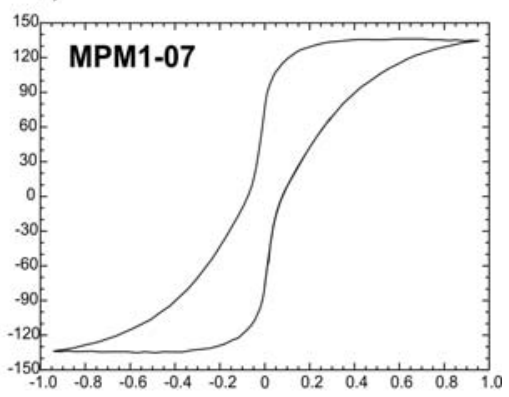

f)

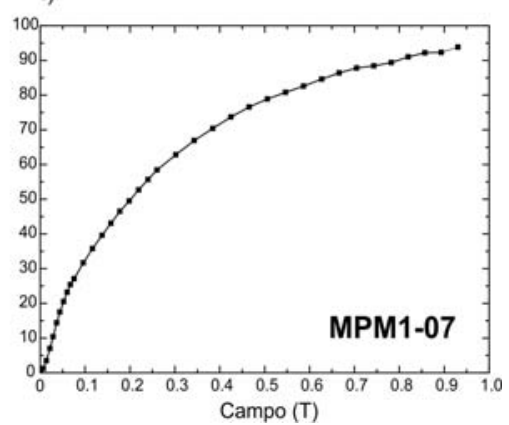

Figura 4.11: Medidas de magnetismo de rochas realizadas em três típicos exemplos da coleção de amostras do Sudeste. Em (a-c), ciclos de histerese e em (d-f) curvas de aquisição da MRI.

As curvas de susceptibilidade magnética variando em função da temperatura foram feitas até $550{ }^{\circ} \mathrm{C}-600{ }^{\circ} \mathrm{C}$ (Figura 4.12). A reversibilidade das curvas entre o aquecimento e o resfriamento foi utilizada para selecionar os fragmentos adequados para os experimentos de 
paleointensidade, e somente os fragmentos que apresentaram boa estabilidade térmica foram selecionados para os experimentos de paleointensidade. Nesta etapa foram rejeitados 47 fragmentos por causa de alteração magnetomineralógica. A Figura 4.13 mostra seis exemplos de amostras que foram descartadas para os experimentos de paleointensidade.
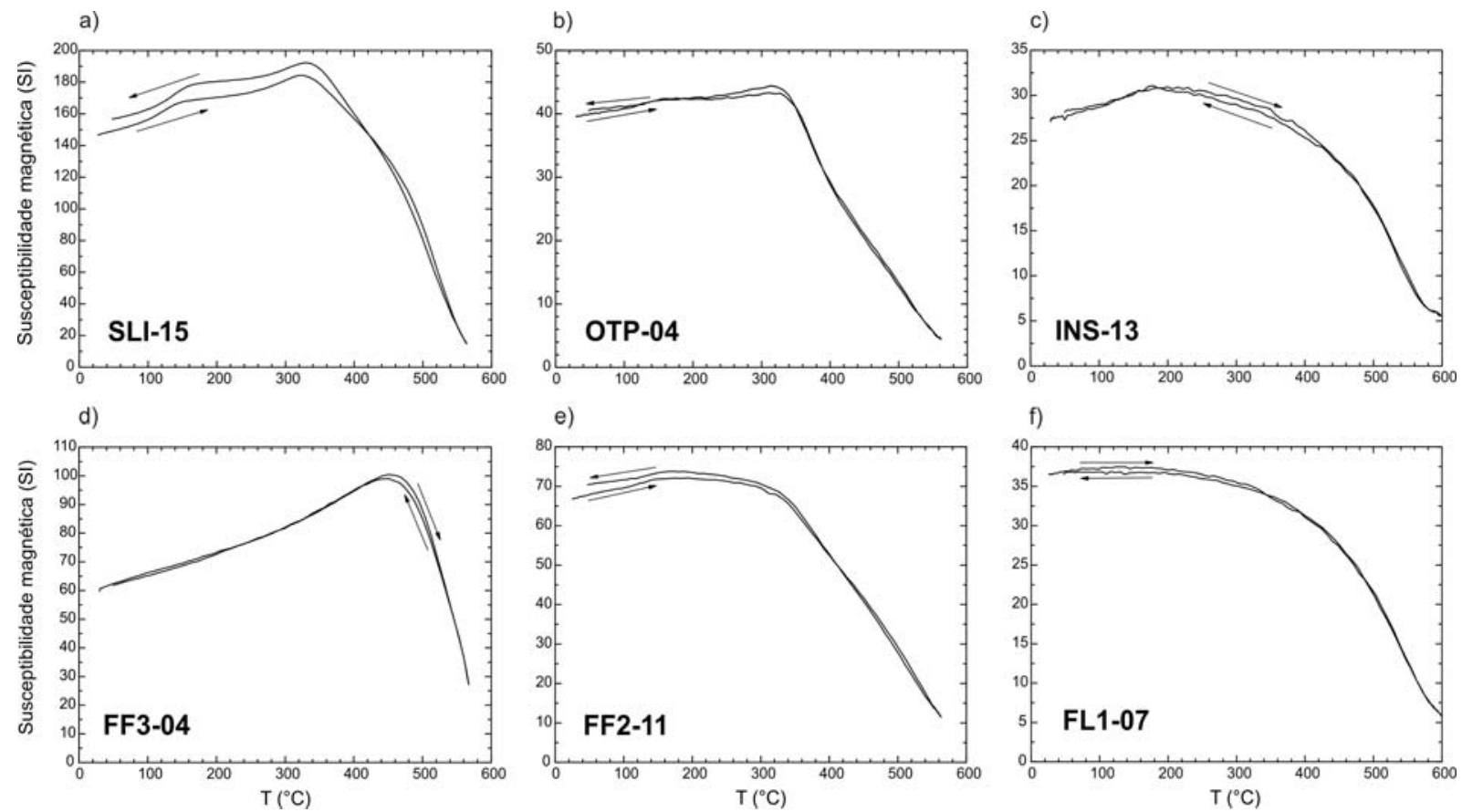

Figura 4.12: Exemplos de curvas de susceptibilidade magnética medidas em ciclos de aquecimento-resfriamento até $550{ }^{\circ} \mathrm{C}-600^{\circ} \mathrm{C}$. A susceptibilidade é adimensional.
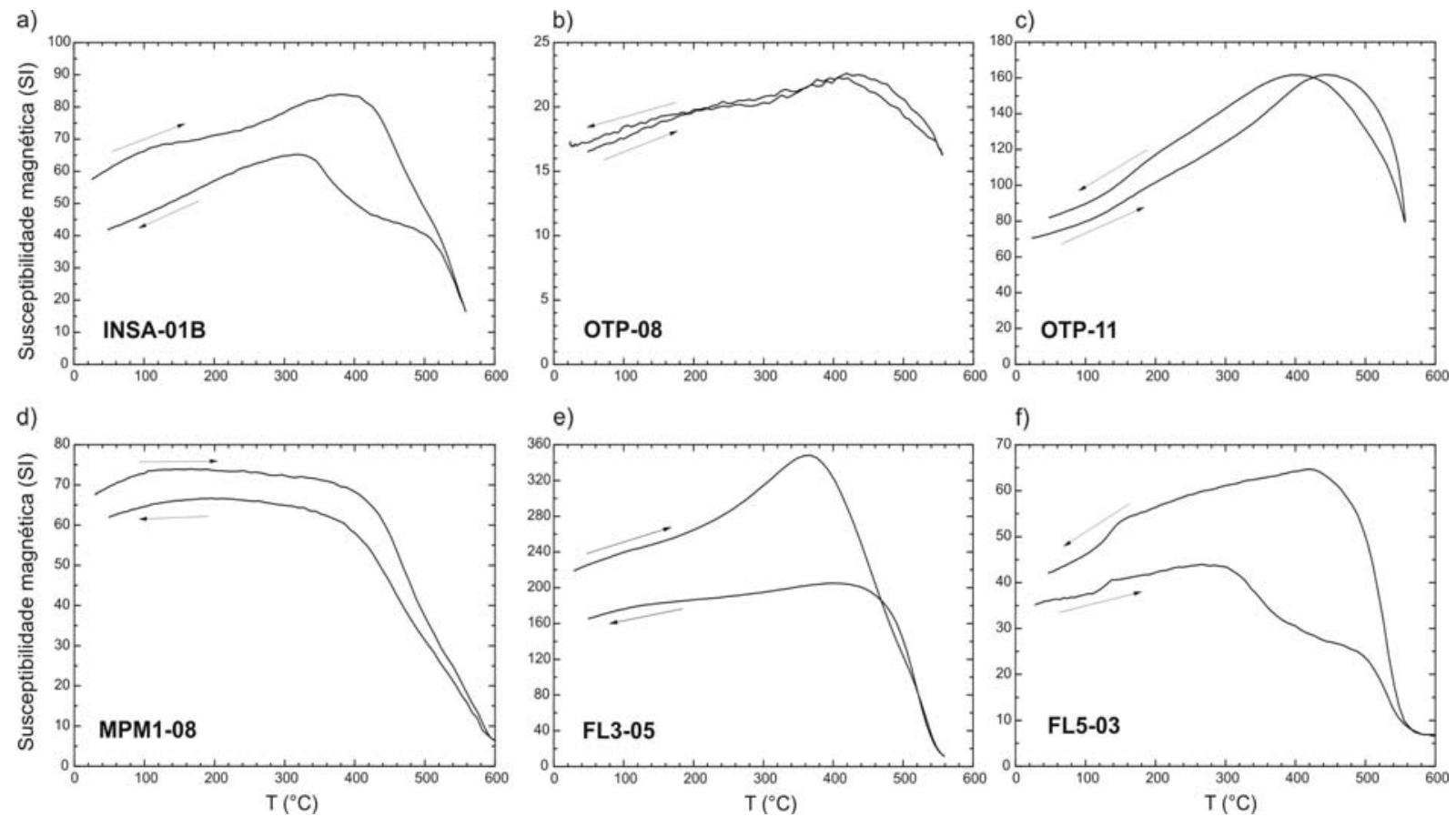

Figura 4.13: Exemplos de curvas de susceptibilidade magnética medidas em ciclos de aquecimento-resfriamento até $550{ }^{\circ} \mathrm{C}-600{ }^{\circ} \mathrm{C}$, indicando amostras inadequadas para os experimentos de paleointensidade. A susceptibilidade é adimensional. 


\subsubsection{Resultados de arqueointensidade}

As medidas foram feitas em 89 fragmentos dos 11 sítios que compõe a coleção Sudeste, totalizando 289 espécimes medidos através dos protocolos TT-ZI e/ou Triaxe. Considerando os critérios de análise e seleção apresentados no Capítulo 3, um total de 43 fragmentos (150 espécimes) foi utilizado para o cálculo dos valores médios de intensidade, o que equivale a uma taxa de sucesso de $52 \%$. Todos os resultados em nível de sítio são apresentados na Tabela 4.2 .

\subsubsection{Resultados pelo protocolo TT-ZI}

O protocolo TT-ZI foi aplicado em um conjunto de 40 fragmentos (80 espécimes) de 8 sítios arqueológicos. Foram medidos por sítio entre 4 e 7 fragmentos obtendo-se uma taxa de sucesso de $\sim 38 \%$, uma vez que apenas 15 fragmentos atenderam aos critérios de seleção (ver Tabela A3 do Apêndice D). Boa parte dos espécimes foi rejeitada por conta de diagramas de Arai não-lineares devido a alteração magnética durante os experimentos (Figura 4.14a). Isso ocorreu, particularmente, para todos os fragmentos dos sítios FF4 (Fábrica de Ferro 4, 4 fragmentos) e FFY (Fábrica de Ferro Ypanema, 4 fragmentos). Alguns fragmentos foram rejeitados porque a fração da MRN utilizada para cálculo da intensidade foi inferior a $40 \%$ (Figura 4.14b). Em alguns tijolos do forno FF2, a magnetização primária foi parcialmente remagnetizada por uma magnetização secundária, indicando que estes tijolos foram parcialmente cozidos em temperaturas mais baixas que a queima original (Figura 4.14f). Os demais sítios apresentaram excelentes resultados.

A Figura 4.15 traz três exemplos de determinações de intensidade que obedecem aos critérios de qualidade, com as medidas representadas nos diagramas de Arai e nos diagramas de projeção vetorial. Esta figura mostra que a componente de magnetização primária foi isolada em temperaturas acima de $100{ }^{\circ} \mathrm{C}-250{ }^{\circ} \mathrm{C}$ e que a determinação da intensidade foi feita no mesmo intervalo de temperatura na qual a componente magnética foi isolada.

Nesta coleção foi utilizada a mesma abordagem de correção de anisotropia utilizada na coleção Nordeste. $\mathrm{O}$ fator $f_{1}$ foi aplicado quando a fração da MRN envolvida para o cálculo do tensor em $350{ }^{\circ} \mathrm{C}$ foi superior a $40 \%$ e quando nenhuma alteração magnética tenha sido detectada acima de $500{ }^{\circ} \mathrm{C}$ (Figura 4.15e); o fator $f_{2}$ foi usado quando a fração da MRN foi inferior a $40 \%$ em $350{ }^{\circ} \mathrm{C}$ e quando nenhuma alteração magnética foi detectada abaixo de 500 ${ }^{\circ} \mathrm{C}$ (Figura 4.15a e Figura 4.15c). A média entre os fatores foi usada para a correção de anisotropia da MTR somente nos fragmentos FF2-05 e FL1-07. A anisotropia da MTR 
observada nesta coleção de tijolos é semelhante àquela obtida para a coleção Nordeste (Figura 4.16a). De todos os fragmentos, cerca de $80 \%$ apresenta grau de anisotropia entre 1,0 e 1,2, enquanto que o restante apresenta grau de anisotropia entre 1,2 e 1,4. Este fato reforça a importância desta correção em materiais construtivos, levando a correções entre $15 \%$ a 20\% do valor de intensidade obtido em um determinado fragmento (Figura 4.16b). Nota-se também a mesma distribuição de $K_{1} / K_{3}$ observada em tijolos da Síria datadas da idade do Bronze (Genevey et al., 2008) e em tijolos e telhas medievais da França e da Bulgária (Kovacheva et al., 2009).

a)

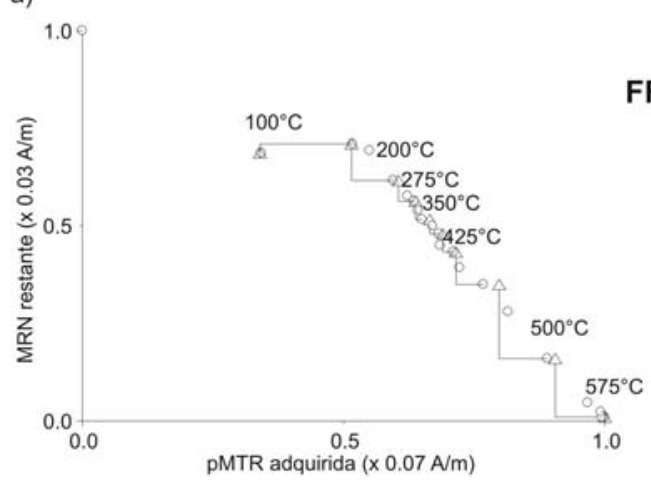

c)
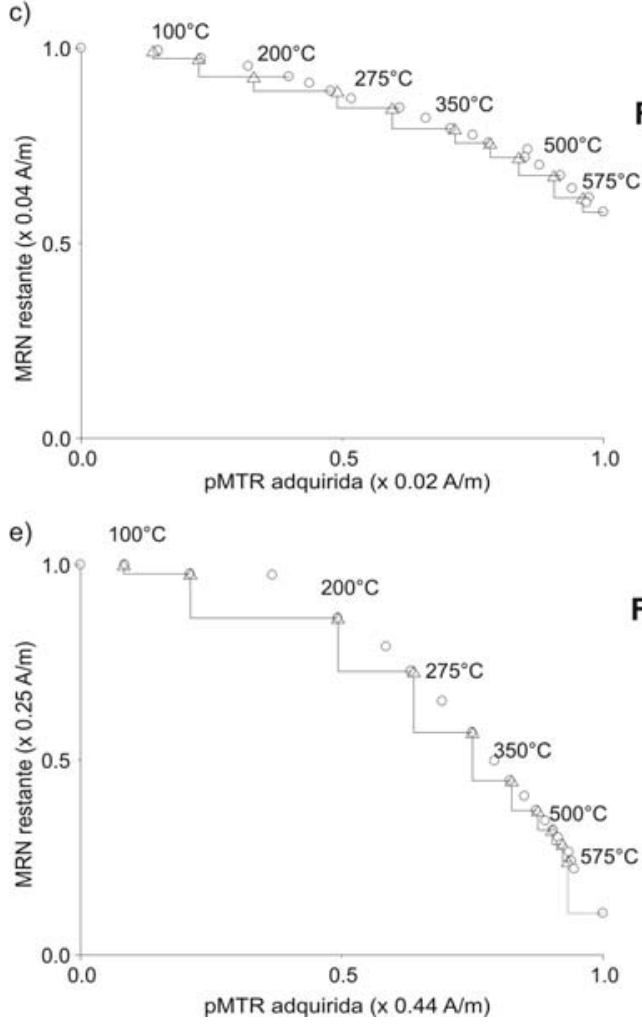
$5^{\circ} \mathrm{C}$ b)

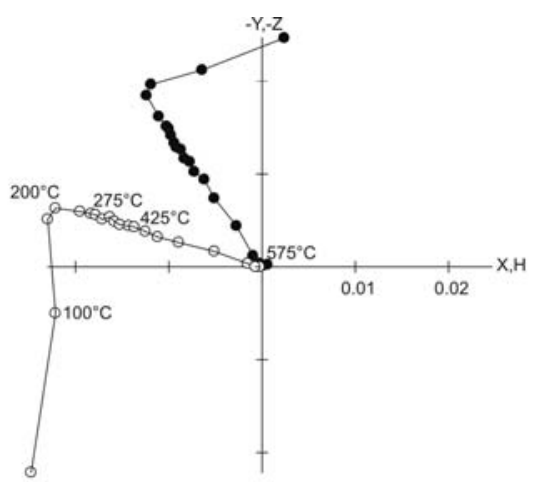

d)

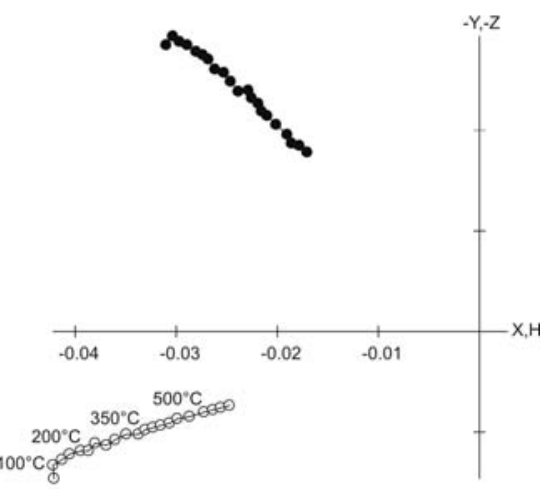

FFY-02-01

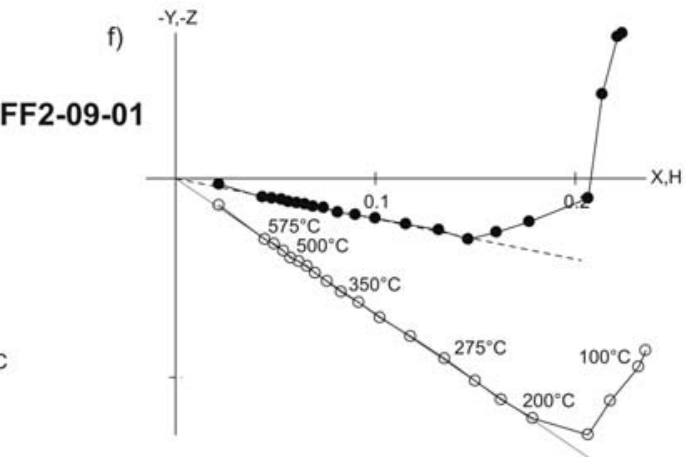

Figura 4.14: Experimentos de paleointensidade utilizando o protocolo TT-ZI. Exemplos de espécimes rejeitados nas análises de paleointensidade devido à problemas nos diagramas de Arai (a, c, e) e os respectivos digramas ortogonais (b, d, f, h). Nos diagramas de Arai, os círculos representam a MRN restante versus a MTR adquirida e os triângulos mostram os pTRM's checks realizados a cada 2 passos de temperatura. Nos diagramas ortogonais, os símbolos cheios indicam o vetor magnetização projetado no plano horizontal e os símbolos vazados indicam o vetor projetado no plano vertical (sistema de coordenadas do espécime). 


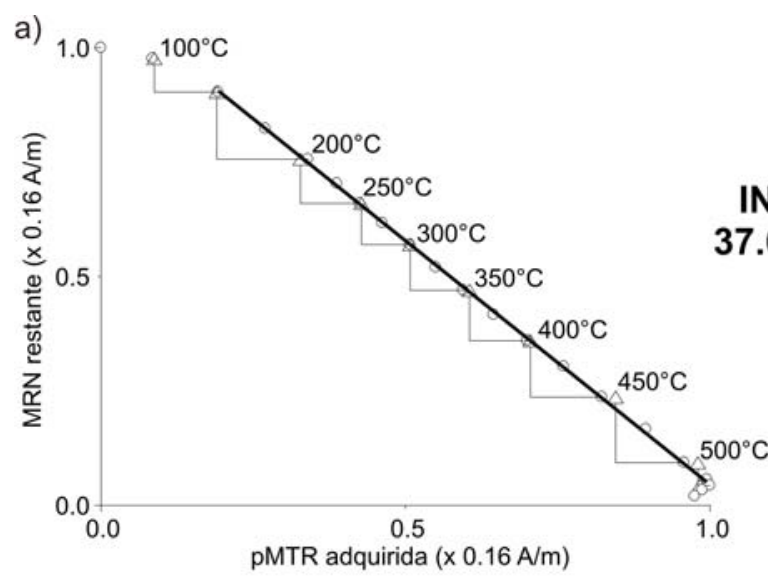

b)

INS-13-01

$37.6 \pm 0.2 \mu \mathrm{T}$
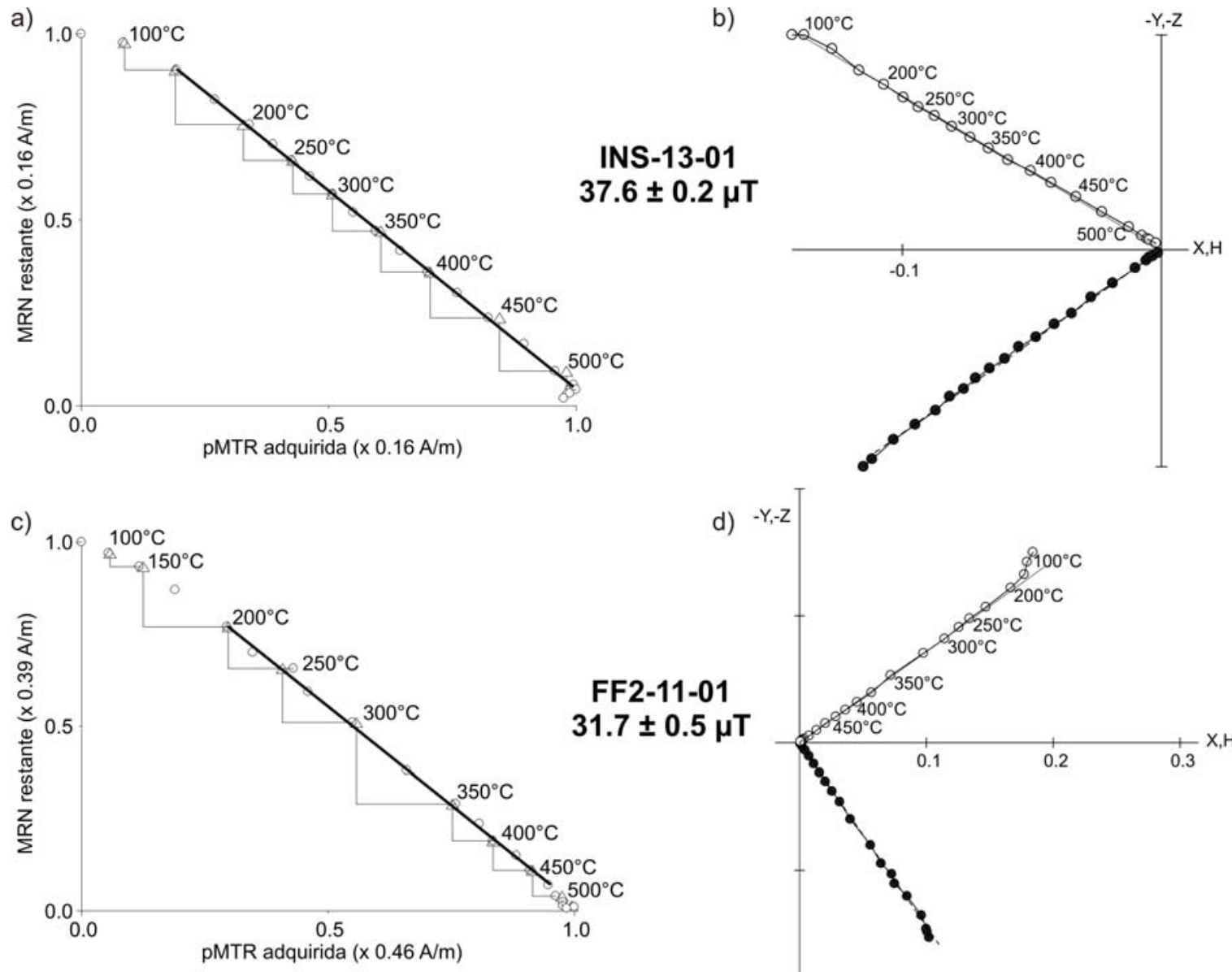

d) $-Y,-Z$

FF2-11-01
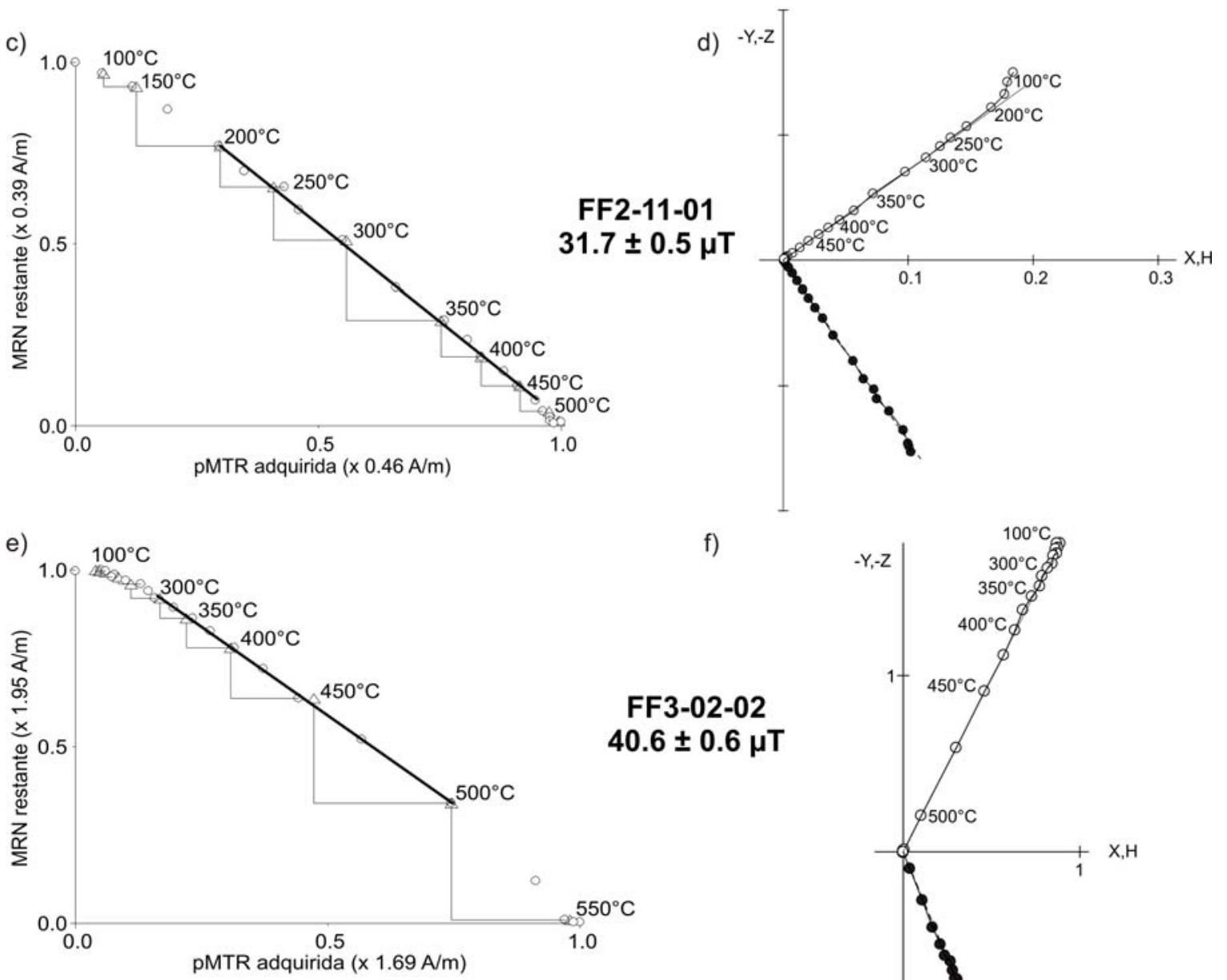

FF3-02-02

f)

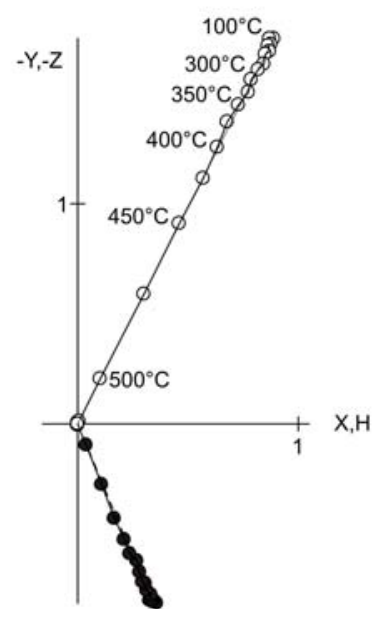

Figura 4.15: Determinações de intensidade pelo protocolo TT-ZI. Exemplos de diagramas de Arai (a, c, e) e os respectivos digramas de desmagnetização térmica (b, d, f). Nos diagramas de Arai, os círculos representam a MRN restante versus a MTR adquirida e os triângulos mostram as checagens de pMTR's ( $p$ TRM's checks) realizados a cada 2 passos de temperatura. Os valores de intensidade foram calculados a partir o ajuste linear dos diagramas. Nos diagramas de desmagnetização térmica, os símbolos cheios indicam o vetor magnetização projetado no plano horizontal e os símbolos vazados indicam o vetor projetado no plano vertical (sistema de coordenadas do espécime).

O efeito da taxa de resfriamento na MTR foi corrigido pela taxa de $25 \mathrm{~h}$, implicando em uma diminuição dos valores de intensidade entre 5\% e 15\% com média de redução em 
torno de 9\% (Figura 4.17a). Os resultados mostram que todos os tijolos desta coleção, assim como aqueles da coleção Nordeste, apresentam valores de correção moderados.
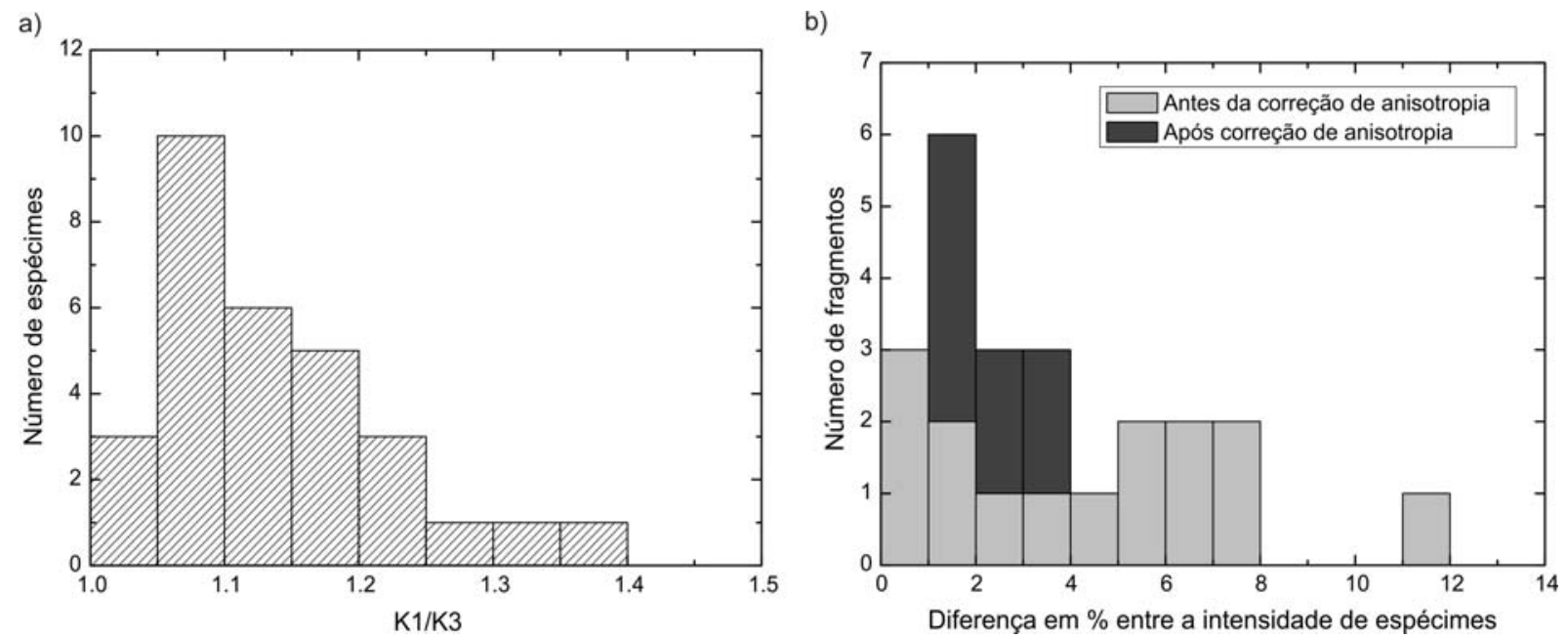

Figura 4.16: Correção do efeito de anisotropia da MTR. Em (a) é mostrado o diagrama com o grau de anisotropia obtido para todos os espécimes utilizados no cálculo das médias. Em (b) é mostrado o diagrama das diferenças calculadas entre espécimes do mesmo fragmento antes (cinza claro) e depois (cinza escuro) da correção para o efeito de anisotropia.
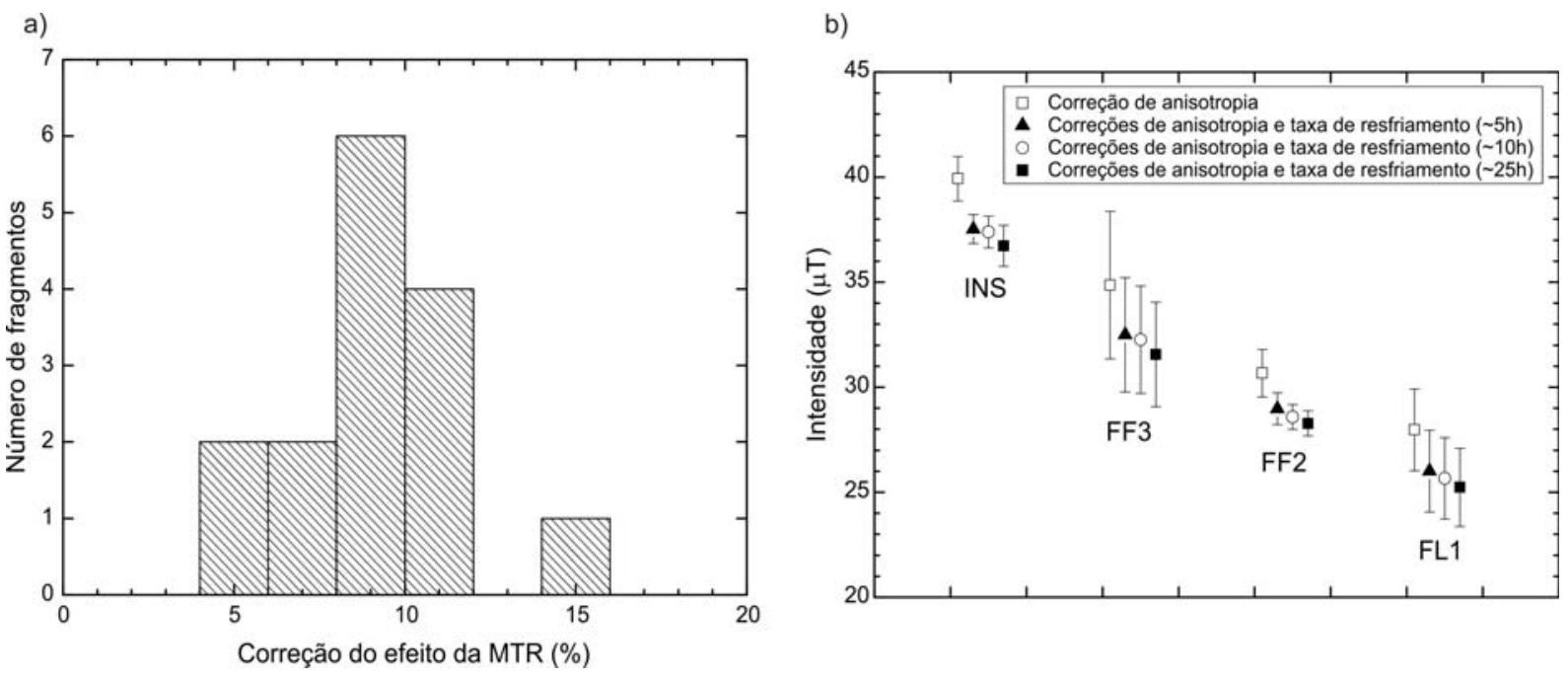

Figura 4.17: Correção do efeito da taxa de resfriamento na MTR. A figura (a) mostra o histograma da estimativa de correção da MTR considerando o tempo de resfriamento lento de $\sim 25$ h. A figura (b) mostra uma comparação entre médias de intensidade calculadas antes (quadrados vazados) e após a correção da taxa de resfriamento para as taxas: $\sim 5 \mathrm{~h}$ (triângulos cheios), $\sim 10 \mathrm{~h}$ (círculos vazados) e $\sim 25 \mathrm{~h}$ (quadrados cheios), entre a temperatura de $450{ }^{\circ} \mathrm{C}$ e a temperatura ambiente. Note que as intensidades médias foram calculadas quando no mínimo dois fragmentos por sítio foram analisados e que a correção por perda de massa não foi realizada porque foi desprezível para todos os espécimes.

\subsubsection{Resultados pelo protocolo Triaxe}

O protocolo Triaxe foi aplicado em um conjunto de 73 fragmentos (209 espécimes) de 9 sítios, com 1 a 14 fragmentos analisados por grupo. Trinta e cinco fragmentos (120 
espécimes) atenderam aos critérios de seleção, o que levou a uma taxa de sucesso de 57\% (ver Tabela A4 do Apêndice D). Os fragmentos foram rejeitados por causa de alteração magnética detectada durante as medidas ou porque o desvio das curvas de $R^{\prime}\left(T_{i}\right)$ foram superiores a 10\%. A Figura 4.18 mostra quatro exemplos de espécimes que foram descartados das análises de paleointensidade. Para a maioria dos fragmentos aceitos, a intensidade foi calculada em um intervalo de temperaturas compreendido entre $130^{\circ} \mathrm{C}-220^{\circ} \mathrm{C}$ e $480^{\circ} \mathrm{C}-520^{\circ} \mathrm{C}$ (ver Tabela A4 do Apêndice D). Para alguns fragmentos dos fornos FF2 e FF3, que foram parcialmente aquecidos durante a operação da Real Fábrica de Ferro Ipanema, a temperatura $T_{1}$ foi escolhida com valores um pouco mais altos $\left(T_{1}, \sim 250^{\circ} \mathrm{C}-330^{\circ} \mathrm{C}\right)$ e a intensidade foi determinada no intervalo de temperaturas no qual a MTR primária foi completamente isolada. A Figura 4.19 mostra as determinações de intensidade que atenderam aos critérios de seleção, obtidas em quatro sítios diferentes através do protocolo Triaxe. Cada diagrama mostra o valor de $R^{\prime}\left(T_{i}\right)$ obtido em diferentes espécimes de um mesmo sítio. A Figura 4.19 enfatiza a boa consistência dos resultados em nível de fragmento para os diferentes sítios estudados.
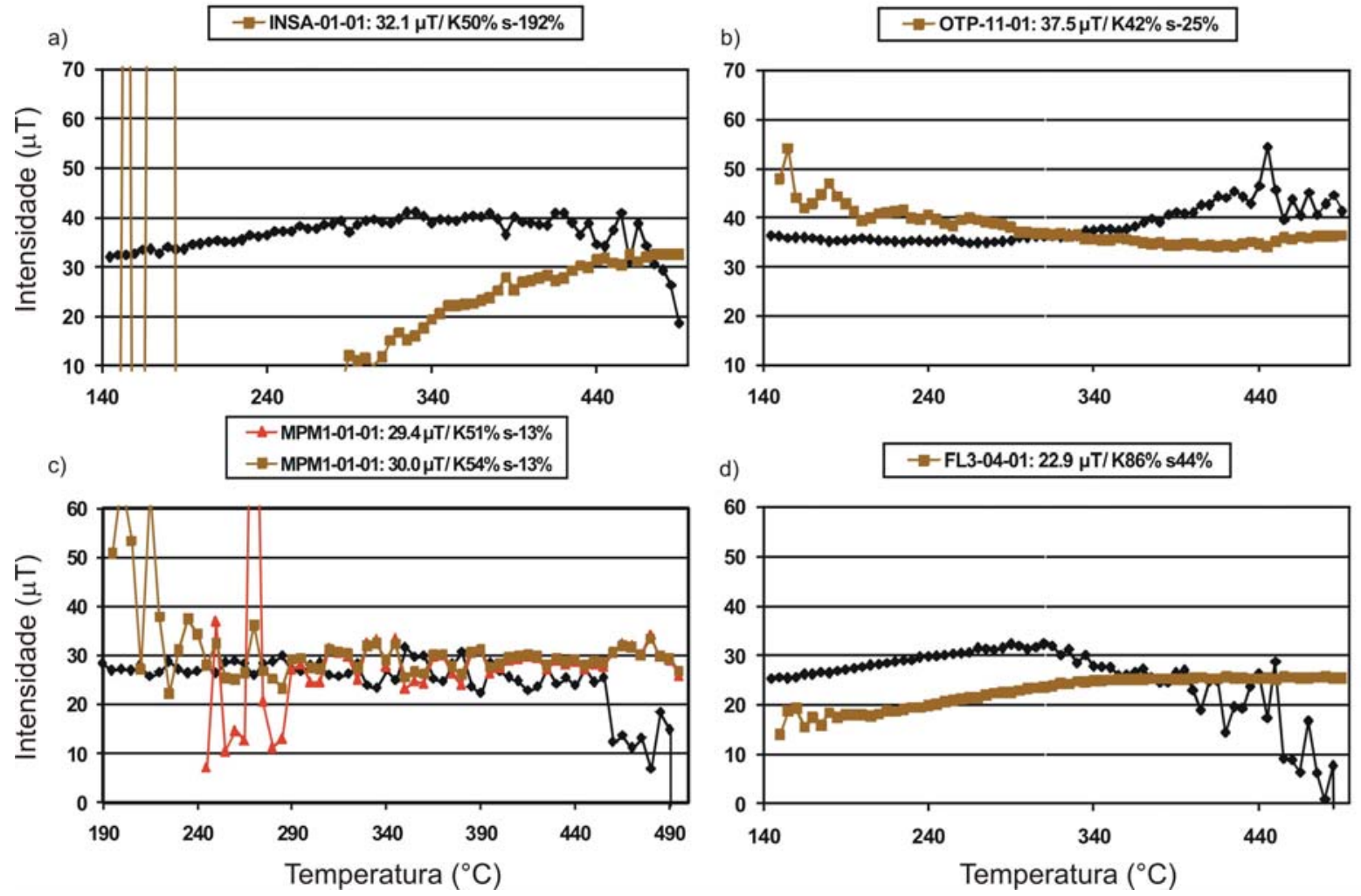

Figura 4.18: Exemplos de paleointensidade utilizando o protocolo Triaxe. Exemplos de espécimes rejeitados para as análises de paleointensidade. Cada curva representa os valores de $R^{\prime}(T i)$ obtidos a partir de um determinado espécime. Note que as curvas são significativamente dispersas em baixas temperaturas porque a fração da magnetização considerada em $R$ '(Ti) é pequena. Note que estes espécimes foram descartados porque os resultados violaram um ou mais critérios de seleção. 
a)
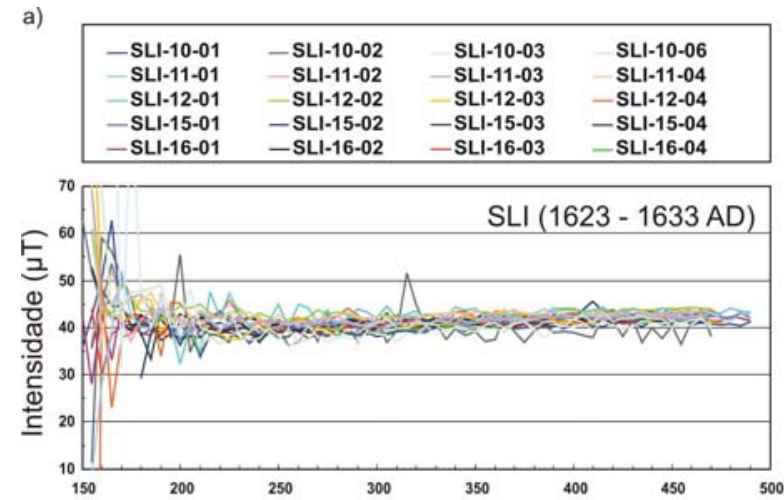

c)
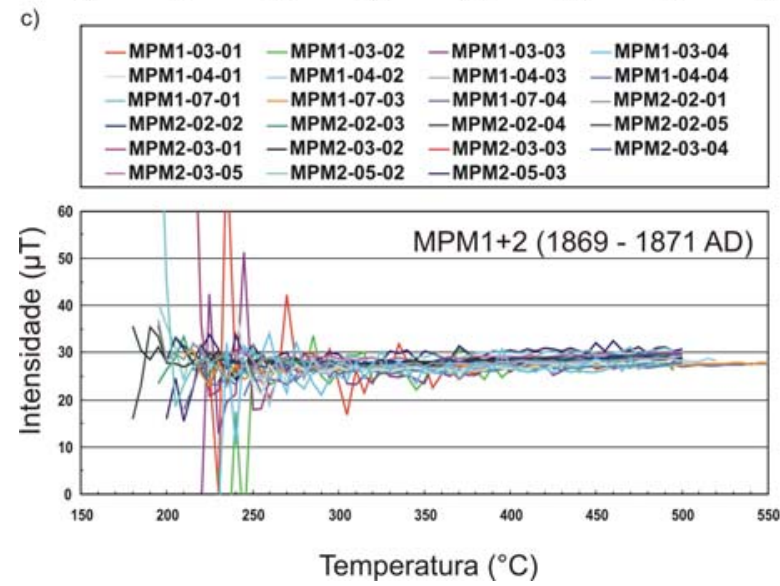

b)

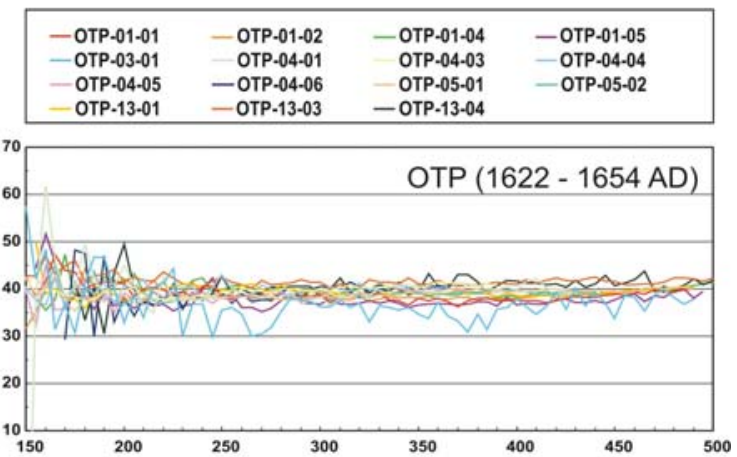

d)

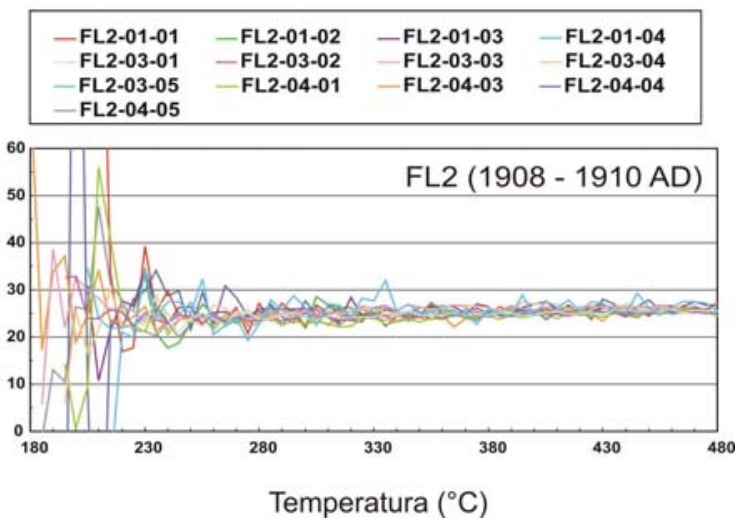

Figura 4.19: Exemplos de intensidade obtidos pelo protocolo Triaxe. Cada curva representa os valores de $R$ '(Ti) obtidos a partir de um determinado espécime. Note que as curvas são significativamente dispersas em baixas temperaturas porque a fração da magnetização considerada em $R^{\prime}(T i)$ é pequena. Entretanto, este ruído não contribui para o cálculo médio de $R^{\prime}(T i)$ no intervalo de temperatura entre $T_{1}$ e $T_{2}$. A boa consistência dos resultados de intensidade obtidos em cada sítio arqueomagnético é constatada visualmente nos diagramas.

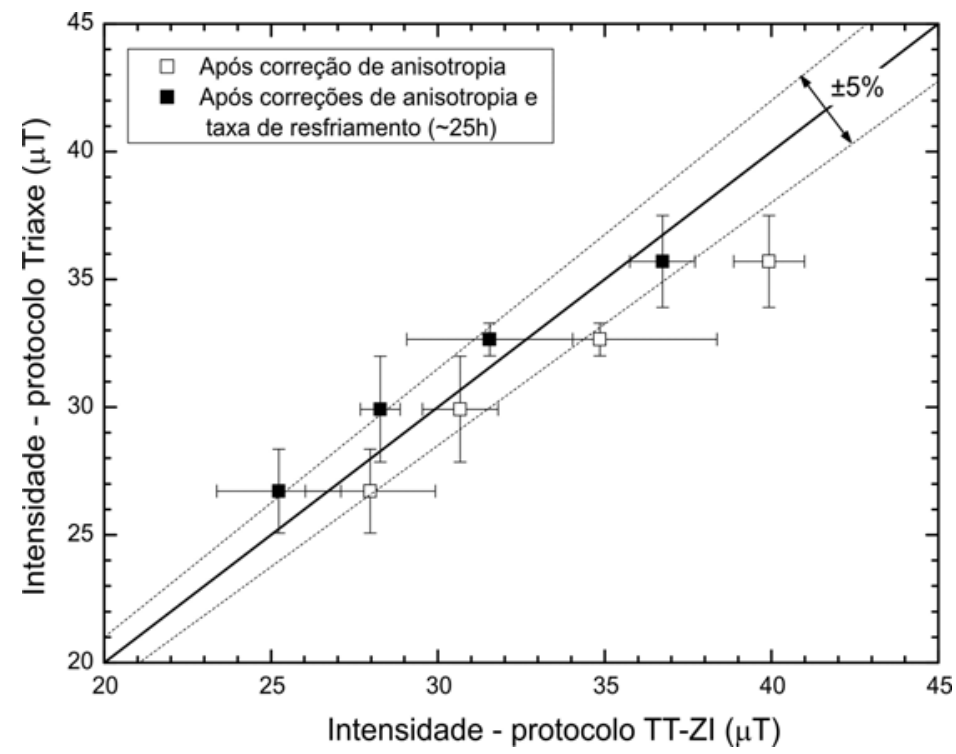

Figura 4.20: Comparação entre os valores médios em nível de sítio para os protocolos TT-ZI e Triaxe. As médias foram calculadas utilizando pelo menos 1 fragmento que foi analisado com sucesso em cada protocolo. Para o protocolo TT-ZI, os valores médios foram calculados antes (quadrados vazados) e após (quadrados cheios) a correção da taxa de resfriamento. As linhas tracejadas limitam a área de consistência de $\pm 5 \%$. 
Para esta coleção de amostras foi possível comparar os resultados obtidos pelos protocolos TT-ZI e Triaxe em apenas quatro sítios. A comparação entre os dois protocolos foi feita em sete fragmentos dos sítios INS, FF2, FF3 e FL1+3+4+5. Da mesma forma que na coleção Nordeste, a consistência entre os resultados TT-ZI (após a correção da taxa de resfriamento de $25 \mathrm{~h}$ ) e os resultados do Triaxe em nível de sítio é bastante satisfatória (Figura 4.20). As discrepâncias são sistemáticas entre os dois conjuntos de dados antes da correção do efeito da taxa de resfriamento. Após esta correção os valores de intensidade TT-ZI e Triaxe são semelhantes com diferenças em torno de $\pm 5 \%$. Pode-se observar novamente que a consistência dos resultados obtidos por protocolos distintos é bastante importante e que a correção da taxa de resfriamento é um fator crítico nas determinações de arqueointensidade.

Tabela 4.2: Resultados de arqueointensidade obtidos nos fragmentos da coleção da região Sudeste do Brasil.

\begin{tabular}{|c|c|c|c|c|c|c|}
\hline Sítio & Idade (AD) & Métodos & N Frag. & n Esp. & $\begin{array}{c}\mathbf{F m} \pm \sigma F \\
(\mu T)\end{array}$ & $\begin{array}{c}\text { Fm SP } \\
(\mu T)\end{array}$ \\
\hline $\begin{array}{l}\text { Igreja de Nossa Senhora da } \\
\text { Assunção (INSA) } \\
\text { Cidade: Anchieta } \\
\left(20.8^{\circ} \mathrm{S}, 40.6^{\circ} \mathrm{W}\right)\end{array}$ & $1584-1598$ & Triaxe & $3 / 6$ & $12 / 24$ & $40.8 \pm 2.4$ & 42.2 \\
\hline $\begin{array}{l}\text { Igreja de São Lourenço dos } \\
\text { Índios (SLI) } \\
\text { Cidade: Niterói } \\
\left(22.9^{\circ} \mathrm{S}, 43.1^{\circ} \mathrm{W}\right)\end{array}$ & $1623-1633$ & Triaxe & $5 / 9$ & $20 / 26$ & $41.3 \pm 0.9$ & 41.6 \\
\hline $\begin{array}{l}\text { Igreja da Venerável Ordem } \\
\text { Terceira de São Francisco da } \\
\text { Penitência (OTP) } \\
\text { Cidade: Rio de Janeiro } \\
\left(22.9^{\circ} \mathrm{S}, 43.2^{\circ} \mathrm{W}\right)\end{array}$ & $1622-1654$ & $\begin{array}{l}\text { TT-ZI e } \\
\text { Triaxe }\end{array}$ & $5 / 14$ & $17 / 51$ & $39.0 \pm 1.2$ & 39.3 \\
\hline $\begin{array}{l}\text { Igreja de Nossa Senhora da } \\
\text { Saúde (INS) } \\
\text { Cidade: Rio de Janeiro } \\
\left(22.9^{\circ} \mathrm{S}, 43.2^{\circ} \mathrm{W}\right)\end{array}$ & $1742-1750$ & $\begin{array}{l}\text { TT-ZI e } \\
\text { Triaxe }\end{array}$ & $4 / 9$ & $15 / 22$ & $35.4 \pm 1.8$ & 35.7 \\
\hline $\begin{array}{l}\text { Real Fábrica de Ferro Ipanema } 3 \\
\text { (FF3) } \\
\text { Cidade: Iperó } \\
\left(23.3^{\circ} \mathrm{S}, 47.7^{\circ} \mathrm{W}\right) \\
\end{array}$ & $1790-1800$ & $\begin{array}{l}\text { TT-ZI e } \\
\text { Triaxe }\end{array}$ & $3 / 6$ & $12 / 21$ & $31.4 \pm 2.4$ & 31.5 \\
\hline $\begin{array}{l}\text { Real Fábrica de Ferro Ipanema } 2 \\
\text { (FF2) } \\
\text { Cidade: Iperó } \\
\left(23.3^{\circ} \mathrm{S}, 47.7^{\circ} \mathrm{W}\right) \\
\end{array}$ & $1815-1819$ & $\begin{array}{l}\text { TT-ZI e } \\
\text { Triaxe }\end{array}$ & $6 / 9$ & $16 / 25$ & $29.1 \pm 1.8$ & 29.2 \\
\hline $\begin{array}{l}\text { Museu Prudente de Moraes 1 e } 2 \\
\text { (MPM1+2) } \\
\text { Cidade: Piracicaba } \\
\left(22.7^{\circ} \mathrm{S}, 47.6^{\circ} \mathrm{W}\right)\end{array}$ & 1870 & Triaxe & $6 / 9$ & $23 / 34$ & $27.7 \pm 1.1$ & 28.0 \\
\hline $\begin{array}{l}\text { Real Fábrica de Ferro Ipanema } 4 \\
\text { (FF4) } \\
\text { Cidade: Iperó } \\
\left(23.3^{\circ} \mathrm{S}, 47.7^{\circ} \mathrm{W}\right)\end{array}$ & 1888-1895 & $\begin{array}{l}\text { TT-ZI e } \\
\text { Triaxe }\end{array}$ & $0 / 5$ & $0 / 16$ & - & - \\
\hline
\end{tabular}




\begin{tabular}{|c|c|c|c|c|c|c|}
\hline Sítio & Idade (AD) & Métodos & N Frag. & n Esp. & $\begin{array}{c}\mathbf{F m} \pm \sigma \mathbf{F} \\
(\mu T)\end{array}$ & $\begin{array}{c}\text { Fm SP } \\
(\mu T)\end{array}$ \\
\hline $\begin{array}{l}\text { Real Fábrica de Ferro Ipanema Y } \\
(\text { FFY) } \\
\text { Cidade: Iperó } \\
\left(23.3^{\circ} \mathrm{S}, 47.7^{\circ} \mathrm{W}\right)\end{array}$ & $1888-1895$ & $\begin{array}{l}\text { TT-ZI e } \\
\text { Triaxe }\end{array}$ & $0 / 5$ & $0 / 13$ & - & - \\
\hline $\begin{array}{l}\text { Fazenda Lageado } 1,3,4 \text { e } 5 \\
\text { (FL1+3+4+5) } \\
\text { Cidade: Botucatu } \\
\left(22.9^{\circ} \mathrm{S}, 48.4^{\circ} \mathrm{W}\right)\end{array}$ & $1895-1901$ & $\begin{array}{l}\text { TT-ZI e } \\
\text { Triaxe }\end{array}$ & $8 / 13$ & $22 / 36$ & $26.2 \pm 1.8$ & 26.4 \\
\hline $\begin{array}{l}\text { Fazenda Lageado } 2 \text { (FL2) } \\
\text { Cidade: Botucatu } \\
\left(22.9^{\circ} \mathrm{S}, 48.4^{\circ} \mathrm{W}\right)\end{array}$ & 1908-1910 & Triaxe & $3 / 4$ & $13 / 15$ & $25.2 \pm 0.4$ & 25.4 \\
\hline
\end{tabular}

Na coluna "Sítio" está indicado o nome do sítio e a respectiva sigla. Na coluna "Idade" está indicado o intervalo de idade atribuído para cada sítio. A coluna "Métodos" indica os métodos de paleointensidade utilizado em cada sítio. A coluna "N Frag." indica o número de fragmentos utilizados no cálculo das médias de intensidade e o número de fragmentos estudado. A coluna "n Esp." indica o número de espécimes utilizados no cálculo das médias de intensidade e o número total de espécimes estudados. A coluna "Fm $\pm \sigma F(\mu T)$ " é a média calculada a nível de sítio e o respectivo desvio padrão em $\mu \mathrm{T}$. A coluna "Fm SP $(\mu \mathrm{T})$ " é a média para a latitude da cidade de São Paulo, calculada por um campo dipolar geocêntrico axial (GAD). 


\section{Capítulo 5}

\section{Aplicação do Arqueomagnetismo à datação de materiais arqueológicos}

Diferentes processos físicos podem ser utilizados para definir a idade de artefatos arqueológicos, ou ainda para determinar sua proveniência. Uma aplicação crescente nos dias atuais é o uso das variações do campo magnético da Terra registradas nos materiais arqueológicos. Neste capítulo serão apresentados os princípios da datação arqueomagnética que possibilita o uso das variações do campo na datação de materiais arqueológicos, bem como um exemplo de aplicação dessa técnica no Brasil. Este capítulo está estruturado em torno de um artigo e um capítulo de livro escritos durante o período de tese. O artigo foi publicado na Revista do Museu de Arqueologia e Etnologia e tem cunho essencialmente metodológico. Já o capítulo de livro, que será publicado no livro do Projeto Monumenta de Salvador desenvolvido pelo Instituto do Patrimônio Histórico e Artístico Nacional (IPHAN), mostra um exemplo de datação arqueomagnética em uma casa do Pelourinho.

\subsection{Datação arqueomagnética}

A datação arqueomagnética é uma técnica de datação baseada na capacidade de alguns materiais arqueológicos adquirirem uma magnetização remanente estável quando expostos ao campo magnético da Terra (CMT) no momento da produção ou descarte (e.g. Aitken, 1999). Os materiais arqueológicos podem registrar a direção (declinação e inclinação) e/ou a intensidade do campo geomagnético. Os materiais feitos de argila e que sofreram aquecimento (como por exemplo, tijolos, telhas, cerâmicas, fornos, utensílios cerâmicos) adquirem uma magnetização termoremanente (MTR) após o resfriamento. Desse modo, eles registram a intensidade e a direção do campo. Os materiais que não sofreram aquecimento tais como pinturas rupestres, sedimentos e cimentos, podem adquirir uma magnetização remanente deposicional (MRD) no momento da sedimentação ou secagem, registrando somente a direção do CMT. Procedimentos experimentais classicamente utilizados em 
paleomagnetismo ou em estudos de paleointensidade permitem determinar os elementos do campo geomagnético nos materiais arqueológicos. A partir dos dados direcionais e/ou de intensidade obtidos em materiais de idade desconhecida, pode-se obter a sua idade pela comparação com valores de referência para a região do globo onde eles foram confeccionados. O sucesso na obtenção de uma idade arqueomagnética depende tanto da qualidade dos dados magnéticos obtidos nos materiais arqueológicos, quanto da qualidade dos dados de referência. A partir dos erros da curva de referência, que envolve os erros dos elementos geomagnéticos e de idades, e dos erros experimentais nos resultados do material de idade desconhecida, calcula-se a probabilidade de que ambos apresentem o mesmo valor. A idade e o erro respectivo serão dados pelo intervalo de confiança do ajuste de maior probabilidade entre ambos os registros (e.g. Le Goff et al., 2002).

$\mathrm{O}$ artigo intitulado "Arqueomagnetismo e datação arqueomagnética: princípios e métodos”, por G. A. Hartmann, M. C. Afonso e R. I. F. Trindade, teve por objetivo principal apresentar os aspectos gerais da técnica de datação arqueomagnética para pesquisadores que trabalham com arqueologia, arqueometria, arquitetura e história. $\mathrm{Na}$ primeira parte do trabalho é feita uma breve introdução sobre o campo geomagnético e os principais aspectos da variação secular em escalas de centenas a poucos milhares de anos. Em seguida são apresentados os princípios de aquisição da magnetização remanente em materiais arqueológicos. $\mathrm{Na}$ terceira parte são apresentados os métodos experimentais utilizados em campo e no laboratório, mostrando como são feitas as amostragens nos sítios arqueológicos, as diferentes técnicas de preparação dos espécimes, os procedimentos de desmagnetização e os métodos de determinação da direção e da intensidade do campo geomagnético. A quarta parte apresenta as bases da datação arqueomagnética e mostra um exemplo de aplicação da técnica em um sítio arqueológico da França. Por fim, as considerações finais tratam das potencialidades e perspectivas de utilização da técnica em diferentes regiões do Brasil e da América do Sul. 
Artigo:

“Arqueomagnetismo e datação arqueomagnética: princípios e métodos"

G.A. Hartmann, M.C. Afonso e R.I.F. Trindade

Revista do Museu de Arqueologia e Etnologia, 17, 445-459, 2007. 


\title{
Arqueomagnetismo e datação arqueomagnética: princípios e métodos
}

\author{
Gelvam A. Hartmann* \\ Marisa C. Afonso ** \\ Ricardo I. F. Trindade*
}

\begin{abstract}
HARTMANN, G.A.; AFONSO, M.C.; TRINDADE, R.I.F. Arqueomagnetismo e datação arqueomagnética: princípios e métodos. Revista do Museu de Arqueologia e Etnologia, São Paulo, 17: 445-459, 2007.
\end{abstract}

Resumo: O campo magnético da Terra oscila em várias escalas de tempo tanto em direção quanto em intensidade. As oscilações na escala de tempo arqueológico $\left(1,7 \mathrm{X} 10^{3}\right.$ a $1 \mathrm{X} 10^{4}$ anos) são de origem interna (no núcleo externo, líquido e condutor), têm abrangência regional $\left(\sim 200.000 \mathrm{~km}^{2}\right)$ e correspondem à parte das variações seculares do campo geomagnético. $\mathrm{O}$ estudo dessas variações em diferentes partes do globo permite construir curvas de referência. Quando bem conhecidas, essas curvas podem ser utilizadas na datação arqueomagnética, que consiste na comparação de um dado arqueomagnético obtido em um artefato ou estrutura arqueológica com a curva de referência para a região em estudo. Neste trabalho são apresentados os princípios do arqueomagnetismo, as formas como o campo é registrado em material arqueológico, as técnicas para obtenção de dados arqueomagnéticos e os métodos utilizados na datação arqueomagnética. Além disso, são apresentadas as perspectivas para o arqueomagnetismo no Brasil e a aplicação desta técnica de datação na porção meridional da América do Sul.

Palavras-chave: Artefatos cerâmicos - Estruturas de combustão - Pinturas rupestres - Arqueomagnetismo - Datação arqueomagnética.

\section{Introdução}

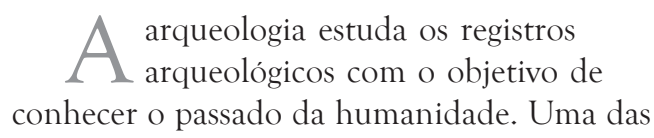

$\left({ }^{*}\right)$ Departamento de Geofísica, Instituto de Astronomia, Geofísica e Ciências Atmosféricas, Universidade de São Paulo. G.A.H. (gelvam@iag.usp.br); R.I.F.T. (rtrindad@iag.usp.br) $\left.{ }^{* *}\right)$ Museu de Arqueologia e Etnologia, Universidade de São Paulo. (marisa@br2001.com.br) informações mais importantes para este tipo de estudo é a idade em que determinados eventos ocorreram. Para isso, existem dois tipos de datação: a datação relativa e a datação absoluta. $\mathrm{Na}$ datação relativa, os artefatos, fósseis e sítios são relacionados a uma escala temporal que é baseada nas correlações estratigráficas, nos processos estilísticos ou na seqüência evolucionária dos indivíduos em estudo. Além disso, a cronologia pré-histórica humana pode ser balizada pelo registro de eventos geológicos recentes (Período Quaternário), como varia- 
ções climáticas, que por sua vez podem ser inferidas e servir de marcadores temporais. A datação absoluta é o processo que determina uma idade específica para um sítio ou artefato arqueológico. A datação absoluta utiliza-se de propriedades físicas ou químicas dos materiais em estudo para definir um ponto ou intervalo no tempo. A determinação do intervalo de tempo em que os processos físicos ocorreram indica quando os artefatos ou fósseis de interesse foram produzidos ou abandonados. Em geral, as técnicas de datação absoluta se utilizam de curvas de calibração, que dependem da região do globo em que os vestígios foram submetidos aos processos físicos, como, por exemplo, a datação por $\mathrm{C}^{14}$, por termoluminescência e por dendrocronologia. Outra técnica de datação que utiliza curvas de calibração é o arqueomagnetismo, no qual as variações de direção (declinação e inclinação) e intensidade do campo magnético da Terra no passado arqueológico e geológico servem como marcos temporais para a datação de artefatos e estruturas arqueológicas.

O campo magnético da Terra é definido, em cada ponto, a partir de sua declinação $(D$, ângulo do vetor campo magnético com relação ao norte), inclinação ( $I$, ângulo do vetor campo magnético com relação ao plano horizontal) e intensidade $(H$, módulo do vetor campo magnético). O campo magnético da Terra é bastante complexo e apresenta uma grande variabilidade, em escalas de tempo que vão de milisegundos a milhões, ou mesmo bilhões de anos (e.g., Merrill et al. 1998). As variações de curto período decorrem de flutuações no fluxo de correntes na ionosfera e magnetosfera, da variação diurna e de tempestades magnéticas. Estas variações são detectadas a partir de dados de observatórios magnéticos, ativos desde meados do século XIX e, mais recentemente, por dados de satélites (e.g., MAGSAT, OERSTED e CHAMP). As variações mais lentas, por outro lado, são decorrentes essencialmente da atividade interna do planeta, pela movimentação do fluido condutor no núcleo externo da Terra. Estas variações são chamadas de "variação secular" do campo magnético da Terra, que atuam na escala de anos a milhares de anos. A Figura 1 exemplifica como a declinação do campo magnético da Terra varia no tempo e no espaço. As variações de longo período compreendem as excursões e também as reversões do campo. Durante as reversões, ocorre uma inversão entre o norte e o sul magnético, isto é, a declinação do campo varia de $180^{\circ}$. As excursões correspondem a mudanças importantes na declinação, mas que não resultam em uma inversão completa. Esses fenômenos têm duração de aproximadamente 5.000 anos e podem apresentar uma periodicidade de dezenas de milhares de anos até dezenas de milhões de anos. Nessas escalas de tempo, diversas bases de dados, advindas dos observatórios geomagnéticos e de dados obtidos em materiais arqueológicos e em rochas, têm fornecido informações importantes quanto às variações direcionais do campo e, em menor grau, sobre as variações na intensidade do campo que as acompanham. Neste contexto, a porção Sul do globo contribui com menos de $5 \%$ dos dados da base mundial, sendo que somente $1 \%$ dos dados provém da América do Sul (Perrin e Schnepp 2004).

O estudo das variações temporais do campo magnético da Terra depende da base de dados utilizada. As variações na escala temporal de $1 \times 10^{\circ}$ a $5 \times 10^{2}$ anos (no máximo) são conhecidas como 'variações do campo no período histórico', variações da ordem de $1,7 \times 10^{3}$ a $1 \times 10^{4}$ anos são conhecidas como 'variações arqueomagnéticas' e variações da ordem de $7,8 \times 10^{5}$ e $5 \times 10^{6}$ anos são conhecidas como 'variações paleomagnéticas' (Carlut et al. 1999). Atualmente, dados arqueomagnéticos preenchem uma lacuna importante que existe entre os campos histórico e paleomagnético.

$\mathrm{O}$ arqueomagnetismo é o estudo do campo magnético da Terra em escalas de tempo arqueológico. O conhecimento dessas variações em uma dada região pode ser utilizado como uma ferramenta de datação. A chamada "datação arqueomagnética" é uma técnica de datação baseada em dois fenômenos físicos: a variação secular do campo magnético da Terra para uma determinada região do globo e a capacidade de certos materiais arqueológicos registrarem uma magnetização remanente estável quando expostos ao campo magnético 


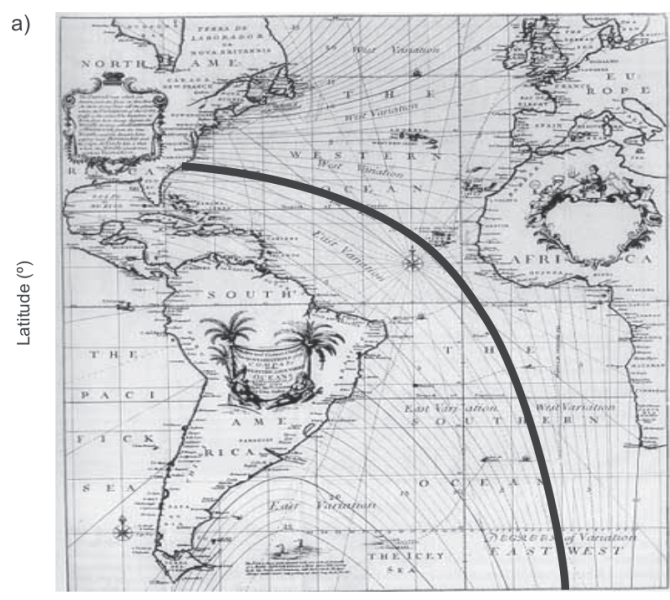

Longitude $\left({ }^{\circ}\right)$

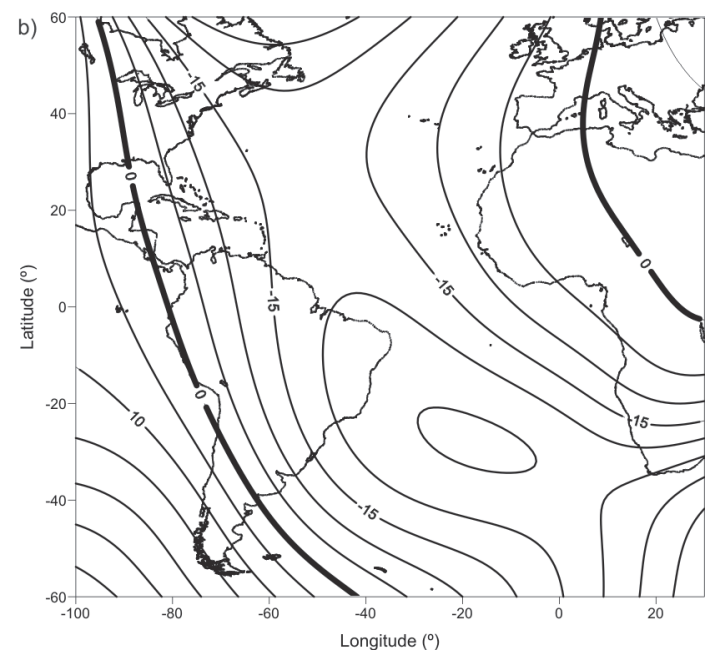

Fig. 1. Mapas de declinação magnética. Em (a) o mapa com linhas de mesma declinação construído para o ano 1700 AD por Halley (modificado de Courtillot e LeMöuel 2007). Em (b) o mapa de 2005 obtido a partir do modelo do International Geomagnetic Reference Field. Observe que em 305 anos a linha que indica declinação zero (linha grossa em ambos os mapas) migrou mais de $5.000 \mathrm{~km}$ para oeste.

da Terra no momento da produção ou descarte (Aitken 1999). O princípio desta datação reside na comparação de um dado de direção ou intensidade obtido em materiais arqueológicos de idade desconhecida, com o valor de direção e/ou intensidade da curva de variação do campo magnético da Terra para a região de estudo, conhecida também como "curva de referência” (e.g., Le Goff et al. 2002). Neste trabalho, serão apresentados as formas de registro do campo magnético terrestre em materiais arqueológicos e os métodos para aquisição de dados arqueomagnéticos. Por fim, será apresentada a técnica para determinação de idades arqueomagnéticas, aplicada atualmente com sucesso na Europa, e as perspectivas do arqueomagnetismo no Brasil.

\section{Aquisição de magnetização em materiais arqueológicos e geológicos}

Os artefatos e estruturas arqueológicas, as rochas e os sedimentos, contêm pequenas frações de minerais magnéticos (e.g., magnetita, hematita) que têm a capacidade de reter uma magnetização remanente. Essa magnetização pode ser registrada de duas formas (Figura 2): (i) durante o aquecimento e resfriamento de um material cerâmico ou estrutura de combustão, ou (ii) durante a deposição de partículas magnéticas em pinturas, cimentos ou sedimentos. A remanência magnética associada com o evento arqueológico estudado é conhecida como magnetização remanente primária. A magnetização remanente natural (MRN) do material consiste de uma magnetização primária somada a uma ou mais magnetizações secundárias. As magnetizações secundárias indicam eventos que muitas vezes não têm relação com o evento original de formação ou produção do material estudado (e.g., Butler 1998).

Determinados tipos de material arqueológico podem preservar tanto o registro de direção quanto a intensidade do campo. Eles correspondem aos materiais que sofreram aquecimento, como por exemplo, cerâmicas, tijolos, telhas, utensílios cerâmicos, argila cozida e estruturas de combustão (fornos para tijolos, fornalhas, fornos domésticos, pisos de lareiras e pisos cerâmicos). Após o aquecimento, os materiais resfriam abaixo de uma temperatura crítica (temperatura de bloqueio) e então os minerais magnéticos registram uma magnetização que é paralela e proporcional ao 

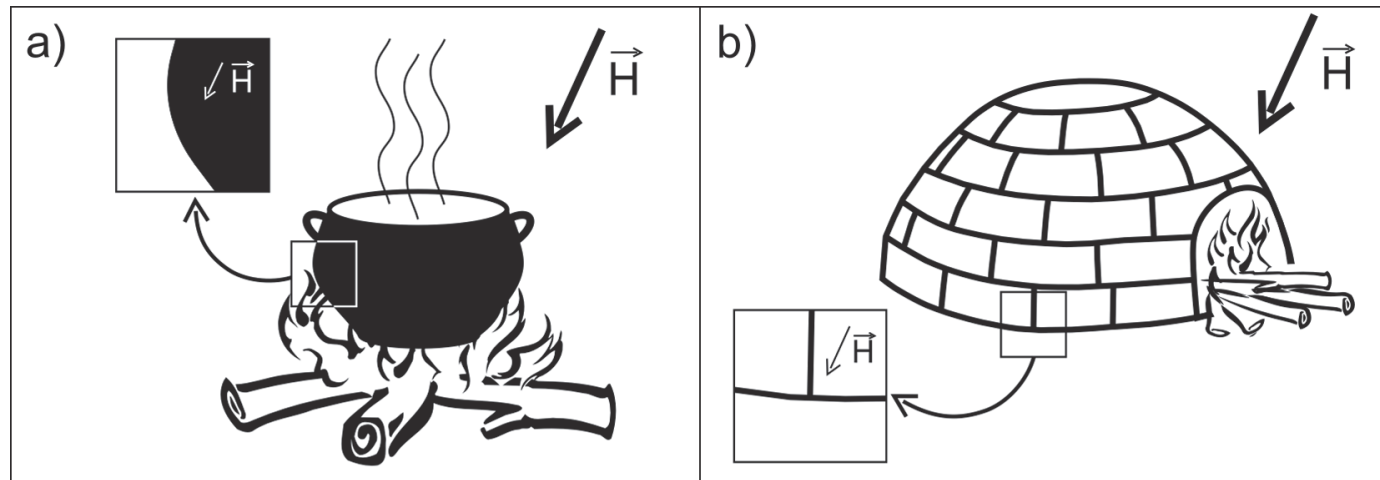

c)

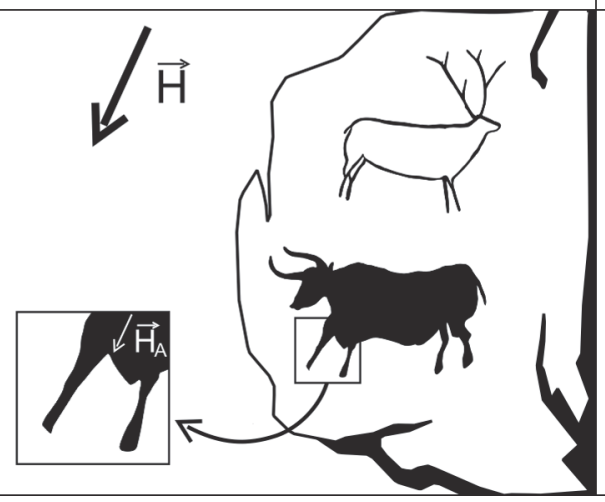

d)

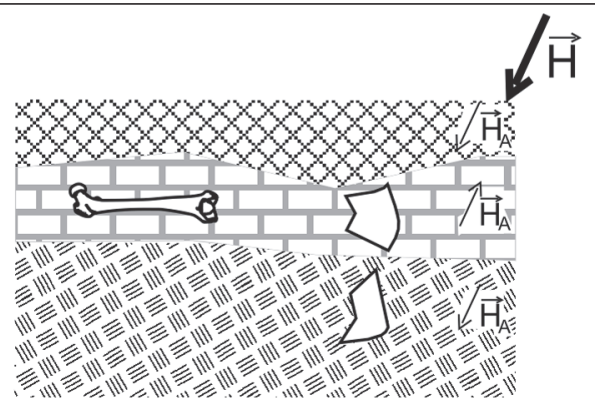

Fig. 2. Processos de aquisição de magnetização remanente em contextos arqueológicos. Em (a) a magnetização é adquirida pelo aquecimento de um utensílio doméstico. Em (b) a magnetização é adquirida pelo aquecimento em um forno cerâmico. Nesses dois exemplos os materiais adquirem uma magnetização térmica. No caso do forno (estrutura arqueológica), além da intensidade do campo $(H)$, o material pode ser utilizado para determinar a orientação do campo magnético (D e I). Em (c) a magnetização é registrada durante a secagem da tinta em uma pintura rupestre. A orientação do campo magnético no momento em que a pintura foi efetuada fica registrada pelas partículas magnéticas contidas no pigmento. Em (d) observa-se um sítio arqueológico com diferentes níveis estratigráficos. Nota-se que as direções do campo antigo $\left(H_{A}\right)$ são diferentes para os diferentes níveis estratigráficos. Pode-se então correlacionar estas variações com o material arqueológico encontrado nos estratos. Tanto em (c) quanto em (d) apenas a informação da direção do campo antigo pode ser recuperada.

campo magnético da Terra da época. Essa magnetização é chamada de magnetização remanente térmica (e.g., Dunlop e Özdemir 1997). Cada vez que o material é reaquecido, ele adquire uma nova magnetização térmica, de forma que o evento registrado no material é aquele do último aquecimento/resfriamento. Assim, telhas, tijolos e cerâmicas que não sofreram reaquecimento preservam a magnetização térmica adquirida no momento da produção. Outros materiais, como as estruturas de combustão, registram a magnetização térmica do último aquecimento/resfriamento, que em geral está associada ao abandono. Do mesmo modo, as lavas de erupções vulcânicas históricas adquirem uma magnetização térmica após resfriarem na presença do campo magnético terrestre. Deste modo, uma seqüência de fluxos de lava pode também ser usada para a construção de curvas de referência arqueomagnéticas (Tanguy et al. 2003). Estes materiais fornecem a intensidade do campo magnético da Terra registrada durante o seu último aquecimento. Com as estruturas de combustão pode-se também determinar a declinação e inclinação do campo no momento da última queima se essas estruturas não foram movimentadas posteriormente. Tijolos e telhas podem 
fornecer dados de inclinação magnética caso tenham sido queimados no plano horizontal, o que nem sempre é possível de determinar. As Figuras 2a e 2b ilustram o registro do campo magnético da Terra através dos processos de aquecimento.

Materiais que não foram submetidos a temperaturas elevadas também têm a capacidade de registrar informações sobre o campo magnético da Terra. Pinturas rupestres e cimentos podem adquirir magnetização estável. Nesses materiais, as partículas magnéticas rotacionam e alinham-se com o campo magnético da Terra, fixando-se nesta posição quando a pintura ou o cimento secam. Esta magnetização é conhecida como magnetização remanente pictórica (Chiari e Lanza 1997, 1999; Zanella et al. 2000; Goguitchaichvili et al. 2004). Neste caso, o evento que corresponde ao registro magnético é a aplicação da pintura ou do cimento. Os sedimentos depositados em fundos de lagos e cavernas podem adquirir uma magnetização deposicional, em um mecanismo muito semelhante ao observado nas pinturas murais e nas pinturas rupestres. Esses materiais fornecem um registro das variações direcionais do campo magnético da Terra e podem, eventualmente, ser utilizados para construir curvas de variação relativa da intensidade do campo (e.g., Valet 2003). As Figuras $2 \mathrm{c}$ e $2 \mathrm{~d}$ mostram como esses processos ocorrem em um sítio arqueológico.

Uma parte da magnetização primária, adquirida durante o resfriamento de artefatos arqueológicos ou de rochas, decai com o tempo mesmo na presença de campos muito fracos como no caso do campo magnético da Terra. Ao decair, esta parte do registro magnético tende a se alinhar com o campo magnético atual gerando uma magnetização viscosa.

Outros processos que alteram a magnetização original envolvem a exposição dos materiais a fortes campos magnéticos ou fortes correntes elétricas, como na presença de raios. Nesse caso as amostras adquirem uma magnetização remanente isotérmica. Magnetizações secundárias podem também ser adquiridas por transformações químicas resultantes da alteração dos minerais magnéticos durante o soterramento.
Em todos esses casos, os procedimentos de desmagnetizações sucessivas permitem eliminar a contribuição secundária e isolar a magnetização primária em rochas e artefatos arqueológicos.

\section{Métodos para determinação da direção e intensidade do campo arqueomagnético}

As variações do campo magnético da Terra tanto em intensidade quanto em direção são obtidas a partir do registro magnético em rochas e artefatos arqueológicos. A magnetização remanente é paralela e proporcional ao campo magnético na época de produção ou abandono do objeto arqueológico em estudo. Embora se baseiem em princípios semelhantes, as técnicas para obtenção de dados de intensidade e dados direcionais são diferentes. Abaixo apresentamos os procedimentos para coleta, preparação, medida e análise das amostras.

\subsection{Coleta e preparação de amostras}

A amostragem depende do tipo de registro que se pretende obter, além do tipo e quantidade de material necessário para o tratamento de laboratório. Para a determinação somente da intensidade magnética as amostras não precisam ser orientadas, como é o caso de fragmentos cerâmicos, mas deve-se conhecer o seu local de origem. Por outro lado, para obtenção de dados direcionais, as amostras precisam ser orientadas na mesma posição na qual se deu a sua produção ou o abandono, no caso de estruturas arqueológicas. Para alguns materiais cuja posição de produção pode ser inferida, como telhas e tijolos, podese obter a inclinação do campo magnético terrestre mesmo que esses objetos tenham sido deslocados após a aquisição da magnetização. A orientação das amostras é feita com o auxílio de uma bússola magnética ou de uma bússola solar. Para uso da bússola magnética deve-se atentar para o fato da existência de anomalias magnéticas locais, que podem interferir nas medidas. A orientação deve ser feita em uma das faces da amostra da seguinte forma (Figura 3): inicialmente, utilizando um 
nível, identifica-se uma linha horizontal na face escolhida para orientação; essa linha deve ser marcada com uma seta na amostra; obtémse então, com a bússola, a orientação dessa linha com relação ao norte geográfico; em seguida obtém-se a inclinação da face da amostra na orientação normal à seta.

O vetor magnetização de uma estrutura ou artefato arqueológico é determinado a partir da média de várias medidas. Portanto, num caso ideal deve-se trabalhar com pelo menos dez amostras de um mesmo objeto para obter uma boa estimativa da orientação e intensidade do campo magnético antigo. $\mathrm{O}$ tamanho das amostras depende da homogeneidade do material a ser amostrado, de sua disponibilidade em função de restrições de preservação e de abundância. Nos casos em que não há restrições para a amostragem podem-se coletar blocos com cerca de $10 \times 10 \times 5 \mathrm{~cm}$, que são cortados no laboratório em amostras cúbicas de $1 \times 1 \times 1 \mathrm{~cm}$. Em situações nas quais há maior restrição para a retirada de amostras do sitio, podem-se coletar cilindros com
$2,5 \mathrm{~cm}$ de diâmetro ou cilindros com $1 \mathrm{~cm}$ de diâmetro, utilizando-se uma broca diamantada. Nos casos onde há muito pouco material disponível para amostragem, coletam-se fragmentos menores do que $1 \mathrm{~cm}$ de diâmetro que são "encapsulados" em alumina ou sal desidratado e moldados na forma de cubos ou cilindros. Amostras de pinturas rupestres e murais são orientadas na face da pintura (procedimento semelhante ao da Figura 3) e extraídas com o auxílio de fita dupla-face.

\section{$3.2 \mathrm{O}$ processo de desmagnetizaç̃es sucessivas}

Para determinação de um valor de intensidade ou direção de magnetização que represente a orientação do campo antigo, deve-se separar a magnetização primária das magnetizações secundárias. Para separação destas componentes utiliza-se a técnica desmagnetização por passos sucessivos de campos alternados ou temperatura (e.g., Butler 1998). Essas técnicas se baseiam no fato de que os grãos magnéticos a)

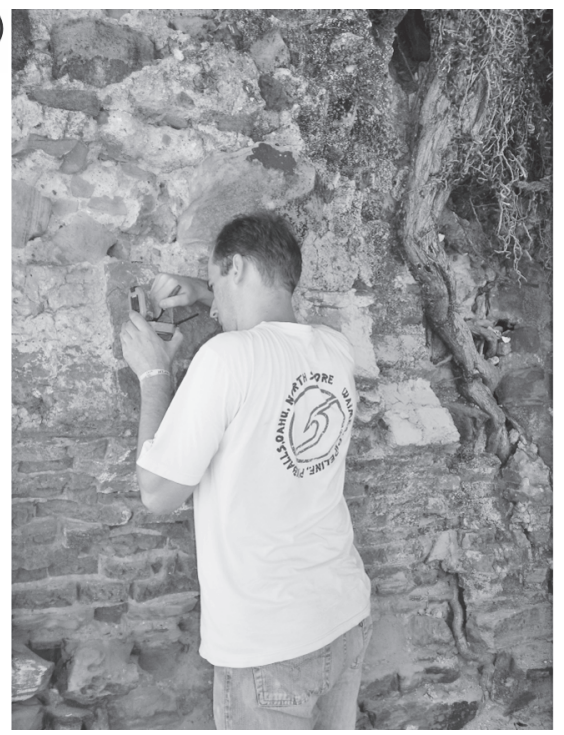

b)

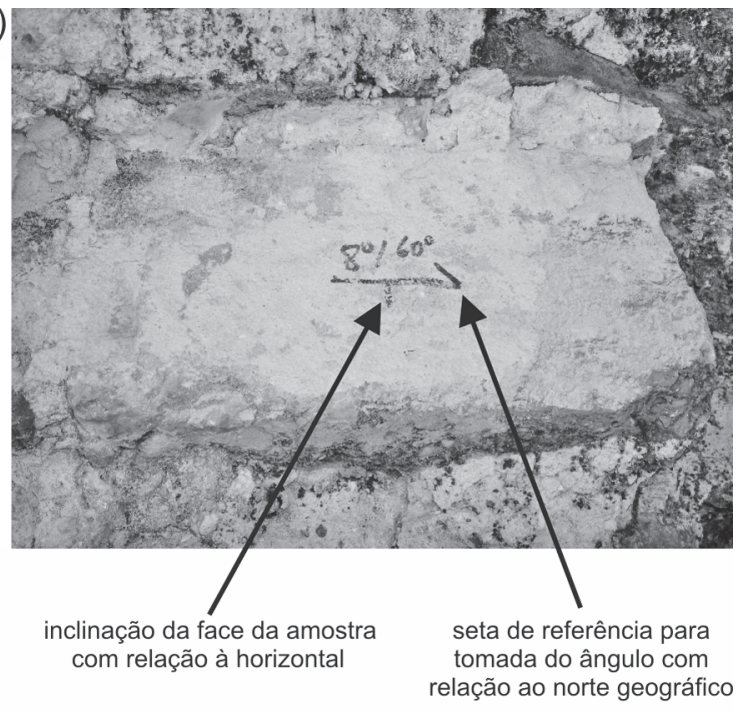

Fig. 3. Coleta e orientação de amostras arqueomagnéticas. Em (a), marcação da orientação de um tijolo de um forno arqueológico em Itaparica (BA) com auxílio de uma bússola magnética. Em (b) estão indicadas as marcações de orientação. A seta corresponde a uma linha horizontal e a linha menor, perpendicular à seta, indica a direção de máxima inclinação da face que foi orientada. Determina-se o ângulo entre a seta e o norte (azimute) e o ângulo entre a face amostrada e a horizontal (mergulho do plano). Ambos os ângulos são marcados na própria amostra. A orientação é feita antes da retirada do material do local. 
mais estáveis, que guardam a magnetização primária, apresentam valores de coercividade e temperaturas de bloqueio mais elevadas. Portanto, ao desmagnetizar as frações de baixa coercividade ou de baixa temperatura de bloqueio estamos "limpando" o sinal das componentes de magnetização secundárias. $\mathrm{Na}$ desmagnetização por campos alternados a amostra é submetida a campos magnéticos alternados cada vez mais elevados. Esses campos variam desde um valor de pico até zero. Assim, elimina-se a magnetização dos grãos com coercividade mais baixa do que o valor de pico do campo alternado. Repetindo-se esse procedimento até campos da ordem de $100 \mathrm{mT}$ (militesla) pode-se isolar o sinal dos grãos com alta coercividade. $\mathrm{Na}$ desmagnetização térmica, as amostras são submetidas ao aquecimento até uma determinada temperatura e resfriadas em campo magnético nulo. Durante esse processo os grãos com temperatura de bloqueio inferior à temperatura do passo de aquecimento perdem sua magnetização original. Este processo é repetido até temperaturas da ordem de $700^{\circ} \mathrm{C}$. Em geral, as componentes secundárias são removidas em torno de 5 a $20 \mathrm{mT}$ para a técnica utilizando campos alternados ou $200^{\circ} \mathrm{C}$ a $450^{\circ} \mathrm{C}$ para a técnica de aquecimentos sucessivos.

\subsection{Determinação da direção do campo magnético}

A direção da magnetização primária em cada amostra é obtida por meio de gráficos vetoriais ortogonais, conforme ilustra a Figura 4a. Neste exemplo a magnetização secundária, indicada pela mudança de orientação nos diagramas, é separada logo nos primeiros passos de desmagnetização. A análise por componentes principais é usada para ajustar o segmento linear da curva que corresponde à magnetização primária (Kirschvink 1980). Assim, a direção de melhor ajuste e o erro correspondente são então calculados para esta componente. Outra forma de visualizar os mesmos dados da Figura 4a é através da projeção estereográfica, como mostra a Figura 4b. Após as direções serem individualmente determinadas em todas as amostras de um determinado sítio, a direção média pode ser calculada pela soma vetorial das direções individuais. Inicialmente são calculadas as médias das amostras em estruturas ou fragmentos. Em seguida, são calculadas as médias das estruturas ou fragmentos do mesmo sítio. Utiliza-se no cálculo da direção média a estatística desenvolvida por Fischer (1953) que permite também estimar a precisão e confiabilidade da estimativa a partir dos parâmetros á (cone de erro) e o $k$ (parâmetro de concentração). Valores altos de $k$ e baixos de á ${ }_{95}$ indicam dados direcionais confiáveis.

\subsection{Determinação da intensidade do campo magnético}

A paleointensidade do campo magnético da Terra é obtida pelo método desenvolvido por Thellier e Thellier (1959) para estudos de cerâmicas arqueológicas, podendo ser aplicado também a qualquer material cuja magnetização tenha origem em um aquecimento. Atualmente, os experimentos de paleointensidade usam versões modificadas do método ThellierThellier original. Entre as mais conhecidas e usadas estão o método Coe (1967) e o método Aitken et al. (1988). Experimentalmente, a determinação da intensidade é muito mais complicada do que a determinação da orientação do campo magnético.

A intensidade da magnetização térmica adquirida por uma rocha ou artefato cerâmico durante o resfriamento é proporcional à intensidade do campo indutor antigo desde que este seja suficientemente baixo (da ordem de algumas dezenas de microteslas). $\mathrm{O}$ método se baseia na comparação da magnetização natural $M_{T}$ com uma magnetização $M_{L}$ de laboratório produzida em um campo conhecido $H_{L}$ (campo de laboratório). O campo antigo $H_{A}$ pode então ser determinado segundo,

$$
H_{A}=H_{L} \frac{M_{T}}{M_{L}}
$$


a)

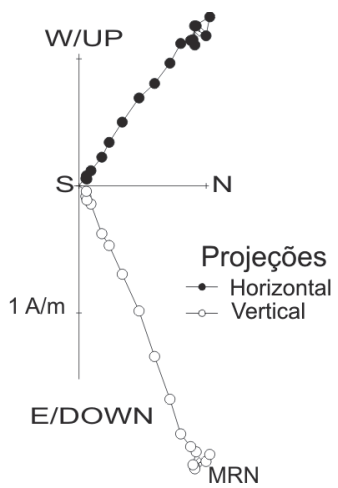

c)

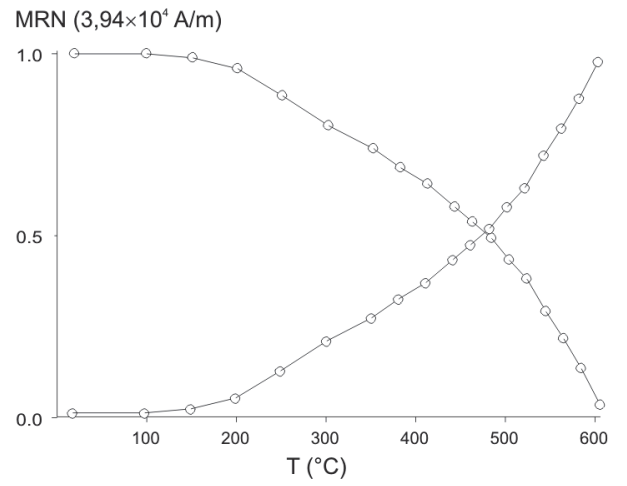

b)

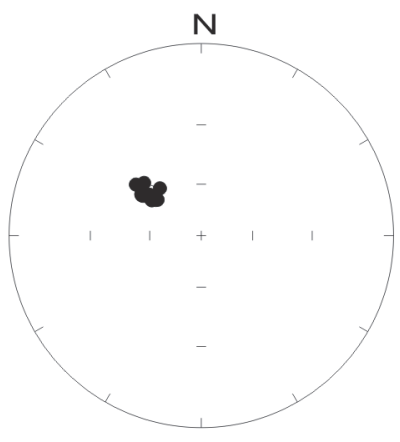

d)

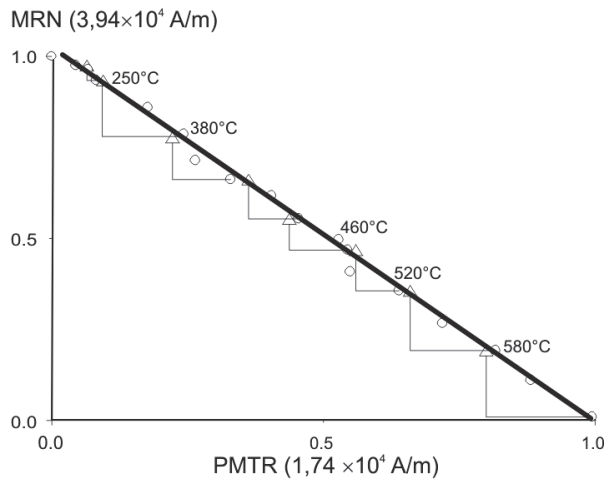

Fig. 4. Representação dos dados de direção e intensidade do campo magnético terrestre. A Figura (a) é um exemplo que mostra as projeções ortogonais obtidas para uma amostra. As duas curvas correspondem à projeção do vetor magnetização nos planos horizontal (símbolos cheios) e vertical (símbolos vazados) após cada etapa de desmagnetização. A Figura (b) mostra os mesmos dados apresentados em (a), mas em projeção estereográfica. Nesse diagrama a orientação do vetor após cada etapa de desmagnetização é representada como um ponto na rede estereográfica equi-área. A partir desses diagramas são obtidos os dados direcionais ( $D$ e $I$ ) de uma amostra. A Figura (c) representa um experimento do tipo Thellier-Thellier. Neste experimento, ao mesmo tempo em que a magnetização natural do objeto é removida, uma magnetização térmica de laboratório é implantada com um campo magnético de intensidade conhecida. O diagrama mostra a evolução da magnetização removida e da magnetização artificial adquirida. A Figura (d) corresponde a um diagrama de Arai para os mesmos dados de (c). Nesse diagrama representa-se no eixo vertical a magnetização removida e no eixo horizontal a magnetização adquirida em laboratório. $\mathrm{O}$ valor da intensidade do campo registrado na amostra é dado pelo ajuste da reta por mínimos quadrados.

De acordo com a equação (01), a razão entre a magnetização natural e a magnetização de laboratório deve corresponder a uma reta, cuja inclinação é utilizada para determinação de $H_{A}$.

Há várias formas possíveis de substituir progressivamente a magnetização natural por uma magnetização de laboratório. A mais utilizada atualmente é aquela desenvolvida por Coe (1967) e Aitken et al. (1988). Nesses proto- colos de medida a magnetização natural é progressivamente desmagnetizada num processo semelhante à desmagnetização térmica descrita anteriormente. Mas logo após cada passo de desmagnetização a amostra adquire uma magnetização de laboratório na mesma temperatura e com campo conhecido. Os duplos aquecimentos são repetidos em temperaturas cada vez mais elevadas até a 
completa substituição da magnetização natural pela magnetização de laboratório. Os resultados são apresentados na forma de gráficos da magnetização remanente natural (MRN) restante e da magnetização de laboratório (MTR) adquirida contra a temperatura (Figura 4c). Outra forma de apresentação dos dados (e a mais utilizada) é através do gráfico de Arai (Nagata et al. 1963), onde a MRN é representada no eixo vertical e a MTR é representada no eixo horizontal. A inclinação da reta neste diagrama corresponde à razão $-H_{A} / H_{L}$ e permite determinar a paleointensidade (Figura 4d).

Durante as medidas, alguns passos de temperatura podem ser repetidos para determinar se há variação na capacidade de registrar remanência das amostras. Estes passos são chamados de "checagem das magnetizações térmicas parciais" ( $p$ MTR checks). A diferença entre as duas magnetizações, em uma dada temperatura, indica uma mudança nas condições de aquisição de remanência térmica e, portanto, uma estimativa falsa do paleocampo. Além dos pMTR checks, são realizados também testes para determinação da anisotropia magnética e da taxa de resfriamento das amostras. Estes testes são muito importantes para determinação da intensidade em cerâmicas, como já pôde ser observado experimentalmente (e.g., Chauvin et al. 2000; Genevey e Gallet 2002).

\section{Datação arqueomagnética}

A datação arqueomagnética é realizada através da comparação de uma curva de referência para a variação secular com os dados arqueomagnéticos obtidos em artefatos de idade desconhecida (e.g., Aitken 1999). As curvas de referência revelam as variações em direção e intensidade do campo magnético da Terra. Os dados compilados para uma dada região são arbitrariamente corrigidos para um local de referência através da correção para o pólo geomagnético virtual (Daly e LeGoff 1996). Os dados de declinação e inclinação magnéticas para um determinado local são usados no cálculo da posição do pólo geomagnético virtual, que é então utilizado para calcular as declinações e inclinações esperadas para o local de referência. Este tipo de abordagem é válido apenas para uma determinada região do planeta. Atualmente, as curvas de referência estão disponíveis para os últimos 2.000 a 3.000 anos em várias regiões do planeta, incluindo a América do Norte (Stenberg 1989; Labelle e Eighmy 1997; Yu et al. 2000), América Central (Morales et al. 2001; Bowles et al. 2002; Soler-Arechalde et al. 2006), Leste da Ásia (Cong e Wei 1989), Leste e Oeste da Europa (Bucur 1994; Kovacheva 1997; Kovacheva et al. 1998; Chauvin et al. 2000; Genevey e Gallet 2002; Genevey et al. 2003; Kovacheva et al. 2004; Schnepp e Lanos 2005; Gómez-Paccard et al. 2006). Existem também compilações globais, como aquelas de Valet (2003); Perrin e Schnepp (2004) e Korte et al. (2005). No entanto, a área em que uma dada curva de referência pode ser aplicada à datação arqueomagnética é da ordem de $200.000 \mathrm{~km}^{2}$, visto que há sutis diferenças de variação do campo magnético da Terra para locais que são um pouco distantes entre si. Um exemplo deste tipo de variação pode ser observado nas Figuras $5 \mathrm{a}$ e 5b, que mostram uma comparação das curvas arqueomagnéticas para os últimos 3.000 anos, obtidas para a Ibéria, França e Alemanha (Gómez-Paccard et al. 2006). Neste exemplo observam-se as pequenas diferenças de declinação e inclinação quando se comparam locais diferentes, mesmo quando corrigidos para um local de referência. A Figura 5c mostra uma compilação dos dados de intensidade magnética obtidos para os últimos 3.000 anos em artefatos arqueológicos da França. Note que os dados de intensidade variam mais rapidamente do que os dados direcionais. Além de dados arqueomagnéticos, as curvas de referência podem ser construídas também com dados de observatórios, dados históricos (obtidos a partir de cartas de navegação) ou ainda dados paleomagnéticos. No entanto, a datação em amostras paleomagnéticas é feita por métodos radiométricos e, portanto, a precisão é diferente dos métodos utilizados para datação de materiais arqueológicos (Tanguy et al. 2003; McIntosh e Catanzariti 
2006). Além da diferença da precisão entre diferentes métodos de datação, um outro problema associado à construção das curvas de referência é a distribuição desigual dos dados tanto no tempo quanto no espaço. Alguns métodos estatísticos são utilizados para minimizar estes problemas, incluindo estatística bivariada com janelas temporais móveis (LeGoff et al. 2002) ou estatística Bayesiana, na qual o empilhamento estratigráfico local pode ser considerado (Lanos et al. 2005).

A determinação de uma idade arqueomagnética pressupõe que os dados magnéticos obtidos em um artefato ou estrutura arqueológica apresentem características semelhantes aos dados utilizados na curva de referência. Considerando-se os erros da curva de referência e os erros do dado arqueomagnético, estima-se a probabilidade de que ambos compartilhem o mesmo valor. A idade corresponde ao ponto no qual há maior probabilidade de concordância entre ambos. A Figura 6 mostra uma datação arqueomagnética realizada em um forno cerâmico localizado em uma vila próxima a Paris. Esta datação foi realizada utilizando a curva de referência da França, conforme ilustrado na Figura 5a. A curva de probabilidade, determinada pelo teste de Le Goff et al. (2002), indicou que a idade mais provável para a estrutura é em torno de 1010 \pm 35 AD. Este resultado está em concordância com outros vínculos temporais arqueológicos do sítio estudado. A qualidade da datação arqueomagnética depende: da qualidade da curva de referência (densidade e homogeneidade de dados), das taxas de variação do campo no período de interesse e da qualidade da determinação arqueomagnética nos artefatos ou estruturas que se deseja datar. Em geral as incertezas podem variar de \pm 25 a \pm 200 anos (McIntosh e Catanzariti 2006).

\section{Considerações finais}

As principais características do registro do campo magnético da Terra em materiais arqueológicos, bem como os métodos para aquisição de dados arqueomagnéticos foram descritos, utilizando exemplos para os últimos milhares de anos. Além disso, foram introduzidas as técnicas de análise estatística dos dados usados na datação arqueomagnética, que foi ilustrada com um exemplo de datação na França.

São importantes as formas como o campo magnético da Terra é registrado em materiais arqueológicos e como estas informações são recuperadas, pois indicam o tipo de dado a ser obtido (declinação e/ou inclinação e/ou intensidade). A magnetização pode ser obtida em materiais que sofreram aquecimento e que não foram aquecidos. Em geral, materiais que foram aquecidos em altas temperaturas e que não foram reaquecidos, além de poderem ser amostrados in situ, são os mais adequados para a determinação de dados direcionais e de intensidade. Materiais aquecidos e que não possuem orientação permitem apenas recuperar a intensidade magnética antiga. Materiais que não sofreram aquecimento fornecem apenas dados direcionais.

A datação arqueomagnética é obtida através da comparação de um dado arqueomagnético de idade desconhecida com a curva de referência para uma determinada região do globo. A datação arqueomagnética é, portanto, uma datação relativa, porque há a necessidade de um vínculo a priori (que neste caso é a curva de referência) para posterior comparação de um dado obtido em um artefato arqueológico. A datação arqueomagnética pode ser aplicada para regiões com curvas de referência bem definidas, que por sua vez podem ser construídas com outros tipos de dados, como dados de observatórios, históricos, arqueomagnéticos e paleomagnéticos. As curvas de referência utilizadas para datação arqueomagnética devem apresentar uma boa cobertura temporal e espacial dos dados. A precisão e confiabilidade da datação dependem de vários fatores, entre eles a qualidade da curva de referência e dos dados arqueomagnéticos usados para datação. As incertezas podem variar de \pm 25 a \pm 200 anos.

Os estudos arqueomagnéticos realizados até o momento indicam uma pobre cobertura espacial, principalmente para o hemisfério Sul do planeta. Neste sentido, o Brasil surge 


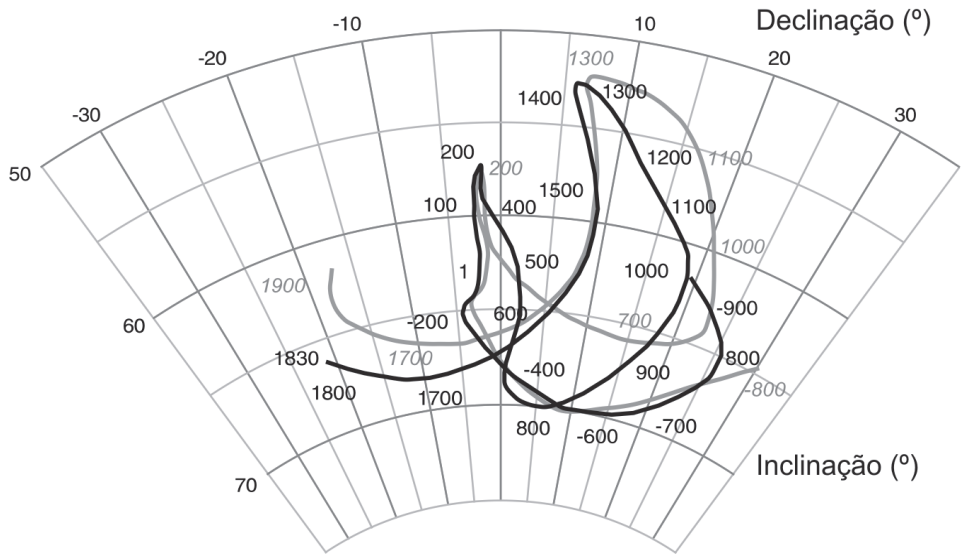

b) Curvas de variação secular para a Ibéria

) e Alemanha

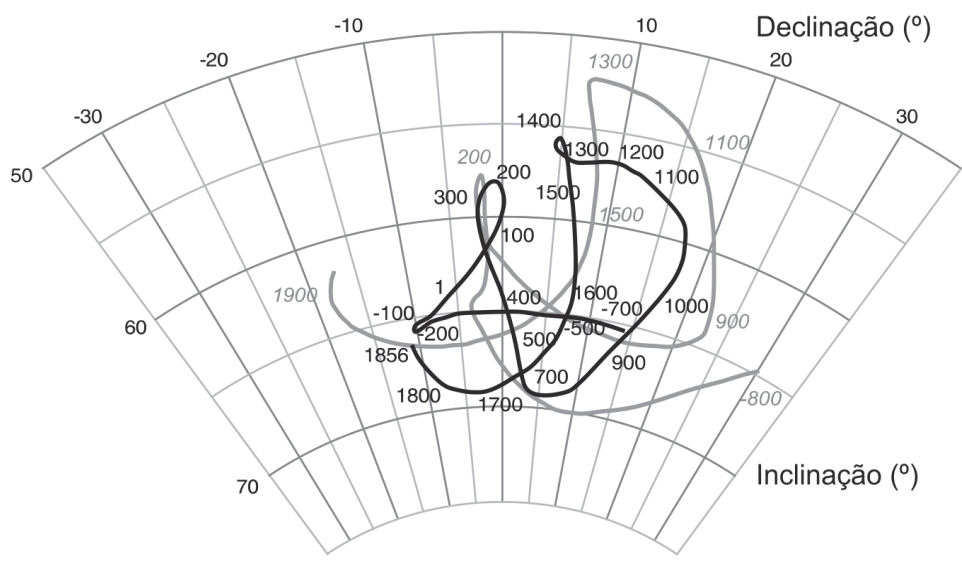

c) Curva de variação de intensidade para a França

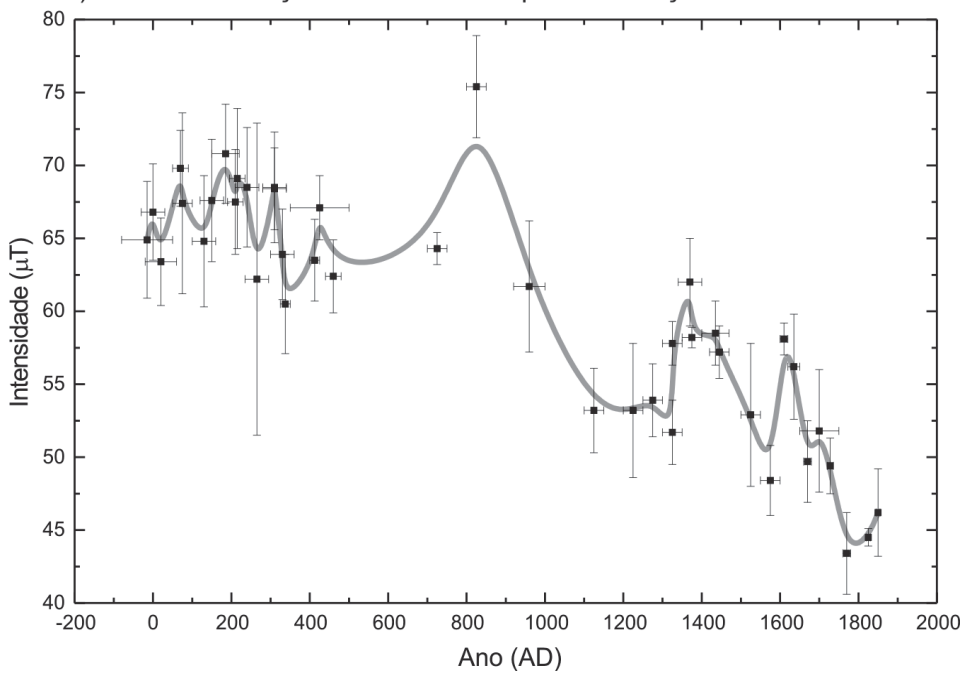

Fig. 5. As Figuras (a) e (b) mostram curvas de variação direcional ( $D$ e $I$ ) entre regiões da Europa. Em (a) as curvas da Ibéria e da França e em (b) as curvas da Ibéria e da Alemanha. Note que as diferenças entre as curvas são mais significativas entre a Ibéria e a Alemanha. Para fins de comparação todas as curvas foram reduzidas para a cidade de Madri. A Figura (c) mostra a variação da intensidade do campo magnético na França nos últimos 3.000 anos obtida a partir de estudos em cerâmicas. (curvas extraídas de GómezPaccard et al. 2006; Chauvin et al. 2000; Genevey e Gallet 2002; Gallet et al. 2005). 


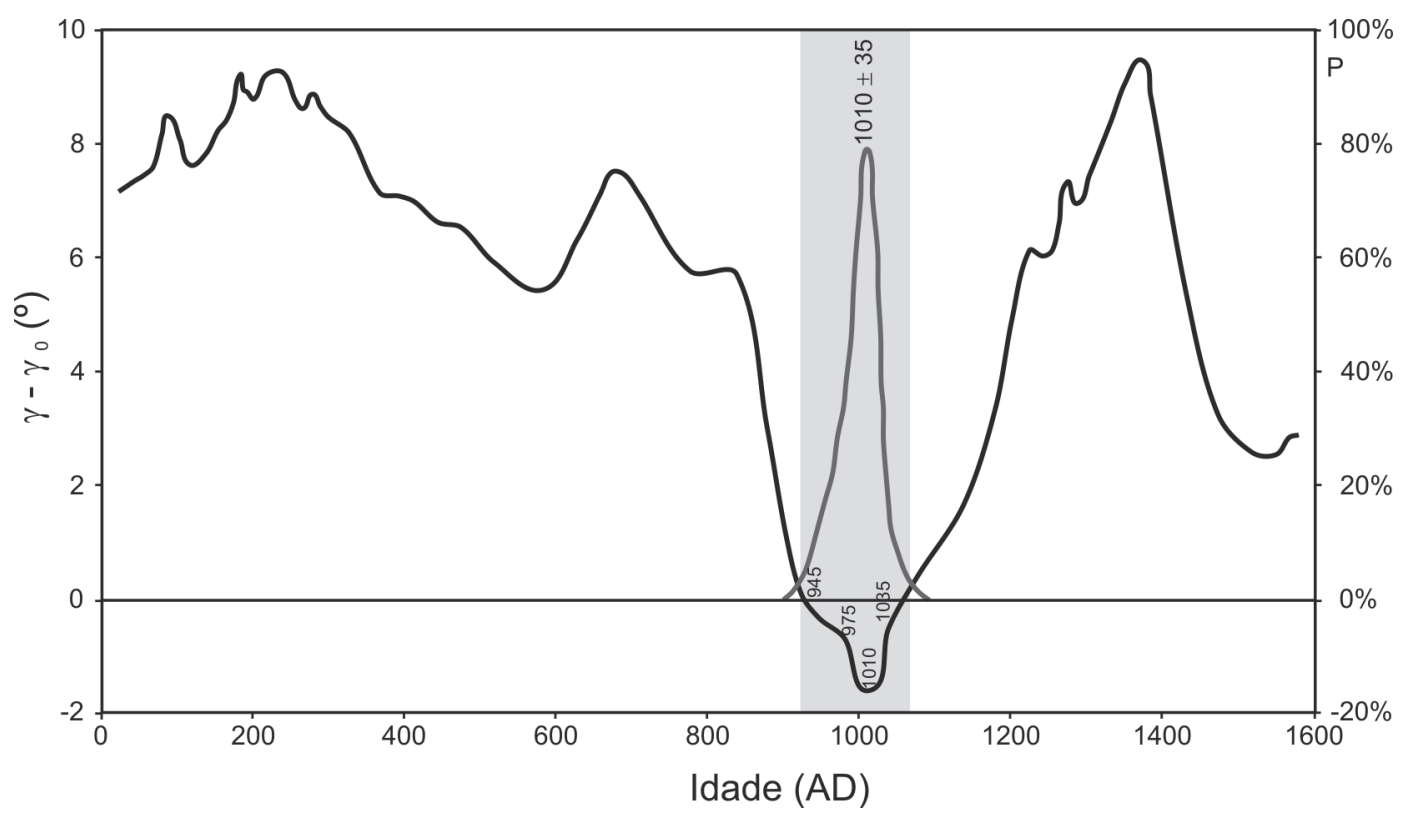

Fig. 6. Exemplo de uma datação arqueomagnética realizada em um forno da França. A datação utilizou a estatística bivariada e indicou um valor de 1010 \$35 AD, que está em concordância com o contexto arqueológico. A curva de referência utilizada para esta datação foi a curva de variação direcional para a França, mostrada na Figura 4a (figura modificada de Le Goff et al. 2002).

como um local importante para estudos de arqueomagnetismo. O projeto de arqueomagnetismo no Brasil vem sendo desenvolvido através de parceria firmada entre os grupos de paleomagnetismo do Instituto de Astronomia, Geofísica e Ciências Atmosféricas (Universidade de São Paulo) e do Institut de Physique du Globe de Paris e com os arqueólogos dos Museus de Arqueologia e Etnologia da Universidade de São Paulo e da Universidade Federal da Bahia. Os primeiros resultados de intensidade magnética obtidos em fragmentos cerâmicos coloniais e pré-coloniais do estado de São Paulo foram apresentados recentemente (Hartmann et al. 2007a, 2007b). Os dados obtidos apontam para a construção de uma curva de referência de boa qualidade para o Sudeste do Brasil. Esse trabalho resultará em breve na construção de uma curva de referência para a porção sul da América do Sul, abrindo a possibilidade de utilização do arqueomagnetismo como uma ferramenta alternativa para datação de artefatos arqueológicos dessa região.

\section{Agradecimentos}

Os autores agradecem ao MAE/USP e ao IAG/USP, pelo apoio institucional, à FAPESP (bolsa de doutorado 05/57782-4) e ao CNPq (bolsas de produtividade e pesquisa), pelo apoio financeiro, e aos Professores José Luiz de Morais (MAE/USP) e Carlos Etchevarne (MAE/UFBA) pelas amostras arqueológicas de projetos por eles coordenados. Lucimara Vianna e Lelis Melo do setor gráfico do IAG/USP foram os responsáveis pela elaboração da Figura 2. 
HARTMANN, G.A.; AFONSO, M.C.; TRINDADE, R.I.F. Archaeomagnetism and archaeomagnetic dating: principles and methods. Revista do Museu de Arqueologia e Etnologia, São Paulo, 17: 445-459, 2007.

\begin{abstract}
The direction and intensity of the Earth's magnetic field oscillates in different time-scales. Variations within $1,7 \mathrm{X} 10^{3}$ to $1 \times 10^{4}$ years are referred to as archaeomagnetic variations. They correspond to a part of the geomagnetic secular variation, have an internal origin (in the conductive fluid outer core), and are coherent over regions of $\sim 200.000 \mathrm{~km}^{2}$. The study of the archaeomagnetic variations in different parts of the globe enables the construction of regional master curves. Well-constrained master curves allow the use of archaeomagnetic variations as a dating tool. The archaeomagnetic dating corresponds to the comparison of an archaeomagnetic data obtained from an archaeological artifact or structure to the master curve for the region of interest. In this paper, we present the basis of archaeomagnetism, the mechanisms by which archaeological artifacts, structures and geological material record the ancient magnetic field, and how the magnetic signal is measured and interpreted, as well as the principles of archaeomagnetic dating. Also discussed are the perspectives for archaeomagnetic studies in Brazil and its application as a dating technique in southern South America.
\end{abstract}

Keywords: Ceramic artifacts - Burnt structures - Mural paintings Archaeomagnetism - Archaeomagnetic dating.

\title{
Referências bibliográficas
}

AITKEN, M.J.

1999 Archaelogical dating using physical phenomena. Rep. Prog. Phys., 62: 1333-1376.

AITKEN, M.J.; ALLSOP, A.L.; BUSSERLL, G.D.; WINTER, M.B.

1988 Determination of the intensity of the Earth's magnetic field during archaeological times: Reability of the Thellier technique. Rev. Geophys., 26: 3-12.

BOWLES J.; GEE J.; HILDEBRAND J.; TAUXE L.

2002 Archaeomagnetic intensity results from California and Ecuador: evaluation of regional data. Phys. Earth Planet. Inter., 203 (3-4): 967-981.

BUCUR, I.

1994 The direction of the terrestrial magnetic field in France, during the last 21 centuries. Recent progress. Phys. Earth Planet. Int., 87: 95-109.

BUTLER, R.F.

1998 Paleomagnetism: magnetic domains to geologic terranes. Tucson: Department of Geosciences, University of Arizona.

CARluT, J.; COURTILlOT, V.; HUlOT, G.

1999 Over how much time should the geomagnetic field be averaged to obtain the mean-paleomagnetic field? Terra Nova, 11: 239-243.

CHAUVIN, A.; GARCIA, Y.; LANOS, PH.; LAUBENHEIMER, F.

2000 Paleointensity geomagnetic field recovered on archaeomagnetic sites from France. Phys. Earth Planet. Int., 120: 111-136.

CHIARI, G.; LANZA, R.

1997 Pictorial remanent magnetization as an indicator of secular variation of the Earth's magnetic field. Phys. Earth Planet. Int., 101: 79-83.

1999 Remanent magnetization of mural paintings from the Bibliotheca Apostolica (Vatican, Rome). J. App. Geophys., 41: 137-143. 
COE, R.S.

1967 The determination of paleo-intensities of the Earth's magnetic field with emphasis on mechanisms which could cause nonideal behavior in Thelier's method. J. Geomag. Geoelectric., 19: 157-179.

CONG, Y.Z; WEI, Q.Y.

1989 Study of secular variation (2000 BC $1900 \mathrm{AD}$ ) based on comparison of contemporaneous records in marine sediments and baked clays. Phys. Earth Planet. Int., 56: 79-85.

COURTILLOT, V.; LEMÖUEL, J-L.

2007 The study of Earth's magnetism (1269 1950): a foundation by Peregrinus and subsequent development of Geomagnetism and Paleomagnetism. Rev. Geophys., 45 (RG3008): 1-31.

DALY, L.; LE GOFF, M.

1996 An updated and homogeneous world secular variation data base.1. Smoothing of the archaeomagnetic results. Phys. Earth Planet. Int., 93: 159-190.

DUNLOP, D.; ÖZDEMIR, Ö.

1997 Rock Magnetism - Fundamentals and Frontiers, New York: Cambridge University Press.

FISCHER, R.A.

1953 Dispersion on a sphere. Proc. Roy. Soc. London, A217: 295-305.

GALLET, Y.; GENEVEY, A.; FLUTEAU, F.

2005 Does Earth's magnetic field secular variation control centennial climate change? Earth Planet. Sci. Let., 236: 339-347.

GENEVEY, A.; GALLET, Y.

2002 Intensity of the geomagnetic field in western Europe over the past 2000 years: New data from ancient French pottery. J. Geophys. Res., 107(B11) article number: 2285.

GENEVEY, A.; GALLET, Y.; MARGUERON, J.C.

2003 Eight thousand years of geomagnetic field intensity variations in the eastern Mediterranean. J. Geophys. Res., 108 (B5) article number: 2228.

GOGUITCHAICHVILI, A.; SOLER, A.M.;

ZANELLA, E.; CHIARI, G.; LANZA, R.; URRUTIA-FUCUGAUCHI, J; GONZALEZ, T.

2004 Pre-columbian mural paintings from Mesoamerica as geomagnetic field recorders. Geophys. Res. Lett., 31: L12607.

GÓMEZ-PACCARD, M.; CHAUVIN, A.; LANOS,

PH.; THIRIOT, J.; JIMÉNEZ-CASTILLO, P.

2006 Archaeomagnetic study of seven contemporaneous kilns from Murcia (Spain). Phys. Earth Planet. Int., 157: 16-32.
HARTMANN, G.A.; TRINDADE, R.I.F.; GOGUITCHAICHVILI, A.; AFONSO, M.C.

2007a Archaeointensity from 1300-200 BP Brazilian Pottery. In: 2007 Joint Assembly, American Geophysical Union.

HARTMANN, G.A.; AFONSO, M.C.; TRINDADE, R.I.F.

2007b Arqueomagnetismo no Brasil: primeiros resultados de cerâmicas históricas e préhistóricas. In: 1० Simpósio Latino Americano sobre Métodos Físicos e Químicos em Arqueologia, Arte e Conservação de Patrimônio Cultural, Sociedade Brasileira de Física. MASP, São Paulo, junho de 2007: 19.

KIRSCHVINK, J.L.

1980 The least-squares line and plane and analysis of paleomagnetic data. Geophys. J. R. Astron. Soc., 62: 699-718.

KORTE, M.; GENEVEY, A.; CONSTABLE, C.G.; FRANDK, U.; SCHNEPP E.

2005 Continuous geomagnetic field models for the past 7 millennia: 1 . A new global data compilation, Geochem. Geophys. Geosyst., 6: Q02H15.

KOVACHEVA, M.

1997 Archaeomagnetic database from Bulgaria: the last 8000 years. Phys. Earth Planet. Int., 102: 145-151.

KOVACHEVA, M.; HEDLEY, I.; JORDANOVA, N.; KOSTADINOVA, M.; GIGOV, V.

2004 Archaeomagnetic dating of archaeological sites from Switzerland and Bulgaria. J. Archaeol. Sci., 31: 1463-1479.

KOVACHEVA, M; JORDANOVA, N.; KARLOUKOVSKI, V.

1998 Geomagnetic field variations as determined from Bulgarian archaeomagnetic data. Part II: the last 8000 years. Surv. Geophys., 19: 431-460.

LABELLE, J.M.; EIGMY, J.L.

1997 Additional archaeomagnetic data on the variations as determined from Bulgarian archaeomagnetic data. Part II: the last 8000 years. Surv. Geophys., 9(5): 413-439.

LANOS, PH.; LE GOFF, M.; KOVACHEVA, M; SCHNEPP, E.

2005 Hierarchical modelling of archaeomagnetic data and curve estimating by moving average technique. Geophys. J. Int., 160: 440-476.

LE GOFF, M.; GALlet, Y.; GENEVEY, A.; WARME, N.

2002 On archaeomagnetic secular variation 
curves and archaeomagnetic dating. Phys. Earth Planet. Int., 134, (3-4): 203-211.

MCFADDEN, P.L.; MCELHINNY, M.W.

1990 Classification of the reversal test in palaeomagnetism. Geophys. J. Int., 103: 725-729.

MCINTOSH, G.; CATANZARITI, G.

2006 An introduction to archaeomagnetic dating, Geochronometria, 25: 11-18.

MERRILL, R.T.; MCELHINNY, M.W.; MCFADDEN, P.L.

1998 The Magnetic Field of the Earth: Paleomagnetism, the Core, and the Deep Mantle. International Geophysics Series, vol. 63, Academic Press.

MORALES, J.; GOGUITCHAICHVILI, A.; URRUTIA-FUCUGAUCHI, J.

2001 A rock-magnetic and paleointensity study of some Mexican volcanic lava flows during the Latest Pleistocene to the Holocene. Earth Planets Space, 53: 893-902.

NAGATA, T.; ARAI, Y.; MOMOSE, K.

1963 Secular variation of the geomagnetic total force during the last 5000 years. J. Geophys. Res., 68: 5277-5281.

PARÉS, J.M.; PÉREZ-GONZÁLEZ, A.; ROSAS, A.; BENITO, A.; BERMÚDEZ DE CASTRO, J.M.; CARBONELL, E.; HUGUET, R.

2006 Matuyama-age lithic tools from the Sima del Elefante site, Atapuerca (northern Spain). J. Hum. Evol., 50: 163-169.

PERRIN, M.; SCHNEPP, E.

2004 IAGA paleointensity database: distribution and quality of the data set. Phys. Earth Planet. Int., 147: 255-267.

PERRIN, M.; SCHNEPP, E.

2004 IAGA paleointensity database: distribution and quality of the data set. Phys. Earth Planet. Int., 147: 255-267.

SCHNEPP, E; LANOS, PH.

2005 Archaeomagnetic secular variation in
Germany during the past 2500 years. Geophys. J. Int., 163: 479-490.

SOLER-ARECHALDE, A.M.; SANCHEZ, F.; RODRIGUEZ, M.; GOGUITCHAICHVILI, A.; URRUTIA-FUCUGAUCHI, J.

2006 Archaeomagnetic investigation of oriented pre-Columbian lime-plasters from Teotihuacan, Mesoamerica. Earth Planets Space, 58: 1433-1439, 2006.

STENBERG, R.

1999 Secular variation of archaeomagnetic direction in the American southwest, AD 750-1452. J. Geophys. Res., 94 (B1): $527-546$

TANGUY, J-C.; LE GOFF, M.; PRINCIPE, C.; ARRIGHI, S.; CHILLEMI, V.; PAIOTTI, A.; LA DELFA, S.; PATÀNE, G.

2003 Archaeomagnetic dating of Mediterranean volcanics of the last 2100 years: validity and limits. Earth Planet. Sci. Lett., 211: 111-124.

TAUXE, L.

2005 Lectures in Paleomagnetism http:// earthref.org/MAGIC/books/Tauxe/ 2005.

THELLIER, E.; THELLIER, O.

1959 Sur l'intensité du champ magnetique terrestre dans le passé historique et géologique. Ann. Geophys., 15: 285-376.

VALET, J.-P.

2003 Time Variations in Geomagnetic Intensity. Rev. Geophys., 41: 1.

YU, Y.; DUNLOP, D.J.; PAVLISH, L.; COOPER, M.

2000 Archaeomagnetism of Ontario potsherds from the last 2000 years. J. Geophys. Res., 105(B8): 19419-19434.

ZANELLA, E.; GURIOLI, L.; CHIARI, G.; CIARALLO, A.; CIONI, R.; DE CAROLIS, E.; LANZA, R.

2000 Archaeomagnetic results from mural paintings and pyroclastic rocks in Pompeii and Herculaneum. Phys. Earth Planet. Int., 118: 227-240. 


\subsection{Um exemplo de datação arqueomagnética}

Como visto acima, a datação arqueomagnética depende da qualidade da curva de referência para uma determinada região do planeta e da qualidade do dado geomagnético obtido em um material arqueológico de idade desconhecida. Na datação podem ser utilizados um ou mais elementos geomagnéticos, sendo que a forma mais comum de datação é a utilização dos elementos direcionais, através de uma análise estatística bivariada para a declinação e a inclinação (e.g. McFadden e McElhinny, 1990; Le Goff et al., 2002). A aplicação de curvas de variação da intensidade ainda não é muito utilizada para datação arqueomagnética (e.g. Gallet et al., 2009). Porém, se as variações de intensidade da curva de referência forem rápidas o bastante para evitar possíveis ambigüidades no cálculo das idades ela pode ser aplicada sem maiores problemas como ferramenta de datação. A estatística bivariada não é aplicada para os dados de intensidade, pois a análise é feita em somente um elemento geomagnético. Neste caso, ao invés de usar a estatística bivariada, a idade é estabelecida pela simples comparação do dado obtido com a curva de referência. As variações de intensidade para a região Nordeste do Brasil são rápidas nos últimos 500 anos, conforme observado nos resultados apresentados no Capítulo 4. Além disso, o intervalo entre os séculos XVII e XVIII apresenta um número significativo de sítios bem datados, o que assegura uma maior confiabilidade na aplicação da curva para datação. Para o restante da curva a cobertura temporal dos sítios não é tão farta, mas as variações verificadas são amplas o suficiente para serem utilizadas em datação arqueomagnética.

O Projeto Monumenta de Salvador (Bahia) consiste no trabalho de resgate arqueológico e reconstrução das casas, edifícios e igrejas do centro histórico da primeira capital do Brasil. O IPHAN executa o Projeto Monumenta em diversas cidades históricas do Brasil, sendo o núcleo de Salvador o maior deles. As coletas de material arqueológico (tijolos, telhas, cerâmicas) foram feitas em diversas construções do centro histórico, entre elas a Casa dos Sete Candeeiros (1650-1700), o Solar Berquó (1691-1693) e várias casas do Pelourinho durante os trabalhos de resgate arqueológico feitos pela Equipe de Arqueologia do Projeto Monumenta. A casa de número 27 da Rua Monte Alverne (aqui nomeada de CP27) representou um alvo interessante para exemplificar a aplicação da datação arqueomagnética utilizando a curva de referência de Salvador. Esta casa está localizada em uma área de ocupação estimada historicamente e arquitetonicamente entre o começo do século XVII e a metade do século XVIII. As análises de paleointensidade foram feitas em 7 tijolos dos quais 5 apresentaram resultados satisfatórios, permitindo determinar um valor de intensidade de 
$35.8 \pm 2.1 \mu \mathrm{T}$ (erro de $6 \%$ em relação à média). Este valor é equivalente àqueles observados para o intervalo entre 1650 e 1750 . Considerando-se a média e o erro de intensidade do sítio CP27, pode-se estimar que esta casa foi construída entre 1675 e 1725 . Caso a estimativa de erro na determinação da intensidade tivesse sido menor, o intervalo de idades poderia também ser reduzido. Os detalhes desta datação são apresentados em um capítulo de livro intitulado "Estreitando laços. A relação entre o Arqueomagnetismo e a Arqueologia", por G. A. Hartmann e R. I. F. Trindade, que faz parte do volume sobre o Projeto Monumenta de Salvador, que está em fase de edição.

Como o capítulo de livro foi escrito antes da conclusão das medidas para a região Nordeste, faz-se aqui algumas ressalvas a respeito da curva de referência apresentada. O sítio “Corpo de Bombeiros" (1767-1777), cujos resultados foram apresentados no Capítulo 4, não aparece na Figura 5 do capítulo do livro porque esses dados ainda não estavam disponíveis quando o capítulo foi escrito. O sítio "Museu de Arqueologia e Etnologia” (1556-1591) foi retirado da curva final apresentada no Capítulo 4, porque após análises mais detalhadas em nível de fragmento constatou-se que os fatores de anisotropia dos tijolos amostrados possuíam valores bastante distintos, resultando em duas médias de intensidade distintas para o mesmo conjunto de fragmentos, fato este que será futuramente investigado com novas amostragens naquele sítio. Como o erro de intensidade para este sítio ficou em torno de 14\%, o sítio não foi considerado nas médias apresentadas no Capítulo 4. Contudo, essas modificações na curva de referência não interferem na datação do CP27, visto que as idades e as intensidades são bastante distintas das do CP27. Outro pequeno detalhe a ser comentado refere-se ao intervalo de idades apresentado no Capítulo 4 e no capítulo do livro. No capítulo do livro, a média de intensidade do CP27 foi calculada com 6 fragmentos de tijolos $(36.9 \pm 2.4 \mu \mathrm{T})$ e a idade foi estimada entre 1670 e 1710 . Após a análise final de todos os fragmentos oriundos de 7 tijolos do CP27 optou-se por retirar mais um fragmento do cálculo final porque apenas um espécime deste havia sido aproveitado e fornecia uma intensidade discrepante com relação à média. Esta análise mais detalhada, com 5 fragmentos de tijolos, revelou um valor médio de intensidade de $35.8 \pm 2.1 \mu \mathrm{T}$, que corresponde a uma estimativa da idade de 1675-1725 para o sítio CP27. Estas considerações se fazem necessárias e exemplificam a necessidade de aprimoramento contínuo da curva de variação, com a análise de mais sítios com idades confiáveis. 
Capítulo de livro:

65. Estreitando laços. A relação entre o arqueomagnetismo e a arqueologia"

G.A. Hartmann e R.I.F. Trindade

Capítulo do Livro do Projeto Monumenta de Salvador 


\section{Estreitando laços. A relação entre o arqueomagnetismo e a arqueologia}

Gelvam A. Hartmann

Ricardo I. F. Trindade ${ }^{1}$

\section{Introdução}

Antes de mais nada, e com o objetivo de desde já esclarecer, o arqueomagnetismo é, dentre outras coisas, uma ferramenta de datação precisa e refinada, que localiza a origem do objeto estudado, ou seja, informa de qual porção do planeta ele provém. A chamada datação arqueomagnética consiste na comparação de um dado geomagnético obtido a partir de um material arqueológico de idade desconhecida com o dado geomagnético de uma curva de referência para uma determinada região do planeta. Neste capítulo, apresentamos a curva de variação da intensidade do campo magnético terrestre, determinada a partir do magnetismo fóssil de tijolos de construções históricas de Salvador, e a datação arqueomagnética de uma das casas do Pelourinho - a Casa n. 27 na rua Monte Alverne -, estudada pelo Projeto de Pesquisa Arqueológica da $7^{\mathrm{a}}$ Etapa de Recuperação do Centro Histórico de Salvador-BA (Iphan/Monumenta) ou Projeto Pelourinho de Arqueologia.

O campo magnético da Terra, ou campo geomagnético, origina-se no núcleo externo através de processos turbulentos de movimentação de um fluido eletricamente condutor. O campo geomagnético é definido por parâmetros direcionais da declinação $(D)$ e inclinação $(I)$ e pela intensidade total do campo $(H)$. A declinação corresponde ao ângulo entre o vetor campo e o norte geográfico, a inclinação é o ângulo entre vetor campo e o plano horizontal, e a intensidade é o módulo do vetor campo geomagnético. Estas três componentes definem o campo geomagnético em cada ponto da superfície da Terra e variam no tempo e no espaço.

A evolução do campo geomagnético nos últimos 200 anos tem sido investigada por meio de observações feitas na superfície da Terra ou do espaço, com magnetômetros em observatórios e estações itinerantes ou com magnetômetros instalados em satélites. A evolução do campo geomagnético em períodos mais antigos é investigada a partir da análise do magnetismo fóssil registrado em materiais arqueológicos e rochas. Esse tipo de observação permite reconstruir a evolução do campo geomagnético em diferentes escalas de tempo. O magnetismo fóssil pode ser determinado quando os objetos arqueológicos e as rochas possuem a capacidade de

\footnotetext{
${ }^{1}$ Departamento de Geofísica, Instituto de Astronomia, Geofísica e Ciências Atmosféricas, Universidade de São Paulo, rua do Matão, 1226, 05508-090, São Paulo, Brasil.

G. A. Hartmann (e-mail: gelvam@iag.usp.br)

R. I. F. Trindade (e-mail: rtrindad@iag.usp.br)
} 
registrar uma magnetização remanente estável, produzida pelo campo geomagnético existente no momento de sua formação (ou produção).

$\mathrm{O}$ arqueomagnetismo pode ser definido como um domínio de pesquisa multidisciplinar que une a arqueologia, o magnetismo de rochas e o geomagnetismo. Assim, o arqueomagnetismo se ocupa de estudar a evolução do campo magnético da Terra em escalas de tempo arqueológico (por exemplo, Hartmann et al., 2007). Essas variações podem, inclusive, ser utilizadas como ferramenta de datação. A datação arqueomagnética consiste na comparação das variações do campo geomagnético em uma determinada região com o registro geomagnético obtido em materiais arqueológicos de idade desconhecida. A precisão de uma datação arqueomagnética depende muito da resolução da curva geomagnética de referência da região em estudo e também do tipo de registro (direcional e/ou de intensidade) (por exemplo, Mcintosh e Catanzariti, 2006). Embora a datação arqueomagnética seja uma técnica de datação que forneça resultados com muita precisão (incertezas inferiores a 10 anos em alguns casos), é importante salientar que ela pode apresentar ambiguidades que devem ser resolvidas com o bom conhecimento do contexto arqueológico dos sítios estudados (Le Goff et al., 2002). Para que se efetuem datações arqueomagnéticas é fundamental construir uma curva de referência com materiais que apresentem uma boa precisão de idades. Além disso, o material a ser datado deve guardar um registro de boa qualidade do campo magnético antigo.

$\mathrm{O}$ arqueomagnetismo no Brasil vem sendo desenvolvido a partir de aquisições da intensidade do campo geomagnético em tijolos, telhas e cerâmicas de construções históricas das regiões Nordeste e Sudeste. Uma curva de referência de arqueointensidade magnética para os últimos cinco séculos foi determinada a partir de materiais arqueológicos da Bahia. Em função da resolução obtida para essa curva, é possível utilizá-la para determinar idades em estruturas do Projeto Pelourinho de Arqueologia, em Salvador, Bahia. Neste capítulo será apresentada a curva de referência para a Bahia e um exemplo de aplicação dessa curva em uma casa histórica do Projeto Pelourinho.

\section{Magnetismo fóssil e as análises arqueomagnéticas}

Os materiais arqueológicos (ou geológicos) que contêm óxidos de ferro, como magnetita e hematita, são capazes de adquirir uma magnetização remanente estável. Isso ocorre quando os minerais magnéticos aquecem e resfriam em temperaturas superiores à temperatura crítica característica de cada mineral magnético (temperatura de bloqueio). A direção dessa magnetização é paralela ao campo geomagnético no momento em que os materiais são fabricados. Essa magnetização é também proporcional à intensidade do campo geomagnético (por exemplo, Dunlop e Özdemir, 1997). Caso as estruturas encontrem-se in situ e sem indícios de perturbação por meios externos, é possível determinar tanto a intensidade quanto a direção do campo geomagnético no mesmo artefato. No caso de fragmentos de cerâmicas, 
telhas ou tijolos, onde a posição original de queima não pode ser determinada com certeza, é possível somente determinar a intensidade do campo geomagnético.

Em estudos arqueomagnéticos devem-se extrair as informações direcionais e de intensidade primárias, ou seja, aquelas que foram registradas durante a produção do artefato arqueológico (a queima para sua confecção) ${ }^{2}$. Mas geralmente o registro magnético original está parcialmente corrompido por efeitos secundários, que devem ser identificados e eliminados durante as análises. O princípio de obtenção da direção geomagnética antiga reside no fato de que a magnetização primária é mais estável, ou seja, ela está registrada nos grãos minerais com temperaturas de bloqueio e coercividades ${ }^{3}$ mais elevadas. Desse modo, para suprimir as magnetizações secundárias utilizam-se etapas sucessivas de desmagnetização, seja com incrementos de temperatura, seja com incrementos de campo magnético artificial. Nesses procedimentos são utilizados fornos com controles precisos de temperaturas e encapsulados em blindagens magnéticas ou aparatos que induzem campos que oscilam entre os valores de pico até zero. O dado direcional é obtido a partir da análise por componentes principais dos resultados da desmagnetização (Kirschvink, 1980). Determinadas as direções para cada amostra, são calculadas as direções médias por fragmento ou estrutura; em seguida é calculada a direção média para um determinado sítio com idade conhecida. Os parâmetros estatísticos direcionais (Fischer, 1953), $\alpha_{95}$ (cone de erro) e o $k$ (parâmetro de concentração), permitem determinar com precisão a direção geomagnética média para uma determinada época.

Diferentemente da direção, a intensidade geomagnética pode ser determinada em materiais que foram deslocados de sua posição original, ou seja, não há necessidade da amostragem de materiais in situ, porém, é necessário conhecer a origem do material. A intensidade geomagnética é determinada pela técnica desenvolvida por Thellier e Thellier (1959) para materiais arqueológicos e rochas. A magnetização adquirida por um material arqueológico que foi submetido a aquecimento é proporcional ao campo geomagnético da época em que esse material foi produzido. O método de aquisição da paleointensidade ou arqueointensidade é baseado na comparação da magnetização primária (ou natural) $\left(M_{T}\right)$ com uma magnetização de laboratório $\left(M_{L}\right)$ produzida por um campo magnético de laboratório $\left(H_{L}\right)$. Assim, a intensidade do campo geomagnético antigo $\left(H_{A}\right)$ pode ser estimada pela seguinte equação:

$$
H_{A}=H_{L} \frac{M_{T}}{M_{L}}
$$

\footnotetext{
${ }^{2}$ Artefatos que sofreram mais de uma queima, como panelas, não são apropriados para o estudo.

${ }^{3}$ Coercividade é a capacidade que um certo material tem em reter uma magnetização espontânea quando submetido a um campo externo; materiais fortemente coercivos são aqueles que guardam de forma mais efetiva um magnetismo fóssil.
} 
A inclinação da reta obtida pelo ajuste de $M_{T}$ e $M_{L}$ fornece diretamente o valor de $H_{A}$. Na prática, a determinação da paleointensidade é muito mais complexa que a aquisição de um dado direcional. Para obtenção da paleointensidade são utilizados fornos que, além de possuírem blindagens para desmagnetização térmica, têm acopladas bobinas de indução de campo magnético. O controle de temperatura e campo aplicado deve ser o mais preciso possível para minimizar os problemas de alteração magnética e substituição da $M_{T}$ pela $M_{L}$. As medidas de magnetização em cada etapa são realizadas em magnetômetros sensíveis e de preferência em salas magneticamente blindadas, para evitar interferências externas. Da mesma maneira que na aquisição direcional, um valor de intensidade médio para um sítio de idade conhecida é calculado a partir de uma média de diversos fragmentos, sendo que a média intrafragmento é obtida a partir de diversos espécimes do mesmo fragmento. Em ambos os casos, os valores devem ser coerentes entre si e apresentar baixo desvio padrão.

\section{Variações temporais do campo magnético da Terra no período colonial}

\section{Modelos globais de variação do campo geomagnético}

O campo magnético da Terra apresenta uma morfologia complexa, embora boa parte da sua variação seja devida ao dipolo geomagnético axial. Se o campo tivesse a configuração exata de um dipolo inclinado, seria idêntico ao esquema da figura 1. A linha que passa pelo centro da Terra junto ao eixo do dipolo intercepta a superfície em dois pontos chamados de polos geomagnéticos. Esses polos diferem dos polos magnéticos de inclinação, que são as regiões sobre a superfície da Terra onde o campo é vertical. Do mesmo modo, o equador geomagnético é aquele obtido pelo melhor ajuste a um dipolo ideal, enquanto o equador magnético é definido pela linha cuja inclinação do vetor magnético é nula, variando de maneira não uniforme em função da complexidade do campo magnético terrestre. Os polos e o equador geomagnético e magnético deveriam coincidir se o campo fosse dipolar e geocêntrico. Mas este não é o caso, e cerca de 10\% a 20\% do campo na superfície da Terra é de natureza não-dipolar (Merrill et al., 1998). Assim, na média, o campo dipolar pode responder por até $90 \%$ da intensidade total do campo terrestre.

Em função das diferenças e complexidades do campo magnético da Terra são necessários modelos que permitam melhor descrevê-lo no tempo e no espaço. Atualmente, as medidas diretas do campo são realizadas continuamente por meio de observatórios e satélites. Como a orientação magnética foi o método mais utilizado durante o período das grandes navegações, há registros de dados magnéticos direcionais distribuídos globalmente, que fornecem uma boa descrição da variação secular. As primeiras medidas de declinação foram feitas pelos navegadores em torno de 1590, as medidas de inclinação iniciaram-se no começo do século XVII, e as medidas de intensidade total foram iniciadas apenas por volta de 1835 (Jonkers et al., 2003). Além dos dados obtidos por meio de medidas diretas, dados arqueomagnéticos (direção e intensidade) também têm sido incorporados em modelos de variação secular 
(Hongre et al., 1998; Korte e Constable, 2005; Gubbins et al., 2006). As variações do campo magnético terrestre para o intervalo de tempo compreendido entre 1550 até o presente são conhecidas como variações para o período histórico (ou colonial), ou seja, variações na escala de anos a centenas de anos (Merrill et al., 1998).

Para esse intervalo de tempo, a evolução do campo magnético da Terra pode ser analisada através de modelos de campo obtidos por harmônicos esféricos ${ }^{4}$, por causa da boa cobertura espacial e temporal dos dados. O modelo mais usado atualmente é o IGRF (International Geomagnetic Reference Field), que é construído a cada cinco anos desde 1900 e é obtido a partir de dados de observatórios e satélites, principalmente. Para o período anterior a 1900 há outros modelos de campo, como os modelos Barraclough (1974), Bloxham e Jackson (1992), Hongre et al. (1998) Jackson et al. (2000), Korte e Constable (2005), Gubbins et al. (2006) e Korte et al. (2009). O modelo de Jackson et al. é o mais utilizado atualmente para estudos do campo magnético terrestre no período histórico, pois cobre continuamente (com modelos anuais) o intervalo de 1590-1990.

A figura 2 mostra exemplos de mapas feitos a partir do cálculo dos harmônicos esféricos de modelos de campo. Os mapas mostram a variação secular para dois períodos distintos. Os mapas de 1590 foram determinados a partir do modelo de Jackson et al. (2000), e os mapas de 2005 a partir do modelo IGRF. Nota-se a evolução das isolinhas ao longo do tempo, indicando claramente a variação temporal e espacial. Os modelos de campo no período histórico foram determinados basicamente a partir de dados direcionais coletados por navegadores. Resultados de arqueointensidade têm sido obtidos nos últimos anos e incorporados aos modelos de campo geomagnético (Gubbins et al., 2006; Finlay, 2008). No entanto, a correta análise do campo depende de uma boa cobertura temporal e espacial de dados de intensidade. Nesse quesito, o hemisfério Sul do planeta contribui com apenas 5\% dos dados globais para os últimos dez mil anos (Genevey et al., 2008). Na América do Sul, apenas o Bolívia, Equador e Peru apresentam dados de intensidade geomagnética para intervalos de tempo anteriores ao período histórico, porém, são resultados de baixa resolução temporal. Portanto, a determinação de valores de intensidade do campo geomagnético para intervalos de tempo arqueológico no Brasil é de suma importância.

\section{A curva de variação de arqueointensidade para a Bahia}

No Brasil, os estudos arqueomagnéticos estão sendo desenvolvidos em duas regiões distintas: Nordeste e Sudeste. Em ambas foram iniciadas medidas de intensidade magnética em

\footnotetext{
${ }^{4}$ Os harmônicos esféricos são funções matemáticas que permitem representar a parte angular da solução da equação de Laplace em coordenadas esféricas. No caso do campo magnético terrestre, essas funções representam o potencial magnético na superfície do planeta, sendo que o primeiro termo da série representa o campo dipolar. Uma descrição detalhada de modelagem por harmônicos esféricos pode ser encontrada em Langel (1987).
} 
materiais construtivos históricos (tijolos e telhas) e fragmentos cerâmicos (por exemplo, vasos). No Nordeste, foram obtidos resultados a partir de materiais do estado da Bahia, oriundos principalmente de Salvador.

O desenvolvimento da curva de variação de intensidade geomagnética para a Bahia conta com o apoio do Projeto Pelourinho Iphan/Monumenta em Salvador e do Museu de Arqueologia e Etnologia da Universidade Federal da Bahia - MAE/Ufba. Boa parte dos resultados foi obtida a partir de tijolos de construções históricas de Salvador. A opção por determinar a curva de referência a partir de materiais construtivos é importante, pois em geral esse tipo de material apresenta um bom controle cronológico. Em grande parte dos sítios estudados, a atribuição das idades foi feita a partir do contexto histórico de construção dos imóveis, utilizando-se fontes documentais. Em alguns casos, usou-se também informações do contexto arqueológico e/ou arquitetônico. Para períodos recentes, a atribuição de idades por meio do contexto histórico e/ou arqueológico muitas vezes é melhor do que a obtida por outro método de datação, como por exemplo, a termoluminescência ou radiocarbono. A boa precisão de idades é fundamental para determinação de uma curva arqueomagnética, pois é a partir dela que se definem as idades de outros sítios. A tabela 1 apresenta uma descrição dos sítios estudados para a construção da curva de referência da Bahia, incluindo tipo de amostras e atribuição de idades.

A figura 3 mostra os resultados de arqueointensidade obtidos na Bahia. Os resultados são comparados com o modelo de campo geomagnético histórico (Jackson et al., 2000). Cada média (sítio) foi determinada a partir da média de diversos fragmentos (no mínimo três) e a partir de diversos espécimes por fragmento (mínimo de dois); ou seja, para cada sítio há no mínimo seis determinações independentes de intensidade. A média leva em conta a coerência em termos de fragmento (desvio padrão inferior a 5\%) e também a coerência em termos de sítio, com baixo desvio padrão quanto ao sítio. A precisão na determinação de idades em materiais não-datados, cujos resultados arqueomagnéticos serão comparados com a curva de referência, é definida a partir das incertezas de idade e de intensidade dos sítios estudados e da quantidade de sítios (ou médias) que compõem a curva. As determinações de idades variam, portanto, em função da qualidade da curva de referência. Quanto menor forem as incertezas nas idades e nas intensidades dos sítios que compõem a curva, melhores serão as determinações de idades de sítios com idades desconhecidas. Outro fator que influencia a precisão da datação arqueomagnética é o número de elementos geomagnéticos disponíveis para construção da curva. Por exemplo, na França os materiais são basicamente datados a partir da comparação dos elementos direcionais de inclinação, declinação e, em alguns casos, também intensidade (por exemplo, Le Goff et al., 2002). 


\section{A datação da Casa n. 27 da rua Monte Alverne}

Como mostrado acima, um estudo de arqueomagnetismo sistemático foi realizado na cidade de Salvador para determinação de uma curva arqueomagnética de referência, que é válida para toda a região Nordeste do Brasil. A partir dessa curva de referência, é possível datar artefatos arqueológicos produzidos na região e que guardam um magnetismo fóssil. Algumas casas do Projeto Pelourinho, para as quais não existem vínculos diretos de idade, foram estudadas sob o aspecto arqueomagnético. Nesse contexto, uma das casas apresentou resultados arqueomagnéticos satisfatórios, que serão mostrados aqui como um exemplo de utilização do arqueomagnetismo como ferramenta de datação arqueológica.

Na Casa de número 27 (CP27), da rua Monte Alverne (quadra 19), foram coletadas amostras de tijolos das trincheiras F, G e H, oriundas da base da construção, ou seja, do mesmo contexto arqueológico. Todas as amostras de tijolos foram submetidas a duas análises magnéticas antes das medidas de paleointensidade: (a) determinação da estabilidade da mineralogia magnética durante o aquecimento e (b) determinação da natureza da mineralogia magnética presente nas amostras. A análise da estabilidade térmica da mineralogia magnética é importante para descartar as amostras que apresentam alteração dos minerais magnéticos durante os experimentos de paleointensidade. Para isso, foram feitas curvas de variação da susceptibilidade magnética em função da temperatura $\left(\sim 30{ }^{\circ} \mathrm{C}\right.$ a $\left.\sim 550{ }^{\circ} \mathrm{C}\right)$, usando-se $\mathrm{o}$ susceptômetro kappabridge KLY3-CS3 (Agico Ltd.). O tipo de mineral e suas características magnéticas podem também influenciar as determinações de paleointensidades. Para determinação do mineral magnético (ou minerais magnéticos) e seu estado de domínio foram feitas curvas de histerese magnética em campos de até 1 Tesla. As medidas foram feitas em um magnetômetro de amostra vibrante do Institut de Physique du Globe de Paris.

Por fim, as medidas de paleointensidade foram realizadas usando um magnetômetro de amostra vibrante triaxial - Triaxe (Le Goff e Gallet, 2004). A figura 4a mostra a grande estabilidade térmica das amostras da Casa 27 durante seu aquecimento e resfriamento, indicando que elas praticamente não apresentam alteração magnética durante o ciclo de aquecimento e resfriamento. Observa-se na figura $\mathbf{4 b}$ que a curva de histerese apresenta um comportamento típico de mistura de minerais, visto que não ocorre a saturação da magnetita em campos próximos a $100 \mathrm{mT}$. Essa curva pode indicar a presença de minerais de baixa coercividade magnética (como a titanomagnetita) e minerais de alta coercividade (como a hematita).

A figura 4c mostra um gráfico da intensidade do campo magnético fóssil em função da temperatura em que as medidas foram efetuadas no Triaxe. Note que os resultados obtidos em altas temperaturas convergem para o mesmo valor de intensidade nos dois métodos de ajuste utilizados (curvas com cores diferentes), revelando uma boa coerência dos resultados na escala da amostra. Foram obtidos resultados de intensidades em três tijolos da Casa 27. A 
média, para todo o nível amostrado, foi obtida com mais de seis determinações distintas, atendendo assim ao critério estatístico de confiabilidade do sítio. O valor médio de intensidade para essa casa foi de $36.9 \pm 2.4$ micro Tesla. Essa média pode ser comparada com os valores de intensidade da curva de referência da Bahia (figura 3). Valores muito próximos aos da Casa 27 foram obtidos em vários sítios (figura 3), inclusive nos tijolos do Solar Berquó (Salvador), que tem idade bem determinada entre 1691 e 1693 AD. O erro na intensidade magnética determinado para a Casa 27 é um pouco superior ao erro determinado para o Solar Berquó. Levando em conta todos os dados da curva de referência e as incertezas na determinação da intensidade da Casa 27 pode-se estimar sua idade entre 1670 e 1720, ou seja, entre o final do século XVII e o início do século XVIII. A figura 5 apresenta os mesmos valores de intensidade da figura 3, além do valor médio para o sítio Casa 27 (CP27, ponto em vermelho com os respectivos valores de intensidades e idades). De modo geral, esse resultado é condizente com os estudos arqueológicos realizados pela equipe do Projeto Pelourinho nessa casa.

\section{Considerações finais}

Os estudos arqueomagnéticos realizados em Salvador forneceram resultados excelentes. A determinação de uma curva de referência para a Bahia possibilitou uma aplicação do método de datação arqueomagnética a uma casa do Projeto Pelourinho, a Casa 27. Isso foi possível graças a dois fatores básicos: as informações arqueológicas a priori para este estudo de caso e a boa resolução da curva de referência para esse intervalo de tempo. As informações arqueológicas e arquitetônicas da Casa 27 foram essenciais para um bom delineamento do intervalo cronológico obtido a partir do arqueomagnetismo. Estudos similares em outras casas do Projeto Pelourinho permitirão delinear zoneamentos urbanos e, consequentemente, indicar com grande precisão possíveis intervalos para as ocupações.

A datação arqueomagnética no Brasil está ainda em sua infância, mas esse exemplo em Salvador é forte indicativo de sua potencialidade, pelo menos para o período colonial e póscolonial. As variações de intensidades para esse período são grandes o suficiente para possibilitar datações a partir da intensidade geomagnética. No entanto, as curvas de referência podem ainda ser melhoradas com dados de outros elementos geomagnéticos (declinação e inclinação). É necessário também que os estudos sejam ampliados na Bahia e iniciados em outros locais do país. Além da datação arqueomagnética, as técnicas magnéticas podem ser aplicadas também em outros problemas arqueológicos, como por exemplo, os processos de formação de sítios arqueológicos e a proveniência de materiais arqueológicos (Stenberg, 2008). Nesse sentido, esse trabalho é um primeiro exemplo de um extenso campo de aplicações em diferentes contextos e regiões que se abre à comunidade arqueológica brasileira. 


\section{Referências}

BARRACLOUGH, D. R. Spherical harmonic analyses of the geomagnetic field for eight epochs between 1600 and 1910. Geophysical Journal of the Royal Astronomical Society, London, n. 36, p. 497-513, 1974.

BLOXHAM, J.; JACKSON A. Time-dependent mapping of the magnetic field at the core-mantle boundary. Journal of Geophysical Research, Washington, American Geophysical Union, v. 97, B13, 19537-19563, 1992.

DUNLOP, D.; ÖZDEMIR, Ö. Rock Magnetism. Fundamentals and Frontiers. New York: Cambridge University Press, 1997.

FINLAY, C. C. Historical variation of the axial geomagnetic dipole. Physics of the Earth and Planetary Interiors, Amsterdam, Elsevier, v. 170, p. 1-14, 2008.

FISCHER, R. A. Dispersion on a sphere. Proceedings of the Royal Society, London, A 217, 295-305, 1953.

GENEVEY, A., GAllet, Y., CONSTABle, C. G., KORTE, M. and HUlOT, G. ArcheoInt: An upgraded compilation of geomagnetic field intensity data for the past ten millennia and its application to the recovery of the past dipole moment. Geochemistry, Geophysics, Geosystems, American Geophysical Union, n. 9, 2008.

GUBBINS, D., JONES, A. L. and FINLAY, C. C. Fall in earth's magnetic field is erratic. Science, American Association for the Advancement of Science, v. 312, n. 5775, p. 900-902, 2006.

HARTMANN, G. A., AFONSO, M. C. e TRINDADE, R. I. F. Datação arqueomagnética: princípios e métodos. Revista do Museu Arqueologia Etnologia, São Paulo, n. 17, p. 445-459, 2007.

HONGRE, L.; HULOT, G.; KHOKHLOV, A. An analysis of the geomagnetic field over the past 2000 years. Phys. Physics of the Earth and Planetary Interiors, Amsterdam, Elsevier, v. 106, p. 311-335, 1998.

JACKSON, A.; JONKERS, A. R. T.; WALKER, M. Four centuries of geomagnetic secular variation from historical records. Philosophical Transactions of the Royal Society, London, A 358, p. 957-990, 2000.

JONKERS, A. R. T.; JACKSON, A.; MURRAY, A. Four centuries of the geomagnetic data from historical records. Reviews of Geophysics, University of Liverpool, v. 41, n. 2, 2003.

KIRSCHVINK, J. L. The least-squares line and plane and analysis of paleomagnetic data. Geophysical Journal of the Royal Astronomical Society, London, v. 62, p. 699-718, 1980.

KORTE, M. and CONSTABLE, C. G. Continuous geomagnetic field for the past 7 millennia. Part 2: CALS7K. Geochemistry, Geophysics, Geosystems, American Geophysical Union, v. 6, Q02H16, 2005.

KORTE, M.; DONADINI, F.; CONSTABLE, C. G. Geomagnetic field for 0-3 ka. Part 2: A new series of time-varing global models. Geochemistry, Geophysics, Geosystems, American Geophysical Union, v. 10, Q06008, 2009.

LANGEL, R. A. The main field. In JACOBS, J. A., ed., Geomagnetism. New York: Academic Press, 1987. v. 1, c. 4, p. 249-512. 
LE GOFF, M.; GALLET, Y. A new three-axis vibrating sample magnetometer for continuous hightemperature magnetization measurements: applications to paleo- and archeo-intensity determinations. Earth and Planetary Science Letters, Amsterdam, Elsevier, v. 229, p. 31-43, 2004.

LE GOFF, M.; GALLET, Y.; GENEVEY, A.; WARME, N. On archeomagnetic secular variation curves and archeomagnetic dating. Physics of the Earth and Planetary Interiors, Amsterdam, Elsevier, v. 134, n. 3, p. 203-211, 2002.

MCINTOSH, G.; CATANZARITI, G. An introduction to archaeomagnetic dating. Geochronometria, Gliwice, Silesian University of Technology, v. 25, p. 11-18, 2006.

MERRILL, R. T.; MCELHINNY, M. W.; MCFADDEN, P. L. The magnetic field of the Earth: paleomagnetism, the core, and the deep mantle. Amsterdam: Elsevier/Academic Press, 1998. v. 63. (International Geophysics Series.)

STERNBERG, R. S. Archaeomagnetism in archaeometry. A semi-centennial review. Archaeometry, University of Oxford, v. 50, n. 6, p. 983-998, 2008.

THELLIER, E.; THELLIER, O. Sur l'intensité du champ magnetiqué terrestre dans le passé historique et géologique. Annales de Géophysique, Paris, Centre National de la Recherche Scientifique, v. 15, p. 285-376, 1959. 


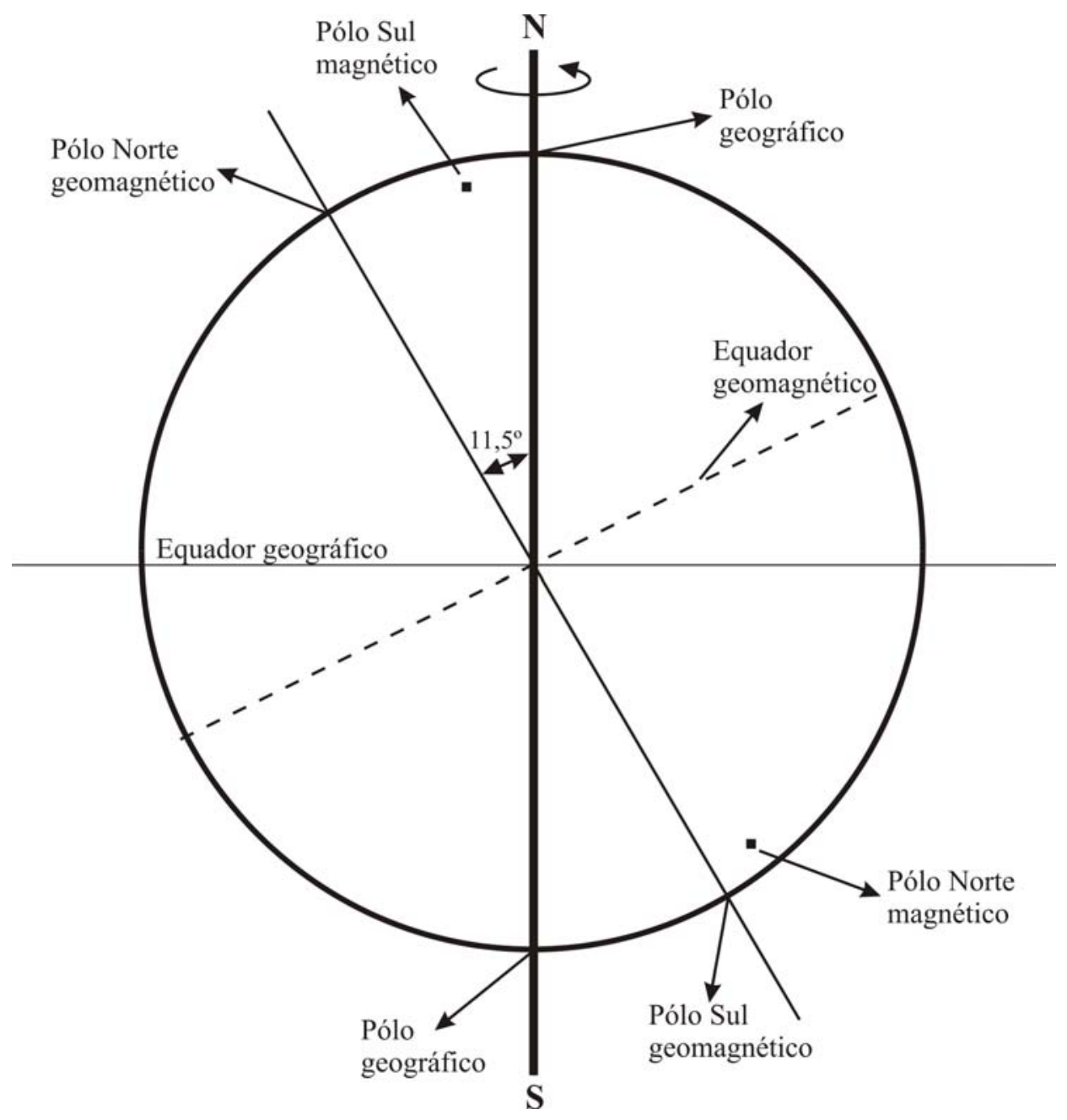

Figura 1: Localização dos polos geográficos, geomagnéticos e magnéticos; do equador geográfico e geomagnético 
a) Declinação 1590

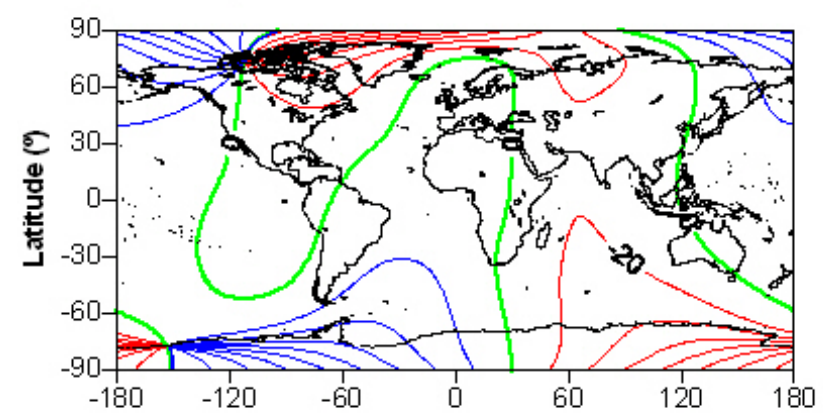

c) Inclinação 1590

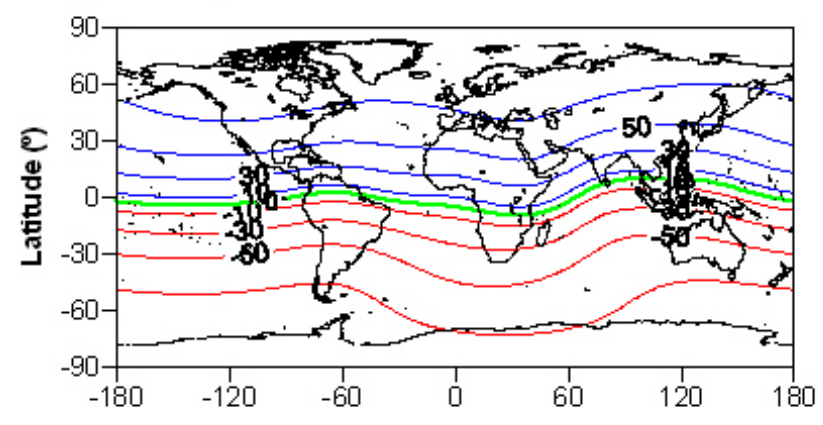

e) Intensidade total 1590

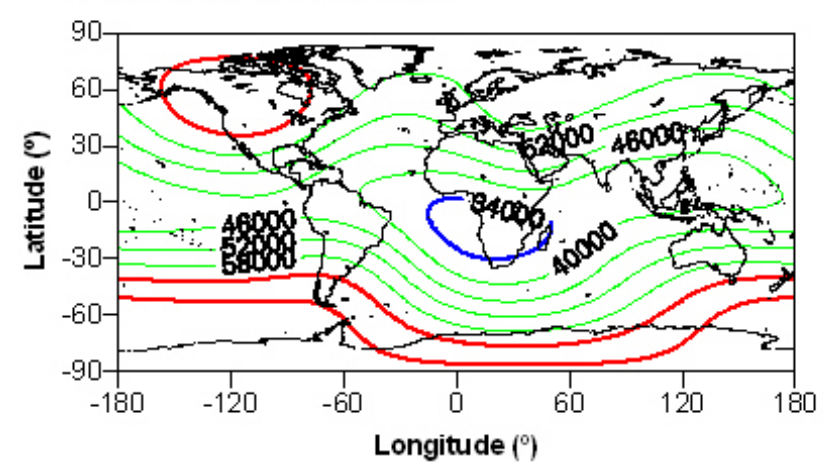

b) Declinação 2005

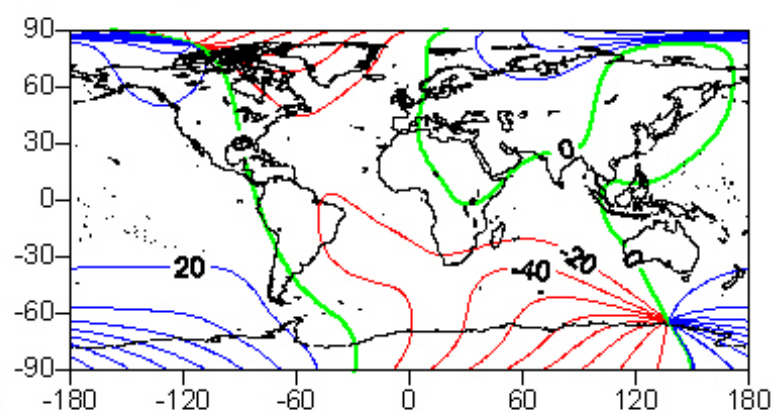

d) Inclinação 2005

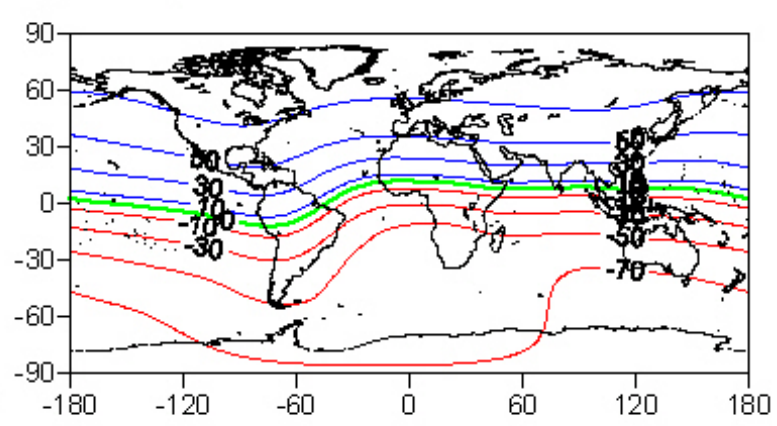

f) Intensidade total 2005

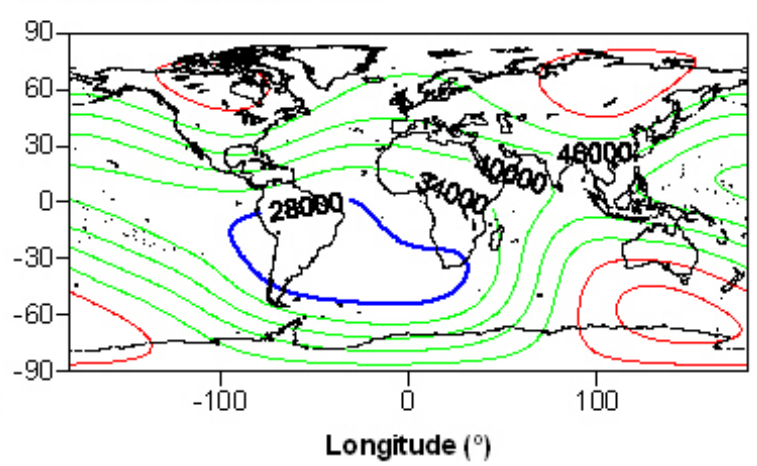

Figura 2: Exemplos de mapas que descrevem a variação secular do campo magnético da Terra para o período histórico. Em (a) e (b) mapas de declinação; em (c) e (d) mapas de inclinação e em (e) e (f) mapas de intensidade total. As linhas de isovalores nos mapas direcionais são dadas em graus, enquanto que nos mapas de intensidade total a unidade é o nano Tesla. 


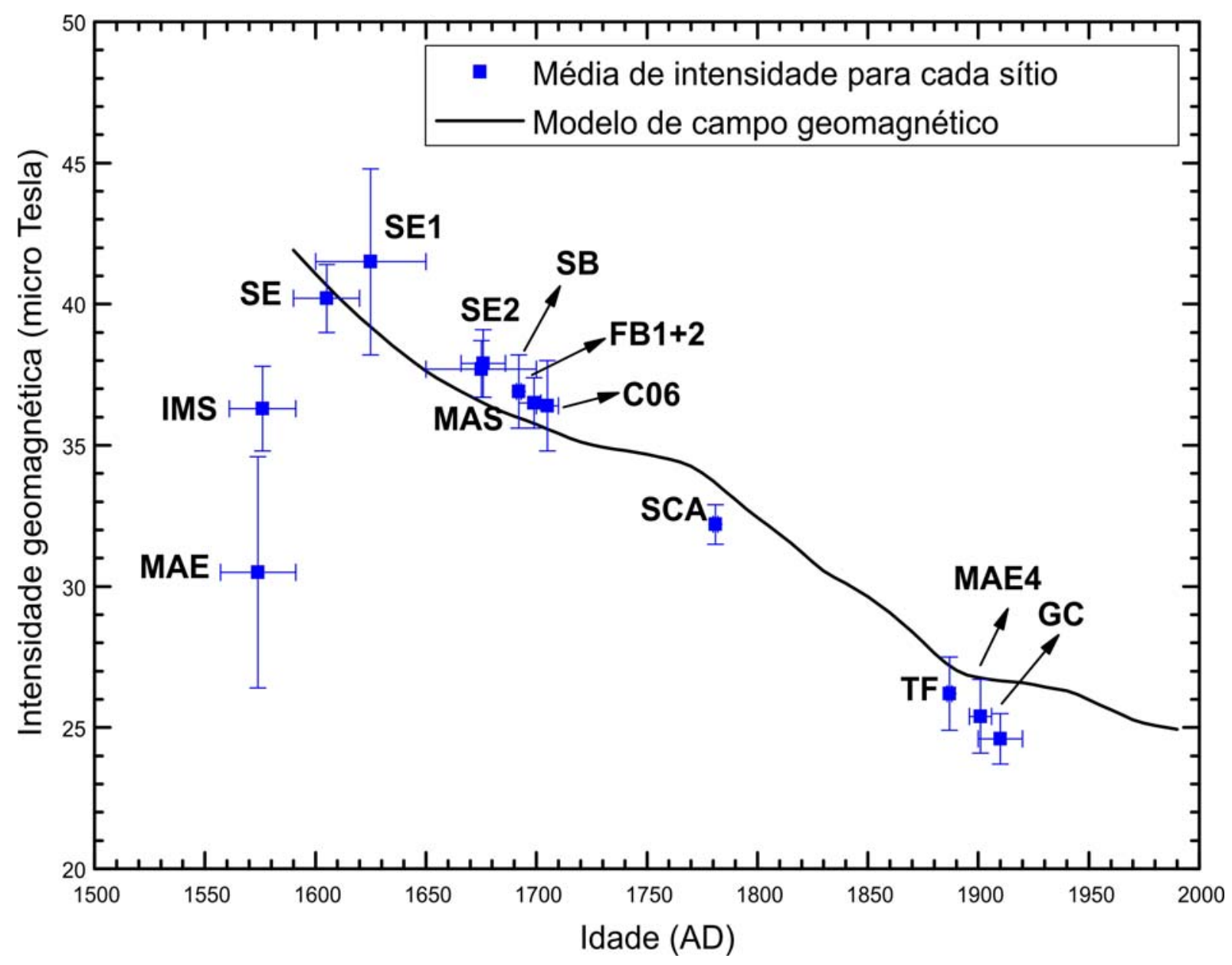

Figura 3: Diagrama da intensidade geomagnética versus idades (AD) para todos os sítios estudados (ver tabela 1 para as respectivas siglas). A figura mostra os respectivos erros de idades e intensidades. A curva em preto representa o modelo de campo geomagnético determinado por Jackson et al. (2000). 
a)

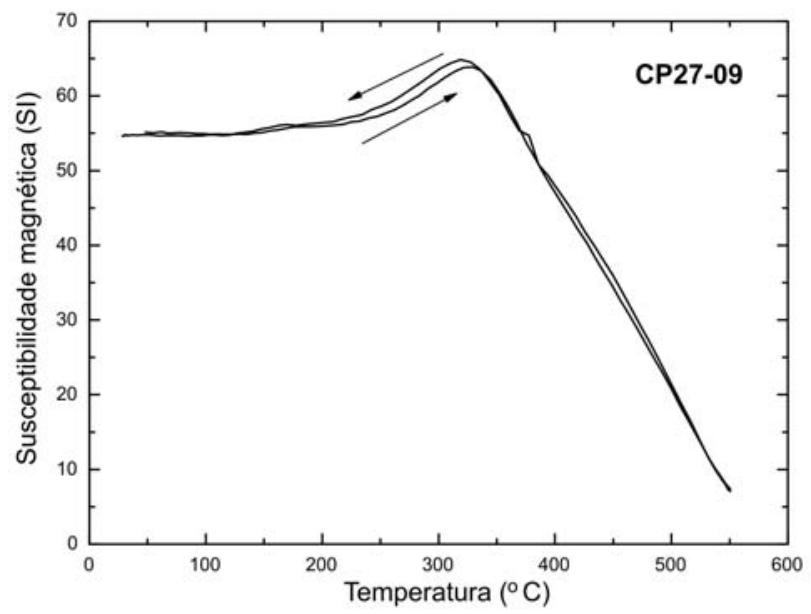

b)

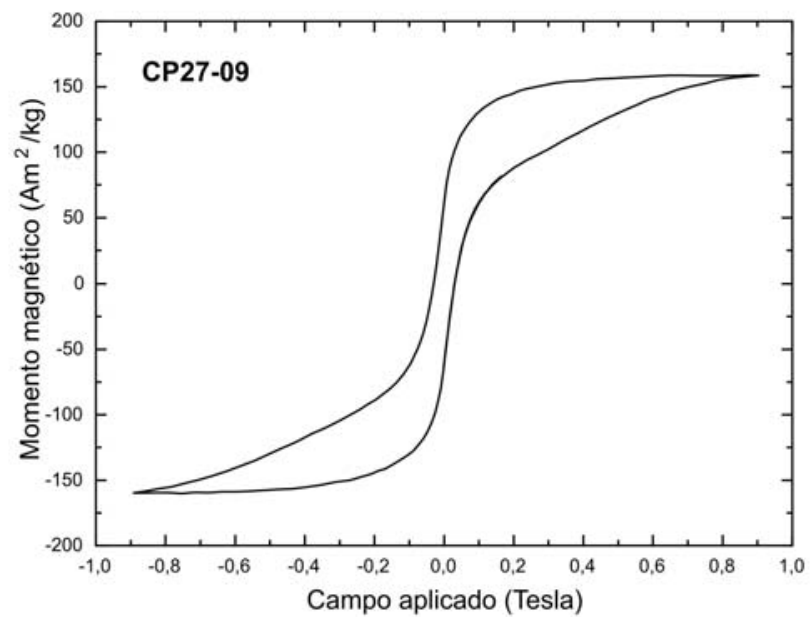

c)

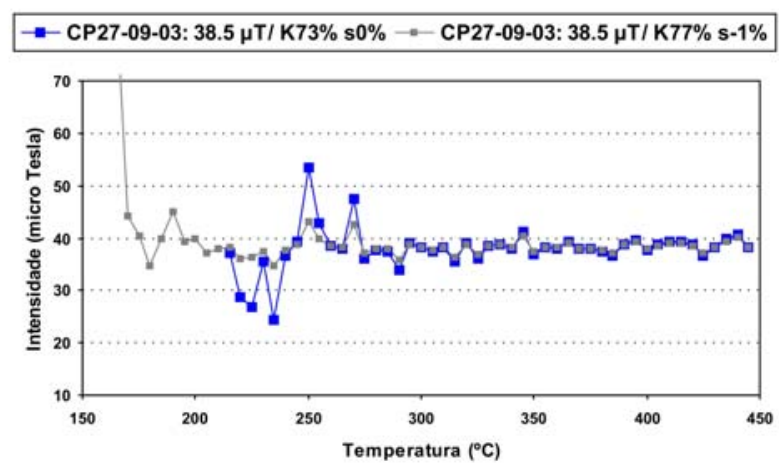

Figura 4: Exemplo dos resultados obtidos para o tijolo 09 da CP27. Em (a) está representada a curva de susceptibilidade magnética em função da temperatura; as setas indicam a sequência do aquecimento e do resfriamento e a unidade de medida é adimensional. Em (b) está a curva de histerese magnética para a amostra desse tijolo; a curva mostra a variação do momento de dipolo em função do campo aplicado - a direção do campo indica a mudança de formato da curva. Em (c), o exemplo de aquisição de intensidade em função da temperatura para uma amostra do tijolo 09; a curva em cinza aponta o ajuste para toda a gama de temperatura, enquanto que a curva em azul representa o melhor ajuste para a componente primária da magnetização; na legenda, os valores de intensidade obtidos (em micro Tesla), K é o percentual de magnetização usado no ajuste da curva e s é o desvio padrão do ajuste. 


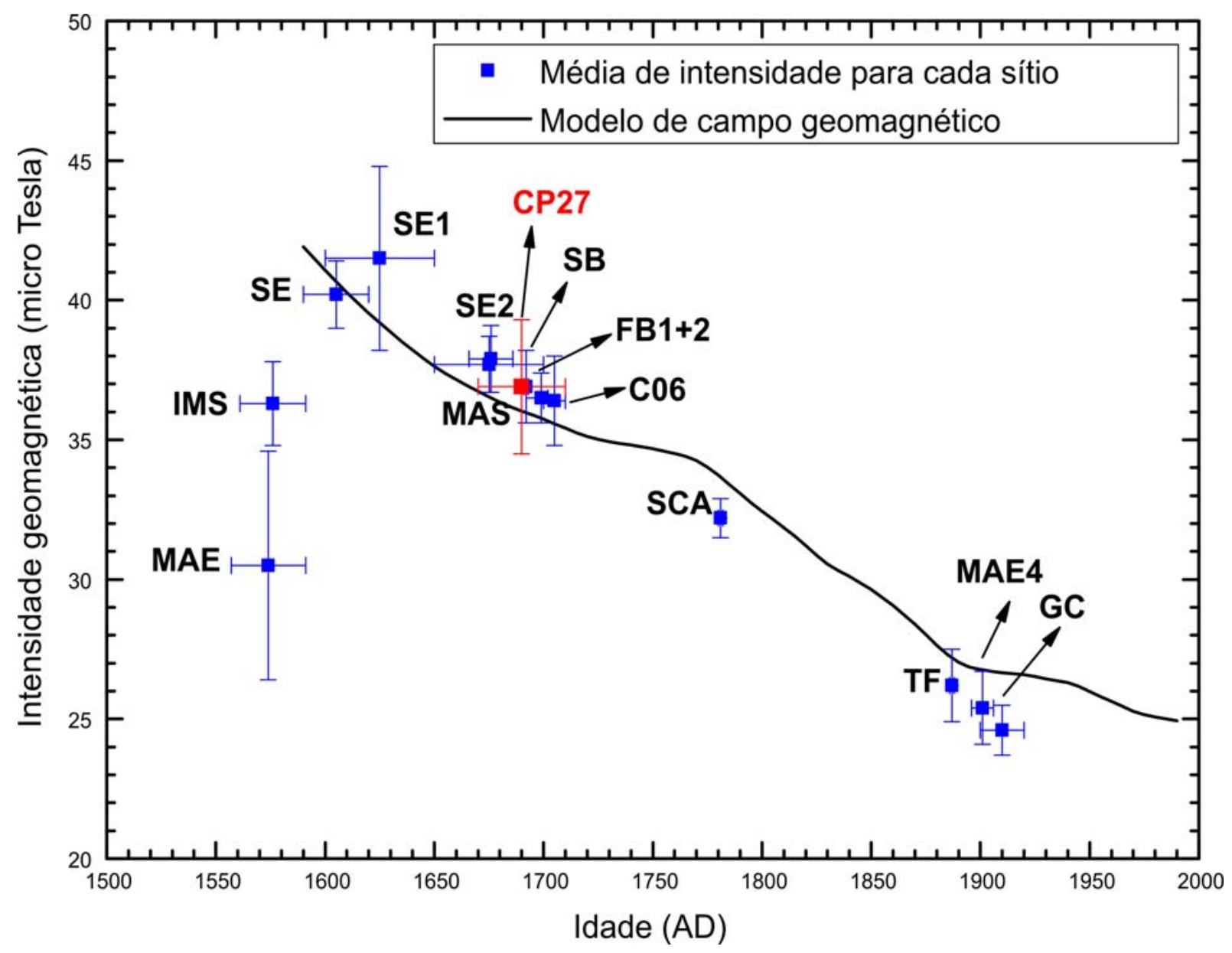

Figura 5: Diagrama idêntico ao da figura 3, mas com a adição da média do sítio CP27. Para esse sítio estão também representados os erros de intensidades e idades, obtidos a partir da comparação com os sítios de intensidades magnéticas idênticas. 
Tabela 1: Sítios arqueológicos estudados. Sítios: nome e sigla utilizada em cada sítio; Localização em termos de latitude (Sul) e longitude (Oeste) dada em graus; Amostras: tipo de material estudado e descrição geral das amostras; Datação: estimativas de idades em termos de contextos Histórico (Hist.) e Arqueológico (Arq.).; Intervalo de idade: dado em anos AD.

\begin{tabular}{|c|c|c|c|c|c|}
\hline \multirow{2}{*}{ Sítios } & \multicolumn{2}{|r|}{ Amostras } & \multicolumn{2}{|c|}{ Datação } & \multirow{2}{*}{$\begin{array}{l}\text { Intervalo } \\
\text { de idade } \\
\text { (AD) }\end{array}$} \\
\hline & Tipo & Descrição geral & Hist. & Arq. & \\
\hline $\begin{array}{l}\text { Museu de Arqueologia e } \\
\text { Etnologia } 1 \text { e } 2 \text { (MAE1+2) } \\
\text { Salvador, BA }\end{array}$ & Tijolos & $\begin{array}{l}\text { Tijolos de coloração vermelha, argila de } \\
\text { granulação grossa com presença de quartzo }\end{array}$ & $x$ & & $1556-1591$ \\
\hline $\begin{array}{l}\text { Igreja Mem de Sá (IMS) } \\
\text { Salvador, BA }\end{array}$ & Tijolos & $\begin{array}{l}\text { Tijolos de coloração vermelha, argila de } \\
\text { granulação grossa com presença de quartzo }\end{array}$ & $x$ & $x$ & 1561-1591 \\
\hline $\begin{array}{l}\text { Praça da Sé (SE) } \\
\text { Salvador, BA }\end{array}$ & $\begin{array}{l}\text { Tijolos e } \\
\text { telhas }\end{array}$ & $\begin{array}{l}\text { Tijolos de coloração vermelha, argila de } \\
\text { granulação fina; telhas de argila vermelha, } \\
\text { granulação grossa com presença de quartzo }\end{array}$ & $x$ & $x$ & $1590-1620$ \\
\hline $\begin{array}{l}\text { Praça da Sé } 1 \text { (SE1) } \\
\text { Salvador, BA }\end{array}$ & $\begin{array}{l}\text { Tijolos e } \\
\text { telhas }\end{array}$ & $\begin{array}{l}\text { Tijolos de coloração vermelha, argila com } \\
\text { granulação grossa com presença de quartzo }\end{array}$ & $x$ & $x$ & $1600-1650$ \\
\hline $\begin{array}{l}\text { Praça da Sé } 2 \text { (SE2) } \\
\text { Salvador, BA }\end{array}$ & $\begin{array}{l}\text { Tijolos e } \\
\text { telhas }\end{array}$ & $\begin{array}{l}\text { Tijolos de coloração vermelha, argila de } \\
\text { granulação grossa com presença de quartzo }\end{array}$ & $x$ & $x$ & $1650-1700$ \\
\hline $\begin{array}{l}\text { Museu de Arte Sacra (MAS) } \\
\text { Salvador, BA }\end{array}$ & Tijolos & $\begin{array}{l}\text { Tijolos de coloração clara, argila de granulação } \\
\text { grossa com presença de quartzo }\end{array}$ & $x$ & & $1666-1686$ \\
\hline $\begin{array}{l}\text { Solar Berquó (SB) } \\
\text { Salvador, BA }\end{array}$ & Tijolos & $\begin{array}{l}\text { Tijolos de coloração escura a vermelha, argila } \\
\text { de granulação grossa com presença de quartzo }\end{array}$ & $x$ & & 1691-1693 \\
\hline $\begin{array}{l}\text { Farol da Barra } 1 \text { e } 2 \\
\text { (FB1+2) } \\
\text { Salvador, BA }\end{array}$ & Tijolos & $\begin{array}{l}\text { Tijolos de coloração clara a vermelha, argila de } \\
\text { coloração grossa com presença de quartzo }\end{array}$ & $x$ & & $1696-1702$ \\
\hline $\begin{array}{l}\text { Casa número } 6 \text { (C06) } \\
\text { Salvador, BA }\end{array}$ & Tijolos & $\begin{array}{l}\text { Tijolos de coloração vermelha, argila de } \\
\text { coloração grossa com presença de quartzo }\end{array}$ & $x$ & & $1700-1710$ \\
\hline $\begin{array}{l}\text { Solar Conde dos Arcos } \\
\text { (SCA) } \\
\text { Salvador, BA }\end{array}$ & Tijolos & $\begin{array}{l}\text { Tijolos de coloração clara a vermelha, argila de } \\
\text { granulação grossa com presença de quartzo }\end{array}$ & $x$ & & 1780-1781 \\
\hline $\begin{array}{l}\text { Tijoleira Farias (TF) } \\
\text { Salvador, BA }\end{array}$ & Tijolos & $\begin{array}{l}\text { Tijolos de coloração clara a vermelha, argila de } \\
\text { coloração grossa com presença de quartzo e } \\
\text { fragmentos de tijolos }\end{array}$ & $x$ & & 1886-1887 \\
\hline $\begin{array}{l}\text { Museu de Arqueologia e } \\
\text { Etnologia } 4 \text { (MAE4) } \\
\text { Salvador, BA }\end{array}$ & Tijolos & $\begin{array}{l}\text { Tijolos de coloração vermelha, argila de } \\
\text { granulação fina com presença de quartzo }\end{array}$ & $x$ & $x$ & 1896-1906 \\
\hline $\begin{array}{l}\text { Galeria Canizares (GC) } \\
\text { Salvador, BA }\end{array}$ & Tijolos & $\begin{array}{l}\text { Tijolos de coloração vermelha, argila com } \\
\text { granulação grossa e presença de quartzo e } \\
\text { fragmentos de tijolos }\end{array}$ & $x$ & $x$ & $1900-1920$ \\
\hline
\end{tabular}





\section{Capítulo 6}

\section{Discussão e conclusões}

Os resultados de arqueointensidade obtidos para as regiões Nordeste e Sudeste do Brasil permitem traçar a evolução do campo geomagnético destas regiões para o período histórico dos últimos cinco séculos. Além disso, os dados foram utilizados como uma ferramenta de datação arqueológica, para definir a idade de uma casa do Pelourinho. Nesse Capítulo serão definidas as duas curvas de referência para o Nordeste e Sudeste, com base nos resultados finais de arqueointensidade. Em seguida, essas curvas serão comparadas com os modelos de campo mais utilizados para estudos da variação secular nessa escala de tempo. As implicações dos resultados obtidos neste trabalho de tese para o entendimento da evolução do momento de dipolo e de eventuais influências de componentes não dipolares do campo no hemisfério sul serão também discutidas.

\subsection{Variação da intensidade do CMT para os últimos 500 anos}

\subsubsection{Curva de referência para a região Nordeste do Brasil}

A curva de referência para a região Nordeste do Brasil foi construída a partir da análise de 57 fragmentos (183 espécimes) de 14 sítios arqueológicos distintos. Os valores médios de intensidade variam entre 25,0 $\mu \mathrm{T}$ (sítio GC) e 41,4 $\mu \mathrm{T}$ (sítio SE1). Todos os sítios desta coleção foram estudados a partir de amostras coletadas na cidade de Salvador, o que elimina a necessidade de correção de latitude pela aproximação do dipolo geocêntrico axial (GAD) para comparação entre os sítios.

Os resultados de arqueointensidade são apresentados na Figura 6.1 e indicam o comportamento do campo geomagnético para a região Nordeste nos últimos cinco séculos. A boa consistência dos resultados de intensidade obtidos para os sítios com idades semelhantes reforça a confiabilidade das determinações de intensidade e dos critérios utilizados para datação dos sítios. Os resultados para a segunda metade do século XVI sugerem que a 
intensidade do campo geomagnético alcançou um máximo em torno de $1625 \mathrm{AD}$, seguido por uma queda contínua de intensidade ao longo dos últimos 400 anos, que corresponde a um decréscimo de cerca de $40 \%$ para os valores obtidos entre a primeira metade do século XVII e o começo do século XX.

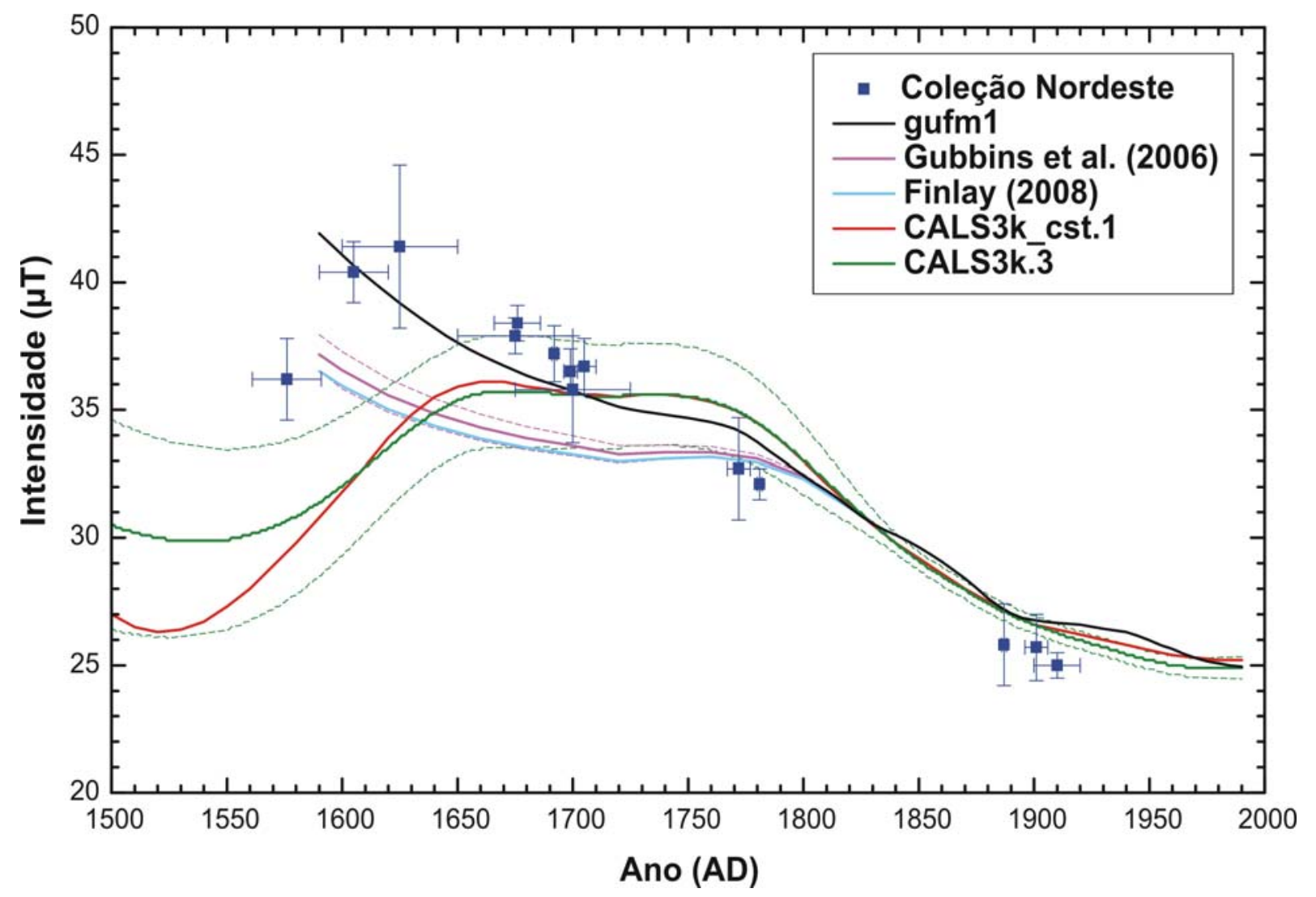

Figura 6.1: Evolução da intensidade do campo geomagnético para a região Nordeste deduzida a partir dos resultados de arqueointensidade e modelos de campo para os últimos cinco séculos. Os resultados de arqueointensidade são representados pelos quadrados azuis. Os modelos são representados pelas seguintes curvas: preto, modelo gufm1 de Jackson et al. (2000); rosa, modelo de Gubbins et al. (2006) (as curvas em tracejado rosa representam o limite superior e inferior desse modelo); azul, modelo de Finlay (2008); verde e vermelho, modelo de Korte et al. (2009) (as curvas em tracejado verde representam o limite superior e inferior do modelo CALS3k.3).

Os resultados de arqueointensidade do Nordeste podem ser comparados com as curvas de intensidade calculadas a partir dos modelos de campo geomagnético para a cidade de Salvador $\left(13^{\circ} \mathrm{S}, 38,5^{\circ} \mathrm{W}\right)$. Como discutido no Capítulo 1 , os modelos do tipo gufml de Jackson et al. (2000), Gubbins et al. (2006) e Finlay (2008) utilizam ajustes lineares para o

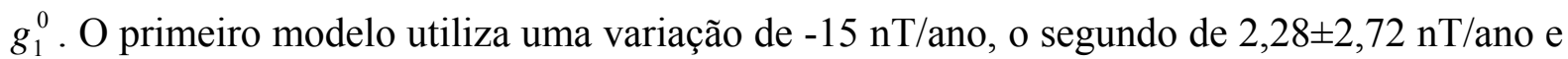
o terceiro considera que o $g_{1}^{0}$ é constante entre $1590 \mathrm{AD}$ e 1840 AD. Os modelos CALS3k_cst.1 e CALS3k.3 apresentam $g_{1}^{0}$ variável ao longo do tempo, embora na prática 
utilizem a geometria do modelo gufm1 para o período entre 1650 AD e 1840 AD através de uma técnica de penalização dos coeficientes (Korte et al., 2009). A comparação mostra que os resultados de arqueointensidade obtidos para a coleção do Nordeste estão muito próximos da curva de variação prevista pelo modelo gufm1 de Jackson et al. (2000), com exceção do sítio mais antigo (IMS). Já as curvas calculadas por Gubbins et al. (2006) e Finlay (2008) apresentam valores bem mais baixos do que aqueles obtidos com as medidas de arqueointensidade no intervalo entre 1600 AD e 1750 AD. As curvas obtidas pelos modelos CALS3k_cst.1 e CALS3k.3 também não reproduzem os dados de arqueointensidade para as idades anteriores a 1600 AD, muito embora apresentem uma tendência de queda para esse intervalo de tempo definindo assim uma forma semelhante àquela apresentada pela curva de referência para o Nordeste. Os modelos e os dados concordam, dentro das margens de erro, a partir de $1750 \mathrm{AD}$.

\subsubsection{Curva de referência para a região Sudeste do Brasil}

A curva de referência para a região Sudeste do Brasil foi obtida a partir da análise de 43 fragmentos (150 espécimes) de 9 sítios arqueológicos. Os valores de intensidade nessa região oscilam entre 25,4 $\mu \mathrm{T}$ (sítio FL2) e 42,2 $\mu \mathrm{T}$ (sítio INSA). Os sítios analisados são procedentes de 6 cidades localizadas dentro de uma área de $2,5^{\circ}$ em latitude e $7,8^{\circ}$ em longitude. Embora essa região seja fortemente afetada por fontes não dipolares, optou-se por recalcular os valores de intensidade utilizando a aproximação do GAD tendo em vista as distâncias em latitude relativamente pequenas entre os diferentes sítios amostrados. Para esta comparação foi escolhida a latitude da cidade de São Paulo $\left(23,5^{\circ} \mathrm{S}, 46,6^{\circ} \mathrm{W}\right)$.

A Figura 6.2 mostra a evolução da intensidade do CMT para a região Sudeste. Esta curva apresenta valores de intensidade que são bastante consistentes, indicando uma diminuição contínua em cerca de $5 \mu \mathrm{T}$ por século entre o começo do século XVII e o começo do século XX, o que corresponde a uma variação de aproximadamente $35 \%$ da intensidade desde $1600 \mathrm{AD}$.

A curva de referência do Sudeste pode também ser comparada com as curvas de variação previstas pelos modelos de campo geomagnético para o período histórico calculadas para a cidade de São Paulo. A comparação entre os dados de arqueointensidade e os modelos mostra que, ao contrário do que se observa no Nordeste, os valores determinados pelo modelo gufm1 de Jackson et al. (2000) são sistematicamente mais elevados do que os valores de arqueointensidade para todo o período anterior a $1840 \mathrm{AD}$, embora o modelo acompanhe a 
tendência de queda na intensidade indicada pelos dados. Notadamente, os resultados de arqueointensidade seguem a tendência definida pelos modelos de Gubbins et al. (2006) e Finlay (2008), que prevêem uma pequena variação do $g_{1}^{0}$ entre 1590 AD e 1840 AD. A comparação entre os dados arqueomagnéticos e os modelos CALS3k.3 e CALS3k_cst.1 determinados por Korte et al. (2009) são menos satisfatórias do que aquelas obtidas com os modelos de Gubbins et al. (2006) e Finlay (2008). Os modelos mais atuais foram construídos com base na mais completa base de dados arqueomagnéticos compilada por Donadini et al. (2009). A diferença entre os dados de arqueointensidade e os modelos explicita a limitação destes na descrição de curvas regionais, principalmente para o hemisfério Sul do planeta.

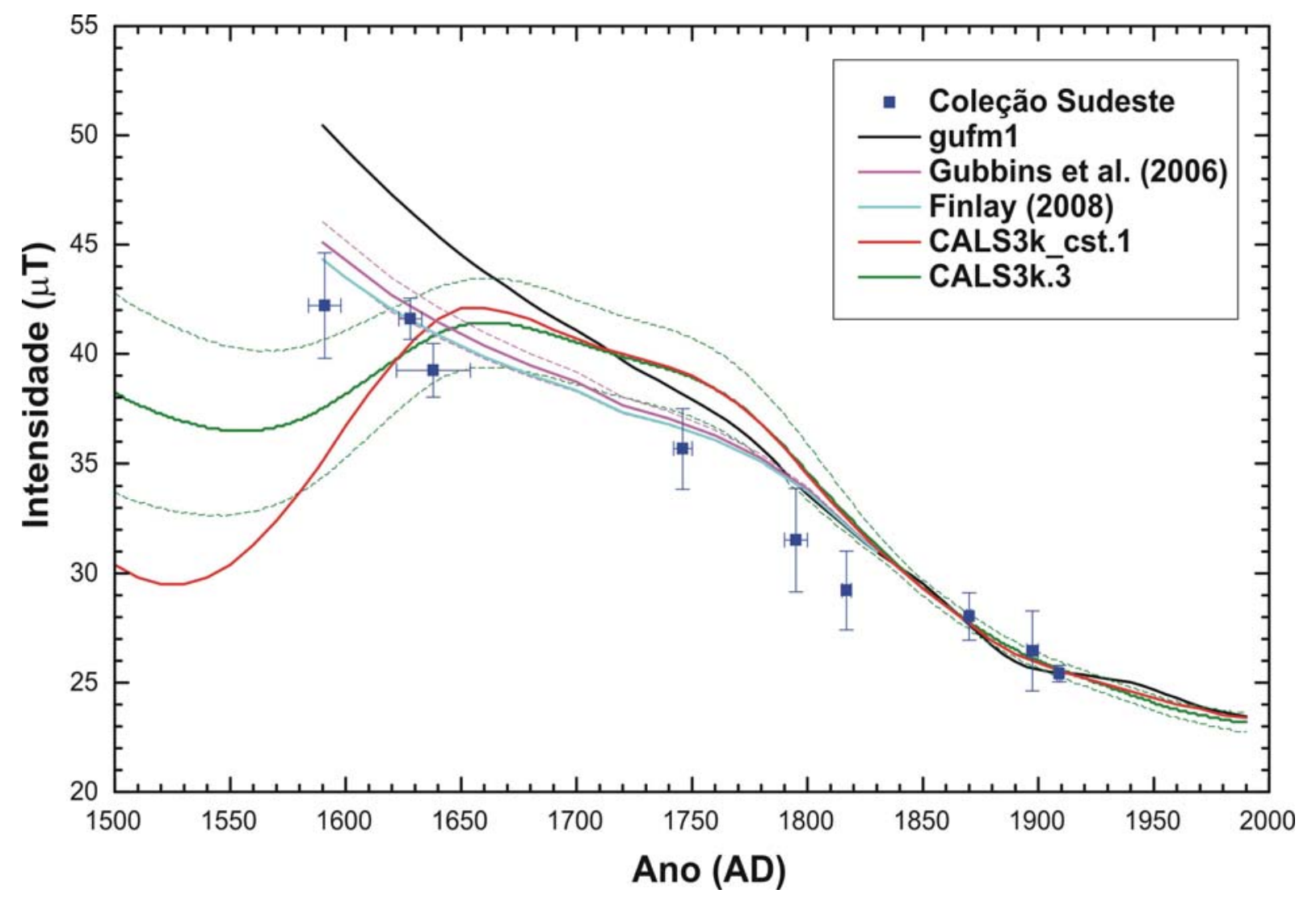

Figura 6.2: Evolução da intensidade do campo geomagnético para a região Sudeste deduzida a partir dos resultados de arqueointensidade e modelos de campo para os últimos cinco séculos. Os resultados de arqueointensidade são representados pelos quadrados azuis. Os modelos são representados pelas seguintes curvas: preto, modelo gufm1 de Jackson et al. (2000); rosa, modelo de Gubbins et al. (2006) (as curvas em tracejado rosa representam o limite superior e inferior desse modelo); azul, modelo de Finlay (2008); verde e vermelho, modelo de Korte et al. (2009) (as curvas em tracejado verde representam o limite superior e inferior do modelo CALS3k.3).Todos os resultados e os modelos estão reduzidos à latitude da cidade de São Paulo $\left(23,5^{\circ} \mathrm{S}, 46,6^{\circ} \mathrm{W}\right)$. 


\subsubsection{Implicações na evolução do CMT em escala de centenas de anos}

Algumas inferências acerca das diferenças no comportamento da variação do campo entre as regiões Nordeste e Sudeste podem ser efetuadas a partir da comparação direta entre as duas curvas após a redução dos dados para a mesma latitude. Na Figura 6.3 são apresentados os dados de intensidade das duas regiões reduzidos para a latitude de São Paulo. Observa-se que os valores de intensidade médios para o Sudeste são sistematicamente mais baixos do que aqueles obtidos para o Nordeste após a redução em latitude. Esta redução é baseada no modelo do GAD, portanto as diferenças entre as duas curvas estão provavelmente associadas às fortes componentes não-dipolares presentes na região Sudeste, que são responsáveis pelas baixas intensidades do campo neste setor do país. Como observado anteriormente por Hartmann e Pacca (2009) os efeitos da SAMA apresentam grande abrangência espacial. Por exemplo, para o ano de 1900 AD a contribuição do campo não-dipolar alcança cerca de 50\% do campo total na região Sudeste.

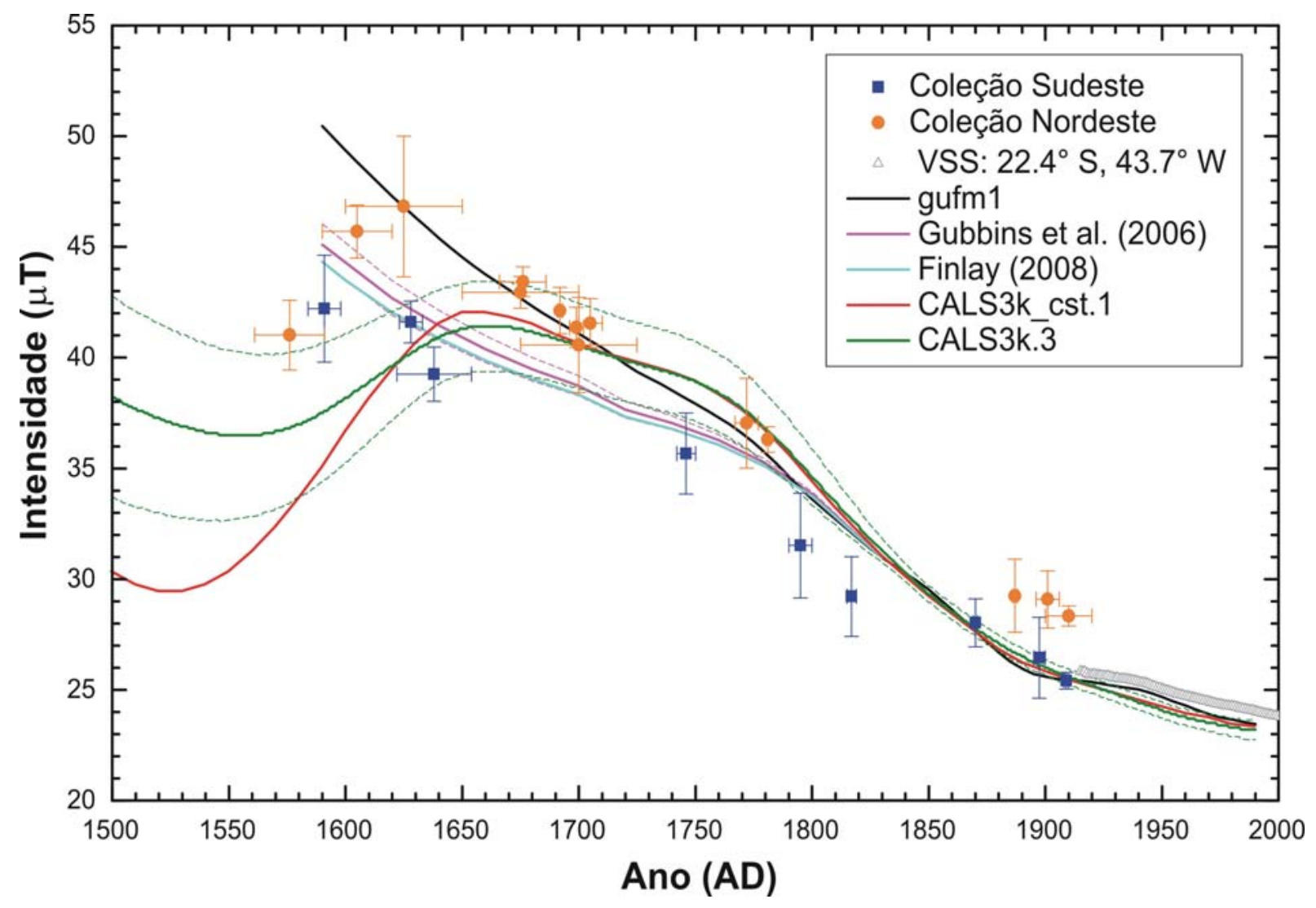

Figura 6.3: Os resultados de arqueointensidade das duas regiões do Brasil reduzidas à latitude da cidade de São Paulo $\left(23.5^{\circ} \mathrm{S}, 46.6^{\circ} \mathrm{W}\right)$. As curvas dos modelos e os dados de intensidade total do Observatório de Vassouras (VSS, localizado no estado do Rio de Janeiro) também foram reduzidos para a localização de São Paulo. 
Os dados obtidos aqui permitem também testar a evolução do termo mais fundamental do campo geomagnético, $\mathrm{o} g_{1}^{0}$. Para tal, utilizou-se o procedimento adotado por Gubbins et al. (2006) e Genevey et al. (2009), onde os dados de arqueointensidade são normalizados pelo modelo gufml e então comparados com o $g_{1}^{0}$ definido pelo mesmo modelo. Esta abordagem é baseada no teorema de Hulot et al. (1997) que afirma que a morfologia do campo dipolar pode ser determinada com base apenas em dados direcionais e que um registro simples de intensidade (ou paleointensidade) é suficiente para determinar a magnitude do campo global. Os dados do Brasil foram representados na Figura 6.4 juntamente com os valores de $g_{1}^{0}$ dos modelos de Jackson et al. (2000), Gubbins et al. (2006) e Finlay (2008) e com um conjunto de dados de intensidade de alta qualidade da França para o mesmo período de tempo (Genevey et al., 2009). Os dados apresentam forte dispersão durante o século XVII e uma boa coerência para períodos mais recentes. De um modo geral, os dados mostram uma oscilação com valores elevados em torno de $1650 \mathrm{AD}$ e valores baixos em torno de $1800 \mathrm{AD}$. É interessante observar que por volta de $1800 \mathrm{AD}$ todos os valores de $g_{1}^{0}$ calculados a partir dos três conjuntos de dados arqueomagnéticos do Brasil e da França têm valores semelhantes e são inferiores ao dipolo axial determinado pelos modelos de campo. Isto indica que um aumento moderado do dipolo axial em um intervalo de aproximadamente 75 anos provavelmente precedeu a queda do momento de dipolo, que é bem marcada no registro dos observatórios magnéticos a partir de 1840 AD. Essa observação reforça a idéia de que o momento de dipolo oscila em intervalos de várias dezenas a centenas de anos (Genevey et al., 2009). A hipótese de um dipolo oscilatório tem duas conseqüências diretas para as feições geomagnéticas observadas em escala de tempo arqueomagnética: (a) a queda do $g_{1}^{0}$ observada para os últimos 160 anos seria uma feição de curto período; (b) a evolução do $g_{1}^{0}$ para o último milênio seria bem mais complexa do que a simples tendência de queda sugerida nos modelos atuais e em diferentes compilações (e.g. Yang et al., 2000; Korte e Constable, 2005b; Genevey et al., 2008; Korte et al., 2009; Donadini et al., 2010). Estas comparações mostram claramente a limitação dos modelos de campo para o período de tempo histórico no Brasil. Essa limitação muito provavelmente também pode ser estendida para uma porção significativa da América do Sul e Atlântico Sul. 


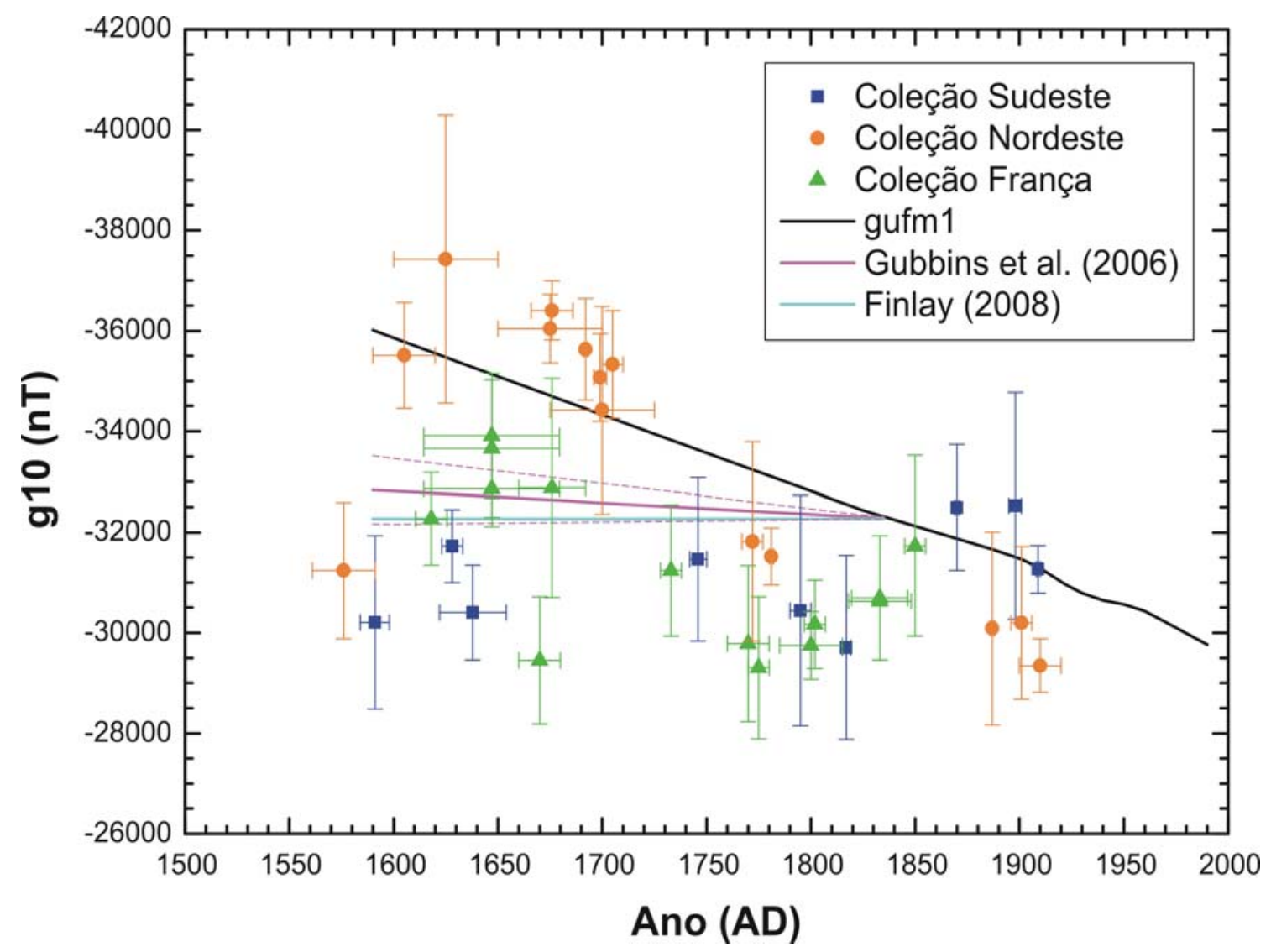

Figura 6.4: Comparação entre as diferentes evoluções do $g_{1}^{0}$ entre os modelos de campo geomagnético e os dados normalizados de arqueointensidade (ver texto para detalhes). A curva em preto representa o modelo gufm1 (Jackson et al., 2000), a curva em rosa representa o modelo de Gubbins et al. (2006) (as curvas em tracejado rosa representam os limites superior e inferior desse modelo), e a curva em azul representa o modelo de Finlay (2008).

\subsection{Considerações finais e perspectivas}

As análises de paleointensidade nas duas coleções estudadas foram efetuadas em fragmentos coletados em sítios com contextos históricos, arqueológicos e arquitetônicos muito bem definidos. Somente sítios que não apresentavam ambigüidade com relação à idade foram considerados na construção das curvas de arqueointensidade. Esses materiais foram testados através de investigação da mineralogia magnética e somente os mais promissores foram analisados. Os procedimentos experimentais (TT-ZI e Triaxe) se mostraram adequados para determinação da paleointensidade nesses materiais, com taxa de sucesso global de 57\%. Neste ponto, salienta-se a importância da aplicação da correção de anisotropia, para diminuição da dispersão intra-fragmento, e da correção da taxa de resfriamento, para diminuição significativa de valores de intensidade espúrios. Após as análises experimentais 
foram aplicados rígidos critérios de seleção aos resultados, onde somente fragmentos e sítios que tivessem uma boa coerência nos valores de intensidade foram incluídos nas curvas de referência. Portanto, os resultados alcançados neste trabalho podem ser considerados de boa qualidade e definem as bases para estudos futuros de arqueointensidade na região.

Os resultados apresentados nesta tese são os primeiros obtidos em materiais arqueológicos históricos do Brasil e preenchem uma lacuna importante em uma das regiões mais carentes de dados arqueomagnéticos em todo o globo. Os dados de intensidade são fortemente influenciados pelas fontes não dipolares do campo presentes na América do Sul e mostram diferenças significativas entre as curvas de variação para as regiões Nordeste e Sudeste. Esse comportamento contrasta com aquele observado na Eurásia, onde as curvas de variação de arqueointensidade são coerentes ao longo de grandes regiões, o que revela a necessidade de obtenção de curvas regionais para a América do Sul com boa qualidade temporal e espacial para que se possa reconstruir a variação do campo no passado. Isso implica no aprimoramento das curvas obtidas para o Nordeste e Sudeste, mas também na construção de novas curvas para outros setores do continente. Além de estudos de arqueointensidade, um dos desafios futuros será a obtenção de dados paleodirecionais devido à ausência desse tipo de registro no continente para os últimos séculos.

As variações rápidas da intensidade observadas nas curvas regionais têm um forte potencial de aplicação em estudos arqueológicos, como demonstrado nos estudos efetuados no Pelourinho. Esse trabalho deverá ser expandido com o intuito de estudar a história de ocupação do centro histórico de Salvador juntamente com os arqueólogos do Projeto Monumenta. Além da utilização como ferramenta de datação, os métodos arqueomagnéticos podem ser utilizados em diversas outras aplicações. Dentro do tema de estudo desta tese, dois outros trabalhos de aplicação do arqueomagnetismo em estudos arqueológicos estão sendo conduzidos: estudos de proveniência de material cerâmico a partir do contraste de intensidade entre o material originário do Brasil e aquele proveniente da Europa; análise de processos de fabricação de material construtivo, a partir da comparação das formas de manufatura e os parâmetros de anisotropia magnética em materiais construtivos. Esses estudos revelam o interesse no desenvolvimento do Arqueomagnetismo, um domínio de pesquisa multidisciplinar com interfaces entre a Arqueologia, o Geomagnetismo e o Magnetismo de Materiais. 


\section{Referências}

Aitken, M.J., 1999. Archaelogical dating using physical phenomena. Rep. Prog. Phys., 62, 1333-1376.

Aitken, M.J., Alcock, P.A., Bussel, G.D., Shaw, C.J., 1981. Archaeomagnetic determination of the past geomagnetic intensity using ancient ceramics: allowance for anisotropy. Archaeometry, 23, 53-64. doi: 10.1111/j.1475-4754.1981.tb00954.x

Aitken, M.J., Allsop, A.L., Bussell, G.D., Winter, M.B., 1988. Determination of the intensity of the Earth's magnetic field during archaeological times: Reliability of the Thellier technique. Rev. Geophys., 26, 3-12.

Alexandrescu, M., Courtillot, V., Le Mouël, J.L., 1996. Geomagnetic field direction in Paris since the mid-sixteenth century. Phys. Earth Planet. Int., 120, 111-136. doi: 10.1016/S0031-9201(96)03194-9

Alvim, S., 1996. Arquitetura religiosa e colonial no Rio de Janeiro. Vol. 1 e 2. Rio de Janeiro: Editora UFRJ, IPHAN.

Bahia, 1997. Secretaria da Cultura e Turismo IPAC-BA: Inventário de Proteção do Acervo Cultural da Bahia, $1^{\text {a }}$ ed., Salvador.

Barbetti, M., 1977. Measurements of recent geomagnetic secular variation in southeast Australia and the question of dipole wobble. Earth Planet. Sci. Lett., 36, 207-218.

Barletta, F., St-Onge, G., Channell, J.E.T., Rochon, A., Polyak, L., Darby, D., 2008. Highresolution paleomagnetic secular variation and relative paleointensity records from the western Canadian Arctic: implication for Holocene stratigraphy and geomagnetic field behaviour. Can. J. Earth Sci., 45, 1265-1281. doi: 10.1139/E08-039

Barraclough, D.R., 1974. Spherical harmonic analyses of the geomagnetic field for eight epochs between 1600 and 1910. Geophys. J. R. Astron. Soc., 36, 497-513.

Barraclough, D.R., 1995. Observations of the Earth's magnetic field made in Edinburgh from 1670 to the present day. Trans. R. Soc. Edin. Earth Sci., 85, 239-252.

Bloxham, J., Gubbins, D., 1985. The secular variation of the Earth's magnetic field. Nature, 317, 777-781. doi: $10.1038 / 317777 \mathrm{a} 0$

Bloxham, J., Gubbins, D., Jackson, A., 1989. Geomagnetic Secular Variation. Phil. Trans. Royal Soc. London A, 329, 415-502.

Bloxham, J., Jackson A., 1989. Simultaneous Stochastic Inversion for Geomagnetic Main Field and Secular Variation 2. 1820-1980. J. Geophys. Res., 94, 15753-15769.

Bloxham, J., Jackson A., 1992. Time-dependent mapping of the magnetic field at the coremantle boundary. J. Geophys. Res., 97, 19537-19563.

Boyd, M., 1986. A new method for measuring paleomagnetic intensities. Nature, 319, 208209. 
Bullard, E., 1955. A discussion on magneto-hydrodynamics: Introduction. Proc. R. Soc. London A, 233, 289-296.

Bullard, E.C., Freedeman, C., Gellman, H., Nixon, J., 1950. The westward drift of the Earth's magnetic field. Phil. Trans. Roy. Soc. A, 243, 67-92.

Burakov, K., Nachasova, I., 1978. A method and results of studying the geomagnetic field of Khiva from the middle of the sixteenth century, Izv. Earth Phys., 14, 833-838.

Busse, F.H., 2000. Homogeneous Dynamos in Planetary Cores and in the Laboratory. Annu. Rev. Fluid Mech., 32, 383-408.

Cafarella, L., De Santis, A., Meloni, A., 1992. Secular variation in Italy from historical geomagnetic field measurements. Phys. Earth Planet. Int., 73, 206-221. doi: 10.1016/00319201(92)90091-9

Carlut, J., Courtillot, V., 1998. How complex is the time averaged geomagnetic field over the last 5 Myr?. Geophys. J. Int., 134, 527-544. doi: 10.1046/j.1365-246x.1998.00577.x

Carlut, J., Courtillot, V., Hulot, G., 1999. Over how much time should the geomagnetic field be averaged to obtain the mean-palaeomagnetic field?. Terra Nova, 11, 239-243. doi: 10.1046/j.1365-3121.1999.00253.x

Chapman, S., Bartels, J., 1940. Geomagnetism, Vol. 2, 1049p., University Press, Oxford.

Chauvin, A., Garcia, Y., Lanos, Ph., Laubenheimer, F., 2000. Paleointensity geomagnetic field recovered on archaeomagnetic sites from France. Phys. Earth Planet. Int., 120, 111 136. doi: 10.1016/S0031-9201(00)00148-5

Coaracy, V., 1988. Memórias da Cidade do Rio de Janeiro, São Paulo: EDUSP.

Coe, R.S., 1967. The determination of paleo-intensities of the Earth's magnetic field with emphasis on mechanisms which could cause non-ideal behavior in Thelier's method. J. Geomag. Geoelectric., 19, 157-179.

Coe, R.S., Grommé, C.S., Mankinen, E.A., 1978. Geomagnetic paleointensities from radiocarbon dated lava flows on Hawaii and the question of the Pacific non-dipole low. J. Geophys. Res., 83, 1740-1756.

Constable, C.G., Johnson, C.L, Lund, S.P., 2000. Global geomagnetic field models for the past 3000 years: Transient or permanent flux lobes?. Phil. Trans. R. Soc. London A, 358, 991-1008.

Constable, C.G., Korte, M., 2006. Is Earth's magnetic field reversing?. Earth Planet. Sci. Lett., 246, 1-16. doi: 10.1016/j.eps1.2006.03.038

Costa, C.A.S., 2005a. Materiais construtivos do sítio da primeira catedral do Brasil: modelos de estudos para telhas, tijolos, cravos e azulejos aplicados aos materiais do sítio da antiga igreja da Sé, Salvador, Bahia. Clio Arqueológica, 19, 43-78.

Costa, C.A.S., 2005b. A influência do Colégio dos Jesuítas na configuração da malha urbana de Salvador-BA (1549-1760). Dissertação de Mestrado. Departamento de História, Centro de Filosofia e Ciências Humanas, Universidade Federal de Pernambuco.

Daly, L., Le Goff, M., 1996. An updated and homogeneous world secular variation data base. 1. Smoothing of the archaeomagnetic results. Phys. Earth Planet. Int., 93, 159-190. doi: 10.1016/0031-9201(95)03075-1

Day R., Fuller, M.D., Schmidt, V.A., 1977. Hysteresis properties of titanomagnetites: Grain size and composition dependence. Phys. Earth Planet. Int., 13, 260-267. 
Dodson, M., McClelland-Brown, E., 1980. Magnetic blocking temperatures of single-domain grains during slow cooling. J. Geophys. Res., 85, 2625-2637.

Donadini, F., Korte, M., Constable, C.G., 2009. Geomagnetic field for 0 - 3ka: 1. New data sets for global modeling. Geochem. Geophys. Geosyst., 10, 6, Q06007. doi: 10.1029/2008GC002295

Donadini, F., Korte, M., Constable, C.G., 2010. Millennial Variations of the Geomagnetic Field: from Data Recovery to Field Reconstruction. Space Sci. Rev. doi: 10.1007/s11214010-9662-y

Dunlop, D.J., 2008. Paleointensity determination using continuous thermal measurements by a high-temperature vibrating thermomagnetometer. Geochem. Geophys. Geosyst., 9, Q09Y03, doi: 10.1029/2008GC002054

Dunlop, D.J., Özdemir, Ö., 1997. Rock Magnetism, Fundamental and Frontiers, Cambridge Univ. Press, New York.

Dunlop, D.J., Özdemir, Ö., 2001. Beyond Néel's theories: thermal demagnetization of narrow-band partial thermoremanent magnetizations. Phys. Earth Planet. Int., 126, 43-57. doi: 10.1016/S0031-9201(01)00243-6

Dunlop, D.J., Xu, S., 1994. Theory of partial thermoremanent magnetization in multidomain grains. 1. Repeated identical barriers to wall motion (single microcoercivity). J. Geophys. Res., 99, B5, 9005-9023. doi: 10.1029/93JB02566

Fausto, B., 2008. História do Brasil, 13ª ed., Ed. Univ. São Paulo, São Paulo.

Finlay, C.C., 2008. Historical variation of the geomagnetic axial dipole. Phys. Earth Planet. Int., 170, 1-14. doi: 10.1016/j.pepi.2008.06.029

Fox, J.M.W., Aitken, M.J., 1980. Cooling-rate dependence of thermoremanent magnetization, Nature, 283, 462-463. doi:10.1038/283462a0

Fraser-Smith, A.C., 1987. Centered and Eccentric Geomagnetic Dipoles and Their Poles, 1600-1985. Rev. Geophys., 25, 1-16.

Friis-Christensen, E., Lühr, H., Hulot, G., 2006. Swarm: A constellation to study the Earth's magnetic field. Earth Plan. Space, 58, 351-358.

Gailitis, A., Lielausis, O., Platacis, E., Gerbeth, G., Stefani, F., 2002. Colloquium: Laboratory experiments on hydromagnetic dynamos. Rev. Mod. Phys., 74, 973-990. doi: 10.1103/RevModPhys.74.973

Gallet, Y., Genevey, A., Courtillot, V., 2003. On the possible occurrence of archeomagnetic jerks in the geomagnetic field over the past three millennia. Earth Planet. Sci. Lett., 214, 237-252. doi: 10.1016/S0012-821X(03)00362-5

Gallet, Y., Genevey, A., Le Goff, M., Fluteau, F., Eshraghi, S.A., 2006. Possible impact of the Earth's magnetic field on the history of ancient civilizations. Earth Planet. Sci. Lett., 246, 17-26. doi: 10.1016/j.eps1.2006.04.001

Gallet, Y., Hulot, G., Chulliat, A., Genevey, A., 2009. Geomagnetic field hemisphere asymmetry and archeomagnetic jerks. Earth Planet. Sci. Lett., 284, 179-186. doi: 10.1016/j.eps1.2009.04.028

Gallet, Y., Le Goff, M., 2006. High-temperature archeointensity measurements from Mesopotamia. Earth Planet. Sci. Lett., 241, 159-173. doi: 10.1016/j.eps1.2005.09.058 
Genevey, A., Gallet, Y., 2002. Intensity of the geomagnetic field in western Europe over the past 2000 years: New data from ancient French pottery, J. Geophys. Res., B11, 107, 2285. doi:10.1029/2001JB000701

Genevey, A., Gallet, Y., Constable, C.G., Korte, M., Hulot, G., 2008. ArcheoInt: An upgrated compilation of geomagnetic field intensity data for the past ten millennia and its application to the recovery of the past dipole moment. Geochem. Geophys. Geosyst., 9, 4, Q04038. doi: 10.1029/2007/GC001881

Genevey, A., Gallet, Y., Rosen, J., Le Goff, M., 2009. Evidence for rapid geomagnetic field intensity variations in Western Europe over the past 800 years from new French archeomagnetic data. Earth Planet. Sci. Lett., 284, 132-143. doi: 10.1016/j.epsl.2009.04.024

Glatzmaier, G.A., Roberts, P.H., 1995a. A three-dimensional convective dynamo solution with rotating and finitely conducting inner core and mantle. Phys. Earth Planet. Int., 91, $63-75$.

Glatzmaier, G.A., Roberts, P.H., 1995b. A three-dimensional self-consistent computer simulation of a geomagnetic field reversal. Nature, 377, 203-209.

Goméz-Paccard, M., Chauvin, A., Lanos, Ph., Thiriot, J., Jiménez-Castillo, P., 2006. Archeomagnetic study of seven contemporaneous kilns from Murcia (Spain), Phys. Earth Planet. Inter., 157, 16-32. doi: 10.1016/j.pepi.2006.03.001

Gubbins, D., Jones, A.L., Finlay, C.C., 2006. Fall in Earth's Magnetic Field is Erratic. Science, 312, 900-902. doi: 10.1126/science.1124855

Halgedahl, S., Day, R., Fuller, M., 1980. The effect of the cooling rate on the intensity of weak field TRM in single domain magnetite. J. Geophys. Res., 85, 3690-3698.

Hartmann, G.A., Genevey, A., Gallet, Y., Trindade, R.I.F., Etchevarne, C., Le Goff, M., Afonso, M.C., 2010a. Archeointensity in Northeast Brazil over the past five centuries. Earth Planet. Sci. Lett., 296, 340-352. doi: 10.1016/j.eps1.2010.05.016

Hartmann, G.A., Pacca, I.G., 2009. Time evolution of the South Atlantic Magnetic Anomaly. An. Acad. Bras. Ciênc., 81, 243-255. doi: 10.1590/S0001-37652009000200010

Hartmann, G.A., Trindade, R.I.F., Gallet, Y., Genevey, A., Berquó, T.S., Le Goff, M., Lagroix, F., 2010b. Magnetic properties of Brazilian archeological bricks: Further evidence for the widespread occurrence of a Low-T High-Coercivity stable magnetization carrier. In: 2010 The Meeting of the Americas, 2010, Foz do Iguaçu, Brazil.

Hulot, G., Finlay, C.C., Constable, C.G., Olsen, N., Mandea, M., 2010. The magnetic field of the planet Earth. Space Sci. Rev., 152, 159-222. doi: 10.1007/s11214-010-9644-0

Hulot, G., Khokhlov, A., Le Mouël, J.L., 1997. Uniqueness of mainly dipolar magnetic fields recovered from direction data. Geophys. J. Int., 129, 347-354. doi: 10.1111/j.1365246X.1997.tb01587.x

Jackson, A., Jonkers, A.R.T., Walker, M., 2000. Four centuries of geomagnetic secular variation from historical records. Phil. Trans. R. Soc. London, A 358, 957-990. doi: 10.1098/rsta.2000.0569

Jackson, M.J., 1991. Anisotropy of magnetic remanence: A brief review of mineralogical sources, physical origins, and geological applications, and comparison with susceptibility anisotropy. Pure Appl. Geophys., 136, 1-28. 
Johnson, C.L., Constable, C.G., Tauxe, L., Barendregt, R., Brown, L.L., Coe, R.S., Layer, P., Mejia, V., Opdyke, N.D., Singer, B.S., Staudigel, H., Stone, D.B., 2008. Recent investigations of the $0-5$ Ma geomagnetic field recorded by lava flows. Geochem. Geophys. Geosyst., 9, Q04032, doi: 10.1029/2007GC001696

Jones, C.A., 2007. Geodynamo. In: Encyclopedia of Geomagnetism, (D. Gubbins, E. HerreroBervera, ed.), Springer, Dordrecht, pp. 287-296.

Jonkers, A.R.T., Jackson, A., Murray, A., 2003. Four centuries of the geomagnetic data from historical records. Rev. Geophys., 41, 2.

Kageyama, A., Sato, T., 1995. Complexity Simulation Group. Computer simulation of a magnetohydrodynamic dynamo II, Phys. Plasmas, 2, 1421-1431.

Korhonen, K., Donadini, F., Riisager, P., Pesonen, L.J., 2008. GEOMAGIA50: An archeointensity database with PHP and MySQL. Geochem. Geophys. Geosyst., 9, Q04029, doi: $10.1029 / 2007 \mathrm{GC} 001893$

Korte, M., Constable, C. G., 2003. Continuous global geomagnetic field models for the past 3000 years. Earth Planet. Sci. Let., 140, 73-89.

Korte, M., Constable, C.G., 2005a. Continuous geomagnetic field for the past 7 millennia: 2.CALS7K. Geochem. Geophys. Geosyst., 6, 1, Q02H16. doi:10.1029/2004GC000801

Korte, M., Constable, C.G., 2005b. The geomagnetic dipole moment over the last 7000 years - new results from a global model. Earth Planet. Sci. Let., 236, 348-358.

Korte, M., Donadini, F., Constable, C.G., 2009. Geomagnetic field for 0 - 3ka: 2. A new series of time-varying global models. Geochem. Geophys. Geosyst., 10, 6, Q06008. doi: 10.1029/2008GC002297

Korte, M., Genevey, A., Constable, C.G., Frank, U., Schnepp, E., 2005. Continuous geomagnetic field models for the past 7 millenia: 1. A new global data compilation. Geochem. Geophys. Geosyst., 6, 2, Q02H15. doi: 10.1029/2004GC000800

Kovacheva, M., 1980. Summarized results of the archaeomagnetic investigation of the geomagnetic field variation for the last $8000 \mathrm{yr}$ in south-eastern Europe. Geophys. J. R. Astron. Soc., 61, 57-64.

Kovacheva, M., Chauvin, A., Jordanova, N., Lanos, Ph., Karloukovski, V., 2009. Remanence anisotropy effect on the paleointensity results obtained from various archaeological materials, excluding pottery. Earth Planet. Space, 61, 711-732.

Kovacheva, M., Veljovich, D., 1977. Geomagnetic field variations in southeasthern Europe between 6500 and 100 years BC. Earth Planet. Sci. Let., 37, 131-138.

Kuang, W., Bloxham, J., 1997. An Earth-like numerical dynamo model. Nature, 389, 371374.

Langel, R. A., 1987. The main field. In Geomagnetism, (Jacobs, J.A., ed.), Academic Press, New York. Vol. 1, cap. 4, p. 249-512.

Lawrence, K., C. G. Constable, and C. L. Johnson (2006), Paleosecular Variation and the average geomagnetic field at \pm 20 _ latitude, Geochem. Geophys. Geosyst., 7, Q07007, doi: 10.1029/2005GC001181

Le Goff, M., Gallet, Y., 2004. A new three-axis vibrating sample magnetometer for continuous high-temperature magnetization measurements: applications to paleo- and 
archeo-intensity determinations. Earth Planet. Sci. Lett., 229, 31-43. doi: 10.1016/j.epsl.2004.10.025

Le Goff, M., Gallet, Y., Genevey, A., Warmé, N., 2002. On archeomagnetic secular variation curves and archeomagnetic dating. Phys. Earth Planet. Int., 134, 203-211. doi: 10.1016/S0031-9201(02)00161-9

Leonhardt, R., Matzka, J., Menor, E.A., 2003. Abolute paleointensities and paleodirections of Miocene and Pliocene lavas from Fernando de Noronha, Brazil. Phys. Earth planet. Inter., 139, 285-303. doi: 10.1016/j.pepi.2003.09.008

Lowes, F.J., 1974. Spatial power spectrum of the main geomagnetic field and extrapolation to the core. Geophys. J. Roy. Astron. Soc., 36, 717-730.

Lowrie, W., 1990. Identification of ferromagnetic minerals in a rock by coercivity and unblocking temperatures properties. Geophys. Res. Lett., 17, 159-162. doi: 10.1029/GL017i002p00159

Malin, S.R.C., Bullard, E., 1981. The Direction of the Earth's Magnetic Field at London, 1570-1975 Phil. Trans. R. Soc. London A, 299, 357-423.

Maus, S., Macmillan, S., Chernova, T., Choi, S., Dater, D., Golovkov, V., Lesur, V., Lowes, F., Lühr, H., Mai, W., McLean, S., Olsen, N., Rother, M., Sabaka, T., Thomson, A., Zvereva, T., 2005a. The 10th-Generation Internation Geomagnetic Reference Field, Geophys. J. Int., 161, 561-565. doi: 10.1111/j.1365-246X.2005.02641.X

Maus, S., McLean, S., Dater, D., Lühr, H., Rother, M., Mai, W., Choi, S., 2005b. NGDC/GFZ candidate models for the 10th generation International Geomagnetic Reference Field, Earth, Planets and Space, 57, 1151-1156.

McFadden, P., McElhinny, M., 1990. Classification of the reversal test in palaeomagnetism. Geophys. J. Int. 103, 725-729.

McIntosh, G., Kovacheva, M., Catanzariti, G., Osete, M.L., Casas, L., 2007. Widespread occurence of a novel high coercivity, thermally stable, low unblocking temperature magnetic phase in heated archeological material. Geophys. Res. Lett., 34, L21302. doi: 10.1029/2007GL031168

Merrill, R.T., McElhinny, M.W., McFadden, P.L., 1998. The magnetic field of the Earth: Paleomagnetism, the core, and the deep mantle, Vol. 63 (International Geophysics Series.), Elsevier, Academic Press, Amsterdam.

Michelin, G.A., Argollo-Ferrão, A.M., 2008. Mudanças de uso em áreas históricas: Processos visíveis na apropriação dos terreiros de café da Fazenda Lageado. In: II Seminário do Café História e Historiografia, 2008, Itu. Seminário do Café.

Muxworthy, A., 2010. Revisiting a domain-state independent method of palaeointensity determination. Phys. Earth Planet. Int., 179, 21-31. doi: 10.1016/j.pepi.2010.01.003

Nagata, T., Arai, Y., Momose, K., 1963. Secular variation of the geomagnetic total force during the last 5000 years. J. Geophys. Res., 68, 5277-5281.

Najjar, R., 1999. A arqueologia histórica e a restauração de monumentos: a experiência na Igreja de Nossa Senhora da Assunção, Espírito Santo. In: Anais da X Reunião Científica da Sociedade de Arqueologia Brasileira - SAB, 1999, Recife.

Najjar, R., 2000a. Projeto de Prospecções Arqueológicas na Igreja de São Lourenço dos Índios (Projeto de Pesquisa Arqueológica). Assessoria de Arqueologia, $6^{\mathrm{a}}$ Superintendência Regional do Instituto do Patrimônio Histórico e Artístico Nacional. 
Najjar, R., 2000b. Projeto de Prospecções Arqueológicas na Igreja de São Lourenço dos Índios (Relatório de Pesquisa Arqueológica). Assessoria de Arqueologia, $6^{\mathrm{a}}$ Superintendência Regional do Instituto do Patrimônio Histórico e Artístico Nacional.

Najjar, R., 2000c. Programa de Restauração da Igreja da Venerável Ordem Terceira da Penitência. (Projeto de Pesquisa Arqueológica). Assessoria de Arqueologia, $6^{\mathrm{a}}$ Superintendência Regional do Instituto do Patrimônio Histórico e Artístico Nacional.

Najjar, R., 2004. Projeto de Prospecções Arqueológicas da Igreja de Nossa Senhora da Saúde, Rio de Janeiro, RJ (Relatório de Pesquisa Arqueológica). Assessoria de Arqueologia, $6^{\text {a }}$ Superintendência Regional do Instituto do Patrimônio Histórico e Artístico Nacional.

Nataf, H.-C., 2003. Dynamo and convection experiments. In: Earth's Core and Lower mantle, (Jones, C.A., Soward, A.M., and Zhang, K., eds.), Abingdon, UK, Taylor and Francis, pp. 153-179.

Néel, L., 1949. Théorie du traînage magnétique des ferromagnétiques en grains fins avec applications aux terres cuites, Ann. Géophys., 5, 99-136.

Néel, L., 1955. Some theoretical aspects of rock-magnetism. Adv. Phys., 4, 191-243. doi: $10.1080 / 00018735500101204$

Ohno, M., Hamano, Y., 1992. Geomagnetic poles over the past 10.000 years. Geophys. Res. Letters, 19, 16, 1715-1718.

Ohno, M., Hamano, Y., 1993. Global analysis of geomagnetic field: Time variation of the dipole moment and the geomagnetic pole in the Holocene. J. Geomagn. Geoelectr., 45, $1455-1466$.

Olsen, N., Haagmans, R., Sabaka, T.J., Kuvshinov, A., Maus, S., Purucker, M.E., Rother, M., Lesur, V., Mandea, M., 2006. The Swarm End-to-End mission simulator study: A demonstration of separating the various contributions to Earth's magnetic field using synthetic data. Earth Planet. Space, 58, 359-370.

Olson, P., 2002. The disappearing dipole. Nature, 416, 591-594. doi: 10.1038/416591a

Olson, P., Amit, H., 2006. Changes in Earth's dipole, Naturwissenschaften, 93, 519-542. doi: $10.1007 / \mathrm{s} 00114-006-0138-6$

Pereira, J.W., 2004. Pesquisa Arqueológica na Igreja de Nossa Senhora da Saúde (Relatório

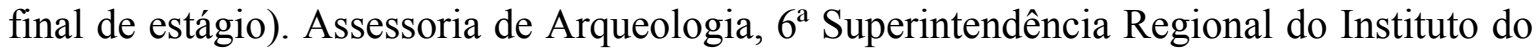
Patrimônio Histórico e Artístico Nacional.

Plens, C.R., Fortuna, C.A., Macedo, J., Suarez, S.M., 2000. Ordem Terceira de São Francisco da Penitencia (Relatório de Pesquisa Arqueológica). Assessoria de Arqueologia, $6^{\mathbf{a}}$ Superintendência Regional do Instituto do Patrimônio Histórico e Artístico Nacional.

Riisager, P., Riisager, J., 2001. Detecting multidomain magnetic grains in Thellier paleointensity experiments. Phys. Earth planet. Inter., 125, 111-117. doi: 10.1016/S00319201(01)00236-9

Roberts, P.H., Glatzmaier, G.A., 2000. Geodynamo theory and simulations. Rev. Modern Phys., 72, 4, 1081-1123.

Rogers, J., Fox, J., Aitken, M.J., 1979. Magnetic anisotropy in ancient pottery, Nature 277, 644-646. doi:10.1038/277644a0

Ross, J., 2005. Geografia do Brasil, $5^{\text {a }}$ ed., Ed. Univ. São Paulo, São Paulo. 
Sabaka, T.J., Olsen, N., Purucker, M., 2004. Extending comprehensive models of the Earth's magnetic field with Oersted and CHAMP data. Geophys. J. Int., 159, 521-547. doi: 10.1111/j.1365-246X.2004.02,421.x

Salazar, J.M., 1998. Araçoiaba e Ipanema: A história daquela maravilhosa região, desde as forjas de Afonso Sardinha até a Real Fábrica de Ferro. Sorocaba: Gráfica e Editora Digipel.

Schnepp, E., 2003. On correction of loss of mass during Thellier experiments. Phys. Earth Planet. Int., 135, 225-229. doi: 10.1016/S0031-9201(02)00213-3

Snowball, I., Sandgren, P., 2004. Geomagnetic field intensity changes in Sweden between 9000 and 450 cal BP: extending the record of "archaeomagnetic jerks" by means of lake sediments and the pseudo-Thellier technique. Earth Planet. Sci. Let., 227, 361-376.

Tanaka, H., Athanassopoulos, J., Dunn, J., Fuller, M., 1995. Paleointensity determinations with measurements at high temperature. J. Geomagn. Geoelectr., 47, 103-113.

Tarling, D.H., Hrouda, F., 1993. The Magnetic Anisotropy of Rocks. Chapmann and Hall, London.

Tauxe, L., 2010. Essentials of Paleomagnetism. Univ. California Press, Berkeley.

Thellier, E., 1938. Sur l'aimantation des terres cuites et ses applications géophysiques. Ann. Inst. Phys. Globe Univ. Paris, 16, 157-302.

Thellier, E., Thellier, O., 1959. Sur l'intensité du champ magnetiqué terrestre dans le passé historique et géologique. Ann. Geophys., 15, 285-376.

Tilgner, A., 2000. Towards experimental fluid dynamos. Phys. Earth Planet. Int., 117, 171177.

Valet, J.P., Herrero-Bervera, E., Le Mouël, J.L., Plenier, G., 2008. Secular variation of the geomagnetic dipole during the past 2000 years. Geochem. Geophys. Geosyst., 9, 1, Q01008. doi: 10.1029/2007GC001728

Veitch, R., Hedley, I., Wagner, J.J., 1984. An investigation of the intensity of the geomagnetic field during Roman times using magnetically anisotropic bricks and tiles, Arch. Sci., 37, 359-373.

Walton, D., 1984. Re-evaluation of Greek archaeomagnitudes, Nature, 310, 740-743.

Wilson, R.L., 1961. The thermal demagnetization of natural magnetic moments in rocks. Geophys. J. Int., 5, 45-58.

Wilson, R.L., 1962. An instrument for measuring vector magnetization at high temperatures. Geophys. J. Int., 7, 125-130.

Yang, S., Odah, H., Shaw, J., 2000. Variations in the geomagnetic dipole moment over the last 12000 years, Geophys. J. Int., 140, 158-162. doi: 10.1046/j.1365-246x.2000.00011.x

York, D., 1966. Least-squares fitting of a straight line. Can. J. Phys., 44, 1079-1086.

York, D., 1967. The best isochron. Earth Planet. Sci. Lett., 2, 479-482.

Yu, Y., Doh, S-J., Kim, W., Park, Y-H., Lee, H-J., Yim, Y., Cho, S-G., Oh, Y-S., Lee, D-S., Lee, H-H., Gong, M-G., Hyun, D-H., Cho, J-K., Sin, Y-S., Do, M-S., 2010. Archeomagnetic secular variation from Korea: Implication for the occurrence of global archeomagnetic jerks. Earth Planet. Sci. Lett., 294, 173-181. doi: 10.1016/j.epsl.2010.03.024 
Yukutake, T., 1967. The westward drift of the Earth's magnetic field in historic times. J. Geomagn. Geoelectr., 19, 2, 103-116.

Yukutake, T., 1993. The geomagnetic non-dipole field in the Pacific. J. Geomagn. Geoelectr., 45, 1441-1453.

Zequini, A., 2006. Arqueologia de uma fábrica de ferro: Morro de Araçoiaba, séculos XVI e XVIII (Tese de Doutorado). São Paulo: Museu de Arqueologia e Etnologia, Universidade de São Paulo.

Zequini, A., 2007. Arqueologia de uma fábrica de ferro no Brasil: séculos XVI-XVIII. Arqueologia Industrial, 1-2, 51-59. 


\section{Apêndices}

Apêndice A

Artigo sobre a implantação da metodologia de paleointensidade no Laboratório de Paleomagnetismo do IAG-USP

Artigo:

${ }^{66}$ First archeointensity results from portuguese potteries (1550 1750 AD)"

G.A. Hartmann, R.I.F. Trindade, A. Goguitchaichvili, C. Etchevarne, J. Morales, M.C. Afonso

Earth, Planets and Space, 61, 93-100, 2009. 


\title{
First archeointensity results from Portuguese potteries (1550-1750 AD)
}

\author{
Gelvam A. Hartmann ${ }^{1}$, Ricardo I. F. Trindade ${ }^{1}$, Avto Goguitchaichvili ${ }^{2,3}$, \\ Carlos Etchevarne ${ }^{4}$, Juan Morales ${ }^{2,3}$, and Marisa C. Afonso ${ }^{5}$ \\ ${ }^{1}$ Departamento de Geofísica, Instituto de Astronomia, Geofísica e Ciências Atmosféricas, Universidade de São Paulo, \\ Rua do Matão, 1226, 05508-090, São Paulo, Brazil \\ ${ }^{2}$ Laboratorio de Paleomagnetismo y Geofisica Nuclear, Instituto de Geofisica, Universidad Nacional Autónoma de México, \\ Ciudad Universitaria, 04510, México, DF, Mexico \\ ${ }^{3}$ Laboratorio Interinstitucional de Magnetismo Natural, Instituto de Geofisica, Universidad Nacional Autónoma de México, \\ Tzintzuntzan, 310, 58098, Morelia, Mexico \\ ${ }^{4}$ Departamento de Antropologia, Universidade Federal da Bahia, Terreiro de Jesus, \\ Prédio da Faculdade de Medicina, 40026-010, Salvador, Brazil \\ ${ }^{5}$ Museu de Arqueologia e Etnologia, Universidade de São Paulo, Av. Prof. Almeida Prado, 1466, 05508-090, São Paulo, Brazil
}

(Received November 22, 2007; Revised February 21, 2008; Accepted February 29, 2008; Online published January 23, 2009)

\begin{abstract}
Geomagnetic field variations at archeomagnetic timescales can be obtained from well-dated heated structures and archeological potsherds. Here, we present the first archeointensity results obtained on Portuguese ceramics (1550 to $1750 \mathrm{AD})$ collected at Brazilian archeological sites. The results are compared to those obtained from Western Europe and currently available geomagnetic field models. Continuous thermomagnetic and IRM acquisitions curves indicate that Ti-poor titanomagnetite is responsible for the remanence in these ceramic fragments. Five fragments (24 samples) out of twelve analyzed yielded reliable intensity estimates. The row archeointensity data were corrected for TRM anisotropy and cooling rate effect. The mean dipole moments are obtained for three different age intervals: $1550 \pm 30 \mathrm{AD}, 1600 \pm 30 \mathrm{AD}$ and $1750 \pm 50 \mathrm{AD}$. Mean intensities vary from $37.9 \pm 4.2 \mu \mathrm{T}$ to $54.8 \pm 7.6 \mu \mathrm{T}$ in agreement with the previously reported data for $1550 \mathrm{AD}$ and $1750 \mathrm{AD}$. Relatively weaker, but still highly dispersed, values were obtained for 1600 AD ceramics.
\end{abstract}

Key words: Archeointensity, secular variation, cooling rate correction, Portuguese pottery.

\section{Introduction}

The variations of the Earth's magnetic field at archeomagnetic timescales $\left(10^{2}\right.$ to several $10^{3}$ of years) can be obtained from well-dated heated structures and archeological potsherds. Directional and intensity data obtained from these materials have been used to produce reference curves for the past few millennia. Reference curves (also called master curves), which reveal the variations in the intensity of the geomagnetic field are now available for several regions, including North America, Meso-America, Eastern Asia, Eastern and Western Europe (e.g., Kovacheva, 1997; Yu et al., 2000; Morales et al., 2001; Bowles et al., 2002; Genevey et al., 2003; Soler-Arechalde et al., 2006; see also the compilations of Valet, 2003; Perrin and Schnepp, 2004; Korte et al., 2005). Archeointensity data for Western Europe are concentrated on archeological sites from France (e.g., Chauvin et al., 2000; Gallet et al., 2002; Genevey and Gallet, 2002; Gallet et al., 2005) while only few results are available for the Iberian Peninsula (Kovacheva et al., 1995; Gómez-Paccard et al., 2006). Although abundant archeological remains are available in Portugal and Brazil, archeomagnetic studies are almost nonexistent. Here we present the first archeointensity results obtained from Portuguese pottery. The principal aim of this study is to try to contribute

Copyright (c) The Society of Geomagnetism and Earth, Planetary and Space Sciences (SGEPSS); The Seismological Society of Japan; The Volcanological Society of Japan; The Geodetic Society of Japan; The Japanese Society for Planetary Sciences; TERRAPUB. to the reference archeointensity curve for Iberian Peninsula. Our results, which are limited to the 1550-1750 AD interval are compared to those obtained from Western Europe (Chauvin et al., 2000; Genevey and Gallet, 2002; Gallet et al., 2005; Gómez-Paccard et al., 2006) and to the available theoretical and statistical models of the geomagnetic field (Jackson et al., 2000; Korte and Constable, 2005).

\section{Archeological Context and Age Estimation}

The studied material was collected at the colonial archeological site of Sé, in Salvador, Northeast Brazil. Salvador was the first post-colonial capital established in South America while Sé represents a main catholic church at colonial times. Its construction started at 1552 and was concluded during the second half of the XVII century. The building, demolished in 1933, was placed at the border of a sea cliff in an unstable area. In an attempt to keep the building structure, several layers of ceramic fragments, including wall-tile (azulejos), faience, pottery, bricks and tiles were deposited at the border of the sea cliff. The stratigraphy of these deposits has been used to track the evolution of social and alimentary habits of the inhabitants of Salvador through the colonial period (Etchevarne, 2003). The decorative pottery, azulejos and faience collected in the Sé site have been produced in Portugal (Etchevarne, 2006). For the periods mentioned above, the greatest centers of ceramic production in Portugal were Lisbon, Vila Nova de GaiaPorto and Aveiro-Coimbra. The studied ceramics are proba- 

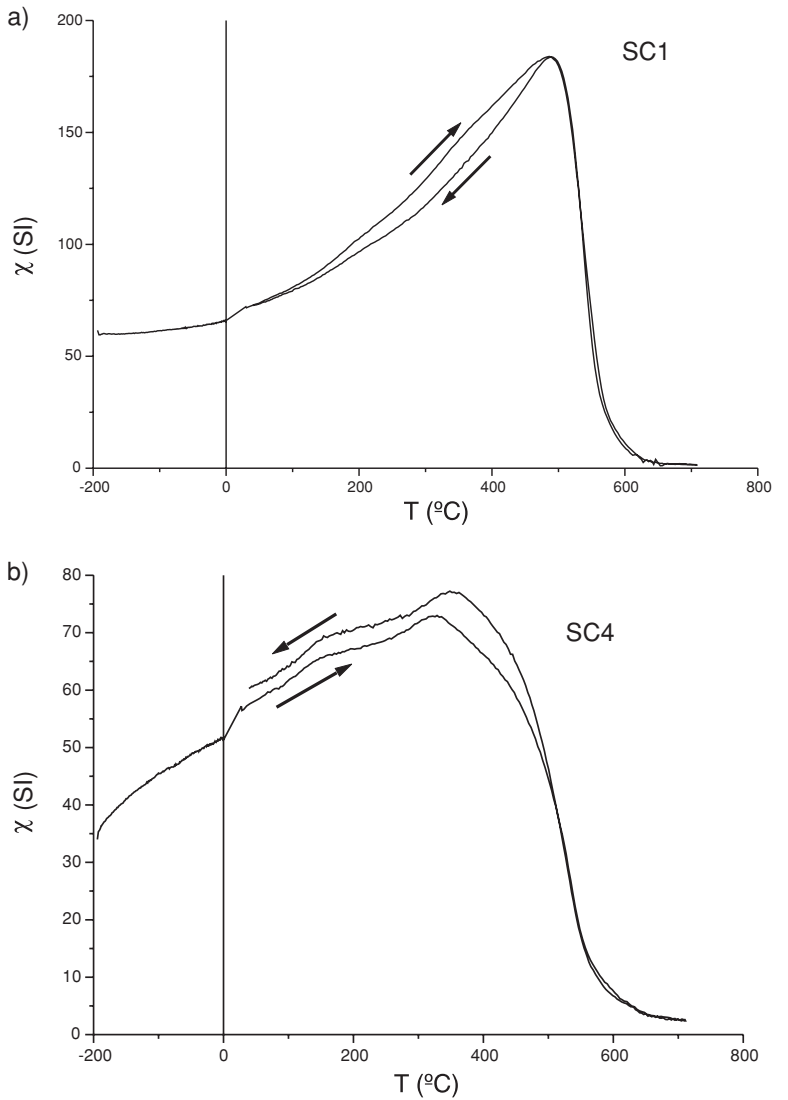

Fig. 1. Thermomagnetic curves for two representative samples of Portuguese ceramic collection. Low and high-temperature measurements were performed in the same sample. Susceptibility values were corrected from furnace signal.

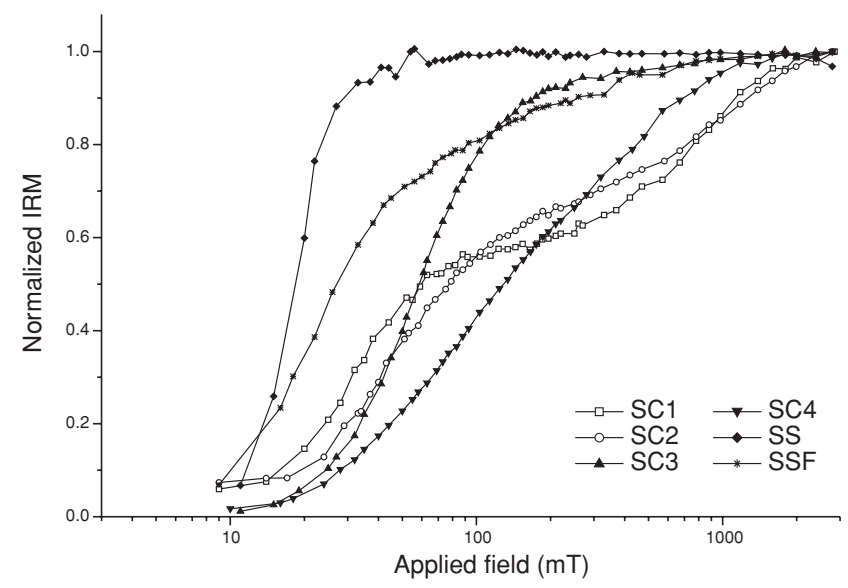

Fig. 2. IRM acquisition curves for six samples used in our analysis.

bly originated from one of these production centers. For this study we have selected 12 fragments of azulejos (1), faience (1), glazed ceramics (3) and decorative potteries (6) of Portuguese origin. We have included only one fragment of utilitarian pottery (the SC1 fragment) but keeping in mind that this material could have been re-heated. Bricks and tiles were avoided due to their likely Brazilian origin. A description of the analyzed fragments is given in Table 1 . The age of these potsherds was inferred archeologically, from written documentation and the ceramics style itself. Three main periods of production are identified: $1550 \pm 30 \mathrm{AD}$, $1600 \pm 30 \mathrm{AD}$ and 1750 $\pm 50 \mathrm{AD}$ (Etchevarne, 2006, 2007).

\section{Methods}

Paleointensity measurements were carried out at the paleomagnetic laboratories of the University of São Paulo (USP) and National University of Mexico (UNAM). Fragments analyzed in Mexico were inserted in ultrapure salt $(\mathrm{NaCl})$ pellets of $25 \mathrm{~mm}$ of diameter per $22 \mathrm{~mm}$ of height; an arbitrary orientation was given for each specimen. Remanent magnetization was measured with a JR-6 (Agico Ltd.) spinner magnetometer and thermal treatment was achieved by using a dual-chamber ASC furnace with $1 \mathrm{~h}$ heating cycles. Magnetization per unit volume of 'blank' pellets ranges on the order of $10^{-5} \mathrm{~A} / \mathrm{m}$, whereas magnetization of typical archeomagnetic cores prepared for archeointensity determinations ranges on the order of $10^{-2}$ to $10^{-1} \mathrm{~A} / \mathrm{m}$. Archeointensity experiments were carried out under air using the Thellier and Thellier (1959) method modified by Coe (1967). For each double-heating step, the samples were first partially demagnetized in zero-field, and then remagnetized in a laboratory inducing field $\left(H_{\mathrm{lab}}\right)$. Fragments analyzed in São Paulo were cut in cylinders of $8 \mathrm{~mm}$ of diameter per $10 \mathrm{~mm}$ of height. Remanent magnetization was measured with a $2 \mathrm{G}$-cryogenic magnetometer (2G Enterprises). Heating cycles of 45 minutes were performed in a modified MMTD-60 furnace (Magnetic Measurements Ltd.) that incorporates a water-cooling system. The paleointensity protocol used in São Paulo laboratory was that of Aitken et al. (1988). In this protocol, the samples are first partially remagnetized in a $H_{\text {lab }}$ and then demagnetized in zero-field. In both paleomagnetic laboratories, we have used a $H_{\text {lab }}$ of $30 \mu \mathrm{T}$. Same thirteen doubleheating steps from $200^{\circ} \mathrm{C}$ up to $550^{\circ} \mathrm{C}$ were employed. The pTRM checks were carried out after every two temperature steps in order to detect any magnetic alteration. Thermomagnetic curves were measured with a KLY4-CS3 (Agico Ltd.) susceptometer while a IRM (isothermal remanent magnetization) acquisition were performed using both a Pulse Magnetizer MMPM-10 (Magnetic Measurements Ltd.) and a Molspin spinner magnetometer (Molspin Ltd.). Both measurements were made at the University of São Paulo.

TRM anisotropy and cooling rate corrections were performed on all samples. The TRM anisotropy tensor represents the preferential alignment of magnetic carriers produced by stretching of clay when ceramics were molded. Chauvin et al. (2000) and Genevey and Gallet (2002) showed that the correction for TRM is very important in order to obtain reliable intensity values in pottery samples. The TRM anisotropy tensor was obtained after the paleointensities measurements by the acquisition of six pTRMs in different positions: $X,-X, Y,-Y, Z$ and $-Z$. After each measurement, one diagonal term and two symmetric terms $\left(K_{1 j}, K_{2 j}, K_{3 j}, j=1,2,3\right)$ of the tensor are obtained. Subsequently, $K_{i j}(i \neq j)$ terms are replaced by $\left(K_{i j} / K_{j i}\right) / 2$ terms and eigenvalues and the TRM anisotropy tensor is calculated. The TRM anisotropy was applied on samples showing less than $20 \%$ of variation of the TRM acquisition capacity (see below). The TRM anisotropy was performed 
G. A. HARTMANN et al.: FIRST ARCHEOINTENSITY RESULTS FROM PORTUGUESE POTTERIES (1550-1750 AD)

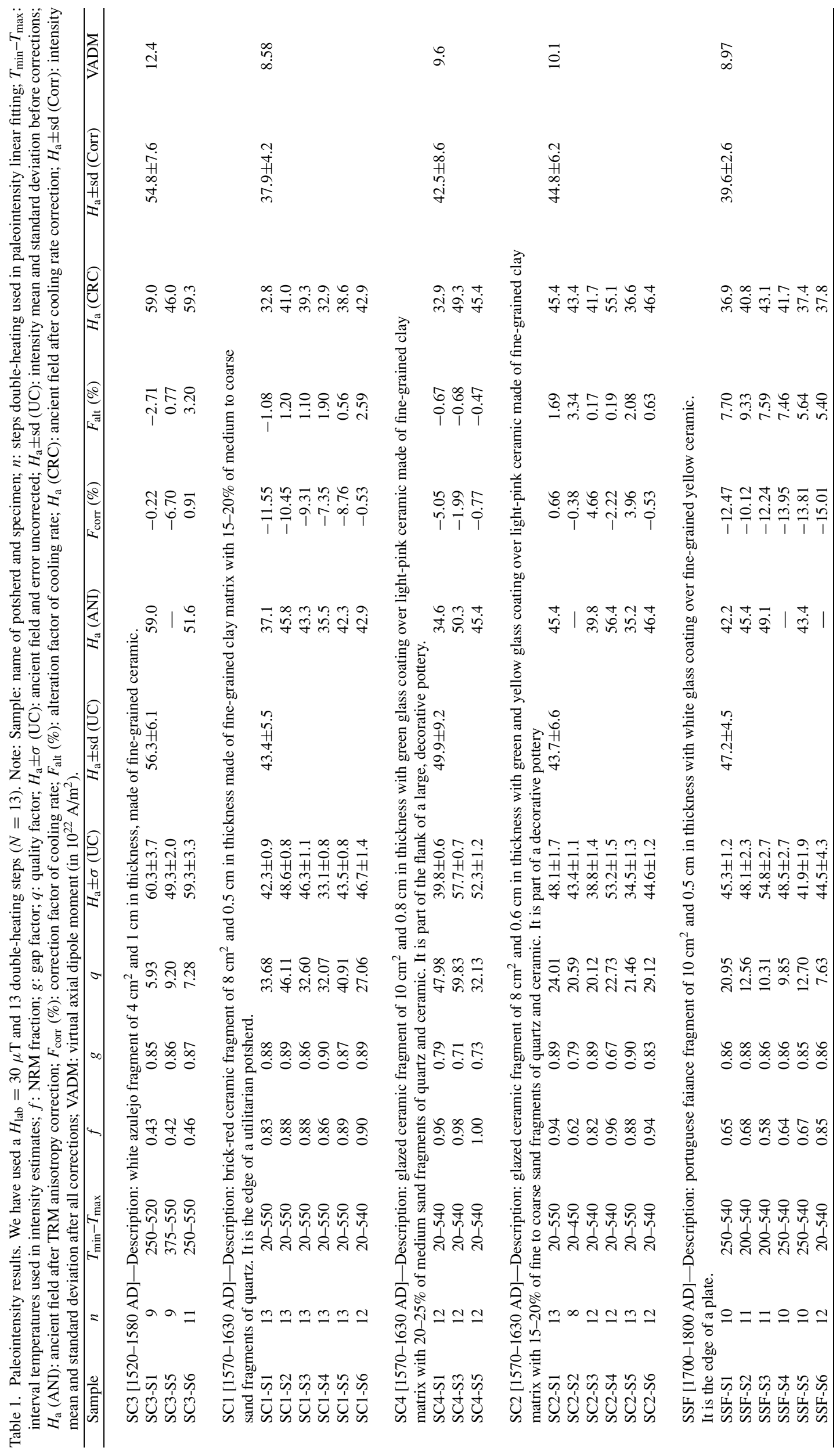


a) SS-S1

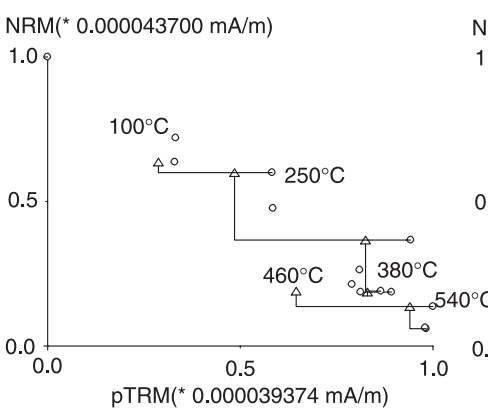

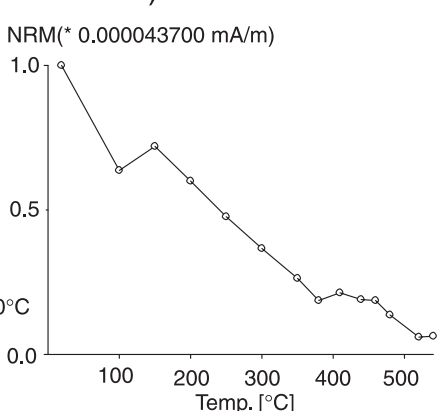

b) SSI-S5
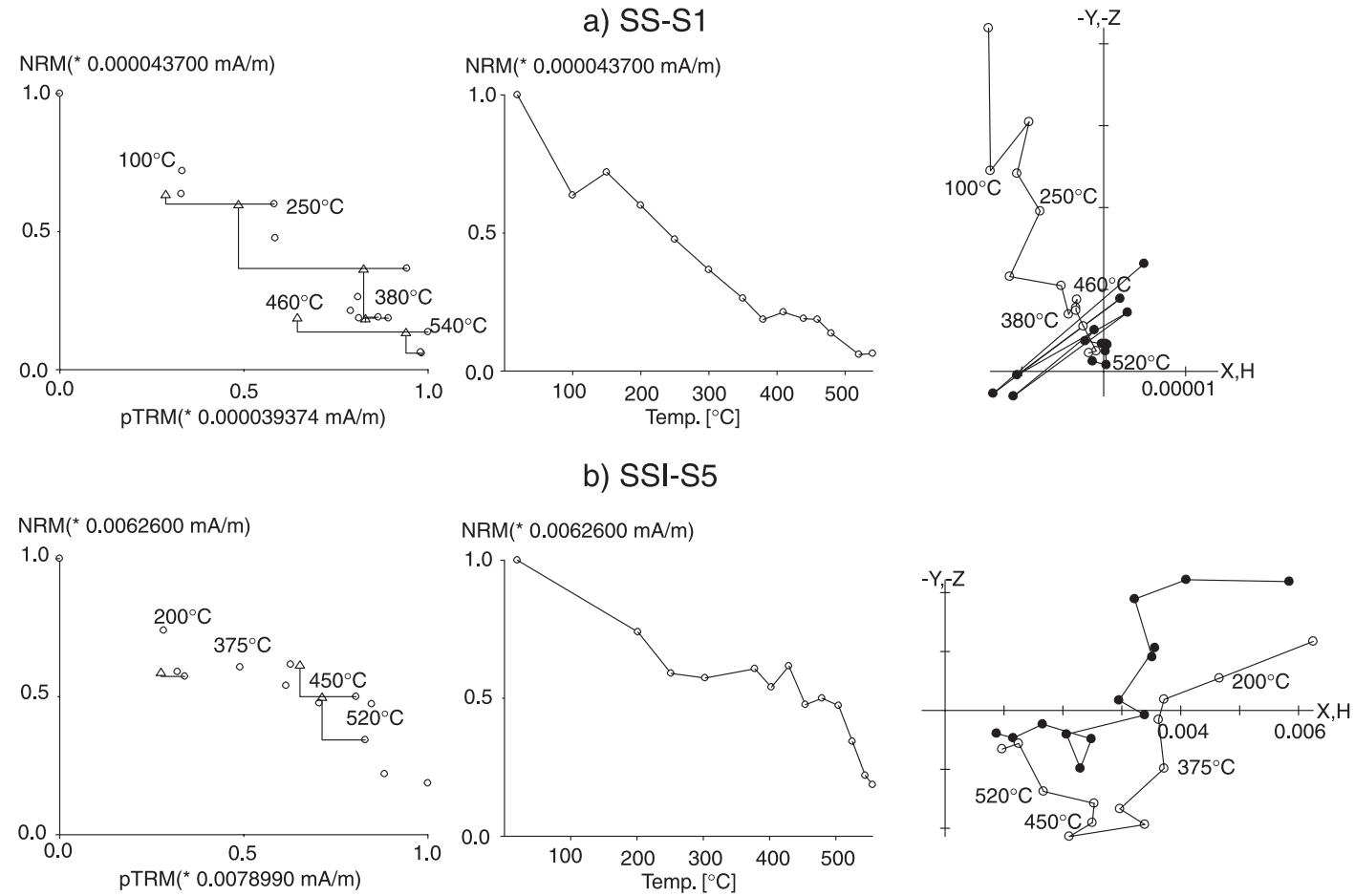

c) SQT-S1
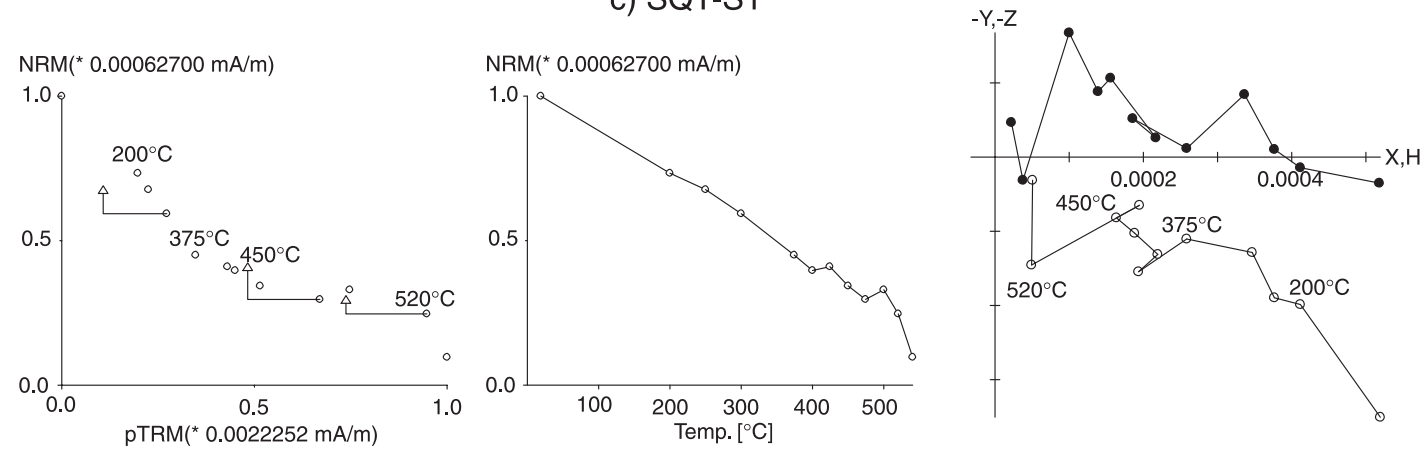

Fig. 3. NRM-TRM, decay and orthogonal vector plots corresponding to the rejected data: erratic behavior ((a) and (b)) and so-called concave-up behavior (c). Sample SS-S1 was analyzed in the USP lab, whereas samples SSI-S5 and SQT-S1 were analyzed in the UNAM lab.

after the archeointensity measurements (on a temperature of $550^{\circ} \mathrm{C}$ ), when $\sim 70 \%$ to $\sim 95 \%$ of NRM was removed.

Cooling rate dependence was theoretically reported by Néel (1955) for single-domain grains. This effect consists of a progressive increase of TRM intensity with the decrease of the cooling rate. For laboratory cooling times this effect is significant in potteries (e.g., Fox and Aitken, 1980; Chauvin et al., 2000) and occasionally for rock samples as well (Morales et al., 2006). In order to quantify the cooling rate effect, we carried out three in-field heatings after the paleointensity measurements: (a) fast-cooling ( $\sim 1 \mathrm{~h})$, (b) slow-cooling ( $\sim 20 \mathrm{~h})$ and (c) fast-cooling $(\sim 1 \mathrm{~h})$ again. The cooling rate correction factor is obtained from the difference between the slow-cooling step and the first fast-cooling step. The alteration factor is defined by difference between first and second fast-cooling steps; this factor indicates the magnetic alterations which occur during the archeointensity experiments. We corrected the intensity estimates for cooling rate effects when the correction factor was bigger than the alteration factor (e.g., Gómez-Paccard et al., 2006).

\section{Results}

\subsection{Magnetic mineralogy}

Thermomagnetic curves were carried out on selected samples in order to access the thermal stability and Curie temperatures of magnetic carriers. We have performed in air low-field susceptibility measurements from $-194^{\circ} \mathrm{C}$ up to $700^{\circ} \mathrm{C}$ on all 12 fragments. The thermomagnetic curves showed that the Curie temperature of magnetic carriers varies from $560^{\circ} \mathrm{C}$ up to $585^{\circ} \mathrm{C}$ (Fig. 1), indicating low-Ti titanomagnetite to pure magnetite in our samples. Some samples also show a small fraction of hematite. Thermomagnetic curves also revealed a reasonably high thermal stability and reversibility suggesting minor mineralogical changes during heating. This behavior is favorable for paleointensity determinations.

IRM acquisitions were made on 6 representative samples of the 12 studied fragments. Figure 2 shows IRM acquisitions for samples of SC1, SC2, SC3, SC4, SS and SSF fragments. Three different behaviors are distinguished from IRM curves. Three samples (SC3, SS, SSF) reach the saturation at fields between $0.1 \mathrm{~T}$ and $0.3 \mathrm{~T}$, indicat- 
a) SC1-S2
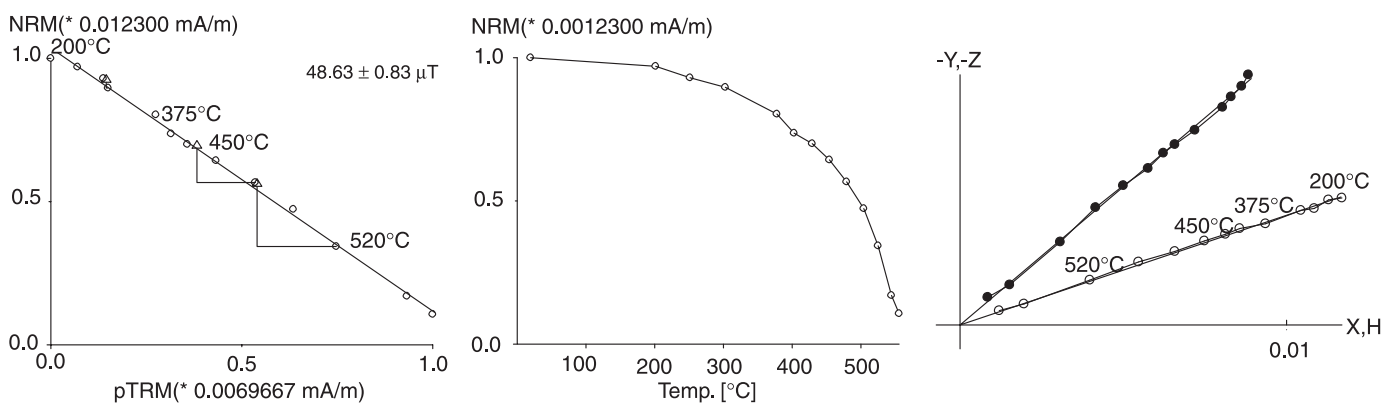

b) SC1-S4
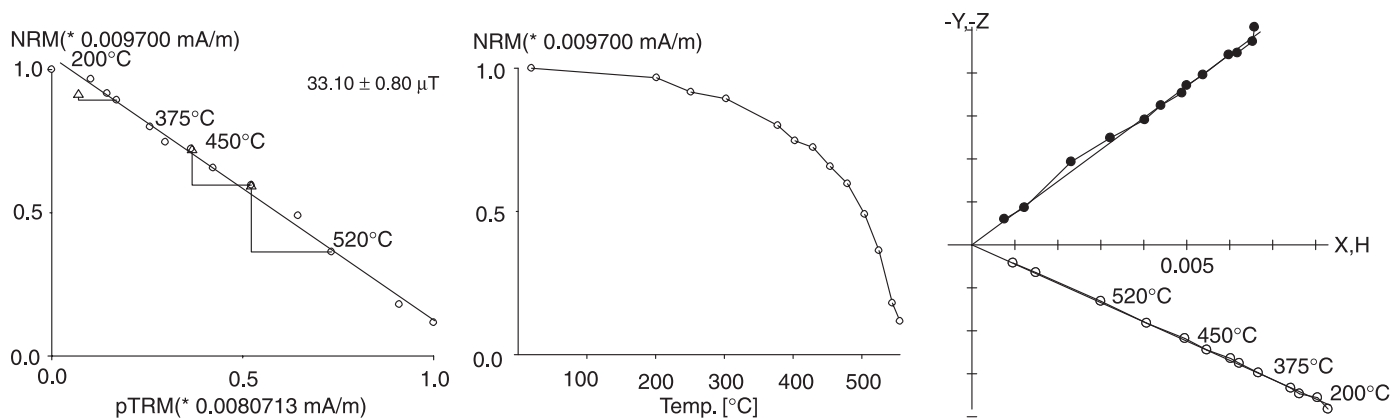

c) SC2-S1
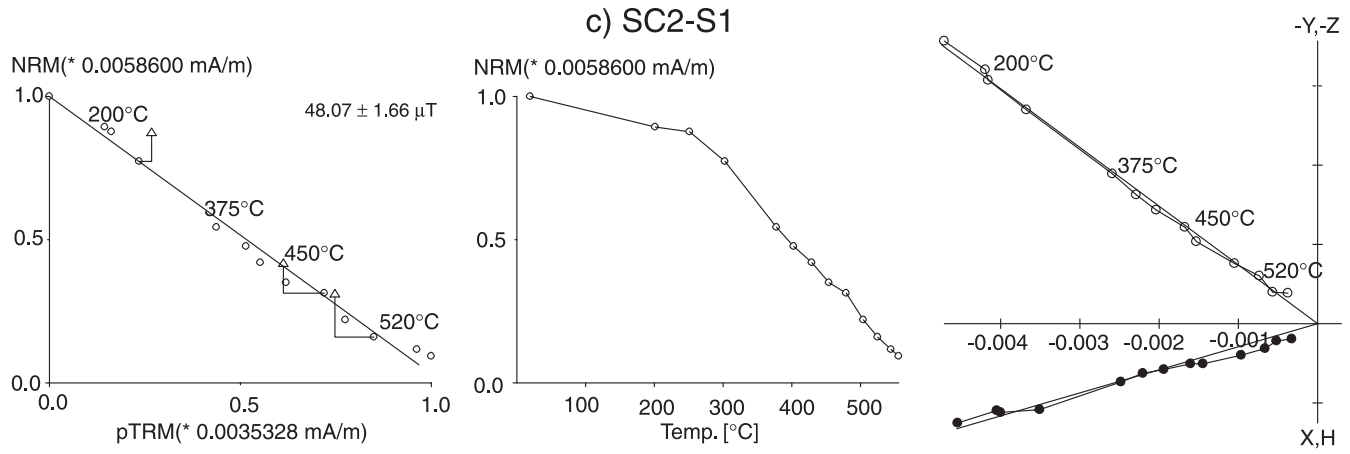

d) SC2-S5
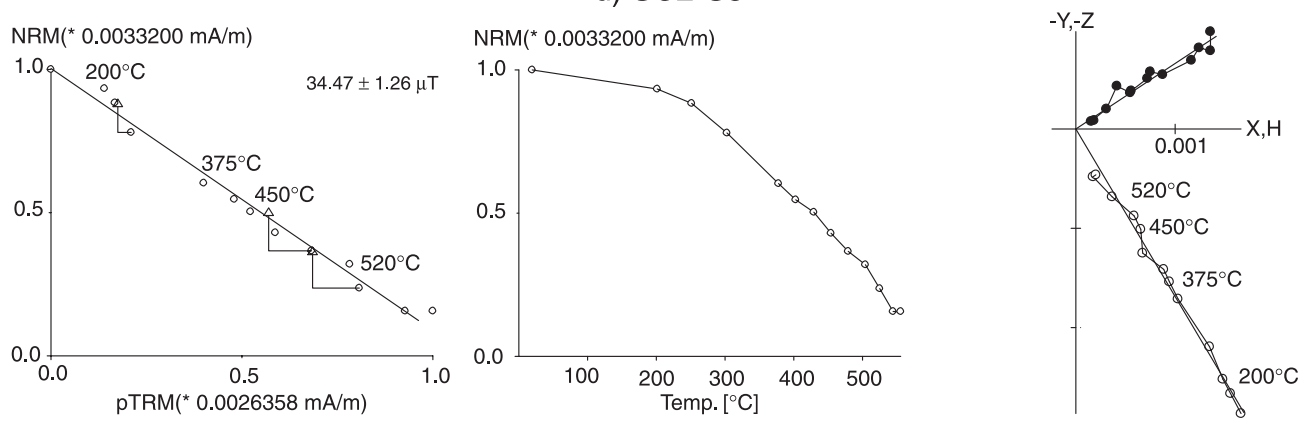

Fig. 4. NRM-TRM, decay and orthogonal vector plots for eight representative samples.

ing that their magnetization is carried by pseudo-singledomain spinel phases-most probably magnetite or titanomagnetite. A single sample (SC4) reaches saturation magnetization at fields $>1.2 \mathrm{~T}$, indicating the presence of some antiferromagnetic contribution. The high thermal stability observed on the thermomagnetic curve (Fig. 1(b)) is suggestive of a substituted hematite phase as recently reported by McIntosh et al. (2007). Other two samples (SC1 and
SC2) show a mixed behavior indicating the coexistence of (titano)magnetite and (titano)hematite.

\subsection{Archeointensity}

Unfortunately, all archeointensity experiments performed in São Paulo laboratory failed (10 specimens of six different potsherds, mostly decorative pottery). The Arai diagrams were erratic (Fig. 3(a)) and no intensity value could be determined from these samples. Samples ana- 
e) SC3-S5

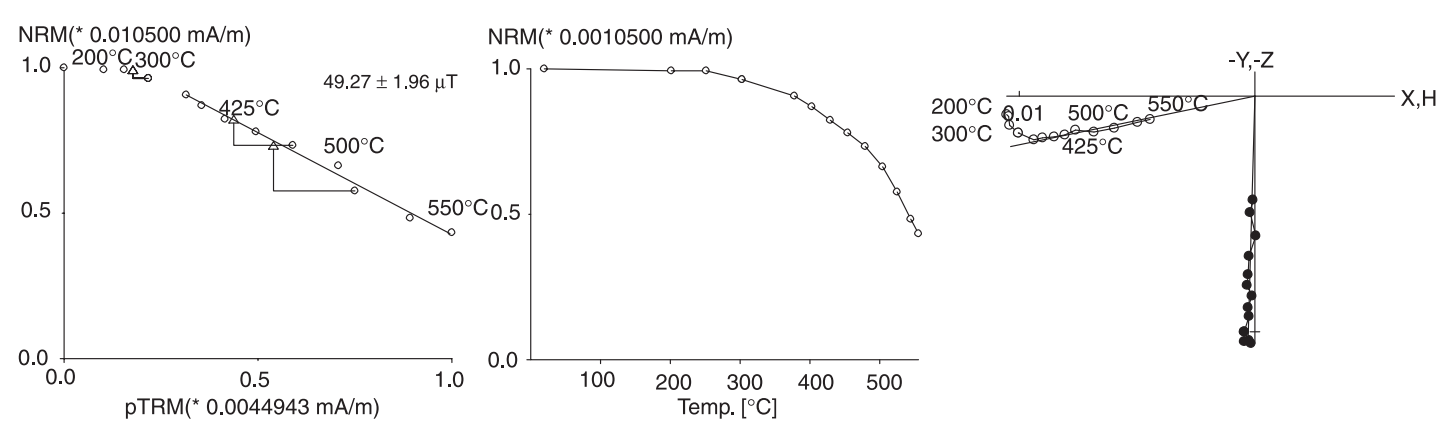

f) SC4-S1
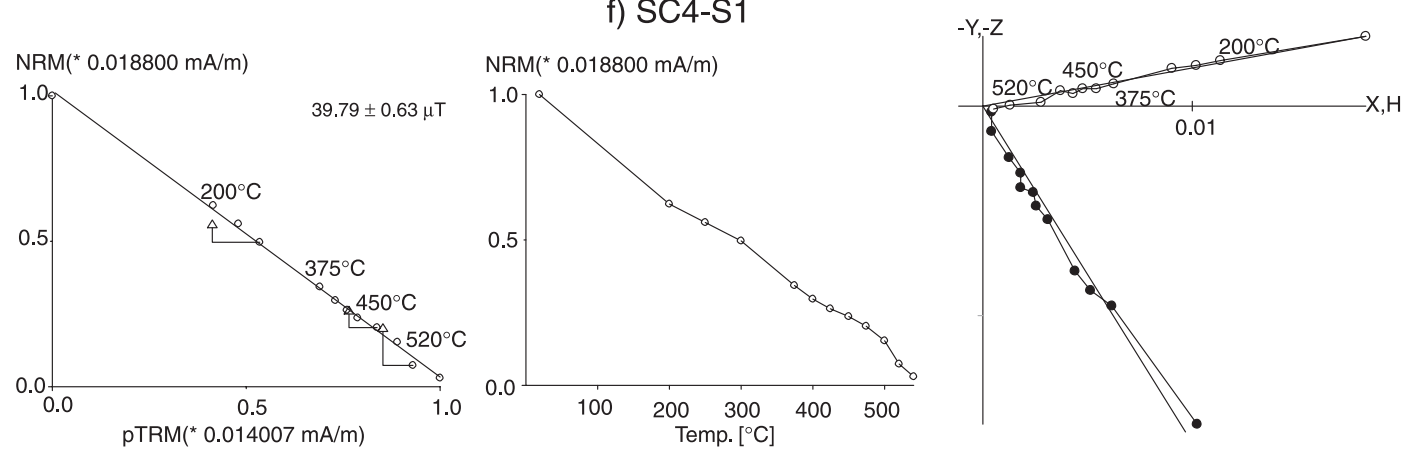

g) SC4-S3
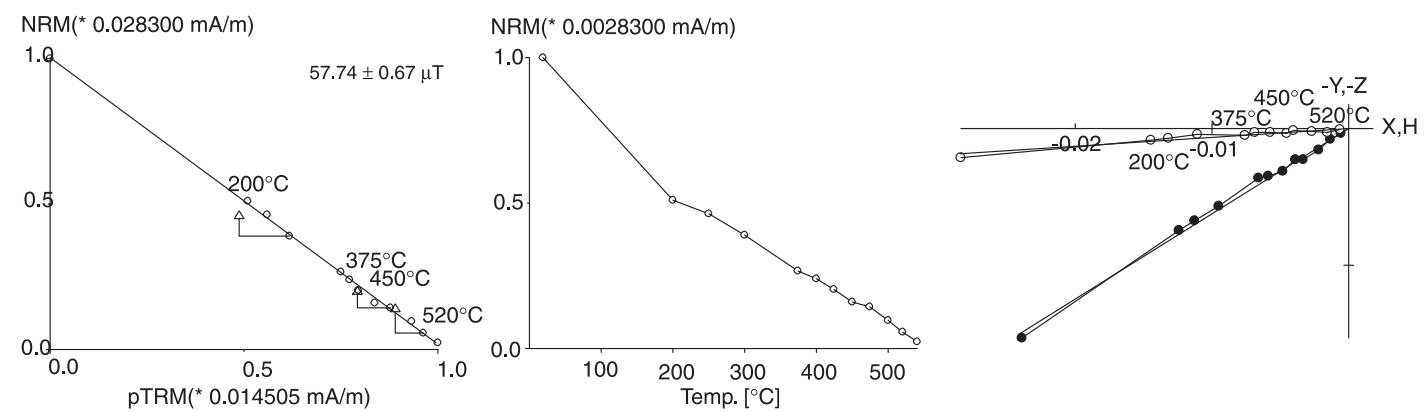

h) SSF-S1
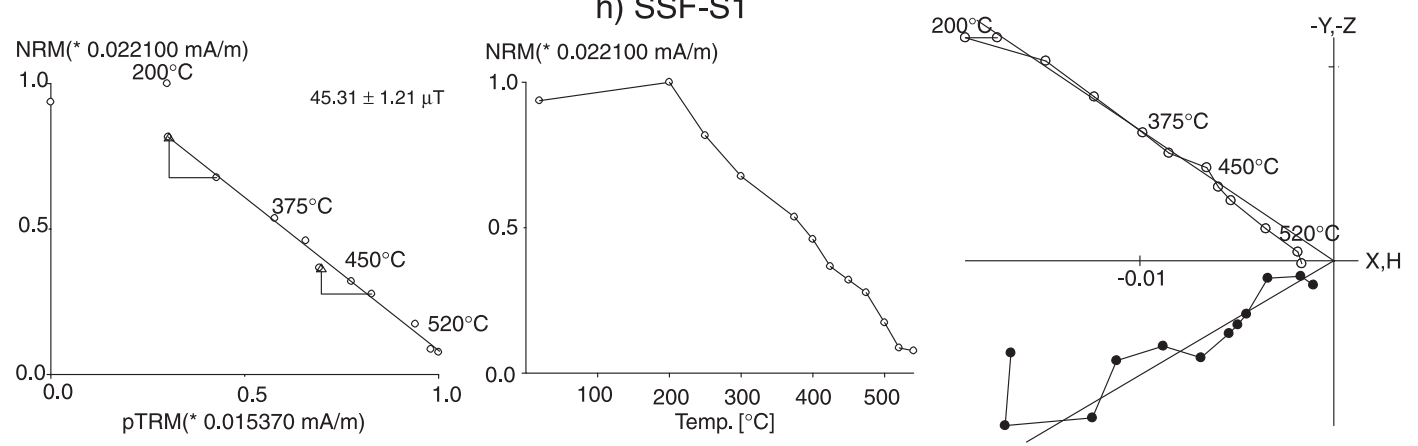

Fig. 4. (continued).

lyzed in the UNAM paleomagnetic laboratory comprise six sister-samples of those analyzed in São Paulo plus six other fragments. One-third of the 72 samples (belonging to 12 fragments) analyzed at UNAM gave reliable results. Rejected samples showed rather erratic behavior (Fig. 3(b)) or concave-up Arai plots (Fig. 3(c)). It is worth noting that all rejected sites correspond to fragments of brick-red coarse- grained ceramics, including most of the sister-samples of those analyzed in São Paulo. The only retained result obtained on this kind of material was that of site SC1, a fragment of utilitarian pottery.

Figure 4 shows examples of archeointensity estimates for five ceramic fragments that yielded acceptable results. NRM-TRM plots and associated orthogonal diagrams indi- 
cate a strong magnetic stability and linearity during almost whole paleointensity procedure. In some cases, however, we observe two components on the orthogonal diagrams. The first one is usually removed on temperatures below $350^{\circ} \mathrm{C}$ (for most of samples below to $250^{\circ} \mathrm{C}$ ). Such behavior probably characterizes a secondary viscous magnetic component. All intensity determinations were computed using the temperature interval of the primary (characteristic) remanent magnetization only.

Archeointensity data can be assessed by quality parameters. Table 1 shows the most reliable intensity results from these Portuguese potsherds. For each specimen, we indicate the temperature interval used in the intensity estimate, number of points $(n)$ used (at least five) and NRM fraction $(f)$ in the linear fitting, the $g$ (gap) and $q$ (quality) factors as defined by Coe et al. (1978). We have used at least $40 \%$ of NRM for paleointensity determinations with associated quality factor greater than 5 .

As mentioned above, the TRM anisotropy correction was applied in cases when the change in TRM acquisition capacity was lower than $20 \%$. Thus, following samples: SC2S2, SC3-S5, SSF-S4 and SSF-S6 were not corrected for the remanence anisotropy. In general, the studied samples show a rather high TRM anisotropy degree varying from 1.06 to 1.57 with no systematic predominance of prolate or oblate ellipsoids. Cooling rate experiments were carried out on all samples using a cooling time of about $20 \mathrm{~h}$. We note that so-called alteration factor was found systematically lower with respect to cooling rate correction. From our selected samples, only the SC3-S1, SC1-S6, SC4-S5, SC2-S1, SC2$\mathrm{S} 2$ and SC2-S6 were not corrected for cooling rate (see Table 1). After TRM anisotropy and cooling rate corrections, the intensity means vary from $37.9 \pm 4.2 \mu \mathrm{T}$ (SC1) up to $54.8 \pm 7.6 \mu \mathrm{T}$ (SC3).

\section{Discussion and Conclusion}

Generally speaking, the Portuguese potteries studied here showed a low success rate. But most of the fragments that failed archeointensity experiments, both in São Paulo and Mexico, were coarse-grained brick-red ceramic samples. Faience, glazed ceramic and azulejos showed $75 \%$ success in archeointensity determinations, indicating their great potential in recording the ancient field. Thermomagnetic curves show a high thermal stability during the heatings indicating that these materials are suitable for Thellier paleointensity experiments. Both $K-T$ and IRM acquisition curves demonstrate that the main magnetic carriers are pseudo-single-domain magnetite or low-Ti titanomagnetite. Five fragments yield reliable intensity estimates for three different age intervals $(1550 \pm 30 \mathrm{AD}, 1600 \pm 30$ $\mathrm{AD}$ and $1750 \pm 50 \mathrm{AD}$, Table 1). After cooling rate and anisotropy corrections the standard deviation of intensity values has been reduced for the three potsherds corresponding to $1600 \pm 30 \mathrm{AD}$ reinforcing the importance of these additional experiments for archeointensity determination. However, even after these corrections, there is still some dispersion between these potsherds (SC1, SC2 and SC4). There are two possible interpretations for the dispersion of archeointensity values for 1600 AD samples: either they correspond to a true dispersion, similar to the behavior observed by Gómez-Paccard et al. (2006) for seven values in Murcia (Spain), or they represent younger thermal remagnetization, since they correspond to displaced material from Portugal. In our case, we prefer the latter interpretation, since the lowest and most divergent value was obtained on the SC1 potsherd, which corresponds to brick-red utilitarian pottery, which could have been re-heated after its over-seas displacement. This sample is indicated in grey in Fig. 5 to differentiate it from samples SC2 and SC4, which correspond to decorative glazed ceramic fragments.

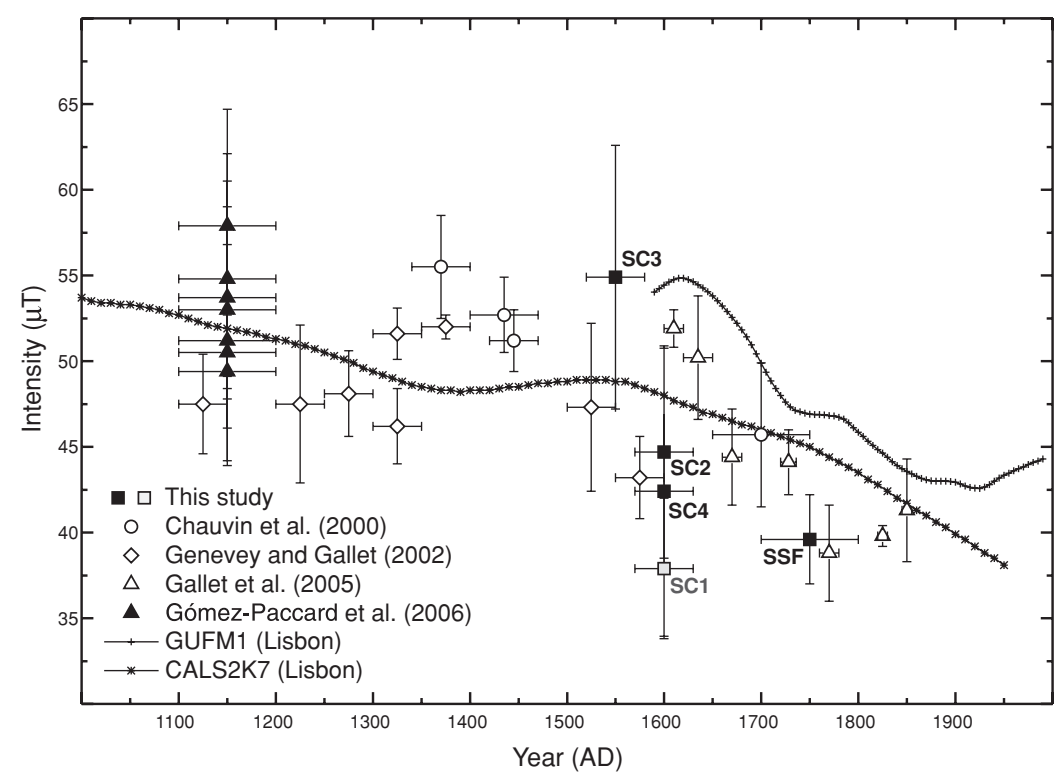

Fig. 5. Geomagnetic field intensity variation for Western Europe. All data were corrected for the latitude of Lisbon (see also the text). GUFM1 and CALS2K7 geomagnetic field models are from Jackson et al. (2000) and Korte and Constable (2005), respectively. The SC1 site was represented in grey since the archeointensity results were obtained on utilitarian pottery and could thus have been re-heated in Brazil. 
Figure 5 shows the geomagnetic field intensity evolution for the last millennium for Western Europe. We compared our results to a compilation of currently available data (Chauvin et al., 2000; Genevey and Gallet, 2002; Gallet et al., 2005; Gómez-Paccard et al., 2006) and to the geomagnetic field models of Jackson et al. (2000) and Korte and Constable (2005). Jackson et al. (2000) model starts at 1590 AD, whereas Korte and Constable curve encompasses the last 7000 years. At the beginning of the XII century, the intensity obtained from French and Spanish potteries present a large spread with mean values around $50 \mu \mathrm{T}$ at the latitude of Lisbon. These results are followed by a rapid increase in the field strength during the XIV and XV centuries up to $\sim 55 \mu \mathrm{T}$. For the second half of the XVI century, the intensity values fall back to $45 \mu \mathrm{T}-50 \mu \mathrm{T}$ values. Our data for this period provide $54.8 \pm 7.6 \mu \mathrm{T}$ paleointensities and agree with the geomagnetic field models of Jackson et al. (2000), but they are higher than the results from France obtained by Genevey and Gallet (2002). The archeointensity values of SC1, SC2 and SC4 potsherds (beginning of XVII century) are similar to the available experimental results obtained from France (Genevey and Gallet, 2002), but smaller than those of the geomagnetic field models of Korte and Constable (2005) and Jackson et al. (2000). In fact, they seem to reinforce the work of Gubbins et al. (2006) indicating a smaller $g_{0}^{1}$ coefficient at that time. The SSF site (XVII century) presents an intensity value near to the contemporary results obtained by Gallet et al. (2005). Both results are slightly lower than those predicted by the geomagnetic field models of Korte and Constable (2005) and Jackson et al. (2000).

The archeointensity results obtained for the first time on Portuguese ceramics are not numerous but they are of high quality, suggesting that the Portuguese pottery may be a suitable study target to establish a reference intensity curve for the Iberian Peninsula.

Acknowledgments. We are indebt to FAPESP (grant 05/577824, to G. A. Hartmann) and CNPq (Research Fellowship to R. I. F. Trindade, C. Etchevarne and M. C. Afonso). A. Goguitchaichvili is grateful for the financial support from CONACYT (grant 54957). We appreciate the constructive comments by E. Schnepp and M. Kovacheva that helped in improving this manuscript.

\section{References}

Aitken, M. J., A. L. Allsop, G. D. Bussell, and M. B. Winter, Determination of the intensity of the Earth's magnetic field during archaeological times: Reability of the Thellier technique, Rev. Geophys., 26, 3-12, 1988.

Bowles, J., J. Gee, J. Hildebrand, and L. Tauxe, Archaeomagnetic intensity results from California and Ecuador: evaluation of regional data, Phys. Earth Planet. Inter., 203(3-4), 967-981, 2002.

Chauvin, A., Y. Garcia, Ph. Lanos, and F. Laubenheimer, Paleointensity geomagnetic field recovered on archaeomagnetic sites from France, Phys. Earth Planet. Inter., 120, 111-136, 2000.

Coe, R. S., The determination of paleo-intensities of the Earth's magnetic field with emphasis on mechanisms which could cause non-ideal behavior in Thelier's method, J. Geomag. Geoelectr., 19, 157-179, 1967.

Coe, R. S., C. S. Gromm, and E. A. Mankinen, Geomagnetic paleointensities from radiocarbon dated lava flows on Hawaii and the question of the Pacific non-dipole low, J. Geophys. Res., 83, 1740-1756, 1978.
Etchevarne, C., A reciclagem da faiança em Salvador: contextos arqueológicos e tipos de utilização, Clio, 16, 2003.

Etchevarne, C., Aspectos da cerâmica colonial do século XVII, em Salvador, Bahia, Clio, 20, 2006.

Etchevarne, C., A faiança portuguesa do século XVII na Bahia. Patrimônio e Estudos, IPPAR, 10, 2007.

Fox, J. M. W. and M. J. Aitken, Cooling-rate dependence of thermoremanent magnetization, Nature, 283, 462-463, 1980.

Gallet, Y., A. Genevey, and M. LeGoff, Three millennia of direction variation of the Earth's magnetic field in Western Europe as revealed by archeological artefacts, Phys. Earth Planet. Inter., 131, 81-89, 2002.

Gallet, Y., A. Genevey, and F. Fluteau, Does Earth's magnetic field secular variation control centennial climate change?, Earth Planet. Sci. Lett., 236, 339-347, 2005.

Genevey, A. and Y. Gallet, Intensity of the geomagnetic field in western Europe over the past 2000 years: New data from ancient French pottery, J. Geophys. Res., 107(B11), 2285, 2002.

Genevey, A. S., Y. Gallet, and J. C. Margueron, Eight thousand years of geomagnetic field intensity variations in the eastern Mediterranean, $J$. Geophys. Res., 108(B5), 2228, 2003.

Gómez-Paccard, M., A. Chauvin, Ph. Lanos, J. Thiriot, and P. JiménezCastillo, Archeomagnetic study of seven contemporaneous kilns from Murcia (Spain), Phys. Earth Planet. Inter., 157, 16-32, 2006.

Gubbins, D., A. L. Jones, and C. C. Finlay, Fall in Earth's Magnetic Field is Erratic, Science, 312, 900-902, 2006.

Jackson, A., A. R. T. Jonkers, and M. Walker, Four centuries of geomagnetic secular variation from historical records, Phil. Trans. R. Soc. London A, 358, 957-990, 2000.

Korte, M. and C. G. Constable, Continuous geomagnetic field for the past 7 millennia: 2.CALS7K, Geochem. Geophys. Geosyst., 6, 1, 2005.

Korte, M., A. Genevey, C. G. Constable, U. Frank, and E. Schnepp, Continuous geomagnetic field models for the past 7 millennia: 1 . A new global data compilation, Geochem. Geophys. Geosyst., 6, Q02H15, 2005.

Kovacheva, M., Archeomagnetic database from Bulgaria: the last 8000 years, Phys. Earth Planet. Inter., 102, 145-151, 1997.

Kovacheva, M., J. M. Parés, N. Jordanova, and V. Karloukovski, A new contribution to the archaeomagnetic study of a Roman pottery kiln from Calahorra (Spain), Geophys. J. Int., 123, 931-936, 1995.

McIntosh, G., M. Kovacheva, G. Catanzariti, M. L. Osete, and L. Casas, Widespread occurrence of a novel high coercivity, thermally stable, low unblocking temperature magnetic phase in heated archeological material, Geophys. Res. Lett., 34, L21302, 2007.

Morales, J., A. Goguitchaichvili, and J. Urrutia-Fucugauchi, A rockmagnetic and paleointensity study of some Mexican volcanic lava flows during the Latest Pleistocene to the Holocene, Earth Planets Space, 53, 893-902, 2001.

Morales, J., L. M. Alva-Valdivia, A. Goguitchaichvili, and J. UrrutiaFucugauchi, Cooling rate corrected paleointensities from the Xitle lava flow: Evaluation of within-site scatter for single spot-reading cooling units, Earth Planets Space, 58, 1341-1347, 2006.

Néel, L., Some theoretical aspects of rock magnetism, Adv. Phys., 4, 191243, 1955.

Perrin, M. and E. Schnepp, IAGA paleointensity database: distribution and quality of the data set, Phys. Earth Planet. Inter., 147, 255-267, 2004.

Soler-Arechalde, A. M., F. Sanchez, M. Rodriguez, C. Caballero-Miranda, A. Goguitchaichvili, J. Urrutia-Fucugauchi, L. Manzanilla, and D. $\mathrm{H}$. Tarling, Archaeomagnetic investigation of oriented pre-Columbian lime-plasters from Teotihuacan, Mesoamerica, Earth Planets Space, 58, 1433-1439, 2006.

Thellier, E. and O. Thellier, Sur l'intensité du champ magnetiqué terrestre dans le passé historique et géologique, Ann. Geophys., 15, 285-376, 1959.

Valet, J.-P., Time Variations in Geomagnetic Intensity, Rev. Geophys., 41, $1,2003$.

Yu, Y., D. J. Dunlop, L. Pavlish, and M. Cooper, Archeomagnetism of Ontario potsherds from the last 2000 years, J. Geophys. Res., 105(B8), 19419-19434, 2000.

G. A. Hartmann (e-mail: gelvam@iag.usp.br), R. I. F. Trindade, A. Goguitchaichvili, C. Etchevarne, J. Morales, and M. C. Afonso 


\section{Apêndice B}

Artigo sobre a curva de variação da intensidade do CMT na região Nordeste do Brasil

Artigo:

"Archeointensity in Northeast Brazil over the past five centuries"

G.A. Hartmann, A. Genevey, Y. Gallet, R.I.F. Trindade,

C. Etchevarne, M. Le Goff, M.C. Afonso

Earth and Planetary Science Letters, 296, 340-352, 2010. 


\title{
Archeointensity in Northeast Brazil over the past five centuries
}

\author{
Gelvam A. Hartmann ${ }^{\mathrm{a}, \mathrm{c}, *}$, Agnès Genevey ${ }^{\mathrm{b}}$, Yves Gallet ${ }^{\mathrm{c}}$, Ricardo I.F. Trindade ${ }^{\mathrm{a}}$, Carlos Etchevarne ${ }^{\mathrm{d}}$, \\ Maxime Le Goff ${ }^{\mathrm{c}}$, Marisa C. Afonso ${ }^{\mathrm{e}}$ \\ a Departamento de Geofísica, Instituto de Astronomia, Geofísica e Ciências Atmosféricas, Universidade de São Paulo, Rua do Matão, 1226, 05508-090, São Paulo, Brazil \\ b Centre de Recherche et de Restauration des Musées de France, UMR CNRS 171, Palais du Louvre, Porte des Lions, 14 quai F. Mitterrand, 75001 , Paris, France \\ c Equipe de Paléomagnétisme, Institut de Physique du Globe de Paris, UMR CNRS 7154, 4 place Jussieu, 75005, Paris, France \\ d Departamento de Antropologia, Universidade Federal da Bahia, Terreiro de Jesus, Prédio da Faculdade de Medicina, 40026-100, Salvador, Brazil \\ e Museu de Arqueologia e Etnologia, Universidade de São Paulo, Av. Prof. Almeida Prado, 1466, 05508-090, São Paulo, Brazil
}

\section{A R T I C L E I N F O}

\section{Article history:}

Received 14 January 2010

Received in revised form 14 May 2010

Accepted 17 May 2010

Available online 16 June 2010

Editor: P. DeMenocal

\section{Keywords:}

archeomagnetism

archeointensity

geomagnetic secular variation

historical geomagnetic field

Northeast Brazil

southern hemisphere

\begin{abstract}
A B S T R A C T
This study presents the first archeointensity results from Northeast Brazil obtained from 14 groups of architectural brick fragments sampled in the city of Salvador, Bahia State $\left(13^{\circ} \mathrm{S}, 38.5^{\circ} \mathrm{W}\right)$ and dated between the middle of the XVIth century and the beginning of the XIXth century. The dating is ascertained by historical documents complemented by archeological constraints, yielding in all cases age uncertainties of less than 50 years. Analyses were carried out using two experimental protocols: 1 - the "zero field-in field" version of the classical Thellier and Thellier method as proposed by Coe (TT-ZI), including partial thermoremanent magnetization (pTRM) and pTRM-tail checks, and $2-$ the Triaxe procedure involving continuous high temperature magnetization measurements. Both TRM anisotropy and cooling rate effects were taken into account for the intensity determinations. The cooling rate effect was further explored for the TT-ZI protocol using three increasing slow cooling times $\left(5 \mathrm{~h}, 10 \mathrm{~h}\right.$ and $25 \mathrm{~h}$ ) between $450^{\circ} \mathrm{C}$ and room temperature. Following archeological constraints, the slowest cooling time was retained in our study, yielding decreases of the raw intensity values by $4 \%$ to $14 \%$. For each fragment, a mean intensity was computed and retained only when the data obtained from all specimens (between 2 and 6 ) satisfied a coherence test at $\sim 5 \%$. A total of 57 fragments (183 specimens) was considered for the computations of site-mean intensity values, with derived standard deviations of less than $8 \%$ of the corresponding means. When separately computed using the two experimental techniques, the site-mean intensity values always agree to within $5 \%$. A good consistency is observed between intensity values of similar or close ages, which strengthen their reliability. Our data principally show a significant and continuous decrease in geomagnetic field intensity in Northeast Brazil between the first half of the XVIIth century and the XXth century. One result dated to the second half of the XVIth century further suggests that the geomagnetic field intensity reached a maximum around $1600 \mathrm{AD}$. This evolution is in good agreement with that expected in the city of Salvador from the available global geomagnetic field models. However, the accuracy of these models appears less well constrained between $\sim 1550 \mathrm{AD}$ and $\sim 1650 \mathrm{AD}$.
\end{abstract}

(C) 2010 Elsevier B.V. All rights reserved.

\section{Introduction}

Improving the reliability of global geomagnetic field models over the past few millennia is still very much needed (e.g. Hongre et al., 1998; Korte and Constable, 2005; Korte et al., 2009). Several studies recently focused on large compilations of archeomagnetic (i.e. obtained from archeological materials) and paleomagnetic (obtained from volcanic and sedimentary rocks) data covering the past 10 millennia (Korte et al., 2005; Genevey et al., 2008; Donadini et al., 2009). These data compilations include intensity and directional

\footnotetext{
* Corresponding author. Departamento de Geofísica, Instituto de Astronomia, Geofísica e Ciências Atmosféricas, Universidade de São Paulo, Rua do Matão, 1226, 05508-090, São Paulo, Brazil.

E-mail address: gelvam@iag.usp.br (G.A. Hartmann).
}

information on the geomagnetic field. But the data are unevenly distributed geographically and temporally. In particular, there is only a very small proportion of data available from the southern hemisphere. This obviously is a strong limiting factor for constraining the accuracy of global field modeling. Concerning intensity data determined from archeological baked-clay materials and volcanics, Genevey et al. (2008) underlined the fact that only $~ 5 \%$ of all available data were obtained from the southern hemisphere, and among those data, $75 \%$ were obtained on the western side of South America in Peru. The next generation of global field modeling clearly needs more data from the Southern hemisphere to decipher the geomagnetic field evolution at all time scales, to test the occurrence of rapid field variations and the persistence of non-dipole features, and possibly to understand the role of flux patches at the core-mantle boundary (e.g. Bloxham and Gubbins, 1985; Kelly and Gubbins, 1997; Gallet et al., 
2003; Dumberry and Finlay, 2007; Gallet et al., 2009; Hartmann and Pacca, 2009).

Several recent studies also highlighted our limited knowledge of the century-scale dipole field moment evolution over the past few millennia (e.g. Genevey et al., 2008; Valet et al., 2008; Korte et al., 2009). This has strong implications for a wide range of processes, such as the shielding effect of the geomagnetic field on the nucleation rate of cosmogenic nuclides, the latter being used for recovering the past variations in solar activity and climate (e.g. St-Onge et al., 2003; Muscheler et al., 2007). Perhaps more surprisingly, even the detailed evolution of the dipole field moment over the past few centuries (i.e. immediately before the first "direct"-instrumental-intensity measurements were made available in the mid-XIXth century) is still discussed. Jackson et al. (2000), Gubbins et al. (2006) and Finlay (2008) propose different decreasing linear trends for the axial dipole field moment $\left(g_{1}^{0}\right)$ (from rapid to null, respectively) between $1590 \mathrm{AD}$ and $1840 \mathrm{AD}$, arguing that the available data do not allow to resolve more variability. More recently, Genevey et al. (2009) have suggested a more oscillatory behavior based on new archeointensity data from Western Europe (France) which they used to rescale the global geomagnetic field models constructed by Jackson et al. (2000). This approach is based on a theorem of Hulot et al. (1997) which states that purely directional data are enough to recover the morphology of a mainly dipolar magnetic field, and therefore implies that even a single local paleointensity record can be used to scale the global magnitude of the field. It is however much dependent on the quality of the historical global geomagnetic field model used and must be tested by the acquisition of new archeointensity data from another region distant from France. The present study of archeointensity data from Brazil (Eastern side of South America) obtained from baked-clay architectural bricks historically dated to the past five centuries is an important first step towards this goal.

a)

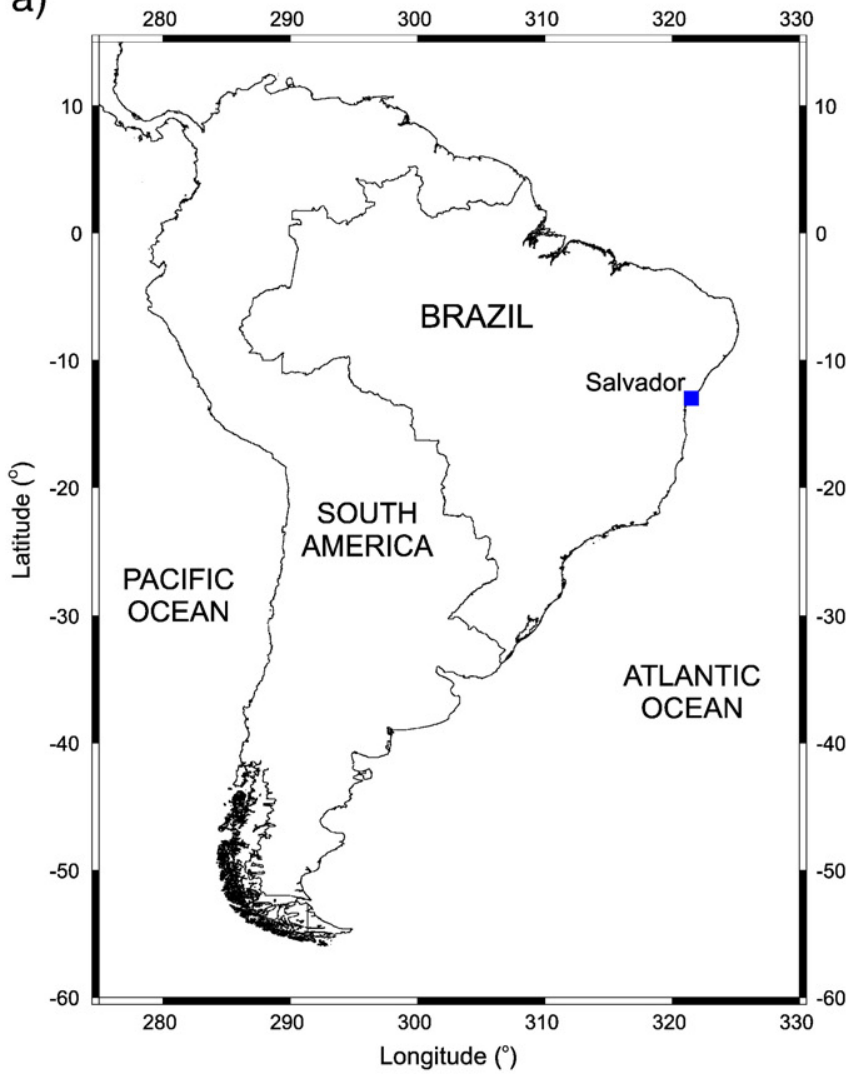

\section{Archeological sampling}

Our collection consists of fourteen groups of architectural brick fragments sampled in the city of Salvador $\left(13^{\circ} \mathrm{S}, 38.5^{\circ} \mathrm{W}\right)$, capital of Bahia State in the Northeast region, Brazil (Fig. 1a, Table 1). Salvador, settled in 1549, was one of the most important centers in the Americas during the XVIth and XVIIth centuries, owing to its privileged geographic position along the sea routes between Europe, Africa, India and China. During that period, it experienced an accelerated growth with the construction of governmental, religious and private buildings, implying that bricks were used shortly after manufacturing. Our fragments were mainly collected from buildings located in the Salvador historic center (Pelourinho area) and neighborhood (Table 1).

Only well documented and well dated buildings were considered for our study. Their dating is mainly ensured by historical constraints. This includes official and non-official reports presented in the Inventário de Proteção do Acervo Cultural da Bahia (Bahia, 1997). These archives allow precise and accurate age estimations sometimes better than 3 years but in any case less than 50 years (Table 1 ). The C06 group of brick fragments is, for example, from the basement of house number 06 known as "Centro Automobilístico da Bahia" whose foundations, mentioned in the archives, are dated to around $1705 \pm 5$ years AD (Fig. 1b and c). For the SCA group sampled in the famous house of the first mayor of the city of Salvador, the dating is even more precise being ensured from a direct inscription on the pediment of the building (Fig. 1d).

Additional age constraints were provided by archeological information, including the architectural style of the buildings, the stratigraphy of the archeological excavations, the typology evolution of the bricks from the rough-textured bricks made by the Jesuits in the XVIth century to the refined, pressed bricks of the XIXth century

b)

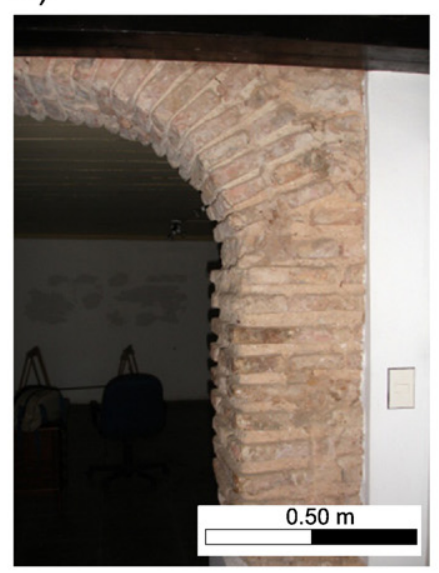

d)

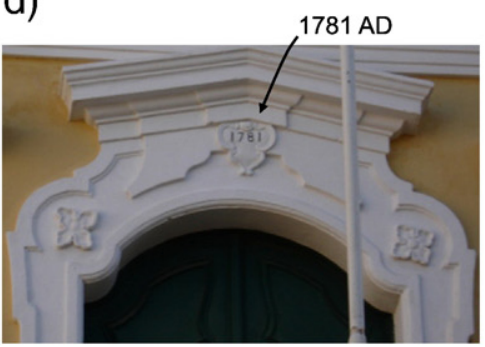

c)

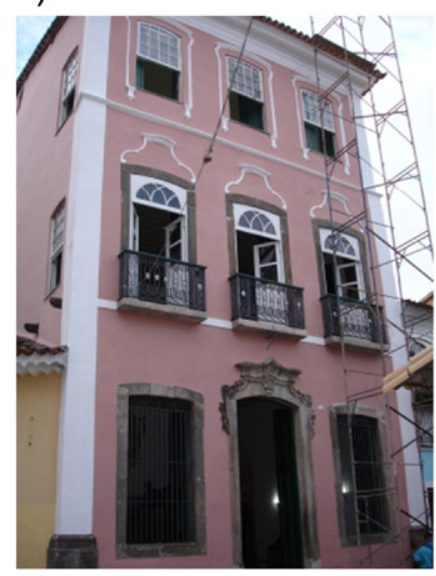

e)

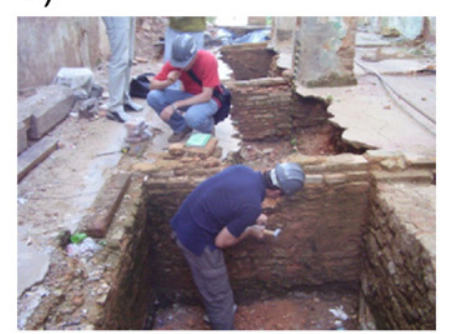

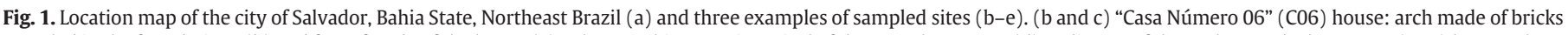

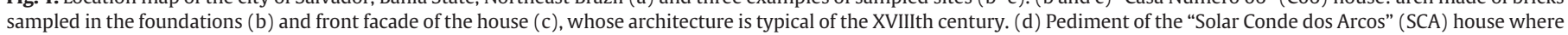
the date of its construction is inscribed. (e) Sampling being performed in the basement of the "Casa do Pelourinho 27" (CP27) house. 
Table 1

Archeointensity results obtained from our collection of fragments sampled in the city of Salvador $\left(13^{\circ} \mathrm{S}, 38.5^{\circ} \mathrm{W}\right)$.

\begin{tabular}{|c|c|c|c|c|c|c|c|c|}
\hline \multirow[t]{2}{*}{ Site } & \multirow[t]{2}{*}{ Site description } & \multicolumn{2}{|c|}{ Dating method } & \multirow{2}{*}{$\begin{array}{l}\text { Age interval } \\
(\mathrm{AD})\end{array}$} & \multirow{2}{*}{$\begin{array}{l}\text { Intensity } \\
\text { methods }\end{array}$} & \multirow{2}{*}{$\begin{array}{l}N \\
\text { fragment }\end{array}$} & \multirow{2}{*}{$\begin{array}{l}n \\
\text { specimen }\end{array}$} & \multirow{2}{*}{$\begin{array}{l}\text { Fmean } \pm \sigma F \\
(\mu \mathrm{T})\end{array}$} \\
\hline & & Historic & Arch & & & & & \\
\hline Igreja Mem de Sá (IMS) & $\begin{array}{l}\text { The "Mem de Sá" Church was built by the } \\
\text { Jesuits at the end of XVIth century and was } \\
\text { named after the Governor of the Bahia } \\
\text { State who financed its construction. }\end{array}$ & $\mathrm{X}$ & $\mathrm{X}$ & $1561-1591$ & $\begin{array}{l}\text { TT-ZI and } \\
\text { Triaxe }\end{array}$ & $3 / 4$ & $17 / 20$ & $36.2 \pm 1.6$ \\
\hline Praça da Sé (SE) & $\begin{array}{l}\text { The church of Sé is the main religious } \\
\text { construction built by the Jesuits in the } \\
\text { city of Salvador during the XVIIth century. } \\
\text { The site SE belongs to its initial } \\
\text { phase of construction. }\end{array}$ & $\mathrm{X}$ & $\mathrm{X}$ & $1590-1620$ & $\begin{array}{l}\text { TT-ZI and } \\
\text { Triaxe }\end{array}$ & $4 / 6$ & $16 / 23$ & $40.4 \pm 1.2$ \\
\hline Praça da Sé 1 (SE1) & $\begin{array}{l}\text { Site SE1 belongs to the second phase of } \\
\text { extension of the Church of Sé. }\end{array}$ & $\mathrm{X}$ & $\mathrm{X}$ & $1600-1650$ & $\begin{array}{l}\text { TT-ZI and } \\
\text { Triaxe }\end{array}$ & $4 / 6$ & $15 / 25$ & $41.4 \pm 3.2$ \\
\hline Praça da Sé 2 (SE2) & $\begin{array}{l}\text { Site SE2 belongs to the third phase of } \\
\text { extension of the Church of Sé. }\end{array}$ & $\mathrm{X}$ & $\mathrm{X}$ & $1650-1700$ & $\begin{array}{l}\text { TT-ZI and } \\
\text { Triaxe }\end{array}$ & $3 / 5$ & $10 / 21$ & $37.9 \pm 0.7$ \\
\hline Museu de Arte Sacra (MAS) & $\begin{array}{l}\text { Site MAS was sampled in the current Art } \\
\text { Sacra Museum of Bahia, which was initially } \\
\text { built at the end of the XVIIth (as indicated } \\
\text { in archives) to host the Santa Teresa de } \\
\text { Ávila Convent. }\end{array}$ & $\mathrm{X}$ & & $1666-1686$ & $\begin{array}{l}\text { TT-ZI and } \\
\text { Triaxe }\end{array}$ & $4 / 6$ & $12 / 25$ & $38.3 \pm 0.6$ \\
\hline Solar Berquó (SB) & $\begin{array}{l}\text { The SB house is clearly identified by its } \\
\text { architectural style, characteristic of the } \\
\text { second half of the XVIIth century. Historical } \\
\text { documents further attest for a short period } \\
\text { of construction. }\end{array}$ & $\mathrm{X}$ & & 1691-1693 & Triaxe & $5 / 5$ & $13 / 17$ & $37.2 \pm 1.1$ \\
\hline Farol da Barra 1 + $2($ FB1 +2$)$ & $\begin{array}{l}\text { Farol da Barra is a famous fortress initially } \\
\text { built to defend the city of Salvador and later } \\
\text { used as a lighthouse for the guidance of ships. } \\
\text { The numbers } 1 \text { and } 2 \text { refer to two sampling } \\
\text { zones both dated to the initial phase of } \\
\text { construction of the fortress. }\end{array}$ & $\mathrm{X}$ & & $1696-1702$ & $\begin{array}{l}\text { TT-ZI and } \\
\text { Triaxe }\end{array}$ & $4 / 7$ & $11 / 18$ & $36.5 \pm 0.9$ \\
\hline Casa do Pelourinho 27 (СР27) & $\begin{array}{l}\text { The Pelourinho area is the historical center of the } \\
\text { city of Salvador. The site CP } 27 \text { was sampled in } \\
\text { one of the different houses situated in this area. }\end{array}$ & $\mathrm{X}$ & $\mathrm{X}$ & $1675-1725$ & Triaxe & $5 / 7$ & $14 / 21$ & $35.8 \pm 2.1$ \\
\hline Casa Número 6 (C06) & $\begin{array}{l}\text { This site C06 was sampled in the house known } \\
\text { as the "Centro Automobilistico da Bahia." Both } \\
\text { historical and architectural constraints allow to } \\
\text { precisely dating its construction at the } \\
\text { beginning of XVIIIth century. }\end{array}$ & $\mathrm{X}$ & & $1700-1710$ & $\begin{array}{l}\text { TT-ZI and } \\
\text { Triaxe }\end{array}$ & $3 / 6$ & $9 / 18$ & $36.7 \pm 1.1$ \\
\hline Corpo de Bombeiros (CB) & $\begin{array}{l}\text { The site CB was sampled in the ancient } \\
\text { Chapel Nossa Senhora de Guadalupe, whose } \\
\text { construction lasted } 10 \text { years as indicated in } \\
\text { historical documents. }\end{array}$ & $\mathrm{X}$ & $\mathrm{X}$ & 1767-1777 & Triaxe & $3 / 6$ & $9 / 29$ & $32.7 \pm 2.0$ \\
\hline Solar Conde dos Arcos (SCA) & $\begin{array}{l}\text { Site SCA is associated to an important house } \\
\text { built for the first mayor of the city of Salvador } \\
\text { at the end of the XVIIIth century. The precise } \\
\text { dating of its construction is ensured by a direct } \\
\text { inscription on the pediment of the house } \\
\text { and complemented by historical documents. } \\
\text { This building currently hosts the } \\
\text { Colégio } 2 \text { de Julho. }\end{array}$ & $\mathrm{X}$ & & $1780-1781$ & TT-ZI & $4 / 7$ & $8 / 14$ & $32.1 \pm 0.6$ \\
\hline Tijoleira Farias (TF) & $\begin{array}{l}\text { The precise dating of the construction of the } \\
\text { house where the site TF was taken out is } \\
\text { ensured by a stamp on a brick indicating } \\
\text { the year of manufacture and by historical } \\
\text { documents. }\end{array}$ & $\mathrm{X}$ & & 1887 & $\begin{array}{l}\text { TT-ZI and } \\
\text { Triaxe }\end{array}$ & $5 / 7$ & $14 / 21$ & $25.8 \pm 1.6$ \\
\hline $\begin{array}{l}\text { Museu de Arqueologia } \\
\text { e Etnologia } 4 \text { (MAE4) }\end{array}$ & $\begin{array}{l}\text { The sampled building is part of the current } \\
\text { Archeology and Ethnology Museum of the } \\
\text { Federal University of Bahia. The bricks } \\
\text { collected are associated to the final phase of } \\
\text { extension of this architectural ensemble. }\end{array}$ & $\mathrm{X}$ & $\mathrm{X}$ & 1896-1906 & Triaxe & $5 / 6$ & $15 / 18$ & $25.7 \pm 1.3$ \\
\hline Galeria Canizares (GC) & $\begin{array}{l}\text { Site GC was sampled in one house located in a } \\
\text { neighborhood developed at the beginning of the } \\
\text { XXth century. Historical and architectural } \\
\text { constraints ensure the dating of the house } \\
\text { now hosting an art gallery. }\end{array}$ & $\mathrm{X}$ & $\mathrm{X}$ & 1900-1920 & Triaxe & $5 / 6$ & $20 / 25$ & $25.0 \pm 0.5$ \\
\hline
\end{tabular}

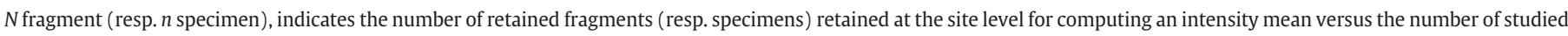

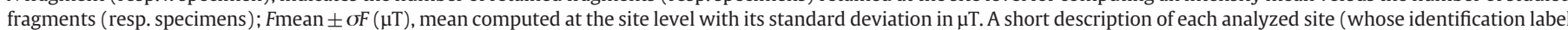

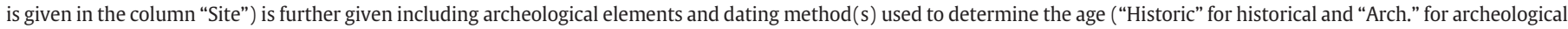
constraints).

(Costa, 2005). This typology was particularly useful to detect (and avoid) sectors with more recent reconstructions. But more importantly, our sampling was systematically carried out in the foundations of the buildings to ensure that the chosen bricks, all locally manufactured (Costa, 2005), are really associated with the initial dated phase of construction excluding any later restorations. 
Between four and nineteen fragments were collected per site. For the FB1 + 2 and MAE4 sites, a portable driller was used to perform the sampling of standard cores of $2.2 \mathrm{~cm}$ in diameter. For the others groups, brick fragments were directly removed from the walls by hand or with the help of a hammer (Fig. 1e).

\section{Archeointensity methods}

Two protocols, both deriving from the Thellier and Thellier intensity method (Thellier and Thellier, 1959), were used in the present work for the archeointensity determinations. The first one follows the classical double-heating technique developed by Thellier and Thellier as modified by Coe (1967) with measurements at ambient temperatures and the second, hereafter called the "Triaxe protocol" involves high temperature measurements using the Triaxe three-axis vibrating sample magnetometer (Le Goff and Gallet, 2004). The choice between protocols was partly dictated by the magnitude of magnetization of the fragments. The Triaxe protocol was used for fragments with remanent magnetization above $40 \times 10^{-2} \mathrm{~A} / \mathrm{m}$ while fragments with weaker remanence were analyzed using the other protocol. Moreover several fragments were measured using both techniques for allowing comparisons between them.

\subsection{TT-ZI protocol}

This classical protocol combines at each increasing temperature step, a first zero-field demagnetization of the natural remanent magnetization (NRM; $Z$ steps for "zero-field" steps) then a pTRM acquisition in a known laboratory field ( $H_{l a b}$ - I steps for "In-field" steps) and is referred in the following as to the "TT-ZI protocol" (Coe, 1967). From each fragment, we prepared three cubic specimens of volume $\sim 1 \mathrm{~cm}^{3}$, two for paleointensity determination and one for the cooling rate experiment. In-air heating and cooling cycles (30 min each) were performed with a small laboratory-built oven of the Institut de Physique du Globe de Paris specially devoted to archeointensity experiments. Note that the specimens position inside the oven and their orientation regarding the $H_{l a b}$ field were strictly kept the same during the whole experimental chain. For the in-field steps, a $H_{l a b}$ of $35 \mu \mathrm{T}$ was applied parallel to an arbitrary-chosen $X$ axis both during heating and cooling. For each pair of specimens from the same fragment, a rotation of the coordinate system was made to obtain $\mathrm{x}$ axes perpendicular to each other in order to test the reliability in the determination of the TRM anisotropy tensor. Magnetization measurements were made on a horizontal SQUID magnetometer (2G Enterprises) housed within a magnetically shielded room. Twenty double heating-cooling steps were performed between $100{ }^{\circ} \mathrm{C}$ and $600{ }^{\circ} \mathrm{C}$, with temperature intervals of $50{ }^{\circ} \mathrm{C}$ from $100{ }^{\circ} \mathrm{C}$ to $150^{\circ} \mathrm{C}$ and $25^{\circ} \mathrm{C}$ above. pTRM-checks were included every two temperature steps in order to monitor any alteration of the magnetic mineralogy during the thermal treatment and pTRM-tail checks were added at six temperature steps to allow the detection of multidomain (MD) grains in our fragments. TRM anisotropy and cooling rate effects on the intensity determinations were also taken into account (see below). We finally measured the weight of each analyzed specimen during the course of the TT-ZI and cooling rate experiments in order to evaluate and correct the results from the loss of mass (Schnepp, 2003).

\subsubsection{TRM anisotropy}

Biases due to TRM anisotropy in archeological artifacts such as bricks, tiles or ceramics have been largely documented in several studies (e.g. Rogers et al., 1979; Aitken et al., 1981; Veitch et al., 1984; Chauvin et al., 2000; Genevey et al., 2008; Kovacheva et al., 2009). For these materials, the TRM anisotropy is usually interpreted as linked to a preferential alignment of the magnetic grains caused by the stretching of the clay during the manufacturing process. The TRM anisotropy tensor was determined during the course of the TT-ZI intensity experiments at two different temperature steps $\left(350{ }^{\circ} \mathrm{C}\right.$ and $\left.500{ }^{\circ} \mathrm{C}\right)$ through pTRM acquisition along six successive positions $(X,-X, Y,-Y, Z$ and $-Z)$. For each of the two temperatures, a correction factor ( $f 1$ and $f 2$ ) was then computed following Veitch et al. (1984).

\subsubsection{Cooling rate dependence of TRM acquisition}

The cooling rate dependence of TRM acquisition may noticeably affect the intensity determinations obtained using Thellier-type methods (e.g. Fox and Aitken, 1980; Genevey et al., 2008). This effect arises from the differences experienced by the artifacts between the cooling rate prevailing during the acquisition of the ancient and original TRM (the so-called NRM) and the rate used for TRM acquisition during laboratory experiments. The experimental cooling rate is generally faster than the original one which usually induces, as experimentally observed, an overestimation of the ancient field intensity (e.g. Chauvin et al., 2000; Genevey and Gallet, 2002; Goméz-Paccard et al., 2006). Such behavior is predicted from models for single domain grains (Néel, 1955; Dodson and McClelland-Brown, 1980; Halgedhal et al., 1980).

Here we evaluated the cooling rate effect for each fragment through additional experiments performed on a specimen specially prepared for those measurements. The procedure follows the one described in Genevey and Gallet (2002) (see also Chauvin et al., 2000). It implies the successive acquisition, from the same temperature, of three partial TRM with, at first, a rapid cooling rate (as used for the TTZI protocol; $\left.\mathrm{pTRM}_{\mathrm{r} 1}\right)$ then a slow cooling rate $\left(\mathrm{pTRM}_{\text {slow }}\right)$ and again a rapid cooling rate $\left(\mathrm{pTRM}_{\mathrm{r} 2}\right)$. As a pTRM-check test, the comparison between $\mathrm{pTRM}_{\mathrm{r} 1}$ and $\mathrm{pTRM}_{\mathrm{r} 2}$ allows one to monitor the stability of the TRM acquisition capacity during the experiments. When no alteration is detected, the cooling rate correction factor is then computed from the ratio between the average of the two rapidly acquired PTRM and

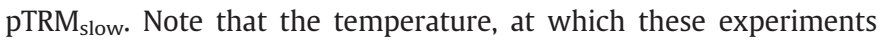
were carried out, was chosen for each fragment to include at least 50\% of the magnetization.

For accurately correcting the raw intensity values from the cooling rate effect, it is important to consider a slow cooling rate similar to the original one. Here experiments involving three increasing cooling rates were successively carried out and the sequence of measurements described above was therefore repeated three times. A cooling rate correction factor was then computed for each rate if no major evolution of the magnetic mineralogy was observed through the entire procedure. The three rates correspond to cooling time durations of $5 \mathrm{~h}, 10 \mathrm{~h}$, and then $25 \mathrm{~h}$ from $450{ }^{\circ} \mathrm{C}$. Theses different rates were chosen to mimic different possible cooling conditions experienced by the archeological artifacts which are partly related to the size of the ovens where these artifacts were fired, from small to bigger size, respectively. However, from archeological evidences (Costa, 2005), it seems that the slower cooling rate would be the closest to the original one and it was thus chosen for correcting the intensity values. Nevertheless, the two faster rates provided information on the error that would be made in the intensity determination if the rate was not properly estimated.

\subsubsection{TRM tail checks}

Paleointensity determinations can be biased by the presence of multidomain (MD) grains which may violate the principles of reciprocity and additivity of pTRM on which relies the Thellier and Thellier method (and modified versions, e.g. Dunlop and Özdemir, 1997; Yu and Dunlop, 2003). Different tests or procedures were recently proposed to allow the detection of these large grains (e.g. Krása et al., 2003; Yu et al., 2004) and MD were tracked in our TT-ZI experiments using the "pTRM-tail check" of Riisager and Riisager (2001). This test requires making an additional zero-field step after the double-heating ZI steps. It allows detecting pTRM "tails" corresponding to the fraction of pTRM acquired at a given blocking 
a)

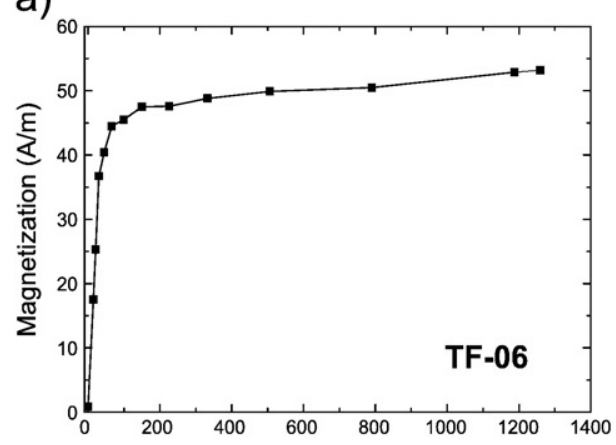

d)

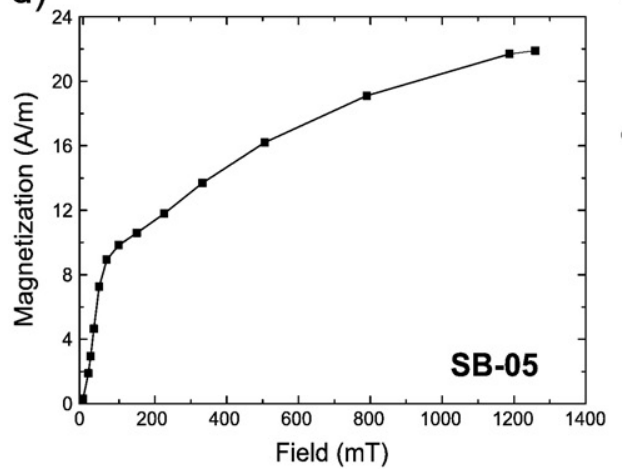

b)

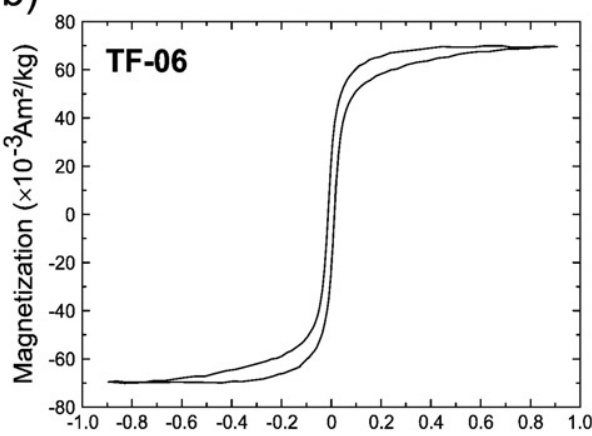

e)

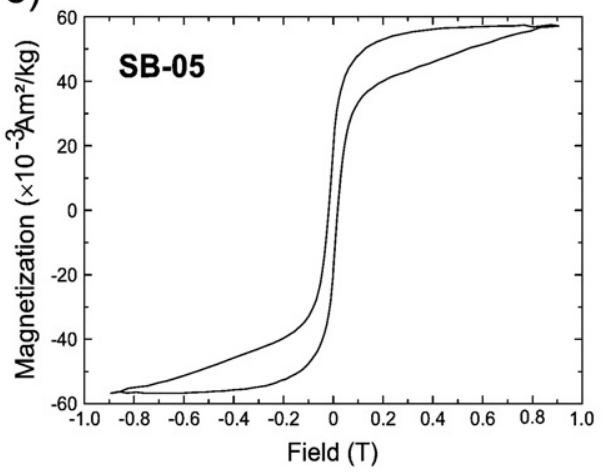

c)

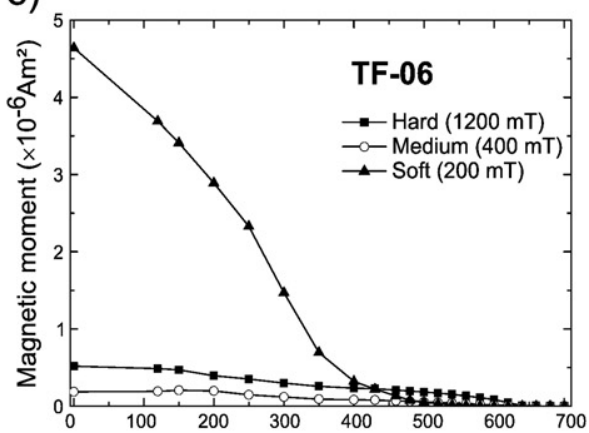

f)

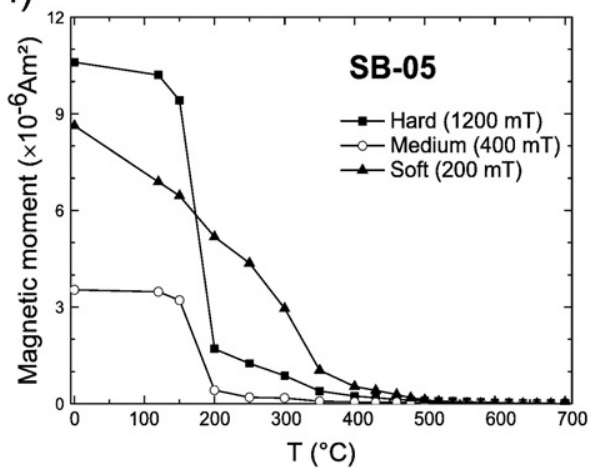

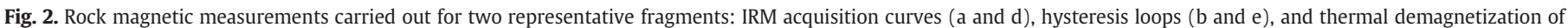
three-axis IRM (hard, soft and medium) acquired along perpendicular directions ( $c$ and $f$ ).

temperature that is left after zero-field heating at the same temperature. Six "pTRM-tail checks" were performed at $200{ }^{\circ} \mathrm{C}$, $300{ }^{\circ} \mathrm{C}, 350{ }^{\circ} \mathrm{C}, 400{ }^{\circ} \mathrm{C}, 500{ }^{\circ} \mathrm{C}$ and $600{ }^{\circ} \mathrm{C}$. The percentage of pTRM tails was computed for each relevant temperature using the ThellierTool4.0 software (Leonhardt et al., 2004) which takes into account the dependence of pTRM-tail intensity on the angular a)

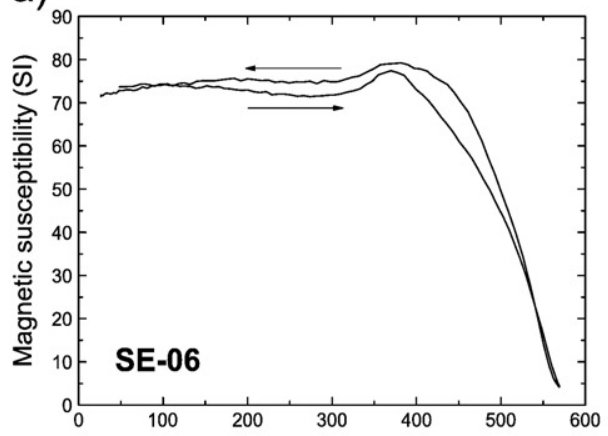

d)

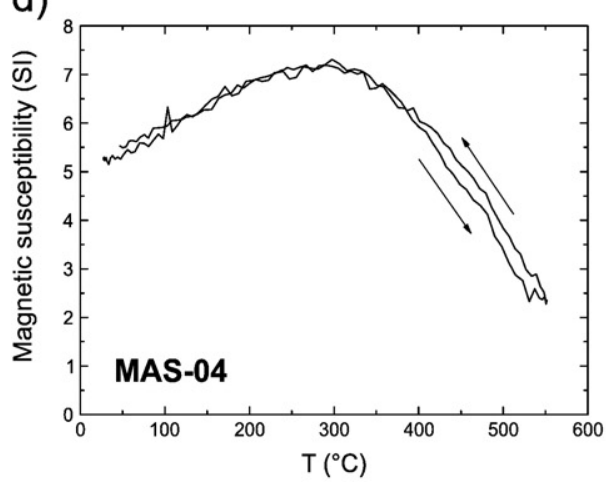

b)

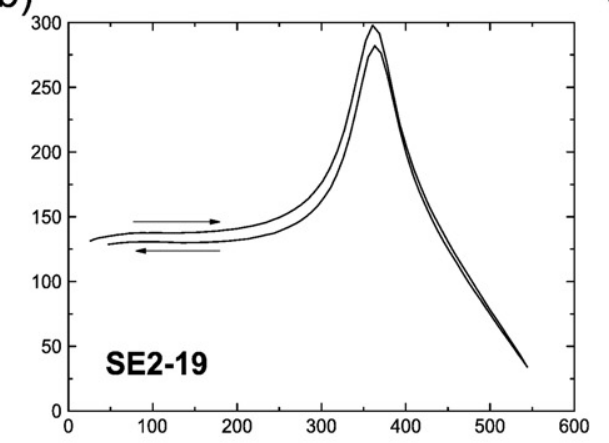

e)

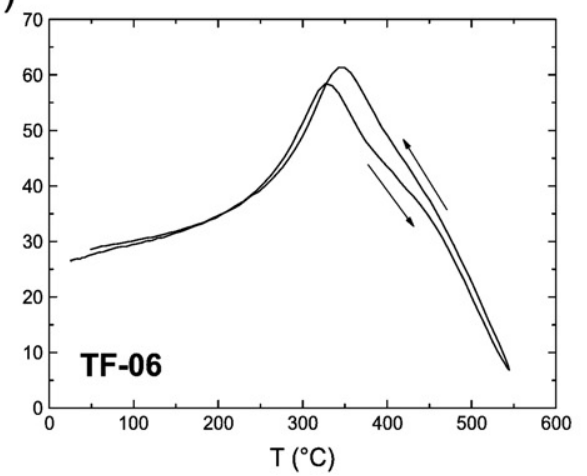

c)

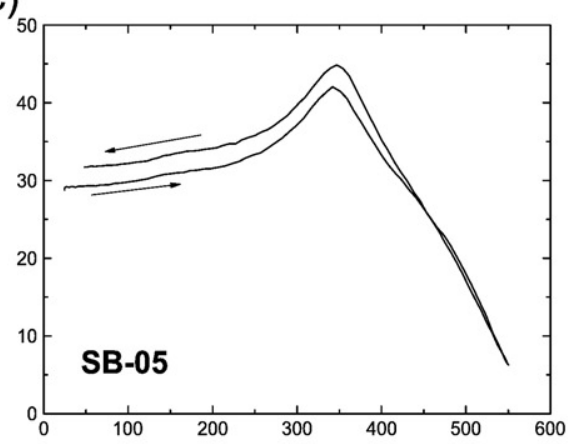

f)

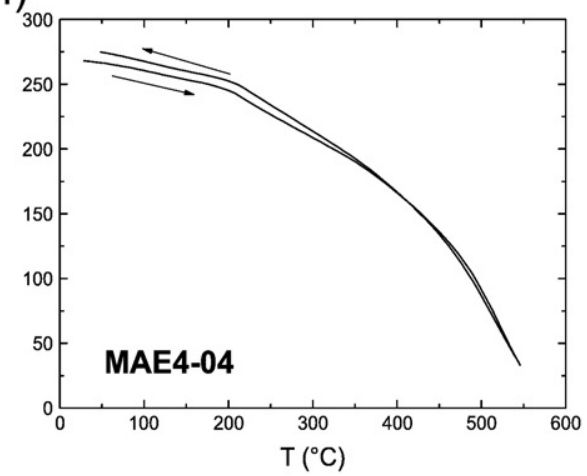

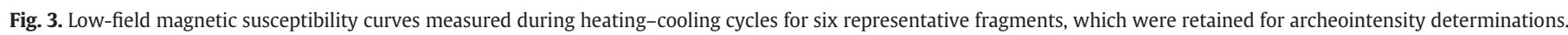
Susceptibilities are in arbitrary units. 
difference between NRM and laboratory field directions (Yu et al., 2004).

\subsubsection{Analysis and selection criteria}

The interpretation of the TT-ZI experiments was made for each specimen using a "NRM remained versus TRM gained" diagram (socalled Arai diagram; Nagata et al., 1963) and an intensity value was computed from a least-square slope fitting over linear segments (Coe et al., 1978).

The criteria used in our study to select the most reliable intensity determinations are very close to those defined by Genevey and Gallet (2002) and Genevey et al. (2009). First the intensity value must be determined through the same temperature interval for which the main magnetic component is isolated in the corresponding orthogonal Zidjerveld diagram. This main "primary" component must be well defined with a limit of $5^{\circ}$ for the $\alpha 95^{\circ}$. Note that in the present study, the $\alpha 95^{\circ}$ was in all cases of less than $3^{\circ}$. A minimum of 5 temperature steps is required, which must include at least $40 \%$ of the total NRM and the standard error on the slope must be less than $5 \%$. The magnetic alteration measured by the pTRM-checks must be small and a $5 \%$ limit was set as a cutoff value for differences between the pTRM and pTRM-check steps normalized either by the length of the hypotenuse of the NRM/pTRM data used in slope calculation (Selkin and Tauxe, 2000) or by the total TRM intensity as considered in Chauvin et al. (2000). In addition, the cumulative check error as defined by Leonhardt et al. (2003) was tested to exclude fragments showing progressive magnetic alteration and a maximum value of $\sim 10 \%$ was considered. A $5 \%$ limit was also applied for the pTRM-tail checks. At the fragment level, a mean intensity was retained when the alteration measured during the cooling rate experiments was less than $5 \%$ and when the difference between two individual intensity values obtained for the two specimens was less than $5 \%$.

\subsection{Triaxe protocol}

The Triaxe is a three-axis vibrating sample magnetometer developed recently at the Institut de Physique du Globe de Paris to perform automated high temperature magnetization measurements on small cylindrical archeological and geological specimens of $1 \mathrm{~cm}$ in diameter and height (Le Goff and Gallet, 2004; Gallet and Le Goff, 2006). It comprises a small furnace placed within a set of 10 pick-up coils, the whole system being installed with a set of orthogonal Helmholz coils for producing a laboratory field up to $200 \mu \mathrm{T}$ in any direction (see Le Goff and Gallet, 2004 for a complete description of this apparatus). Le Goff and Gallet (2004) specially designed an intensity protocol for the Triaxe. This protocol involves 5 automatic series of continuous measurements, hereafter referred to as M1 to M5. The first step (step \#1, M1) corresponds to the almost complete demagnetization of the NRM monitored every $\sim 5{ }^{\circ} \mathrm{C}$ between a temperature $T_{1}$, usually close to $150{ }^{\circ} \mathrm{C}$, and a relatively high temperature $T_{2}$. The specimen is then cooled down in zero field between $T_{2}$ and $T_{1}$ ( zero field between $T_{1}$ and $T_{2}$ (step \#3, M3) to investigate the thermal variations of the NRM fraction remaining blocked above $T_{2}$. In a fourth step (M4), the specimen is cooled down from $T_{2}$ to $T_{1}$ in a laboratory field whose direction is set parallel to the ancient field and intensity is chosen to be close to the expected one. Finally, the newly acquired TRM is demagnetized in zero field between $T_{1}$ and $T_{2}$ (step \#5, M5) before the specimen is cooled down to the ambient temperature. For each running temperature $T_{i}$ between $T_{1}$ and $T_{2}$, Le Goff and Gallet (2004) proposed two different parameters for computing the ancient field intensity. First, they considered the ratio of the unblocking fractions of NRM and TRM between $T_{i}$ and $T_{2}$ and computed the ancient intensity at $T_{i}$ as:

$R\left(T_{i}\right)=\left[\frac{M 1\left(T_{i}\right)-M 3\left(T_{i}\right)}{M 5\left(T_{i}\right)-M 3\left(T_{i}\right)}\right] \times H_{l a b}$
Using the unblocked fraction of NRM and TRM between $T_{1}$ and $T_{i}$, the intensity may also be obtained from the $R^{\prime}\left(T_{i}\right)$ parameter defined as:

$R^{\prime}\left(T_{i}\right)=\left[\frac{\Delta 1^{\prime}\left(T_{i}\right)}{\Delta 5^{\prime}\left(T_{i}\right)}\right] \times H_{l a b}$,

with:

$\Delta 1^{\prime}\left(T_{i}\right)=\left(M 1\left(T_{1}\right)-M 1\left(T_{i}\right)\right)-\left(M 3\left(T_{1}\right)-M 3\left(T_{i}\right)\right)$

and

$\Delta 5^{\prime}\left(T_{i}\right)=\left(M 5\left(T_{1}\right)-M 5\left(T_{i}\right)\right)-\left(M 3\left(T_{1}\right)-M 3\left(T_{i}\right)\right)$.

It is important to underline that the MD grains (if any) should not affect the intensity determinations using the Triaxe protocol as the NRM and TRM are acquired (and demagnetized) in very similar conditions from a high temperature $T_{2}$ which is close to the Curie temperature of the magnetic minerals carrying the magnetization.

\subsubsection{TRM anisotropy}

The Triaxe paleointensity determinations are intrinsically devoid of TRM anisotropy effect since the laboratory TRM is acquired in such a way that its direction is closely aligned along the direction of the NRM. This condition is satisfied because the laboratory field is applied in the direction of the NRM and its direction adjusted when the anisotropy is found to be too strong. This is checked by measuring the angular difference between the NRM and the TRM acquired within a limited temperature interval from $T_{2}$. When this difference is less than $4^{\circ}$ the Triaxe continues its normal cycle of TRM acquisition as the TRM anisotropy effect on the intensity estimation will not exceed $1 \%$; otherwise the specimen is reheated to $T_{2}$ and a new direction for $H_{\text {lab }}$ is set (Le Goff and Gallet, 2004).

\subsubsection{Cooling rate correction}

The cooling rate effect when using the Triaxe protocol was investigated by Le Goff and Gallet (2004). From experiments in which laboratory TRM were acquired using successively different cooling rates, these authors observed that, on the contrary to the $R\left(T_{i}\right)$ ones, the $R^{\prime}\left(T_{i}\right)$ values obtained from the Triaxe measurements were almost independent of the cooling rate (for a detailed discussion see Le Goff and Gallet, 2004). This led these authors to compute the ancient magnetic field intensity values from the $R^{\prime}\left(T_{i}\right)$ data as this tends to minimize the cooling rate effect which appears to essentially affect the grains unblocked at high temperatures. The efficiency and validity of this approach was demonstrated from numerous comparisons carried out between intensity data obtained using the classical Thellier and Thellier method revised by Aitken and coauthors (e.g. Aitken et al., 1988) or the IZZI procedure (Yu et al., 2004) and using the Triaxe $R^{\prime}\left(T_{i}\right)$ protocol (Genevey et al., 2009). In those comparisons, agreements between the two data sets, both at the fragment and site levels were generally obtained within $\pm 5 \%$ (only 4 fragments among 42 from the retained sites show differences $> \pm 5 \%$, but in all cases $< \pm 9 \%$; see in Genevey et al., 2009).

\subsubsection{Analysis and selection criteria}

The intensity of the ancient magnetic field was derived for a specimen from averaging the $R^{\prime}\left(T_{i}\right)$ values computed between $T_{1}$ and $T_{2}$. When a secondary magnetization component was observed above $T_{1}$ the averaging was then performed within the temperature interval characteristic of the main ("primary") magnetization component. In any case and following Gallet and Le Goff (2006), the fraction of the latter component must comprise more than $50 \%$ of the NRM between $T_{1}$ and $T_{2}$. Additionally, Gallet and Le Goff (2006) proposed to only retain the specimens for which the slope of the linear segment 
a)

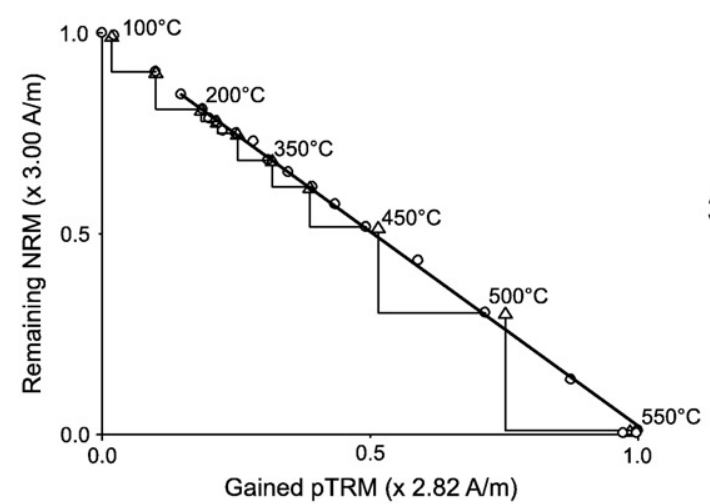

c)

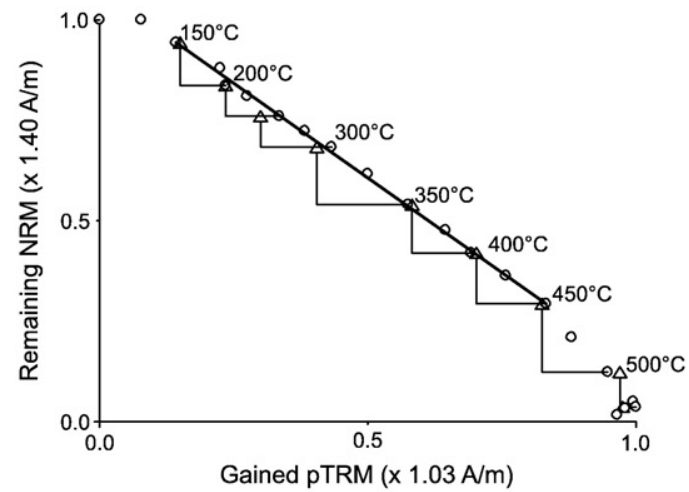

e)

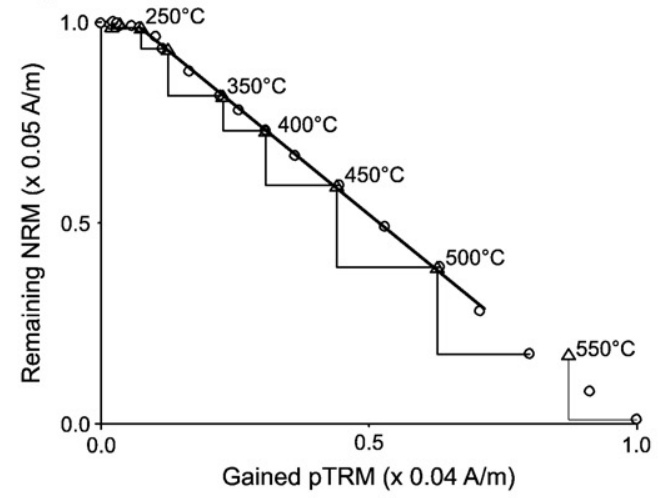

g)

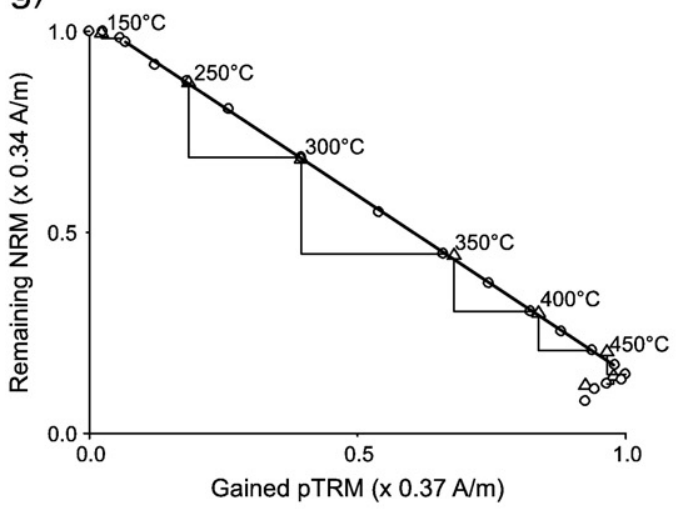

b)

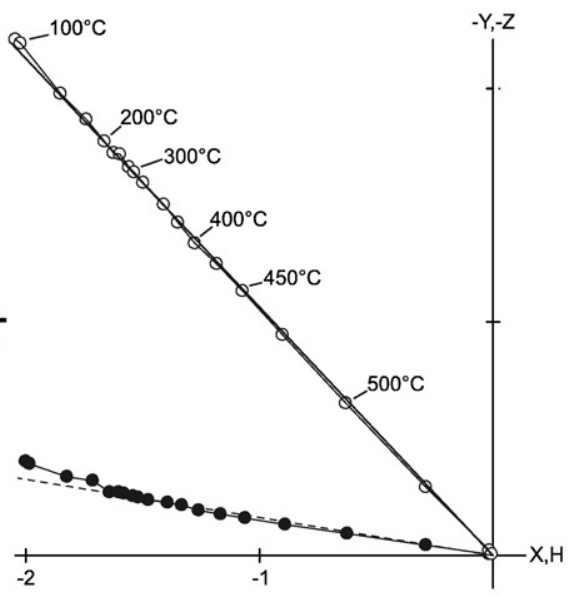

d)

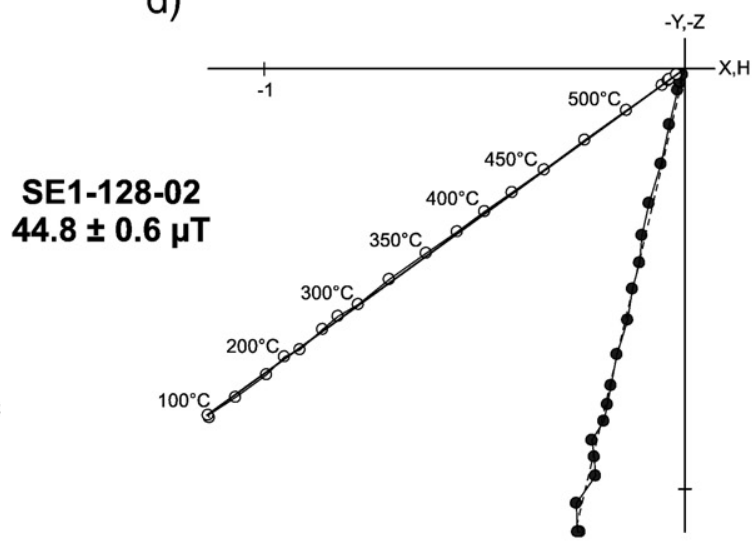

f)

FB1-02-01

$39.9 \pm 0.5 \mu \mathrm{T}$

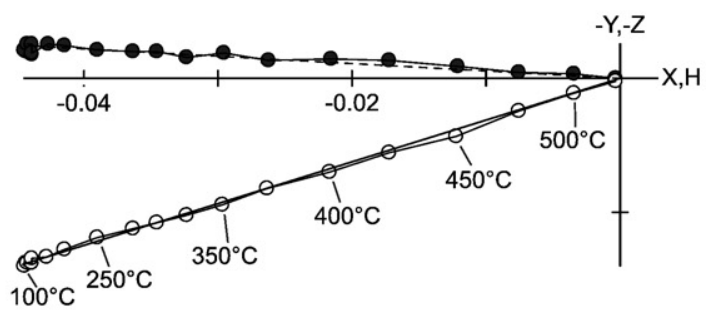

h)

TF-04-02

$28.6 \pm 0.1 \mu \mathrm{T}$

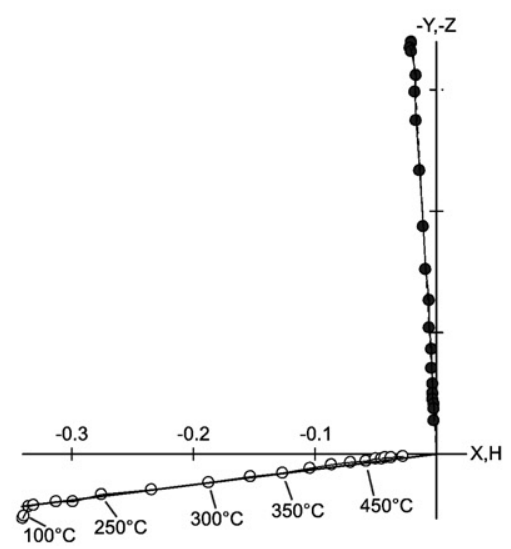


computed between $R^{\prime}\left(T_{1}\right)$ and $R^{\prime}\left(T_{2}\right)$ was less than $15 \%$. In our study and following stricter criteria now used for data acquired with the Triaxe (Genevey et al., 2009), a cutoff value of $10 \%$ was here considered for this slope. Finally, when two or more specimens were analyzed per fragment, a mean intensity value was computed and considered reliable if its standard deviation was less than $5 \%$ (note that the worse value of standard deviation is $5.2 \%$ for sample CB-02, that we nevertheless kept).

\section{Results}

\subsection{Magnetic mineralogy}

All samples from our collection (104 fragments) were subjected to rock magnetic experiments in order to characterize their magnetic mineralogy and to test the stability of the latter during the thermal treatment.

Hysteresis loops curves were acquired using a laboratory-built inductometer coupled with an electromagnet reaching fields up to 1 Tesla. In addition, using another electromagnet allowing the application of a field of up to 1.2 Tesla, progressive isothermal remanent magnetization (IRM) acquisition and thermal demagnetization of three-axis IRM were carried out on a selection of samples. For the latter experiments, we successively acquired three IRM along perpendicular directions $(1.2 \mathrm{~T}, 0.4 \mathrm{~T}$, and $0.2 \mathrm{~T}$ ) before thermally demagnetizing them (Lowrie, 1990). These high-field measurements reveal for all fragments a similar magnetic behavior but with more or less enhanced characteristics. For most fragments, we observe a magnetization dominated by low-coercivity minerals with unblocking temperatures of less than $580^{\circ} \mathrm{C}$, which are likely magnetite or titanomagnetite with different Titanium contents. The presence of a small fraction of high-coercivity minerals is put in evidence by unreached IRM saturation (Fig. 2a) and slightly wasp-waisted hysteresis loops (Fig. 2b) and is further confirmed by the thermal demagnetization of the three-axis IRM (Fig. 2c). Although generally small, the proportion of high-coercivity minerals varies among the samples (Figs. 2d to 4f), in some cases with strongly wasp-waisted hysteresis loops (Fig. 2e). Of interest is the fact that the hard fraction of the magnetization exhibits very variable unblocking temperatures, generally ranging from $\sim 200{ }^{\circ} \mathrm{C}$ to $400{ }^{\circ} \mathrm{C}$, being in rare cases $>650{ }^{\circ} \mathrm{C}$. Such property suggests different phases of hematite as the magnetic carrier of that magnetization fraction. The rather common presence of hematite with low-unblocking temperatures $\left(<500{ }^{\circ} \mathrm{C}\right)$ in archeological baked-clay material was already proposed by several authors (e.g. Chauvin et al., 2000; Genevey and Gallet, 2002; McIntosh et al., 2007). In particular, high-coercivity minerals with unblocking temperatures as low as $\sim 200{ }^{\circ} \mathrm{C}$ (see Fig. $2 \mathrm{f}$ ) have been reported by McIntosh et al. (2007), and identified by these authors as being more likely a substituted hematite.

Low-field magnetic susceptibility versus temperature curves were obtained up to $550{ }^{\circ} \mathrm{C}$ using a Kappabridge KLY3-CS3 (AGICO) system. Note that $550{ }^{\circ} \mathrm{C}$ is the maximum temperature considered for almost all intensity experiments. The reversibility between the heating and cooling susceptibility curves was here used for testing the stability of the magnetic mineralogy upon temperature. Only those samples showing a good stability of their magnetic mineralogy were further kept for intensity determinations (94 fragments). Examples of thermomagnetic curves obtained for six retained samples are reported in Fig. 3. It is worth mentioning that these curves confirm the thermal stability of the high-coercivity and low-unblocking temperature magnetic phase highlighted by McIntosh et al. (2007).

\subsection{Archeointensity results}

\subsubsection{TT-ZI results}

The TT-ZI protocol was applied to 50 fragments (100 specimens) from 9 sites, among the 14 which compose our collection, with two to seven fragments analyzed per site. Considering the whole set of our selection criteria, 28 fragments (56 specimens) were retained for mean computation, the others being mainly discarded because of magnetic alteration detected during the archeointensity or the cooling rate experiments. This yields a success rate of $56 \%$ (see Table S1 in the Appendix). It is worth mentioning that no specimen was rejected on the basis of noticeable biases linked to the presence of multi-domain grains (the pTRM-tail checks were less than 5\%). Moreover, no fragment was rejected because of a negative coherence test at $5 \%$. For most specimens, the mass variations measured during the TT-ZI experiments was found to be very moderate, being less than $5 \%$ for $90 \%$ of the collection. For a few friable specimens, the loss of mass was however more important, reaching $11 \%$. The NRM and TRM moments measured for each specimen were systematically corrected from its mass variations, as proposed by Schnepp (2003), and the intensity value was then deduced from the linear fit in the corresponding mass-corrected Arai diagram (note that the mass corrections sensibly improve the precision of the linear fits in the Arai diagrams).

Fig. 4 displays four representative examples of Arai and corresponding orthogonal diagrams obtained for specimens which passed our selection criteria. Except a small viscous component removed at low temperatures $\left(<150{ }^{\circ} \mathrm{C}-200{ }^{\circ} \mathrm{C}\right)$, the thermal demagnetization revealed for all fragments only a single magnetization component generally isolated between $\sim 150-200{ }^{\circ} \mathrm{C}$ and $600{ }^{\circ} \mathrm{C}$ (Fig. 4b, d, f, h). In the Arai diagrams, however, the intensity values were often computed from a narrower temperature interval in order to take only into account the temperature steps for which no magnetic alteration was detected (Fig. 4c, e and g). When an alteration occurred below $500{ }^{\circ} \mathrm{C}$ (Fig. $4 \mathrm{C}$ and g), it is important to mention that the raw intensity value was corrected from the TRM anisotropy effect using only the $f 1$ correcting factor determined at $350^{\circ} \mathrm{C}$. In those cases (a little less than half of the specimens), it was checked that the demagnetization percentage at $350{ }^{\circ} \mathrm{C}$ was higher than $40 \%$ to allow a reliable determination of the TRM anisotropy tensor. When this percentage was lower than $40 \%$ and when no magnetic alteration was observed until $500{ }^{\circ} \mathrm{C}$, the $f 2$ factor (determined at $500{ }^{\circ} \mathrm{C}$ ) was then used alone for the TRM anisotropy correction (Fig. 4a and e). For only one fragment, the TRM correction factor was computed from the mean of the $f 1$ and $f 2$ values (demagnetization percentage $>40 \%$ at $350{ }^{\circ} \mathrm{C}$ and no alteration until $500{ }^{\circ} \mathrm{C}$ ).

The TRM anisotropy degrees (K1/K3) obtained for the retained specimens are reported in Fig. 5a. This histogram shows that the majority of the specimens (70\%) present a relatively weak TRM anisotropy, with $K 1 / K 3$ degrees between 1.05 and 1.2 , while $~ 30 \%$ of the bricks analyzed here are more anisotropic with $K 1 / K 3$ degrees between 1.2 and 1.45 . We note that a similar distribution of anisotropy degrees was recently reported by Kovacheva et al. (2009) from the analysis of a large collection of bricks and tiles collected from France and Bulgaria (see also a discussion in Genevey et al., 2008).

Fig. 5b displays a histogram of the differences (in percentages) computed between the two intensity values obtained at the specimen level from the same fragment before and after TRM anisotropy correction. These results clearly show the very good and better 
a)

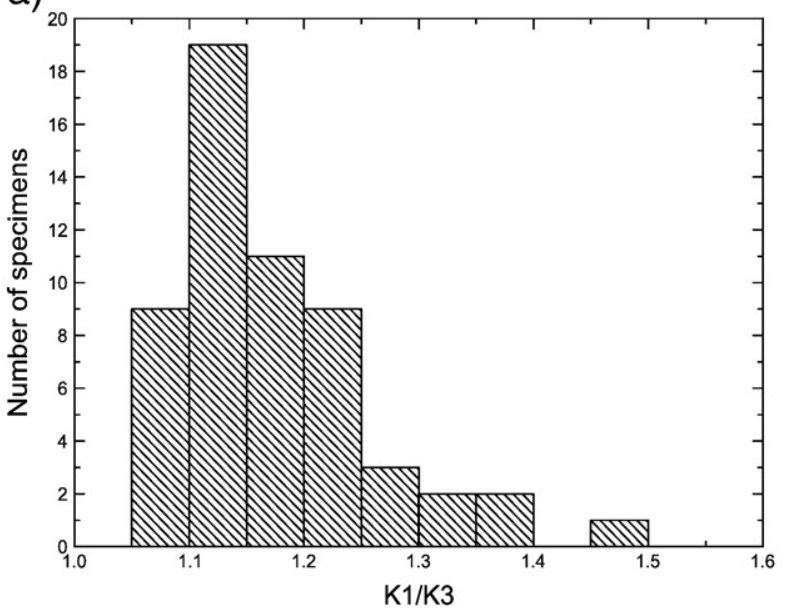

c)

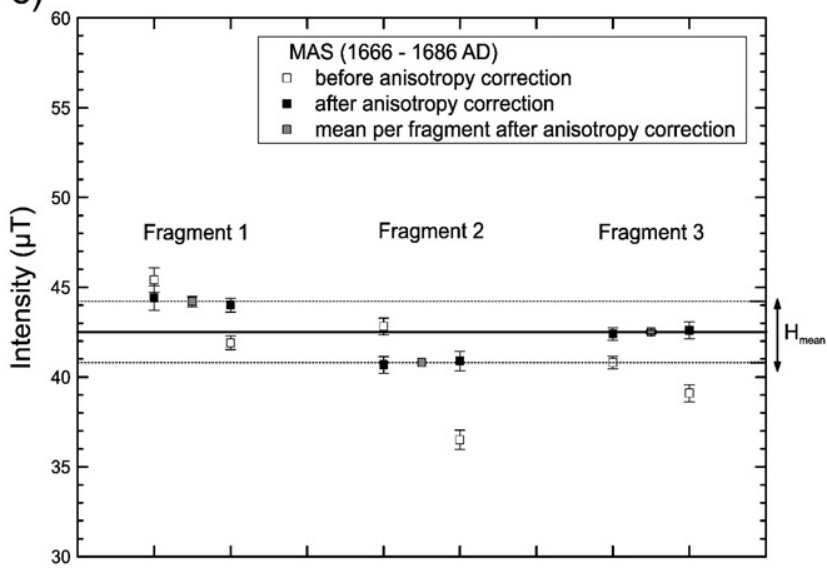

b)

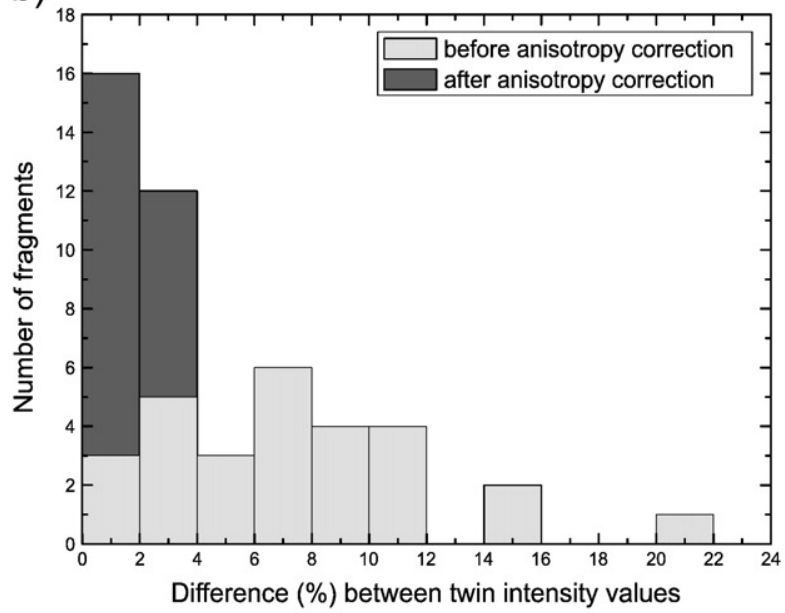

d)

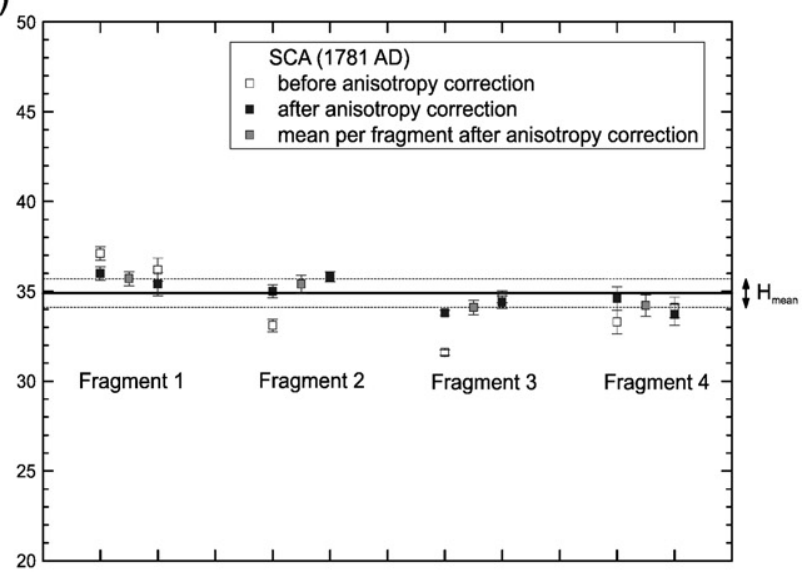

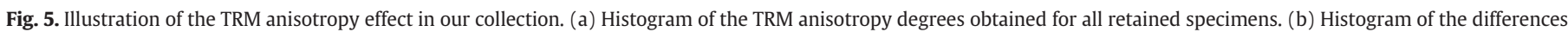

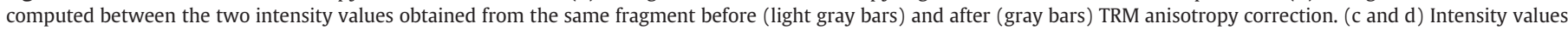

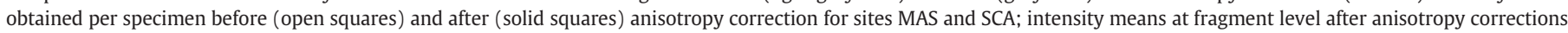

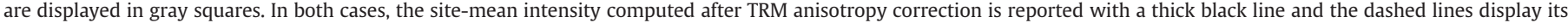
standard deviation.

agreement between twin intensity values after TRM anisotropy correction, which again underlines our ability to efficiently correct this effect and also the importance of this correction for intensity determinations. This is further illustrated in Fig. $5 \mathrm{c}$ and $\mathrm{d}$ for the fragments from sites MAS and SCA showing that the scatter between intensity results obtained both at the fragment and site levels is significantly reduced after taking into account the TRM anisotropy effect.

The cooling rate effect on the TRM acquisition was investigated for the TT-ZI protocol using three different slow cooling times of $5 \mathrm{~h}, 10 \mathrm{~h}$ and $25 \mathrm{~h}$ from $450{ }^{\circ} \mathrm{C}$ to room temperature. Our results indicate a systematic over-estimate of the TRM moments acquired with a slow cooling rate compared to those measured after a rapid cooling time (as used routinely in the TT-ZI experiments). This is clearly illustrated in Fig. 6a where the intensity mean values obtained at the site level are always lower when corrected for the cooling rate effect. Moreover, as previously discussed in Genevey et al. (2008), the slower the cooling rate, the stronger the correction for this effect. Our data also underline that the cooling rate effect can be large, even if the bricks were originally cooled "rapidly," as for example the SE site with an averaged effect of $7 \%$ for the cooling time of $5 \mathrm{~h}$.

In our study, we chose the slowest cooling rate $(25 \mathrm{~h})$ which should better reproduce the initial cooling conditions of brick manufacture, as known from archeological constraints. This choice results in a decrease of the intensity data at the fragment level between $4 \%$ and $14 \%$, with an average of $9 \%$ (Fig. $6 \mathrm{~b}$ ). An important point is that if the cooling rate chosen was too slow, the error on the intensity determination would be quite limited as can be seen from comparisons between the corrected intensity means for $5 \mathrm{~h}, 10 \mathrm{~h}$, and 25 h (Fig. 6a).

\subsubsection{Triaxe data and their comparison with the TT-ZI results}

The Triaxe protocol was applied to 60 fragments (195 specimens) from 13 sites, among 14 of our archeological collection. For each group, magnetization measurements were performed on several specimens collected from one to seven fragments. All retained intensity determinations (44 fragments, 127 specimens) strictly obey the selection criteria described above (see Section 3.2.3 and Table S2 in the Appendix). The success rate of these determinations is $\sim 65 \%$, which is quite similar to the rate reached in previous studies (e.g. Gallet et al., 2008; Genevey et al., 2009). The rejections are mainly due to evidence of magnetic alteration observed during the experiments and to slopes in the $R^{\prime}\left(T_{i}\right)$ data (fitted using linear segments) greater than $10 \%$ (no fragment being rejected on the basis solely of a negative coherence test). Note that for sites FB1+2, C06 and TF, only two fragments were productive per site, but principally because of the weak magnetization of the fragments with regard to the sensibility of the Triaxe magnetometer. Fig. 7 shows four examples of the intensity determinations obtained from four different groups of fragments. We recall that each curve from each panel 
a)

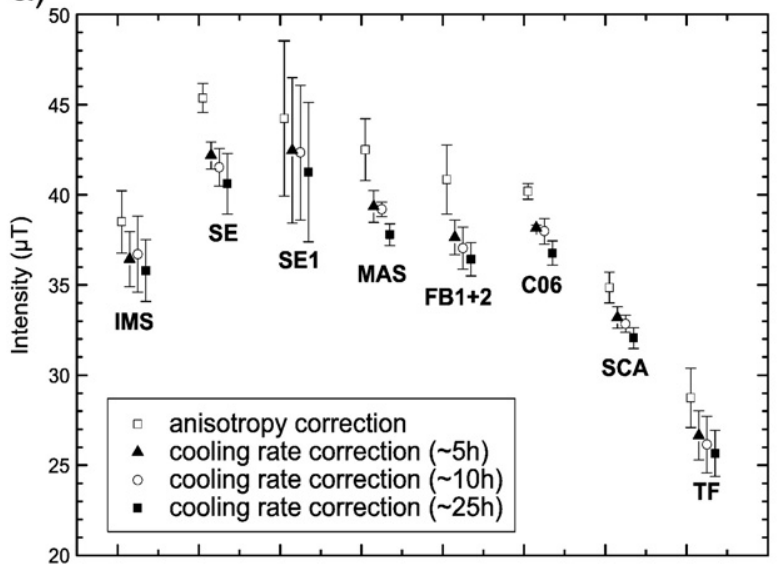

b)

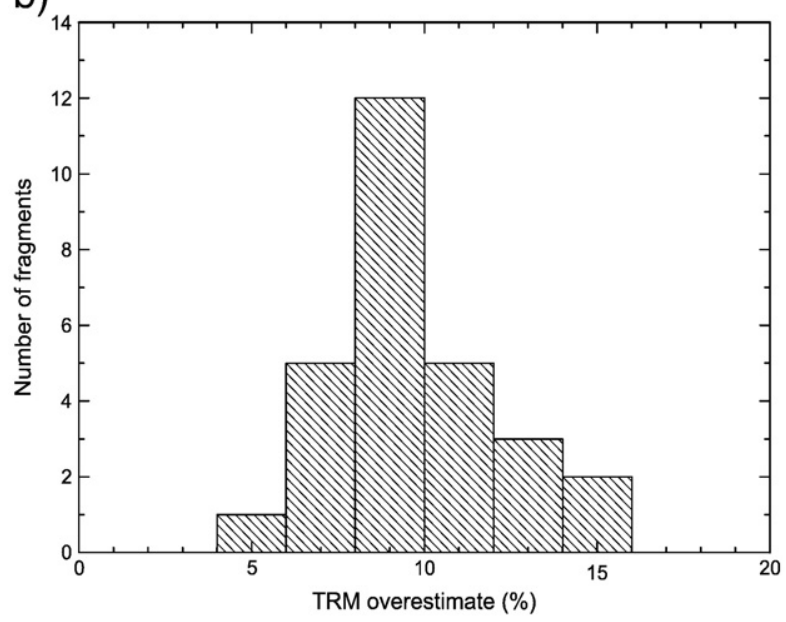

Fig. 6. Illustration of the cooling rate effect. (a) Comparison between site-mean intensity values computed before (open squares) and after cooling rate correction obtained for three increasing slow cooling times $(\sim 5 \mathrm{~h}-$ solid triangles, $\sim 10 \mathrm{~h}-$ open circles and $\sim 25 \mathrm{~h}-$ solid squares) between $450{ }^{\circ} \mathrm{C}$ and the room temperature. Note that mean intensities were computed when at least two fragments per site were successfully analyzed and that no mass correction was performed because the loss was found negligible for all fragments. (b) Histogram of the TRM overestimates considering the slow cooling time of $\sim 25 \mathrm{~h}$.

represents the $R^{\prime}\left(T_{i}\right)$ data obtained from one specimen, with generally several specimens studied per fragment. These plots clearly underline the very good consistency of the data obtained both at the fragment and site levels.

The rather moderate magnetization of the fragments of our collection was the principal limiting factor for the Triaxe measurements. This is the reason why numerous fragments were only studied using the TT-ZI protocol. In contrast, only Triaxe measurements were performed when the analyzed fragments were in sufficient number (for sites SB, CP27, CB, MAE4 and GC). These two cases prevent a systematic comparison between the Triaxe and TT-ZI results. But such comparison was possible for fifteen fragments from six different sites (IMS, SE, SE1, MAS, C06 and TF). For all but three fragments, agreements between the TT-ZI values (after cooling rate correction) and the Triaxe values are within $\pm 5 \%$ (and within $\pm 9 \%$ for the three remaining). Considering all the fragments, the comparison at the site level between TT-ZI and Triaxe mean intensity values is shown in Fig. 8. The results obtained using the TT-ZI method are reported before and after the $25 \mathrm{~h}$ cooling rate correction. While there is a systematic deviation between the two data sets before the correction for the cooling rate effect (toward higher intensity TT-ZI values; open squares in Fig. 8), we observe that the TT-ZI and Triaxe mean intensity values become similar to within $\pm 5 \%$ after the cooling rate correction (solid squares in Fig. 8). Such good agreement therefore demonstrates the reliability of the Triaxe measurements with regard to the intensity data derived from the classical Thellier and Thellier (1959) method, and also confirms the fact that the $R^{\prime}\left(T_{i}\right)$ obtained using the Triaxe protocol satisfactorily takes into account the cooling rate dependence on TRM acquisition (see also Gallet and Le Goff, 2006; Gallet et al., 2006; Genevey et al., 2009).

\section{First archeointensity variation curve from Brazil and concluding remarks}

A total of 57 fragments (183 specimens) from 14 sites were considered for computations of site-mean intensity values. When several specimens were analyzed per fragment using the two experimental procedures, a mean was first computed at the fragment level from all individual (i.e. specimen) values and validated if its standard deviation was less than $5 \%$ (no fragment being rejected at this step although sample MAS-03 has a standard deviation of 5.2\%) before deriving a mean intensity value at the site level. All these values are reported in Tables S1 and S2 in the Appendix both at the fragment and site levels. The site-mean intensity values are very well defined with standard deviations of less than $7.7 \%$ of the corresponding means. They range from $25.0 \mu \mathrm{T}$ (GC site) to $41.4 \mu \mathrm{T}$ (SE1 site) and are reported in Fig. 9 versus their age (see Table 1). All studied sites being located inside the city of Salvador, we note that any possible bias that might be due to latitudinal correction is avoided here.

Fig. 9 first shows a good consistency between intensity results obtained for sites of similar or close ages, which strengthens their reliability. These results, which are the first archeointensity data obtained for Brazil, provide a description of the geomagnetic field intensity behavior for the Bahia region over the past five centuries. They principally show a significant and regular decrease by $\sim 40 \%$ of the geomagnetic field intensities between the first half of the XVIIth century and the XXth century. One result dated to the second half of the XVIth century further suggests that the geomagnetic field intensity reached a maximum around $1600 \mathrm{AD}$, immediately preceding a large decrease all over the past four centuries. It is worth mentioning that this diminution offers a very promising tool for dating purposes.

We compared our data with the intensity variations expected at the city of Salvador from different generations of geomagnetic field models (Fig. 9). The gufm1 models proposed by Jackson et al. (2000) were developed from the inversion of direct field measurements performed between $1590 \mathrm{AD}$ and $1990 \mathrm{AD}$. Prior to $1840 \mathrm{AD}$, however, as no direct intensity measurement is available, these authors extrapolated, for calibrating their models, the same linear decreasing rate of the $g_{1}^{0}$ term as the one prevailing after $1840 \mathrm{AD}$ (i.e. $15 \mathrm{nT} /$ year; see the predicted intensity curve in black in Fig. 9). Taking advantage of the worldwide archeointensity compilation made by Korte et al. (2005), Gubbins et al. (2006) next proposed a more limited linear decreasing trend for the $g_{1}^{0}$ term between $1590 \mathrm{AD}$ and $1840 \mathrm{AD}$ (i.e. $2.28 \pm 2.72 \mathrm{nT} / \mathrm{year}$ ), that we used to recalibrate the Jackson et al. (2000) models (pink curve in Fig. 9). More recently, Finlay (2008) performed a new inversion of the direct directional data, also using the available archeointensity data, and concluded to a flat evolution of the $g_{1}^{0}$ term before $1840 \mathrm{AD}$ as the most probable (blue curve in Fig. 9). Two other expected intensity variation curves reported in Fig. 9 were derived from a new set of archeomagnetic models spanning the past 3000 years proposed by Korte et al. (2009). These models were constructed from the inversion of the most advanced global compilation of both directional and intensity data obtained from archeological artifacts, volcanic deposits and sediments (Donadini et al., 2009). The model referred to as CALS3K.3 was developed using all data (green curve in Fig. 9), while CALS3K_cst.1 was constructed from a selection, based on quality criteria, of those data (red curve in Fig. 9). An important point is that after $1650 \mathrm{AD}$ for 
a)
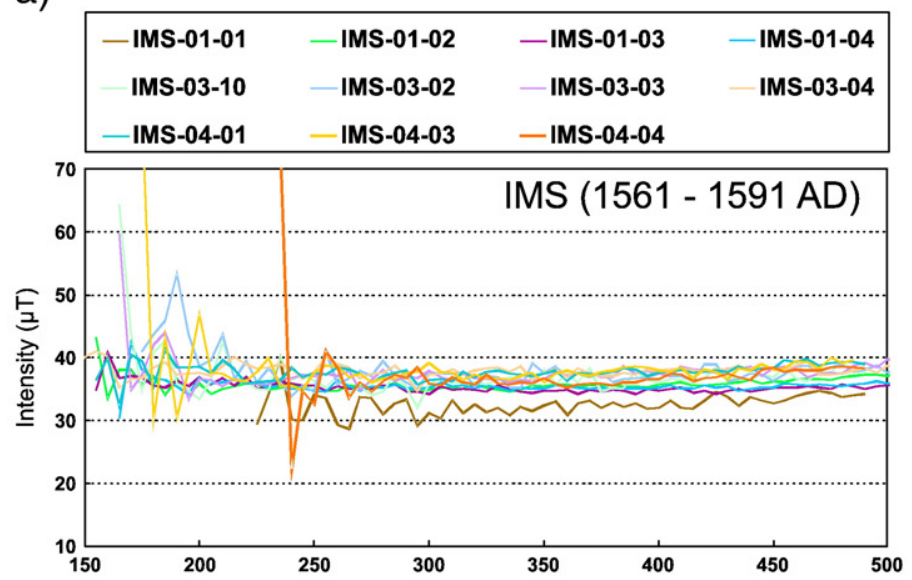

c)
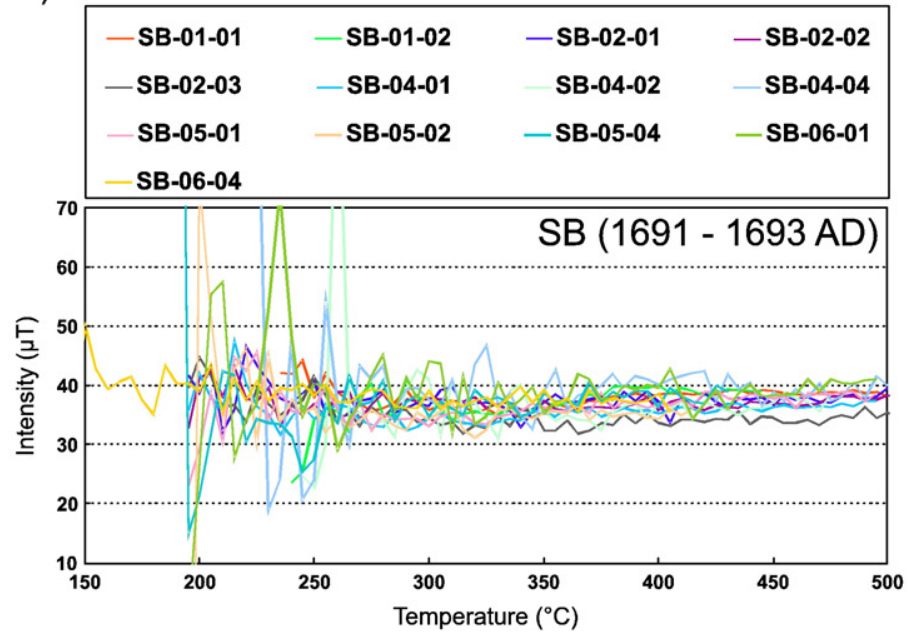

b)

\begin{tabular}{|rrrr|}
\hline SE-06-02 & SE-06-03 & - SE-12-01 & -SE-12-03 \\
SE-12-04 & SE-14-01 & - SE-14-02 & SE-14-03 \\
- SE-14-04 & - SE-18-01 & - SE-18-02 & - SE-18-03 \\
\hline
\end{tabular}

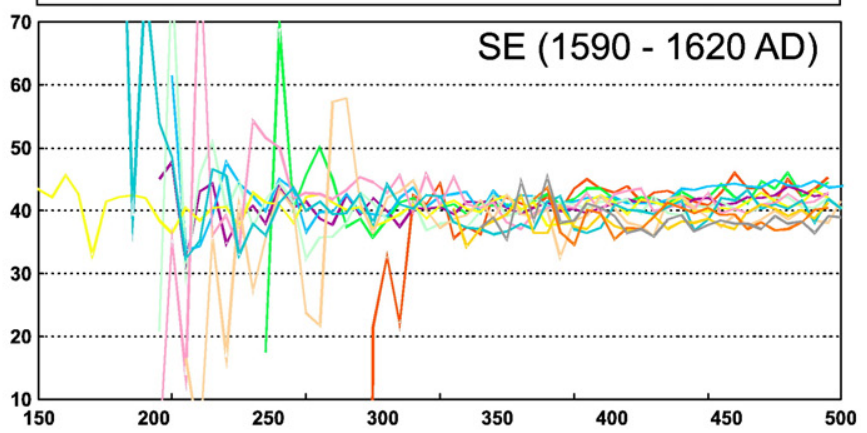

d)

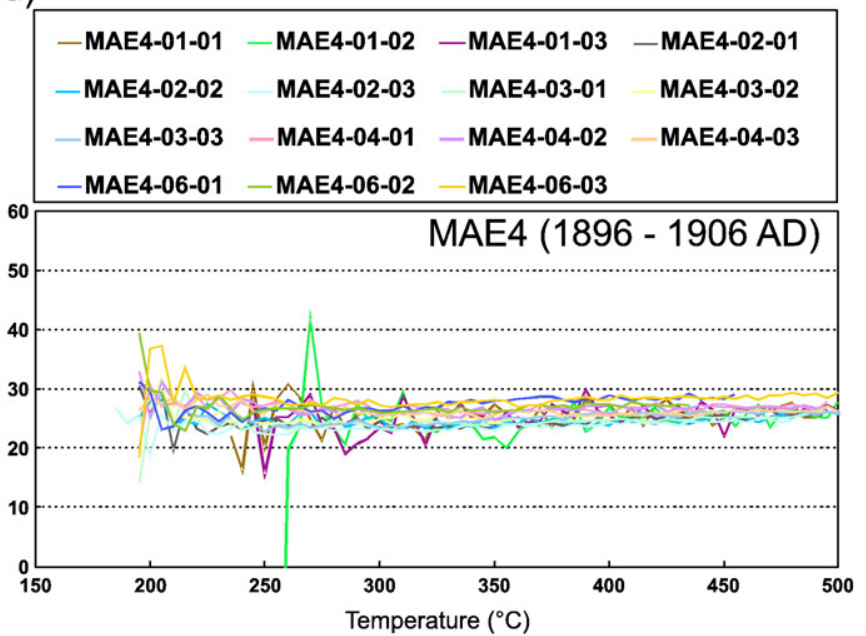

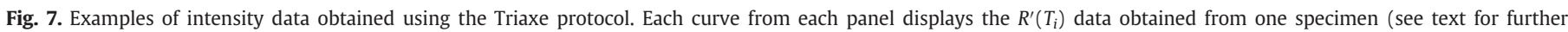

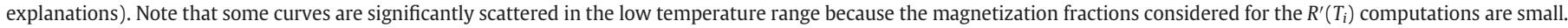

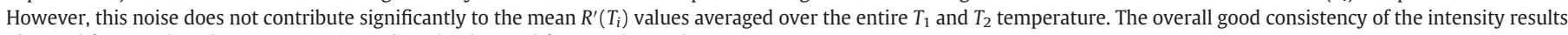
obtained from each archeomagnetic site is directly observed from each panel.

the directions and $1840 \mathrm{AD}$ for the intensities, the CALS3K.3 and CALS3K_cst.1 models were constrained using the gufm1 historical modeling via a penalization technique (Korte et al., 2009).

The Brazilian archeointensity results reported in this study are in particularly good agreement with the intensity variation curve derived from the gufm 1 models of Jackson et al. (2000). In contrast, the gufm 1 models recalibrated using the $g_{1}^{0}$ evolution proposed by Gubbins et al. (2006; and also by Finlay, 2008) predict intensity values too low with respect to our intensity data between $1600 \mathrm{AD}$ and $1750 \mathrm{AD}$. On the other hand, a good agreement is observed after $1650 \mathrm{AD}$ between our data and the predictions provided both by the CALS3K.3 and CALS3K_cst.1 models. Significant differences are observed before $1650 \mathrm{AD}$, but it is interesting to see that our data nevertheless exhibit the same evolution marked by an increase in geomagnetic field intensity between $\sim 1550$ AD and $\sim 1600$ AD.

As a concluding remark, we highlight the fact that our new archeointensity determinations allow one to draw a consistent pattern of intensity variations for the Bahia region (Northeast Brazil), which is in rather good agreement with the existing historical and archeomagnetic global field models, especially for the $\sim 1650-1900$ AD time interval. This is particularly remarkable considering the occurrence of important non-dipole features in Brazil over the past five centuries (e.g. Bloxham and Gubbins, 1985; Hartmann and Pacca, 2009). Our study now demands further archeomagnetic investigations in more southerly regions of Brazil (and over older periods) in order to detect any effect that might be related to the displacement or the sporadic occurrence of the South Atlantic magnetic anomaly over the past millennium.

\section{Acknowledgments}

We are very grateful to the archeologists, architects and museum curators who helped us in collecting archeological samples and for fruitful discussions: Carlos Costa, Fabiana Comerlato, Luydy Fernandes, Alvandyr Bezerra, Rosana Najjar, Cláudio de Souza e Silva, Luiz Pacheco, Catarina Menezes, Samuel Gordenstein, Paula Paoli, Carlos Caroso, Reuben Costa, Francisco Portugal, Daniel Rangel, and technicians of "Bahia Arqueológica" team and "Projeto Monumenta de Salvador." We also thank the Instituto do Patrimônio Histórico e Artístico Nacional (IPHAN) and Museu de Arqueologia e Etnologia of Federal University of Bahia (MAE/UFBA) for institutional supports. We are pleased to thank France Lagroix for constructive discussions on rock magnetism, Ruven Pillay for his help on the manuscript and three anonymous reviewers for their useful comments. G.A. Hartmann also thanks the paleomagnetic laboratory of IPGP, in particular Bernard Henry and Jean-Claude Tanguy, for their nice welcome.

This work was supported by the FAPESP (grant 2005/57782-4), CAPES (international grant 3971/08-2 to G.A. Hartmann), CNPq (research fellowship to R.I.F. Trindade, C. Etchevarne and M.C. Afonso) 


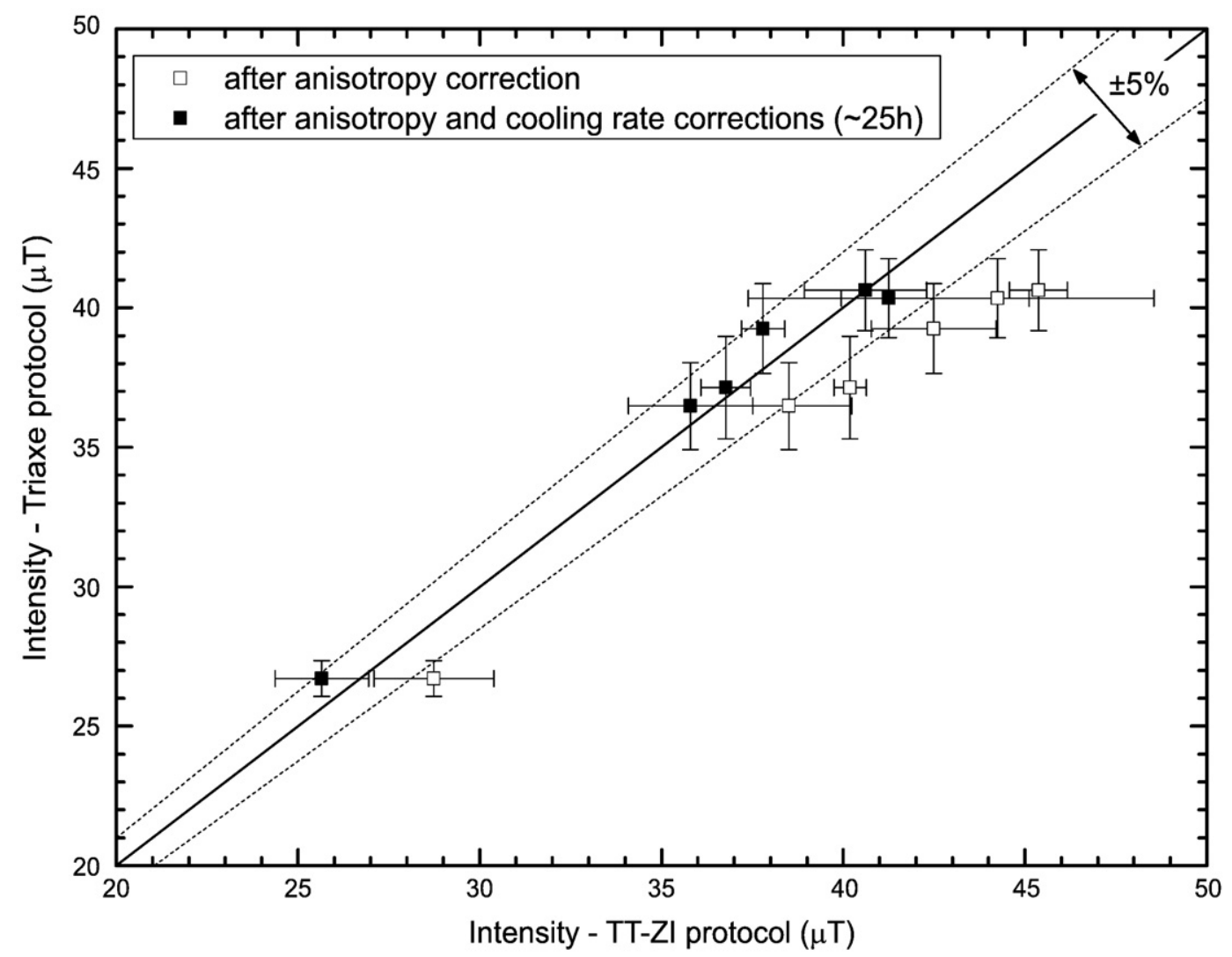

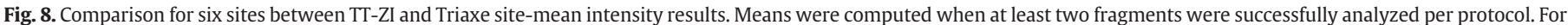

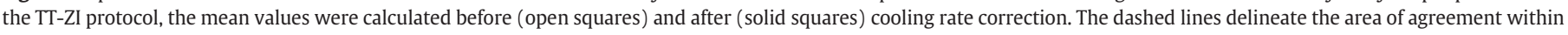
$5 \%$.

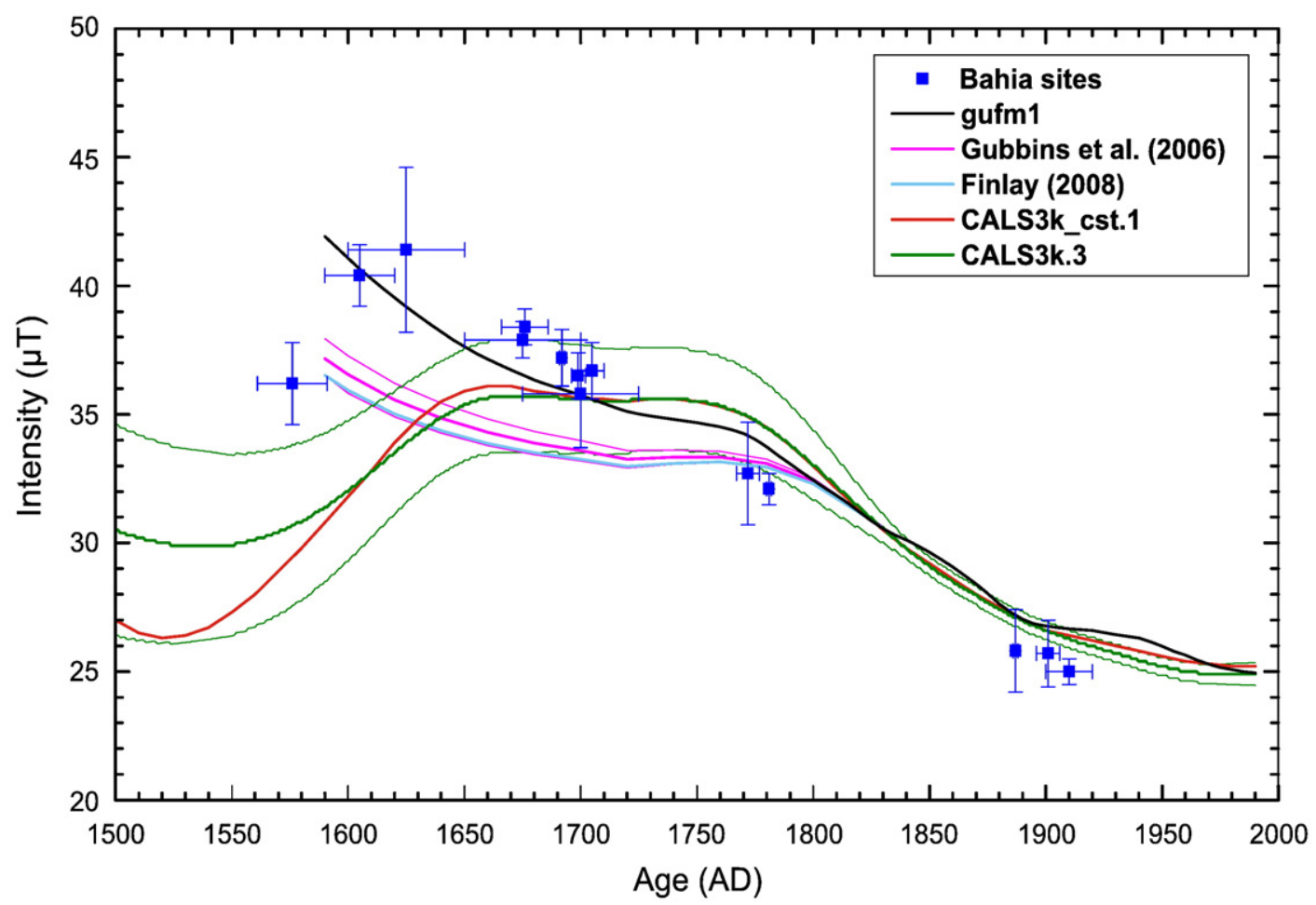

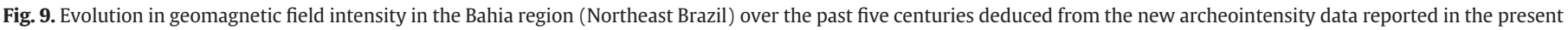

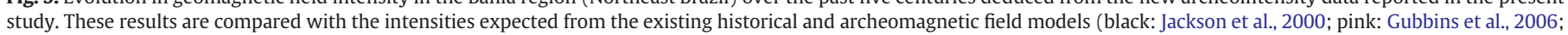
blue: Finlay, 2008; green and red: Korte et al., 2009). See text for further explanations. 
and partly financed by the INSU-CNRS program "SYSTER.” This is IPGP contribution no. 2651.

\section{Appendix A. Supplementary data}

Supplementary data associated with this article can be found, in the online version, at doi:10.1016/j.epsl.2010.05.016.

\section{References}

Aitken, M.J., Alcock, P.A., Bussel, G.D., Shaw, C.J., 1981. Archaeomagnetic determination of the past geomagnetic intensity using ancient ceramics: allowance for anisotropy. Archaeometry 23, 53-64. doi:10.1111/j.1475-4754.1981.tb00954.x.

Aitken, M.J., Allsop, A.L., Bussell, G.D., Winter, M.B., 1988. Determination of the intensity of the Earth's magnetic field during archaeological times: reliability of the Thellier technique. Rev. Geophys. 26, 3-12.

Bahia, 1997. Secretaria da Cultura e Turismo IPAC-BA: Inventário de Proteção do Acervo Cultural da Bahia, $1^{\mathrm{a}}$ ed., Salvador.

Bloxham, J., Gubbins, D., 1985. The secular variation of the Earth's magnetic field. Nature 317, 777-781. doi:10.1038/317777a0.

Chauvin, A., Garcia, Y., Lanos, Ph., Laubenheimer, F., 2000. Paleointensity geomagnetic field recovered on archaeomagnetic sites from France. Phys. Earth Planet. Inter. 120, 111-136. doi:10.1016/S0031-9201(00)00148-5.

Coe, R.S., 1967. The determination of paleo-intensities of the Earth's magnetic field with emphasis on mechanisms which could cause non-ideal behavior in Thelier's method. J. Geomagn. Geoelec. 19, 157-179.

Coe, R.S., Grommé, C.S., Mankinen, E.A., 1978. Geomagnetic paleointensities from radiocarbon dated lava flows on Hawaii and the question of the Pacific non-dipole low. J. Geophys. Res. 83, 1740-1756.

Costa, C.A.S., 2005. Materiais construtivos do sítio da primeira catedral do Brasil: modelos de estudos para telhas, tijolos, cravos e azulejos aplicados aos materiais do sítio da antiga igreja da Sé, Salvador, Bahia. Clio Arqueológica 19, 43-78.

Dodson, M., McClelland-Brown, E., 1980. Magnetic blocking temperatures of singledomain grains during slow cooling. J. Geophys. Res. 85, 2625-2637.

Donadini, F., Korte, M., Constable, C.G., 2009. Geomagnetic field for 0-3 ka: 1. New data sets for global modeling. Geochem. Geophys. Geosyst., 10, 6, Q06007. doi:10.1029/ 2008GC002295.

Dumberry, M., Finlay, C.C., 2007. Eastward and westward drift of the Earth's magnetic field for the last three millennia. Earth Planet. Sci. Lett. 254, 146-157. doi:10.1016/ j.epsl.2006.11.026.

Dunlop, D.J., Özdemir, Ö., 1997. Rock Magnetism, Fundamental and Frontiers. Cambridge Univ. Press, New York.

Finlay, C.C., 2008. Historical variation of the geomagnetic axial dipole. Phys. Earth Planet. Inter. 170, 1-14. doi:10.1016/j.pepi.2008.06.029.

Fox, J.M.W., Aitken, M.J., 1980. Cooling-rate dependence of thermoremanent magnetization. Nature 283, 462-463. doi:10.1038/283462a0.

Gallet, Y., Le Goff, M., 2006. High-temperature archeointensity measurements from Mesopotamia. Earth Planet. Sci. Lett. 241, 159-173. doi:10.1016/j.epsl.2005.09.058.

Gallet, Y., Genevey, A., Courtillot, V., 2003. On the possible occurrence of archeomagnetic jerks in the geomagnetic field over the past three millennia. Earth Planet. Sci. Lett. 214, 237-252. doi:10.1016/S0012-821X(03)00362-5

Gallet, Y., Genevey, A., Le Goff, M., Fluteau, F., Eshraghi, S.A., 2006. Possible impact of the Earth's magnetic field on the history of ancient civilizations. Earth Planet. Sci. Lett. 246, 17-26. doi:10.1016/j.epsl.2006.04.001.

Gallet, Y., Hulot, G., Chulliat, A., Genevey, A., 2009. Geomagnetic field hemisphere asymmetry and archeomagnetic jerks. Earth Planet. Sci. Lett. 284, 179-186. doi:10.1016/j.epsl.2009.04.028.

Gallet, Y., Le Goff, M., Genevey, A., Margueron, J.C., Matthiae, P., 2008. Geomagnetic field intensity behavior in the Middle East between 3000 BC and 1500 BC. Geophys. Res. Lett. 35, L02307. doi:10.1029/2007GL031991, 2008.

Genevey, A., Gallet, Y., 2002. Intensity of the geomagnetic field in western Europe over the past 2000 years: New data from ancient French pottery, J. Geophys. Res., B11, 107, 2285. doi:10.1029/2001JB000701.

Genevey, A., Gallet, Y., Constable, C.G., Korte, M., Hulot, G., 2008. ArcheoInt: An upgrated compilation of geomagnetic field intensity data for the past ten millennia and its application to the recovery of the past dipole moment. Geochem. Geophys. Geosyst., 9, 4, Q04038. doi:10.1029/2007/GC001881.

Genevey, A., Gallet, Y., Rosen, J., Le Goff, M., 2009. Evidence for rapid geomagnetic field intensity variations in Western Europe over the past 800 years from new French archeomagnetic data. Earth Planet. Sci. Lett. 284, 132-143. doi:10.1016/ j.epsl.2009.04.024.

Goméz-Paccard, M., Chauvin, A., Lanos, Ph., Thiriot, J., Jiménez-Castillo, P., 2006. Archeomagnetic study of seven contemporaneous kilns from Murcia (Spain). Phys. Earth Planet. Inter. 157, 16-32. doi:10.1016/j.pepi.2006.03.001.

Gubbins, D., Jones, A.L., Finlay, C.C., 2006. Fall in Earth's magnetic field is erratic. Science 312, 900-902 doi:10.1126/science. 1124855

Halgedhal, S., Day, R., Fuller, M., 1980. The effect of the cooling rate on the intensity of weak field TRM in single domain magnetite. J. Geophys. Res. 85, 3690-3698.
Hartmann, G.A., Pacca, I.G., 2009. Time evolution of the South Atlantic Magnetic Anomaly. An. Acad. Bras. Ciênc. 81, 243-255. doi:10.1590/S0001-37652009000200010.

Hongre, L., Hulot, G., Khokhlov, A., 1998. An analysis of the geomagnetic field over the past 2000 years. Phys. Earth Planet. Inter. 106, 311-335. doi:10.1016/S0031-9201 (97)00115-5.

Hulot, G., Khokhlov, A., Le Mouël, J.L., 1997. Uniqueness of mainly dipolar magnetic fields recovered from direction data. Geophys. J. Int. 129, 347-354. doi:10.1111/ j.1365-246X.1997.tb01587.x.

Jackson, A., Jonkers, A.R.T., Walker, M., 2000. Four centuries of geomagnetic secular variation from historical records. Philos. Trans. R. Soc. London, Ser. A 358, 957-990. doi:10.1098/rsta.2000.0569.

Kelly, P., Gubbins, D., 1997. The geomagnetic field over the past 5 million years. Geophys. J. Int. 128, 315-330. doi:10.1111/j.1365-246X.1997.tb01557.x.

Korte, M., Constable, C.G., 2005. Continuous geomagnetic field for the past 7 millennia: 2.CALS7K. Geochem. Geophys. Geosyst., 6, 1, 002H16. doi:10.1029/2004GC000801.

Korte, M., Genevey, A., Constable, C.G., Frank, U., Schnepp, E., 2005. Continuous geomagnetic field models for the past 7 millenia: 1 . A new global data compilation. Geochem. Geophys. Geosyst., 6, 2, Q02H15. doi:10.1029/2004GC000800.

Korte, M., Donadini, F., Constable, C.G., 2009. Geomagnetic field for 0-3 ka: 2. A new series of time-varying global models. Geochem. Geophys. Geosyst., 10, 6, Q06008. doi:10.1029/2008GC002297.

Kovacheva, M., Chauvin, A., Jordanova, N., Lanos, Ph., Karloukovski, V., 2009 Remanence anisotropy effect on the paleointensity results obtained from various archaeological materials, excluding pottery. Earth Planet. Space 61, 711-732.

Krása, D., Heunemann, C., Leonhardt, R., Petersen, N., 2003. Experimental procedure to detect multidomain remanence during Thellier-Thellier experiments. Phys. Chem. Earth 28, 681-687. doi:10.1016/S1474-7065(03)00122-0.

Le Goff, M., Gallet, Y., 2004. A new three-axis vibrating sample magnetometer for continuous high-temperature magnetization measurements: applications to paleoand archeo-intensity determinations. Earth Planet. Sci. Lett. 229, 31-43. doi:10.1016/j.epsl.2004.10.025

Leonhardt, R., Matzka, J., Menor, E.A., 2003. Abolute paleointensities and paleodirections of Miocene and Pliocene lavas from Fernando de Noronha, Brazil. Phys. Earth planet. Inter. 139, 285-303. doi:10.1016/j.pepi.2003.09.008.

Leonhardt, R., Heunemann, C., Krása, D., 2004. Analyzing absolute paleointensity determinations: acceptance criteria and the software Thellier Tool 4.0. Geochem. Geophys. Geosyst. 5, Q12016. doi:10.1029/2004GC000807.

Lowrie, W., 1990. Identification of ferromagnetic minerals in a rock by coercivity and unblocking temperatures properties. Geophys. Res. Lett. 17, 159-162. doi:10.1029/ GL017i002p00159.

McIntosh, G., Kovacheva, M., Catanzariti, G., Osete, M.L., Casas, L., 2007. Widespread occurence of a novel high coercivity, thermally stable, low unblocking temperature magnetic phase in heated archeological material. Geophys. Res. Lett. 34, L21302. doi:10.1029/2007GL031168.

Muscheler, R., Joos, F., Beer, J., Müller, S.A., Vonmoos, M., Snowball, I., 2007. Solar activity during the last $1000 \mathrm{yr}$ inferred from radionuclide records. Quat. Sci. Rev. 26, 82-97. doi:10.1016/j.quascirev.2006.07.012.

Nagata, T., Arai, Y., Momose, K., 1963. Secular variation of the geomagnetic total force during the last 5000 years. J. Geophys. Res. 68, 5277-5281.

Néel, L., 1955. Some theoretical aspects of rock-magnetism. Adv. Phys. 4, 191-243. doi:10.1080/00018735500101204.

Riisager, P., Riisager, J., 2001. Detecting multidomain magnetic grains in Thellier paleointensity experiments. Phys. Earth Planet. Inter. 125, 111-117. doi:10.1016 S0031-9201(01)00236-9.

Rogers, J., Fox, J., Aitken, M.J., 1979. Magnetic anisotropy in ancient pottery. Nature 277, 644-646. doi:10.1038/277644a0.

Schnepp, E., 2003. On correction of loss of mass during Thellier experiments. Phys. Earth Planet. Inter. 135, 225-229. doi:10.1016/S0031-9201(02)00213-3.

Selkin, P.A., Tauxe, L., 2000. Long-term variations in paleointensity. Philos. Trans. R. Soc London, Ser. A 358, 1065-1088. doi:10.1098/rsta.2000.0574.

St-Onge, G., Stoner, J., Hillaire-Marcel, C., 2003. Holocene paleomagnetic records from the St. Lawrence Estuary, eastern Canada: centennial- to millennial-scale geomagnetic modulation of cosmogenic isotopes. Earth Planet. Sci. Lett. 209, 113-130. doi:10.1016/S0012-821X(03)00079-7.

Thellier, E., Thellier, O., 1959. Sur l'intensité du champ magnetiqué terrestre dans le passé historique et géologique. Ann. Geophys. 15, 285-376.

Valet, J.P., Herrero-Bervera, E., Le Mouël, J.L., Plenier, G., 2008. Secular variation of the geomagnetic dipole during the past 2000 years. Geochem. Geophys. Geosyst., 9, 1 , Q01008. doi:10.1029/2007GC001728.

Veitch, R., Hedley, I., Wagner, J.J., 1984. An investigation of the intensity of the geomagnetic field during Roman times using magnetically anisotropic bricks and tiles. Arch. Sci. 37, 359-373.

Yu, Y., Dunlop, D.J., 2003. On partial thermoremanent magnetization tail checks in Thellier paleointensity determination. J. Geophys. Res. 108, 2523. doi:10.1029/ 2003JB002420, 2003.

Yu, Y., Tauxe, L., Genevey, A., 2004. Toward an optimal geomagnetic field intensity determination technique. Geochem. Geophys. Geosyst., 5, 2, Q02H07. doi:10.1029/ 2003GC000630. 


\section{Apêndice C}

Artigo sobre a curva de variação da intensidade do CMT na região Sudeste do Brasil

Artigo:

"New historical data from Brazil: Evidence for a large non-dipole field contribution over the past few centuries"

G.A. Hartmann, A. Genevey, Y. Gallet, R.I.F. Trindade,

M. Le Goff, R. Najjar, C. Etchevarne, M.C. Afonso

(Artigo a ser submetido para a revista Journal of Geophysical Research). 


\title{
New historical archeointensity data from Brazil: Evidence for a large non-dipole field contribution over the past few centuries
}

\author{
Gelvam A. Hartmann ${ }^{1,3}$, Agnès Genevey ${ }^{2}$, Yves Gallet ${ }^{3}$, Ricardo I.F. Trindade ${ }^{1}$, Maxime Le \\ Goff $^{3}$, Rosana Najjar ${ }^{4}$, Carlos Etchevarne ${ }^{5}$, Marisa C. Afonso ${ }^{6}$ \\ ${ }^{1}$ Departamento de Geofísica, Instituto de Astronomia, Geofísica e Ciências Atmosféricas, Universidade de São Paulo, \\ Rua do Matão, 1226, 05508-090, São Paulo, Brazil \\ ${ }^{2}$ Centre de Recherche et de Restauration des Musées de France, UMR CNRS 171, Palais du Louvre, Porte des Lions, \\ 14 quai F. Mitterrand, 75001, Paris, France \\ ${ }^{3}$ Equipe de Paléomagnétisme, Institut de Physique du Globe de Paris, UMR CNRS 7154, 4 place Jussieu, 75005, Paris, \\ France \\ ${ }^{4}$ Assessoria de Arqueologia, Assessoria de Arqueologia, 6a Superintendência Regional do Instituto do Patrimônio \\ Histórico e Artístico Nacional, Av. Rio Branco, 46, 20090-002, Rio de Janeiro, Brazil \\ ${ }^{5}$ Departamento de Antropologia, Universidade Federal da Bahia, Terreiro de Jesus, Prédio da Faculdade de Medicina, \\ 40026-100, Salvador, Brazil \\ ${ }^{6}$ Museu de Arqueologia e Etnologia, Universidade de São Paulo, Av. Prof. Almeida Prado, 1466, 05508-090, São \\ Paulo, Brazil
}

\begin{abstract}
We studied nine groups of architectural brick fragments from six different cities located in three States of Southeast Brazil and dated between the end of the XVIth century and the beginning of the XXth century. Ages are ascertained by historical documents and complemented by archeological constraints giving accurate and consistent dating for the sites with age uncertainty of less than 32 years. Intensity determinations were made using two different protocols: (1) the "TT-ZI protocol" (Zero field-In field) corresponds to the classical Thellier and Thellier method as modified by Coe, with partial thermoremanent magnetization (pTRM) checks and pTRM-tail checks; (2) the Triaxe protocol which involves continuous high-temperature magnetization measurements. TRM anisotropy and cooling rate effects were monitored in both protocols and intensity determinations were properly corrected. For all fragments analyzed with TT-ZI protocol, the cooling rate effect was further studied using three different slow cooling times $(5 \mathrm{~h}, 10 \mathrm{~h}$ and $25 \mathrm{~h})$ from $450{ }^{\circ} \mathrm{C}$ to room temperature. Regarding the archeological constraints, the slow cooling time of $25 \mathrm{~h}$ was applied to
\end{abstract}


correct the intensity values, giving a decrease between $\sim 5 \%$ and $15 \%$. At fragment level, an intensity value was computed using between two and six specimens and satisfying coherence test at $5 \%$. At the site level, intensity means were computed using between three and eight fragments, with a maximum standard deviation of less than $8 \%$. A total of 43 fragments (150 specimens) were used in nine site-means that compose this archeointensity dataset. Intensity values at the latitude of São Paulo $\left(23.5^{\circ} \mathrm{S}, 46.6^{\circ} \mathrm{W}\right)$ vary from $\sim 25 \mu \mathrm{T}$ to $\sim 42 \mu \mathrm{T}$. These values describe in Southeast Brazil a clear and continuous decreasing trend by $\sim 5 \mu \mathrm{T}$ per century for the past four centuries. Comparison between results of the previous study from Northeast and this study relocated at the latitude of São Paulo shows that geocentric axial dipole approximation is not valid between the two regions distant by $\sim 10^{\circ}$, which probably is linked to the occurrence of the large non-dipole features of the South Atlantic Magnetic Anomaly. We also used the two Brazilian archeointensity datasets and a selection of French dataset to recalibrate the $g_{1}^{0}$ term relying on the geometry of the gufm1 field model, which shows a large scatter between the different datasets. This scatter probably is due to the limitation in the global geomagnetic field geometry. If confirmed this hypothesis, the consequences would be twofold: (a) the significant decrease in $g_{1}^{0}$ observed over the past 160 years would be only a short-term feature, (b) the short-term evolution of the axial dipole over the past millennium would be most probably more complex than a long decreasing trend as previously envisaged from global data compilation.

Keywords: archeomagnetism, archeointensity, geomagnetic secular variation, historical geomagnetic field, Southeast Brazil, South Atlantic Magnetic Anomaly. 


\section{Introduction}

Considerable efforts have been made to produce compilations of all archeomagnetic and paleomagnetic (i.e. from volcanics and sediments) data that can be used to describe the behavior of the Earth's magnetic field over the past millennia (Daly and Le Goff, 1996; Korte et al., 2005a; Genevey et al., 2008; Donadini et al., 2009). These data compilations have been used to construct successive global spherical harmonic "archeomagnetic" field models of invaluable interest for scrutinizing the core dynamics over centennial and millennial scales (e.g. Hongre et al., 1998; Korte and Constable, 2003; 2005a; Korte et al., 2009). However, the reliability of these models is obviously limited by the irregular temporal and geographic distributions of the directional and intensity data. In this respect, the weak number of archeomagnetic results obtained from the southern hemisphere, for instance noting that geomagnetic field intensity data represent only $5 \%$ of all archeointensity results (e.g. Genevey et al., 2008), is particularly penalizing. Because of these limitations, Valet et al. (2008) argued that only the fluctuations of the axial and equatorial dipolar parts of the geomagnetic field could be inferred at present with some confidence.

The geomagnetic field evolution is better constrained during the historical period, i.e. over the past four centuries, thanks to numerous direct field measurements essentially made by mariners on the main seaways around the world (Bloxham et al., 1989; Jackson et al., 2000; Jonkers et al., 2003). The compilation of these data led Jackson et al. (2000) to construct spherical harmonic field models (the so-called gufm1 models), which revealed the signature of rather stationary high-latitude magnetic flux patches at the core mantle boundary (e.g. Bloxham and Gubbins, 1985; Hulot et al., 2002). Although the evolution in the field geometry provided by such models is generally considered reliable, there is much debate on the relative calibration of the Gauss coefficients describing the models. The reason for this is a lack of direct measurements of the geomagnetic field intensity before the middle of the XIXth century (e.g. Barraclough, 1974). To circumvent this problem, Jackson et al. (2000) made a rough approximation, backward extrapolating the linear decreasing trend of the axial dipole moment well established since 1840 AD. Considering that 
archeomagnetic studies could bring more constraints on that behavior, Gubbins et al. (2006) and Finlay (2008) relied on two different approaches (see further discussion in Finlay, 2008) to also make use of archeointensity data available worldwide during the 1590-1840 time interval. Both analyses support the view that the axial dipole moment remained more or less constant between $1590 \mathrm{AD}$ and $1840 \mathrm{AD}$, its decrease after $1840 \mathrm{AD}$ being thus only a recent trend. On the other hand, acknowledging the large scatter existing in regional archeointensity data compilations, most probably due to the fact that they contain outliers, Genevey et al. (2009) used a limited high-quality data set obtained from France to recalibrate the Gauss coefficients of the gufm1 models. Such an approach relies on a theorem by Hulot et al. (1997), also used by Gubbins et al. (2006), and supposes that the field geometry provided by gufm1 is correct. Genevey et al. (2009) hence proposed that the axial dipole field moment first decreased between $\sim 1600 \mathrm{AD}$ and $\sim 1775 \mathrm{AD}$, then increased until $\sim 1840 \mathrm{AD}$ and finally decreased again after this date. Dealing with data for constraining the dipole evolution over the past four centuries thus presently brings us to two alternative conclusions depending on whether we consider all the scattered archeointensity data or only a restricted selection of them (based on severe selection criteria).

It is beyond the scope of this paper to review the reasons for the large and puzzling dispersion seen in most regional archeointensity data sets (e.g. Genevey et al., 2008). However, there is a clear need of new data dated to the historical period, meeting all the modern quality criteria for intensity experiments and obtained from various regions over the world. As previously pointed out, the archeointensity data available from the southern hemisphere are presently not numerous enough. Furthermore, analyses of the secular variation in Brazil during the XIXth century have shown the occurrence of a strong non-dipole field contribution in this region that was linked to the westward drift of the South Atlantic Magnetic Anomaly (SAMA; e.g. Bloxham and Gubbins, 1985; Bloxham et al., 1989; Hartmann and Pacca, 2009). SAMA is doubtless one of the most intriguing and prominent anomaly of the recent geomagnetic field characterized by the lowest geomagnetic field intensity and connected to a reverse flux patch beneath the South Atlantic and 
South Africa, but also affecting South America (e.g. Bloxham and Gubbins, 1985; Bloxham et al., 1989; Hulot et al., 2002; Gubbins et al., 2006; Hartmann and Pacca, 2009). The centennial-scale evolution of SAMA, that might give some indication on its future development, is directly related to the accuracy of the historical geomagnetic field models. For this reason we started an archeomagnetic project on the geomagnetic field intensity variations in Brazil during the past few centuries. In a first study, we presented new archeointensity data obtained in Northeast Brazil (Hartmann et al., 2010a). In the present paper, we report new results from Southeast Brazil (states of São Paulo, Rio de Janeiro and Espírito Santo). Together these two studies allow one to test the first order the reliability of the time varying dipole and non-dipole contribution described in the available historical geomagnetic field models. Our study carried out in one region bordering the South Atlantic is therefore a first step toward a better knowledge of this ancient evolution.

\section{Archeological collection}

Our archeological collection comprises a total of 136 fragments of baked clay elements collected from eleven different sites (hereafter referred as to archeomagnetic sites). Among those sites, seven consist of architectural bricks and four sets of brick fragments involved in the construction of kilns, with 6 to 31 independent fragments taken per site. The archeomagnetic sites were sampled in six urban centers located in three different States of Southeast Brazil (São Paulo, Rio de Janeiro and Espírito Santo), delimiting a 2.5 ${ }^{\circ}$-latitude and $7.8^{\circ}$-longitude wide sampling area

(Figure 1a, Table 1). They are dated from the end of the XVIth century to the beginning of the XXth century, thus spanning the colonial and post-colonial period in Brazil. During that period, the coastal cities first emerged in Northeast and Southeast Brazil (e.g. Fausto, 2008) and were developed around religious and governmental buildings with private buildings spreading in the neighborhoods. The hinterland cities grew up later accompanying the development of mineral (e.g. iron) exploration and agriculture (e.g. coffee). It is worth mentioning that the fast expansion of these 
cities required a local production of architectural baked bricks and tiles and their rapid use after that manufacturing (e.g. Costa, 2005).

The different structures sampled in this study were selected because their history, retrieved in old archives, is well known, from their construction to later possible extension and restoration for the architectural sites or to their last use (abandon) for the four kilns analyzed here. These documents allow us to obtain a precise and reliable dating for the sites, with age uncertainty of less than 14 years for all but one site whose date is known within 32 years. We notably worked on the first Brazilian steel mill, known as the "Real Fábrica de Ferro Ipanema". This factory was established by royal decree of the Portuguese king Dom João VI in 1810 AD and experimented several periods of activity, some documented by the analyzed kilns, until 1895 AD when it was officially closed (e.g. Salazar, 1998). Another example is provided by the ancient residence of the first president of the Brazilian republic, Prudente de Moraes, located in the city of Piracicaba (State of São Paulo) and whose year of construction, in 1870 AD, is precisely known. The archeomagnetic site MPM(1+2) was sampled in the foundations of this building to ensure that the selected fragment are linked to its initial construction phase. The same strategy of sampling, in the basement of the building and with the help of a portable drill was used for the "Fazenda Lageado" house (Figure 1b; site $\mathrm{FL} 1+3+4+5)$.

In four cases (sites SLI, INSA, OTP, INS), we collected brick fragments from reserves where the bricks were deposited after the recent (XXth century) restoration of the concerned Jesuit churches, such as the "Igreja de São Lourenço dos Índios" Church (city of Niterói, State of Rio de Janeiro) whose architectural style is typical of the Jesuit churches built during the colonial period (Figure 1c). In those cases, archeological constraints including stratigraphy and the typology of bricks were further used to guide and ensure the sampling of the fragments corresponding only to the initial phase of construction of these buildings. 
Measurements were carried out using two protocols derived from the classical Thellier and Thellier (1959) paleointensity method. These procedures are exactly the same as those recently adopted by Hartmann et al. (2010a) for analyzing Brazilian baked brick fragments from the city of Salvador (Bahia State) and we therefore only summarize their main characteristics below.

The first procedure, hereafter called "TT-ZI protocol” ( $Z$ for zero-field steps and $I$ for infield steps) corresponds to the Coe (1967) version of the Thellier and Thellier (1959) method. It relies on double heating steps performed between $100{ }^{\circ} \mathrm{C}$ and $600{ }^{\circ} \mathrm{C}$, with temperature intervals of $50{ }^{\circ} \mathrm{C}$ from $100{ }^{\circ} \mathrm{C}$ to $150{ }^{\circ} \mathrm{C}$ and $25^{\circ} \mathrm{C}$ above, with magnetization measurements acquired at room temperature. This protocol was applied to two cubic specimens $(1 \mathrm{~cm}$ of side) per fragment. The $H_{l a b}$ of $35 \mu \mathrm{T}$ was applied parallel to $X$-axis of the specimens during the partial Thermo Remanent Magnetization (pTRM) acquisitions. It further includes pTRM checks every two temperature steps in order to control the stability of the TRM acquisition capacity and pTRM-tail tests (Riisager and Riisager, 2001) at six temperature steps $\left(200^{\circ} \mathrm{C}, 300^{\circ} \mathrm{C}, 350{ }^{\circ} \mathrm{C}, 400{ }^{\circ} \mathrm{C}, 500{ }^{\circ} \mathrm{C}\right.$ and $\left.600{ }^{\circ} \mathrm{C}\right)$ to detect possible biases due to multidomain grains. The second procedure involves continuous hightemperature magnetization measurements made using the Triaxe magnetometer (Le Goff and Gallet, 2004) and will be referred in the following as the "Triaxe protocol". It was applied for samples with magnetization greater than $40 \times 10^{-2} \mathrm{~A} / \mathrm{m}$, while fragments with weaker remanence were analyzed using the TT-ZI protocol. Several fragments were however analyzed using both techniques to allow a direct comparison between the two data sets.

Intensity determination using the Triaxe relies on the comparison between an almost complete demagnetization of the Natural Remanent Magnetization (NRM) of a cylindrical specimen (of $1 \mathrm{~cm}$ in height and diameter) between a temperature $T_{1}$ (usually $150{ }^{\circ} \mathrm{C}$ ) and a high temperature $T_{2}$ and the demagnetization on the same temperature interval of a laboratory TRM previously acquired between $T_{2}$ and $T_{1}$. The intensity of this laboratory field is chosen to be close to the expected one and its direction is adjusted so that the laboratory TRM has a direction nearly 
identical to that of the NRM. For each specimen, an intensity value is computed from the averaging of $R^{\prime}\left(T_{i}\right)$ data, each $R^{\prime}\left(T_{i}\right)$ being equal to the ratio of the NRM and TRM fractions unblocked between $T_{1}$ (or a higher $T_{1}$, temperature if a secondary magnetization component is detected) and a running $T_{i}$ comprised between $T_{1}$ (or $T_{1}$ ') and $T_{2}$ multiplied by the intensity of the laboratory field (see Le Goff and Gallet, 2004 for a complete description of the Triaxe protocol).

TRM anisotropy and cooling rate effects on the intensity determination were both taken into account in our experiments. These two effects are respectively linked to the manufacturing process of the analyzed objects and to the fact that the experimental conditions in which the laboratory TRM is acquired may not reproduce the original conditions of NRM acquisition (e.g. Genevey et al., 2008).

For the TT-ZI protocol, the TRM anisotropy effect was corrected for each specimen using the $f$ factor proposed by Veitch et al. (1984). This factor was in fact computed twice ( $f 1$ and $f 2$ ) from the determination at two temperatures, respectively $350{ }^{\circ} \mathrm{C}$ and $500{ }^{\circ} \mathrm{C}$, of the $\mathrm{TRM}$ anisotropy tensor derived from successive pTRM acquired along six different positions with respect to specimen's orientation $(X,-X, Y,-Y, Z,-Z)$. In order to further test the consistency in the determination of the TRM anisotropy tensor, the $X$-axes of the two specimens of each fragment were rotated to be perpendicular to each other. On another hand, no TRM anisotropy correction was necessary for the Triaxe results because the laboratory field TRM is always acquired in a direction very close to that of the NRM (see Le Goff and Gallet, 2004).

For all fragments analyzed with the TT-ZI protocol, the cooling rate effect on TRM acquisition was explored considering three different cooling times $(5 \mathrm{~h}, 10 \mathrm{~h}$ and $25 \mathrm{~h})$ from $450{ }^{\circ} \mathrm{C}$ to room temperature. In each case, the procedure, performed on a third specimen specially prepared for these measurements, has involved the acquisition of three successive pTRM: first using a rapid cooling rate $(\sim 30$ minutes, i.e. the one used in routine), then the slow cooling rate $(5 \mathrm{~h}, 10 \mathrm{~h}$ and 25 h) and again the rapid cooling rate. When no alteration was detected during the whole cycle, a cooling rate correction factor was then computed from the comparison between the two rapidly 
acquired pTRM and the one acquired in slow conditions. In the present study, as in Hartman et al. (2010a), our TT-ZI intensity results were corrected using the slowest cooling rate because the latter, based on historical constraints, seems to better approximate the one which prevailed during the original manufacturing of the objects. The situation was much more simple for the data acquired with the Triaxe protocol. Indeed, several comparative studies involving TT-ZI, TT-IZZI (Yu et al., 2004) and/or TT-IZ (Aitken et al., 1988) versus Triaxe data have experimentally shown that the $R^{\prime}(T i)$ data are almost independent from the cooling rate effect (Le Goff and Gallet, 2004; Gallet and Le Goff, 2006; Genevey et al., 2009; Hartmann et al., 2010a).

Finally, several criteria were used for selecting the most reliable intensity determinations. They are exactly the same as those applied by Hartmann et al. (2010a) and very similar to that previously defined by Genevey and Gallet (2002) and Genevey et al. (2009). There are all summarized in Table 1 of supplementary material.

\section{$4 \quad$ Magnetic mineralogy}

Thermal variations of low-field susceptibility, hysteresis loops and Isothermal Remanent Magnetization (IRM) acquisition curves were carried out to characterize the magnetic mineralogy of each fragment of our collection (a total of 136 fragments) and to test its stability upon heating.

Hysteresis and IRM acquisition curves were performed using a laboratory-built inductometer coupled with an electromagnet reaching fields up to 1 Tesla. These high-field measurements show two main magnetic behaviors. For $\sim 40 \%$ of the fragments, the measurements show narrow hysteresis loops (Figure 2a) and IRM acquisition curves (Figure 2d) saturating at fields between $\sim 0.1 \mathrm{~T}$ and $\sim 0.3 \mathrm{~T}$. This behavior indicates that the magnetization is carried by a low-coercivity magnetic phase, which is likely a mineral from the (titano)magnetite family in the pseudo single domain range. For the remaining $\sim 60 \%$ of our fragment collection, the hysteresis loops are clearly wasp-waisted and the IRM acquisition curves do not show saturation up to $1 \mathrm{~T}$. 
This behavior therefore reveals the presence of a mixture of low and high-coercivity phases with varying proportions among the fragments, from weak to large proportion of the hard fraction illustrated in Figures $2 \mathrm{~b}$ and 2e (weak) and Figures $2 \mathrm{c}$ and $2 \mathrm{f}$ (large). Thermal demagnetization diagrams further indicate that the high-coercivity mineral has an unblocking temperature below 580 ${ }^{\circ} \mathrm{C}$. Although not yet completely identified (Genevey and Gallet, 2002; McIntosh et al., 2007; Hartmann et al., 2010a), this magnetic phase is probably a form of stable substituted hematite (Hartmann et al., 2010b).

Low-field magnetic susceptibility versus temperature (up to $550{ }^{\circ} \mathrm{C}-600^{\circ} \mathrm{C}$ ) curves were performed in air using a Kappabridge KLY3-CS3 (AGICO) system. The reversibility between the heating and cooling curves was used to retain only the fragments showing a good stability of their magnetic mineralogy for further intensity experiments (Figure 3). At this stage, a total of 47 fragments were rejected to paleointensity experiments because of mineralogical alteration.

\section{Archeointensity results}

Intensity measurements were performed on 89 fragments from the 11 groups that compose our archeological collection, with 289 specimens analyzed using either the TT-ZI or the Triaxe protocol. Considering the whole set of our selection criteria (see Table 1 of supplementary material), 43 fragments (150 specimens) were finally kept for the computation of mean intensity values yielding an averaged success rate of $52 \%$.

The TT-ZI protocol was applied for analyzing a set of 40 fragments (i.e. 80 specimens) from 8 different archeological groups. Between 4 and 7 fragments were measured per site and we obtained a relatively low success rate of $38 \%$, with only 15 fragments retained (see Table 2 of supplementary material for all retained intensity results at the specimen level). Non linear (often convex) curves observed in the so called Arai diagrams (Nagata et al., 1963) motivated the majority of the rejections. In particular, all fragments from groups FF4 (Fábrica de Ferro 4, 4 fragments) and 
FFY (Fábrica de Ferro Ypanema, 4 fragments) were rejected for this reason. A few fragments were additionally abandoned because the fraction of NRM available for intensity computation was too small. This was the case for some bricks from the oven FF2, for which the primary magnetization component was overprinted by a secondary component indicating their partial re-firing at rather low temperature. Figure 4 displays three representatives examples of successful intensity determination with measurements reported in an Arai diagram and in the corresponding orthogonal demagnetization plot. This figure shows that the principal magnetization component was usually isolated above $100{ }^{\circ} \mathrm{C}-250{ }^{\circ} \mathrm{C}$ and that the intensity determination was made on the same temperature range of isolation of that component.

The approach used for correcting fragments from the TRM anisotropy effect was the same as the one described in Hartmann et al. (2010a): i.e., the factor $f 1$ was applied alone when the NRM fraction involved for the tensor computation at $350{ }^{\circ} \mathrm{C}$ was higher than $40 \%$ and when a non linear behavior or an alteration was observed above $500{ }^{\circ} \mathrm{C}$ (see Figure $4 \mathrm{e}$ ); the factor $f 2$ was used alone when the NRM fraction was lower than $40 \%$ at $350{ }^{\circ} \mathrm{C}$ and when no alteration was detected below $500{ }^{\circ} \mathrm{C}$ (see Figures $4 \mathrm{a}$ and $4 \mathrm{c}$ ). In rare cases, the averaging of both factors was used for TRM anisotropy correction (only in FF2-05 and FL1-07 fragments). The TRM anisotropy observed for this collection of bricks is very similar to that already described for the bricks from the Bahia State (Hartmann et al., 2010a; Figure 5a). Taken together, $80 \%$ of the fragments present an anisotropy degree between 1.0 and 1.2 while for the remaining $20 \%$ the ratios $K 1 / K 3$ range between 1.2 and 1.4. This again highlights the fact that the anisotropy effect can be relatively important in this type of objects leading to correction as high as $15 \%-20 \%$ for the raw intensity values (see Figure 1a of supplementary material). Interestingly, we note that a very same distribution of $K 1 / K 3$ was observed for old (Bronze age) Syrian bricks (Genevey et al., 2008) and also for a collection of bricks and tiles from France and Bulgaria of various age analyzed by Kovacheva et al. (2009). The distribution of anisotropy degrees obtained from the historical Brazilian bricks seems therefore very characteristic of this type of material. 
Regarding the cooling rate correction, the 25 hours slow cooling time that we considered implied a decrease by $\sim 5 \%$ to $15 \%$ of the intensity values, with a mean centered around $9 \%$ (Figure 5b). Reducing this slow cooling time leads to more moderate correction factors (Figure $1 \mathrm{~b}$ of supplementary material). However the differences induced at the site level are relatively moderate, which indicates that only a limited error would be done if the original cooling conditions were indeed misestimated. On the other hand, our results show for all the bricks analyzed from the Southeast and Northeast regions (Hartmann et al., 2010a, and this study) that even with a fast original cooling rate, intensity would be over-estimated by $9 \%$ if not corrected (Figure $1 \mathrm{~b}$ of supplementary material).

The Triaxe protocol was applied on a set of 73 fragments (209 specimens) from 9 different groups, with 1 to 14 fragments analyzed per group. Thirty-five fragments (120 specimens) satisfied our selection criteria (see Table 1 of supplementary material) yielding a success rate of $57 \%$, thus higher than the one obtained with the TT-ZI protocol. Fragments were mainly rejected because of alteration detected during the continuous magnetization measurements or because the slopes of the $R^{\prime}\left(T_{i}\right)$ values were too high $(>10 \%)$ to allow reliable intensity determinations. For most successful fragments, intensity was computed over a large temperature interval comprised between $130{ }^{\circ} \mathrm{C}-$ $220{ }^{\circ} \mathrm{C}$ and $480{ }^{\circ} \mathrm{C}-520{ }^{\circ} \mathrm{C}$ (see Table 3 of supplementary material). For some fragments from ovens FF2 and FF3 for which partial re-firing was observed, the $T_{1}$ temperature was shifted toward higher temperature $\left(T_{1}{ }^{\prime} \sim 250{ }^{\circ} \mathrm{C}-330{ }^{\circ} \mathrm{C}\right)$ in order to perform the intensity analysis strictly on the temperature interval of isolation of the primary TRM. Figure 6 shows successful intensity determinations obtained from four different sites using the Triaxe. Each panel displays the $R^{\prime}\left(T_{i}\right)$ data obtained over the relevant temperature intervals from the different specimens analyzed for one site. It is worth mentioning that this Figure visually emphasizes the very good consistency of our data both at the fragment and at site levels. Note that some curves are significantly scattered in the low temperature range because the magnetization fractions considered for the $R^{\prime}\left(T_{i}\right)$ computations 
are small. However, this noise does not contribute significantly to the mean $R^{\prime}\left(T_{i}\right)$ values averaged over the entire $T_{1}$ and $T_{2}$ temperature.

Suitable intensity values using both protocols were obtained for seven fragments of our collection (Tables 2 and 3 of supplementary material), allowing direct comparison between them. At the site level, such a comparison between Triaxe and TT-ZI results was possible only for 4 sites for which at least two fragments were analyzed using each method. In Figures $7 \mathrm{a}$ and $7 \mathrm{~b}$, we further expanded the comparison to the data that we previously obtained from Northeast Brazil (Hartmann et al., 2010a). A good agreement is first observed at the fragment level, with differences between TT-ZI and Triaxe results lying within a span of $\pm 5 \%$ for the majority of the fragments (17 over 22 ; Figure 7a). The differences are in any case less than $\pm 9 \%$. At the site level, the Triaxe and the TTZI mean intensity values appear also very consistent, with a maximum difference reaching $6.5 \%$ for site INS (Figure 7b). Together with previous results obtained from archeological artifacts sampled in France and Syria (Gallet and Le Goff 2006; Genevey et al. 2009), we now have numerous examples of satisfactory agreement between results obtained using the high-temperature Triaxe procedure and the classical Thellier and Thellier method procedure (i.e. TT-ZI, TT-IZ and TTIZZI). Considering that large collection of data obtained from fragments and sites of different origin and age, and with different magnetic mineralogy and conditions of manufacturing and preservation, there is therefore increasing evidence in the reliability of the intensity results obtained using the Triaxe protocol.

\section{Discussion}

Applying the same selection criteria as those used by Genevey et al. (2009) and Hartmann et al. (2010a), mean intensity values were successfully determined from 43 fragments (the detailed results are reported in Tables 2 and 3 of supplementary material). In all cases, the standard deviations are less than $4.8 \%$ of the corresponding means. Averaging was then performed at the site 
level using a minimum of three different fragments per site (Table 1). This led to 9 site-mean intensity values determined from 3 to 8 fragments and defined with relative standard deviations between $1.5 \%$ (site FL2) and 7.6\% (site FF3). These values are reported in Figure 8 after their reduction to the latitude of São Paulo $\left(23.5^{\circ} \mathrm{S}, 46.6^{\circ} \mathrm{W}\right)$ using the geocentric axial dipole (GAD) approximation. We note that the sites analyzed are all located within a narrow geographical area only $2.5^{\circ}$-latitude large, which likely allows one to avoid significant errors due to possible nondipole features (Hartmann and Pacca, 2009).

The relocated intensity values vary from $\sim 25 \mu \mathrm{T}$ (site FL2) to $\sim 42 \mu \mathrm{T}$ (site INSA). They describe in Southeast Brazil a clear, continuous decreasing trend by $\sim 5 \mu \mathrm{T}$ per century between the beginning of the XVIIth century and the XXth century. That decrease amounts $\sim 35 \%$ of the intensity since $\sim 1600 \mathrm{AD}$. We compared this evolution to that expected from the available historical geomagnetic field models (Figure 8; Jackson et al., 2000; Gubbins et al., 2006; Finlay, 2008; Korte et al., 2009). We briefly remind that before 1840 AD, in contrast with the other models which integrate archeointensity data, the magnitude of the Gauss coefficients derived from the gufm1 modeling (Jackson et al., 2000) relies on the extrapolation toward older periods of the linear decreasing behavior of the $g_{1}^{0}$ observed during the last $\sim 160$ years $(\sim 15 \mathrm{nT} /$ year $)$. Figure 8 shows that this approximation yields in São Paulo field intensities systematically larger than the values found in our study, although the two data sets exhibit a significant decreasing trend between the XVIIth and the XXth centuries. The new archeointensity data are in much better agreement with the models of Gubbins et al. (2006) and Finlay (2008), both using a global archeointensity data compilation, in which the axial dipole term is supposed to have remained nearly constant between $1590 \mathrm{AD}$ and $1840 \mathrm{AD}$. Such agreement is less satisfactory for the new CALS3k.3 and CALS3k_cst1 models constructed by Korte et al. (2009) relying for the intensities on the most recent data compilation (Donadini et al., 2009; with all available intensity data considered for constructing CALS3k.3 and only a selection of the best data for constructing CALS3k_cst.1). 
Hartmann et al. (2010a) recently reported new archeointensity data from the city of Salvador (Bahia State) in Northeast Brazil, distant by $\sim 10^{\circ}$ in latitude from São Paulo. We underline the fact that after $1600 \mathrm{AD}$ the comparison between the latter data set and the different field intensity variation curves derived in Salvador from the available historical field models leads to a situation opposite to that observed for Southeast Brazil: there is a perfect agreement with the curve derived from the gufm1 models (Jackson et al., 2000), while between $\sim 1600$ AD and $\sim 1750$ AD the intensities expected from the models of Gubbins et al. (2006) and Finlay (2008) appear too low with respect to the archeointensity data (see Figure 9 in Hartmann et al., 2010a). This discrepancy indicates that the relative calibration between the Gauss coefficients in the historical field models, i.e. the field geometry that they describe, is presently not precise enough to reliably reproduce the effects of the non-dipole field structures existing between the northeastern and the southeastern Brazil. These effects are probably large, knowing for instance that in 1900 AD the non-dipole field in Southeast Brazilian coastal region contributes to $\sim 50 \%$ of the total field (Hartmann and Pacca, 2009). For older periods, they can be further illustrated by transferring the archeointensity data obtained from Salvador to São Paulo using the GAD hypothesis (Figure 9a). This indeed produces two different curves with systematically higher intensity values observed for the data transferred from the Bahia State and perhaps a different field intensity evolution during the first half of the XVIIth century marked by an intensity peak in Northeast Brazil apparently not existing in Southeast Brazil. The GAD approximation is therefore not valid between the two Brazilian regions distant by $\sim 1100 \mathrm{~km}$. At this step, it is tempting to link the occurrence of these large non-dipole features to the well-known SAMA.

Following Gubbins et al. (2006) and Genevey et al. (2009), we also used the two new Brazilian archeointensity data sets to recalibrate the $g_{1}^{0}$ term relying on the gufm1 field geometry (Figure 9b). In Figure 9b, we further report the $g_{1}^{0}$ values computed from French archeointensity data encompassing the past four centuries (Genevey et al., 2009), together with the GAD evolutions proposed by Jackson et al. (2000), Gubbins et al. (2006) and Finlay (2008). During the XVIIth 
century, the recalibrated $g_{1}^{0}$ values show a large scatter between the different data sets, which again probably illustrates some inconsistencies in the global geomagnetic field geometry provided by the gufm1 models (Jackson et al., 2000). The scatter, however, appears less pronounced during the second half of the XVIIIth and the beginning of the XIXth century, which may indicate that the models are then more reliable. Of interest is the fact that around $1800 \mathrm{AD}$ the $g_{1}^{0}$ values computed from the new Brazilian data, in particular those from Southeast Brazil, are in rather good agreement with the $g_{1}^{0}$ values derived from the French archeointensity data, being in general lower than the axial dipole field moment given by the different geomagnetic field models. Such observation strengthens the suggestion of Genevey et al. (2009) that a $\sim 75$ year-long moderate increase of the axial dipole preceded its decrease otherwise observed since $\sim 1850$ AD. If confirmed, the consequences would be twofold: (a) the significant decrease in $g_{1}^{0}$ observed over the past 160 years would be (at present) only a short-term feature, (b) the short-term (century-scale) evolution of the axial dipole over the past millennium would be most probably more complex than a long decreasing trend as previously envisaged from global data compilation (e.g. Yang et al., 2000; Korte and Constable, 2005b; Genevey et al., 2008; Korte et al., 2009).

\section{Conclusions}

Our new archeointensity data from Southeast Brazil, together with the other data we previously obtained from Northeast Brazil (Hartmann et al., 2010a) illustrate the present limitation of the historical field models for the Brazilian coastal region. This relatively poor reliability is more probably due to the difficulty in tracking the temporal evolution of SAMA through the South Atlantic (Bloxham and Gubbins, 1985; Bloxham et al., 1989; Hartmann and Pacca, 2009). In this regard, our study shows the potential of archeointensity studies for deciphering that behavior.

The new Brazilian data also allow one to better constrain the behavior of the axial dipole field moment during the past few centuries. Although such a purpose still requires the continuing 
acquisition of high-quality archeointensity data from widely distributed regions, the recent data obtained by our joint Brazilian and French group make emerging a rather oscillatory (bell-shape) behavior of $g_{1}^{0}$ over the past two-three centuries. One consequence, for instance, would be that the interpretation of the significant decrease in $g_{1}^{0}$ observed since $\sim 1850 \mathrm{AD}$ as a precursor for a future geomagnetic field reversal is elusive (see further discussion in Gubbins, 1987; Constable, 2000; Hulot et al., 2002; Olson, 2002; Constable and Korte, 2006).

\section{References}

Aitken, M.J., Allsop, A.L., Bussell, G.D., Winter, M.B., 1988. Determination of the intensity of the Earth's magnetic field during archaeological times: Reliability of the Thellier technique. Rev. Geophys., 26, 3-12. doi: 10.1029/RG026i001p00003

Barraclough, D.R., 1974. Spherical Harmonic Analyses of the Geomagnetic Field for Eight Epochs between 1600 and 1910. Geophys. J. R. Astron. Soc., 36, 497-513. doi: 10.1111/j.1365246X.1974.tb00611.x

Bloxham, J., Gubbins, D., 1985. The secular variation of the Earth's magnetic field. Nature, 317, 777-781. doi: 10.1038/317777a0

Bloxham, J., Gubbins, D., Jackson, A., 1989. Geomagnetic Secular Variation. Phil. Trans. R. Soc. London, A, 329, 415-502. doi: 10.1098/rsta.1989.0087

Coe, R.S., 1967. The determination of paleo-intensities of the Earth's magnetic field with emphasis on mechanisms which could cause non-ideal behavior in Thelier's method. J. Geomag. Geoelectric., 19, 157-179.

Constable, C.G., 2000. On rates of occurrence of geomagnetic reversals. Phys. Earth Planet. Inter., 118, 181-193. doi: 10.1016/S0031-9201(99)00139-9

Constable, C.G., Korte, M., 2006. Is Earth's magnetic field reversing?. Earth Planet. Sci. Lett., 246, 1-16. doi: 10.1016/j.epsl.2006.03.038

Costa, C.A.S., 2005. Materiais construtivos do sítio da primeira catedral do Brasil: modelos de estudos para telhas, tijolos, cravos e azulejos aplicados aos materiais do sítio da antiga igreja da Sé, Salvador, Bahia. Clio Arqueológica, 19, 43-78.

Daly, L., Le Goff, M., 1996. An updated and homogeneous world secular variation data base 1. Smoothing of the archeomagnetic results. Phys. Earth Planet. Int., 93, 159-190. doi: 10.1016/0031-9201(95)03075-1

Donadini, F., Korte, M., Constable, C.G., 2009. Geomagnetic field for 0 - 3ka: 1. New data sets for global modeling. Geochem. Geophys. Geosyst., 10, 6, Q06007. doi: 10.1029/2008GC002295

Fausto, B., 2008. História do Brasil, Ed. Univ. São Paulo, São Paulo.

Finlay, C.C., 2008. Historical variation of the geomagnetic axial dipole. Phys. Earth Planet. Int., 170, 1-14. doi: 10.1016/j.pepi.2008.06.029

Gallet, Y., Le Goff, M., 2006. High-temperature archeointensity measurements from Mesopotamia. Earth Planet. Sci. Lett., 241, 159-173. doi: 10.1016/j.eps1.2005.09.058

Genevey, A., Gallet, Y., 2002. Intensity of the geomagnetic field in western Europe over the past 2000 years: New data from ancient French pottery, J. Geophys. Res., B11, 107, 2285. doi:10.1029/2001JB000701

Genevey, A., Gallet, Y., Constable, C.G., Korte, M., Hulot, G., 2008. ArcheoInt: An upgrated compilation of geomagnetic field intensity data for the past ten millennia and its application to 
the recovery of the past dipole moment. Geochem. Geophys. Geosyst., 9, 4, Q04038. doi: $10.1029 / 2007 / \mathrm{GC} 001881$

Genevey, A., Gallet, Y., Rosen, J., Le Goff, M., 2009. Evidence for rapid geomagnetic field intensity variations in Western Europe over the past 800 years from new French archeomagnetic data. Earth Planet. Sci. Lett., 284, 132-143. doi: 10.1016/j.eps1.2009.04.024

Gubbins, D., 1987. Mechanisms for geomagnetic polarity reversals. Nature, 326, 167-169. doi: $10.1038 / 326167 \mathrm{a} 0$

Gubbins, D., Jones, A.L., Finlay, C.C., 2006. Fall in Earth's Magnetic Field is Erratic. Science, 312 , 900-902. doi: 10.1126/science. 1124855

Hartmann, G.A., Genevey, A., Gallet, Y., Trindade, R.I.F., Etchevarne, C., Le Goff, M., Afonso, M.C., 2010a. Archeointensity in Northeast Brazil over the past five centuries. Earth Planet. Sci. Lett., 296, 340-352. doi: 10.1016/j.eps1.2010.05.016

Hartmann, G.A., Pacca, I.G., 2009. Time evolution of the South Atlantic Magnetic Anomaly. An. Acad. Bras. Ciênc., 81, 243-255. doi: 10.1590/S0001-37652009000200010

Hartmann, G.A., Trindade, R.I.F., Gallet, Y., Genevey, A., Berquó, T.S., Le Goff, M., Lagroix, F., 2010b. Magnetic properties of Brazilian archeological bricks: Further evidence for the widespread occurrence of a Low-T High-Coercivity stable magnetization carrier. In: 2010 The Meeting of the Americas, 2010, Foz do Iguaçu, Brazil.

Hongre, L., Hulot, G., Khokhlov, A., 1998. An analysis of the geomagnetic field over the past 2000 years. Phys. Earth Planet. Int., 106, 311-335. doi: 10.1016/S0031-9201(97)00115-5

Hulot, G., Eymin, C., Langlais, B., Mandea, M., Olsen, N., 2002. Small-scale structure of the geodynamo inferred from Oersted and Magsat satellite data. Nature, 416, 620-623. doi: $10.1038 / 416620 \mathrm{a}$

Hulot, G., Khokhlov, A., Le Mouël, J.L., 1997. Uniqueness of mainly dipolar magnetic fields recovered from direction data. Geophys. J. Int., 129, 347-354. doi: 10.1111/j.1365246X.1997.tb01587.x

Jackson, A., Jonkers, A.R.T., Walker, M., 2000. Four centuries of geomagnetic secular variation from historical records. Phil. Trans. R. Soc. London, A 358, 957-990. doi: 10.1098/rsta.2000.0569

Jonkers, A.R.T., Jackson, A., Murray, A., 2003. Four centuries of geomagnetic data from historical records. Rev. Geophys., 41, 1006. doi: 10.1029/2002RG000115, 2003

Korte, M., Constable, C.G., 2003. Continuous global geomagnetic field models for the past 3000 years. Phys. Earth Planet. Int., 140, 73-89. doi: 10.1016/j.pepi.2003.07.013

Korte, M., Constable, C.G., 2005a. Continuous geomagnetic field for the past 7 millennia: 2.CALS7K. Geochem. Geophys. Geosyst., 6, 1, Q02H16. doi:10.1029/2004GC000801

Korte, M., Constable, C.G., 2005b. The geomagnetic dipole moment over the last 7000 years - new results from a global model. Earth Planet. Sci. Lett., 236, 348-358. doi: 10.1016/j.epsl.2004.12.031

Korte, M., Donadini, F., Constable, C.G., 2009. Geomagnetic field for $0-3 \mathrm{ka}$ : 2. A new series of time-varying global models. Geochem. Geophys. Geosyst., 10, 6, Q06008. doi: 10.1029/2008GC002297

Korte, M., Genevey, A., Constable, C.G., Frank, U., Schnepp, E., 2005. Continuous geomagnetic field models for the past 7 millenia: 1. A new global data compilation. Geochem. Geophys. Geosyst., 6, 2, Q02H15. doi: 10.1029/2004GC000800

Kovacheva, M., Chauvin, A., Jordanova, N., Lanos, Ph., Karloukovski, V., 2009. Remanence anisotropy effect on the paleointensity results obtained from various archaeological materials, excluding pottery. Earth Planet. Space, 61, 711-732.

Le Goff, M., Gallet, Y., 2004. A new three-axis vibrating sample magnetometer for continuous high-temperature magnetization measurements: applications to paleo- and archeo-intensity determinations. Earth Planet. Sci. Lett., 229, 31-43. doi: 10.1016/j.eps1.2004.10.025 
McIntosh, G., Kovacheva, M., Catanzariti, G., Osete, M.L., Casas, L., 2007. Widespread occurence of a novel high coercivity, thermally stable, low unblocking temperature magnetic phase in heated archeological material. Geophys. Res. Lett., 34, L21302. doi: 10.1029/2007GL031168

Nagata, T., Arai, Y., Momose, K., 1963. Secular variation of the geomagnetic total force during the last 5000 years. J. Geophys. Res., 68, 5277-5281.

Olson, P., 2002. The disappearing dipole. Nature, 416, 591-594. doi: 10.1038/416591a

Riisager, P., Riisager, J., 2001. Detecting multidomain magnetic grains in Thellier paleointensity experiments. Phys. Earth planet. Inter., 125, 111-117. doi: 10.1016/S0031-9201(01)00236-9

Salazar, J.M., 1998. Araçoiaba e Ipanema: A história daquela maravilhosa região, desde as forjas de Afonso Sardinha até a Real Fábrica de Ferro. Sorocaba: Gráfica e Editora Digipel.

Thellier, E., Thellier, O., 1959. Sur l'intensité du champ magnetiqué terrestre dans le passé historique et géologique. Ann. Geophys., 15, 285-376.

Valet, J.P., Herrero-Bervera, E., Le Mouël, J.L., Plenier, G., 2008. Secular variation of the geomagnetic dipole during the past 2000 years. Geochem. Geophys. Geosyst., 9, 1, Q01008. doi: 10.1029/2007GC001728

Veitch, R., Hedley, I., Wagner, J.J., 1984. An investigation of the intensity of the geomagnetic field during Roman times using magnetically anisotropic bricks and tiles, Arch. Sci., 37, 359-373.

Yang, S., Odah, H., Shaw, J., 2000. Variations in the geomagnetic dipole moment over the last 12000 years, Geophys. J. Int., 140, 158-162. doi: 10.1046/j.1365-246x.2000.00011.x

Yu, Y., Tauxe, L., Genevey, A., 2004. Toward an optimal geomagnetic field intensity determination technique. Geochem. Geophys. Geosyst., 5, 2, Q02H07. doi: 10.1029/2003GC000630 


\section{Figure captions}

Figure 1: (a) Location map of the different cities in Southeast Brazil where the baked clay fragments that composed our collection were collected. (b) Foundation wall of the "Fazenda Lageado" House in which bricks were sampled using a portable driller (site FL $1+3+4+5$, each number referring to a different wall of the house's basement). (c) Front facade of Church "Igreja de São Lourenço dos Índios" where brick fragments of its initial construction phase were collected (site SLI).

Figure 2: Rock magnetic measurements carried out for three representative fragments: (a-c) hysteresis loops and (d-f) IRM acquisition curves.

Figure 3: Low-field magnetic susceptibility curves measured during heating-cooling cycles for six representative fragments retained for archeointensity determinations. Susceptibilities values are dimensionless.

Figure 4: Archeointensity determinations using the TT-ZI protocol. (a, c, e) Three representative examples of Arai diagrams; (b, d, f) Corresponding thermal demagnetization diagrams. In Arai diagrams, the circles represent the remaining NRM versus gained TRM and the triangles show the pTRM-checks performed every two temperature steps. Intensity values were computed from the linear fit displayed on the diagrams. In the thermal demagnetization diagrams, the solid (resp. open) symbols indicate the vector end points projected onto the horizontal (resp. vertical) plane (arbitrary specimen coordinate system).

Figure 5: TRM anisotropy and cooling rate effects. (a) Histogram of the TRM anisotropy degrees measured for the specimens retained in this study and comparison with the degrees previously 
obtained from a collection of brick fragments collected in Northeast Brazil (city of Salvador, State of Bahia, Hartmann et al., 2010). (b) Histogram of TRM overestimates obtained for the fragments analyzed in the present study considering a slow cooling time of $\sim 25 \mathrm{~h}$.

Figure 6: Archeointensity results obtained using the Triaxe protocol. Each curve from each panel displays the $R^{\prime}\left(T_{i}\right)$ data obtained from one specimen (see text for further explanations).

Figure 7: Comparison between our TT-ZI and Triaxe results obtained from Southeast and Northeast Brazil. Intensity means were computed from at least two fragments successfully analyzed per protocol. For the TT-ZI protocol, the mean values were computed after anisotropy and cooling rate corrections $(\sim 25 \mathrm{~h})$. (a) Means computed at the fragment level; the dashed lines delineate the $5 \%$ and $9 \%$ of agreement. (b) Means computed at the site level; the dashed lines delineate the $5 \%$ of agreement.

Figure 8: Geomagnetic field intensity variations in the Southeast Brazil over the past five centuries as deduced from our new archeointensity data reported in this study. Results are compared with the intensities expected from the available historical and archeomagnetic field models (black: Jackson et al., 2000; magenta: Gubbins et al., 2006; blue: Finlay, 2008; green and red: Korte et al., 2009). All archeointensity results and geomagnetic field predictions were computed to the latitude of the city of São Paulo $\left(23.5^{\circ} \mathrm{S}, 46.6^{\circ} \mathrm{W}\right)$.

Figure 9: Comparison between archeointensity and direct measurements and geomagnetic field models over the past five centuries. Data are from the two regions in Brazil: Southeast (blue squares), Northeast (orange circles), intensity direct measurements from the Vassouras Observatory (gray triangles, VSS: $22.4^{\circ} \mathrm{S}, 43.7^{\circ} \mathrm{W}$, city of Vassouras, State of Rio de Janeiro); France: data obtained from Genevey et al. (2009) (green triangles); geomagnetic field models (black: Jackson et 
al., 2000; magenta: Gubbins et al., 2006; blue: Finlay, 2008; green and red: Korte et al., 2009). (a) Comparison between archeointensity data obtained from the two regions in Brazil and direct measurements from VSS (all archeointensity results and geomagnetic field predictions were computed to the latitude of the city of São Paulo, i.e. $23.5^{\circ} \mathrm{S}, 46.6^{\circ} \mathrm{W}$ ). (b) Comparison between different evolutions in $g_{1}^{0}$ from the geomagnetic models and the $g_{1}^{0}$ values computed from the three archeointensity datasets considering the geomagnetic field geometry proposed by Jackson et al. (2000). See text for more details. 


\section{Table captions}

Table 1: Archeointensity results obtained from fragments sampled in the Southeast Brazil.

$\mathrm{N}$ fragment (resp. $\mathrm{n}$ specimen), indicates the number of fragments (resp. specimens) retained for computing at the site level an intensity mean versus the number of studied fragments (resp. specimens); Fmean $\pm \sigma \mathrm{F}(\mu \mathrm{T})$, mean computed at the site level with its standard deviation in $\mu \mathrm{T}$; Fmean in São Paulo $(\mu \mathrm{T})$, mean intensity reduced to the latitude of the city of São Paulo $\left(23.5^{\circ} \mathrm{S}\right)$. A short description of each analyzed site and the geographical location (whose identification label is given in the column "Site and geographical location") are further given including archeological elements and dating method(s) used to constrain the age ("Historic" for historical and "Arch." for archeological constraints). 


\section{Supplementary material}

Table 1: Selection criteria considered for our archeointensity determinations using the TT-ZI and/or the Triaxe protocols.

Table 2: Arheointensity results obtained using the TT-ZI protocol.

$\mathrm{n}$ : number of temperature steps used for intensity computations; Tmin-Tmax: temperature interval (in ${ }^{\circ} \mathrm{C}$ ) along which the slope was computed in the Arai diagram; f: NRM fraction involved in the computation; g and q: gap and quality factors as defined by Coe et al. (1978); F uncorrected: raw intensity value per specimen in $\mu \mathrm{T}$; SE: standard error on $\mathrm{F}$ in $\mu \mathrm{T}$; $\mathrm{F}$ anisotropy corrected: intensity value per specimen after anisotropy correction in $\mu \mathrm{T}$; Fmean corrected for anisotropy and cooling rate effects: mean intensity value computed at the fragment level after correction for TRM anisotropy and cooling rate effects in $\mu \mathrm{T}$; SD: standard deviation on the intensity value computed at the fragment level in $\mu \mathrm{T} ;(*)$ : indicates the ratio between the number of retained fragments (and specimens) and the number of studied fragments (and specimens). Note that intensity experiments were carried out with a laboratory field of $35 \mu \mathrm{T}$.

Table 3: Archeointensity results obtained using the Triaxe protocol.

Tmin-Tmax: temperature interval (in ${ }^{\circ} \mathrm{C}$ ) used for intensity determination; Hlab: laboratory field in $\mu \mathrm{T}$; NRM T1 (\%): NRM fraction involved from T1 in the computation; Slope $R$ '(\%): slope of the $R^{\prime}\left(T_{i}\right)$ data along the temperature interval used for the intensity determination expressed as a percentage (as defined by Le Goff and Gallet, 2004); F Triaxe: intensity value obtained per specimen in $\mu \mathrm{T}$; Fmean: mean intensity value computed at the fragment level in $\mu \mathrm{T}$; SD: standard deviation of the mean computed at the fragment level in $\mu \mathrm{T} ;(*)$ : indicates the ratio between the number of retained fragments (and specimens) and the number of studied fragments (and specimens). 
Figure 1: TRM anisotropy and cooling rate effects. (a) Histogram of the differences, in percentage, between twin intensity values obtained at the fragment level before and after TRM anisotropy correction. The dispersion is clearly reduced after the TRM anisotropy correction with difference for all fragments less than $5 \%$, indicating that the intensity values were efficiently corrected from this effect. (b) Comparisons of the mean intensity values obtained per group of fragments before and after cooling rate correction. Three slow cooling times of $5 \mathrm{~h}, 10 \mathrm{~h}$ and $25 \mathrm{~h}$ were successively applied. 
a)

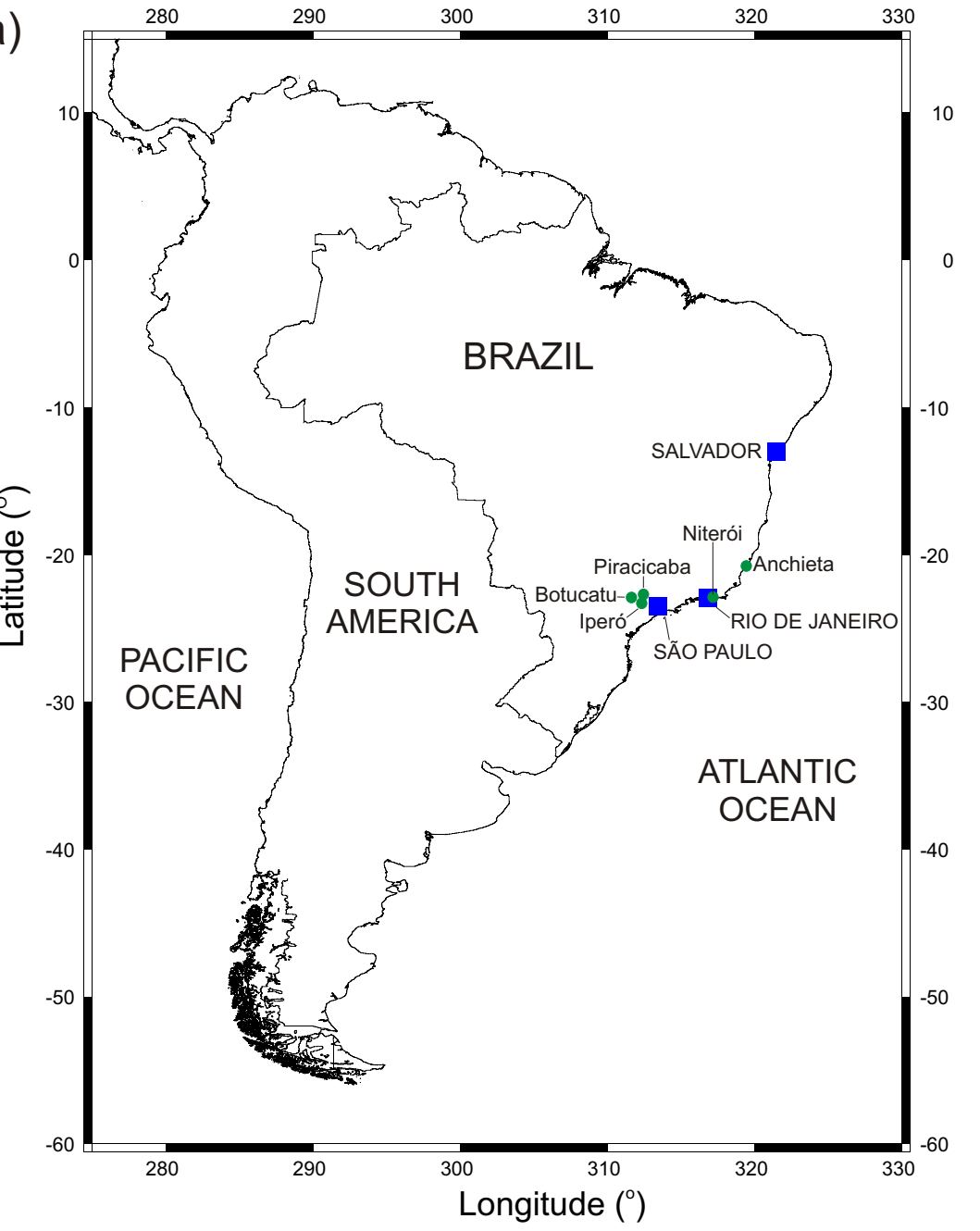

b)

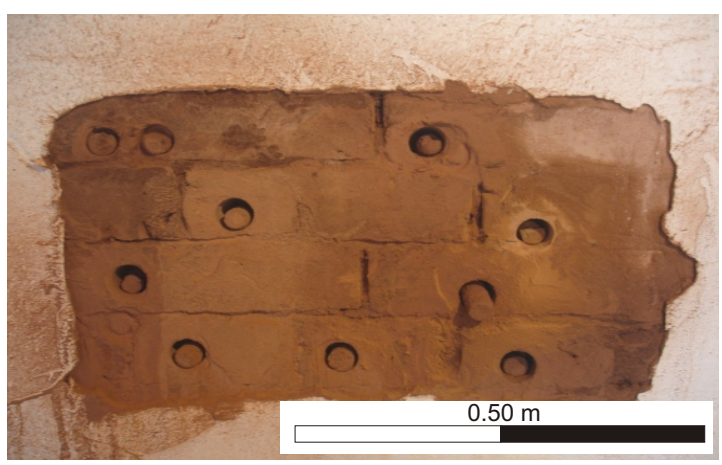

c)

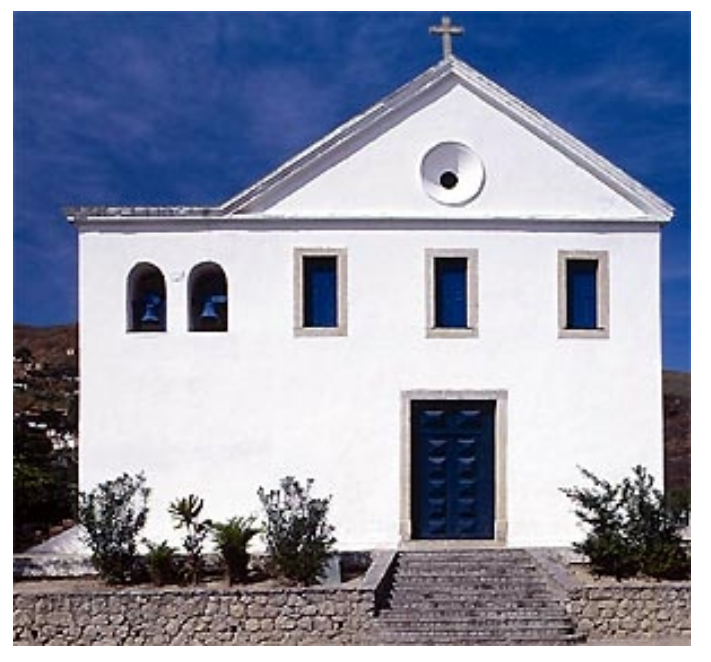

Figure 1 
a)

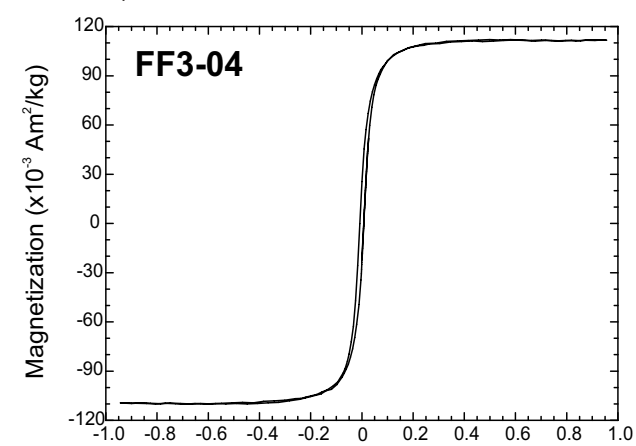

d)

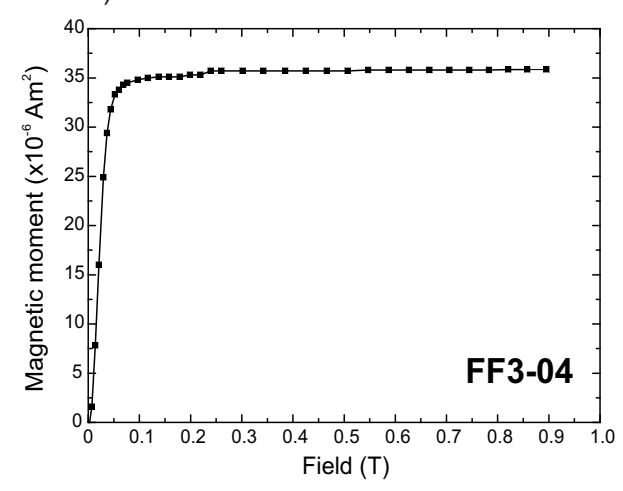

b)

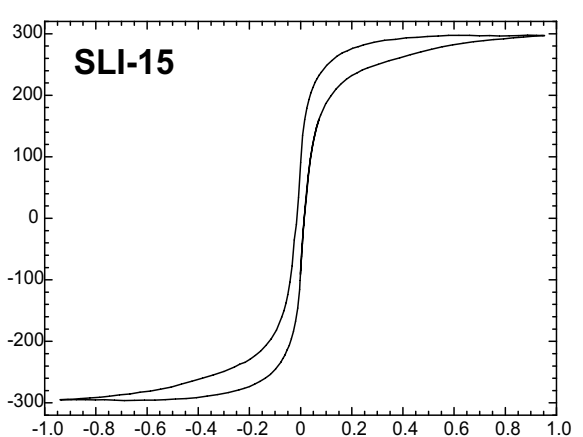

e)

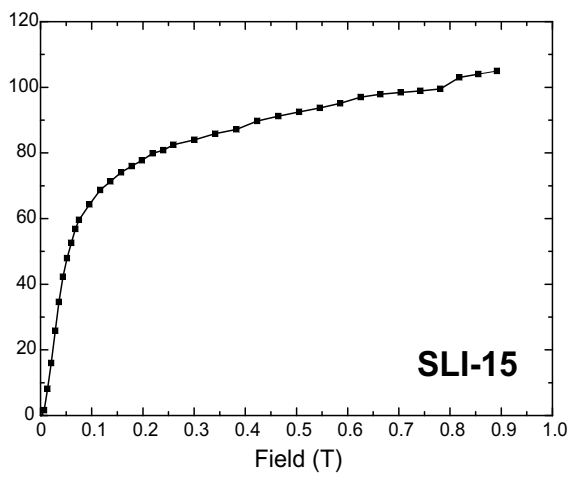

c)

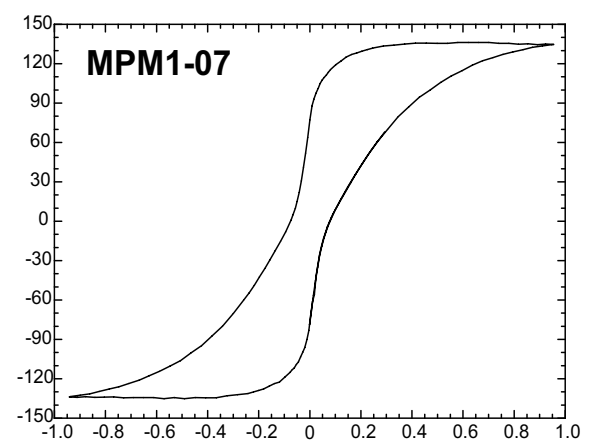

f)

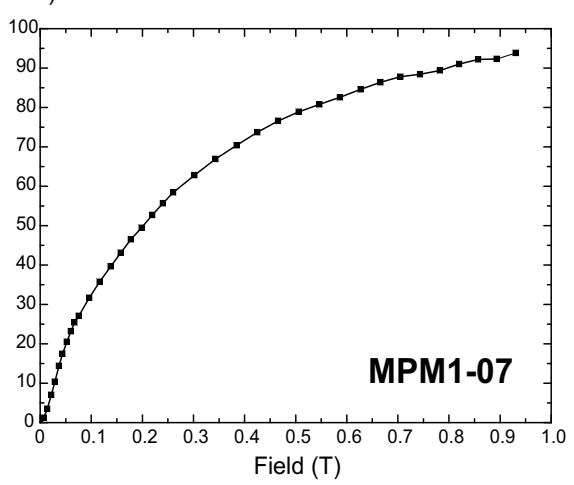

Figure 2 
a)

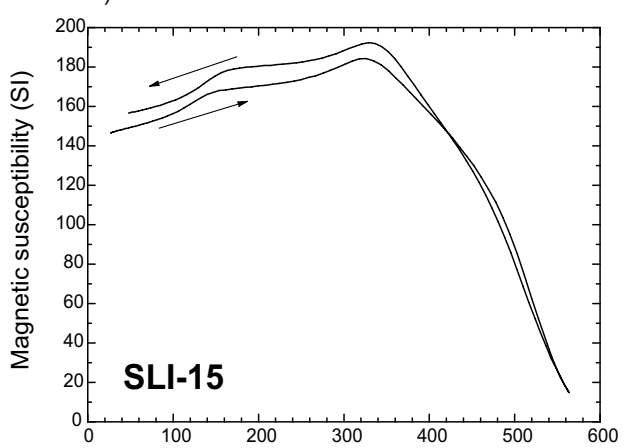

d)

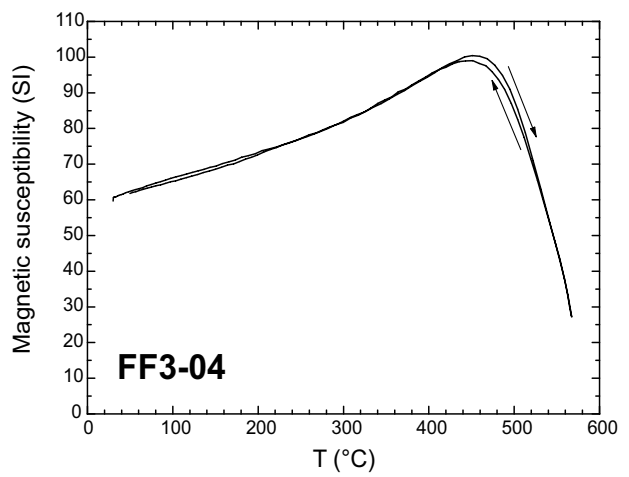

b)

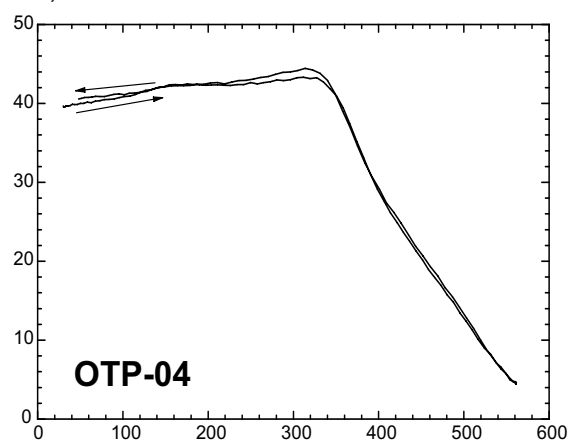

e)

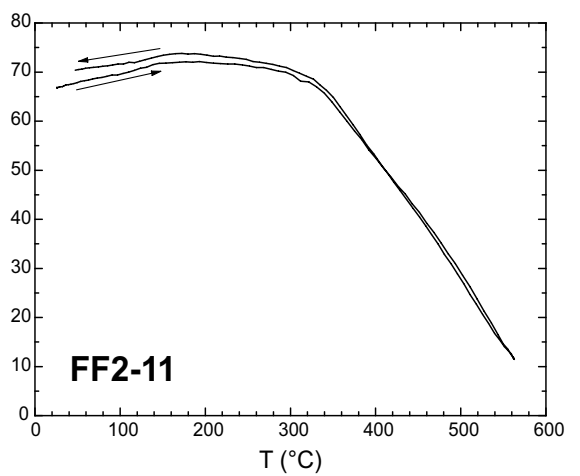

c)
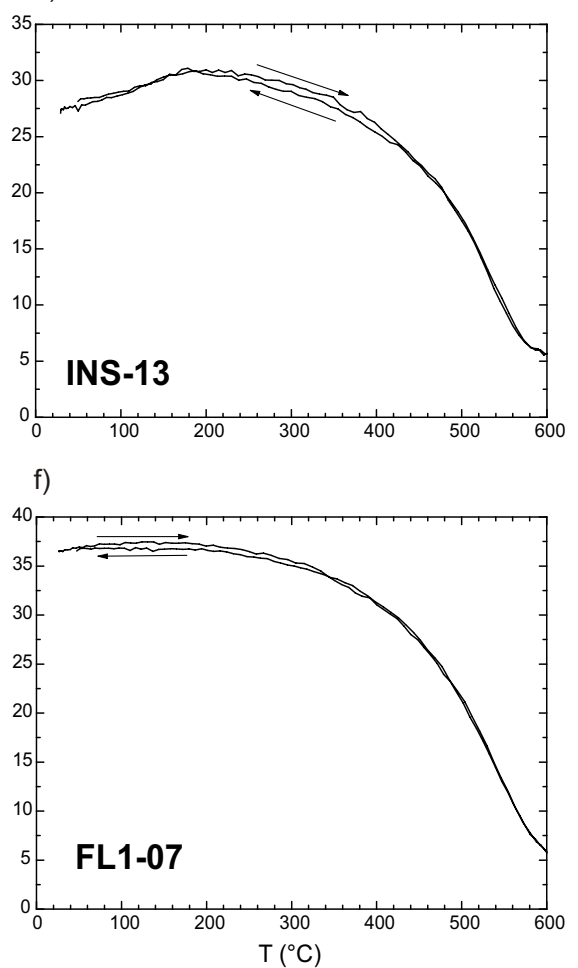

Figure 3 

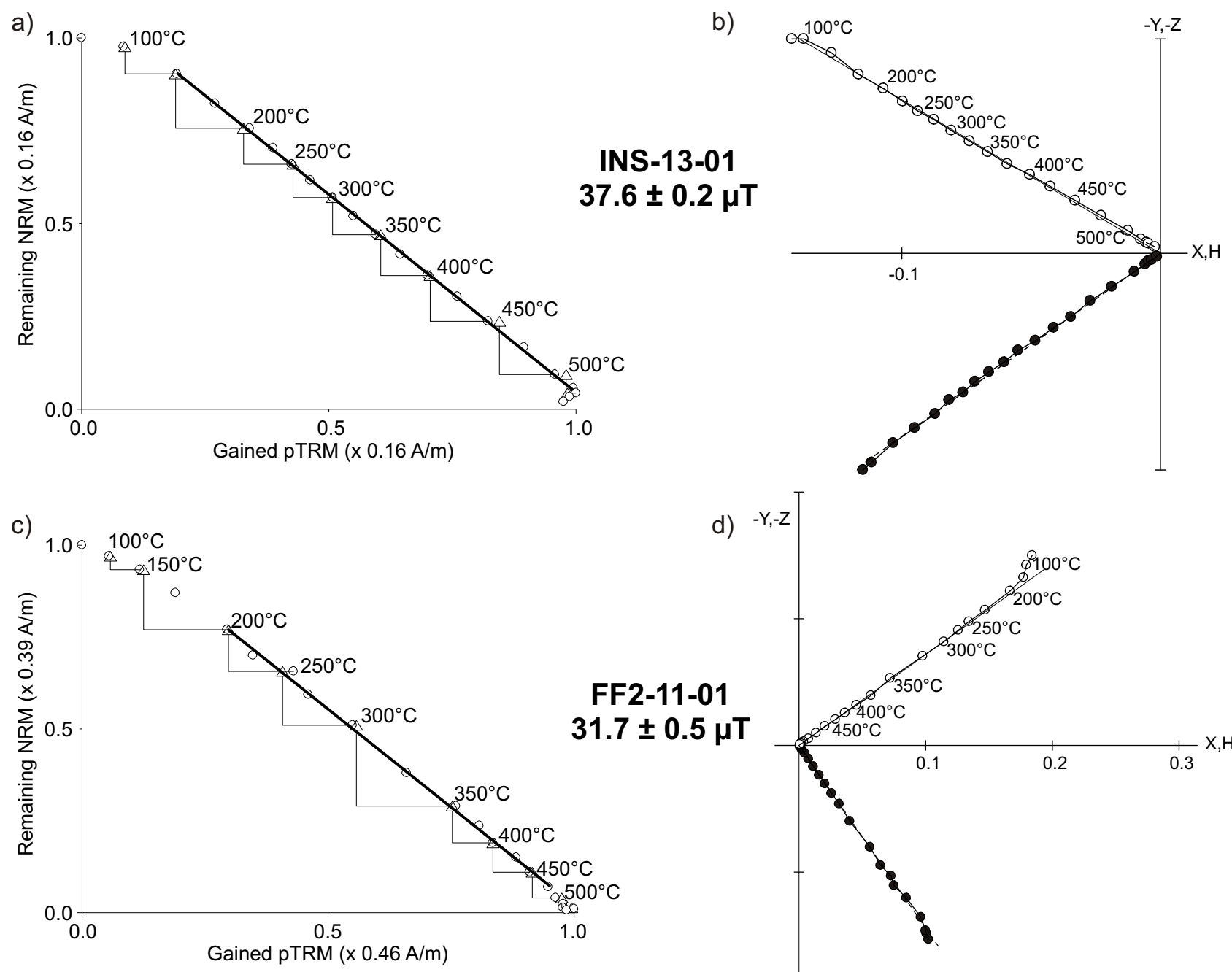

d) $-Y,-Z$

F2-11-01
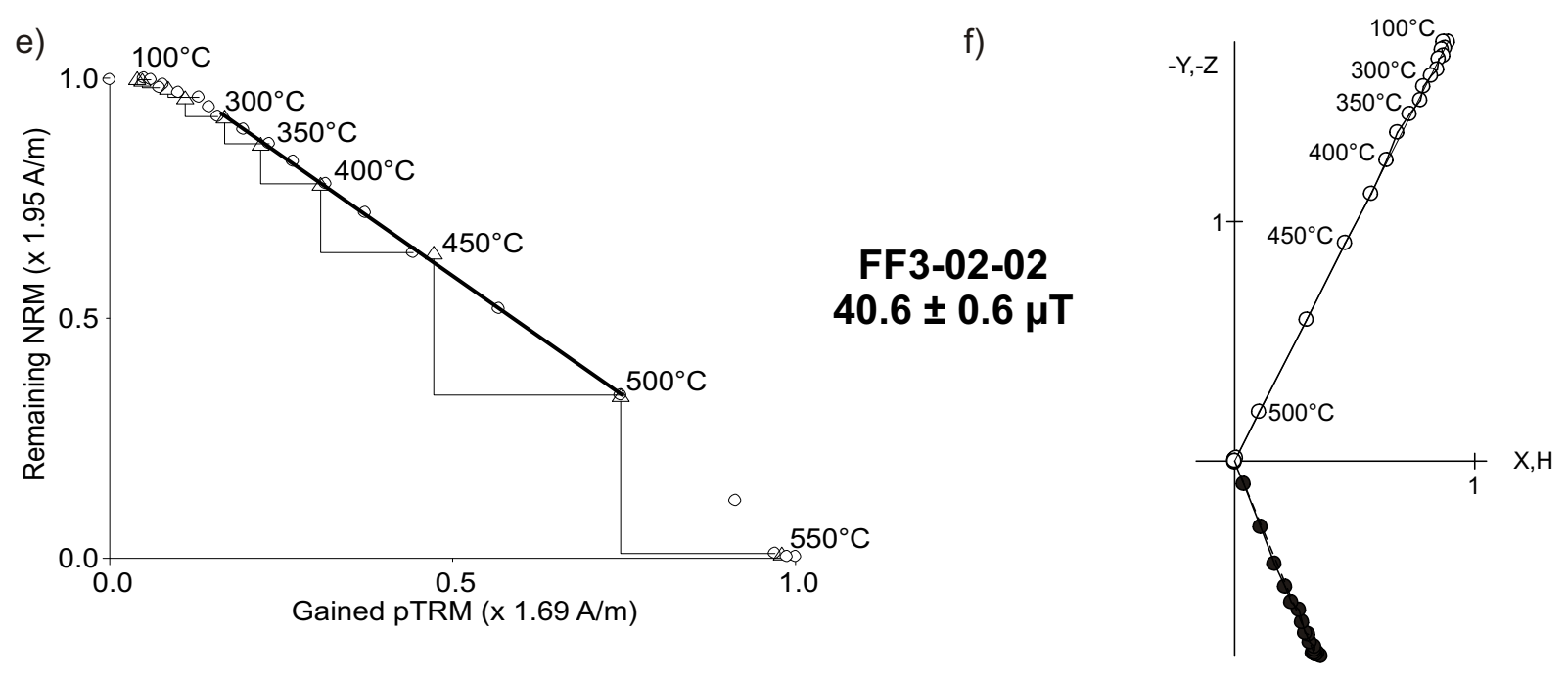

Figure 4 

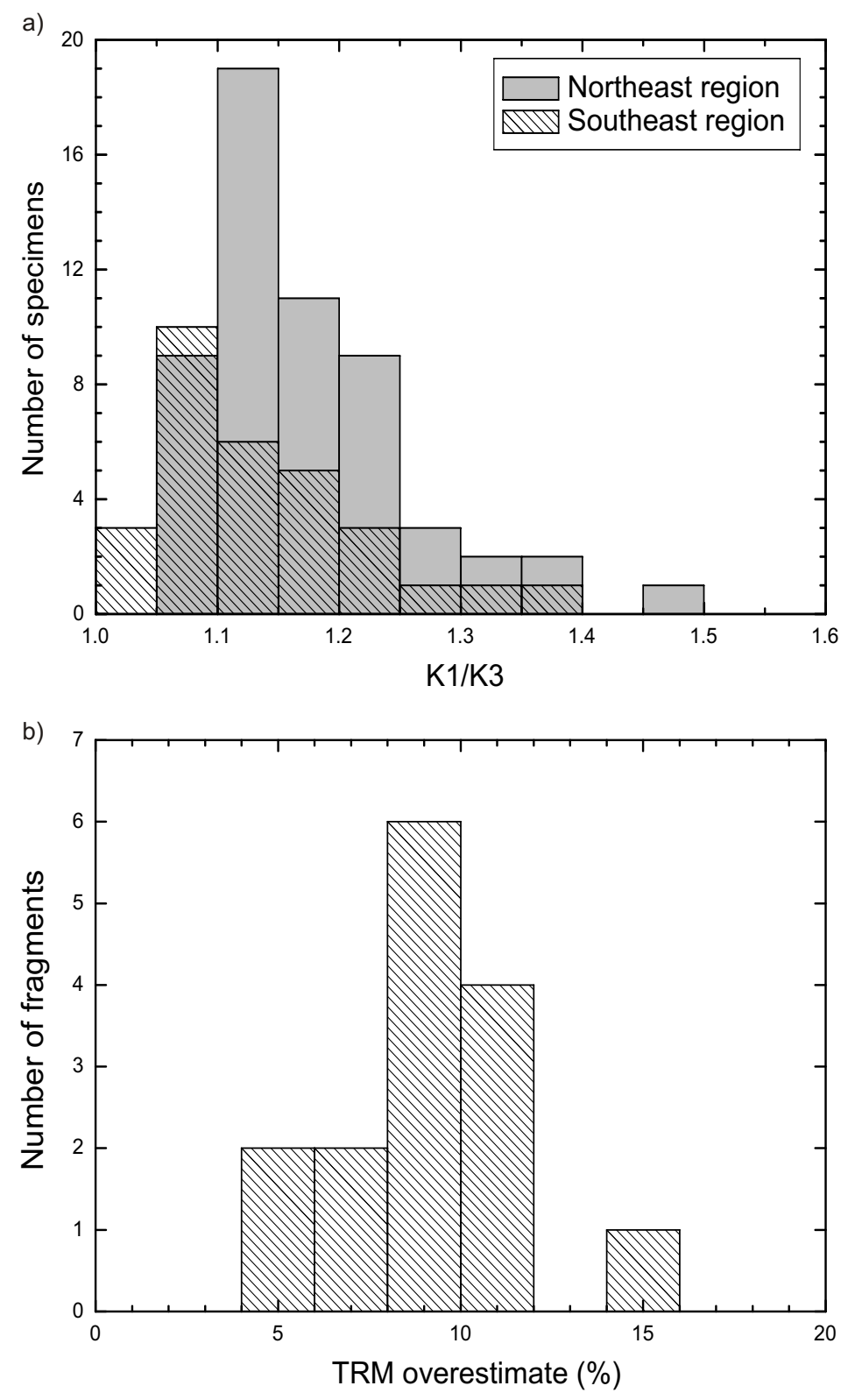

Figure 5 
a)

\begin{tabular}{|c|c|c|c|}
\hline -SLI-10-01 & —SLI-10-02 & SLI-10-03 & SLI-10-06 \\
\hline -SLI-11-01 & —SLI-11-02 & —SLI-11-03 & SLI-11-04 \\
\hline -SLI-12-01 & —SLI-12-02 & —SLI-12-03 & -SLI-12-04 \\
\hline -SLI-15-01 & —SLI-15-02 & -SLI-15-03 & -SLI-15-04 \\
\hline - SLI-16-01 & -SLI-16-02 & -SLI-16-03 & -SLI-16-04 \\
\hline
\end{tabular}

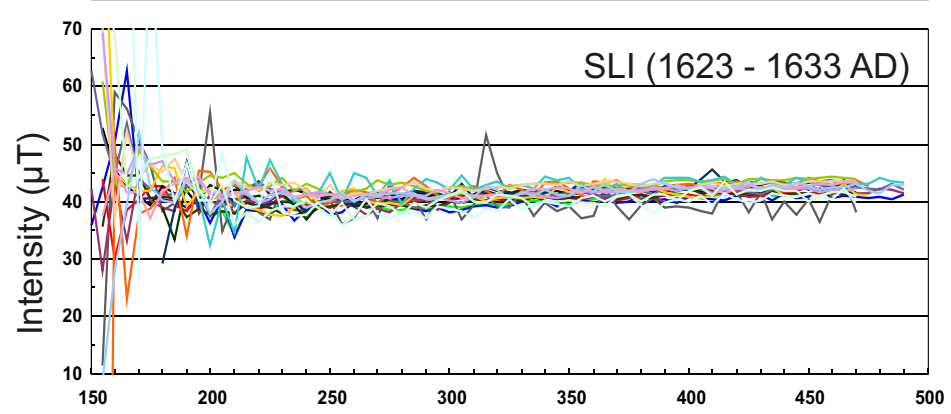

c)
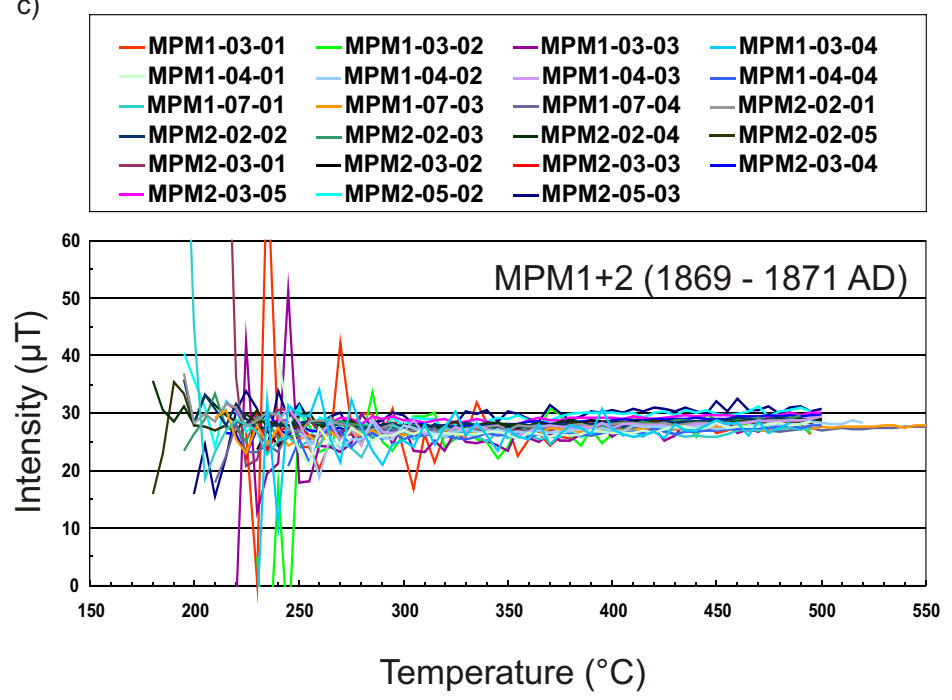

b)

\begin{tabular}{|rrrr|}
\hline - OTP-01-01 & - OTP-01-02 & - OTP-01-04 & - OTP-01-05 \\
- OTP-03-01 & OTP-04-01 & OTP-04-03 & - OTP-04-04 \\
- OTP-04-05 & - OTP-04-06 & - OTP-05-01 & - OTP-05-02 \\
- OTP-13-01 & - OTP-13-03 & - OTP-13-04 & \\
\hline
\end{tabular}

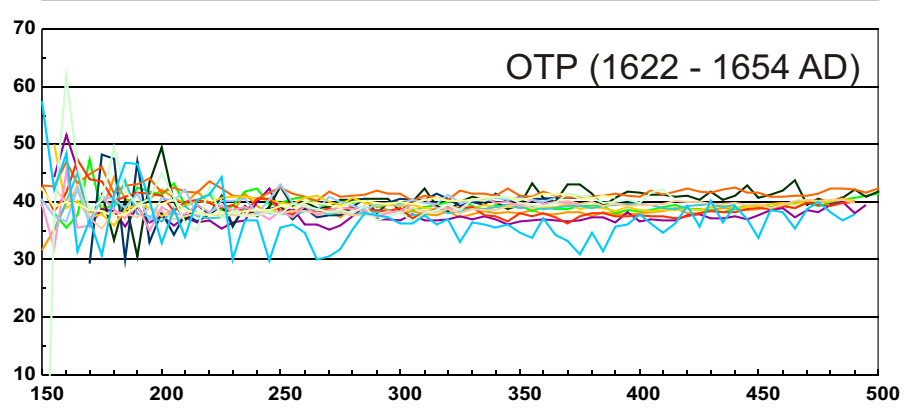

d)
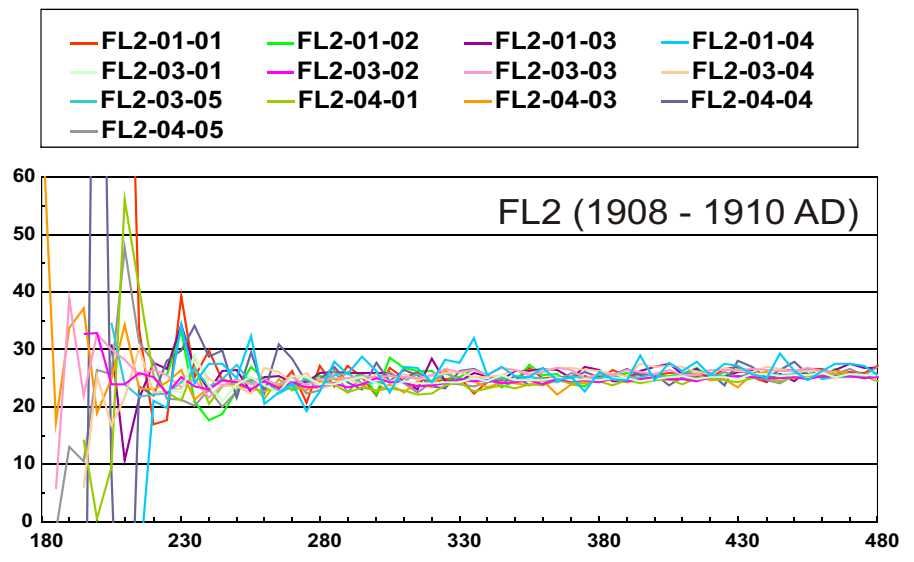

Temperature $\left({ }^{\circ} \mathrm{C}\right)$ 

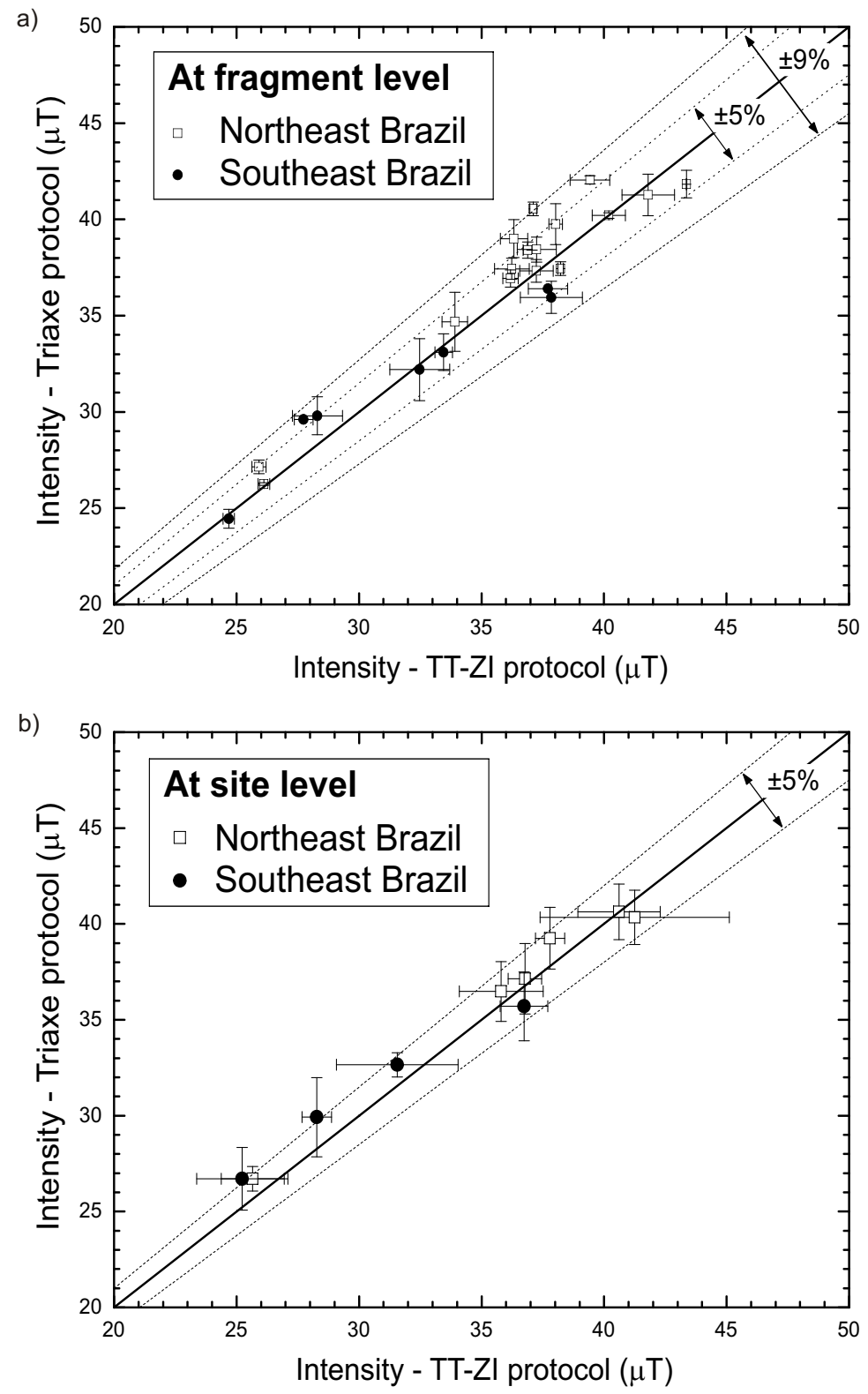

Figure 7 


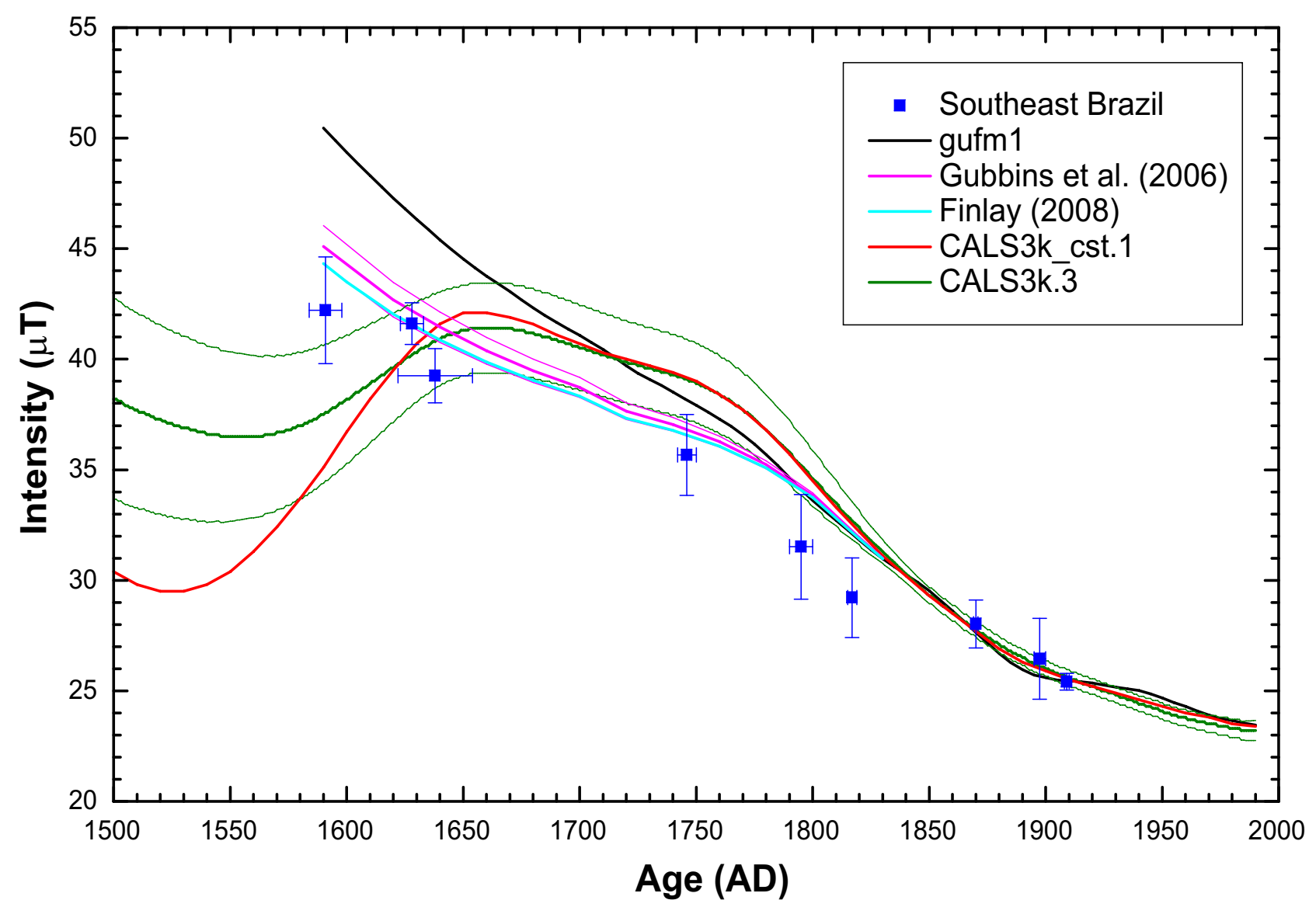

Figure 8 
a)

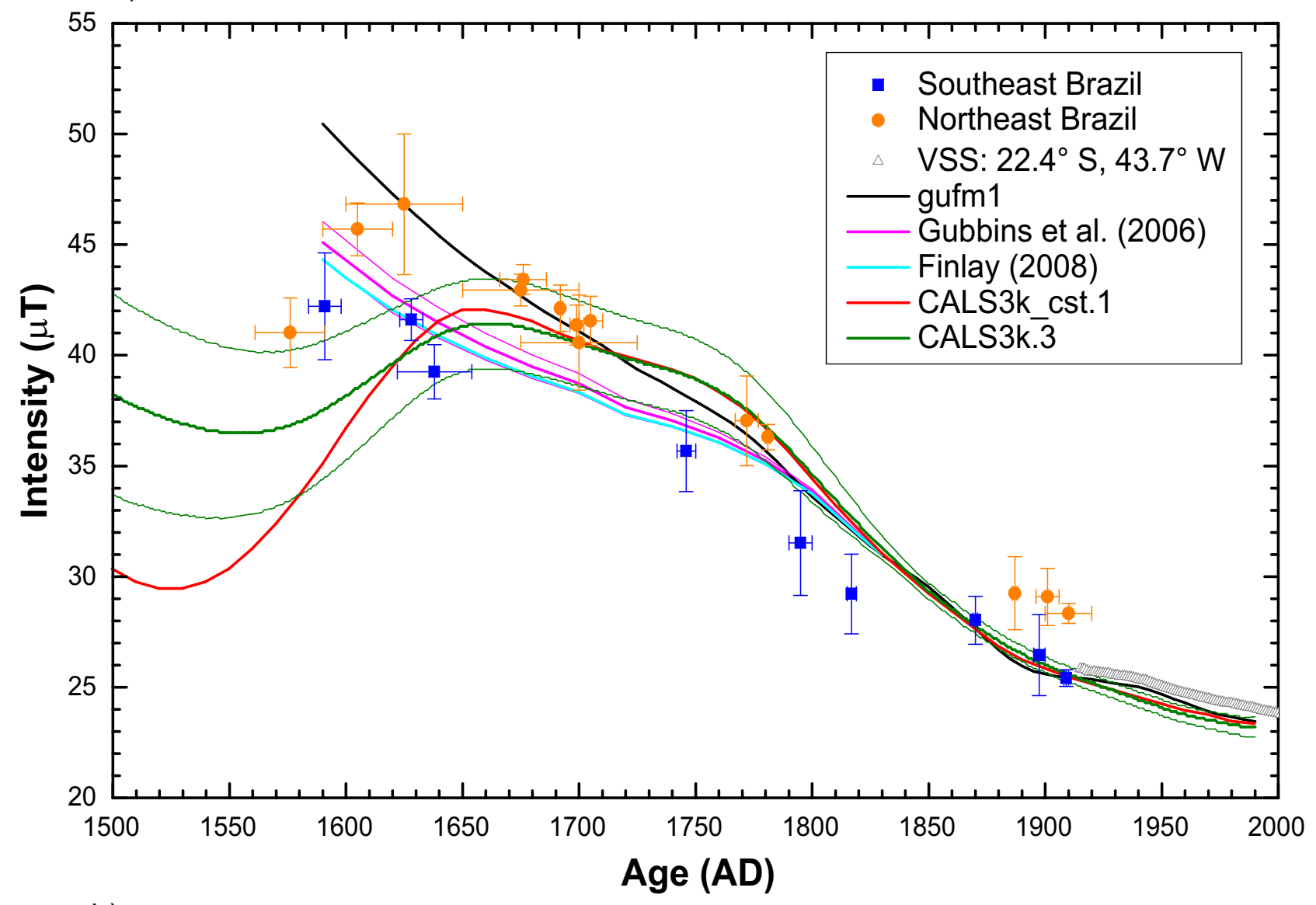

b)

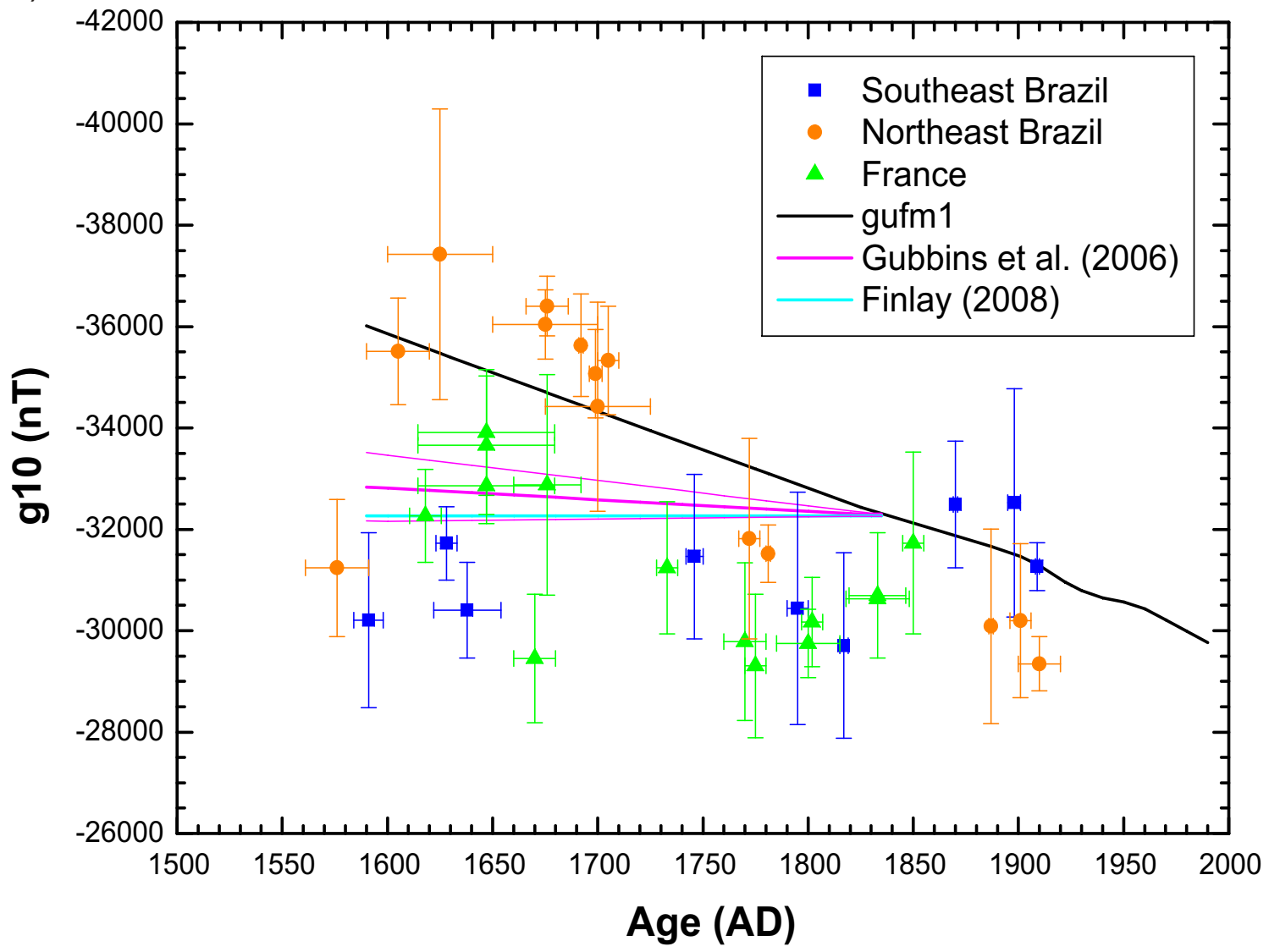

Figure 9 


\section{Table 1}

\begin{tabular}{|c|c|c|c|c|c|c|c|c|c|}
\hline \multirow{2}{*}{$\begin{array}{c}\text { Site and geographical } \\
\text { location }\end{array}$} & \multirow{2}{*}{ Site description } & \multicolumn{2}{|c|}{ Dating method } & \multirow{2}{*}{$\begin{array}{l}\text { Age interval } \\
\text { (AD) }\end{array}$} & \multirow{2}{*}{$\begin{array}{l}\text { Intensity } \\
\text { methods }\end{array}$} & \multirow{2}{*}{$\begin{array}{c}\mathrm{N} \\
\text { Fragment }\end{array}$} & \multirow{2}{*}{$\begin{array}{c}\mathbf{n} \\
\text { Specimen }\end{array}$} & \multirow{2}{*}{$\begin{array}{c}\text { Fmean } \pm \sigma F \\
(\mu T)\end{array}$} & \multirow{2}{*}{$\begin{array}{c}\text { Fmean in } \\
\text { São Paulo } \\
\quad(\boldsymbol{\mu T})\end{array}$} \\
\hline & & Historic & Arch & & & & & & \\
\hline $\begin{array}{l}\text { Igreja de Nossa Senhora } \\
\text { da Assunção (INSA) } \\
\text { City: Anchieta } \\
\left(20.8^{\circ} \mathrm{S}, 40.6^{\circ} \mathrm{W}\right)\end{array}$ & $\begin{array}{l}\text { The Church of Nossa Senhora da Assunção was } \\
\text { built by the Jesuits at the end of XVIth century. } \\
\text { Its construction was mainly done under the } \\
\text { responsibility of Priest José de Anchieta who } \\
\text { died shortly before its inauguration. This is the } \\
\text { only site from the Espírito Santo state. }\end{array}$ & $\mathrm{X}$ & $X$ & $1584-1598$ & Triaxe & $3 / 6$ & $12 / 24$ & $40.8 \pm 2.4$ & 42.2 \\
\hline $\begin{array}{l}\text { Igreja de São Lourenço } \\
\text { dos Î́ndios (SLI) } \\
\text { City: Niterói } \\
\left(22.9^{\circ} \mathrm{S}, 43.1^{\circ} \mathrm{W}\right)\end{array}$ & $\begin{array}{l}\text { The Church of São Lourenço do Índios was built } \\
\text { by the Jesuits during the second quarter of the } \\
\text { XVIIth century. Its architectural style is } \\
\text { characteristic of the Jesuits churches. }\end{array}$ & $X$ & $\mathrm{X}$ & $1623-1633$ & Triaxe & $5 / 9$ & $20 / 26$ & $41.3 \pm 0.9$ & 41.6 \\
\hline $\begin{array}{l}\text { Igreja da Venerável } \\
\text { Ordem Terceira de São } \\
\text { Francisco da Penitência } \\
\text { (OTP) } \\
\text { City: Rio de Janeiro } \\
\left(22.9^{\circ} \mathrm{S}, 43.2^{\circ} \mathrm{W}\right)\end{array}$ & $\begin{array}{l}\text { The Church of Venerável Ordem Terceira de São } \\
\text { Francisco da Penitência was built by the } \\
\text { "fraternity of the Third Order" during the second } \\
\text { quarter of the XVIIth century. This is still one of } \\
\text { the most important churches of Rio de Janeiro. }\end{array}$ & $\mathrm{X}$ & $\mathrm{X}$ & $1622-1654$ & $\begin{array}{l}\text { TT-ZI and } \\
\text { Triaxe }\end{array}$ & $5 / 14$ & $17 / 51$ & $39.0 \pm 1.2$ & 39.3 \\
\hline $\begin{array}{l}\text { Igreja de Nossa Senhora } \\
\text { da Saúde (INS) } \\
\text { City: Rio de Janeiro } \\
\left(22.9^{\circ} \mathrm{S}, 43.2^{\circ} \mathrm{W}\right)\end{array}$ & $\begin{array}{l}\text { The Church of Nossa Senhora da Saúde was built } \\
\text { at the middle of XVIIIth century in the ancient } \\
\text { farm of Manuel da Costa Negreiros. At that time } \\
\text { it was common to construct churches with farms } \\
\text { thus distant from the city center. Now, this farm } \\
\text { is located in the so called Morro da Saúde area. }\end{array}$ & $X$ & $\mathrm{X}$ & $1742-1750$ & $\begin{array}{l}\text { TT-ZI and } \\
\text { Triaxe }\end{array}$ & $4 / 9$ & $15 / 28$ & $35.4 \pm 1.8$ & 35.7 \\
\hline $\begin{array}{l}\text { Real Fábrica de Ferro } \\
\text { Ipanema } 3 \text { (FF3) } \\
\text { City: Iperó } \\
\left(23.3^{\circ} \mathrm{S}, 47.7^{\circ} \mathrm{W}\right)\end{array}$ & $\begin{array}{l}\text { The Ipanema farm is a large complex located in } \\
\text { the Ipanema forest and composed of several } \\
\text { buildings constructed along the activity period of } \\
\text { extraction and production of iron, between the } \\
\text { end of the XVIth century and the XIXth century. } \\
\text { The FF3 group was sampled in one oven in use } \\
\text { for melting iron at the very end of the XVIIIth } \\
\text { century. }\end{array}$ & $\mathrm{X}$ & & $1790-1800$ & $\begin{array}{l}\text { TT-ZI and } \\
\text { Triaxe }\end{array}$ & $3 / 6$ & $12 / 21$ & $31.4 \pm 2.4$ & 31.5 \\
\hline
\end{tabular}


Real Fábrica de Ferro Ipanema 2 (FF2)

City: Iperó

$\left(23.3^{\circ} \mathrm{S}, 47.7^{\circ} \mathrm{W}\right)$

Museu Prudente de

Moraes 1 and 2

(MPM1+2)

City: Piracicaba

$\left(22.7^{\circ} \mathrm{S}, 47.6^{\circ} \mathrm{W}\right)$

Real Fábrica de Ferro Ipanema 4 (FF4)

City: Iperó

$\left(23.3^{\circ} \mathrm{S}, 47.7^{\circ} \mathrm{W}\right)$

Real Fábrica de Ferro Ipanema Y (FFY)

City: Iperó

$\left(23.3^{\circ} \mathrm{S}, 47.7^{\circ} \mathrm{W}\right)$

Fazenda Lageado 1, 3, 4 and $5(\mathrm{FL} 1+3+4+5)$

City: Botucatu

$\left(22.9^{\circ} \mathrm{S}, 48.4^{\circ} \mathrm{W}\right)$

Fazenda Lageado 2 (FL2)

City: Botucatu

$\left(22.9^{\circ} \mathrm{S}, 48.4^{\circ} \mathrm{W}\right)$
The FF2 group was sampled from an oven used for melting iron during the first quarter of the XIXth century. It is part of the Ipanema farm more specifically of the so called "Real Fábrica de Ferro Ipanema” which was established by royal decree and operated between 1811 AD and $1895 \mathrm{AD}$

This museum was originally the residence of the first Republic President of Brazil, Prudente de Moraes. This building which presents an imperial architectural style was built in $1870 \mathrm{AD}$ and is notably known for having housed several political meetings during the period of the Proclamation of Republic of Brazil on November 15, 1889 AD. The 1 and 2 numbers refer to two different brick walls of same age sampled in the foundations of the house.

The FF4 group was sampled from one of the last oven used for melting iron in the Ipanema farm. This oven was built to melt 7 ton of iron per day. Note that for this group was not possible to retain any archeointensity result.

The FFY group was also sampled in one of the last oven used for melting iron in the Ipanema farm. Note that for this group was not possible to retain any archeointensity result.

The Fazenda Lageado was an important farm for production and exportation of coffee. Today, this farm housed the Coffee Museum of the State University Júlio de Mesquita Filho. The FL group was sampled in different brick walls (numerated as 1, 3, 4 and 5) of the main house.

The FL2 group is from Fazenda Lageado farm and was sampled from a paved zone made of bricks where coffee was left to dry in the sun (yard of coffee). The precise dating is asserted by many historical archives. 


\begin{tabular}{|c|c|}
\hline \multicolumn{2}{|c|}{ Selection criteria for archeointensity determinations } \\
\hline $\begin{array}{l}\text { 1. Orthogonal demagnetization } \\
\text { diagrams (TT-ZI and Triaxe } \\
\text { protocols) }\end{array}$ & - Well defined direction of the primary magnetic component. \\
\hline 2. Arai diagram (TT-ZI protocol) & $\begin{array}{l}\text { - Intensity value determined through the same temperature } \\
\text { interval for which the main magnetic component was } \\
\text { isolated in the orthogonal thermal diagram. } \\
\text { - At least } 5 \text { temperature steps and } 40 \% \text { of the total NRM } \\
\text { involved for slope computation. } \\
\text { - Magnetic stability: cutoff value of } 5 \% \text { for difference } \\
\text { between pTRM and pTRM-checks normalized either by } \\
\text { the length of the hypotenuse of the NRM/pTRM data used } \\
\text { in the in slope computation or by the total TRM intensity. } \\
\text { Additional cutoff value of } 10 \% \text { for the cumulative error } \\
\text { checks as defined by Leonhardt et al. (2003). } \\
\text { - } 5 \% \text { limit applied for the pTRM-tail checks. }\end{array}$ \\
\hline $\begin{array}{l}\text { 3. Cooling rate experiments (TT- } \\
\text { ZI protocol) }\end{array}$ & $\begin{array}{l}\text { - Magnetic alteration during the cooling rate procedure must } \\
\text { be limited, less than } 5 \% \text {. }\end{array}$ \\
\hline $\begin{array}{l}\text { 4. " } R^{\prime}\left(T_{i}\right) \text { data" versus } \\
\text { "Temperature" diagram (Triaxe } \\
\text { protocol) }\end{array}$ & $\begin{array}{l}\text { - } R^{\prime}\left(T_{i}\right) \text { values must be nearly constant from } T_{1} \text { to } T_{2} \text { with a } \\
10 \% \text { cutoff value considered for the slope of } R^{\prime}\left(T_{i}\right) \text { values } \\
\text { fitted with a linear trend. } \\
\text { - At least } 50 \% \text { of the magnetization fraction with unblocking } \\
\text { temperature higher than } T_{1} \text { used for the intensity } \\
\text { computation. }\end{array}$ \\
\hline $\begin{array}{l}\text { 5. Coherence of the intensity } \\
\text { results obtained at the fragment } \\
\text { level (TT-ZI and Triaxe } \\
\text { protocols) }\end{array}$ & $\begin{array}{l}\text { - Intensity mean value computed at the fragment level from } \\
\text { at least two specimens with a difference of less than } 5 \% \text {. }\end{array}$ \\
\hline $\begin{array}{l}\text { 6. For each dated group (TT-ZI } \\
\text { and Triaxe protocols) }\end{array}$ & $\begin{array}{l}\text { - Mean intensity computed from at least } 3 \text { mean values } \\
\text { obtained at the fragment level with TT-ZI or/and Triaxe } \\
\text { protocols. } \\
\text { - Standard deviation around the mean less than } 10 \% \text { of its } \\
\text { value (note that the maximum percentage of error observed } \\
\text { in this study was of } 7.6 \% \text { for the FF3 site). }\end{array}$ \\
\hline
\end{tabular}




\section{Tmin Tmax}

$\left({ }^{\circ} \mathrm{C}\right) \quad\left({ }^{\circ} \mathrm{C}\right)$ $(\mu \mathrm{T})$
$\mathrm{F}$ anisotropy $\mathrm{F}$
corrected $(\mu \mathrm{T})$

for anisotropy

and cooling rate

effects $(\mu T)$

OTP [1622 - 1654 AD] (fragments: 1/4; specimens: 2/8)*

$\begin{array}{lllllll}01 & 12 & 225 & 500 & 0.41 & 0.88 & 24.2 \\ 02 & 12 & 225 & 500 & 0.44 & 0.87 & 17.0\end{array}$

38.2

0.6

40.8

38.6

0.9

42.1

INS [1742 - 1750 AD] (fragments: 3/7; specimens: 6/14) *

$\begin{array}{llllllll}\text { INS-01 } & 01 & 14 & 175 & 500 & 0.64 & 0.88 & 54.0 \\ & 02 & 14 & 175 & 500 & 0.65 & 0.88 & 41.8 \\ \text { INS-04 } & 01 & 16 & 175 & 550 & 0.58 & 0.91 & 82.1 \\ & 02 & 16 & 175 & 550 & 0.57 & 0.90 & 77.4 \\ \text { INS-13 } & 01 & 16 & 150 & 525 & 0.77 & 0.93 & 146.4 \\ & 02 & 16 & 150 & 525 & 0.74 & 0.93 & 123.6\end{array}$

$\begin{array}{lll}41.7 & 0.4 & 42.1 \\ 45.1 & 0.6 & 40.2 \\ 38.7 & 0.3 & 38.7 \\ 38.7 & 0.3 & 39.9 \\ 37.6 & 0.2 & 39.4 \\ 36.4 & 0.2 & 39.3\end{array}$

FF3 [1790 - $1800 \mathrm{AD}$ ] (fragments: 3/6; specimens: 6/12) *

$\begin{array}{lcccccc}01 & 9 & 300 & 500 & 0.52 & 0.82 & 60.2 \\ 02 & 9 & 300 & 500 & 0.54 & 0.82 & 32.6 \\ 01 & 19 & 100 & 575 & 0.79 & 0.71 & 38.9 \\ 02 & 19 & 100 & 575 & 0.74 & 0.71 & 32.8 \\ 01 & 10 & 225 & 450 & 0.45 & 0.84 & 17.3 \\ 02 & 10 & 225 & 450 & 0.50 & 0.83 & 53.2\end{array}$

37.1

40.6

0.3

37.9

37.3

FF3-03

30.3

0.6

30.6

31.2

FF3-04

40.7

0.5

37.0

35.1

FF2 [1815 - 1819 AD] (fragments: 4/7; specimens: 8/14) *

$\begin{array}{lccccccc}\text { FF2-02 } & 01 & 8 & 225 & 400 & 0.45 & 0.83 & 13.6 \\ & 02 & 8 & 225 & 400 & 0.50 & 0.85 & 27.0 \\ \text { FF2-05 } & 01 & 14 & 225 & 550 & 0.42 & 0.88 & 41.3 \\ & 02 & 15 & 200 & 550 & 0.43 & 0.89 & 24.9 \\ \text { FF2-08 } & 01 & 9 & 250 & 450 & 0.44 & 0.84 & 21.8 \\ & 02 & 9 & 250 & 450 & 0.42 & 0.84 & 19.9 \\ \text { FF2-11 } & 01 & 12 & 200 & 475 & 0.64 & 0.89 & 37.5 \\ & 02 & 12 & 200 & 475 & 0.65 & 0.90 & 42.8\end{array}$

$\begin{array}{lll}31.6 & 0.9 & 31.9 \\ 30.7 & 0.5 & 31.3 \\ 30.7 & 0.3 & 30.6 \\ 27.8 & 0.4 & 29.0 \\ 29.3 & 0.5 & 30.7 \\ 32.6 & 0.6 & 32.6 \\ 31.7 & 0.5 & 30.1 \\ 29.2 & 0.4 & 29.5\end{array}$

28.2

FL1+3+4+5 [1895 - 1901 AD] (fragments: 4/4; specimens: 8/8) *

$\begin{array}{lcccccccccc}\text { FL1-03 } & 01 & 16 & 150 & 525 & 0.84 & 0.90 & 72.4 & 27.7 & 0.3 & 27.5 \\ & 02 & 15 & 150 & 500 & 0.70 & 0.90 & 54.5 & 27.5 & 0.3 & 28.6 \\ \text { FL1-06 } & 01 & 14 & 200 & 525 & 0.79 & 0.89 & 47.6 & 25.8 & 0.4 & 25.8 \\ & 02 & 14 & 200 & 525 & 0.78 & 0.89 & 81.4 & 24.2 & 0.2 & 26.2 \\ \text { FL1-07 } & 01 & 9 & 300 & 500 & 0.52 & 0.87 & 33.1 & 28.2 & 0.4 & 27.0 \\ & 02 & 10 & 275 & 500 & 0.59 & 0.89 & 48.0 & 30.9 & 0.3 & 27.5 \\ \text { FL4-04 } & 01 & 13 & 200 & 500 & 0.65 & 0.90 & 77.9 & 30.8 & 0.2 & 30.2 \\ & 02 & 11 & 250 & 500 & 0.59 & 0.89 & 48.1 & 32.3 & 0.4 & 31.0\end{array}$


INSA [1584 - 1598 AD] (fragments: 3/6; specimens: 12/24)*

\begin{tabular}{|c|c|c|c|c|c|c|c|}
\hline \multirow[t]{3}{*}{ INSA-02 } & 01 & 170 & 500 & 35 & 66 & -5 & 39.8 \\
\hline & 04 & 130 & 530 & 40 & 78 & 3 & 40.3 \\
\hline & 05 & 130 & 530 & 40 & 69 & 2 & 40.7 \\
\hline \multirow[t]{5}{*}{ INSA-03 } & 01 & 220 & 500 & 35 & 78 & 7 & 39.1 \\
\hline & 02 & 220 & 500 & 40 & 80 & 7 & 38.7 \\
\hline & 03 & 150 & 500 & 40 & 79 & -2 & 37.4 \\
\hline & 04 & 220 & 500 & 40 & 82 & 3 & 39.6 \\
\hline & 05 & 150 & 500 & 40 & 73 & -9 & 38.5 \\
\hline \multirow[t]{4}{*}{ INSA-06B } & 01 & 220 & 500 & 40 & 82 & 7 & 42.2 \\
\hline & 02 & 220 & 500 & 40 & 78 & 10 & 43.9 \\
\hline & 03 & 220 & 500 & 40 & 87 & 8 & 43.7 \\
\hline & 04 & 230 & 500 & 40 & 87 & 8 & 43.8 \\
\hline
\end{tabular}

40.3

0.5

38.7

0.8

43.4

0.8

43.7

43.8

SLI [1623 - 1633 AD] (fragments: 5/9; specimens: 20/26)*

$\begin{array}{lllll}\text { SLI-10 } & 01 & 150 & 500 & 40 \\ & 02 & 150 & 480 & 40 \\ \text { SLI-11 } & 03 & 160 & 480 & 40 \\ & 06 & 150 & 480 & 40 \\ & 01 & 150 & 500 & 400 \\ \text { SLI-12 } & 02 & 150 & 480 \\ & 03 & 150 & 480 & 40 \\ & 04 & 150 & 480 & 40 \\ \text { SLI-15 } & 01 & 190 & 500 & 40 \\ & 02 & 150 & 480 & 40 \\ & 03 & 150 & 480 & 40 \\ \text { SLI-16 } & 04 & 150 & 480 & 40 \\ & 01 & 150 & 500 & 40 \\ & 02 & 180 & 480 & 40 \\ & 03 & 180 & 480 & 480 \\ & 04 & 150 & 480 & 40 \\ & 01 & 150 & 500 & 480 \\ & 02 & 150 & 480 & 480 \\ & 03 & 150 & 180 & 4\end{array}$

0

39.7

40.0

40.0

40.7

41.7

41.9

41.7

42.8

43.1

43.1

41.2

42.3

41.4

41.7

41.6

40.1

40.8

41.5

40.5

40.1

40.1

0.4

42.0

0.5

42.4

0.9

41.2

40.7

0.6

OTP [1622 - 1654 AD] (fragments: 5/14; specimens: 15/43)*

$\begin{array}{llll}\text { OTP-01 } & 01 & 150 & 500 \\ & 02 & 150 & 500 \\ \text { OTP-03 } & 04 & 150 & 500 \\ \text { OTP-04 } & 05 & 150 & 500 \\ & 01 & 150 & 500 \\ & 01 & 150 & 500 \\ \text { OTP-05 } & 03 & 130 & 400 \\ & 04 & 130 & 380 \\ \text { OTP-13 } & 05 & 130 & 380 \\ & 06 & 170 & 380 \\ & 01 & 150 & 500 \\ & 02 & 150 & 450 \\ & 01 & 150 & 500 \\ & 03 & 150 & 550 \\ & 04 & 160 & 550\end{array}$

35

38.8

38.9

39.7

37.4

36.4

39.6

39.7

39.8

38.7

39.2

38.8

38.7

39.3

41.8

40.8

38.7

1.0

36.4

39.4

0.5

INS [1742 - 1750 AD] (fragments: 2/7; specimens: 9/14)*

INS-01

$\begin{array}{llll}01 & 150 & 500 & 35 \\ 02 & 150 & 550 & 35 \\ 03 & 150 & 550 & 35 \\ 04 & 150 & 550 & 35 \\ 01 & 150 & 500 & 35 \\ 02 & 140 & 450 & 35 \\ 03 & 130 & 450 & 35 \\ 04 & 130 & 450 & 35 \\ 05 & 130 & 450 & 35\end{array}$

35
35

35.1

35.8

35.8

37.1

32.5

31.3

33.7

32.7

33.1

36.0

0.8

32.7

0.9 
FF3 [1790 - 1800 AD] (fragments: 2/4; specimens: 6/9)*

$\begin{array}{llllllll}\text { FF3-02 } & 01 & 310 & 500 & 30 & 72 & 10 & 32.5 \\ & 02 & 310 & 500 & 25 & 63 & 2 & 32.6 \\ \text { FF3-04 } & 03 & 330 & 520 & 30 & 82 & 7 & 34.2 \\ & 01 & 230 & 500 & 30 & 87 & 10 & 30.7 \\ & 02 & 240 & 500 & 30 & 84 & 7 & 33.9 \\ & 03 & 240 & 500 & 30 & 77 & 2 & 32.0\end{array}$

FF2 [1815 - 1819 AD] (fragments: 4/5; specimens: 8/11)*

$\begin{array}{lll}01 & 240 & 520 \\ 04 & 260 & 510 \\ 01 & 300 & 500 \\ 02 & 280 & 520 \\ 03 & 280 & 520 \\ 01 & 240 & 500 \\ 03 & 230 & 500 \\ 01 & 150 & 500\end{array}$

30
30
30
30
30
30
30
30

FF2-03

MPM1+2 [1869 - 1871 AD] (fragments: 6/9; specimens: 23/34)*

\begin{tabular}{|c|c|c|c|}
\hline \multirow[t]{4}{*}{ MPM1-03 } & 01 & 220 & 500 \\
\hline & 02 & 220 & 500 \\
\hline & 03 & 220 & 500 \\
\hline & 04 & 220 & 500 \\
\hline \multirow[t]{4}{*}{ MPM1-04 } & 01 & 230 & 500 \\
\hline & 02 & 240 & 500 \\
\hline & 03 & 230 & 500 \\
\hline & 04 & 240 & 500 \\
\hline \multirow[t]{3}{*}{ MPM1-07 } & 01 & 180 & 500 \\
\hline & 03 & 200 & 550 \\
\hline & 04 & 200 & 550 \\
\hline \multirow[t]{5}{*}{ MPM2-02 } & 01 & 180 & 500 \\
\hline & 02 & 180 & 500 \\
\hline & 03 & 180 & 500 \\
\hline & 04 & 180 & 500 \\
\hline & 05 & 180 & 500 \\
\hline \multirow[t]{5}{*}{ MPM2-03 } & 01 & 210 & 500 \\
\hline & 02 & 230 & 500 \\
\hline & 03 & 220 & 500 \\
\hline & 04 & 220 & 500 \\
\hline & 05 & 210 & 500 \\
\hline \multirow[t]{2}{*}{ MPM2-05 } & 02 & 180 & 500 \\
\hline & 03 & 200 & 500 \\
\hline
\end{tabular}

$$
88
$$

FL1+3+4+5 [1895 - 1901 AD] (fragments: 5/12; specimens: 14/28)*

FL1-06

$\begin{array}{lllr}01 & 180 & 500 & 25 \\ 02 & 210 & 500 & 25\end{array}$

FL1-09

210

24.8

24.1

25.0

25.9

26.0

25.9

28.8

27.0

28.4

28.2

27.9

29.5

27.8

FL5-09

$\begin{array}{ll}03 & 290 \\ 01 & 220 \\ 02 & 220\end{array}$

$500 \quad 30$

$\begin{array}{llll}01 & 200 & 500 & 25 \\ 02 & 220 & 480 & 25 \\ 03 & 200 & 480 & 25 \\ 04 & 200 & 480 & 25 \\ 01 & 220 & 500 & 25 \\ 02 & 180 & 500 & 25 \\ 03 & 190 & 480 & 25 \\ 04 & 190 & 480 & 25 \\ 05 & 200 & 480 & 25 \\ 01 & 180 & 500 & 25 \\ 03 & 180 & 480 & 25 \\ 04 & 180 & 480 & 25 \\ 05 & 180 & 480 & 25\end{array}$



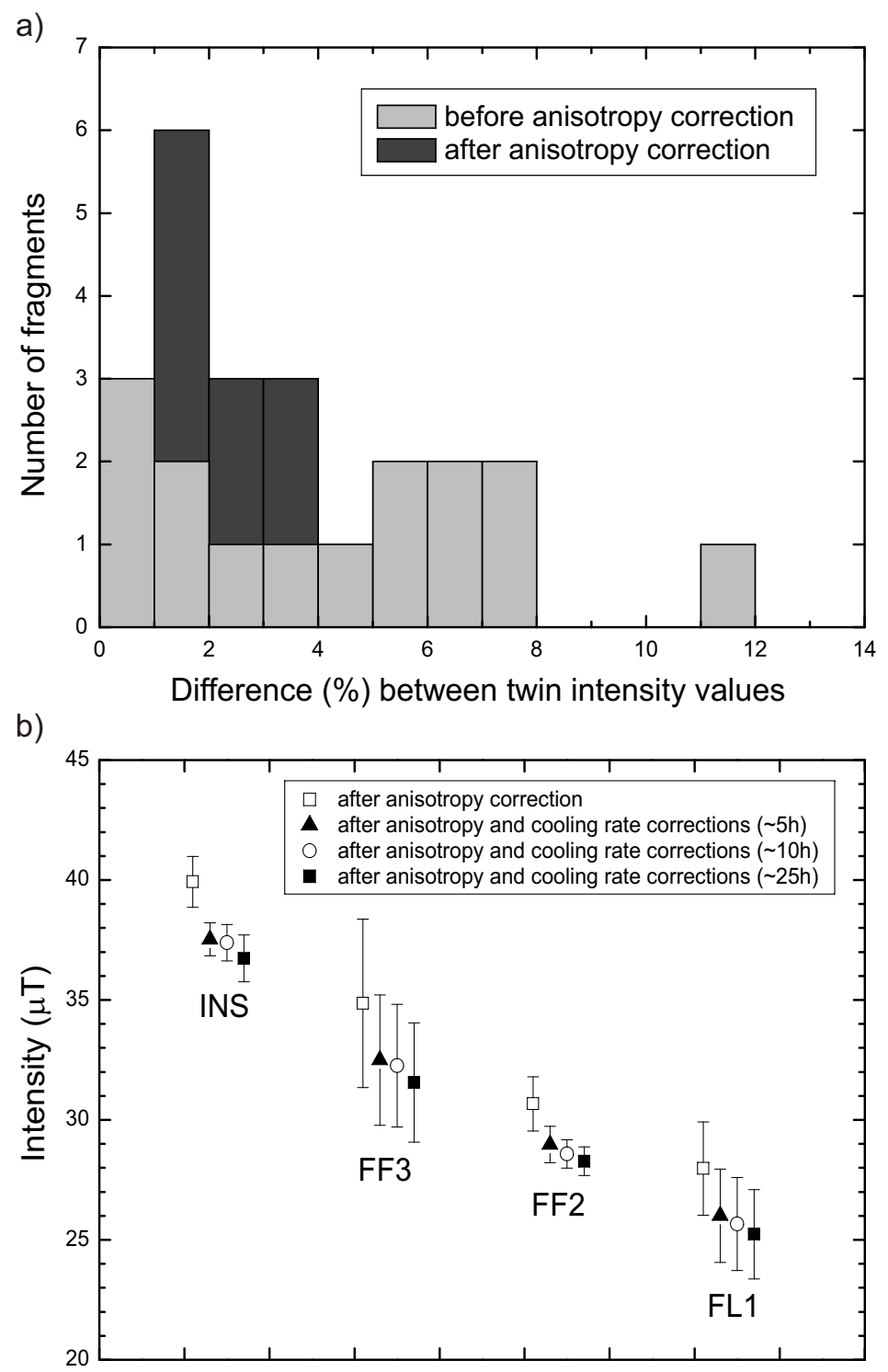

Figure 1 - Supplementary material 


\section{Apêndice D}

Tabelas de resultados de arqueointensidade das coleções Nordeste e Sudeste 
Tabela A1: Resultados obtidos através do protocolo TT-ZI para a coleção Nordeste.

\begin{tabular}{|c|c|c|c|c|c|c|c|c|c|c|c|c|}
\hline Fragmento & Espécime & $\mathbf{n}$ & $\begin{array}{l}\text { Tmin } \\
\left({ }^{\circ} \mathbf{C}\right)\end{array}$ & $\begin{array}{c}\text { Tmax } \\
\left({ }^{\circ} \mathrm{C}\right)\end{array}$ & $\mathbf{f}$ & g & $\mathbf{q}$ & $\begin{array}{c}\text { F não- } \\
\text { corrigida } \\
(\mu \mathrm{T})\end{array}$ & $\begin{array}{c}\text { SE } \\
(\mu T)\end{array}$ & $\begin{array}{c}F \\
\text { anisotropia } \\
\text { corrigida } \\
(\mu \mathrm{T})\end{array}$ & $\begin{array}{c}\text { Fm } \\
(\mu T)\end{array}$ & $\begin{array}{c}\text { SD } \\
(\mu T)\end{array}$ \\
\hline
\end{tabular}

IMS [1561 - 1591 AD] (fragmentos: 3/4; espécimes: 6/8)*

$\begin{array}{lllllllllllll}\text { IMS-01 } & 01 & 14 & 175 & 500 & 0.51 & 0.86 & 27.6 & 38.0 & 0.6 & 36.9 & \mathbf{3 3 . 9} & \mathbf{0 . 6} \\ & 02 & 16 & 175 & 550 & 0.84 & 0.89 & 87.1 & 36.2 & 0.31 & 37.7 & & \\ \text { IMS-03 } & 01 & 14 & 175 & 500 & 0.69 & 0.91 & 58.3 & 37.7 & 0.41 & 40.0 & \mathbf{3 7 . 2} & \mathbf{0 . 7} \\ & 02 & 14 & 175 & 500 & 0.65 & 0.91 & 59.9 & 41.8 & 0.41 & 41.0 & & \\ \text { IMS-04 } & 01 & 15 & 100 & 475 & 0.78 & 0.91 & 58.1 & 34.8 & 0.42 & 37.2 & \mathbf{3 6 . 2} & \mathbf{0 . 7} \\ & 02 & 15 & 100 & 475 & 0.77 & 0.92 & 61.1 & 37.2 & 0.43 & 38.3 & & \end{array}$

SE [1590 - 1620 AD] (fragmentos: 2/3; espécimes: 4/6)*

$\begin{array}{lcccccccccccc}\text { SE-06 } & 01 & 8 & 300 & 475 & 0.42 & 0.85 & 15.7 & 45.9 & 1.05 & 45.5 & \mathbf{3 9 . 4} & \mathbf{0 . 9} \\ & 02 & 8 & 300 & 475 & 0.44 & 0.85 & 15.4 & 50.8 & 1.22 & 44.2 & & \\ \text { SE-12 } & 01 & 13 & 200 & 500 & 0.5 & 0.89 & 30.9 & 42.6 & 0.61 & 45.1 & \mathbf{4 1 . 8} & \mathbf{1 . 2} \\ & 02 & 13 & 200 & 500 & 0.53 & 0.9 & 33.2 & 52.6 & 0.75 & 46.8 & & \end{array}$

SE1 [1600 - 1650 AD] (fragmentos: 4/6; espécimes: 8/12)*

\begin{tabular}{|c|c|c|c|c|c|c|c|c|c|c|c|c|}
\hline \multirow[t]{2}{*}{ SE1-80 } & 01 & 18 & 100 & 550 & 0.68 & 0.81 & 21.2 & 38.8 & 1 & 42.2 & 40.2 & 0.7 \\
\hline & 02 & 18 & 100 & 550 & 0.67 & 0.82 & 22.5 & 41.0 & 0.99 & 43.3 & & \\
\hline \multirow[t]{2}{*}{ SE1-83 } & 01 & 16 & 150 & 525 & 0.58 & 0.91 & 26.2 & 46.3 & 0.94 & 49.5 & 45.1 & 0.7 \\
\hline & 02 & 16 & 150 & 525 & 0.56 & 0.9 & 25.5 & 47.6 & 0.95 & 48.5 & & \\
\hline \multirow[t]{2}{*}{ SE1-128 } & 01 & 13 & 150 & 450 & 0.63 & 0.91 & 29 & 43.5 & 0.86 & 46.1 & 43.4 & 0.0 \\
\hline & 02 & 13 & 150 & 450 & 0.6 & 0.91 & 39.8 & 44.8 & 0.62 & 46.1 & & \\
\hline \multirow[t]{2}{*}{ SE1-193 } & 01 & 16 & 100 & 500 & 0.9 & 0.91 & 66.1 & 39.9 & 0.49 & 39.5 & 36.3 & 0.6 \\
\hline & 02 & 15 & 100 & 475 & 0.78 & 0.92 & 68 & 39.8 & 0.42 & 38.6 & & \\
\hline \multicolumn{13}{|c|}{ SE2 [1650 - 1700 AD] (fragmentos: 1/4; espécimes: 2/8)* } \\
\hline \multirow[t]{2}{*}{ SE2-29 } & 01 & 10 & 200 & 425 & 0.56 & 0.85 & 47.8 & 38.7 & 0.38 & 40.2 & 36.9 & 0.2 \\
\hline & 02 & 10 & 200 & 425 & 0.55 & 0.86 & 37.2 & 42.5 & 0.54 & 40.0 & & \\
\hline \multicolumn{13}{|c|}{ MAS [1666 - 1686 AD] (fragmentos: 3/6; espécimes: 6/12)* } \\
\hline \multirow[t]{2}{*}{ MAS-01 } & 01 & 10 & 100 & 350 & 0.79 & 0.83 & 43.8 & 45.4 & 0.68 & 44.4 & 38.0 & 0.3 \\
\hline & 02 & 10 & 100 & 350 & 0.81 & 0.82 & 72.9 & 41.9 & 0.38 & 44.0 & & \\
\hline \multirow[t]{2}{*}{ MAS-03 } & 01 & 11 & 100 & 375 & 0.85 & 0.86 & 68.6 & 42.8 & 0.46 & 40.7 & 37.1 & 0.2 \\
\hline & 02 & 11 & 100 & 375 & 0.88 & 0.87 & 51.5 & 36.5 & 0.54 & 40.9 & & \\
\hline \multirow[t]{2}{*}{ MAS-04 } & 01 & 13 & 100 & 425 & 0.81 & 0.88 & 83.7 & 40.8 & 0.35 & 42.4 & 38.2 & 0.1 \\
\hline & 02 & 11 & 175 & 425 & 0.74 & 0.85 & 51 & 39.1 & 0.48 & 42.6 & & \\
\hline \multicolumn{13}{|c|}{ FB1+2 [1696 - 1702 AD] (fragmentos: 4/7; espécimes: 8/14)* } \\
\hline \multirow[t]{2}{*}{ FB1-02 } & 01 & 12 & 250 & 525 & 0.66 & 0.89 & 50.2 & 39.9 & 0.47 & 42.7 & 37.0 & 0.3 \\
\hline & 02 & 12 & 250 & 525 & 0.67 & 0.89 & 32.3 & 37.3 & 0.69 & 43.2 & & \\
\hline \multirow[t]{2}{*}{ FB2-02 } & 01 & 19 & 150 & 600 & 0.64 & 0.93 & 34.9 & 44.2 & 0.76 & 41.1 & 37.3 & 1.2 \\
\hline & 02 & 19 & 150 & 600 & 0.66 & 0.92 & 31 & 44.5 & 0.88 & 42.7 & & \\
\hline \multirow[t]{2}{*}{ FB2-03 } & 01 & 13 & 150 & 450 & 0.72 & 0.9 & 60.9 & 44.5 & 0.47 & 38.7 & 36.2 & 0.3 \\
\hline & 02 & 13 & 150 & 450 & 0.63 & 0.9 & 51.9 & 44.5 & 0.49 & 39.2 & & \\
\hline \multirow[t]{2}{*}{ FB2-05 } & 01 & 16 & 100 & 500 & 0.55 & 0.82 & 32.8 & 39.4 & 0.54 & 39.8 & 35.2 & 0.3 \\
\hline & 02 & 16 & 100 & 500 & 0.61 & 0.81 & 26.1 & 40.6 & 0.77 & 39.4 & & \\
\hline \multicolumn{13}{|c|}{ C06 [1700 - 1710 AD] (fragmentos: 2/6; espécimes: 4/12)* } \\
\hline \multirow[t]{2}{*}{ C06-06 } & 01 & 13 & 150 & 450 & 0.49 & 0.89 & 57.3 & 44.2 & 0.34 & 41.1 & 37.3 & 0.9 \\
\hline & 02 & 13 & 150 & 450 & 0.52 & 0.89 & 73.9 & 39.5 & 0.25 & 39.9 & & \\
\hline \multirow[t]{2}{*}{ C06-10 } & 01 & 7 & 250 & 400 & 0.76 & 0.81 & 47.6 & 43.5 & 0.6 & 40.0 & 36.3 & 0.2 \\
\hline & 02 & 7 & 250 & 400 & 0.75 & 0.81 & 66.6 & 39.0 & 0.4 & 39.7 & & \\
\hline
\end{tabular}


SCA [1780 -1781 AD] (fragmentos: 4/7; espécimes: 8/14)*

\begin{tabular}{|c|c|c|c|c|c|c|c|c|c|c|c|c|}
\hline \multirow[t]{2}{*}{ SCA-04 } & 01 & 17 & 200 & 600 & 0.46 & 0.79 & 36.6 & 37.1 & 0.37 & 36.0 & 32.5 & 0.4 \\
\hline & 02 & 17 & 200 & 600 & 0.53 & 0.84 & 24.5 & 36.2 & 0.65 & 35.4 & & \\
\hline \multirow[t]{2}{*}{ SCA-07 } & 01 & 13 & 150 & 450 & 0.51 & 0.9 & 44.3 & 33.1 & 0.35 & 35.0 & 32.6 & 0.5 \\
\hline & 02 & 13 & 150 & 450 & 0.52 & 0.9 & 60.3 & 35.8 & 0.28 & 35.8 & & \\
\hline \multirow[t]{2}{*}{ SCA-08 } & 01 & 12 & 175 & 450 & 0.49 & 0.9 & 90.3 & 31.6 & 0.15 & 33.8 & 31.7 & 0.4 \\
\hline & 02 & 12 & 175 & 450 & 0.55 & 0.89 & 49.8 & 34.7 & 0.34 & 34.4 & & \\
\hline \multirow[t]{2}{*}{ SCA-12 } & 01 & 14 & 175 & 500 & 0.41 & 0.88 & 18.2 & 33.3 & 0.66 & 34.6 & 31.5 & 0.6 \\
\hline & 02 & 14 & 175 & 500 & 0.41 & 0.88 & 21.4 & 34.1 & 0.58 & 33.7 & & \\
\hline \multicolumn{13}{|c|}{ TF [1886 - 1887 AD] (fragmentos: 5/7; espécimes: 10/14)* } \\
\hline \multirow[t]{2}{*}{ TF-02 } & 01 & 9 & 175 & 375 & 0.69 & 0.81 & 295 & 27.0 & 0.05 & 29.7 & 25.9 & 0.3 \\
\hline & 02 & 9 & 175 & 375 & 0.63 & 0.81 & 65.4 & 29.5 & 0.23 & 29.2 & & \\
\hline \multirow[t]{2}{*}{ TF-03 } & 01 & 16 & 175 & 550 & 0.45 & 0.91 & 23.5 & 34.8 & 0.61 & 30.2 & 27.9 & 0.2 \\
\hline & 02 & 16 & 175 & 550 & 0.57 & 0.91 & 57.5 & 30.2 & 0.27 & 30.5 & & \\
\hline \multirow[t]{2}{*}{ TF-04 } & 01 & 12 & 175 & 475 & 0.76 & 0.89 & 146 & 26.5 & 0.12 & 26.3 & 23.6 & 0.0 \\
\hline & 02 & 12 & 175 & 475 & 0.78 & 0.89 & 160 & 28.6 & 0.12 & 26.3 & & \\
\hline \multirow[t]{2}{*}{ TF-06 } & 01 & 15 & 150 & 500 & 0.58 & 0.92 & 48 & 32.1 & 0.36 & 29.9 & 26.1 & 0.3 \\
\hline & 02 & 13 & 200 & 500 & 0.56 & 0.91 & 49.9 & 29.2 & 0.3 & 29.5 & & \\
\hline \multirow{2}{*}{ TF-10 } & 01 & 16 & 200 & 575 & 0.7 & 0.9 & 82.5 & 27.8 & 0.21 & 27.8 & 24.8 & 0.1 \\
\hline & 02 & 14 & 200 & 525 & 0.66 & 0.86 & 50 & 30.1 & 0.34 & 28.0 & & \\
\hline
\end{tabular}

n: número de passos de temperatura utilizados para o cálculo da intensidade; Tmin-Tmax: intervalo de temperatura (em ${ }^{\circ} \mathrm{C}$ ) para o qual a curva foi calculada no diagrama de Arai; f: fração da MRN envolvida no cálculo; g e q: fator gap e fator de qualidade definidos por Coe (1967); F não-corrigida: valor de intensidade por espécime antes das correções (em $\mu \mathrm{T})$; SE: erro padrão de $\mathrm{F}$ (em $\mu \mathrm{T})$; F anisotropia corrigida: valor de intensidade por espécime corrigido do efeito de anisotropia (em $\mu \mathrm{T}$ ); Fm: valor médio de intensidade em nível de fragmento após as correções dos efeitos de anisotropia e da taxa de resfriamento (em $\mu \mathrm{T})$; SD: desvio padrão dos valores de intensidade em nível de fragmento (em $\mu \mathrm{T})$; $(*)$ : indica a razão entre o número de fragmentos (ou espécimes) que foram analisados com sucesso e o número fragmentos (ou espécimes) estudados. O campo de laboratório utilizado nos experimentos foi de $35 \mu \mathrm{T}$. 
Tabela A2: Resultados obtidos através do protocolo Triaxe para a coleção Nordeste.

\begin{tabular}{|c|c|c|c|c|c|c|c|c|c|}
\hline Fragmento & Espécime & $\begin{array}{c}\text { Tmin } \\
\left({ }^{\circ} \mathrm{C}\right)\end{array}$ & $\begin{array}{c}\text { Tmax } \\
\left({ }^{\circ} \mathrm{C}\right)\end{array}$ & $\begin{array}{c}\text { H lab } \\
(\mu T)\end{array}$ & $\begin{array}{c}\text { MRN } \\
\text { T1 } \\
(\%)\end{array}$ & $\begin{array}{c}\text { Slope } \\
\text { R' }^{\prime} \\
(\%)\end{array}$ & $\begin{array}{c}\mathbf{F} \\
\text { Triaxe } \\
(\boldsymbol{\mu T})\end{array}$ & $\begin{array}{c}\text { F mean } \\
(\boldsymbol{\mu T})\end{array}$ & $\mathrm{SD}(\boldsymbol{\mu T})$ \\
\hline
\end{tabular}

IMS [1561 - 1591 AD] (fragmentos: 3/4; espécimes: 11/12)*

\begin{tabular}{llllllll} 
IMS-01 & 01 & 220 & 500 & 35 & 62 & 9 & 32.4 \\
& 02 & 150 & 520 & 35 & 83 & 5 & 35.7 \\
\multirow{3}{*}{ IMS-03 } & 03 & 160 & 520 & 35 & 75 & -2 & 35.2 \\
& 04 & 160 & 520 & 35 & 74 & 0 & 35.4 \\
& 01 & 160 & 500 & 35 & 68 & 3 & 36.5 \\
\multirow{3}{*}{ IMS-04 } & 02 & 180 & 520 & 35 & 78 & 0 & 37.5 \\
& 03 & 160 & 520 & 35 & 77 & 5 & 37.4 \\
& 04 & 130 & 520 & 35 & 78 & 0 & 37.9 \\
& 01 & 150 & 500 & 35 & 86 & 3 & 37.7 \\
& 03 & 170 & 500 & 35 & 83 & 3 & 37.8 \\
& 04 & 230 & 500 & 35 & 78 & 5 & 36.8
\end{tabular}

SE [1590 - 1620 AD] (fragmentos: 4/6; espécimes: 12/17)*

$\begin{array}{llllllll}\text { SE-06 } & 02 & 310 & 500 & 40 & 72 & 8 & 42.2 \\ \text { SE-12 } & 03 & 280 & 500 & 40 & 76 & 8 & 41.9 \\ & 01 & 240 & 500 & 40 & 55 & 7 & 40.8 \\ \text { SE-14 } & 03 & 250 & 520 & 40 & 69 & 8 & 42.5 \\ & 04 & 240 & 520 & 40 & 73 & 3 & 40.5 \\ & 01 & 150 & 500 & 40 & 70 & -3 & 40.9 \\ & 02 & 240 & 500 & 40 & 71 & -8 & 41.9 \\ \text { SE-18 } & 03 & 250 & 500 & 40 & 70 & 1 & 39.3 \\ & 04 & 220 & 500 & 40 & 67 & -4 & 40.1 \\ & 01 & 350 & 500 & 40 & 63 & 5 & 38.7 \\ & 02 & 380 & 500 & 40 & 60 & 1 & 38.8 \\ & 03 & 370 & 500 & 40 & 72 & -7 & 38.5\end{array}$

\begin{tabular}{ll}
42.1 & 0.2 \\
41.3 & 1.1 \\
40.6 & 1.1 \\
\hline 38.7 & 0.2 \\
\hline
\end{tabular}

SE1 [1600 - 1650 AD] (fragmentos: 3/5; espécimes: 7/13)*

$\begin{array}{lllll}\text { SE1-80 } & 01 & 250 & 500 & 40 \\ \text { SE1-128 } & 03 & 140 & 470 & 40 \\ & 02 & 100 & 450 & 40 \\ \text { SE1-193 } & 03 & 100 & 450 & 40 \\ & 07 & 100 & 450 & 40 \\ & 01 & 200 & 500 & 40 \\ & 03 & 100 & 500 & 40\end{array}$

$\begin{array}{llll}40 & 59 & 5 & 40.1 \\ 40 & 51 & -7 & 40.3 \\ 40 & 70 & 5 & 41.7 \\ 40 & 70 & 6 & 41.2 \\ 40 & 61 & 2 & 42.6 \\ 40 & 66 & -4 & 38.3 \\ 40 & 90 & -1 & 39.7\end{array}$

\begin{tabular}{ll}
40.2 & 0.1 \\
41.8 & 0.7 \\
\hline 39.0 & 1.0
\end{tabular}

SE2 [1650 - 1700 AD] (fragmentos: 3/3; espécimes: 8/13)*

$\begin{array}{lllll}\text { SE2-19 } & 01 & 180 & 500 & 35 \\ \text { SE2-28 } & 05 & 130 & 500 & 40 \\ & 01 & 180 & 500 & 35 \\ & 02 & 100 & 360 & 4 \\ \text { SE2-29 } & 03 & 130 & 380 & 40 \\ & 04 & 130 & 380 & 40 \\ & 01 & 210 & 500 & 35 \\ & 03 & 210 & 500 & 4\end{array}$

$\begin{array}{lcccc}95 & 7 & 38.3 & \mathbf{3 7 . 4} & \mathbf{1 . 3} \\ 81 & 7 & 36.5 & & \\ 74 & 8 & 40.0 & \mathbf{3 8 . 8} & \mathbf{0 . 9} \\ 75 & -3 & 38.6 & & \\ 84 & 6 & 38.3 & & \\ 81 & 3 & 38.1 & & \\ 85 & 8 & 38.1 & \mathbf{3 8 . 4} & \mathbf{0 . 4} \\ 80 & 10 & 38.7 & & \end{array}$

MAS [1666 - 1686 AD] (fragmentos: 3/6; espécimes: 6/13)*

$\begin{array}{llllllll}\text { MAS-01 } & 01 & 180 & 500 & 35 & 67 & 9 & 39.0 \\ \text { MAS-03 } & 02 & 160 & 350 & 35 & 64 & 2 & 40.5 \\ & 02 & 130 & 350 & 35 & 56 & -2 & 40.8 \\ \text { MAS-07 } & 03 & 140 & 350 & 35 & 57 & -10 & 40.3 \\ & 01 & 250 & 500 & 35 & 63 & 4 & 37.2 \\ & 02 & 130 & 480 & 35 & 67 & 5 & 37.7\end{array}$

\begin{tabular}{ll}
39.8 & 1.1 \\
\hline 40.6 & 0.4 \\
\hline 37.5 & 0.4
\end{tabular}


SB [1691 - 1693 AD] (fragmentos: 5/5; espécimes: 13/17)*

$\begin{array}{lllll}\text { SB-01 } & 01 & 230 & 500 & 35 \\ \text { SB-02 } & 02 & 230 & 450 & 40 \\ & 01 & 180 & 500 & 35 \\ \text { SB-04 } & 02 & 180 & 530 & 40 \\ & 03 & 180 & 550 & 40 \\ \text { SB-05 } & 01 & 180 & 500 & 35 \\ & 02 & 240 & 480 & 40 \\ \text { SB-06 } & 04 & 230 & 500 & 40 \\ & 01 & 180 & 500 & 35 \\ & 02 & 190 & 420 & 4 \\ & 04 & 180 & 430 & 40 \\ & 01 & 180 & 500 & 35 \\ & 04 & 130 & 410 & 40\end{array}$

$\begin{array}{lcccc}97 & 7 & 37.7 & \mathbf{3 7 . 6} & \mathbf{0 . 1} \\ 95 & 10 & 37.5 & & \\ 58 & -3 & 37.6 & \mathbf{3 6 . 4} & \mathbf{1 . 6} \\ 71 & 1 & 37.1 & & \\ 51 & -6 & 34.6 & & \\ 92 & 2 & 35.6 & \mathbf{3 6 . 9} & \mathbf{1 . 8} \\ 71 & 3 & 36.1 & & \\ 85 & 9 & 38.9 & & \\ 90 & 3 & 36.8 & \mathbf{3 6 . 3} & \mathbf{0 . 8} \\ 74 & -8 & 35.3 & & \\ 71 & -1 & 36.7 & & \\ 81 & -4 & 39.3 & \mathbf{3 8 . 9} & \mathbf{0 . 6} \\ 79 & -10 & 38.4 & & \end{array}$

FB1+2 [1696 - 1702 AD] (fragmentos: 1/1; espécimes: 3/4)* FB2-03

$\begin{array}{lllllll}01 & 240 & 500 & 35 & 68 & 10 & 36.5 \\ 03 & 170 & 500 & 35 & 73 & -2 & 37.4 \\ 04 & 170 & 500 & 35 & 65 & 0 & 36.9\end{array}$

$36.9 \quad 0.5$ 36.9

CP27 [1675 - 1725 AD] (fragmentos: 5/7; espécimes: 14/21)*

$\begin{array}{llllllll}\text { CP27-02 } & 01 & 180 & 500 & 25 & 58 & -8 & 38.2 \\ \text { CP27-03 } & 01 & 230 & 500 & 25 & 78 & 1 & 34.3 \\ & 02 & 230 & 500 & 35 & 79 & 4 & 32.5 \\ & 03 & 230 & 500 & 35 & 59 & 10 & 32.5 \\ & 04 & 230 & 500 & 35 & 69 & 3 & 33.5 \\ \text { CP27-04 } & 05 & 220 & 500 & 35 & 51 & -4 & 35.0 \\ & 07 & 210 & 550 & 35 & 89 & 0 & 32.0 \\ \text { CP27-05 } & 01 & 150 & 500 & 35 & 66 & -2 & 33.7 \\ \text { CP27-09 } & 02 & 150 & 500 & 35 & 75 & -2 & 34.7 \\ & 01 & 160 & 500 & 35 & 76 & 0 & 35.7 \\ & 01 & 180 & 500 & 25 & 78 & 3 & 38.1 \\ & 02 & 190 & 450 & 35 & 65 & 5 & 38.4 \\ & 03 & 190 & 450 & 35 & 75 & 7 & 37.6 \\ & 04 & 190 & 450 & 35 & 68 & 8 & 37.0\end{array}$

C06 [1700 - 1710 AD] (fragmentos: 2/2; espécimes: 5/6)*

\section{C06-06}

C06-09

01

02

150

150

500

480

480

$03 \quad 150$

$01 \quad 150$

02

150

\section{0}

35

35

30

35 $\begin{array}{lcc}88 & 7 & 38.4 \\ 86 & 2 & 39.1 \\ 87 & 6 & 37.8 \\ 65 & 10 & 35.6\end{array}$

$\begin{array}{lll}65 & 9 & 36.1\end{array}$

38.2

33.3

$34.2 \quad 0.7$

35.7

37.8

0.6

CB [1767 - 1777 AD] (fragmentos: 3/6; espécimes: 9/29)*

01

02

CB-08

03

02

03

$\begin{array}{ll}05 & 200 \\ 01 & 180 \\ 04 & 160 \\ 05 & 180\end{array}$

CB-09
CB-02

150
130
150
200
140
200
180
160
180

500

400

400

450

450

500

500

500

500
25

35

35

35

35

35

$$
25
$$

35
35

$\begin{array}{lcl}75 & 3 & 35.6 \\ 64 & 1 & 32.1 \\ 76 & 10 & 34.0 \\ 64 & 10 & 33.2 \\ 71 & 3 & 32.8 \\ 72 & 6 & 35.6 \\ 71 & 2 & 29.2 \\ 67 & -8 & 31.1 \\ 79 & 4 & 30.8\end{array}$

TF [1886 - 1887 AD] (fragmentos: 2/3; espécimes: 4/7)*

$\begin{array}{llllllll}\text { TF-02 } & 02 & 180 & 370 & 25 & 66 & 2 & 26.9 \\ & 03 & 180 & 370 & 25 & 66 & 4 & 27.4 \\ \text { TF-06 } & 02 & 150 & 370 & 25 & 74 & 8 & 26.2 \\ & 03 & 150 & 370 & 25 & 73 & 8 & 26.3\end{array}$

$\begin{array}{ll}38.4 & 0.7\end{array}$

$35.9 \quad 0.4$

$33.9 \quad 1.8$

$33.9 \quad 1.5$

$30.4 \quad 1.0$

$27.2 \quad 0.4$

$26.3 \quad 0.1$ 
MAE4 [1896 - 1906 AD] (fragmentos: 5/6; espécimes: 15/18)*

\begin{tabular}{|c|c|c|c|c|c|c|c|c|c|}
\hline \multirow[t]{3}{*}{ MAE4-01 } & 01 & 230 & 500 & 25 & 70 & 3 & 25.7 & 25.3 & 0.5 \\
\hline & 02 & 250 & 500 & 25 & 73 & 9 & 24.8 & & \\
\hline & 03 & 240 & 500 & 25 & 83 & 10 & 25.3 & & \\
\hline \multirow[t]{3}{*}{ MAE4-02 } & 01 & 180 & 500 & 25 & 89 & 8 & 24.4 & 24.2 & 0.4 \\
\hline & 02 & 180 & 490 & 25 & 87 & 1 & 24.5 & & \\
\hline & 03 & 180 & 490 & 25 & 82 & 7 & 23.7 & & \\
\hline \multirow[t]{3}{*}{ MAE4-03 } & 01 & 180 & 500 & 25 & 84 & 5 & 24.6 & 25.0 & 0.4 \\
\hline & 02 & 180 & 500 & 25 & 93 & 9 & 25.3 & & \\
\hline & 03 & 180 & 500 & 25 & 94 & 9 & 25.0 & & \\
\hline \multirow[t]{3}{*}{ MAE4-04 } & 01 & 180 & 500 & 25 & 70 & -3 & 26.9 & 26.5 & 0.4 \\
\hline & 02 & 180 & 500 & 25 & 83 & 0 & 26.6 & & \\
\hline & 03 & 180 & 500 & 25 & 68 & -4 & 26.1 & & \\
\hline \multirow[t]{3}{*}{ MAE4-06 } & 01 & 180 & 500 & 25 & 90 & 10 & 27.4 & 27.4 & 0.8 \\
\hline & 02 & 180 & 440 & 25 & 82 & 5 & 26.7 & & \\
\hline & 03 & 180 & 500 & 25 & 89 & 2 & 28.2 & & \\
\hline \multicolumn{10}{|c|}{ GC [1900 - 1920 AD] (fragmentos: 5/6; espécimes: 20/25)* } \\
\hline \multirow[t]{4}{*}{ GC-02 } & 01 & 180 & 500 & 25 & 92 & 6 & 24.7 & 24.7 & 0.2 \\
\hline & 02 & 180 & 500 & 25 & 91 & 9 & 24.4 & & \\
\hline & 03 & 180 & 500 & 25 & 90 & 5 & 24.8 & & \\
\hline & 04 & 180 & 500 & 25 & 91 & 2 & 24.9 & & \\
\hline \multirow[t]{4}{*}{ GC-03 } & 01 & 180 & 500 & 25 & 92 & 8 & 25.4 & 25.7 & 0.3 \\
\hline & 02 & 180 & 500 & 25 & 91 & -1 & 26.1 & & \\
\hline & 03 & 180 & 500 & 25 & 92 & 5 & 25.6 & & \\
\hline & 04 & 180 & 500 & 25 & 93 & 9 & 25.5 & & \\
\hline \multirow[t]{4}{*}{ GC-04 } & 01 & 180 & 500 & 25 & 91 & 1 & 25.3 & 25.1 & 0.3 \\
\hline & 02 & 180 & 500 & 25 & 92 & 6 & 24.7 & & \\
\hline & 04 & 180 & 500 & 25 & 91 & -7 & 25.3 & & \\
\hline & 05 & 180 & 500 & 25 & 90 & -7 & 25.0 & & \\
\hline \multirow[t]{4}{*}{ GC-05 } & 01 & 180 & 500 & 25 & 91 & 0 & 25.9 & 25.2 & 0.5 \\
\hline & 02 & 180 & 500 & 25 & 91 & 5 & 24.8 & & \\
\hline & 03 & 180 & 500 & 25 & 91 & 6 & 24.8 & & \\
\hline & 04 & 180 & 500 & 25 & 92 & 1 & 25.2 & & \\
\hline \multirow[t]{4}{*}{ GC-06 } & 01 & 270 & 500 & 25 & 86 & 3 & 24.2 & 24.5 & 0.3 \\
\hline & 02 & 230 & 500 & 25 & 87 & 0 & 24.5 & & \\
\hline & 04 & 180 & 500 & 25 & 89 & 3 & 24.4 & & \\
\hline & 05 & 180 & 500 & 25 & 89 & 3 & 24.8 & & \\
\hline
\end{tabular}

Tmin-Tmax: intervalo de temperatura $\left(\right.$ em ${ }^{\circ} \mathrm{C}$ ) utilizado para a determinação da intensidade; Hlab: campo de laboratório (em $\mu \mathrm{T})$; MRN T1 (\%): corresponde à fração da MRN a partir de T1 envolvida no cálculo da intensidade; Slope R' (\%): corresponde à curva de R'(Ti) ao longo do intervalo de temperatura utilizado para o calculo da intensidade, expresso em \% como definido por Le Goff and Gallet (2004); F Triaxe: valor de intensidade em nível de espécime (em $\mu \mathrm{T})$; Fmean: valor médio de intensidade calculado em nível de fragmento $($ em $\mu \mathrm{T})$; SD: desvio padrão do valor médio calculado em nível de fragmento (em $\mu \mathrm{T})$; $(*)$ :indica a razão entre o número de fragmentos (ou espécimes) que foram analisados com sucesso e o número fragmentos (ou espécimes) estudados. 
Tabela A3: Resultados obtidos através do protocolo TT-ZI para a coleção Sudeste.

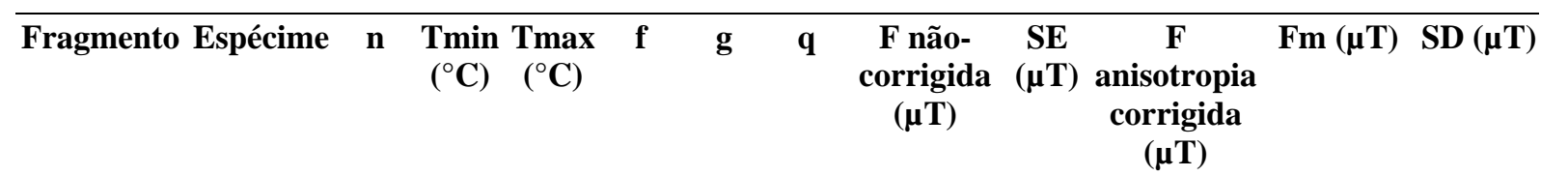

OTP [1622 - 1654 AD] (fragmentos: 1/4; espécimes: 2/8)*

$\begin{array}{llllllllll}01 & 01 & 225 & 500 & 0.41 & 0.88 & 24.2\end{array}$

$\begin{array}{lllllll}02 & 12 & 225 & 500 & 0.44 & 0.87 & 17.0\end{array}$

$\begin{array}{lllll}38.2 & 0.6 & 40.8 & 37.7 & \mathbf{0 . 9}\end{array}$

INS [1742 - 1750 AD] (fragmentos: 3/4; espécimes: 6/8) *

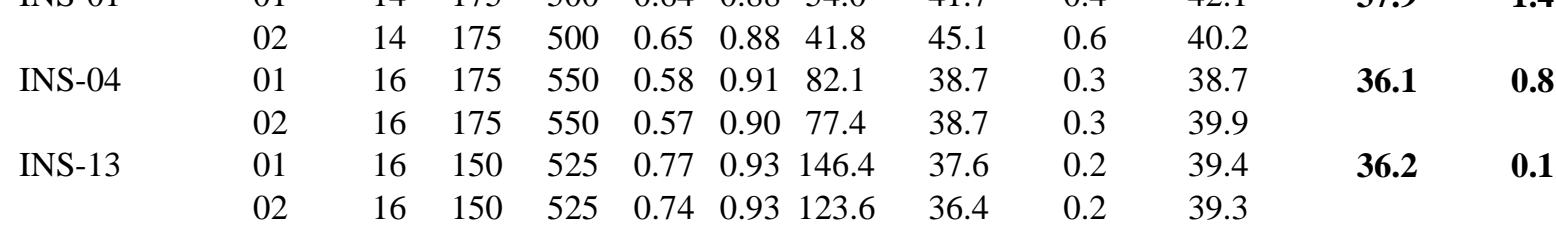

FF3 [1790 - 1800 AD] (fragmentos: 3/6; espécimes: 6/12) *

$\begin{array}{llllllll}\text { FF3-02 } & 01 & 9 & 300 & 500 & 0.52 & 0.82 & 60.2\end{array}$

$\begin{array}{llclllll} & 02 & 9 & 300 & 500 & 0.54 & 0.82 & 32.6\end{array}$

$\begin{array}{lllll}37.1 & 0.3 & 37.9 & \mathbf{3 3 . 5} & \mathbf{0 . 4} \\ 40.6 & 0.6 & 37.3 & & \\ 30.3 & 0.4 & 30.6 & \mathbf{2 8 . 7} & \mathbf{0 . 4} \\ 31.2 & 0.5 & 31.2 & & \\ 40.7 & 0.9 & 37.0 & \mathbf{3 2 . 5} & \mathbf{1 . 4} \\ 34.8 & 0.3 & 35.1 & & \end{array}$

FF2 [1815 - 1819 AD] (fragmentos: 4/7; espécimes: 8/14) *

\begin{tabular}{|c|c|c|c|c|c|c|c|c|c|c|c|c|}
\hline \multirow[t]{2}{*}{ FF2-02 } & 01 & 8 & 225 & 400 & 0.45 & 0.83 & 13.6 & 31.6 & 0.9 & 31.9 & \multirow[t]{2}{*}{28.2} & \multirow[t]{2}{*}{0.4} \\
\hline & 02 & 8 & 225 & 400 & 0.50 & 0.85 & 27.0 & 30.7 & 0.5 & 31.3 & & \\
\hline \multirow[t]{2}{*}{ FF2-05 } & 01 & 14 & 225 & 550 & 0.42 & 0.88 & 41.3 & 30.7 & 0.3 & 30.6 & \multirow[t]{2}{*}{28.3} & \multirow[t]{2}{*}{1.1} \\
\hline & 02 & 15 & 200 & 550 & 0.43 & 0.89 & 24.9 & 27.8 & 0.4 & 29.0 & & \\
\hline \multirow[t]{2}{*}{ FF2-08 } & 01 & 9 & 250 & 450 & 0.44 & 0.84 & 21.8 & 29.3 & 0.5 & 30.7 & \multirow[t]{2}{*}{29.1} & \multirow[t]{2}{*}{1.3} \\
\hline & 02 & 9 & 250 & 450 & 0.42 & 0.84 & 19.9 & 32.6 & 0.6 & 32.6 & & \\
\hline \multirow[t]{2}{*}{ FF2-11 } & 01 & 12 & 200 & 475 & 0.64 & 0.89 & 37.5 & 31.7 & 0.5 & 30.1 & \multirow[t]{2}{*}{27.7} & \multirow[t]{2}{*}{0.4} \\
\hline & 02 & 12 & 200 & 475 & 0.65 & 0.90 & 42.8 & 29.2 & 0.4 & 29.5 & & \\
\hline \multicolumn{13}{|c|}{ FL1+3+4+5 [1895 - 1901 AD] (fragmentos: 4/4; espécimes: 8/8) * } \\
\hline \multirow[t]{2}{*}{ FL1-03 } & 01 & 16 & 150 & 525 & 0.84 & 0.90 & 72.4 & 27.7 & 0.3 & 27.5 & \multirow[t]{2}{*}{25.0} & \multirow[t]{2}{*}{0.8} \\
\hline & 02 & 15 & 150 & 500 & 0.70 & 0.90 & 54.5 & 27.5 & 0.3 & 28.6 & & \\
\hline \multirow[t]{2}{*}{ FL1-06 } & 01 & 14 & 200 & 525 & 0.79 & 0.89 & 47.6 & 25.8 & 0.4 & 25.8 & \multirow[t]{2}{*}{24.7} & \multirow[t]{2}{*}{0.2} \\
\hline & 02 & 14 & 200 & 525 & 0.78 & 0.89 & 81.4 & 24.2 & 0.2 & 26.2 & & \\
\hline \multirow[t]{2}{*}{ FL1-07 } & 01 & 9 & 300 & 500 & 0.52 & 0.87 & 33.1 & 28.2 & 0.4 & 27.0 & \multirow[t]{2}{*}{23.4} & \multirow[t]{2}{*}{0.3} \\
\hline & 02 & 10 & 275 & 500 & 0.59 & 0.89 & 48.0 & 30.9 & 0.3 & 27.5 & & \\
\hline \multirow[t]{2}{*}{ FL4-04 } & 01 & 13 & 200 & 500 & 0.65 & 0.90 & 77.9 & 30.8 & 0.2 & 30.2 & \multirow[t]{2}{*}{27.8} & \multirow[t]{2}{*}{0.6} \\
\hline & 02 & 11 & 250 & 500 & 0.59 & 0.89 & 48.1 & 32.3 & 0.4 & 31.0 & & \\
\hline
\end{tabular}

n: número de passos de temperatura utilizados para o cálculo da intensidade; Tmin-Tmax: intervalo de temperatura (em ${ }^{\circ} \mathrm{C}$ ) para o qual a curva foi calculada no diagrama de Arai; f: fração da MRN envolvida no cálculo; g e q: fator gap e fator de qualidade definidos por Coe (1967); F não-corrigida: valor de intensidade por espécime antes das correções (em $\mu \mathrm{T}$ ); SE: erro padrão de F (em $\mu \mathrm{T}$ ); F anisotropia corrigida: valor de intensidade por espécime corrigido do efeito de anisotropia (em $\mu \mathrm{T})$; Fm: valor médio de intensidade em nível de fragmento após as correções dos efeitos de anisotropia e da taxa de resfriamento (em $\mu \mathrm{T}$ ); SD: desvio padrão dos valores de intensidade em nível de fragmento (em $\mu \mathrm{T})$; $(*)$ : indica a razão entre o número de fragmentos (ou espécimes) que foram analisados com sucesso e o número fragmentos (ou espécimes) estudados. O campo de laboratório utilizado nos experimentos foi de $35 \mu \mathrm{T}$. 
Tabela A4: Resultados obtidos através do protocolo Triaxe para a coleção Sudeste.

Fragmento Espécime $\operatorname{Tmin}\left({ }^{\circ} \mathrm{C}\right) \operatorname{Tmax}\left({ }^{\circ} \mathrm{C}\right) \mathrm{H}$ lab $(\mu \mathrm{T})$ MRN T1 Slope F Triaxe F mean SD $(\mu \mathrm{T})$

$\begin{array}{llll}(\%) & R^{\prime}(\%) & (\mu T) & (\mu T)\end{array}$

\begin{tabular}{|c|c|c|c|c|c|c|c|c|c|}
\hline \multicolumn{10}{|c|}{ INSA [1584 - 1598 AD] (fragmentos: 3/6; espécimes: 12/24)* } \\
\hline \multirow[t]{3}{*}{ INSA-02 } & 01 & 170 & 500 & 35 & 66 & -5 & 39.8 & \multirow[t]{3}{*}{40.3} & \multirow[t]{3}{*}{0.5} \\
\hline & 04 & 130 & 530 & 40 & 78 & 3 & 40.3 & & \\
\hline & 05 & 130 & 530 & 40 & 69 & 2 & 40.7 & & \\
\hline \multirow[t]{5}{*}{ INSA-03 } & 01 & 220 & 500 & 35 & 78 & 7 & 39.1 & \multirow[t]{5}{*}{38.7} & \multirow[t]{5}{*}{0.8} \\
\hline & 02 & 220 & 500 & 40 & 80 & 7 & 38.7 & & \\
\hline & 03 & 150 & 500 & 40 & 79 & -2 & 37.4 & & \\
\hline & 04 & 220 & 500 & 40 & 82 & 3 & 39.6 & & \\
\hline & 05 & 150 & 500 & 40 & 73 & -9 & 38.5 & & \\
\hline \multirow[t]{4}{*}{ INSA-06B } & 01 & 220 & 500 & 40 & 82 & 7 & 42.2 & \multirow[t]{4}{*}{43.4} & 0.8 \\
\hline & 02 & 220 & 500 & 40 & 78 & 10 & 43.9 & & \\
\hline & 03 & 220 & 500 & 40 & 87 & 8 & 43.7 & & \\
\hline & 04 & 230 & 500 & 40 & 87 & 8 & 43.8 & & \\
\hline
\end{tabular}

SLI [1623 - 1633 AD] (fragmentos: 5/9; espécimes: 20/26)*

\begin{tabular}{lccccccc} 
SLI-10 & 01 & 150 & 500 & 40 & 93 & 8 & 39.7 \\
& 02 & 150 & 480 & 40 & 92 & -5 & 40.0 \\
\multirow{3}{*}{ SLI-11 } & 03 & 160 & 480 & 40 & 93 & -1 & 40.0 \\
& 06 & 150 & 480 & 40 & 79 & 0 & 40.7 \\
& 01 & 150 & 500 & 40 & 92 & 6 & 41.7 \\
SLI-12 & 02 & 150 & 480 & 40 & 87 & 4 & 41.9 \\
& 03 & 150 & 480 & 40 & 90 & -1 & 41.7 \\
& 04 & 150 & 480 & 40 & 92 & 1 & 42.8 \\
SLI-15 & 01 & 190 & 500 & 40 & 86 & 1 & 43.1 \\
& 02 & 150 & 480 & 40 & 90 & 2 & 43.1 \\
& 03 & 150 & 480 & 40 & 83 & 3 & 41.2 \\
SLI-16 & 04 & 150 & 480 & 40 & 81 & 6 & 42.3 \\
& 01 & 150 & 500 & 40 & 96 & 4 & 41.4 \\
& 02 & 180 & 480 & 40 & 85 & 10 & 41.7 \\
& 03 & 180 & 480 & 40 & 88 & 8 & 41.6 \\
& 04 & 150 & 480 & 40 & 93 & 9 & 40.1 \\
& 01 & 150 & 500 & 40 & 94 & 6 & 40.8 \\
& 02 & 150 & 480 & 40 & 87 & 4 & 41.5 \\
& 03 & 150 & 480 & 40 & 82 & 4 & 40.5 \\
& 04 & 180 & 480 & 40 & 92 & 8 & 40.1
\end{tabular}

$40.1 \quad 0.4$

42.0 $\quad 0.5$

$42.4 \quad 0.9$

$41.2 \quad 0.7$

$40.7 \quad 0.6$

OTP [1622 - 1654 AD] (fragmentos: 5/14; espécimes: 15/43)*

$\begin{array}{llllllllll}\text { OTP-01 } & 01 & 150 & 500 & 35 & 74 & -7 & 38.8 & \mathbf{3 8 . 7} & \mathbf{1 . 0} \\ & 02 & 150 & 500 & 40 & 68 & -3 & 38.9 & & \\ \text { OTP-03 } & 04 & 150 & 500 & 40 & 89 & -3 & 39.7 & & \\ \text { OTP-04 } & 05 & 150 & 500 & 40 & 77 & 2 & 37.4 & & \\ & 01 & 150 & 500 & 35 & 65 & -2 & 36.4 & \mathbf{3 6 . 4} & \mathbf{0 . 5} \\ & 01 & 150 & 500 & 35 & 95 & 1 & 39.6 & \mathbf{3 9 . 4} & \\ & 03 & 130 & 400 & 40 & 93 & 8 & 39.7 & & \\ \text { OTP-05 } & 04 & 130 & 380 & 40 & 89 & 4 & 39.8 & \\ & 05 & 130 & 380 & 40 & 90 & 7 & 38.7 & & \\ & 06 & 170 & 380 & 40 & 96 & 10 & 39.2 & & \\ & 01 & 150 & 500 & 35 & 89 & 8 & 38.8 & \mathbf{3 8 . 8} & \mathbf{0 . 1} \\ & 02 & 150 & 450 & 40 & 77 & 3 & 38.7 & & \end{array}$


OTP-13

$\begin{array}{lllllcl}01 & 150 & 500 & 35 & 53 & 0 & 39.3 \\ 03 & 150 & 550 & 40 & 76 & -1 & 41.8 \\ 04 & 160 & 550 & 40 & 69 & 6 & 40.8\end{array}$

INS [1742 - 1750 AD] (fragmentos: 2/7; espécimes: 9/14)*

INS-01

\section{1}

02

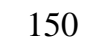

$$
150
$$

500

35

INS-06

$$
03
$$

$$
150
$$

550

$$
550
$$

550

550
500

$$
150
$$$$
140
$$

$\begin{array}{ll}02 & 140 \\ 03 & 130\end{array}$

$$
450
$$$$
450
$$

450

05

450

$\begin{array}{lcc}52 & 2 & 35.1 \\ 98 & 5 & 35.8 \\ 87 & 3 & 35.8 \\ 90 & 3 & 37.1 \\ 60 & 8 & 32.5 \\ 76 & -6 & 31.3 \\ 84 & -6 & 33.7 \\ 84 & -2 & 32.7 \\ 85 & 1 & 33.1\end{array}$

36.0

0.8

$32.7 \quad 0.9$

FF3 [1790 - 1800 AD] (fragmentos: 2/4; espécimes: 6/9)*

FF3-02

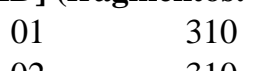

\section{0}

30

$02 \quad 310$

500

$03 \quad 330$

520

25

FF3-04

$\begin{array}{llll}01 & 230 & 500 & 30 \\ 02 & 240 & 500 & 30 \\ 03 & 240 & 500 & 30\end{array}$

FF2 [1815 - 1819 AD] (fragmentos: 4/5; espécimes: 8/11)*

FF2-01

$01 \quad 240$

520

30

FF2-03

$04 \quad 260$

510

30

$01 \quad 300 \quad 500 \quad 30$

$\begin{array}{llll}02 & 280 & 520 & 30\end{array}$

$03 \quad 280 \quad 520 \quad 30$

FF2-05

$01 \quad 240$

500

500

30

FF2-11

$03 \quad 230$

150

$\begin{array}{lcc}85 & 8 & 31.4 \\ 67 & 2 & 33.9 \\ 66 & 2 & 28.1 \\ 78 & 5 & 27.8 \\ 75 & 1 & 27.0 \\ 91 & 9 & 29.1 \\ 97 & 10 & 30.5 \\ 76 & 6 & 29.6\end{array}$

$32.7 \quad 1.8$

$27.6 \quad 0.6$

$29.8 \quad 1.0$

29.6

MPM1+2 [1869 - 1871 AD] (fragmentos: 6/9; espécimes: 23/34)*

$\begin{array}{llllllll}\text { MPM1-03 } & 01 & 220 & 500 & 25 & 88 & 8 & 27.1 \\ & 02 & 220 & 500 & 30 & 81 & 7 & 27.2 \\ \text { MPM1-04 } & 03 & 220 & 500 & 30 & 79 & 8 & 26.3 \\ & 04 & 220 & 500 & 30 & 74 & 1 & 27.0 \\ & 01 & 230 & 500 & 25 & 65 & 9 & 26.8 \\ \text { MPM1-07 } & 02 & 240 & 500 & 30 & 78 & 10 & 27.2 \\ & 03 & 230 & 500 & 30 & 81 & 9 & 27.6 \\ \text { MPM2-02 } & 04 & 240 & 500 & 30 & 80 & 7 & 26.6 \\ & 01 & 180 & 500 & 25 & 51 & 5 & 26.3 \\ & 03 & 200 & 550 & 30 & 90 & 4 & 26.9 \\ & 04 & 200 & 550 & 30 & 77 & 7 & 26.9 \\ \text { MPM2-03 } & 02 & 180 & 500 & 25 & 87 & 0 & 28.1 \\ & 03 & 180 & 500 & 30 & 89 & 2 & 28.2 \\ & 04 & 180 & 500 & 30 & 90 & 7 & 27.8 \\ & 05 & 180 & 500 & 30 & 87 & -2 & 28.4 \\ & 01 & 210 & 500 & 25 & 87 & 3 & 27.9 \\ & 02 & 230 & 500 & 30 & 87 & 10 & 27.8 \\ \text { MPM2-05 } & 03 & 220 & 500 & 30 & 86 & 10 & 27.6 \\ & 04 & 220 & 500 & 30 & 85 & 9 & 28.4 \\ & 05 & 210 & 500 & 30 & 85 & 6 & 29.0 \\ & 02 & 180 & 500 & 30 & 88 & 8 & 29.3 \\ & 03 & 200 & 500 & 30 & 66 & 8 & 29.8\end{array}$

$26.9 \quad 0.4$

$27.1 \quad 0.4$

$26.7 \quad 0.3$

$28.1 \quad 0.2$

$28.1 \quad 0.6$

$29.6 \quad 0.4$ 
FL1+3+4+5 [1895 - 1901 AD] (fragmentos: 5/12; espécimes: 14/28)*

\begin{tabular}{|c|c|c|c|c|c|c|c|c|c|}
\hline \multirow[t]{2}{*}{ FL1-06 } & 01 & 180 & 500 & 25 & 75 & -5 & 24.8 & \multirow[t]{2}{*}{24.5} & \multirow[t]{2}{*}{0.5} \\
\hline & 02 & 210 & 500 & 25 & 67 & 8 & 24.1 & & \\
\hline \multirow{3}{*}{ FL1-09 } & 01 & 180 & 500 & 25 & 71 & 6 & 25.0 & \multirow[t]{3}{*}{25.6} & \multirow[t]{3}{*}{0.6} \\
\hline & 02 & 180 & 500 & 25 & 72 & 3 & 25.9 & & \\
\hline & 03 & 180 & 500 & 25 & 74 & 8 & 26.0 & & \\
\hline \multirow[t]{4}{*}{ FL3-03 } & 01 & 190 & 500 & 25 & 76 & 10 & 25.9 & \multirow[t]{4}{*}{27.5} & \multirow[t]{4}{*}{1.3} \\
\hline & 02 & 220 & 510 & 25 & 85 & 6 & 28.8 & & \\
\hline & 03 & 230 & 520 & 25 & 86 & -2 & 27.0 & & \\
\hline & 04 & 220 & 520 & 25 & 79 & 7 & 28.4 & & \\
\hline \multirow[t]{3}{*}{ FL3-06 } & 01 & 220 & 500 & 30 & 81 & 3 & 28.2 & \multirow[t]{3}{*}{28.5} & \multirow[t]{3}{*}{0.9} \\
\hline & 02 & 200 & 500 & 30 & 81 & 9 & 27.9 & & \\
\hline & 03 & 290 & 500 & 30 & 82 & 7 & 29.5 & & \\
\hline \multirow[t]{2}{*}{ FL5-09 } & 01 & 220 & 500 & 25 & 86 & -4 & 27.8 & \multirow[t]{2}{*}{27.4} & \multirow[t]{2}{*}{0.6} \\
\hline & 02 & 220 & 500 & 25 & 81 & 7 & 27.0 & & \\
\hline \multicolumn{10}{|c|}{ FL2 [1908 - 1910 AD] (fragmentos: 3/4; espécimes: 13/15)* } \\
\hline \multirow[t]{4}{*}{ FL2-01 } & 01 & 200 & 500 & 25 & 82 & 0 & 25.6 & \multirow[t]{4}{*}{25.7} & \multirow[t]{4}{*}{0.4} \\
\hline & 02 & 220 & 480 & 25 & 78 & 8 & 25.1 & & \\
\hline & 03 & 200 & 480 & 25 & 73 & 1 & 25.8 & & \\
\hline & 04 & 200 & 480 & 25 & 78 & 2 & 26.1 & & \\
\hline \multirow[t]{5}{*}{ FL2-03 } & 01 & 220 & 500 & 25 & 89 & 9 & 24.7 & \multirow[t]{5}{*}{25.1} & \multirow[t]{5}{*}{0.5} \\
\hline & 02 & 180 & 500 & 25 & 90 & 7 & 24.5 & & \\
\hline & 03 & 190 & 480 & 25 & 84 & 6 & 25.6 & & \\
\hline & 04 & 190 & 480 & 25 & 84 & 9 & 25.6 & & \\
\hline & 05 & 200 & 480 & 25 & 81 & 6 & 25.0 & & \\
\hline \multirow[t]{4}{*}{ FL2-04 } & 01 & 180 & 500 & 25 & 88 & 3 & 24.3 & \multirow[t]{4}{*}{24.9} & \multirow[t]{4}{*}{0.6} \\
\hline & 03 & 180 & 480 & 25 & 80 & 0 & 24.6 & & \\
\hline & 04 & 180 & 480 & 25 & 79 & -6 & 25.8 & & \\
\hline & 05 & 180 & 480 & 25 & 84 & -1 & 25.0 & & \\
\hline
\end{tabular}

Tmin-Tmax: intervalo de temperatura (em ${ }^{\circ} \mathrm{C}$ ) utilizado para a determinação da intensidade; Hlab: campo de laboratório (em $\mu \mathrm{T})$; MRN T1 (\%): corresponde à fração da MRN a partir de T1 envolvida no cálculo da intensidade; Slope R' (\%): corresponde à curva de R'(Ti) ao longo do intervalo de temperatura utilizado para o calculo da intensidade, expresso em \% como definido por Le Goff and Gallet (2004); F Triaxe: valor de intensidade em nível de espécime (em $\mu \mathrm{T}$ ); Fmean: valor médio de intensidade calculado em nível de fragmento (em $\mu \mathrm{T})$; SD: desvio padrão do valor médio calculado em nível de fragmento (em $\mu \mathrm{T})$; $(*)$ :indica a razão entre o número de fragmentos (ou espécimes) que foram analisados com sucesso e o número fragmentos (ou espécimes) estudados. 